2. To: (Receiving Organization)

Retrieval System Development

5. Proj./Prog./Dept./Div.:

$4 \mathrm{~V} 500$

8. Originator Remarks:

FOR RELEASE
3. From: (Originating Organization) Engineering Labs/Modeling Team

6. Design Authority/Design Agent/Cog. Engr.: Blaine Crea

\begin{tabular}{l} 
4. Related EOT No:: \\
N/A \\
7. Purchase Order No.: \\
\hline 9. Equip./Component No.: \\
\hline 10. System/Bldg./Facility: \\
\hline 12. Major Assm. Dwg. No.:
\end{tabular}

11A. Design Baseline Document? $\square$ Yes $\square$ No

13. Permit/Permit Application No.:

14. Required Response Date: $04 / 14 / 2000$

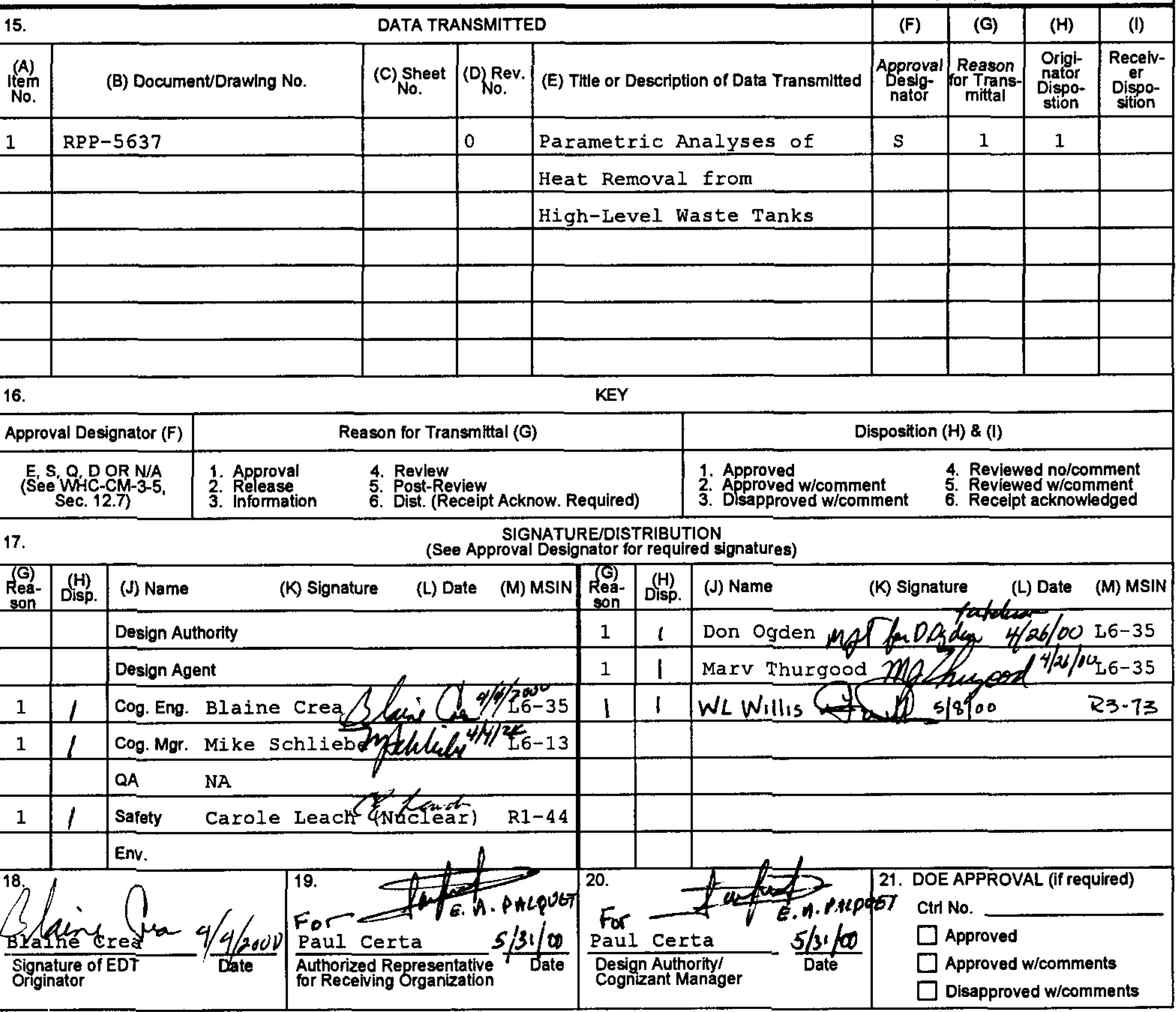




\title{
Parametric Analyses of Heat Removal from High-Level Waste Tanks
}

\author{
B. A. Crea \\ Fluor Hanford \\ K. Sathyanarayana \\ Fluor Hanford \\ D. Ogden \\ John Marvin, Inc.
}

Date Published

February 2000

Prepared for the U.S. Department of Energy

Assistant Secretary for Environmental Management

\section{CH2MHILL \\ Hanford Group, Inc.}

P. O. Box 1500

fichland, Washington

Contractor for the U.S. Department of Energy

Office of River Protection under Contract DE-AC06-99RL14047 


\title{
Parametric Analyses of Heat Removal from High-Level Waste Tanks
}

\author{
B. A. Crea \\ Fluor Hanford
}

Prepared for the U.s. Department of Energy

Assistant secretary for Environmental Management

Richland, WA 99352

U.S. Department of Energy Contract DE-AC06-99RL14047

EDT/ECN: 613077 UC:

Cost Center: 4V500 Charge Code: 111851

B\&R Code:

Total Pages: 352

Key Words: Retrieval, Mixer Pump, sludge, Fluffing Factor,

Thermal Analysis, GOTH SNE, settling

Abstract: The general thermal hydraulics program GOTH_SNF was used to predict the thermal response of the waste in tanks 241-AY-102 and 241-AZ-102 when mixed by two 300 horsepower mixer pumps. This mixing was defined in terms of a specific waste retrieval scenario. Both dome and annulus ventilation system flow are necessary to maintain the waste within temperature control limits during the mixing operation and later during the sludge-settling portion of the scenario are defined.

TRADEMARKDISCLAIMER. Reference herein to any specific commercial product, process, or service by trade name, trademark, manufacturer, or otherwise, does not necessarily constitute or imply its endorsernent, recommendation, or favoring by the United States Government or any agency thereof or lts contractors or subcontractors.

Printed in the United States of America. To obtain copies of this document, contact: Document Control Services, P.O. Box 950, Mailstop H6-08, Richland WA 99352, Phone (509) 372-2420; Fax (509) 376-4989.
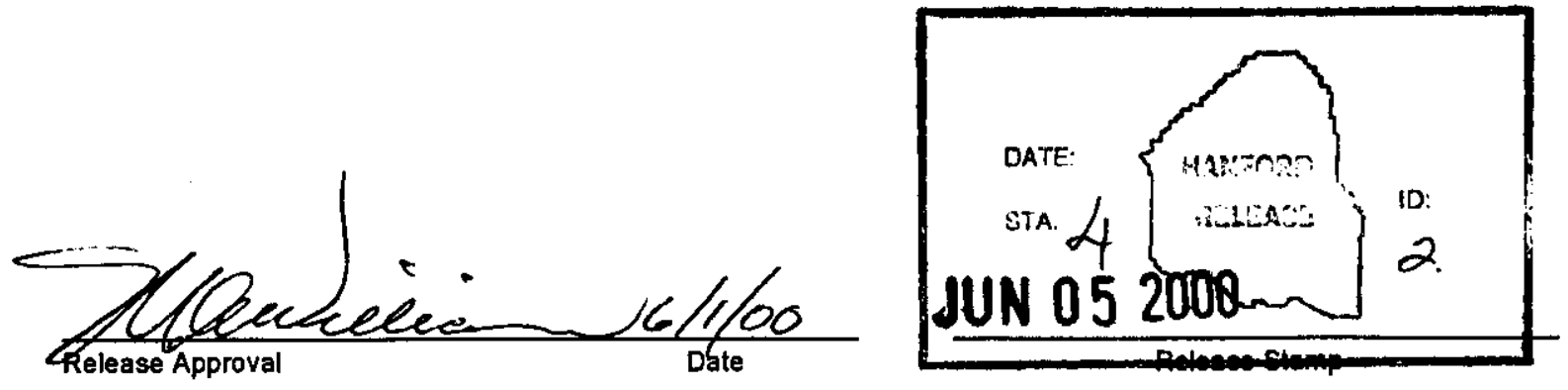

Approved For Public Release 


\section{Executive Summary}

Retrieval operations that are planned for the waste that is currently stored in the aging waste facility at Hanford include the use of mixer pumps to mobilize the sludge in the tanks. These mixer pumps will dissipate power in the waste at levels that are well in excess of the power provided by the radioactive decay heat from the waste in the tanks. Use of these mixer pumps may also result in an eventual alteration of the waste geometry to a configuration that is less favorable for heat removal than the current configuration.

This report describes a series of analyses that have been performed to investigate the effect of these mixer pumps on the temperatures of the waste in these tanks when subjected to a specific mixing and resettling scenario. These analyses have been performed to support a specific subset of the alternatives identified in an alternatives generation and analysis study. The two alternatives that are supported by this report are use of the primary (dome) ventilation system, and use of the secondary (annulus) ventilation system to keep the waste temperatures at a level that is allowed by the current tank farms waste temperature controls.

These analyses were performed by the use of the computer code GOTH_SNF. This computer code has been developed as a simulation tool to address general thermal hydraulic problems. Application of it to tank specific problems benefits from a long history of use for performing similar analyses. The results of this type of simulation have been successfully benchmarked against actual tank temperature data for a series of similar projects. Most recently in support of the successful sluicing of the contents of single shell tank 241-C-106 and the subsequent transfer of the contents to double shell tank (DST) 241-AY-102.

There are four double shelled tanks in the aging waste facility, two each in both the AY and the $\mathrm{AZ}$ tank farms. From this list of candidate tanks a bounding case tank was selected from each farm. The tanks that were selected as bounding for the scenario analyzed were 241-AY-102 and 241-AZ-102. A detailed set of input parameters and specifications were developed to facilitate the analysis of these two tanks

The input parameters for these simulations consist of the waste transport properties and definition of the decay heat load in each tank as well as information concerning the tank geometry, ventilation system configuration, and mixer pump power. The code models the tank and ancillary systems as a series of lumped parameter nodes connected together. The connections transmit either mass or energy between the nodes and so the heat and mass transfer processes that are important to definition of the tank waste temperature are simulated. The results of these simulations are checked against the criteria defined by the tank farms waste temperature controls and appropriate adjustments made to the model boundary conditions that represent the ventilation systems performance until the criteria is met by the results of the simulation.

Specification of the boundary conditions to be used for the simulations, such as ambient air temperature, also has a marked effect of the results. One of the characteristics that is 
important to the overall prediction of the tank transient thermal response is the heat storage capacity of both the waste in the tank and the earth surrounding the tank. This is of a large enough magnitude to significantly damp the annual cyclic variation of ambient temperatures from winter to summer. The values that have been specified for these input parameters have been defined to give conservative temperatures.

The heat sink for both the pump heat developed in the tanks and the radioactive decay heat is the atmosphere. The models that were developed for this simulation faithfully simulate the detailed physics of this rejection mechanism. The consequence of this fidelity to detail is that specification of the ambient temperature to be used as a boundary condition has a first order effect on the calculated waste temperatures. A constant temperature of $28^{\circ} \mathrm{C}\left(82^{\circ} \mathrm{F}\right)$ was used for this parameter. This is consistent with conditions at the hottest time of the year for a hot year.

Another parameter that has a significant effect on the results is the fluffed sludge height. This parameter is proportional to the increased conduction length path that will result in sludge temperatures that may challenge the current tank farms waste temperature controls when the waste settles after mixing. Different approaches were used to define this parameter for the two bounding case tanks. This was defined as a simple multiplier of two for the sludge in 241-AZ-102. This value was defined in a different manner for 241-AY-102. The bulk of the sludge in this tank was recently transferred to the tank as a result of the sluicing of tank 241-C-106. This was transferred in approximately one-foot increments. A continuous record of the sludge height during this transfer operation is available. The pre-sluice sludge depth was fluffed by a factor of two and summed with the initial incremental change in sludge height associated with each transfer to arrive at a value to use for the fluffed sludge height for this tank. Once the pumps were turned off during the analysis scenario the particles were assumed to settle at a defined rate. When the non-convective layer of sludge reached the pre-defined fluffed layer depth it was assumed that no further settling occurred.

The results of these analyses show that the temperatures of the waste will remain within the current criteria defined by the tank farms waste temperature controls for tank 241-AY-102 when the ventilation system flows are maintained at a rate of $0.236 \mathrm{~m} 3 / \mathrm{s}$ $(500 \mathrm{ft} 3 / \mathrm{min})$ for the primary side and $0.472 \mathrm{~m} 3 / \mathrm{s}(1,000 \mathrm{ft} 3 / \mathrm{min})$ for the annulus side, and the inlet conditions are consistent with the defined ambient temperature conditions.

The results of these analyses show that in order to keep the temperatures of the waste within the current criteria defined by the tank farms waste temperature controls for tank 241-AZ-102, ventilation system flows of $0.236 \mathrm{~m} 3 / \mathrm{s}(500 \mathrm{ft} 3 / \mathrm{min})$ for the primary side are adequate. However the annulus side must be increased to $0.944 \mathrm{~m} 3 / \mathrm{s}(2,000 \mathrm{ft} 3 / \mathrm{min})$, and the inlet conditions temperature for the annulus must be chilled to $4{ }^{\circ} \mathrm{C}\left(40^{\circ} \mathrm{F}\right)$.

One other result that is derived from these analyses is that the primary vent system must have the capability to remove (by condensation) approximately $0.000189 \mathrm{~m}^{3} / \mathrm{s}$ (3 $\mathrm{gal} / \mathrm{min})$. 


\section{CONTENTS}

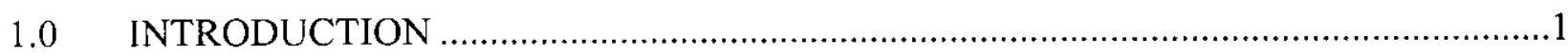

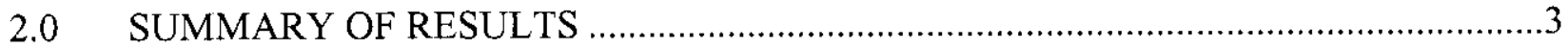

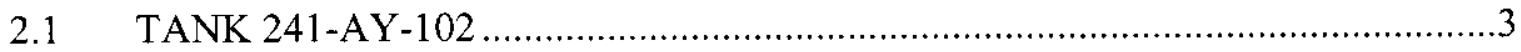

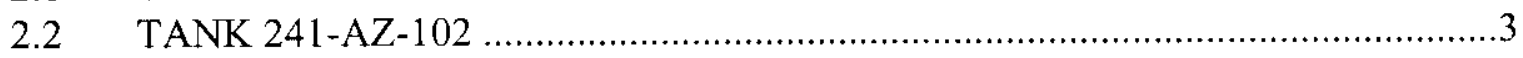

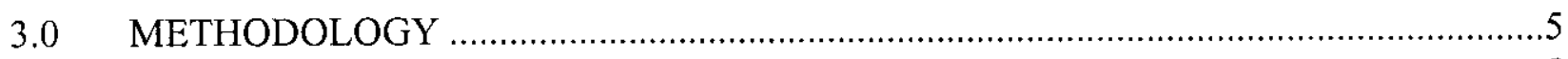

3.1 MAXIMUM WASTE TEMPERATURE CRITERIA ...........................................5

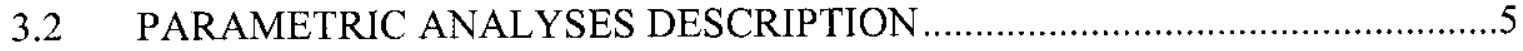

3.2.1 Parametric Study Cases........................................................................

3.2.2 Parametric Study Analysis Sequence..........................................................6

3.3 PARAMETRIC STUDY INPUT PARAMETERS …….......................................

3.3.1 Summary of Input Parameters ...............................................................

3.3.2 Input Parameter Conservatism ...............................................................11

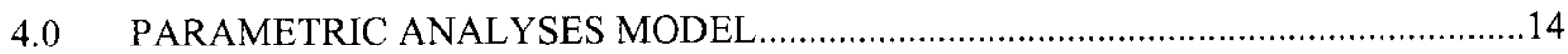

4.1 GOTH_SNF MODEL DESCRIPTION ………..........................................14

4.1.1 GOTH_SNF Computer Program ...........................................................14

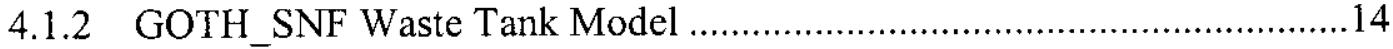

4.2 BENCHMARK ANALYSES ………………...........................................18

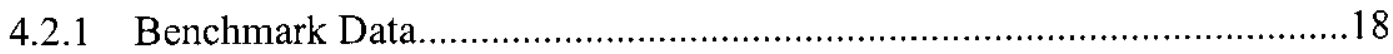

4.2.2 Benchmark Analyses ......................................................................22

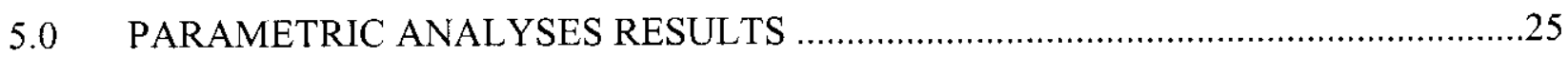

5.1 TANK 241-AY-102 ANALYSES ………………........................................25

5.1.1 Case 1: Primary- Ventilation System Enhancements ...............................25

5.2 TANK 241-AZ-102 ANALYSES.................................................................29

5.2.1 Case 1: Primary-Side Ventilation System Enhancements ..........................29

5.2.2 Case 2: Annulus-Side Ventilation System Enhancements.........................32

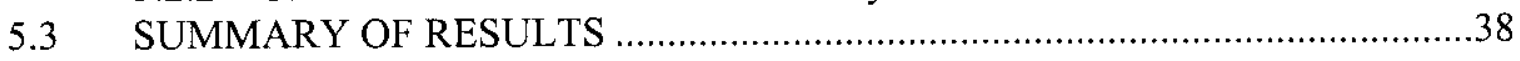

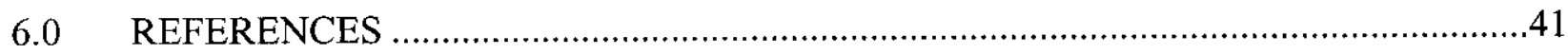




\section{APPENDICES}

A A PARAMETRIC STUDY TO CHARACTERIZE AGA ALTERNATIVES FOR REMOVAL OF HEAT FROM HIGH-LEVEL WASTE TANKS.

B INPUT MODEL PARAMETERS FOR A PARAMETRIC STUDY TO CHARACTERIZE ALTERNATIVES GENERATION ANALYSIS FOR REMOVAL OF HEAT FROM HIGH-LEVEL WASTE TANKS.

C GOTH_SNF VERSION 5.0 VERIFICATION AND VALIDATION NOTEBOOK

D RELATED CORRESPONDENCE D-i

E NOTEBOOK FOR GOTH_SNF SIMULATION OF TANK AY-102 DURING AND AFTER MIXER PUMP OPERATION

F NOTEBOOK FOR GOTH_SNF SIMULATION OF TANK AZ-102 DURING AND AFTER MIXER PUMP OPERATION

\section{FIGURES}

Figure 3-1. Schematic of Predicted Temperatures................................................................

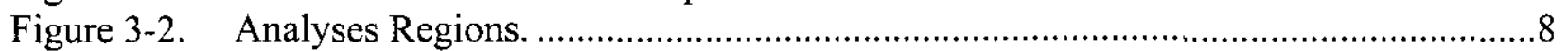

Figure 3-3. Thermal Conductivity Models........................................................................12

Figure 3-4. Ambient 30-Year Average Daily Temperature....................................................13

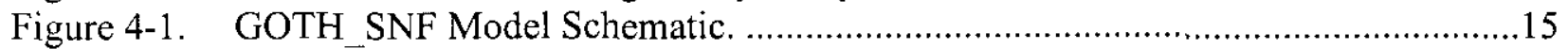

Figure 4-2. GOTH_SNF One-Dimensional - Tank Volume.................................................16

Figure 4-3. Annulus Ventilation Floor Slot Configuration......................................................12

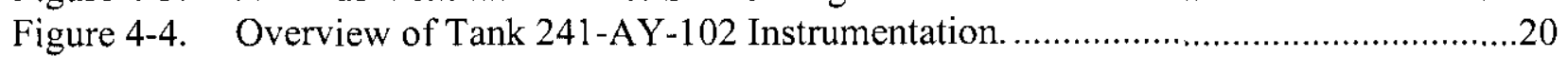

Figure 4-5. Post-Sluice Supernatant Liquid Temperature Comparison....................................21

Figure 4-6. Post-Sluice Waste Temperature Comparison........................................................2

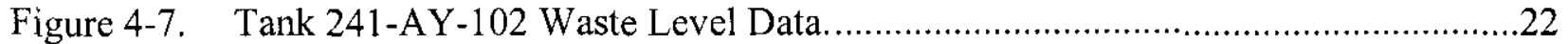

Figure 4-8. Post-Sluice Annulus Outlet Air Temperature Comparison......................................23

Figure 4-9. Outer Bottom Sludge Temperature. ................................................................24

Figure 5-1. Tank 241-AY-102 Temperatures for 500 SCFM Primary Vent System

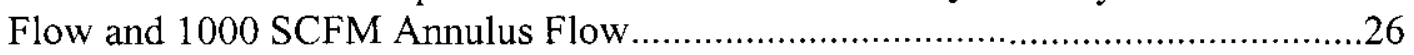

Figure 5-2. Tank 241-AY-102 Water Vapor Evaporation Rates for 500 SCFM Primary Vent System Flow and 1000 SCFM Annulus Flow .............................................26

Figure 5-3. Tank 241-AY-102 Temperatures for 500 SCFM Primary Vent System

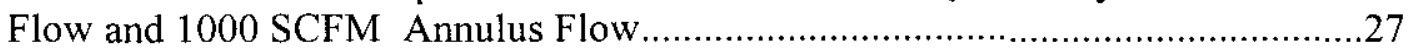

Figure 5-4. Tank 241-AY-102 Waste Axial Temperature Distributions. ...................................28

Figure 5-5. Tank 241-AY-102 Thermal Response upon Loss-of-Ventilation............................29 
Figure 5-6. Tank 241-AZ-102 Case 1 Temperatures for 500 SCFM Primary Vent System Flow and 1000 SCFM Annulus Flow.... 30

Figure 5-7. Tank 241-AZ-102 Water Vapor Evaporation Rates..............................................

Figure 5-8. Tank 241-AZ-102 Case 1 Temperatures with No Annulus Ventilation..................31

Figure 5-9. Tank 241-AZ-102 Case 2 Temperatures for Nominal Ventilation.........................32

Figure 5-10. Descriptions of GOTH_SNF Plot Parameters.......................................................33

Figure 5-11. Tank 241-AZ-102 Case 2 Temperatures with $0.944 \mathrm{~m}^{3} / \mathrm{s}\left(2,000-\mathrm{ft}^{3} / \mathrm{min}\right)$ Flow and Chilled Air. 35

Figure 5-12. Tank 241-AZ-102 Waste Axial Temperature Distribution.....................................36

Figure 5-13. Tank 241-AZ-102 Enhanced Annulus with Loss of Ventilation. ...........................37

Figure 5-14. Tank 241-AZ-102 Case 2 Temperatures with No Annulus Ventilation..................38

\section{TABLES}

Table 3-1. Applicable Temperature Criteria .5

Table 3-2. Description of Input Parameters.

Table 5-1. Summary of Parametric Results.

\section{CONVERSION FACTORS}

English units of measure are used throughout this study to be consistent with the Technical Safety Requirements. Metric conversions for the applicable English units are provided below.

\begin{tabular}{|l|l|l|}
\hline To convert from & To & Multiply by \\
\hline${ }^{\circ} \mathrm{F}$ & ${ }^{\circ} \mathrm{C}$ & $t^{\circ} \mathrm{C}=\left(t_{0^{\circ}}-32\right) / 1.8$ \\
\hline $\mathrm{ft}$ & $\mathrm{m}$ & $3.048000^{*} \mathrm{E}-01$ \\
\hline $\mathrm{ft}^{3} / \mathrm{min}$ & $\mathrm{m}^{3} / \mathrm{s}$ & $4.719474 \mathrm{E}-04$ \\
\hline
\end{tabular}




\section{TERMS}

AGA

ALC

DST

Enraf

HLW

JMI

LCO

LCS

MIT

SL

TSR
Alternatives Generation and Analysis

air lift circulator

double-shell tank

Enraf-Nonius Series 854

high-level waste

John Marvin, Inc.

Limiting Conditions for Operation

Limiting Control Setting

multifunction instrument tree

Safety Limit

Technical Safety Requirement 


\subsection{INTRODUCTION}

The Waste Feed Delivery (WFD) program is responsible for delivering waste from the double shell tanks to a private contractor facility (BNFL) where the waste will be converted into a form appropriate for long-term storage. Four of the double shell tanks planned for delivery of highlevel waste (HLW) to BNFL are the aging waste facility tanks (241-AY-101 and -102, and 241AZ-101 and -102). These tanks contain waste with relatively high concentrations of radioisotopes, which produce decay heat. Additionally, the tanks are to be mixed prior to delivery to mobilize waste sludge, and the mixing process also adds a large quantity of heat to the waste.

A technical safety requirement (TSR) is imposed by HNF-SD-WM-TSR-006 to avoid the tankbump accident, which is assumed to occur at saturation temperature. Currently, this TSR includes both a safety limit for waste temperature of $\leq 121^{\circ} \mathrm{C}\left(250^{\circ} \mathrm{F}\right)$, and a related limiting condition of operation (LCO 3.3.2), which establishes temperature limit controls for double shell tanks (DSTs).

The WFD program must ensure that the safety limit is not exceeded during waste retrieval activities. Additionally, the WFD program should avoid exceeding the LCO temperature to prevent operational limitations. This study predicts the temperature response of the waste under different operational scenarios of the primary and annulus ventilation systems (combinations of inlet temperatures and flow rates). The study addresses operation of the mixer pumps to mobilize and suspend the solids and the re-settling of the solids after the mixer pumps have been turned off. Supporting documentation, related correspondence, and model generation notebooks are provided in Appendices A through F.

Two waste tanks, 241-AY-102 and 241-AZ-102, were selected to represent the HLW tanks in the analyses because the combination of radioactive decay heat rate and sludge depth in these tanks bound the maximum sludge temperature potential in the HLW tanks. Ventilation system performance for the two alternatives was evaluated relative to the TSR Limiting Conditions for Operation (LCO) temperature limits. Ventilation system flow rate and inlet conditions that satisfy the LCO limits were established for each alternative.

The analyses were performed using the GOTH_SNF computer program. This is a general-purpose, thermal-hydraulics computer program developed by John Marvin, Inc. (JMI). The current version and the predecessor program GOTH have been used extensively at Hanford and other U.S. Department of Energy sites and in the commercial nuclear industry for design and safety analyses. The models incorporate lumped-parameter and distributed-parameter volumes, heat conductors, and flow and pressure boundary conditions to provide a one-dimensional model of tanks 241-AY-102 and 241-AZ-102. 
RPP-5637

Rev. 0

This page intentionally left blank. 


\subsection{SUMMARY OF RESULTS}

Parametric thermal analyses were performed to evaluate the need for primary-side and annulus-side ventilation system operation or upgrades to maintain waste temperatures below specified temperature limits during retrieval operations in the HLW tanks. The results of these thermal analyses performed on the bounding case tank for each of the two tank farms under consideration are summarized in the following sections.

\subsection{TANK 241-AY-102}

A thermal evaluation of the primary-side ventilation system was performed for steady-state mixer pump operation. The analyses demonstrated that a primary ventilation system flow rate of $0.236 \mathrm{~m}^{3} / \mathrm{s}$ [500 $\mathrm{ft}^{3} / \mathrm{min}$ ] (once-through ambient air) is adequate to maintain the mixed-waste temperature below the temperature limit of $90.6^{\circ} \mathrm{C}\left(195^{\circ} \mathrm{F}\right)$. The primary ventilation system, in concert with the annulus ventilation system, will maintain resettled waste temperatures below the temperature limit of $101.7^{\circ} \mathrm{C}\left(215^{\circ} \mathrm{F}\right)$.

A thermal evaluation of the annulus-side ventilation system was performed for the mixer pump operation and subsequent waste resettling. The evaluation demonstrated that a ventilation system flow rate of $0.472 \mathrm{~m}^{3} / \mathrm{s}\left[1,000 \mathrm{ft}^{3} / \mathrm{min}\right]$ (ambient air) is adequate to maintain mixed-waste temperatures below the mixed-waste temperature limit and to maintain the resettled-waste temperature below the settled-waste temperature limit. It was also shown that without annulus-side ventilation the initial settled-waste temperatures before mixer pump operation exceeds the applicable temperature limit of $101.7^{\circ} \mathrm{C}\left(215^{\circ} \mathrm{F}\right)$.

\subsection{TANK 241-AZ-102}

A thermal evaluation of the primary-side ventilation system was performed for steady-state mixer pump operation. The analyses demonstrated that a primary ventilation system flow rate of $0.236 \mathrm{~m}^{3} / \mathrm{s}$ [ $500 \mathrm{ft}^{3} / \mathrm{min}$ ] (once-through ambient air) is adequate to maintain the mixed-waste temperature below the temperature criteria of $90.6^{\circ} \mathrm{C}\left(195^{\circ} \mathrm{F}\right)$.

The analyses were also performed without annulus-side ventilation. The initial settled-waste temperatures before mixer pump operation and the steady-state mixed-waste temperatures did not exceed the temperature limits. However, the steady-state resettled-waste temperatures following mixer pump operation exceeded the applicable temperature limit of $101.7^{\circ} \mathrm{C}\left(215^{\circ} \mathrm{F}\right)$.

Parametric analyses of the annulus-side ventilation system was performed for mixer pump operation and subsequent waste resettling. The evaluation demonstrated that the annulus ventilation system flow rate of $0.472 \mathrm{~m}^{3} / \mathrm{s}\left[1,000 \mathrm{ft}^{3} / \mathrm{min}\right.$ ] (ambient air) is not adequate to maintain the resettled waste temperature below the temperature limit of $101.7^{\circ} \mathrm{C}\left(215^{\circ} \mathrm{F}\right)$. Further analysis demonstrated that $0.944 \mathrm{~m}^{3} / \mathrm{s}\left(2,000 \mathrm{ft}^{3} / \mathrm{min}\right)$ flow of chilled $4.4{ }^{\circ} \mathrm{C}\left(40^{\circ} \mathrm{F}\right)$ will maintain the resettled-waste temperatures (following steady-state pump operation) below the applicable temperature limit. 
Conservative values were intentionally specified for selected input parameters to bound uncertainties in input parameters and the thermal analyses. Reduction of this conservatism would reduce the predicted maximum temperatures and reduce them below the temperature limit of $101.7^{\circ} \mathrm{C}\left(215^{\circ} \mathrm{F}\right)$ at lower annulus flow rates using ambient inlet air. 


\subsection{METHODOLOGY}

\subsection{MAXIMUM WASTE TEMPERATURE CRITERIA}

The AGA provides a preferred alternative configuration that satisfies the TSR criteria - LCOs and Safety Limits (SL) - in all conditions of normal operation.

The temperature limits in Table 3-1 were applied as constraints during this study. It has been assumed that the same temperature limits will apply during retrieval operations. However, it is possible that temperature criteria will be established in the future, specifically for retrieval operations in the HLW tanks.

Table 3-1. Applicable Temperature Criteria

\begin{tabular}{|l|l|l|}
\hline Waste Condition & $\begin{array}{l}\text { Limiting Control Setting/ } \\
\text { Limiting Condition of } \\
\text { Operation }\end{array}$ & Temperature \\
\hline $\begin{array}{l}\text { Mixed Waste (fully mixed by } \\
\text { in-tank mixer pump) }\end{array}$ & $3.3 .2 \mathrm{a}$ & $\begin{array}{l}\mathrm{T} \leq 90.6^{\circ} \mathrm{C}\left(195^{\circ} \mathrm{F}\right) \text { (in all } \\
\text { levels of the waste) }\end{array}$ \\
\hline $\begin{array}{l}\text { Settled Waste (both before } \\
\text { mixing and after mixing) }\end{array}$ & $3.3 .2 . \mathrm{b}$ & $\begin{array}{l}\mathrm{T} \leq 90.6^{\circ} \mathrm{C}\left(195^{\circ} \mathrm{F}\right) \text { (in the } \\
\text { top } 4.57 \mathrm{~m}[15 \mathrm{ft}] \text { of waste) } \\
\mathrm{T} \leq 101.7^{\circ} \mathrm{C}\left(215^{\circ} \mathrm{F}\right) \text { (in the } \\
\text { waste below } 4.57 \mathrm{~m}[15 \mathrm{ft}])\end{array}$ \\
\hline
\end{tabular}

Note: Double-shell tanks typically operate with a waste level of $9.14 \mathrm{~m}(30 \mathrm{ft})$.

\subsection{PARAMETRIC ANALYSES DESCRIPTION}

\subsubsection{Parametric Study Cases}

Both primary-side and annulus-side ventilation system enhancements were considered for the AGA parametric analyses. For each case, ventilation system flow rate and inlet conditions were identified. The scenario defined as characteristic of expected retrieval operations consisted of mixing of the waste until the transient temperature rise resulting from the mixer pump power input was nearly completed and then removing the pump input power and allowing the waste to resettle. This scenario was then evaluated by thermal analyses. The results were compared with the temperature criteria established in Section 3.1. Predicted temperature profiles are shown schematically in Figure 3-1. If the predicted waste temperatures exceeded the temperature criteria, parametric analyses were performed to identify primary-side or annulus-side ventilation enhancements required to maintain the waste temperatures below the appropriate temperature limits throughout the scenario. 


\subsubsection{Parametric Study Analysis Sequence}

The initial settled waste steady state and the subsequent scenario appropriate for retrieval operation were evaluated by the AGA parametric studies. These are described in the following:

- Temperature of waste before operation of the mixer pumps (Figure 3-2, Start of Region 1). A steady-state analysis was performed to determine the initial steady-state temperatures of the sludge and supernatant. The steady-state supernatant (Figure 3-1, $\mathrm{T}_{1}$ ), and the maximum settled-waste temperature (Figure 3-1, $\mathrm{T}_{2}$ ) will be compared with the $\mathrm{LCS} / \mathrm{LCO}$ 3.3.2.b temperature criterion. $\mathrm{T}_{3}$ is the temperature that is used as an initial condition for the pump-mixing transient. This is the instantaneously mixed waste temperature and is defined as a volume averaged temperature of the total tank contents.

- Temperature of mixed waste during pump operation (Figure 3-2, Region 1). During retrieval operations, mixer pumps will mobilize and mix the settled sludge. The sludge and supernatant will be fully mixed. $T_{3}$ is the mixed-waste temperature without any pump heat. This represents the minimum mixed-waste temperature. As mixer pumps continue to operate, the mixed-waste temperature approaches a higher steady-state temperature as shown in Figure 3-2, Region 1. The mixed-waste temperature for steady-state pump operation (Figure 3-1, $\mathrm{T}_{4}$ ) is the maximum mixed-waste temperature during retrieval operations. Both $\mathrm{T}_{3}$ and $\mathrm{T}_{4}$ will be evaluated and compared with LSC/LCO 3.3.2.a (discussed in Section 3.1). A typical temperature history plot for region 1 of the analysis is shown in Figure 3-2. 
Figure 3-1. Schematic of Predicted Temperatures.

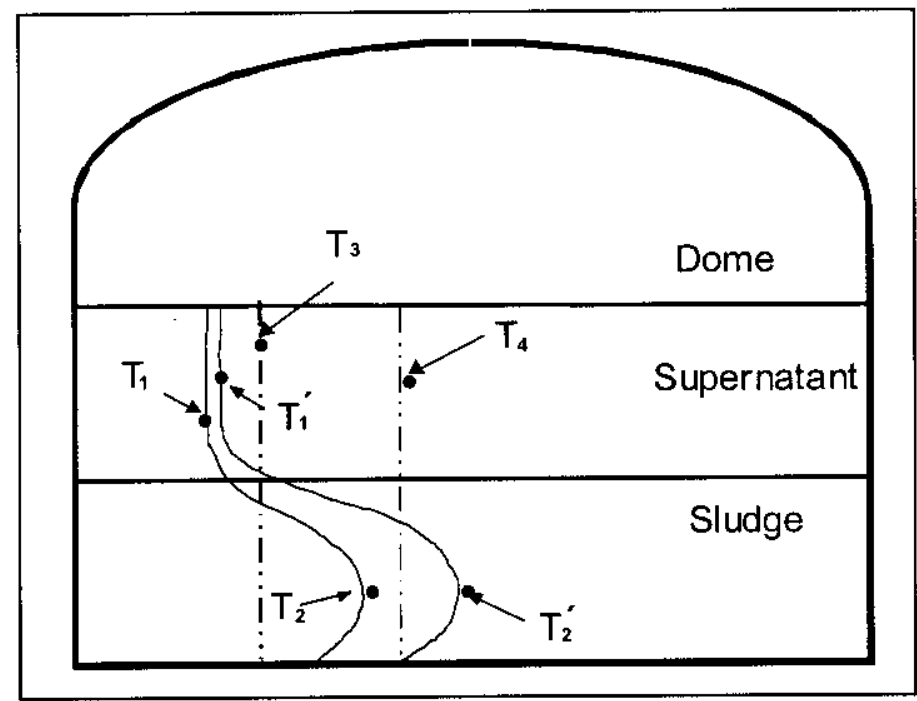

$\mathrm{T}_{!}=$Premixed supernatant temperature

$\mathrm{T}_{2}=$ Premixed maximum waste temperature

$\mathrm{T}_{3}=$ Instantaneous mixed-waste temperature

$\mathrm{T}_{4}=$ Mixed waste, steady-state pump operation temperature

$\mathrm{T}^{\prime}{ }_{1}=$ Post-mixed supernatant temperature

$\mathrm{T}_{2}^{\prime}=$ Post-mixed maximum waste temperature 
Figure 3-2. Analyses Regions.

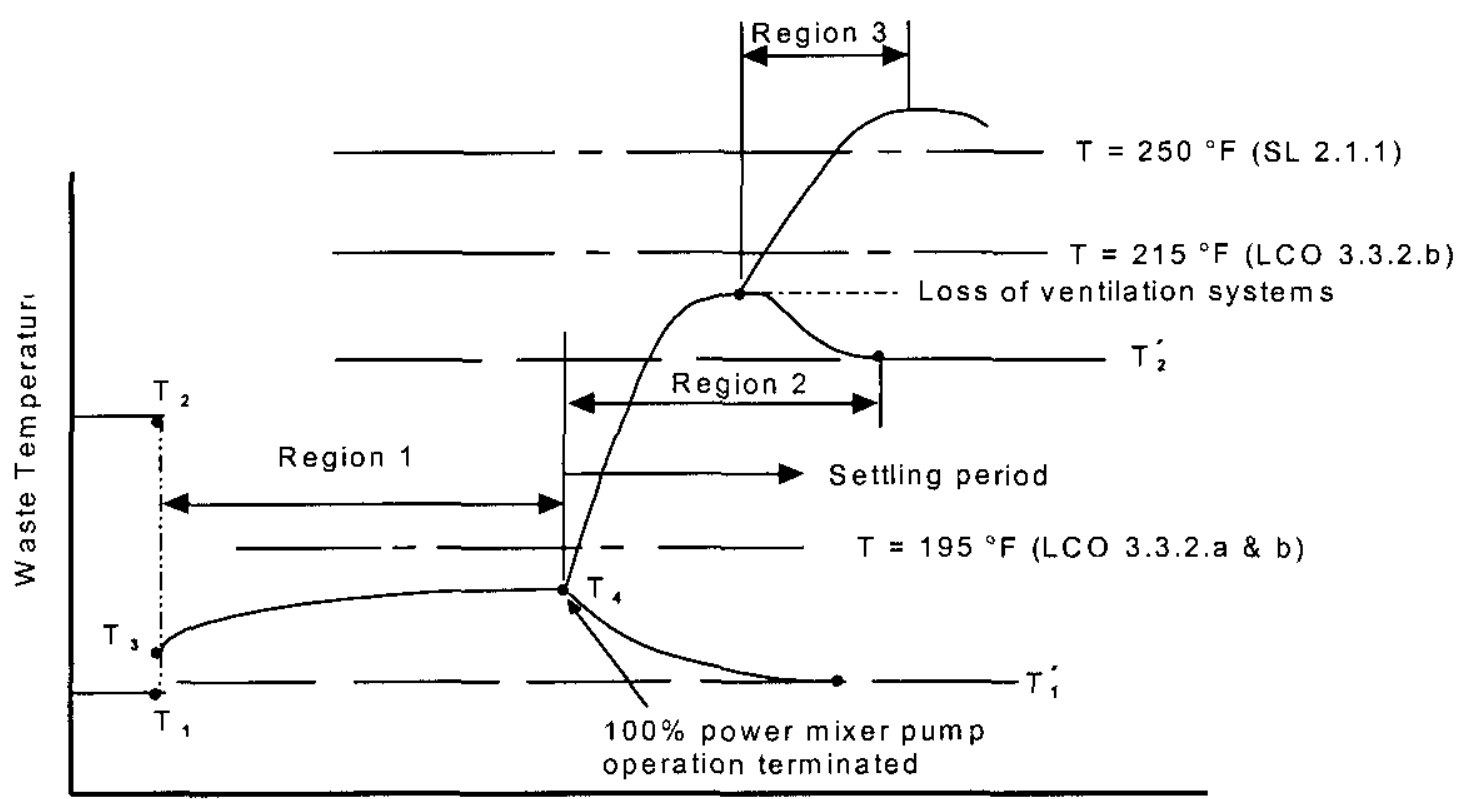

Time

LCO $=$ Limiting Conditions for Operation

$S L=S$ afety Limit

$T S R=$ Technical Safety Requirements

$1981 \cdot 14$

Key to Temperature Response Curves:

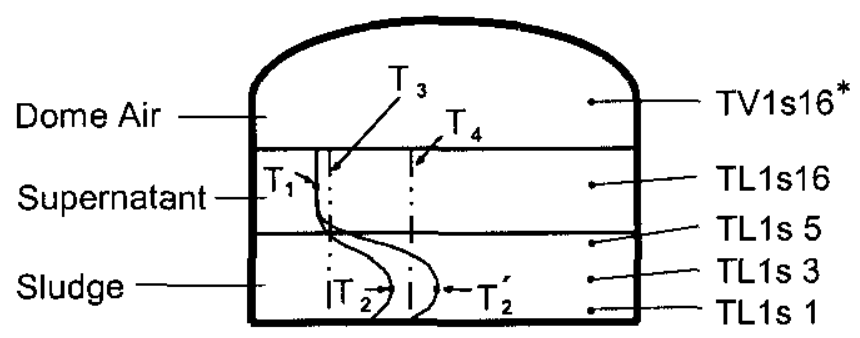

Nominal ventilation flow rate is:

Primary $500 \mathrm{ft}^{3} / \mathrm{min}$ once through

Annular $1000 \mathrm{ft}^{3} / \mathrm{min}$ slot flow

*Temperature response curve number.

The number indicates the locations of

the temperature response in the waste.

TRC.1 
- Temperature of the resettled waste following mixer pump operation (Figure 3-2, Region 2). Following pump operation the waste is allowed to resettle. Representative times for this to occur in the tanks being studied are on the order of 1-2 weeks. The response of both the supernatant liquid (figure $3-1, \mathrm{~T}_{1}$ ') and the resettling sludge (designated $\mathrm{T}_{2}$ ) This would result in elevated temperature of the supernatant in conjunction with elevated temperatures in the settled waste. The most limiting condition is waste resettling after the mixed-waste temperature reaches steady state during pump operation. The temperature of the supernatant (Figure 3-1, $\mathrm{T}_{1}{ }_{1}$ ) and maximum temperature of the settled-waste (Figure 3-1, $\mathrm{T}^{\prime}{ }_{2}$ ) are evaluated with thermal analyses and compared with the LCS/LCO 3.3.2.b temperature criteria.

- Temperature rise on loss of ventilation systems (Figure 3-2, Region 3). The resettledwaste temperature $\mathrm{T}_{2}^{\prime}$ is higher than initial settled-waste temperature of $\mathrm{T}_{2}$. This is a result of waste fluffing, which results in a greater waste depth after resettling. If the ventilation systems fail to operate an additional analysis of the resettled-waste condition determined the time required for the maximum temperature of the settled waste to reach boiling (steam saturation conditions). This time was compared with anticipated ventilation system recovery times (Appendices $\mathrm{E}$ and $\mathrm{F}$ ). The recovery time comparison was intended only as a preliminary evaluation of the potential consequence of operating with settled-waste temperatures near the LCO temperature limits. Parametric analyses were performed when the time to boiling was shorter than the expected recovery time.

\subsection{PARAMETRIC STUDY INPUT PARAMETERS}

The input parameters used for the GOTH_SNF model are provided in Appendix B. The input parameters are summarized in Section 3.3.1, and the conservatism of selected parameter is discussed in Section 3.3.2.

\subsubsection{Summary of Input Parameters}

The GOTH_SNF input parameters can be grouped into four categories. These categories and associated input parameters are summarized in Table 3-2. 
Table 3-2. Description of Input Parameters.

\begin{tabular}{|c|c|}
\hline Category & $\begin{array}{l}\text { Input Parameters } \\
\end{array}$ \\
\hline Waste and Supernatant Liquid Properties & $\begin{array}{l}\text { Supernatant Liquid density, heat capacity, thermal conductivity } \\
\text { Supernatant Liquid vapor suppression } \\
\text { Particle size, density, heat capacity, thermal conductivity } \\
\text { Particle volume fraction } \\
\text { Sludge thermal conductivity model } \\
\text { Sludge fluffing factor after mixing and resettling } \\
\text { Sludge and Supernatant Liquid volumes }\end{array}$ \\
\hline Tank Heat Load & $\begin{array}{l}\text { Supernatant Liquid } \\
\text { Sludge } \\
\text { Pump heat }\end{array}$ \\
\hline Ambient Air Boundary Conditions & $\begin{array}{l}\text { Temperature } \\
\text { Humidity }\end{array}$ \\
\hline $\begin{array}{l}\text { Tank Geometry and Ventilation System } \\
\text { Characteristics }\end{array}$ & $\begin{array}{l}\text { Ventilation system configuration } \\
\text { Primary (Dome) system flows } \\
\text { Annulus (Secondary) system flows } \\
\text { Annulus flow channel configuration } \\
\text { Sludge Depth } \\
\text { Supernatant Liquid Depth }\end{array}$ \\
\hline
\end{tabular}

The GOTH_SNF input parameters for Tank 241-AZ-102 are discussed in Appendix B and summarized in Table B3-1: The GOTH_SNF input parameters for Tank 241-AY-102 are discussed in Appendix B and summarized in Table B4-1.

Most of the values shown in the tables are best-estimate values. However, conservative values were chosen for selected input parameters to bound uncertainty in the thermal analyses. These are discussed in the next section.

Definition of the configuration and boundary conditions associated with the ventilation systems includes the nominal configuration for both the primary-side and annulus-side ventilation and definition of an enhanced configuration. The enhanced configurations selected exceed the current capabilities of the systems, but are judged to be within the scope of ventilation system upgrades that have been done for similar tank ventilation systems.

The nominal configuration for the primary-side is based on the AZ-702 ventilation system. This provides up to $0.236 \mathrm{~m}^{3} / \mathrm{s}\left(500-\mathrm{ft}^{3} / \mathrm{min}\right)$ ambient airflow in a once-through mode. The enhanced mode for the primary-side ventilation is $0.047 \mathrm{~m}^{3} / \mathrm{s}\left(100 \mathrm{ft}^{3} / \mathrm{min}\right)$ once-through ambient air and $0.189 \mathrm{~m}^{3} / \mathrm{s}\left(400 \mathrm{ft}^{3} / \mathrm{min}\right)$ recirculation flow with $4.4^{\circ} \mathrm{C}\left(40^{\circ} \mathrm{F}\right)$ chilled air. To achieve the capabilities defined as the enhanced configuration for the 702-AZ system replacement or augmentation of the existing latent heat cooling tower system with a refrigerated system will be required.

It is assumed in all cases that the configuration of the annulus system is such that the total system flow is discharged into the central plenum under the tank and then flows through the slots in the 
concrete under the tank primary shell. The nominal flow for the annulus-side ventilation is based on the tank 241-AY-102 measured flow data. The system is currently operating near $0.401 \mathrm{~m}^{3} / \mathrm{s}$ $\left(850 \mathrm{ft}^{3} / \mathrm{min}\right)$. However, the measured flow has exceeded $0.472 \mathrm{~m}^{3} / \mathrm{s}\left(1,000 \mathrm{ft}^{3} / \mathrm{min}\right)$.

The enhanced mode for the annulus-side ventilation is a flow rate up to $0.944 \mathrm{~m}^{3} / \mathrm{s}$ $\left(2,000 \mathrm{ft}^{3} / \mathrm{min}\right)$ with inlet chilled air at $4.4^{\circ} \mathrm{C}\left(40^{\circ} \mathrm{F}\right)$. Configuration of the annulus system to achieve the capabilities defined as enhanced will require that the existing blower be either upgraded or replaced. The system must be capable of providing sufficient differential pressure to raise the system flow to the enhanced value. In addition to flow rate enhancements an inlet chiller must be provided to cool the inlet air stream to $4.4^{\circ} \mathrm{C}\left(40^{\circ} \mathrm{F}\right)$.

\subsubsection{Input Parameter Conservatism}

Conservative values were used for selected input parameters. This conservatism resulted in conservative waste temperatures. This conservatism was included to bound uncertainty in the best-estimate input parameters and uncertainty in the thermal analyses.

A conservative thermal conductivity model was used for the sludge. The thermal conductivity's in tables B3-1 and B4-1 for aqueous and solids are best-estimate values. A mathematical model must be used to determine the thermal conductivity of the particle-liquid mixture. Figure 3-3 shows the waste thermal conductivity as a function of particle volume fraction for three thermal conductivity models. The values shown in the figure are based on the aqueous and solid conductivity's in tables B3-1 and B4-1. The parallel model represents the theoretical upper limit for the waste thermal conductivity. The Maxwell model represents a best-estimate, waste thermal conductivity. The Series model is the theoretical lower limit for waste thermal conductivity. The Series model was selected for the AGA parametric analyses. The conservatism of this model for tank 241-AY-102 is shown by the benchmark analyses (Section 4.2). The lower thermal conductivity results in higher maximum waste temperatures. 
Figure 3-3. Thermal Conductivity Models.

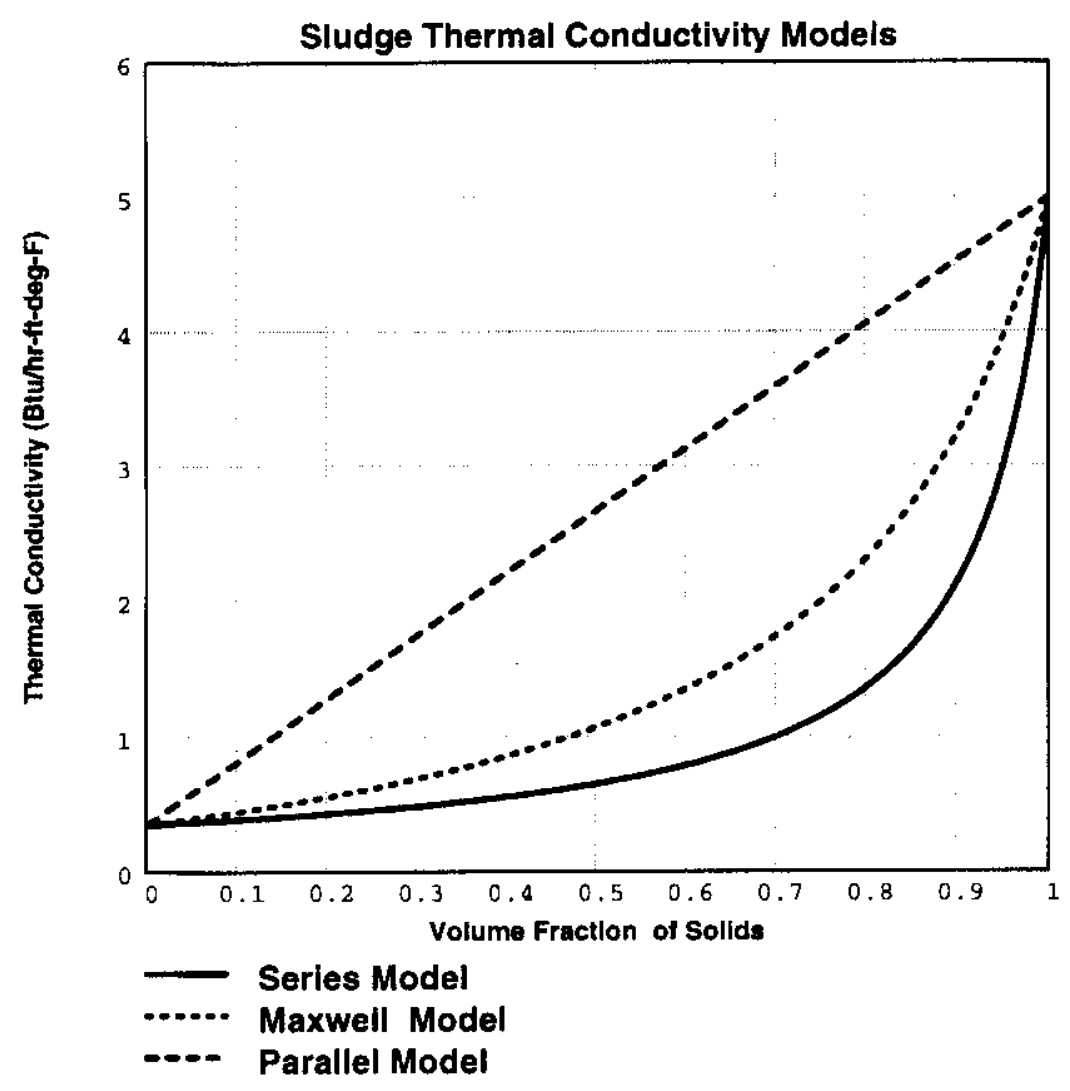

Conservative values were selected for the ambient air boundary conditions. Constant values were selected for the ambient air boundary conditions (temperature and humidity). The 30-year daily average ambient temperature is shown in Figure 3-4. The figure shows the annual variation in temperature. The conservative constant temperature used for the parametric analyses is shown in the figure. This value exceeds the maximum value for the 30 -year average daily temperature. In addition, the analyses assume a constant value. The actual ambient temperature only remains near the maximum temperature for a few weeks so that the tank temperatures do not reach steady state for the maximum seasonal temperature. Thus, the ambient temperature is conservative in both magnitude and duration. 
Figure 3-4. Ambient 30-Year Average Daily Temperature.

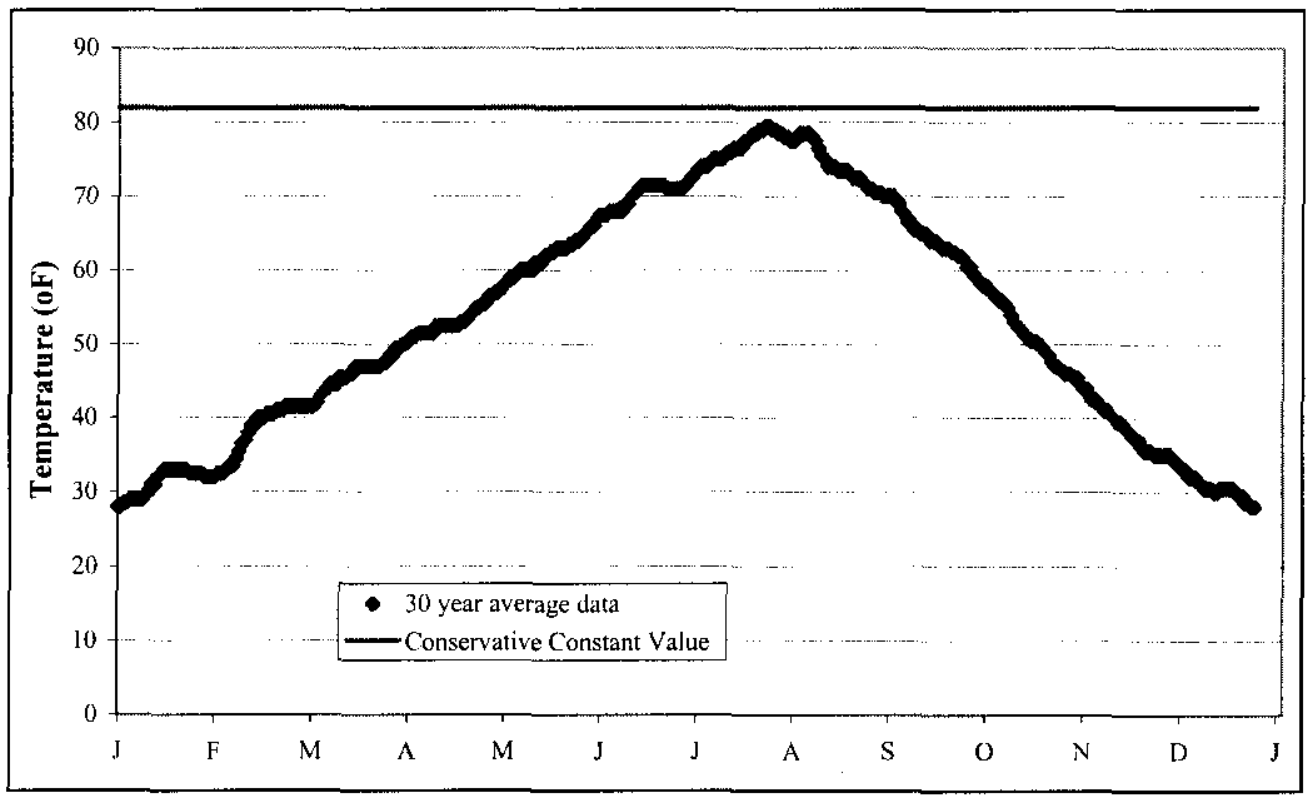

An additional conservatism in the input parameters is the constant resettled-waste fluffing factor. Waste, which has been mixed through the operation of the mixer pumps, and then allowed to settle, will settle to a waste height that is greater than the initial settled-waste height. The ratio of the resettled-waste height to the initial waste height is the fluffing factor. The waste will begin to compact after the initial settling of the waste. This can be observed in the tank 241-AY-102 waste level data discussed in Section 4.2.1. The parametric analyses assumed that the fluffing factor was constant (i.e., no compaction occurs). This results in a larger waste depth and a conservative prediction of settled-waste temperature.

The conservatism of the thermal conductivity model, ambient air temperature, and fluffing factor treatment result in conservative prediction of waste temperatures. This conservatism is intended to bound uncertainties in these input parameters and uncertainties in the thermal analyses. 


\subsection{PARAMETRIC ANALYSES MODEL}

\subsection{GOTH_SNF MODEL DESCRIPTION}

\subsubsection{GOTH_SNF Computer Program}

The GOTH_SNF is a general-purpose, thermal-hydraulics computer program developed by John Marvin, Inc. (JMI). The current version and the predecessor program GOTH have been used extensively at Hanford and other U.S. Department of Energy sites and in the commercial nuclear industry for design, safety, and operations analyses (Thurgood 1999a and 1999b). GOTH_SNF has been verified and validated and is controlled through the JMI Quality Assurance Program (Thurgood and Ogden 1999).

\subsubsection{GOTH_SNF Waste Tank Model}

4.1.2.1 General Description. Schematics of the GOTH_SNF basic model used for the benchmark analyses and AGA alternative study are shown in Figures 4-1 and 4-2. The model incorporates lumped-parameter and distributed-parameter volumes, heat conductors, and flow and pressure boundary conditions to provide a one-dimensional model of tanks 241-AY-102 and 241-AZ-102. The basic model is applied to both waste tanks. The models differ only in the certain tank-specific parameters, which include ventilation flow rates, waste geometry/properties and floor annulus configuration.

The volume inside the tank inner liner is modeled as GOTH_SNF Volume 1s. This is a distributed parameter volume with a one-dimensional model of the waste, supernatant, and dome space. The noding scheme for Volume 1s for tank 241-AY-102 is shown in Figure 4-2. GOTH_SNF control Volume 2 corresponds to the flow volume of the annulus system, in the floor of the tank. The flow volume in the annulus ventilation system, between the steel inner liner and outer liner, is modeled with control Volume 3. Volume 5 models the inlet annulus piping. This includes the drop-legs in the wall annulus region and the horizontal runs of piping leading to the center of the tank. Control Volume 4 shown in Figure 4-1, physically corresponds to the piping volume of the primary ventilation system downstream of the tank outlet. The GOTH_SNF model uses this volume only for condensing water vapor, which is returned through Valve 1 to the top of the waste in volume 1 .

The GOTH_SNF model treats the tank waste and supernatant liquid as fluid volumes with conduction heat transfer, when the mixer pumps are not operating. Other thermal masses associated with the waste tanks are modeled with one-dimensional thermal conductors. The soil directly above the tank is modeled with a one-dimensional wall conductor (thermal conductor 6) shown in Figure 4-1. The thickness of this conductor corresponds to the average soil depth above the tank. This conductor uses the ambient temperatures for the top surface and calculated dome temperatures for the bottom surface. 


\section{Figure 4-1. GOTH_SNF Model Schematic.}

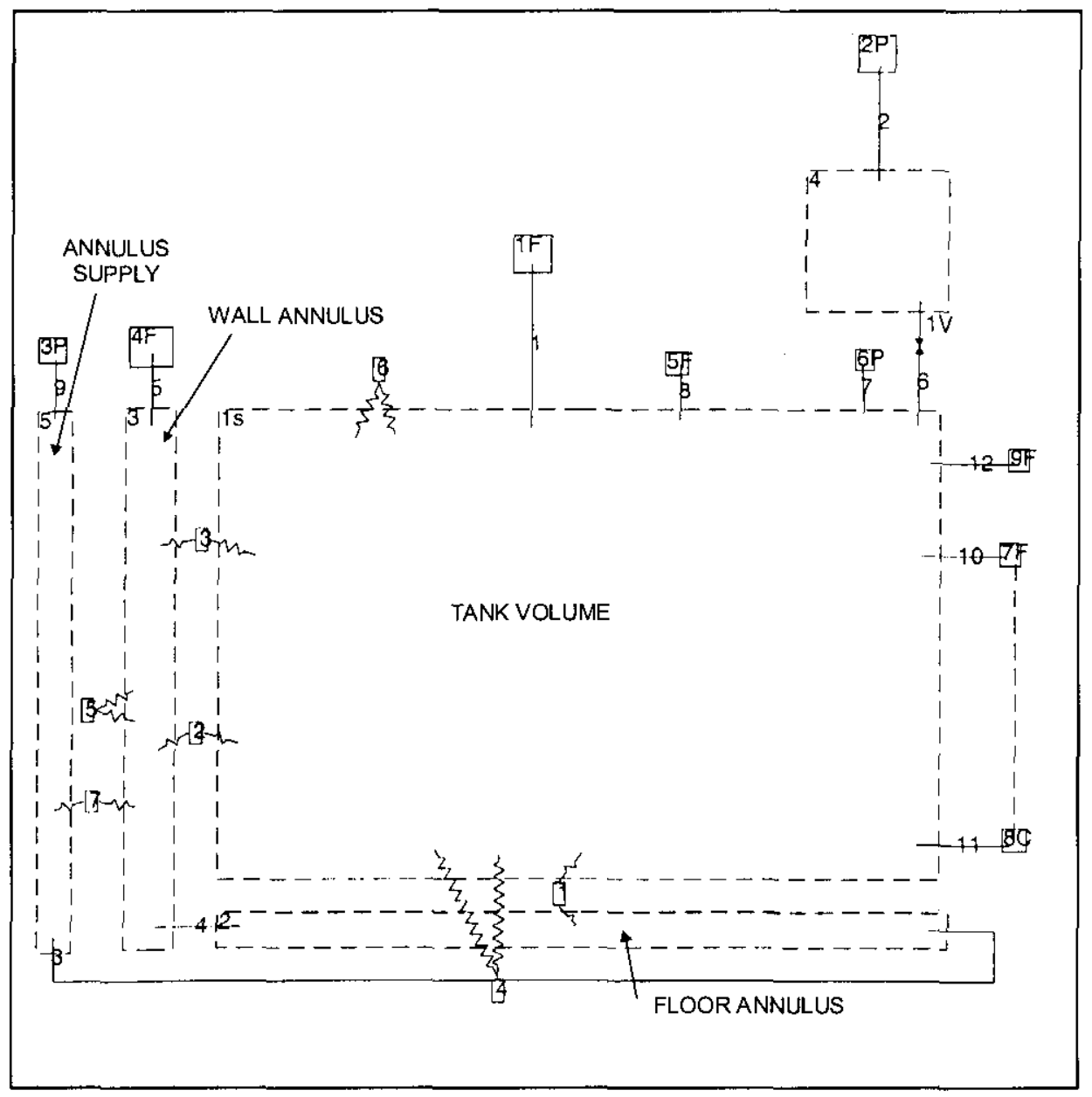

The soil surrounding the tank side is modeled with tube thermal conductor 5. The inside of the tube is connected to the wall annulus (Volume 3). The thickness of the tube conductor corresponds to the mid-point between the modeled tank and the surrounding tanks. The thermal conductor boundary is assumed adiabatic for the outside surface of the tube conductor.

The soil below the tank is modeled with a one-dimensional wall conductor (thermal

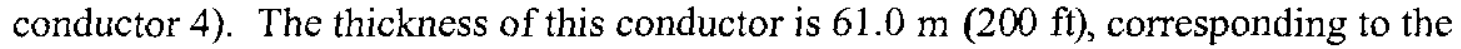
approximate distance to the water table below the tanks. A constant $12^{\circ} \mathrm{C}\left(54^{\circ} \mathrm{F}\right)$ temperature is used for this surface of the thermal conductor. This is the average annual ambient temperature, and therefore the soil temperature at a distance removed from the tanks.

The steel plates of the inner liner are modeled with three conductors. Thermal conductor 1 corresponds with the bottom plate, whereas conductors 2 and 3 model the side wall liner. Thermal conductor 8, shown in Figure 4-1, is not related to any of the physical features of the tanks. It is used to condense vapor from the tank outlet flow and return it through valve 1 to the supernatant liquid pool. This maintains the pool level at a constant value. 
Figure 4-2. GOTH_SNF One-Dimensional - Tank Volume.

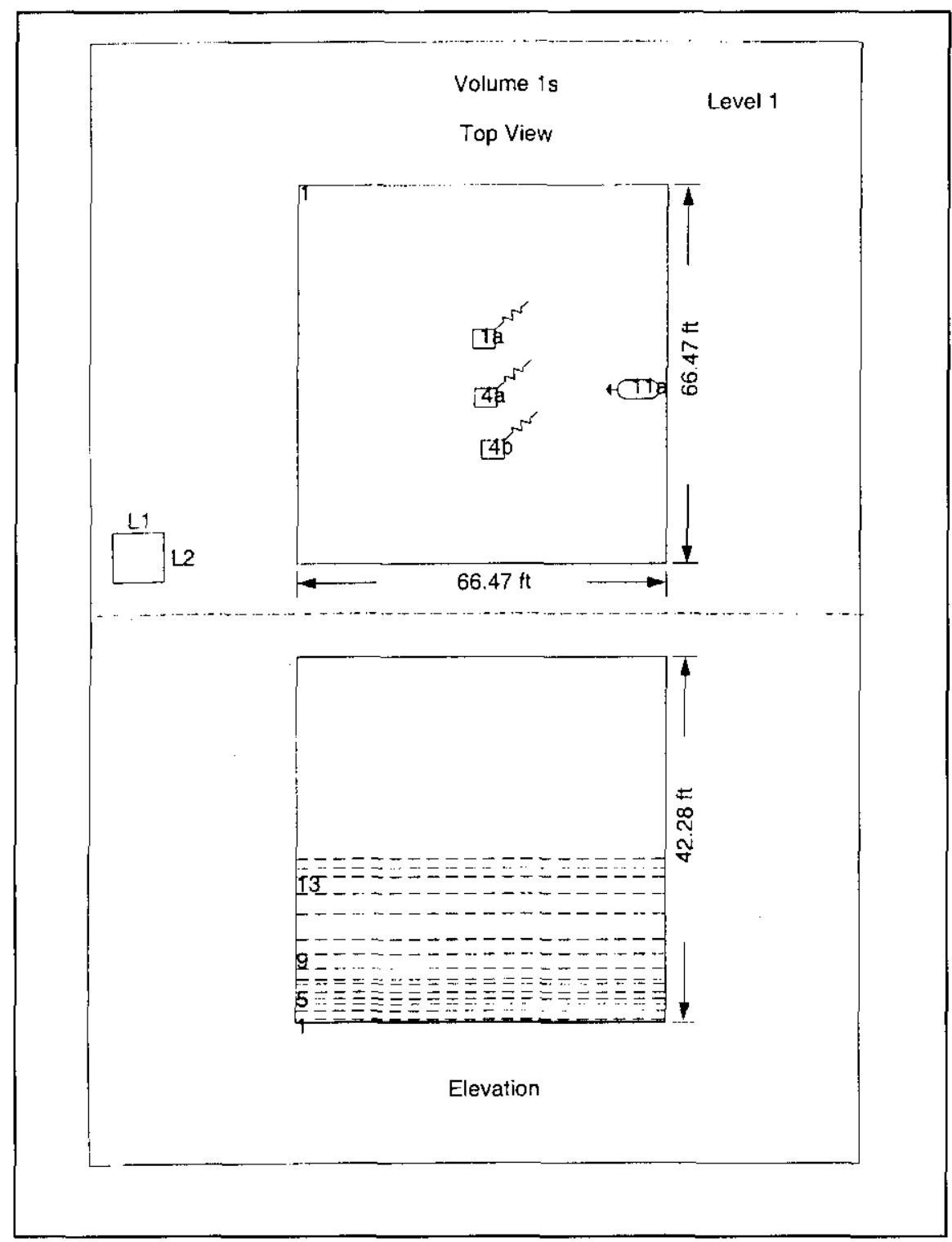

The GOTH_SNF model uses the boundary condition component to establish the temperature, humidity, and ventilation flow rates for the primary and annulus ventilation systems. Boundary conditions 1P and 3P, shown in Figure 4-1, define the ambient temperature and humidity conditions discussed in Section 3.3.

The primary and annulus flow conditions are modeled with flow boundary conditions $5 \mathrm{~F}$ and $4 \mathrm{~F}$ as shown in Figure 4-1.

Flow boundary condition $9 \mathrm{~F}$ shown in Figure 4-1 is used to model the mixer pump flow. Liquid is drawn from the supernatant pool and injected into the bottom level of waste. This provides a mixing of the settled waste. The heat associated with the operation of the pumps is modeled with a GOTH_SNF heater component shown in Figure 4-2. This component is located near the middle of the supernatant pool. 
Figure 4-1 shows the flow connectors used in the GOTH_SNF model. These flow connectors connect the control volumes using flow areas representative of the physical flow area of the tank ventilation system.

4.1.2.2 Annulus Floor Heat Transfer Model. Figure 4-3 shows a schematic of the annulus ventilation flow channel configuration for Tank 241-AZ-102. There are three radial regions of the tank floor. The number of cooling slots doubles for each radial region and the distance between cooling slots increases. The channel side and top surfaces are available for heat transfer to the waste. The cooling slot cross-section area varies in size from $3.8 \mathrm{~cm}$ (1.5 in.) by $7.6 \mathrm{~cm}(3$ in.) for the inner region to $3.8 \mathrm{~cm}(1.5 \mathrm{in}$.) by $3.8 \mathrm{~cm}$ ( $1.5 \mathrm{in}$.) for the outer region.

The floor channel-cooling configuration is modeled by averaging the forced flow heat transfer coefficient (Dittius-Boelter Correlation [Bird et al. 1960]) for the three regions of the tank. Only the top channel surface area is modeled for heat transfer. Using this minimum surface area helps offset the conduction distance between cooling slots. This heat transfer model will be benchmarked with tank data.

Figure 4-3. Annulus Ventilation Floor Slot Configuration.

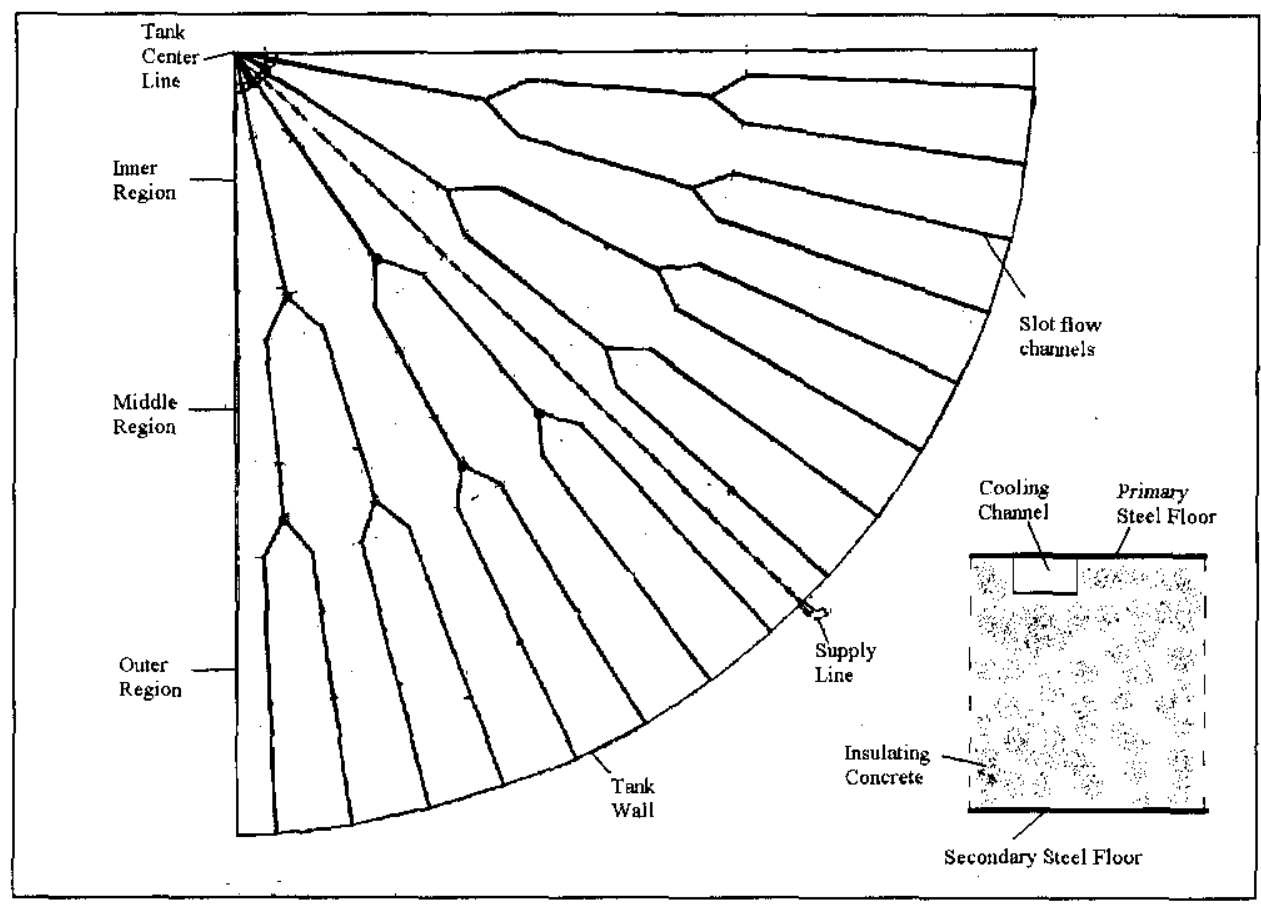




\subsection{BENCHMARK ANALYSES}

\subsubsection{Benchmark Data}

Figure 4-4 shows an overview of the location of the waste level and temperature instruments for Tank 241-AY-102. The temperature data include:

- Bottom Waste Temperatures:

The bottom waste temperatures are measured by thermocouples located on thermocouple trees existing in the tank before the initiation of Project W-320. The thermocouples are located approximately $7.6 \mathrm{~cm}$ (3 in.) from the tank floor. In addition, each airlift circulator (ALC) in Tank 241-AY-102 included a thermocouple also located $7.6 \mathrm{~cm}$ (3 in.) from the tank floor.

- Insulating Concrete Temperatures:

The tank floor is instrumented with thermocouples imbedded in the insulating concrete below the tank liner. These thermocouples are located at three radial locations, approximately 2.13 , 6.40 , and $11.0 \mathrm{~m}(7,21$, and $36 \mathrm{ft})$ from the tank centerline. These are identified as "bottom temps" in the legend of Figure 4-4.

- Multifunction-Instrument Tree:

A multifunction instrument tree (MIT) was installed in Tank 241-AY-102 for Project W-320. The MIT provides measurement of the axial temperature profile within the waste and supernatant pool and dome space. This is shown at the bottom center of Figure 4-4.

- Enraf-Nonius Series 854 (Enraf) Level:

The waste level for Tank 241-AY-102 is measured by the Enraf gauge located midway between the tank wall and centerline. This instrument provides a near continuous measurement of the level of the supernatant pool. The Enraf gauge also can be used as a densitometer. In this mode, the instrument can determine the location of the settled waste-supernatant interface. The location of the Enraf densitometer measurements is near the north wall of the tank as shown in Figure 4-4.

- Other Tank Instrumentation:

Additional measurements not shown in Figure 4-4 were also made during the retrieval of waste from Tank 241-C-106. These included the primary and annulus system volumetric flow rates, primary and annulus system outlet air temperatures, and the tank dome space humidity,

A summary of the Tank 241-AY-102 temperature data used for the GOTH_SNF model benchmark is shown in Appendix C. These data were selected because they are related to the 
energy removal and storage in the tank and indicate the maximum waste temperature. They include the primary and annulus outlet air temperatures, the supernatant liquid temperature, and the waste temperatures. 
Figure 4-4. Overview of Tank 241-AY-102 Instrumentation.

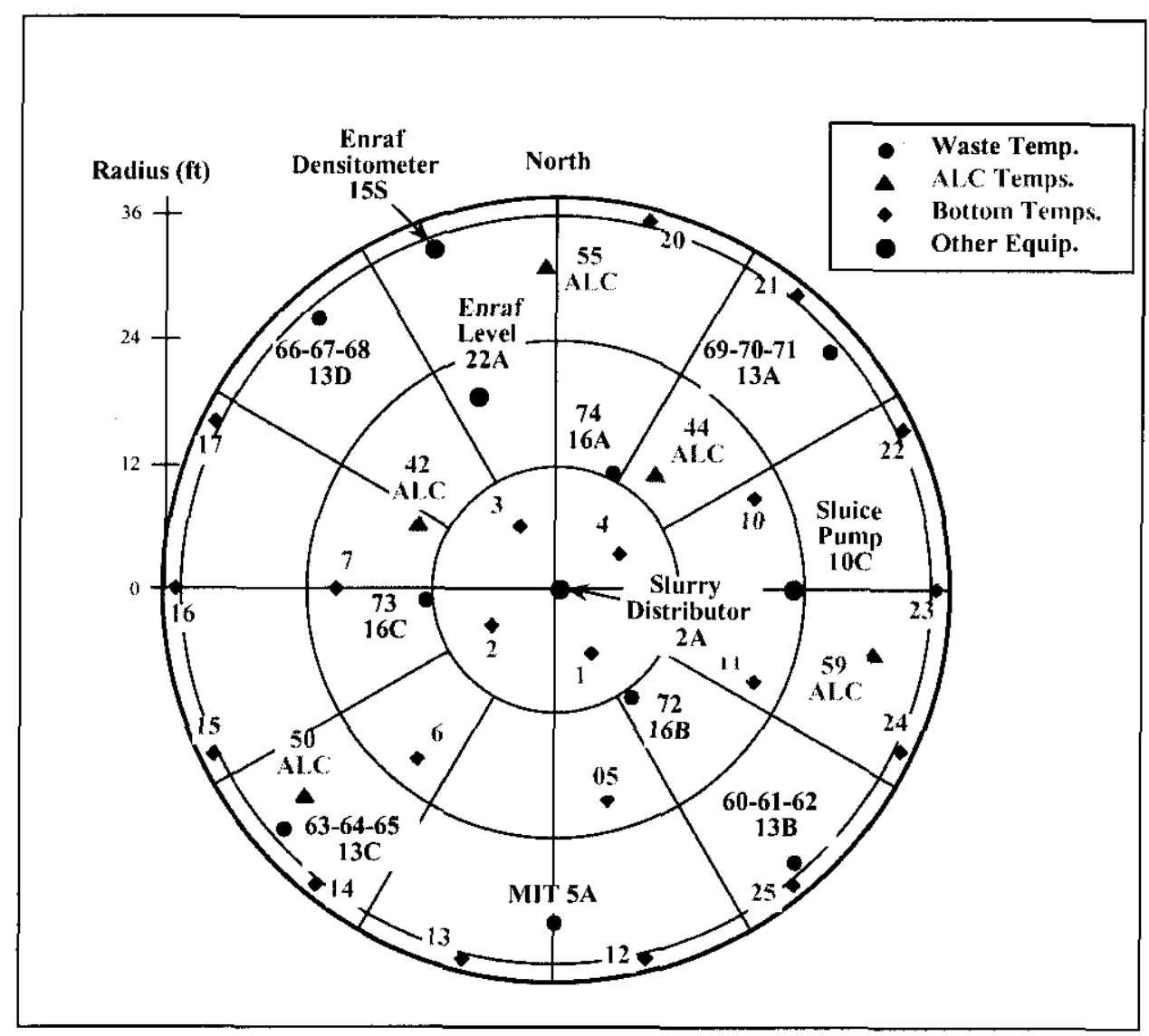

Outlet temperatures are a measure of the heat removed by the ventilation systems. The dome space humidity is also an important parameter for energy removed by the primary system. However, the measured value is nearly constant at $100 \%$, thus a time history plot is not provided.

The rate-of-change of supernatant and waste temperatures is an indication of the energy stored in the tank. These data are included in the benchmark analyses and are shown in Figures 4-5 and 4-6 which are discussed in the next section.

The maximum waste temperature will be compared with the temperature criteria for the AGA study. The maximum waste temperature is, therefore, an important parameter for the benchmark analysis. The selected data for the benchmark analysis provides an assessment of the capability of the GOTH_SNF model to account for the heat generation and removal from Tank 241-AY-102, and prediction of the maximum waste temperature.

The Enraf densitometer measurements of the settled-waste level are shown in Figure 4-7. This data show the settled-waste level near the tank wall (Figure 4-4). The increase in level seen in the figure is a result of waste transfers from Tank 241-C-106. The waste transfers were initiated in November 1998 and were completed in early October 1999. Two regions of data were selected for the benchmark analysis as shown in Figure 4-7. The first region, which is identified as "pre-sluice benchmark data," includes the period from September 1998 to March 1999. Two 
small waste transfers were performed during this period. However, the conditions in the tank are close to pre-sluice conditions. The second region, denoted as the "post-sluice benchmark data," includes the period from September 1999 to December 1999. The final waste transfers were completed early in this period. These data characterize the behavior of the tank waste at the completion of the waste transfers from Tank 241-C-106. These tank conditions will be used for the AGA study.

Figure 4-5. Post-Sluice Supernatant Liquid Temperature Comparison.

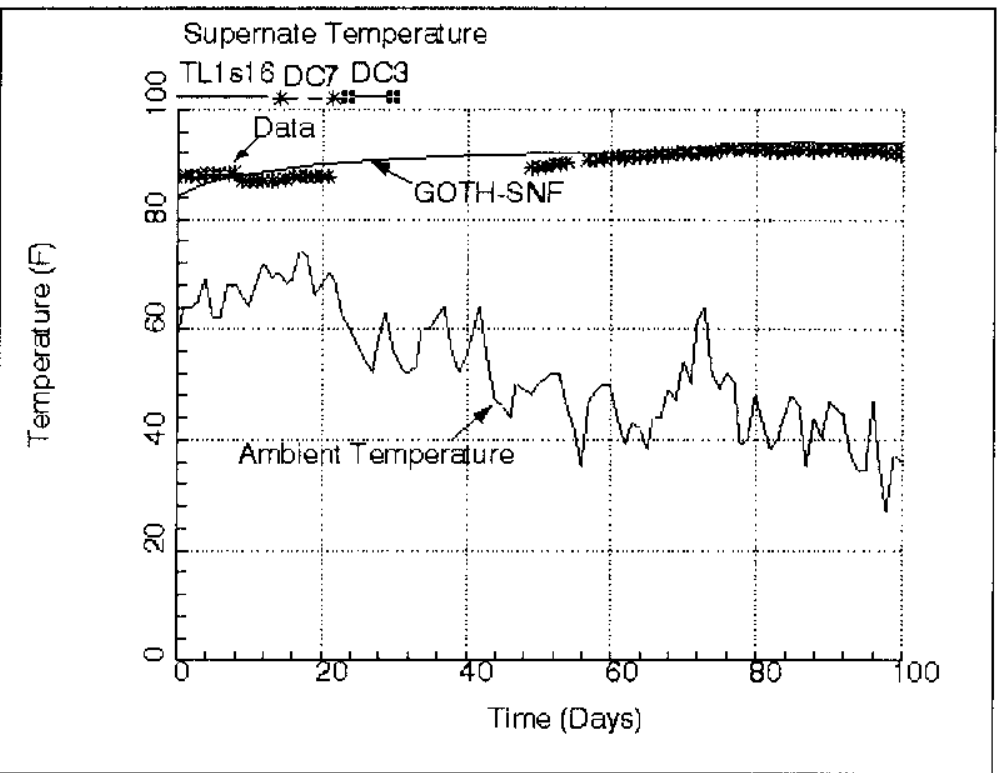

Figure 4-6. Post-Sluice Waste Temperature Comparison.

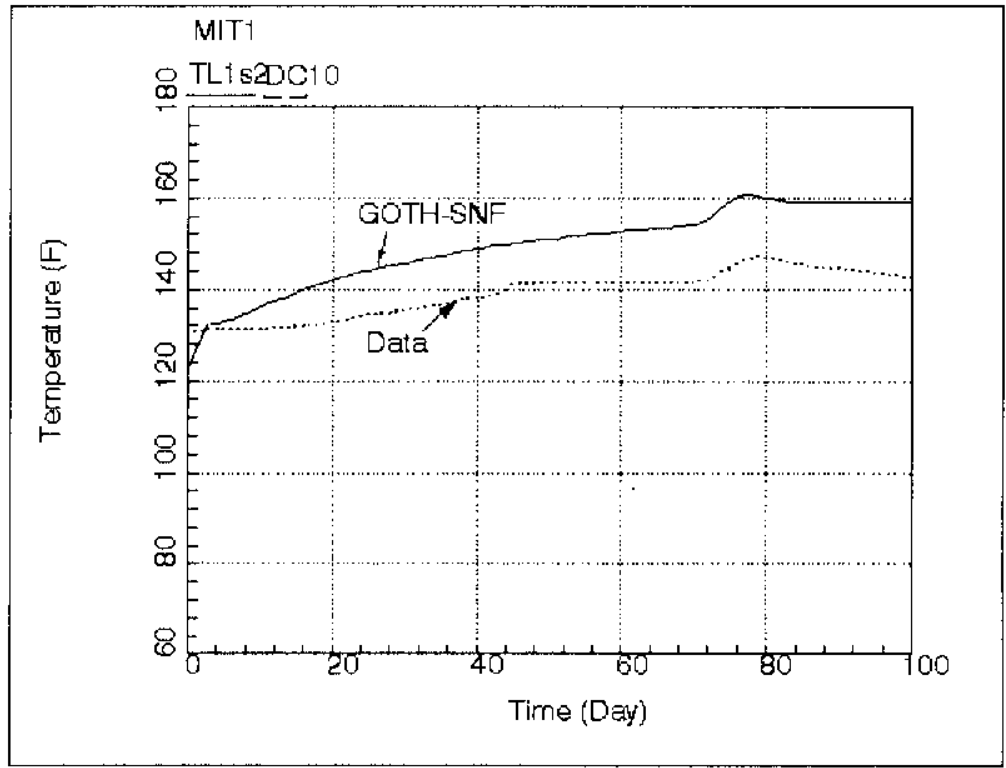


Figure 4-7. Tank 241-AY-102 Waste Level Data.

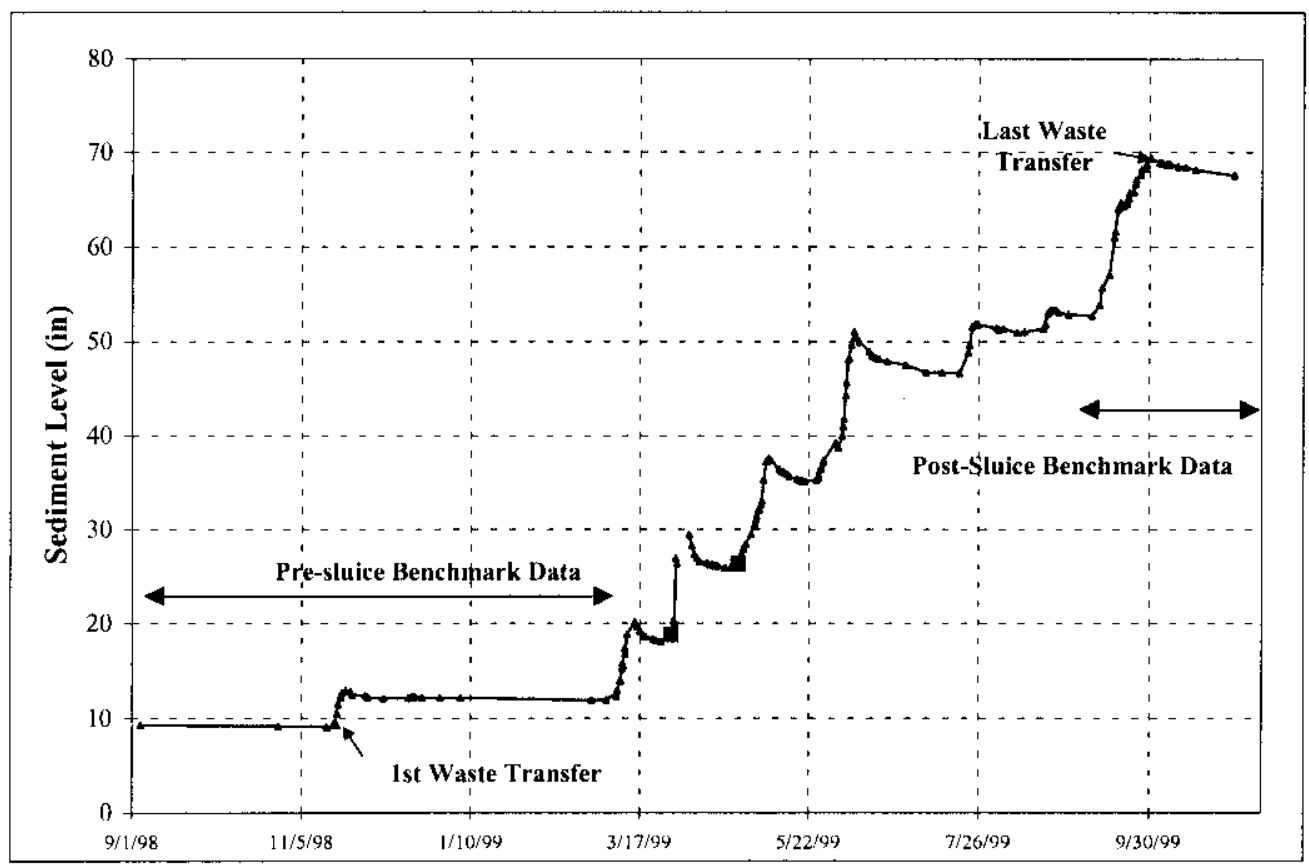

\subsubsection{Benchmark Analyses}

Benchmark analyses were performed for the post-sluicing data. This provides an assessment of the current conditions in Tank 241-AY-102. Comparison with tank data is provided in the following subsections.

A comparison of the GOTH_SNF benchmark analyses and the post-sluicing supernatant liquid temperature is shown in Figure 4-5. There is close agreement with the data. The ambient air temperature also is shown in the figure. The pool temperature remains nearly constant for many days, while the ambient temperature decreases significantly. The close agreement with the supernatant liquid temperature demonstrates that the GOTH_SNF model correctly models the energy storage and removal mechanisms from the waste tank.

A comparison of the measured annulus ventilation system outlet air temperature with the GOTH_SNF model prediction is shown in Figure 4-8. The close agreement with the data indicates that the GOTH_SNF model correctly characterizes the energy removed by the annulus system. This demonstrates that the average slot heat transfer coefficient, with the top-slot surface area, provides a good representation of the heat transfer from the waste to the annulus air. 
Figure 4-8. Post-Sluice Annulus Outlet Air Temperature Comparison.

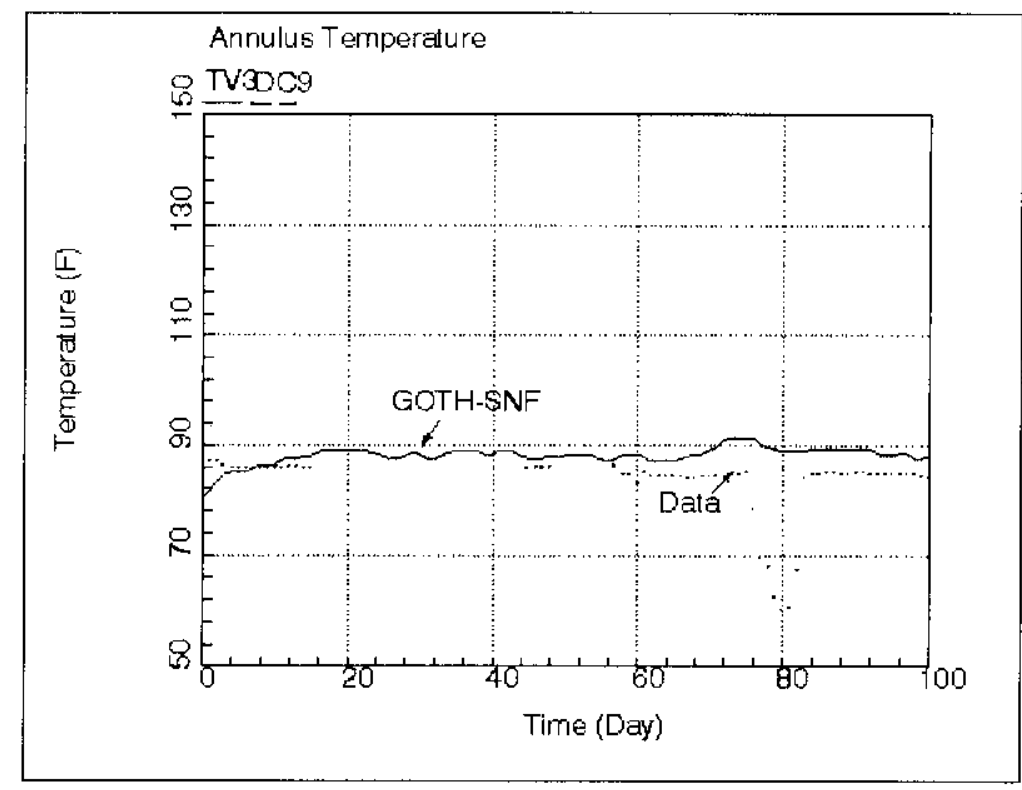

The measured waste temperature at thermocouple 1 of the MIT (28.4 cm [11.2 in.] from the tank floor) is compared with predicted waste temperatures in Figure 4-6. The GOTH_SNF model overpredicts the waste temperature by 5.5 to $8.3^{\circ} \mathrm{C}\left(10\right.$ to $\left.15^{\circ} \mathrm{F}\right)$. This is a result of the waste conduction model discussed in Section 3.3.2. The Series conduction model is conservative, resulting in higher predicted temperatures.

The annulus ventilation system was turned off for a short period following the completion of sluicing from Tank 241-C-106. The waste temperature increase, resulting from this loss of ventilation, is shown in Figure 4-6. There is good agreement with the data and the predicted temperature increase following the loss of ventilation.

Figure 4-9 compares the predicted outer bottom waste sludge temperatures with the average measured data. The figure also shows the maximum expected waste temperature based on three times the standard deviation in the data. The predicted bottom waste temperatures exceeds the average and maximum data. Thus, the application of the Series conduction model bounds the expected azimuthal variation in waste temperature. 
Rev. 0

Figure 4-9. Outer Bottom Sludge Temperature.

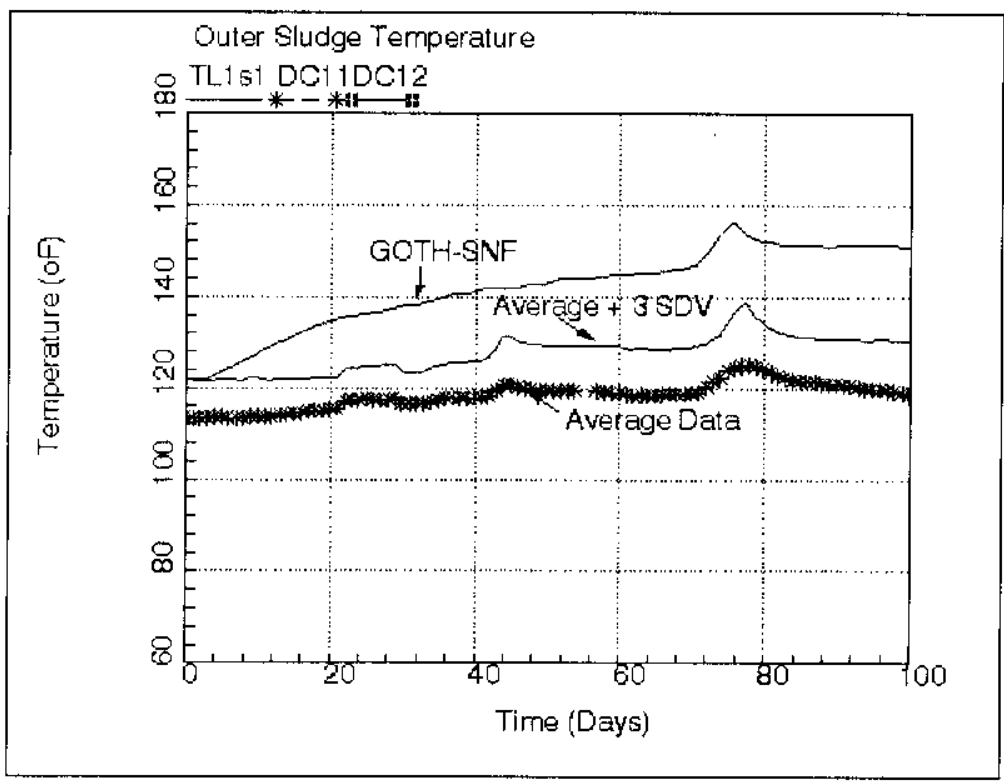




\subsection{PARAMETRIC ANALYSES RESULTS}

Parametric analyses were performed with the GOTH_SNF code to evaluate retrieval operations for the bounding HLW tanks. Predicted supernatant and slurry temperatures were compared with temperature criteria to evaluate the need for primary-side or annulus-side ventilation system upgrades. If temperature limits were exceeded for the nominal ventilation configurations, parametric analyses were performed to determine the required ventilation system performance. The results of the parametric evaluations for Tanks 241-AY-102 and 241-AZ-102 are provided in the following sections.

\subsection{TANK 241-AY-102 ANALYSES}

The evaluations of the primary and annulus ventilation systems for Tank 241-AY-102 during tank retrieval operations are provided below.

\subsubsection{Case 1: Ventilation Systems}

The predicted sludge and supernatant liquid temperatures for the steady-state mixer pump operation are shown in Figure 5-1. The first 30 days of the analyses show the steady-state temperatures for the initial settled waste (There is not any significance attached to the 30-day period prior to pump operation. This is the "numerical" time required to initialize the model). The ventilation flow rates were $0.236 \mathrm{~m}^{3} / \mathrm{s}\left(500 \mathrm{ft}^{3} / \mathrm{min}\right)$ for the primary side and $0.472 \mathrm{~m}^{3} / \mathrm{s}$ $\left(1,000 \mathrm{ft}^{3} / \mathrm{min}\right)$ for the annulus side. The constant ambient temperatures and relative humidity discussed in Section 3.3.2 were used for these analyses. The important predicted temperatures are identified in the figure. Temperatures $T_{1}$ and $T_{2}$ are the initial settled-waste supernatant and maximum waste temperatures. These temperatures are higher than measured tank temperatures shown in Figures 4-5 and 4-6. This is partly because of the conservative ambient boundary conditions. In addition, because the transfer of waste from Tank 241-C-106 was not completed until October 1999, the waste temperatures did not reach the maximum seasonal value. For this reason, Tank 241-AY-102 supernatant and waste temperatures will be higher at the end of next summer.

The instantaneously mixed-waste temperature is identified at temperature $T_{3}$ in Figure 5-1. This temperature, as expected, is well below the identified temperature limit of $90.6^{\circ} \mathrm{C}\left(195^{\circ} \mathrm{F}\right)$. Continuous pump operation (two $224 \mathrm{~kW}$ (300 Hp) pumps) increases the mixed-waste temperature. The mixed-waste temperature approaches steady state after approximately 30 days of pump operation. The steady-state temperature is below the temperature criteria. Therefore, the ventilation systems $\left(0.236 \mathrm{~m}^{3} / \mathrm{s}\left[500 \mathrm{ft}^{3} / \mathrm{min}\right]\right.$ ambient air for the primary side and $0.472 \mathrm{~m}^{3} / \mathrm{min}\left[1,000 \mathrm{ft}^{3} / \mathrm{min}\right]$ ambient air for the annulus side) are adequate to maintain the mixed-waste temperature $\mathrm{T}_{4}$ below the temperature limit of $90.6^{\circ} \mathrm{C}\left(195^{\circ} \mathrm{F}\right)$.

The moisture carryover for the primary ventilation system during steady-state pump operation is shown in Figure $5-2$. Nearly $0.000189 \mathrm{~m}^{3} / \mathrm{s}(3 \mathrm{gal} / \mathrm{min})$ moisture is carried by the primary system exhaust air. This is an important design parameter for the specification of the moisture handling components of the ventilation system. 
Figure 5-1. Tank 241-AY-102 Temperatures for 500 SCFM Primary Vent System Flow and 1000 SCFM Annulus Flow

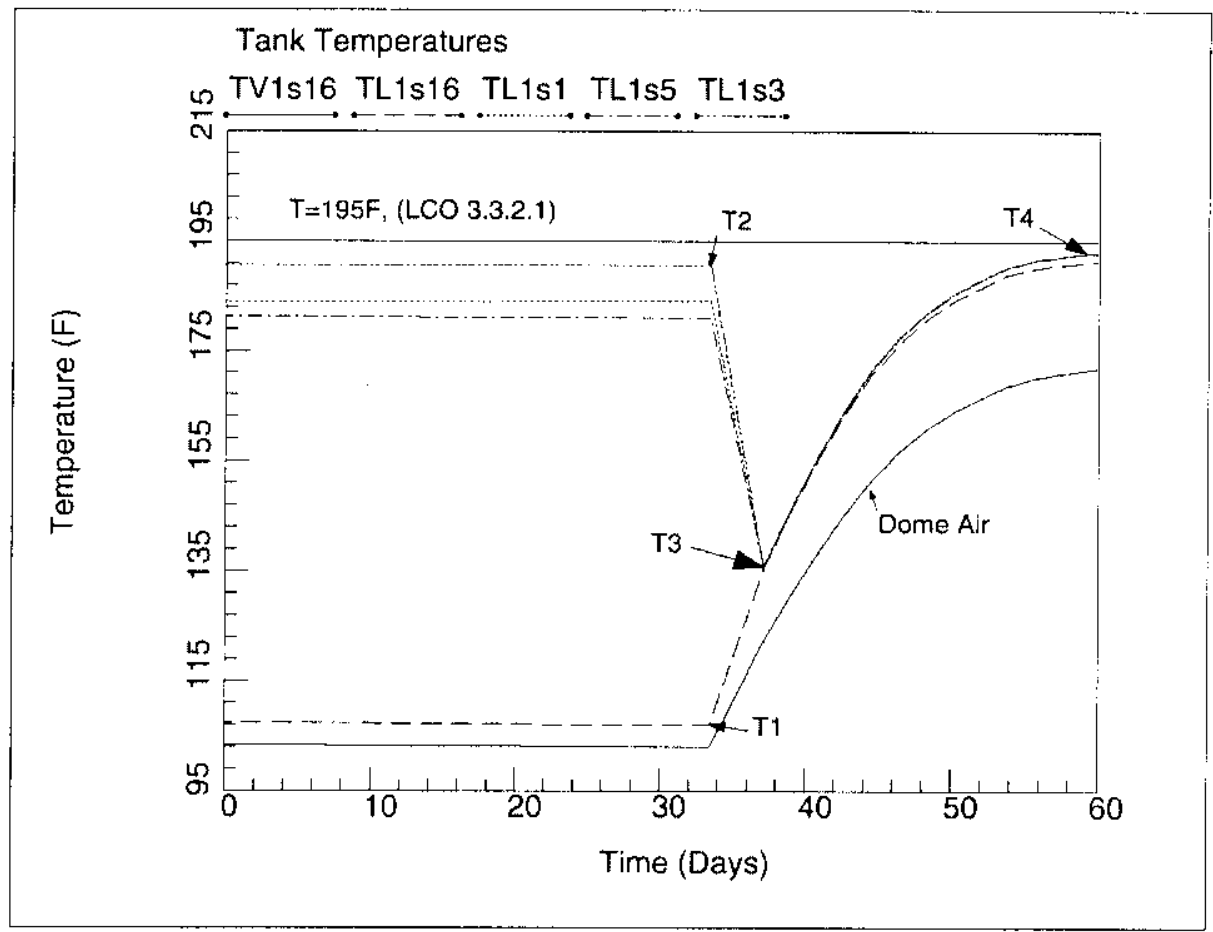

Figure 5-2. Tank 241-AY-102 Water Vapor Evaporation Rates for 500 SCFM Primary Vent System Flow and 1000 SCFM Annulus Flow

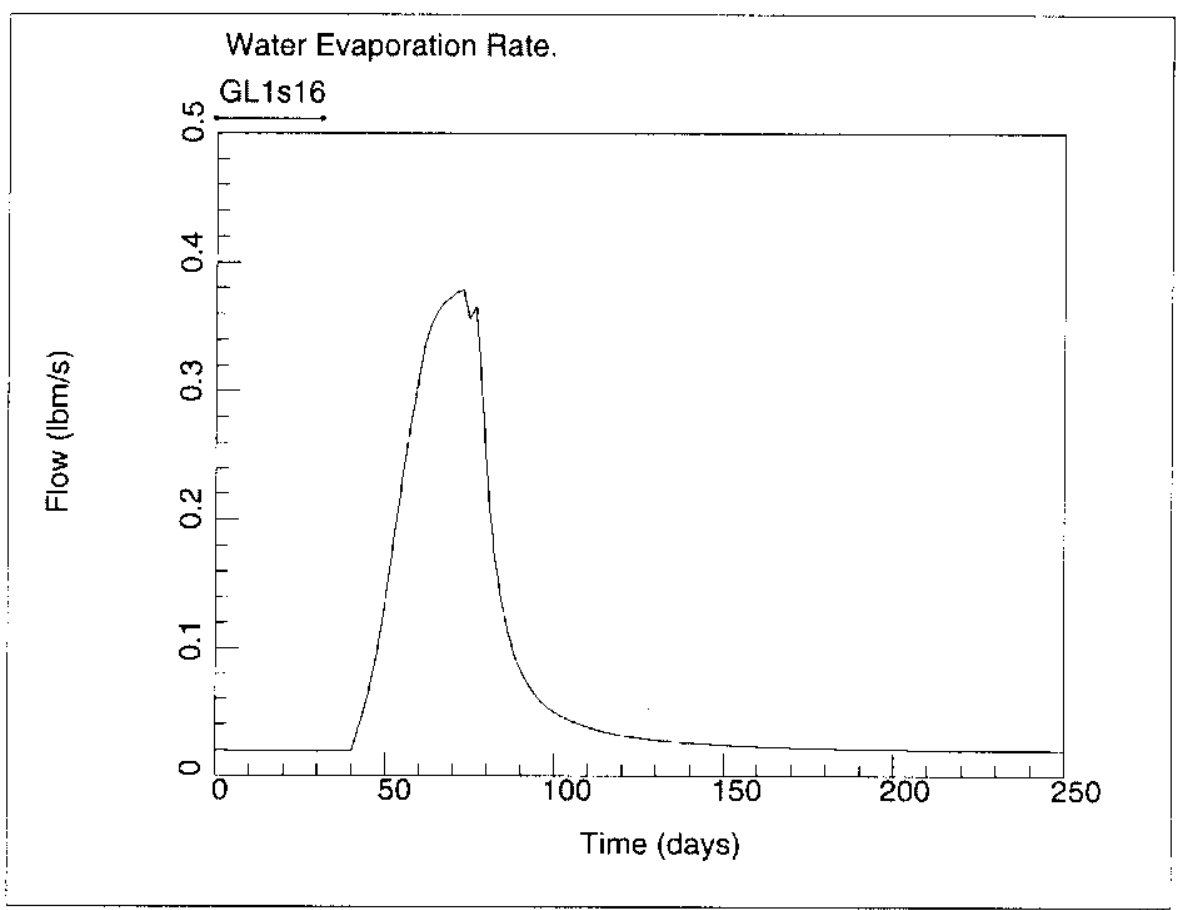


Region 1 of the thermal analyses shown in Figure 3-2, provides an evaluation of the primary ventilation system. Region 2 of the analyses evaluates the settled-waste and supernatant temperatures following the pump operation. The waste settles to a larger waste depth determined by the fluffing factor discussed in Section 3.3.2. During this region of the analyses, the annulus ventilation system is most effective at maintaining the maximum waste temperature below the temperature limits.

Figure 5-3 shows the predicted waste and supernatant temperatures for Tank 241-AY-102 during Region 2 of the analyses. The analyses were performed for ventilation flow rates of $0.236 \mathrm{~m}^{3} / \mathrm{s}$ $\left[500 \mathrm{ft}^{3} / \mathrm{min}\right]$ primary and $0.472 \mathrm{~m}^{3} / \mathrm{s}\left[1,000 \mathrm{ft}^{3} / \mathrm{min}\right]$ annulus. The maximum sludge temperature, $T^{\prime} 2$, is shown in the figure. The maximum steady-state waste temperature is below the temperature limit of $102^{\circ} \mathrm{C}\left(215^{\circ} \mathrm{F}\right)$. Thus, this level of ventilation system performance is adequate to maintain maximum waste temperatures below the LCO limit.

Figure 5-3. Tank 241-AY-102 Temperatures for 500 SCFM Primary Vent System Flow and 1000 SCFM Annulus Flow

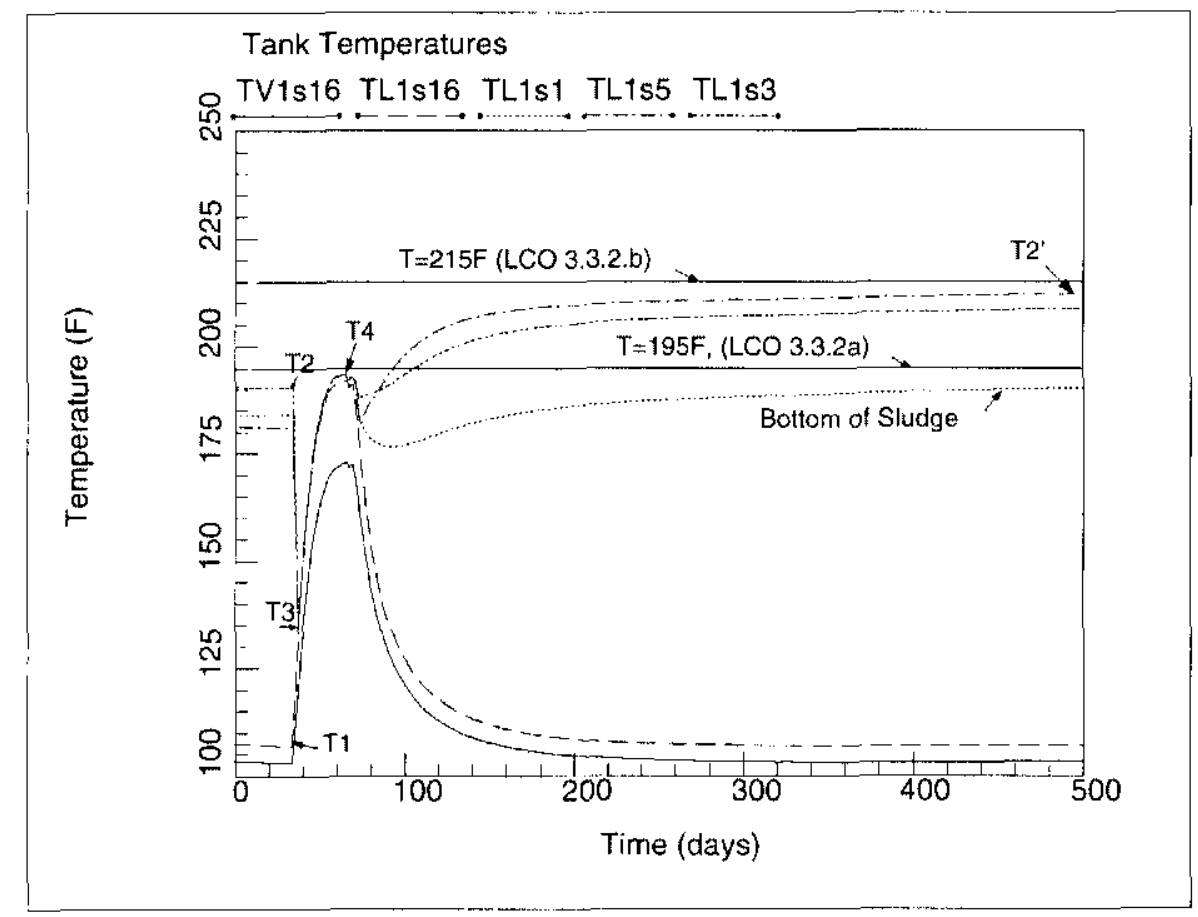

The initial settled-waste axial temperature profile is compared with the resettled-waste (post-pump operation) temperature profile in Figure 5-4. The initial and resettled-waste depths are also shown in the figure. The maximum waste temperatures increased from near $87.8^{\circ} \mathrm{C}$ $\left(190^{\circ} \mathrm{F}\right)$ before pump operation to just over $100^{\circ} \mathrm{C}\left(212^{\circ} \mathrm{F}\right)$ after resettling of the waste. This is a direct result of the larger waste depth.

The analyses shown in Section 5.1.1 show that the flow rates for the primary and annulus ventilation systems that were used during these analyses are able to maintain the waste and supernatant temperatures below the established temperature limits during retrieval operations. 


\subsubsection{Loss of Primary and Annulus Ventilation Flow}

The maximum settled-waste temperatures following pump operation are just below the temperature limit (Figure 5-4). Region 3 of the analyses evaluated the loss-of-ventilation at the time of maximum settled-waste temperature. This evaluation was intended to determine if the waste heat-up rate would allow adequate time to restore the ventilation systems.

The predicted supernatant and waste temperatures following the loss-of-ventilation is shown in Figure 5-5. The waste temperatures increase and reach a maximum temperature just below $121^{\circ} \mathrm{C}\left(250^{\circ} \mathrm{F}\right)$. The GOTH_SNF model predicts waste boiling at this temperature. The time to reach saturation is more than 50 days. This is sufficient time to restore ventilation systems (see Appendix B).

Figure 5-4. Tank 241-AY-102 Waste Axial Temperature Distributions.

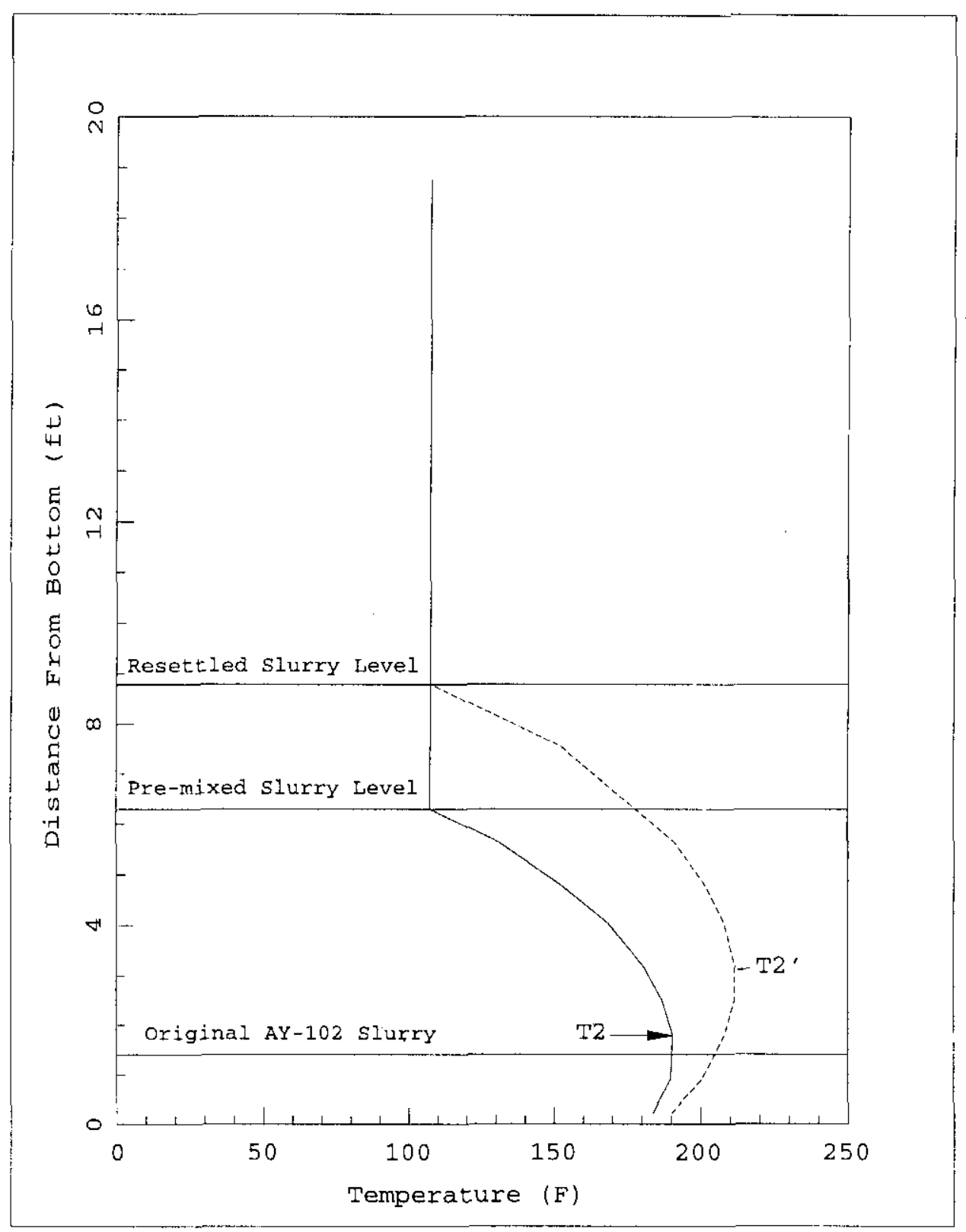


Figure 5-5. Tank 241-AY-102 Thermal Response upon Loss-of-Ventilation.

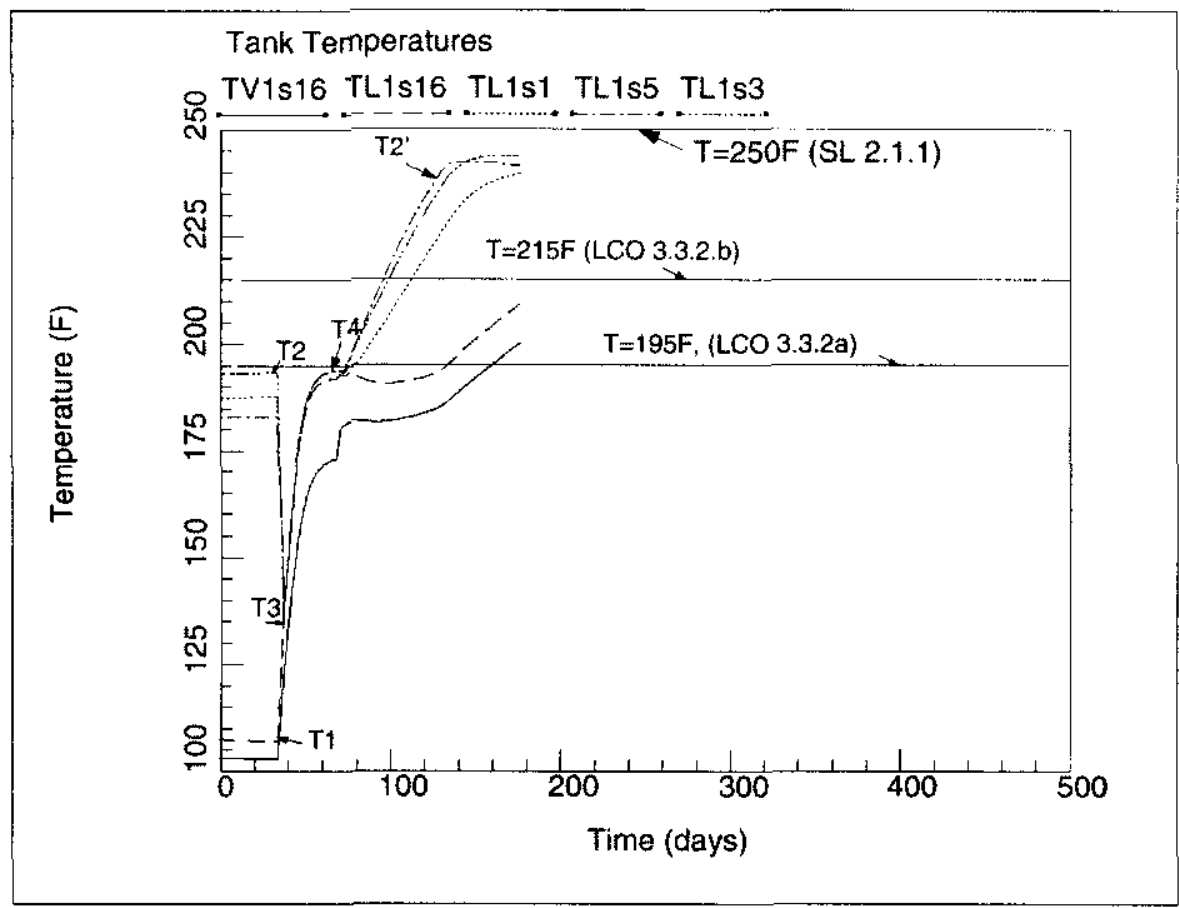

\subsection{TANK 241-AZ-102 ANALYSES}

\subsubsection{Case 1: Primary-Side Ventilation System Enhancements}

5.2.1.1 The predicted waste and temperatures for the steady-state mixer pump operation for Tank 241-AZ-102 are shown in Figure 5-6. The first 30 days of the analyses show the steady-state temperatures for the initial settled waste (There is not any significance attached to the 30-day period prior to pump operation. This is the "numerical" time required to initialize the model). The ventilation flow rates were $0.236 \mathrm{~m}^{3} / \mathrm{s}\left(500 \mathrm{ft}^{3} / \mathrm{min}\right)$ for the primary side and $0.472 \mathrm{~m}^{3} / \mathrm{s}\left(1,000 \mathrm{ft}^{3} / \mathrm{min}\right)$ for the annulus side.

During the waste-mixing operations, the heat from the mixer pump heat is the largest contributor to the heat removal requirement. This heat is generated throughout the waste and must be removed principally as latent heat from the liquid pool surface by the primary-side ventilation system. For this reason, the mixed-waste temperature response for tanks 241-AY-102 and 241-AZ-102 should be very similar. The predicted sludge and liquid temperatures for Tank 241-AZ-102 are shown in Figure 5-6. The settled-waste steady-state temperatures (premixing) are shown in the first 30 days of the analyses. The maximum waste temperature is less than in Tank 241-AY-102 (Figure 5-1), although Tank 241-AZ-102 has nearly double the heat load. This is a result of the smaller settled-waste volume in Tank 241-AZ-102 (Section 3.3.1). During steady-state mixer pump operation, the mixed-waste temperature $\left(\mathrm{T}_{4}\right)$ approaches the $90.6^{\circ} \mathrm{C}$ $\left(195^{\circ} \mathrm{F}\right)$ temperature limits after more than 30 days of continuous pump operation. This 
temperature may exceed the temperature limit of $90.6^{\circ} \mathrm{C}\left(195^{\circ} \mathrm{F}\right)$ with additional pump operation. However, 30 days of continuous, full power pump operation is considered adequate to ensure complete waste mixing. In addition, the mixed-waste temperature after 30 days of pump operation increases very slowly. Additional pump operation would result in mixed-waste temperature only slightly above the temperature limit.

Figure 5-6. Tank 241-AZ-102 Case 1 Temperatures for 500 SCFM Primary Vent System Flow and 1000 SCFM Annulus Flow

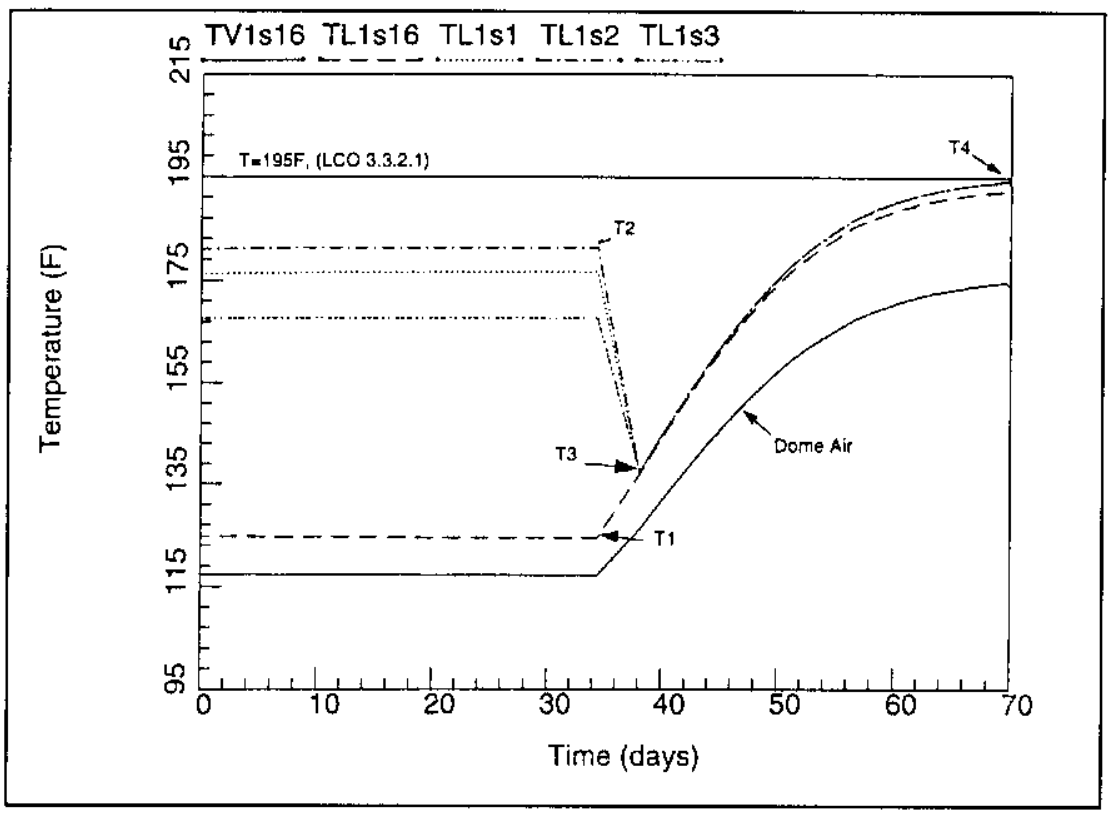

The evaporation rate from the supernatant pool is shown in Figure 5-7. The maximum rate occurs as the supernatant temperature during pump operation approached steady state. Notice that the evaporation rate for Tank 241-AZ-102 is lower than Tank 241-AY-102 during pump operation. This difference is primarily because of enhancement in the annulus-side ventilation for Tank 241-AZ-102.

5.2.1.2 No Annulus Ventilation. The initial settled-waste steady state and steady state pump operation was evaluated assuming no annulus ventilation system operation. The predicted waste and supernatant temperatures are shown in Figure 5-8. Without the annulus-side ventilation, the maximum settled-waste temperature exceeds $93.3^{\circ} \mathrm{C}\left(200^{\circ} \mathrm{F}\right)$, about $11.1^{\circ} \mathrm{C}\left(20^{\circ} \mathrm{F}\right)$ higher than the previous case with annulus-side ventilation (Figure 5-6). However, the settled-waste temperature is still below the temperature limit. The mixed-waste temperature during steady-state pump operation is also higher than the previous case. The mixed-waste temperature exceeds the temperature limit after approximately 30 days of continuous, full power, pump operation. Thus, maximum waste temperatures exceed the applicable temperature limit during the waste mixing (Section 5.2.2.3). 
Figure 5-7. Tank 241-AZ-102 Water Vapor Evaporation Rates.

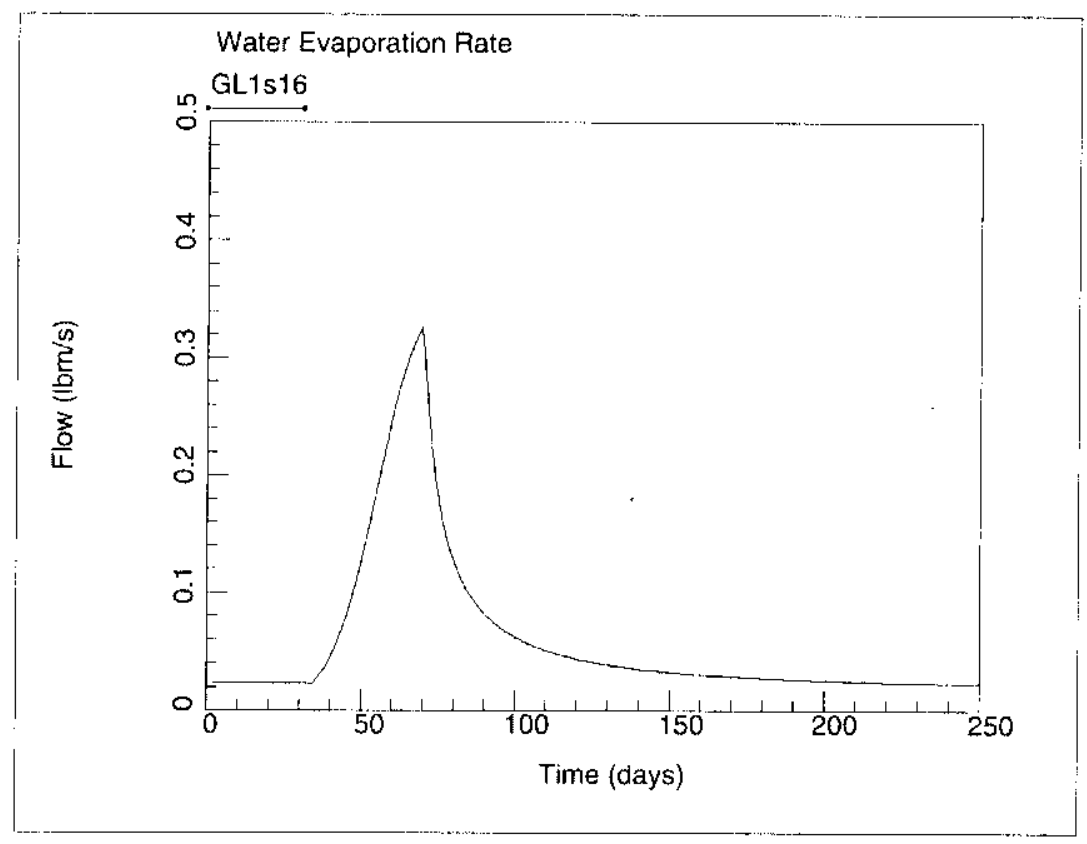

Figure 5-8. Tank 241-AZ-102 Case 1 Temperatures with No Annulus Ventilation.

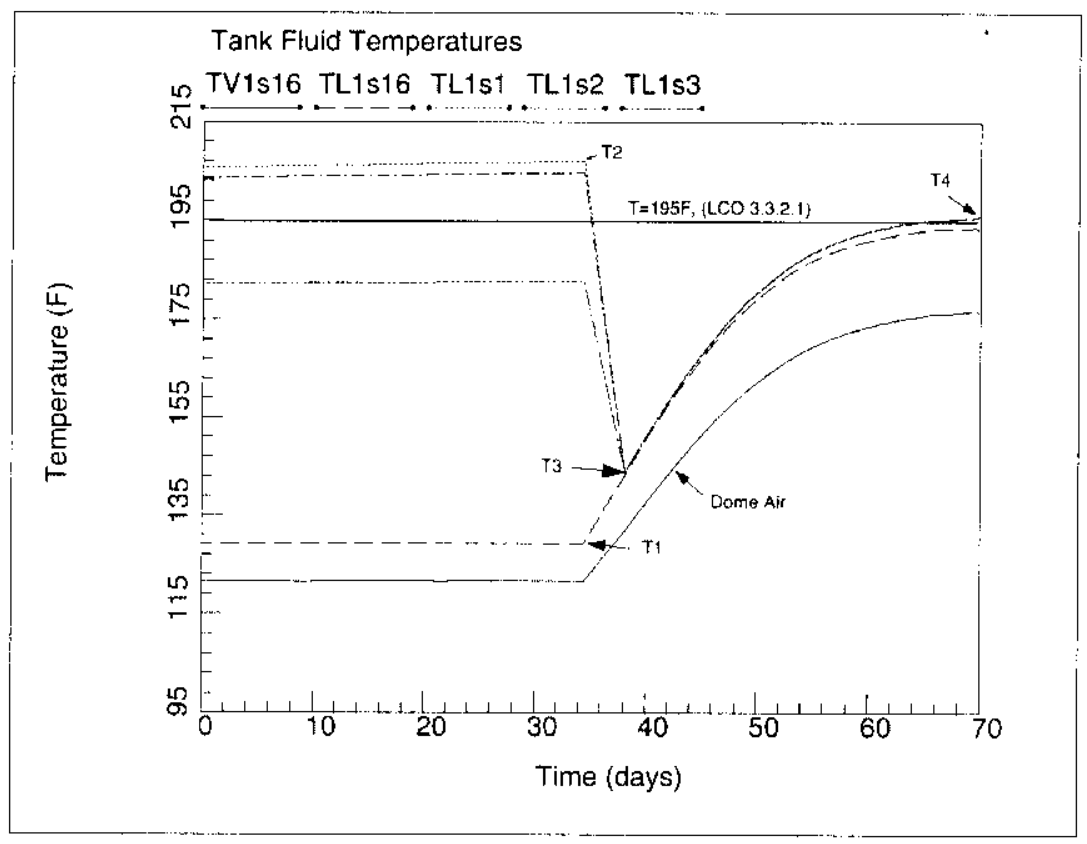




\subsubsection{Case 2: Annulus-Side Ventilation System Enhancements}

5.2.2.1 The predicted resettled-waste maximum and supernatant liquid temperatures, following steady-state pump operation are shown in Figure 5-9. These analyses were performed for the ventilation system flows of $0.236 \mathrm{~m}^{3} / \mathrm{s}\left(500 \mathrm{ft}^{3} / \mathrm{min}\right)$ for the primary side and $0.472 \mathrm{~m}^{3} / \mathrm{s}$ $\left(1,000 \mathrm{ft}^{3} / \mathrm{min}\right)$ for the annulus side. Three sludge temperatures are identified in the figure. These temperatures correspond to the waste temperature for the tank bottom sludge, middle sludge, and top sludge as shown in Figure 5-9. The sludge temperature for most of the resettled waste exceeds the temperature limit of $102^{\circ} \mathrm{C}\left(215^{\circ} \mathrm{F}\right)$.

Conservative values were selected for the three input parameters discussed in Section 3.3.2. The conservatism of these input parameters resulted in a conservative prediction of the maximum waste temperature. This conservatism could be reduced by a careful evaluation of the uncertainty in the input parameters and analyses. A reduction of the conservatism would reduce the predicted waste temperatures. The revised predictions could result in temperatures below the temperature criteria.

Figure 5-9. Tank 241-AZ-102 Case 2 Temperatures for Nominal Ventilation.

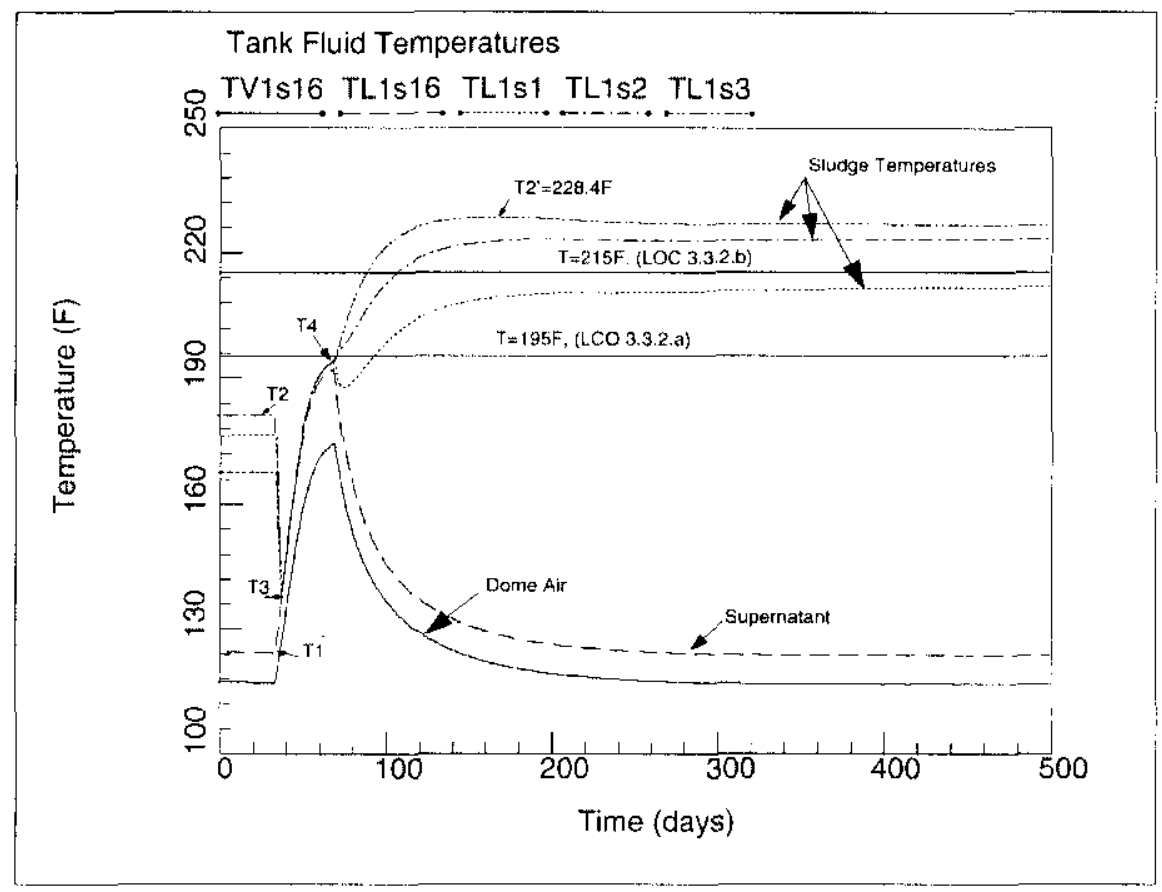


Figure 5-10. Descriptions of GOTH_SNF Plot Parameters

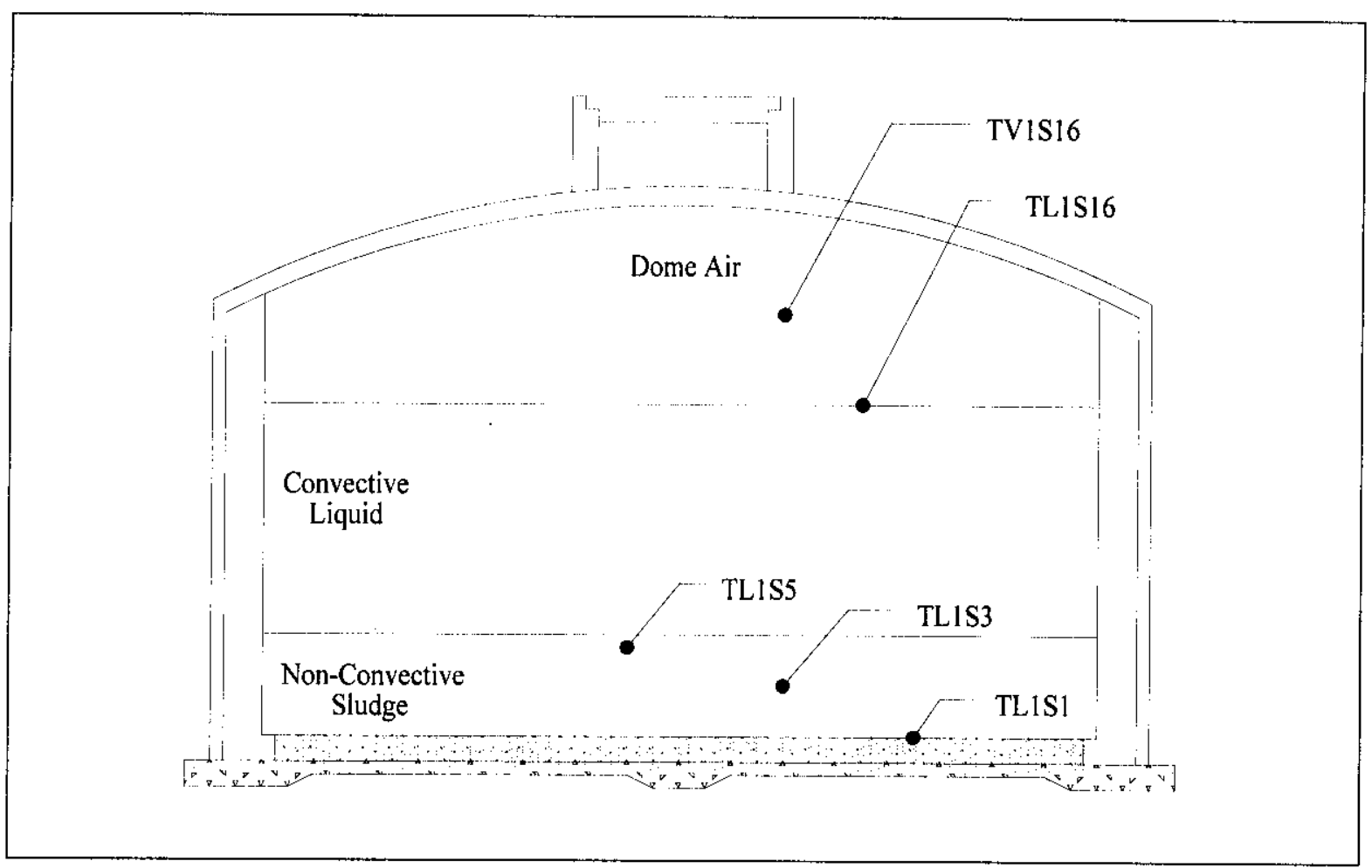


5.2.2.2 Enhanced Annulus Flow with Chilled Air. Parametric analyses were performed to determine the minimum annulus-side ventilation system performance required to maintain the steady-state resettled-sludge temperature below the temperature criteria. These parametric analyses are discussed in Appendix F. The parametric analyses demonstrated that the annulus-side ventilation system requires an enhancement both in flow rate and inlet temperature. Figure 5-11 shows the predicted resettled-sludge and supernatant liquid temperatures for an annulus-side ventilation flow of $0.944 \mathrm{~m} \mathrm{~m}^{3} / \mathrm{s}\left(2,000 \mathrm{ft}^{3} / \mathrm{min}\right)$ and inlet chilled air of $4.4^{\circ} \mathrm{C}\left(40^{\circ} \mathrm{F}\right)$. The waste temperature increases as the mixed waste begins to settle. The sludge temperature identified by TL1s4 (Figure 5-10 provides a schematic of the GOTH_SNF variable definitions, "T" denotes temperature, "L" denotes liquid, " 1 denotes volume 1 and " 4 " denotes the fourth subvolume of volume 1) is the fourth computational cell from the bottom of the waste. The temperature increase at this location occurs later than TL1s2 and TL1s3 as the settled-waste height increases. As the waste temperature increases because of increasing waste height, the supernatant temperature decreases as a result of the reduction in heat input caused by cessation of pump operations. These two effects produce the maximum waste temperature, which occurs near 120 days. This temperature is below the $102^{\circ} \mathrm{C}\left(215^{\circ} \mathrm{F}\right)$ temperature limit. The settledwaste temperature decreases over the next 200 to 300 days, reaching a steady-state temperature well below the temperature limit. Thus, annulus-ventilation system must be enhanced with both flow and inlet air chilling to prevent maximum waste temperature from exceeding the temperature limit during the early portion of the waste settling.

Figure 5-12 shows the settled-waste temperature profiles for the pre- and post-pump operations. The post-pump operations temperature includes both the time of maximum waste temperatures (T2') (approximately 120 days) and the steady-state resettled-waste condition(T2"). The fluffing factor for the resettled waste resulted in a sludge height, which is double the initial height. The maximum waste temperature increases by more than $10^{\circ} \mathrm{C}\left(50^{\circ} \mathrm{F}\right)$. 
RPP-5637

Rev. 0

Figure 5-11. Tank 241-AZ-102 Case 2 Temperatures with 2000 SCFM Annulus Flow and Chilled Air.

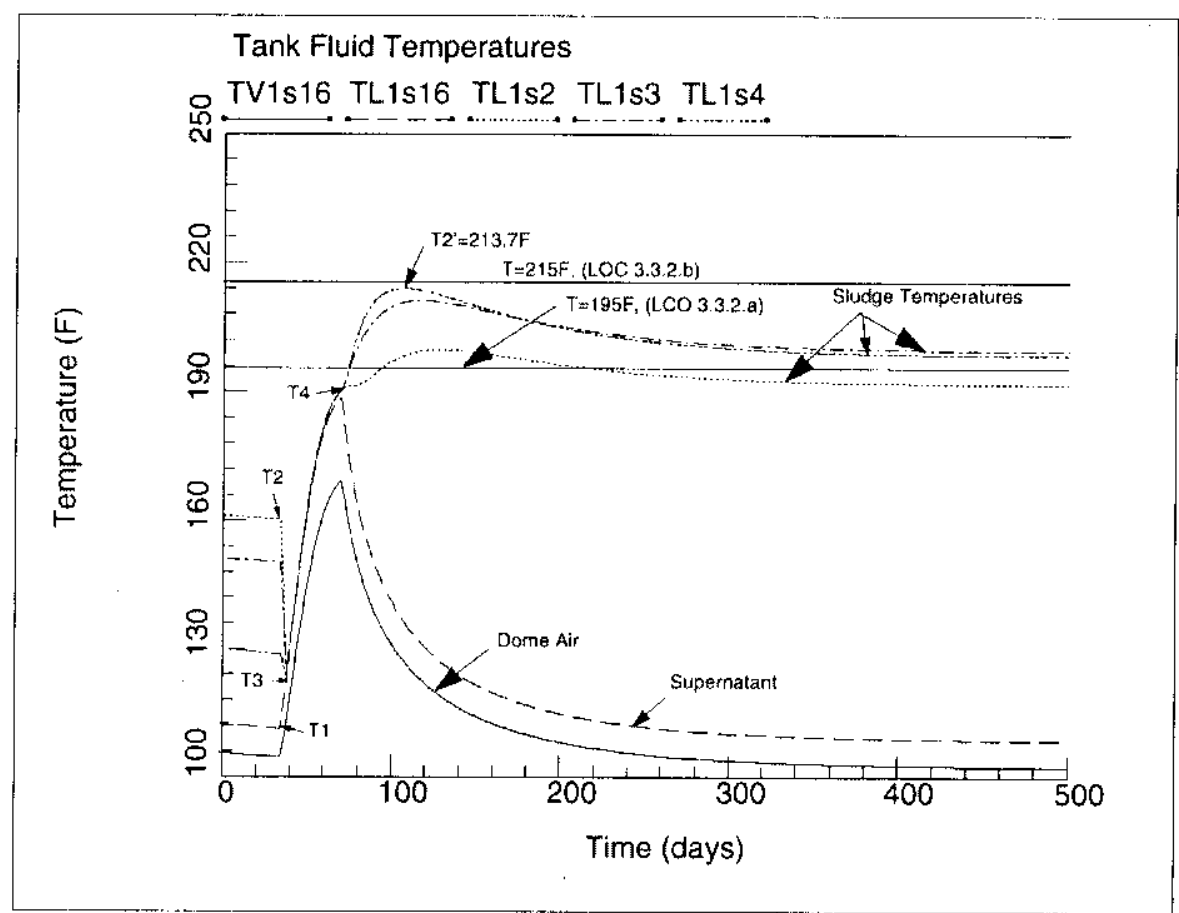


Figure 5-12. Tank 241-AZ-102 Waste Axial Temperature Distribution.

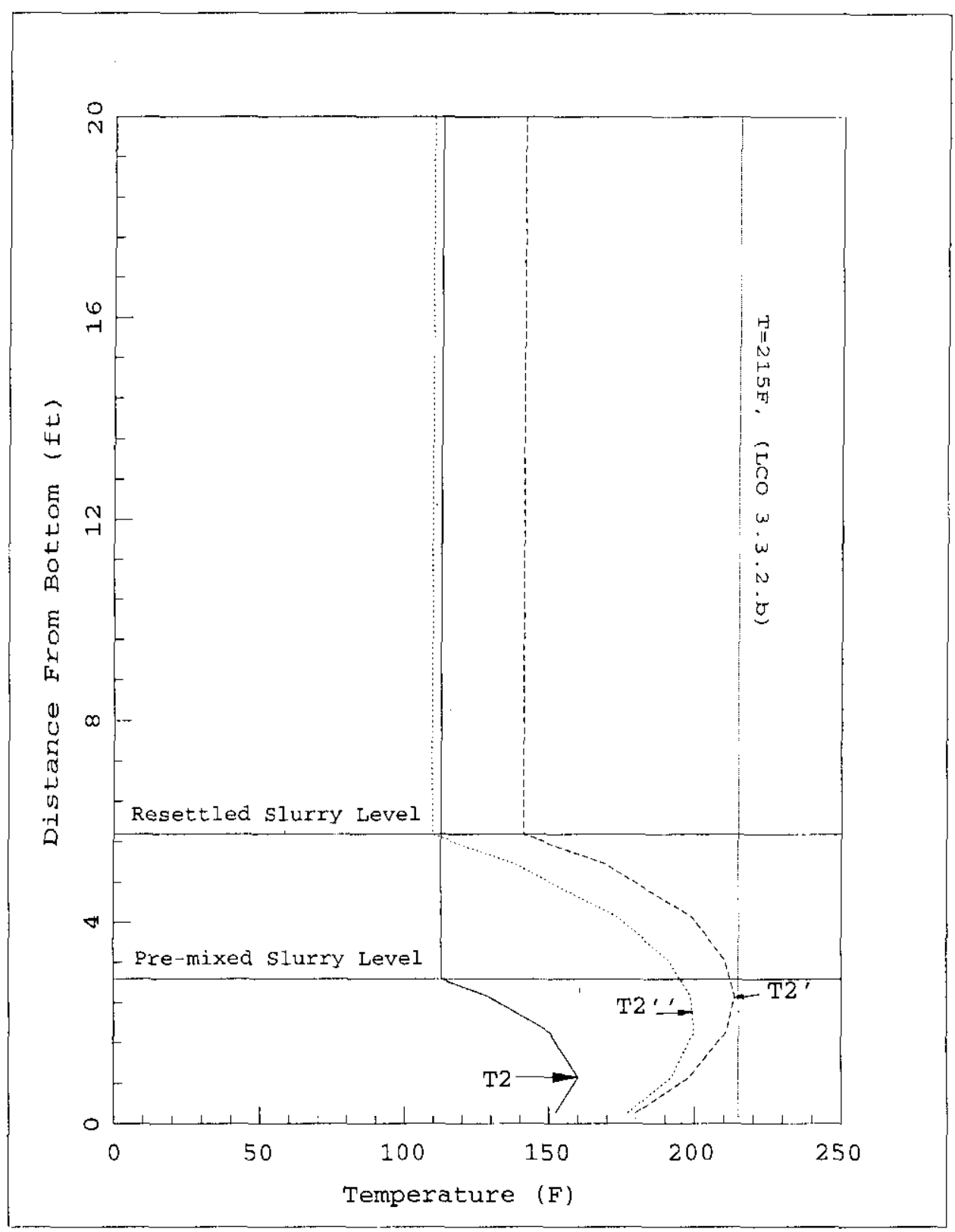

The loss of primary- and annulus-side ventilation analysis was performed for Tank 241-AZ-102. The ventilation was assumed lost when the pool temperature approached the supernatant temperature limit during steady-state pump operation. The GOTH_SNF model predicts that maximum waste temperature will require more than 50 days before the settled waste temperature safety limit is exceeded after the ventilation systems are inoperable (Figure 5-13). This provides adequate time to restore ventilation before waste temperatures reach saturation temperatures. Notice that the waste temperatures for the hottest two computational cells (TL1s2 and TL1s3) reach a near constant temperature near 120 days. This is the saturation temperature computed by the GOTH_SNF model. 
Figure 5-13. Tank 241-AZ-102 Enhanced Annulus with Loss of Ventilation.

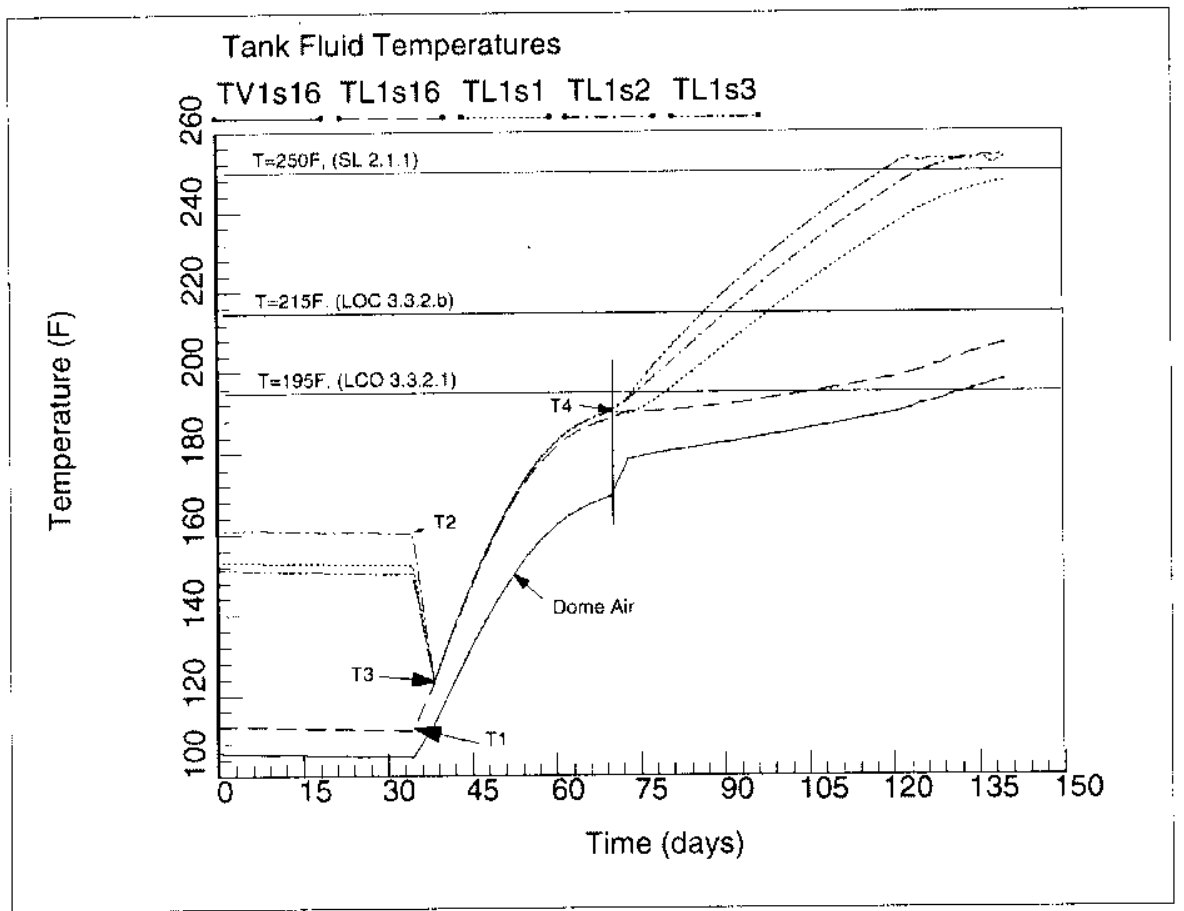

\subsubsection{No Annulus Ventilation}

The post-pumping waste resettling region of retrieval operation was analyzed assuming only primary-side ventilation. The result of the GOTH_SNF analysis is shown in Figure 5-14. The maximum sludge temperatures of the resettled waste exceed the temperature criteria of $102{ }^{\circ} \mathrm{C}$ $\left(215^{\circ} \mathrm{F}\right)$. 
Figure 5-14. Tank 241-AZ-102 Case 2 Temperatures with 500 SCFM Primary Flow and No Annulus Ventilation.

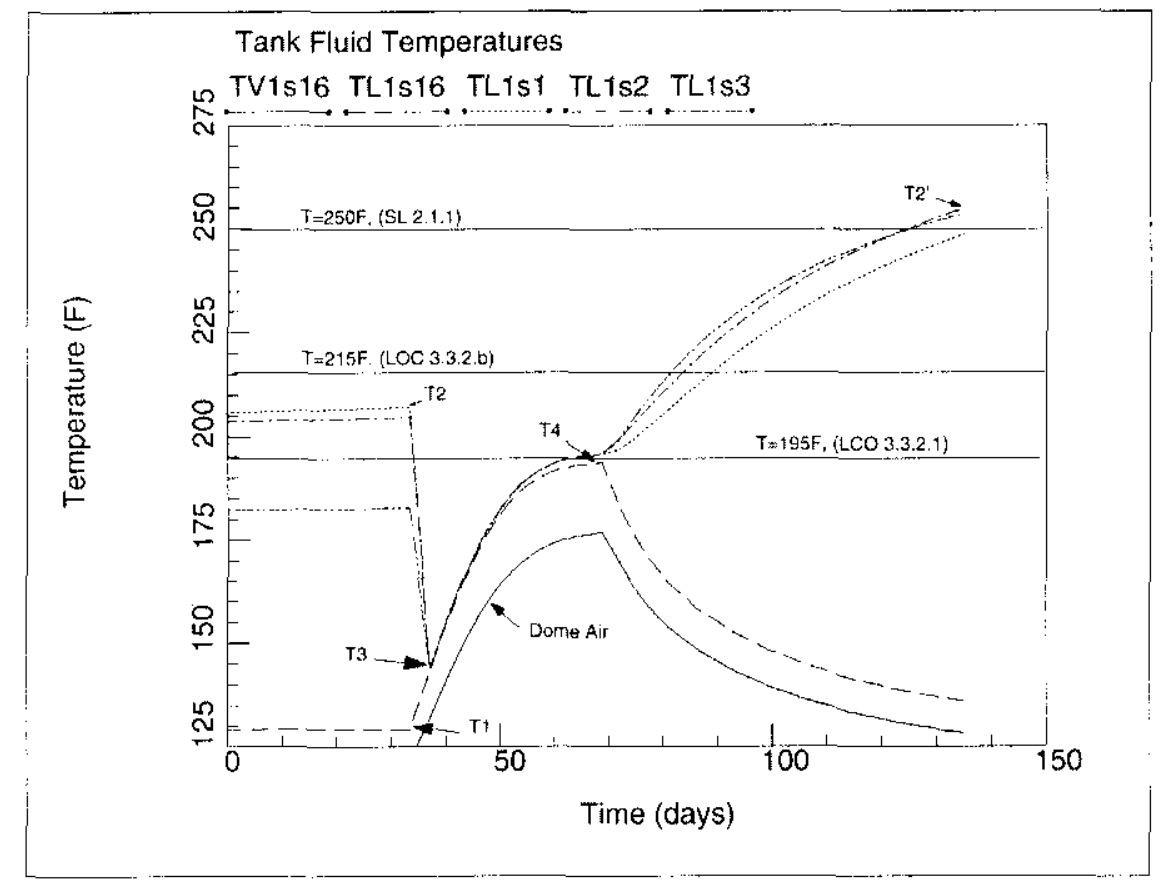

\subsection{SUMMARY OF RESULTS}

A summary of the parametric analyses for the bounding HLW cases is presented in Table 5-1. The ventilation system flows and boundary conditions are shown for each analysis. The maximum predicted temperatures during the pump operation (mixed waste temperature) and subsequent waste resettling are shown in the table. The predicted temperatures that met the temperature criteria are indicated with a bold font.

The evaluation of the primary ventilation systems for both HLW bounding cases showed that the nominal ventilation flow rates defined in the input parameter specifications (Appendix B) are adequate to maintain mixed waste temperatures below the LCO temperature limit. The nominal primary ventilation systems, in concert with the annulus ventilation systems, were sufficient after waste resettling.

The evaluation of the annulus ventilation system for the two bounding HLW cases demonstrated that the nominal annulus ventilation system for tank 241-AY-102 in concert with the nominal primary ventilation system will maintain mixed waste and resettled waste temperature below the applicable temperature criteria.

The evaluation of the annulus ventilation system for tank 241-AZ-102 showed that the nominal annulus ventilation system cannot keep the resettled waste temperature below the LCO temperature limit. Ventilation system modifications are required as shown in Table 5-1. 
Table 5-1. Summary of Parametric Results.

\begin{tabular}{|c|c|c|c|c|c|c|}
\hline \multirow{2}{*}{$\begin{array}{c}\text { HLW } \\
\text { Bounding } \\
\text { Case }\end{array}$} & \multirow{2}{*}{$\begin{array}{l}\text { Ventilation } \\
\text { System }\end{array}$} & \multirow[b]{2}{*}{ Flow Rate } & \multirow{2}{*}{$\begin{array}{c}\text { Inlet } \\
\text { Temperature }\end{array}$} & \multirow{2}{*}{$\begin{array}{l}\text { Mixed Waste } \\
\text { Temperature }\end{array}$} & \multicolumn{2}{|c|}{ Settle Waste Temperature } \\
\hline & & & & & Peak & $\begin{array}{c}\text { Settled } \\
\text { Steady Sate }\end{array}$ \\
\hline \multirow[b]{2}{*}{ AY -102} & Primary & $\begin{array}{c}0.236 \mathrm{~m}^{3} / \mathrm{s} \\
(500 \mathrm{ft} 3 / \mathrm{min}) \\
\end{array}$ & Ambient & \multirow{2}{*}{$\begin{array}{l}\underline{100^{\circ} \mathrm{C}} \\
\left(195^{\circ} \mathrm{F}\right)\end{array}$} & \multirow{2}{*}{$\frac{100^{\circ} \mathrm{C}}{\left(212^{\circ} \mathrm{F}\right)}$} & \multirow{2}{*}{$\frac{100^{\circ} \mathrm{C}}{\left(212^{\circ} \mathrm{F}\right)}$} \\
\hline & Annulus & $\begin{array}{c}0.472 \mathrm{~m}^{3} / \mathrm{s} \\
(1,000 \\
\left.\mathrm{ft}^{3} / \mathrm{min}\right) \\
\end{array}$ & Ambient & & & \\
\hline \multirow[b]{2}{*}{ AZ-102 } & Primary & $\begin{array}{c}0.236 \mathrm{~m}^{3} / \mathrm{s} \\
\left(500 \mathrm{ft}^{3} / \mathrm{min}\right)\end{array}$ & Ambient & \multirow{2}{*}{$\begin{array}{l}100^{\circ} \mathrm{C} \\
\left(195^{\circ} \mathrm{F}\right)\end{array}$} & \multirow{2}{*}{$\begin{array}{c}109.1^{\circ} \mathrm{C} \\
\left(228.4^{\circ} \mathrm{F}\right)\end{array}$} & \multirow{2}{*}{$\begin{array}{l}107.8^{\circ} \mathrm{C} \\
\left(226^{\circ} \mathrm{F}\right)\end{array}$} \\
\hline & Annulus & $\begin{array}{c}0.472 \mathrm{~m}^{3} / \mathrm{s} \\
(1,000 \\
\left.\mathrm{ft}^{3} / \mathrm{min}\right)\end{array}$ & Ambient & & & \\
\hline \multirow[b]{2}{*}{$A Z-102$} & Primary & $\begin{array}{c}0.236 \mathrm{~m}^{3} / \mathrm{s} \\
\left(500 \mathrm{ft}^{3} / \mathrm{min}\right)\end{array}$ & Ambient & \multirow{2}{*}{$\begin{array}{r}100^{\circ} \mathrm{C} \\
\left(195^{\circ} \mathrm{F}\right)\end{array}$} & \multirow{2}{*}{$\begin{array}{l}104.7^{\circ} \mathrm{C} \\
\left(220.5^{\circ} \mathrm{F}\right)\end{array}$} & \multirow{2}{*}{$\begin{array}{l}101.1^{\circ} \mathrm{C} \\
\left(214^{\circ} \mathrm{F}\right)\end{array}$} \\
\hline & Annulus & $\begin{array}{c}0.472 \mathrm{~m}^{3} / \mathrm{s} \\
(1,000 \\
\left.\mathrm{ft}^{3} / \mathrm{min}\right)\end{array}$ & 40 (Chiller) & & & \\
\hline \multirow[b]{2}{*}{$A Z-102$} & Primary & $\begin{array}{c}0.236 \mathrm{~m}^{3} / \mathrm{s} \\
\left(500 \mathrm{ft}^{3} / \mathrm{min}\right)\end{array}$ & Ambient & \multirow{2}{*}{$\begin{array}{l}100^{\circ} \mathrm{C} \\
\left(195^{\circ} \mathrm{F}\right)\end{array}$} & \multirow{2}{*}{$\begin{array}{c}105.2^{\circ} \mathrm{C} \\
\left(221.3^{\circ} \mathrm{F}\right)\end{array}$} & \multirow{2}{*}{$\begin{array}{l}102.8^{\circ} \mathrm{C} \\
\left(217^{\circ} \mathrm{F}\right)\end{array}$} \\
\hline & Annulus & $\begin{array}{c}0.944 \mathrm{~m}^{3} / \mathrm{s} \\
(2,000 \\
\left.\mathrm{ft}^{3} / \mathrm{min}\right) \\
\end{array}$ & Ambient & & & \\
\hline \multirow[b]{2}{*}{$\mathrm{AZ}-102$} & Primary & $\begin{array}{c}0.236 \mathrm{~m}^{3} / \mathrm{s} \\
\left(500 \mathrm{ft}^{3} / \mathrm{min}\right)\end{array}$ & Ambient & \multirow{2}{*}{$\begin{array}{l}100^{\circ} \mathrm{C} \\
\left(195^{\circ} \mathrm{F}\right)\end{array}$} & \multirow{2}{*}{$\frac{100.9^{\circ} \mathrm{C}}{\left(213.7^{\circ} \mathrm{F}\right)}$} & \multirow{2}{*}{$\begin{array}{l}\underline{91.7^{\circ} \mathrm{C}} \\
\left(197^{\circ} \mathrm{F}\right)\end{array}$} \\
\hline & Annulus & $\begin{array}{c}0.944 \mathrm{~m}^{3} / \mathrm{s} \\
(2,000 \\
\left.\mathrm{ft}^{3} / \mathrm{min}\right)\end{array}$ & 40 (Chiller) & & & \\
\hline
\end{tabular}


Rev. 0

This page intentionally left blank. 


\subsection{REFERENCES}

Bird, R., W. Stewart, and E. Lightfoot, 1960; Transport Phenomena, Department of Chemical Engineering, University of Wisconsin, Madison, Wisconsin, John Wiley \& Sons, New York, New York.

HNF-SD-WM-TSR-006, 1999, Tank Waste Remediation System Technical Safety Requirements, Rev. 1, Fluor Daniel Hanford, Inc., Richland, Washington.

Thurgood, M. J,, 1999a, Technical Manual For GOTH_SNF Version 5.0, JMI-980306-3, Rev. 1, John Marvin, Inc., West Richland, Washington.

Thurgood, M. J., 1999b, Users' Manual for GOTH_SNF Version 5.0, JMI-980306-2, Rev. 1, John Marvin, Inc., West Richland, Washington.

Thurgood, M.J. and D.M. Ogden, 1999, Quality Assurance Manual And Procedures, JMI-980306-1, Rev 3, John Marvin, Inc., West Richland, Washington. 
RPP-5637

Rev. 0

This page intentionally left blank. 
RPP-563

Rev.

\section{APPENDIX A}

A PARAMETRIC STUDY TO CHARACTERIZE AGA ALTERNATIVES FOR REMOVAL OF HEAT FROM HIGH-LEVEL WASTE TANKS 
RPP-5637

Rev. 0

This page intentionally left blank.

A-ii 


\section{CONTENTS}

A1.0 INTRODUCTION

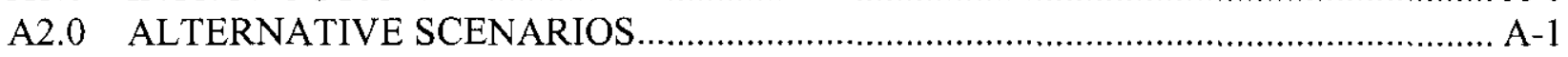

A2.1 PRIMARY-SIDE VENTILATION SYSTEM ENHANCEMENTS .................. A-1

A2.2 ANNULUS-SIDE VENTILATION SYSTEM ENHANCEMENTS ................. A-2

A3.0 MAXIMUM ALLOWABLE WASTE TEMPERATURE CRITERIA........................ A-2

A3.1 TEMPERATURE CONTROLS (TSR 3.3) ……................................... A-2

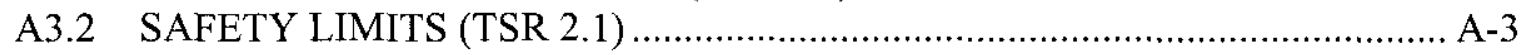

A4.0 THE STUDY SEQUENCE FOR EACH AGA ALTERNATIVE ………..................... A-4

A5.0 CONCLUSION AND RECOMMENDATION SUPPORTED

BY THE PARAMETRIC STUDY

A5.1 CONCLUSION: A CONSERVATIVE VENTILATION SYSTEM

DESIGN AND VALID AGA RECOMMENDATION ……............................. A-7

A5.2 RECOMMENDATION: A REQUIREMENT IDENTIFIED BY THE

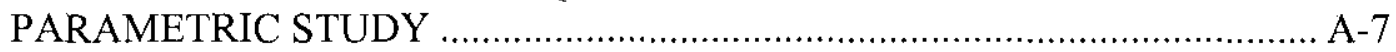

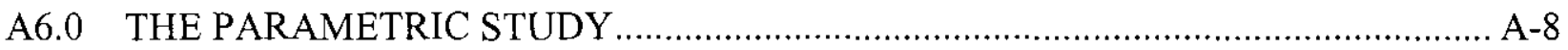

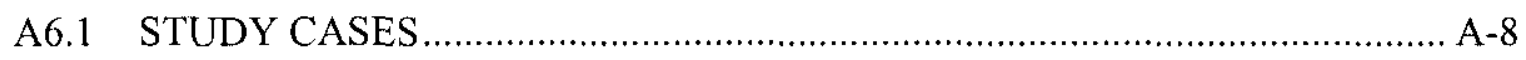

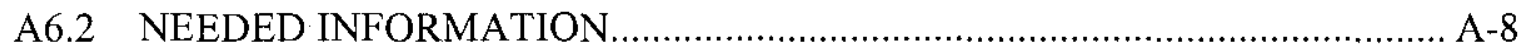

A6.3 THE PARAMETRIC STUDY SUPPORTING DOCUMENT ……………….. A-9

A6.3.1 Develop Supporting Document Outline ...................................... A-9

A6.3.2 Prepare the Supporting Document ................................................ A-10

A6.3.3 Obtain Independent Review for the Supporting Document and

Provide Released Supporting Document ..................................... A-10

A7.0 THE PARAMETRIC STUDY SCHEDULE AND RESOURCE ELEMENTS ......... A-10

A7.1 DEFINE INPUT PARAMETERS FOR PARAMETRIC STUDY ANALYSES

A7.2 DEVELOP GOTH_SNF MODELS ………………….................................. A-13

A7.2.1 Generate GOTH_SNF Models and Provide Calculation Notebook ............................................................................. A-13

A7.2.2 Validate GOTH_SNF Models and Provide Calculation

Notebook.

A7.3 PERFORM GOTH SNF ANALYSES ................................................ A-14

A7.4 DEVELOP SUPPORTING DOCUMENT OUTLINE ………..................... A-14

A7.5 PREPARE THE SUPPORTING DOCUMENT ………............................... A-14

A7.6 OBTAIN INDEPENDENT REVIEW FOR THE SUPPORTING DOCUMENT AND PROVIDE RELEASED SUPPORTING DOCUMENT . 


\section{FIGURES}

Figure A-1. AGA Parametric Study Logic Flow Diagram.................................................. A-16

Figure A-1. AGA Parametric Study Logic Flow Diagram (Continued)................................ A-17

Figure A-2. Waste Temperature Profiles................................................................... A-18

Figure A-3. Parametric Study Step 1: Determine Temperature of Instantaneously Mixed Waste.

Figure A-4. Parametric Study Step 2: Determine Temperature Profile of Instantaneously Mixed Settled-Waste.

Figure A-5. Parametric Study Step 3: Determine Steady-State Temperature of Pump-Mixed Waste.

Figure A-6. Parametric Study Step 4: Determine Temperature Profile of Mixed-Settled Waste.

Figure A-7. Parametric Study Step 5: Calculate the Time for the Waste Temperature to Reach the TSR Safety Limit Following Loss of Primary and Annulus Ventilation Systems. 
RPP-5637

Rev. 0

\section{TERMS}

$\begin{array}{ll}\text { AGA } & \text { Alternatives Generation and Analysis } \\ \text { DST } & \text { double-shell tank } \\ \text { FDH } & \text { Fluor Daniel Hanford, Inc. } \\ \text { FSAR } & \text { Final Safety Analysis Report } \\ \text { HLW } & \text { high-level waste } \\ \text { LCO } & \text { Limiting Conditions for Operation } \\ \text { LCS } & \text { Limiting Control Settings } \\ \text { LMHC } & \text { Lockheed Martin Hanford Corp. } \\ \text { LMSI } & \text { Lockheed Martin Services, Inc. } \\ \text { SD } & \text { Supporting Document } \\ \text { SL } & \text { Safety Limit } \\ \text { TSR } & \text { Technical Safety Requirements }\end{array}$

\section{CONVERSION FACTORS}

English units of measure are used throughout this study to be consistent with the Technical Safety Requirements. Metric conversions for the applicable English units are provided below.

\begin{tabular}{|l|l|l|}
\hline To convert from & To & Multiply by \\
\hline${ }^{\circ} \mathrm{F}$ & ${ }^{\circ} \mathrm{C}$ & $t^{{ }^{\circ} \mathrm{C}}=\left(t_{{ }_{\mathrm{F}}}-32\right) / 1.8$ \\
\hline $\mathrm{ft}$ & $\mathrm{m}$ & $3.048000 * \mathrm{E}-01$ \\
\hline $\mathrm{ft}^{3} / \mathrm{min}$ & $\mathrm{m}^{3} / \mathrm{s}$ & $4.719474 \mathrm{E}-04$ \\
\hline
\end{tabular}


RPP-5637

Rev. 0

This page intentionally left blank.

A-vi 


\section{APPENDIX A}

\section{A PARAMETRIC STUDY TO CHARACTERIZE AGA ALTERNATIVES FOR REMOVAL OF HEAT FROM HIGH-LEVEL WASTE TANKS}

\section{A1.0 INTRODUCTION}

Heat removal alternatives for the high-level waste (HLW) double-shell tanks (DST) are addressed by an Altematives Generation and Analysis (AGA) that is supported by this parametric study. The AGA is intended to identify a preferred alternative concept, which will provide heat removal from HLW tanks during Phase 1 feed delivery. The alternative concept must prevent the waste temperature from exceeding temperature limits, which are specified in HNF-SD-WM-TSR-006, Tank Waste Remediation System Technical Safety Requirement (TSR). Analyses are needed to support the AGA alternative selection.

Nine alternatives were evaluated in the draft AGA: two require supporting analyses. This parametric study will provide analyses for these two alternatives, which are primary-side ventilation system enhancement and annulus-side ventilation system.

Two waste tanks, 241-AZ-102 and 241-AY-102, were selected to represent the HLW tanks. The combination of radioactive decay heat rate and sludge depth in these tanks bound the heat-generation potential in the HLW tanks.

Ventilation system performance for the two alternatives will be determined in terms of the TSR Limiting Conditions for Operation (LCO) temperature limits. Waste temperature and ventilation system flow rate that satisfies the LCO limits will be established for each alternative. Design alternatives and safety analyses are outside the scope of this AGA. The result of this parametric study will provide the starting point for the conceptual design of the selected alternative.

\section{A2.0 ALTERNATIVE SCENARIOS}

Two alternatives will be addressed: primary-side ventilation system enhancement and annulus-side ventilation system enhancement.

\section{A2.1 PRIMARY-SIDE VENTILATION SYSTEM ENHANCEMENTS}

The primary ventilation system removes heat from the waste tank. The existing primary ventilation capacity will be enhanced to accommodate the heat load, which is generated by the waste and by the mixer pumps. Concurrently, the annulus-side ventilation system will be used 
RPP-5637

Rev. 0

without enhancement. Airlift circulators are not used. The mixer pumps are used to mix the waste. After the waste is mixed, the pumps are stopped and the mixed waste is allowed to settle.

\section{A2.2 ANNULUS-SIDE VENTILATION SYSTEM ENHANCEMENTS}

The annulus ventilation system removes heat from the waste tank. The existing annulus-side ventilation capacity will be enhanced to accommodate the heat load, which is generated by the waste and by the mixer pumps. Concurrently, the primary-side ventilation system will be used without enhancement. Airlift circulators are not used. The mixer pumps are used to mix the waste. After the waste is mixed, the pumps are stopped and mixed waste is allowed to settle.

\section{A3.0 MAXIMUM ALLOWABLE WASTE TEMPERATURE CRITERIA}

The waste temperature and ventilation system flow rate for the AGA alternatives will be determined in accordance with allowable waste temperature criteria extracted from the TSR. Two criteria are provided by the TSR: a Limiting Conditions For Operations (LCO) and a Safety Limit (SL).

The AGA provides a preferred alternative configuration that satisfies the TSR criteria in all conditions of normal operation. The AGA is not chartered to evaluate design alternatives that would be addressed in the conceptual design effort.

The criteria and supporting information are summarized in this section for application in this parametric study.

\section{A3.1 TEMPERATURE CONTROLS (TSR 3.3)}

- TSR LCS/LCO 13 3.3.2.a

$\mathrm{T} \leq 195^{\circ} \mathrm{F}$ In all levels of the waste ${ }^{2}$

- TSR LCS/LCO 3.3.2.b

$\mathrm{T} \leq 195^{\circ} \mathrm{F}$ In the top 15 feet of the waste

$\mathrm{T} \leq 215^{\circ} \mathrm{F}$ In the waste below 15 feet

\footnotetext{
' LCS = Limiting Control Setting, $\mathrm{LCO}=$ Limiting Conditions for Operations

${ }^{2}$ English units of measure are used throughout this study to be consistent with the TSRs.
} 
The TSR LCS/LCO temperature limits apply to two waste configurations: one to a mixed waste configuration and one to a settled waste configuration.

When the waste is mixed, the TSR LCS/LCO 3.3.2.a temperature limit applies. Waste radioactive decay heat rate and mixer-pump runtime affect the mixed-waste temperature, which is limited to $195^{\circ} \mathrm{F}$ in all levels of the tank. This temperature limit applies to all mixed waste conditions. For example, following mixer pump operation, the pump-induced heat must not cause the mixed-waste temperature to exceed $195^{\circ} \mathrm{F}$.

In the settled condition, the TSR LCS/LCO 3.3.2.b temperature limits apply. In the top 15 feet of the settled waste, the supernatant temperature must not exceed $195^{\circ} \mathrm{F}$. Likewise, in the bottom 15 feet of the settled waste, the temperature must not exceed $215^{\circ} \mathrm{F}$. The settled waste temperature is affected by the fluffing factor.

\section{A3.2 SAFETY LIMITS (TSR 2.1)}

\section{- TSR SL 2.1.1}

$\mathrm{T} \leq 250^{\circ} \mathrm{F}$ The waste temperature shall be $\leq 250^{\circ} \mathrm{F}$.

In the event ventilation systems are inoperable (lost), radioactive decay heat will cause waste temperature to increase. The temperature will continue to increase until either a physical limit is reached or a corrective action is initiated. During the recovery time, the maximum waste temperature must not exceed the SL criterion, SL 2.1.1.

Neither the TSR nor the Facility Safety Analysis Report (FSAR) provides a definitive time for the maximum waste temperature to exceed the SL criterion or a time for operations to recover from a loss of ventilation system. The TSR provides the following information:

TSR B3.3.2 Tank Bump, Organic Salt-Nitrate Reaction, and Unfiltered Release (Waste Retrieval Sluicing System Operations)

"...the LCS/LCO limits are not required by the analysis to automatically actuate a protective action to protect the SL limit of $\leq 250^{\circ} \mathrm{F}$ because exceeding of the LCS/LCO limits leaves the operator sufficient time to take manual protective actions to prevent exceeding the SL."

"...allows operations adequate time (about 16 days) to detect and to respond..."

- $\quad$ TSR B3.3.2 Applicable Safety Analyses

“...In this postulated accident scenario, tank ventilation (active cooling) is lost and the waste temperature is allowed to increase because of radioactive decay heat...this LCS/LCO serves to prevent this postulated accident."

Though this extracted material does not explicitly reference the loss of ventilation system event, an important concept is forwarded. The TSR material asserts that because of the LCS/LCO limits, the operator will have sufficient time to respond so that the SL is not exceeded. 
The extracted material does explicitly address measures to prevent a tank bump. The same LCS/LCO measures apply to the loss of ventilation event. Accordingly, the TSR implicitly asserts that application of the LCS/LCO limits will provide adequate time for the operator to take appropriate action to preclude exceeding the SL.

The AGA charter does not include safety analysis and design-related issues. Thus, the parametric analyses will not apply the TSR SL as a constraint. The GOTH_SNF (Version 5) computer code will be applied to calculate the time for the maximum waste temperature to reach the SL limit, which is equal to $250^{\circ} \mathrm{F}$. This calculated time will be provided to support the future conceptual design effort and related safety analysis.

\section{A4.0 THE STUDY SEQUENCE FOR EACH AGA ALTERNATIVE}

The study sequence will employ a strategy to characterize ventilation system performance in terms of temperature limits and to show that the selected ventilation system will satisfy the relevant TSR temperature criteria. A series of analyses will be performed for each study alternative to provide the system flow rate and the associated waste temperature profile that are compatible with the TSR temperature limits.

The strategy will provide an opportunity to adjust the ventilation system to achieve TSR temperature limit compliance. The initial analysis will use the existing ventilation system flow rate. If the TSR temperature limits are exceeded, the flow rate will be increased until the limiting value is reached. If the TSR limits are exceeded for the limiting flow rate, chillers will be included and the flow rate will be adjusted. If the TSR temperature limit is exceeded for the available adjustment choices, then the resulting AGA alternative may be affected by programmatic choices that may affect operational considerations.

The study will follow the steps shown in Figure A-1 and described in the following paragraphs.

\section{Step 1: Determine the Temperature Instantaneously Mixed Waste}

The temperature of instantaneously mixed waste is needed to provide the initial condition for subsequent calculations. Subsequent calculations are intended to provide the mixed waste temperature that is in equilibrium with the prescribed ventilation system parameters and the waste radioactive decay heat rate, not to provide a temperature transient response due to expected operation influences. The calculations characterize system performance independent of operation influences such as pump-induced heat. The GOTH_SNF computer code will be applied to calculate the temperature of instantaneously mixed waste.

The temperature of instantaneously mixed waste is affected by the ventilation system flow rate and by the radioactive decay heat rate of the tank waste contents. The temperature is independent of the pump run time and pump-induced heat. The waste content's radioactive decay heat rate is constant. Accordingly, the ventilation system will be adjusted, if needed, until the temperature of instantaneously mixed waste satisfies the TSR criterion. 
The expected temperature profile is illustrated in Figure A-2 as the $\mathrm{T}_{3}$ curve and in Figure A-3, as the $T_{3}$ temperature level. In Figure A-3, the calculated value for $T_{3}$ is illustrated in compliance with the TSR 3.3.2.a criterion.

\section{Step 2: Determine the Temperature Profile of Instantaneously Mixed Settled-Waste}

The temperature profile of instantaneously mixed settled-waste is needed to provide the equilibrium condition for subsequent calculations. The temperature profile is not intended to provide a temperature transient response due to expected operation influences. The post-mixed settled waste depth will be greater than the pre-mixed depth, a phenomenon referred to as the fluffing factor. Because of the increased settled waste depth, the post-mixed waste peak temperature will be greater than the pre-mixed peak temperature $\left(T_{1}<T_{1}^{\prime}\right)$.

This calculation is intended to provide the temperature profile that is in equilibrium with the proscribed ventilation system parameters and the tank waste contents radioactive decay heat rate. The calculation characterizes the system performance independent of operational influences such as pump-induced heat.

The settled waste temperature is affected by the ventilation system flow rate, sludge thickness, waste conductivity, tank waste contents' radioactive decay heat rate, and the fluffing factor. The settled waste temperature is independent of the pump run time and pump-induced heat. The waste contents' radioactive decay heat rate and the fluffing factor are invariant. Accordingly, the ventilation system will be adjusted, if needed, until the temperature profile of the settled waste satisfies the TSR criterion.

The GOTH_SNF computer code will be applied to calculate the instantaneously mixedwaste temperature profile. The expected temperature profile is illustrated in Figure A-2 as the $T_{1}^{\prime}$ to $T_{2}^{\prime}$ curve and in Figure $A-4$, as the $T_{1}^{\prime}$ and the $T_{2}^{\prime}$ temperature levels. In Figure $A-4$, the calculated values for $\mathrm{T}_{1}^{\prime}$ and $\mathrm{T}_{2}{ }_{2}$ are illustrated in compliance with the TSR 3.3.2.b criterion.

\section{Step 3: Determine the Steady-State Temperature of Pump-Mixed Waste Caused by Continuous Full-Speed Mixer-Pump Operation}

The steady-state temperature of pump-mixed waste for a given ventilation system coolant flow rate is the temperature that is expected to remain constant with an increase in pump runtime. The mixer pump run time is a critical parameter in this AGA to identify a creditable heat removal alternative for the high-heat waste tanks. However, the mixer pump run time needed to mix the waste is not known. Further, the heat induced into the waste by the mixer pump will increase as the pump run time is increased. For this calculation, the mixer pump will be run at $100 \%$ power until the mixed waste temperature, $\mathrm{T}_{4}$, is in equilibrium with the ventilation system flow rate and the radioactive decay heat rate of the tank waste contents. The system response to $100 \%$ power mixer pump operation is illustrated in Figure A-5 as the curve from $T_{3}$ to $T_{4}$.

The waste temperature and the corresponding pump run time are obtained through the assertion that the pump can mix the waste in a given run time. The actual time needed to mix the waste is not explicitly known, so the waste is characterized as fully mixed with pump operation. This characterization is illustrated in Figures A-2 and A-3 as $\mathrm{T}_{3}$. 
This performance characteristic is a postulated qualitative attribute of the system. The mixed waste temperature, for a given ventilation system flow rate, will increase with an increase in pump run time. The assertion applied in this parametric study is that a constant mixed waste temperature will be achieved for a sufficiently long pump run time.

The ventilation system flow rate, the tank waste contents radioactive decay heat rate, and the pump run time affect the steady-state temperature of mixed waste. The waste contents radioactive decay heat rate, the fluffing factor, and the pump-induced heat are invariant. Accordingly, the ventilation system will be adjusted, if needed, until the steady-state temperature profile of the mixed waste satisfies the TSR criterion.

The GOTH_SNF computer code will be applied to calculate the steady-state temperature of pump-mixed waste. The expected temperature profile is illustrated in Figure A-2 as the $\mathrm{T}_{4}$ curve and in Figure A-5 as the $T_{3}$ to $T_{4}$ curve. In Figure A-5, the calculated value for $T_{4}$ is illustrated in compliance with the TSR 3.3.2.a criterion.

If the TSR 3.3.2.a temperature limit is exceeded for the available adjustment choices, then the GOTH_SNF code will be applied to calculate the time, $t$ ', that the limit is reached. The calculated time will be provided to support the decision process. The resulting AGA alternative may be affected by programmatic choices that may affect operational considerations. This condition is illustrated in Figure A-5.

\section{Step 4: Determine Temperature Profile of the Pump-Mixed Settled-Waste}

Determining the pump-mixed settled-waste temperature profile and the associated ventilation system flow rate to satisfy the TSR criteria are the objective parameters in this AGA. The system response is illustrated in Figure A-2 as the $\mathrm{T}_{1}$ to $\mathrm{T}_{2}{ }_{2}$ curve and in Figure A-6 as the $T_{4}$ to $T_{1}^{\prime}$ and the $T_{4}$ to $T_{2}^{\prime}$ curves.

The mixed-waste temperature, following the end of mixer pump operation, will contain pump-induced heat. The settled-waste peak temperature, $\mathrm{T}_{2}{ }_{2}$, determined in Step 2 is the equilibrium condition that the pump-mixed waste temperature will achieve. Three possible peak temperature response curves characterize the waste thermal response from $T_{4}$ to $T^{\prime}{ }_{2}$ (Figure A-6).

The acceptable ventilation system flow rate is the one that results in a settled-waste peak temperature that satisfies the TSR criteria.

The peak temperature of the pump-mixed settled-waste is affected by the ventilation system flow rate, radioactive decay heat rate of the tank waste contents, the fluffing factor, and the pump induced heat. The radioactive decay heat rate of the waste contents, the fluffing factor, and the pump-induced heat are invariant. Accordingly, the ventilation system will be adjusted, if needed, until the settled-waste peak temperature satisfies the TSR criteria.

The GOTH_SNF computer code will be applied to calculate pump-mixed settled-waste temperature profiles. The expected temperature profile is illustrated in Figure A-2 as the $T^{\prime}$, to $T_{2}^{\prime}$ curve and in Figure A-6 as the $T_{4}$ to $T_{1}^{\prime}$ and the $T_{4}$ to $T_{2}^{\prime}$ curves. In Figure A-6, the calculated values for $T_{1}^{\prime}$ and $T_{2}^{\prime}$ are illustrated in compliance with the TSR 3.3.2.b criterion. 


\section{Step 5: Calculate the Time To Reach the TSR SL Following Loss of Primary and Annulus Ventilation Systems}

In the event that ventilation systems are lost, the waste temperature will increase because of radioactive decay heat. This temperature response is illustrated in Figure A-7 as the temperature response following the loss of ventilation systems.

The parametric analyses will not apply the TSR SL as a constraint; however, the time to reach the SL following a loss-of-ventilation system event will be provided to support future conceptual design activities. The GOTH_SNF computer code will be applied to calculate the time for the maximum waste temperature to reach the SL. The calculated time is illustrated in Figure A-7.

\section{A5.0 CONCLUSION AND RECOMMENDATION SUPPORTED BY THE PARAMETRIC STUDY}

\section{A5.1 CONCLUSION: A CONSERVATIVE VENTILATION SYSTEM DESIGN AND VALID AGA RECOMMENDATION}

The ventilation system design based on a constant mixed-waste temperature (for a given ventilation flow rate) caused by continuous mixer pump operation at $100 \%$ power will be conservative. Specifically, the design will be conservative because it is expected that the pump will produce a mixed waste with less run time so that the pump-affected waste temperature will be less than the steady-state temperature of mixed waste. Consequently, the demand on the ventilation system will be less than the designed capacity. Thus, if the confirmed pump runtime to mix the waste is less than the calculated steady state time, determined in Step 3 and illustrated in Figure A-5, then the AGA results will be valid and will be conservative.

\section{A5.2 RECOMMENDATION: A REQUIREMENT IDENTIFIED BY THE PARAMETRIC STUDY}

It is expected that the mixer pump run time will be confirmed by an appropriate analytical characterization, which may be performed by the pump specification effort and may be included in the pump specification documentation. Further, it is expected that the pump run time needed to mix the waste will be less than the steady-state time. This information is important because a shorter mixer pump runtime will induce less heat and the ventilation flow rate may be affected favorably. 


\section{A6.0 THE PARAMETRIC STUDY}

The parametric study comprises a series of analyses in which the waste temperature is characterized in terms of pump run time and ventilation system flow rate. Elements of the study include the series of analyses and application of the TSR criteria. Study results will be applied to quantify ventilation flow rate and waste temperature for the AGA alternative.

The following requirements apply to each study case. The analyses for the parametric study will be documented in a supporting document (SD). Specifically, the performer, checker, and independent reviewer will sign the work. The independent reviewer must maintain an independent role in the analysis phase.

\section{A6.1 STUDY CASES}

Two study cases, which are identified in the Alternative Scenarios section, will be addressed.

\section{Study Case 1: Primary-Side Ventilation System Enhancements}

Perform thermal analyses with the GOTH_SNF computer code to characterize tank waste temperature due to primary-side ventilation system flow-rate adjustments. A description of the enhancement is provided in the Alternative Scenarios section. In these analyses, single-pass ventilation system operation without chiller and recirculation ventilation system operation with $20 \%$ through flow with chiller will be characterized. Provide results in terms of the TSR LCO temperature limits. The parametric study sequence is illustrated in Figure A-1.

\section{Study Case 2: Annulus-Side Ventilation System Enhancements}

Perform thermal analyses with the GOTH_SNF computer code to characterize tank waste temperature due to annulus-side ventilation system flow-rate adjustments. A description of the enhancement is provided in the Alternative Scenarios section. In these analyses, single-pass ventilation system operation will be characterized. Provide results in terms of the TSR LCO temperature limits. The parametric study sequence is illustrated in Figure A-1.

\section{A6.2 NEEDED INFORMATION}

The following information is needed to perform the thermal analyses:

- Contents heat load (Solids and Supernatant). Bill Willis will provide documentation for heat load information either contained in the current JMI GOTH computer code run-stream or provided by Don Ogden (JMI). Documentation will be provided for each study case.

- Thermal Conductivity. Don Ogden (JMI) will provide documented thermal conductivity for each study case.

- Particle density and thermal conductivity. Don Ogden (JMI) will provide this information. 
- Sludge thickness. Don Ogden (JMI) will provide this information.

- Fluff Factor. Blaine Crea (Fluor Daniel Hanford [FDH]) will provide a fluffing factor for each bounding waste profile, before and after mixing. ${ }^{3}$

- Waste Tank Model Properties. GOTH_SNF model properties such as the waste tank dimensions and mixer pump parameters will be summarized by JMI and provided to Blaine Crea (FDH), who will provide an independent review.

\section{A6.3 THE PARAMETRIC STUDY SUPPORTING DOCUMENT}

\section{A6.3.1 Develop Supporting Document Outline}

Develop an outline for the SD. The SD will describe the analysis effort and the conclusions. Supporting calculation notebooks, including the parametric study description document, will be included as attachments to the report. The SD outline will be developed in concert with JMI (Marve Thurgood and Don Ogden), FDH (Blaine Crea), and the Lockheed Martin Services, Inc. (LMSI), Technical Editor. The outline will emphasize application of Office 2000 compatible software to the production of the report and associated attachments, unless prior approval is obtained for a deviation. Specific requests to deviate from Office 2000 compatible software will be individually addressed by LMSI Technical Editing (Kathy Freeman and Maggi Nielsen) and LMHC (James Truitt).

Minimally, four figures will be provided for each study case; more data can be provided, if needed. The four figures will include:

Waste Temperature Versus Time: This figure will exhibit waste temperature at selected locations in the waste (see Figure A- 6 for example). The time scale will begin with mixer pump operation. Steady-state waste temperature prior to mixer pump operation will be exhibited for the selected waste locations. Typically, locations should include dome gas; supernatant; and solids at the bottom, middle, and top of the sludge. The location of the maximum waste temperature should be included. It is anticipated that data for this curve will be provided by a parametric study that characterizes waste temperature against time for a particular ventilation system flow rate. This figure should address waste temperature conditions for the maximum allowable waste temperature as determined through application of TSR temperature LCO limits.

Maximum Waste-Temperature Versus Ventilation System Flow-Rate: This figure will exhibit the maximum waste-temperature versus ventilation system flow-rate. The maximum waste temperature should be identified. It is anticipated that data for this curve will be provided by a parametric study. This information should exhibit the effect

\footnotetext{
${ }^{3}$ It is anticipated that Graham MacLean will provide a memo to Bill Willis that will summarize the existing experimental information related to fluff factor magnitude.
} 
of the two criteria. This figure is intended to identify the ventilation system flow rates needed to satisfy the TSR temperature LCO limits.

Maximum Peak Settled Waste Temperature Versus Tank Vertical Location: This figure will exhibit the maximum allowable waste-temperature versus waste tank depth; e.g., temperature versus distance measured from the tank bottom. It is anticipated that data for this curve will be provided by a parametric study. This information should exhibit the effect of TSR temperature LCO limits.

Moisture Content Versus Time. Provide primary-side moisture contents curve for each analysis. This information is needed to establish the moisture removal capacity that is consistent with the HEPA filter.

\section{A6.3.2 Prepare the Supporting Document}

Prepare the SD in accordance with the SD outline. Coordinate the report production with the analysis team and the LMSI Technical Editor so that minimum effort is required to prepare and edit the SD. The document and the supporting attachments will be prepared with Office 2000 compatible software, unless prior approval is obtained for a deviation. Specific requests to deviate from Office 2000 compatible software will be individually addressed by LMSI Technical Editing (Kathy Freeman and Maggi Nielsen) and LMHC (James Truitt).

\section{A6.3.3 Obtain Independent Review for the Supporting Document and Provide Released Supporting Document}

Provide an independent review and comment resolution for the SD, including the supporting attachments. This effort will be accomplished in concert with JMI and the LMSI Technical Editor. The SD will be released to the Site document control function.

\section{A7.0 THE PARAMETRIC STUDY SCHEDULE AND RESOURCE ELEMENTS *}

\section{A7.1 DEFINE INPUT PARAMETERS FOR PARAMETRIC STUDY ANALYSES}

This activity is intended to provide the technical information needed in the analyses to determine ventilation flow rates associated with HLW tank ventilation system upgrades. The technical information will be conservative best-estimate values that will be applied to determine ventilation system flow rates for the design specifications.

The input parameters will be documented with appropriate references and will be written as an attachment to the parametric study report, which will be configured as a Hanford Site SD. The technical editor will review the written material and will provide editorial recommendations and assistance. The attachment will be provided to JMI by memo from Lockheed Martin Hanford Corp. (LMHC) (J. B. Truitt). 
[Responsible performer: Blaine Crea (FDH). Deliverable: written documentation. Due date: December 10, 1999. Personnel: Blaine Crea, three labor days; LMSI Technical Editor, two labor days.]

\section{- Bounding Case}

In Revision 0 of the AGA report for heat removal in the high-level waste tanks, the waste contents in the four high-level waste tanks were characterized by two bounding waste content profiles. These profiles were applied in the thermal-hydraulic analyses that were performed to determine the ventilation system cooling capacity that is needed to ensure safety and operation-related waste temperature limits are not exceeded. The two bounding profiles will be reviewed to determine whether the waste contents are adequately characterized for application in the parametric study to evaluate needed ventilation system cooling capacity.

[Responsible performer: Blaine Crea (FDH). Deliverable: bounding case definition with written documentation. Due date: case definition, due November 23, 1999; written documentation, December 3, 1999. Personnel: Blaine Crea, two labor days.]

- Fluffing Factor

The available waste settling information, which was obtained by observation and by laboratory experiments, will be reviewed to determine the applicable settling characteristics for the high-level waste. A fluffing factor will be identified for each bounding waste profile for both before and after mixing settled conditions.

[Responsible performer: Blaine Crea (FDH). Deliverable: fluffing factors with written documentation. Due date: December 3, 1999. Personnel: Blaine Crea, two labor days.]

\section{- Decay Heat Profile}

A decay heat profile will be provided for each bounding case addressed in the parametric study; e.g., one for the AY-102 and one for the AZ-102 tank. The decay heat profile will characterize the decay heat in the sludge and in the supernatant. The technical descriptions for the decay heat profiles will be reviewed and documented. Experience gained in waste transfer from C-106 to AY-102 (Project W-320) will be applied to develop the profile for tank AY-102 (Don Ogden). Information contained in Revision 0 of the AGA will be applied to develop the profile for tank AZ-102 (K. Sathyanarayana).

[Responsible performer: Don Ogden (JMI). Deliverable: decay heat profiles with written documentation. Due date: December 3, 1999. Personnel: Don Ogden, two labor days; K. Sathyanarayana, one labor day.] $<$ Don will provide a written description of the basis for the decay heat profiles; references will be TBD until the middle of December. > 
- Sludge Thermal Conductivity

The sludge thermal conductivity, or preferably, the parameters to calculate the sludge thermal conductivity (i.e. particle fraction, particle conductivity, supernatant conductivity and applicable mixture conductivity model), will be provided for each bounding case for the before and after mixing states. Experience gained from Project W-320 will be applied to determine the thermal conductivity for AY-102 (Don Ogden); thermal conductivity for the AZ-102 tank will be determined from the information in Revision 0 of the AGA (K. Sathyanarayana).

[Responsible performer: Don Ogden (JMI). Deliverable: Information with written documentation. Due date: November 30, 1999. Personnel: Don Ogden, two labor days; K. Sathyanarayana, two labor days.]

- Waste Depth

The pre-mixed settled waste sludge and supernatant depth will be provided for each bounding case.

[Responsible performer: Don Ogden (JMI). Deliverable: Information with written documentation. Due date: November 30, 1999. Personnel: Don Ogden, one labor day; K. Sathyanarayana, one labor day.]

- Ventilation Inlet Nominal Temperature and Relative Humidity

The inlet nominal temperature and relative humidity for the primary and for the annulus ventilation systems will be provided for each bounding case.

[Responsible performer: Blaine Crea (FDH). Deliverable: Information with written documentation. Due date: December 3, 1999. Personnel: Blaine Crea, one labor day; FDH employee, two labor days.]

- Obtain Needed Drawing and Equipment Specifications

Equipment drawings and specifications needed to support the parametric study will be identified and a written list will be provided by JMI. The correct drawing and specification numbers, including revision numbers, will be provided on a written list by FDH.

[Responsible performer: Blaine Crea (FDH). Deliverable: Information with written documentation. Due date: December 3, 1999. Personnel: Blaine Crea, one labor day; FDH employee, one labor day.]

- Waste Vapor Pressure

The ratio of waste supernatant vapor pressure to water vapor pressure at the same temperature will be provided for each bounding case. 
[Responsible performer: Blaine Crea (FDH). Deliverable: Information with written documentation. Due date: December 3, 1999. Personnel: Blaine Crea, one labor day; K. Sathyanarayana, one labor day.]

- Chiller Outlet Nominal Temperature and Relative Humidity

The nominal temperature and relative humidity will be provided for each bounding case.

[Responsible performer: Blaine Crea (FDH). Deliverable: Information with written documentation. Due date: December 3, 1999. Personnel: Blaine Crea, three labor days; LMSI Technical Editor, one labor day.]

- Primary and Annulus Ventilation Flow Rates

The following information will be provided for each bounding case:

- Once through primary side flow rate for the existing system.

- Once through annulus flow rate for the existing system.

- Primary side-to-chiller flow split.

- Primary-side flow rate value for which chiller operation is initiated. This is the maximum viable flow rate based on dome and annulus pressure limits.

- Annulus flow rate value for which chiller operation is initiated. This is the maximum viable flow rate based on dome and annulus pressure limits.

[Responsible performer: Blaine Crea (FDH). Deliverable: Information with written documentation. Due date: December 10, 1999. Personnel: Blaine Crea, one labor day; FDH employee, five labor days.]

\section{A7.2 DEVELOP GOTH_SNF MODELS}

Revise the existing GOTH models for AY-102 and AZ-101 to include the AGA input parameters and the parametric analysis strategy.

\section{A7.2.1 Generate GOTH_SNF Models and Provide Calculation Notebook}

The existing GOTH models will be revised and documented. Model development will be documented in a calculation notebook. The documentation will be included in the SD as an attachment.

[Responsible performer: Marvin Thurgood (JMI). Deliverable: GOTH_SNF models and written documentation. Due date: December 17, 1999. Personnel: JMI, twelve labor days, K. Sathyanarayana, five labor days; LMSI Technical Editor, two labor days.] 


\section{A7.2.2 Validate GOTH_SNF Models and Provide Calculation Notebook}

The GOTH_SNF models will be validated against AY-102 measured sludge temperature and ventilation system flow rates. The validation studies will be documented in a calculation notebook. The documentation will be included in the SD as an attachment.

[Responsible performer: Marvin Thurgood (JMI). Deliverable: GOTH_SNF model validation and written documentation. Due date: December 17, 1999. Personnel: JMI, twelve labor days; LMSI Technical Editor, two labor days.]

\section{A7.3 PERFORM GOTH_SNF ANALYSES}

Perform the GOTH_SNF analyses for the two bounding cases. The parametric study strategy will be applied to characterize the ventilation system flow rates for the bounding cases. Analysis results will be provided to LMHC as they are completed to facilitate AGA study report preparation. The GOTH_SNF analysis results will be documented in a calculation notebook. The documentation will be included in the SD as an attachment.

[Responsible performer: Marvin Thurgood (JMI). Deliverable: GOTH_SNF analysis results and written documentation. Due date: December 31, 1999. Personnel: JMI, twenty-two labor days; FDH employee, five labor days; LMSI Technical Editor, four labor days.]

\section{A7.4 DEVELOP SUPPORTING DOCUMENT OUTLINE}

Develop an outline for the SD. The SD will be structured to provide a description of the analysis effort, the conclusions, and the results in the document body. Supporting calculation notebooks, including the parametric study description document will be included as attachments to the report. The SD outline will be developed in concert with JMI (Marve Thurgood and Don Ogden) and the LMSI Technical Editor. The outline will emphasize application of Office 2000 compatible software to the production of the report and associated attachments, unless prior approval is obtained for a deviation. Specific requests to deviate from-Office 2000 compatible software will be individually addressed by LMSI Technical Editing (Kathy Freeman and Maggi Nielsen) and LMHC (James Truitt).

.[Responsible performer: Don Ogden (JMI). Deliverable: SD outline. Due date: December 21, 1999. Personnel: Don Ogden, two labor days; LMSI Technical Editor, one labor day.]

\section{A7.5 PREPARE THE SUPPORTING DOCUMENT}

Prepare the SD in accordance with the SD outline. Coordinate the report production with the analysis team and the LMSI Technical Editor so that minimum effort is required to prepare and edit the SD. The document and the supporting attachments will be prepared with Office 2000 compatible software, unless prior approval is obtained for a deviation. Specific requests to deviate from Office 2000 compatible software will be individually addressed by LMSI Technical Editing (Kathy Freeman and Maggi Nielsen) and LMHC (James Truitt). 
[Responsible performer: Don Ogden (JMI). Deliverable: Draft SD. Due date: January 10, 2000. Personnel: JMI, 13 labor days; Blaine Crea, two labor days; LMSI Technícal Editor, five labor days.]

\section{A7.6 OBTAIN INDEPENDENT REVIEW FOR THE SUPPORTING DOCUMENT AND PROVIDE RELEASED SUPPORTING DOCUMENT}

Provide an independent review, and comment resolution for the SD, including the supporting attachments. This effort will be accomplished in concert with JMI and the LMSI Technical Editor. Release the SD to the Site document control function.

[Responsible performer: Blaine Crea (FDH). Deliverable: SD independent review, review comment resolution, and released SD. Due date: January 21, 2000. Personnel: Blaine Crea, five labor days; JMI, two labor days; LMSI Technical Editor, two labor days.] 
Figure A-1. AGA Parametric Study Logic Flow Diagram.

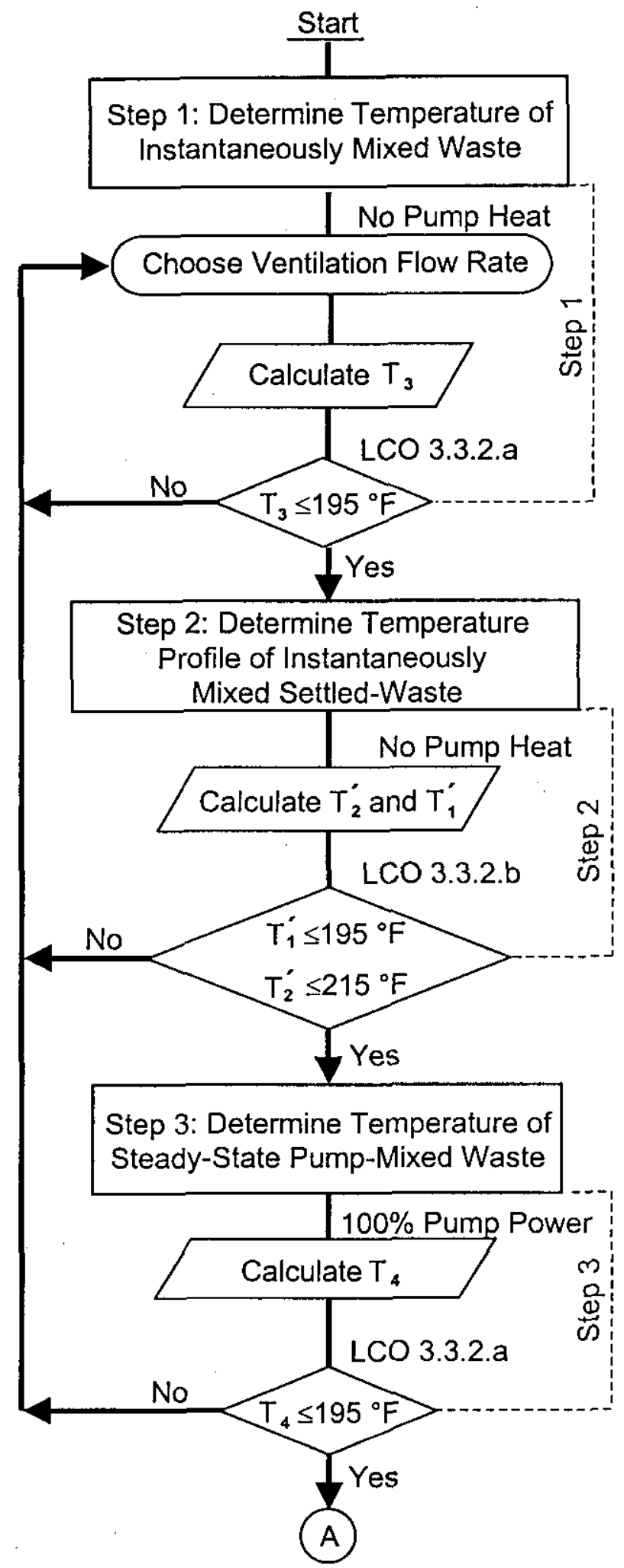

Apply GOTH Code. See

Figures 2 and 3.

Choice hierarchy

- Increased values

- Added chiller

- Operation constraint; not consistent in this parametric study

If $\mathrm{T}_{3}>195^{\circ} \mathrm{F}$, go to step 1 .

Choose an increased ventilation

flow rate and repeat Step 1.

Apply GOTH Code.

See Figure 4.

If either $\mathrm{T}_{1}^{\prime}>195^{\circ} \mathrm{F}$ or $\mathrm{T}_{2}^{\prime}>215^{\circ} \mathrm{F}$, go to

Step 1. Choose an increased ventilation flow rate and repeat Steps 1 and 2 .

Apply GOTH Code.

See Figure 5.

If $\mathrm{T}_{4}>195^{\circ} \mathrm{F}$, go to step 1 .

Choose an increased ventilation

flow rate and repeat Steps 1, 2, and 3 .

$1981.02 a$ 
RPP-5637

Rev. 0

Figure A-1. AGA Parametric Study Logic Flow Diagram (Continued)

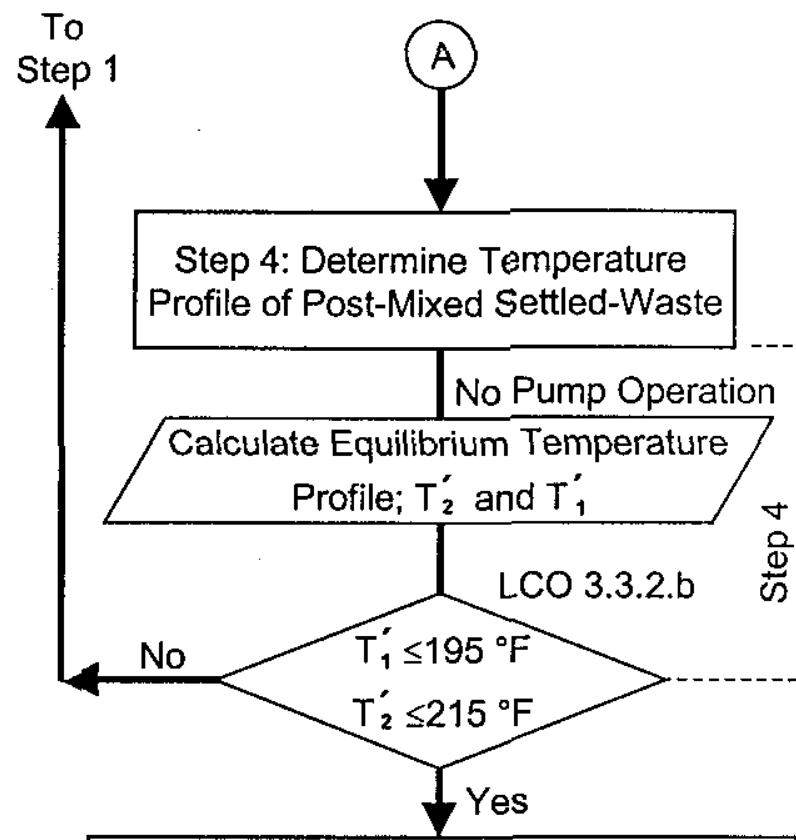

Apply GOTH Code.

See Figure 6.

If either $\mathrm{T}_{1}^{\prime}>195^{\circ} \mathrm{F}$ or $\mathrm{T}_{2}^{\prime}>215^{\circ} \mathrm{F}$, go to Step 1. Choose an increased ventilation flow rate and repeat Steps 1 , 2,3 , and 4 .

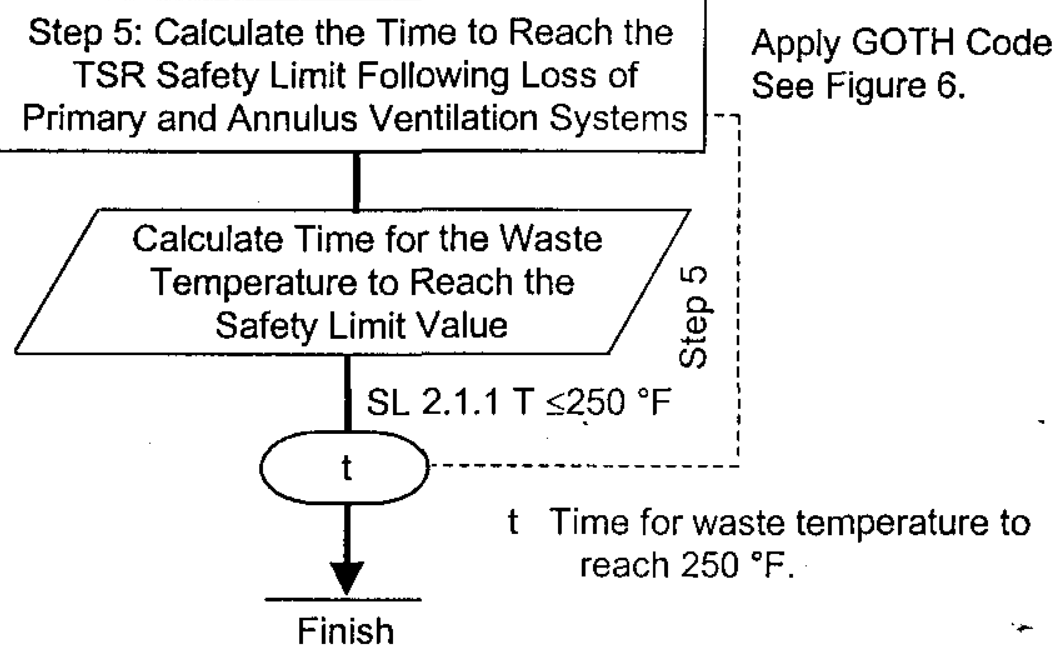

LCO = Limiting Conditions for Operations

TSR $=$ Technical Safety Requirements

To convert ${ }^{\circ} \mathrm{F}$ to ${ }^{\circ} \mathrm{C}: t_{{ }^{\circ} \mathrm{C}}=\left(t_{\circ \mathrm{F}}-32\right) / 1.8$ 
Figure A-2. Waste Temperature Profiles.

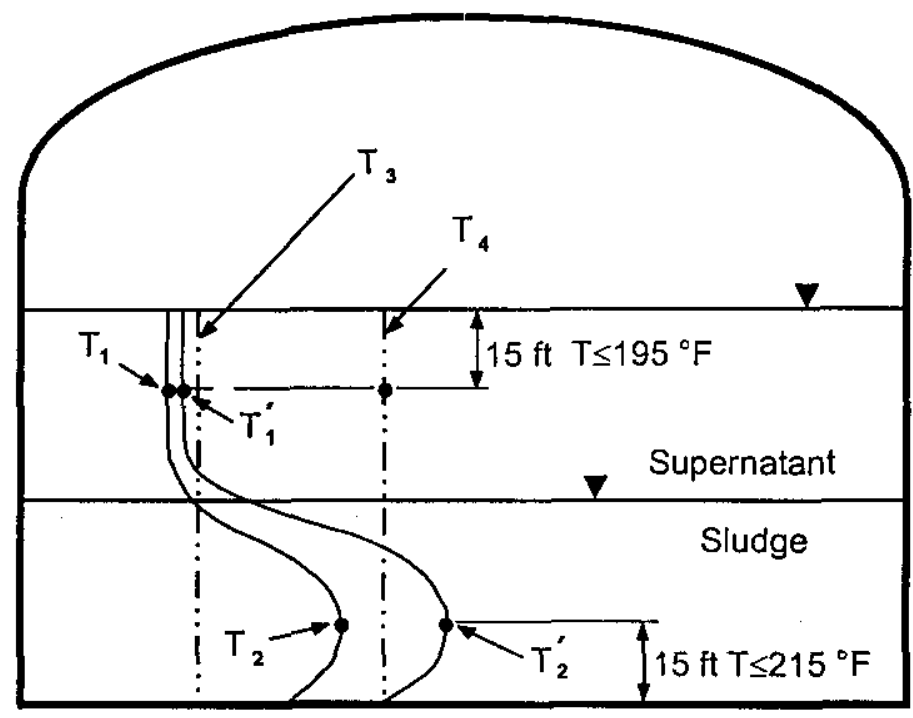

$T_{1}$ Temperature of settled-waste supernatant.

$T$ Peak temperature of settled-waste.

$T^{2}$ Temperature of instantaneously mixed waste. No pump heat.

${ }^{3}$ Existing primary and annulus ventilation systems. Must satisfy LCO 3.3.2.a; e.g., $T \leq 195^{\circ} \mathrm{F}$ in all levels of the waste.

$T^{\prime}$ Temperature of instantaneously mixed settled-waste supernatant. Must satisfy

1 LCO 3.3.2.b; e.g., $\mathrm{T} \leq 195^{\circ} \mathrm{F}$ in top $15 \mathrm{ft}$ of the waste.

$T^{\prime}$ Peak temperature of instantaneously mixed settled-waste. Must satisfy LCO 3.3.2.b; e.g., $\mathrm{T} \leq 215^{\circ} \mathrm{F}$ in lower $15 \mathrm{ft}$ of the waste.

$T^{2}$ Steady-state pump-mixed waste temperature. Pump operates at $100 \%$ power until waste temperature stabilizes. Must satisfy $L C O$ 3.3.2.a; e.g., $T \leq 195^{\circ} \mathrm{F}$ in all levels ${ }_{4}$ of the waste.

LCO = Limiting Conditions for Operations

To convert ${ }^{\circ} \mathrm{F}$ to ${ }^{\circ} \mathrm{C}: t_{\circ} \mathrm{C}=\left(t_{\circ \mathrm{F}}-32\right) / 1.8$

To convert $\mathrm{ft}$ to $\mathrm{m}: \quad 3.048000^{*} \mathrm{E}-01$ 
Figure A-3. Parametric Study Step 1: Determine Temperature of Instantaneously Mixed Waste.

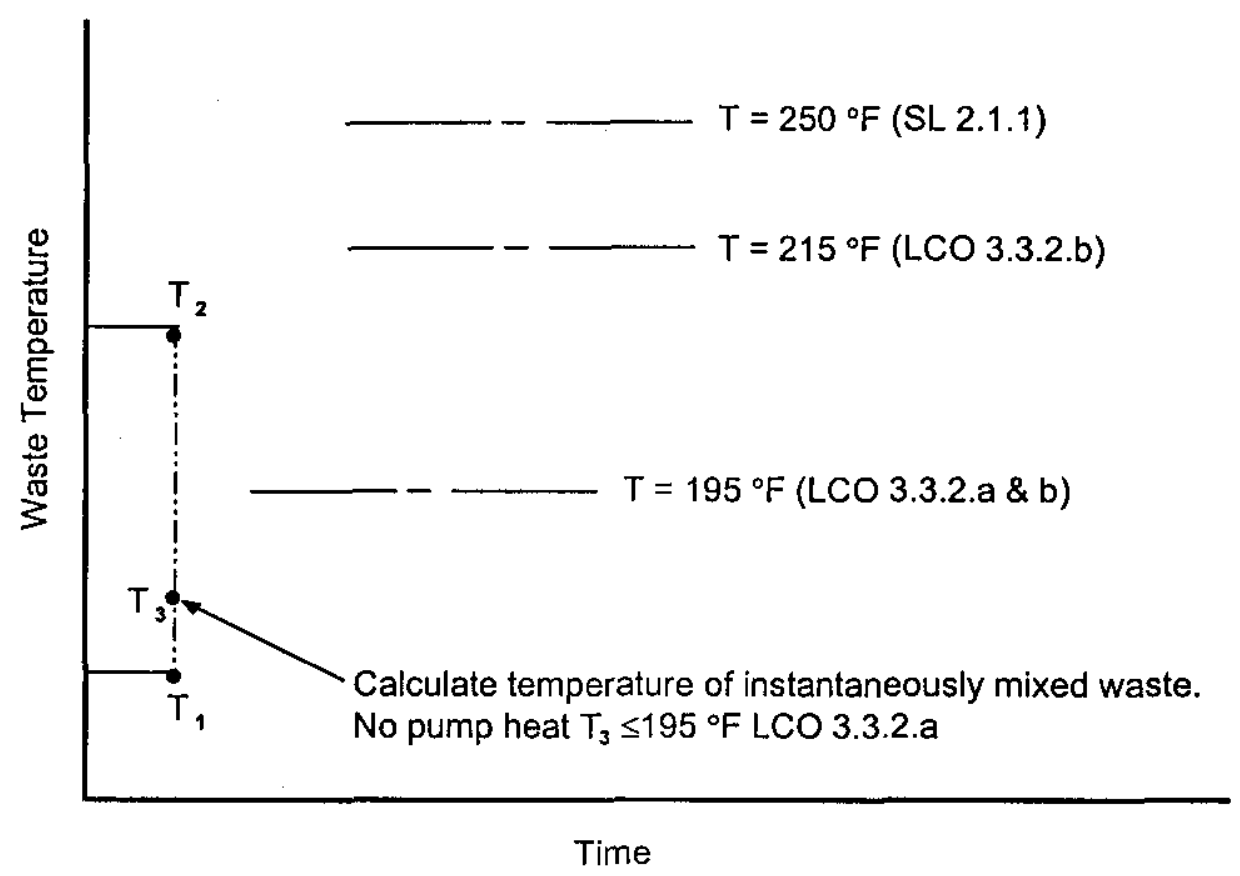

$T_{1}$ Temperature of settled-waste supernatant.

$T_{2}$ Peak temperature of settled-waste.

$\mathrm{T}_{3}$ Temperature of instantaneously mixed waste. No pump heat. Existing primary and annulus ventilation systems.

LCO $=$ Limiting Conditions for Operation

$\mathrm{SL} \quad=$ Safety Limit

To convert ${ }^{\circ} \mathrm{F}$ to ${ }^{\circ} \mathrm{C}: t_{{ }^{\circ} \mathrm{C}}=\left(t_{\circ \mathrm{F}}-32\right) / 1.8$

$1981-07$ 
Figure A-4. Parametric Study Step 2: Determine Temperature Profile of Instantaneously Mixed Settled-Waste.

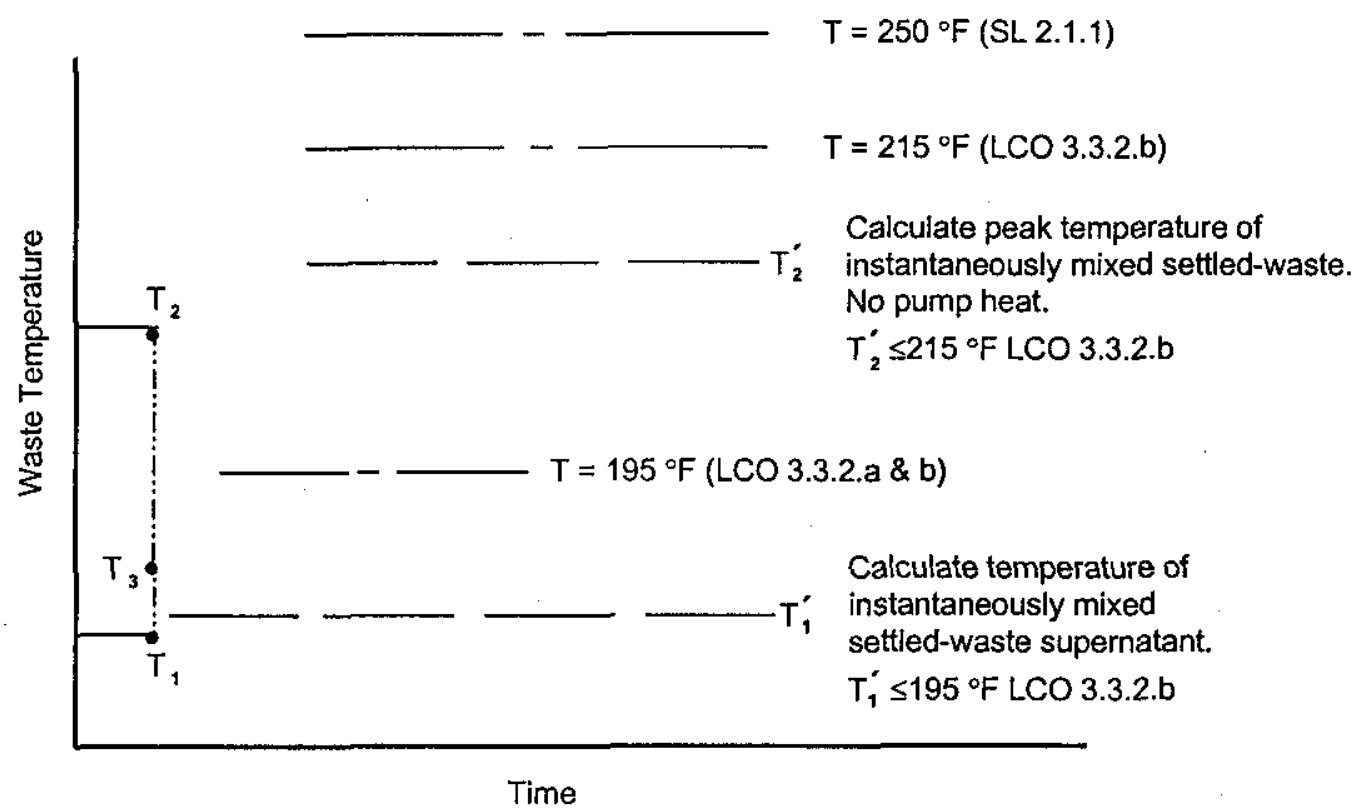

$T_{1}^{\prime}$ Temperature after instantaneous mixing of settled-waste supernatant. must satisfy LCO 3.3.2.b

$\mathrm{T}_{2}^{\prime}$ Peak temperature after instantaneous mixing of settled-waste. Must satisfy LCO 3.3.2.b

LCO $=$ Limiting Conditions for Operation

$S L=$ Safety Limit

To convert ${ }^{\circ} \mathrm{F}$ to ${ }^{\circ} \mathrm{C}: t_{{ }^{\circ} \mathrm{C}}=\left(t_{\mathrm{oF}}-32\right) / 1.8$

1981.08 
Figure A-5. Parametric Study Step 3: Determine Steady-State Temperature of Pump-Mixed Waste.

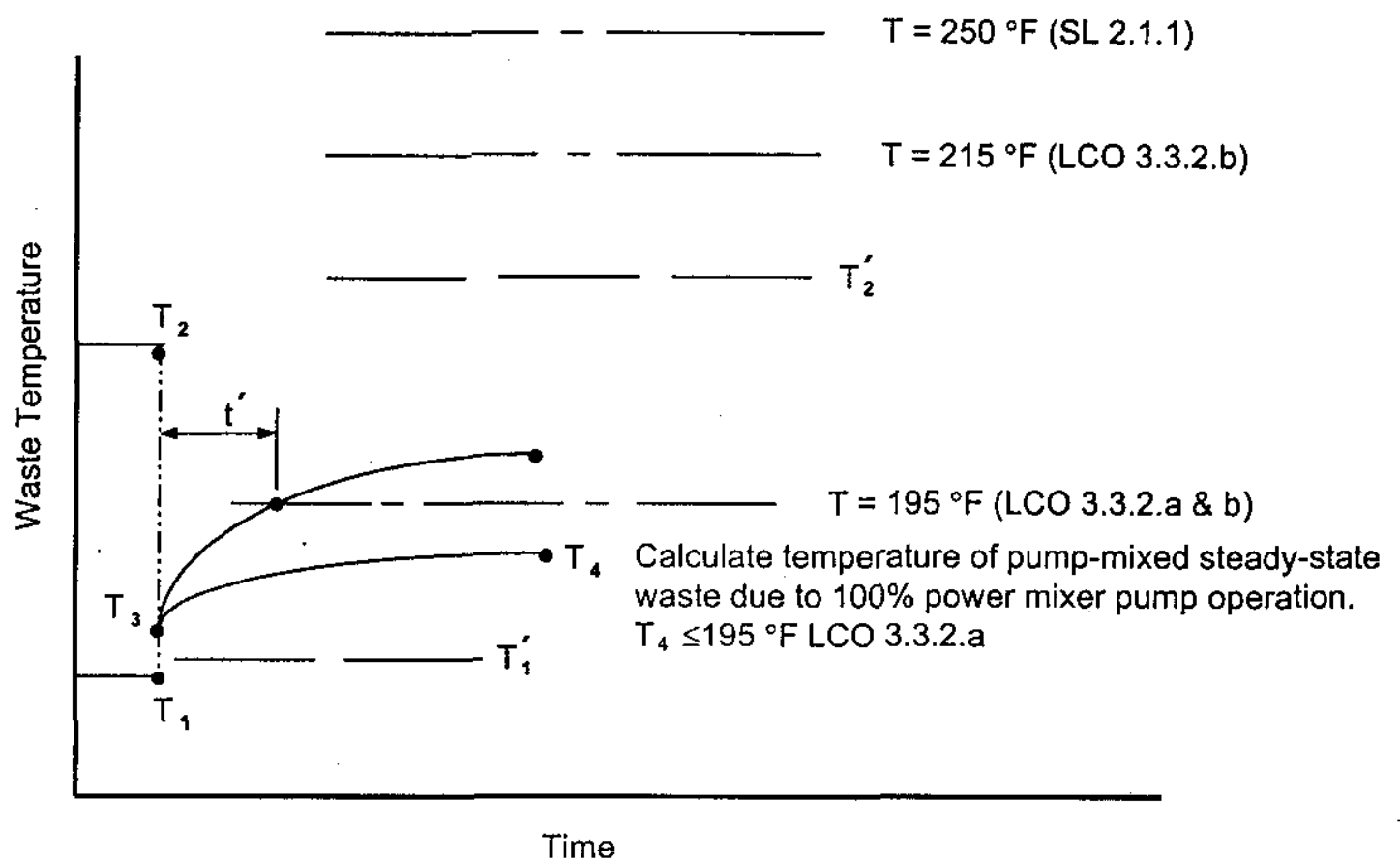

$\mathrm{T}_{4}$ Temperature of steady-state pump mixed waste. Must satisfy LCO 3.3.2.a

$t^{\prime}$ Time to reach the LCO in the event available options to adjust the HVAC systems are exhausted.

LCO = Limifing Conditions for Operation

To convert ${ }^{\circ} \mathrm{F}$ to ${ }^{\circ} \mathrm{C}: t_{{ }^{\circ} \mathrm{C}}=\left(t_{\mathrm{oF}}-32\right) / 1.8$

$1981-09$ 
RPP-5637

Rev. 0

Figure A-6. Parametric Study Step 4: Deternine Temperature Profile of Mixed-Settled Waste.

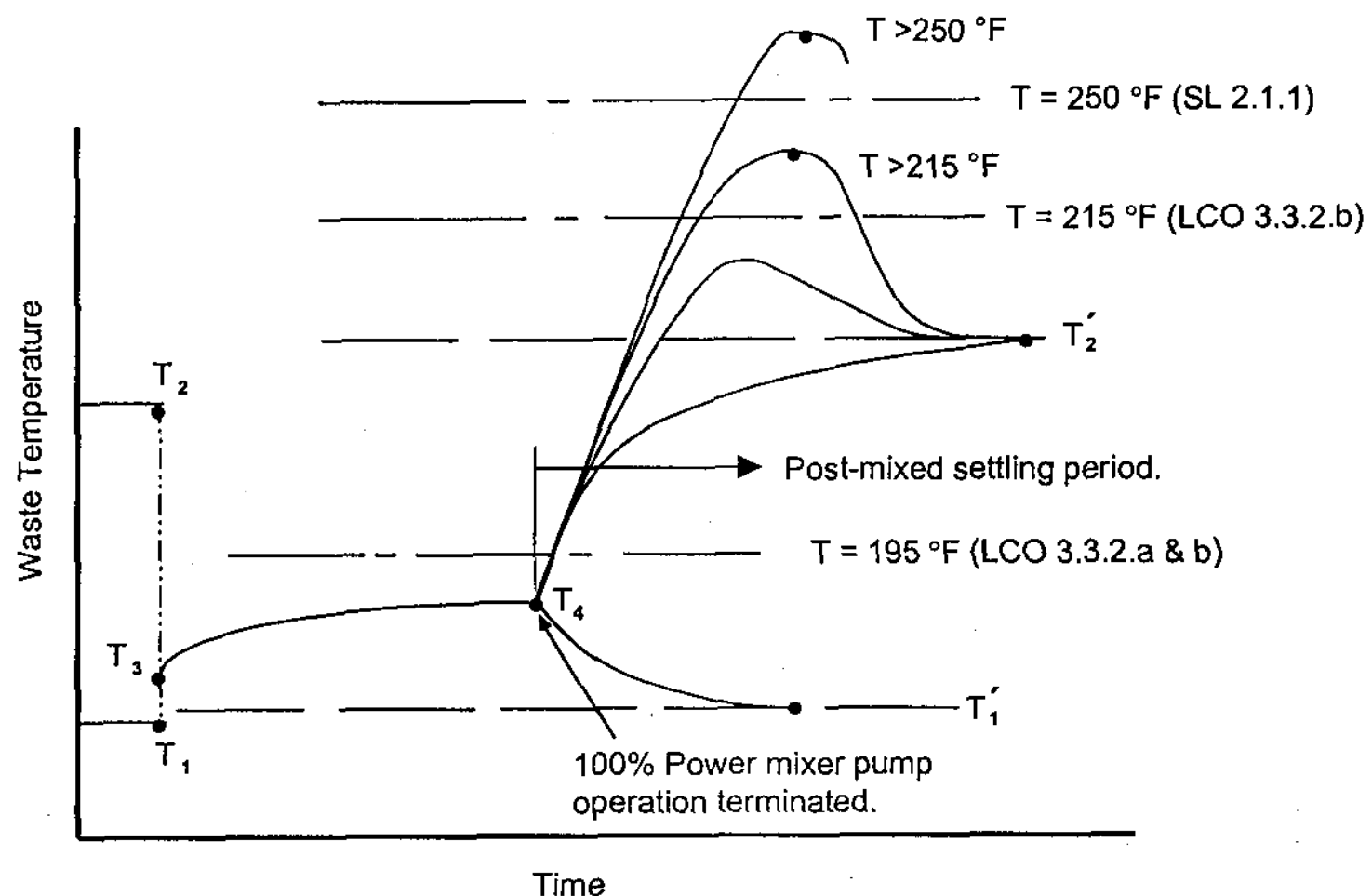

LCO $=$ Limiting Conditions for Operation

$\mathrm{SL}=$ Safety Limit

To convert ${ }^{\circ} \mathrm{F}$ to ${ }^{\circ} \mathrm{C}: t_{{ }^{\circ} \mathrm{C}}=\left(t_{\mathrm{oF}_{\mathrm{F}}}-32\right) / 1.8$

$1981-10$ 
Figure A-7. Parametric Study Step 5: Calculate the Time for the Waste Temperature to Reach the TSR Safety Limit Following Loss of Primary and Annulus Ventilation Systems.

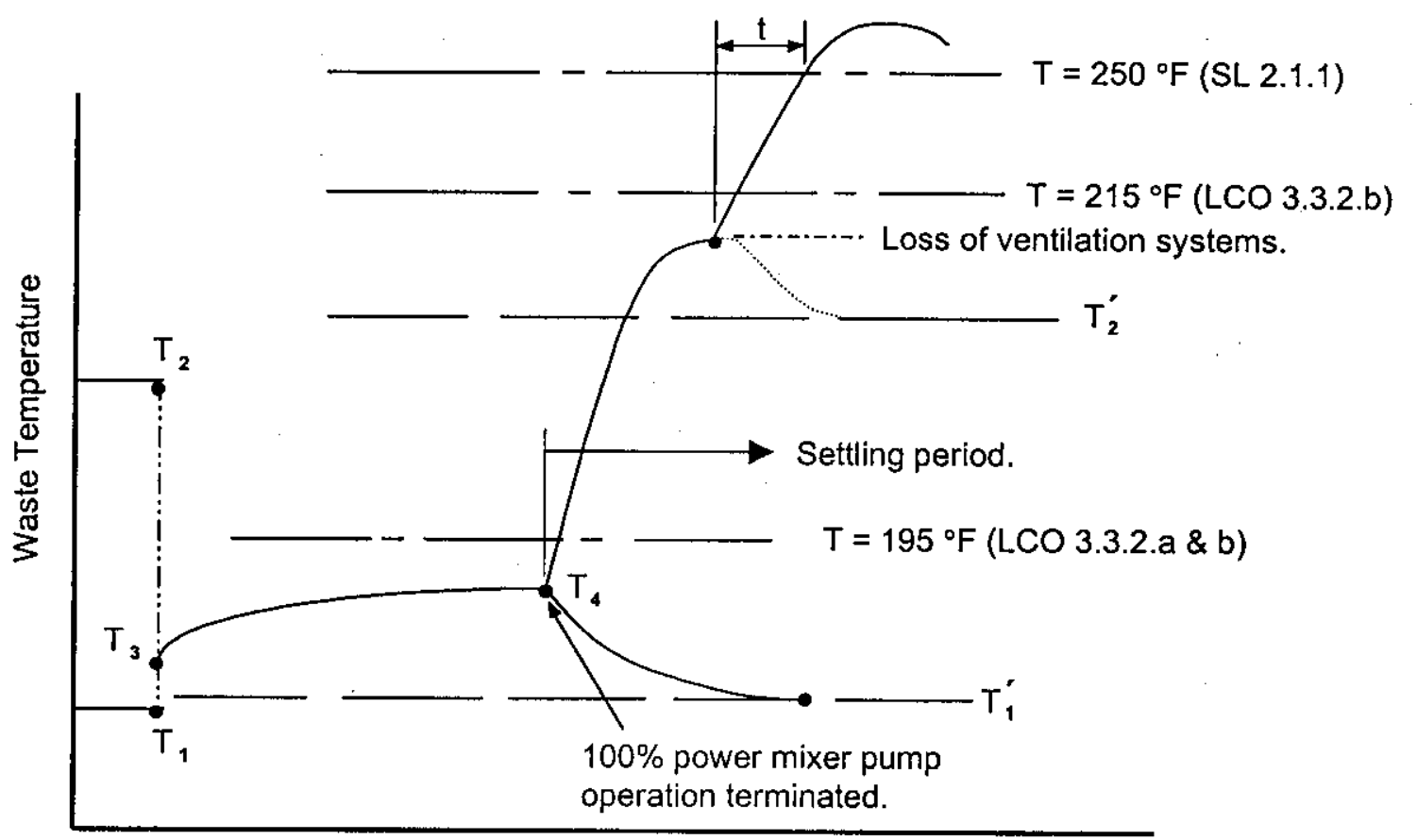

Time

t Time for the waste temperature to reach the Safety Limit after loss of HVAC systems.

LCO = Limiting Conditions for Operation

TSR = Technical Safety Requirements

To convert ${ }^{\circ} \mathrm{F}$ to ${ }^{\circ} \mathrm{C}: t_{{ }^{\circ} \mathrm{C}}=\left(t_{{ }_{\mathrm{FF}}}-32\right) / 1.8$

$1981-11$ 
RPP-5637

Rev. 0

This page intentionally left blank. 
RPP-5637

Rev. 0

APPENDIX B

INPUT MODEL PARAMETERS FOR A PARAMETRIC STUDY TO CHARACTERIZE ALTERNATIVES GENERATION ANALYSIS FOR REMOVAL OF HEAT FROM HIGH-LEVEL WASTE TANKS 
RPP-5637

Rev. 0

This page intentionally left blank.

B-ii 


\section{CONTENTS}

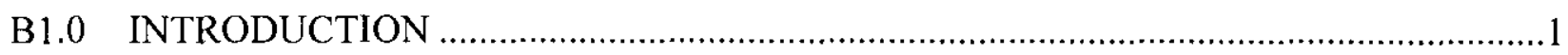

B2.0 BOUNDING CASES: WASTE TANKS AND FLUFFING FACTORS ............................2

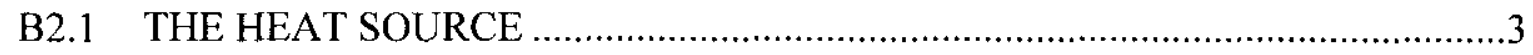

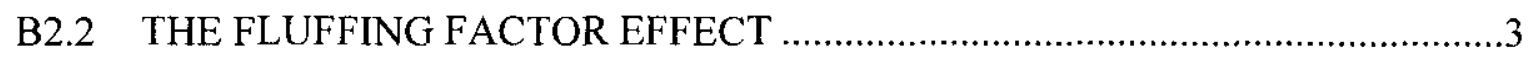

B2.3 BOUNDING CASE, FLUFFING FACTOR, AND

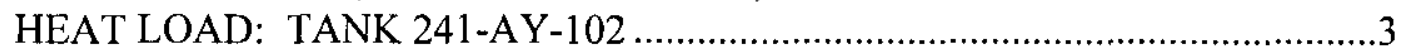

B2.4 BOUNDING CASE, FLUFFING FACTOR, AND

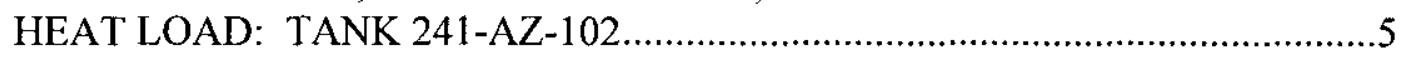

B3.0 TANK 241-AZ-102 THERMAL PARAMETERS (BOUNDING CASE) …….................6

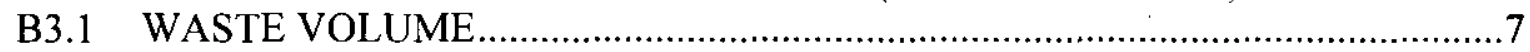

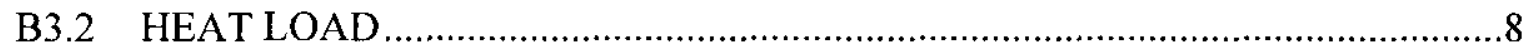

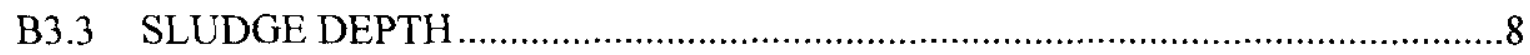

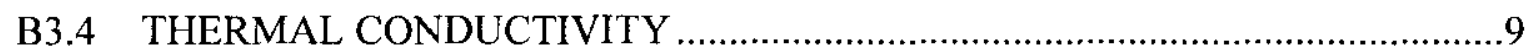

B4.0 TANK 241-AY-102 THERMAL PARAMETERS (BOUNDING CASE) ……….............9

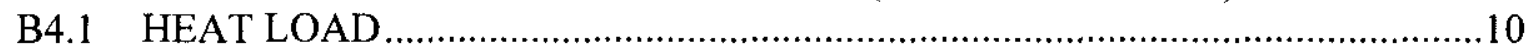

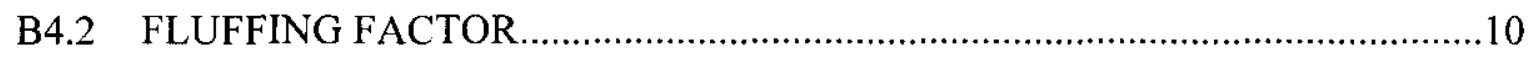

B4.3 WASTE DEPTH

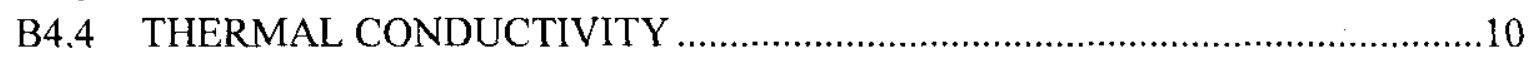

B5.0 TRANSPORT PROPERTY - VAPOR PRESSURE OF AQUEOUS WASTE

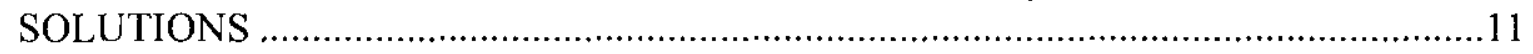

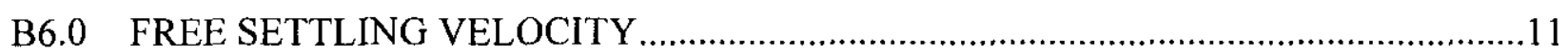

B7.0 BOUNDARY CONDITIONS - VENTILATION INLET NOMINAL TEMPERATURE AND ABSOLUTE HUMIDITY .....................................................12

B7.1 VENTILATION SYSTEMS OPERATION BOUNDARY CONDITIONS ..........12

B7.1.1 Primary Ventilation System Flow Rates ………....................................13

B7.1.2 Annulus Ventilation System Flow Rate ..................................................13

B7.2 CHILLER OUTLET NOMINAL TEMPERATURE AND HUMIDITY ..............13

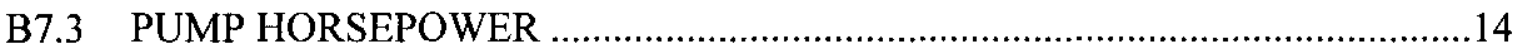

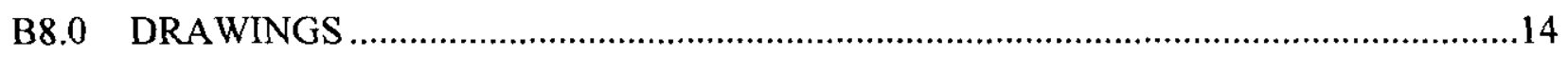

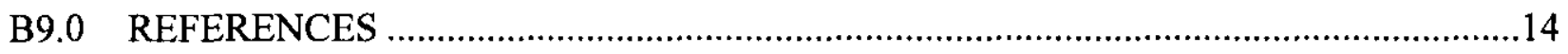




\section{FIGURES}

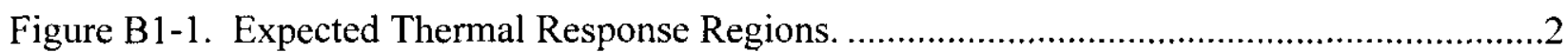

Figure B2-1. Settled Waste Level in Tank 241-AY-102..........................................................

\section{TABLES}

Table B3-1. Model Input Parameters for Tanks 241-AZ-101 and 241-AZ-102 ...........................6

Table B3-2. Waste Contents of Tank 214-AZ-101..................................................................

Table B3-3. Waste Contents of Tank 241-AZ-102 ……….......................................................

Table B4-1. Model Input Parameters for Tank 241-AY-102. ..................................................... 


\section{TERMS}

AGA

HLW

NCAW

TSR
Alternatives Generation and Analysis

high-level waste

neutralized current acid waste

Technical Safety Requïrements

\section{CONVERSION FACTORS}

English units of measure are used throughout this study to be consistent with the Technical Safety Requirements. Metric conversions for the applicable English units are provided below.

\begin{tabular}{|l|l|l|}
\hline To convert from & To & Multiply by \\
\hline${ }^{\circ} \mathrm{F}$ & ${ }^{\circ} \mathrm{C}$ & $t^{\circ} \mathrm{C}=\left(t^{\circ} \mathrm{F}-32\right) / 1.8$ \\
\hline $\mathrm{ft}$ & $\mathrm{m}$ & $3.048000^{*} \mathrm{E}-01$ \\
\hline $\mathrm{ft}^{3} / \mathrm{min}$ & $\mathrm{m}^{3} / \mathrm{s}$ & $4.719474 \mathrm{E}-04$ \\
\hline
\end{tabular}


RPP-5637

Rev. 0

This page intentionally left blank.

B-vi 


\section{APPENDIX B}

\section{INPUT MODEL PARAMETERS FOR A PARAMETRIC STUDY TO CHARACTERIZE ALTERNATIVES GENERATION ANALYSIS FOR REMOVAL OF HEAT FROM HIGH-LEVEL WASTE TANKS}

\section{B1.0 INTRODUCTION}

The technical information provided in this Appendix will be applied in the thermal analyses to quantify heat removal requirements for the high-level waste (HLW) tanks. Two approaches will be used to select model parameters for the analyses. The two approaches are to specify best estimate values in region 1 (see Figure B1-1) and to specify values with a degree of conservatism appropriate to the consequences associated with breaching a Safety Limit (HNF-SD-WM-SAR-067, Tank Waste Remediation System Final Safety Analysis Report) in regions 2 and 3 . The results of these analyses will be applied to quantify heat removal capacity required so that the waste temperature will not exceed the temperature limits specified in HNF-SD-WM-TSR-006, Tank Waste Remediation System Technical Safety Requirements (TSR). The classes of data in this report that are important to the analyses include transport properties, boundary conditions, initial conditions, and geometric and logical relationships. Best estimate values and safety basis values can be related to regions of the expected thermal response illustrated in Figure B1-1. The thermal response regions shown in the figure and their potential impact to tank operation are as follows:

Region 1: This region characterizes the steady-state temperature that the mixed waste achieves after mixer pump and decay heat are in equilibrium with the heat removal capacities of the ventilation systems and the earth. The input parameters for this region will be characterized as best-estimate values. Specification of these values carries the expectation that administrative controls can be applied to avoid TSR temperature limit violation. For example, if natural phenomena, such as either atypical weather or mechanical failure, force the waste temperature to approach the TSR temperature limit, the waste temperature can be reduced through the use of administrative controls such as reduction of pump power.

Region 2: This region characterizes the maximum waste and sludge temperature after cessation of mixing and subsequent settling of the waste. The thermal response exhibited in this region is affected by parameters such as fluffing factor and thermal conductivity. These parameters are not under administrative control and are specified with a degree of conservatism appropriate to the consequences associated with breaching a Safety Limit (HNF-SD-WM-SAR-067). These values are appropriate to their potential impact on the possibility that the sludge temperature may exceed the TSR temperature limit of $215^{\circ} \mathrm{F}$ if the actual values are significantly less conservative than the values used (HNF-SD-WM-TSR-006). 
Figure B1-1. Expected Thermal Response Regions.

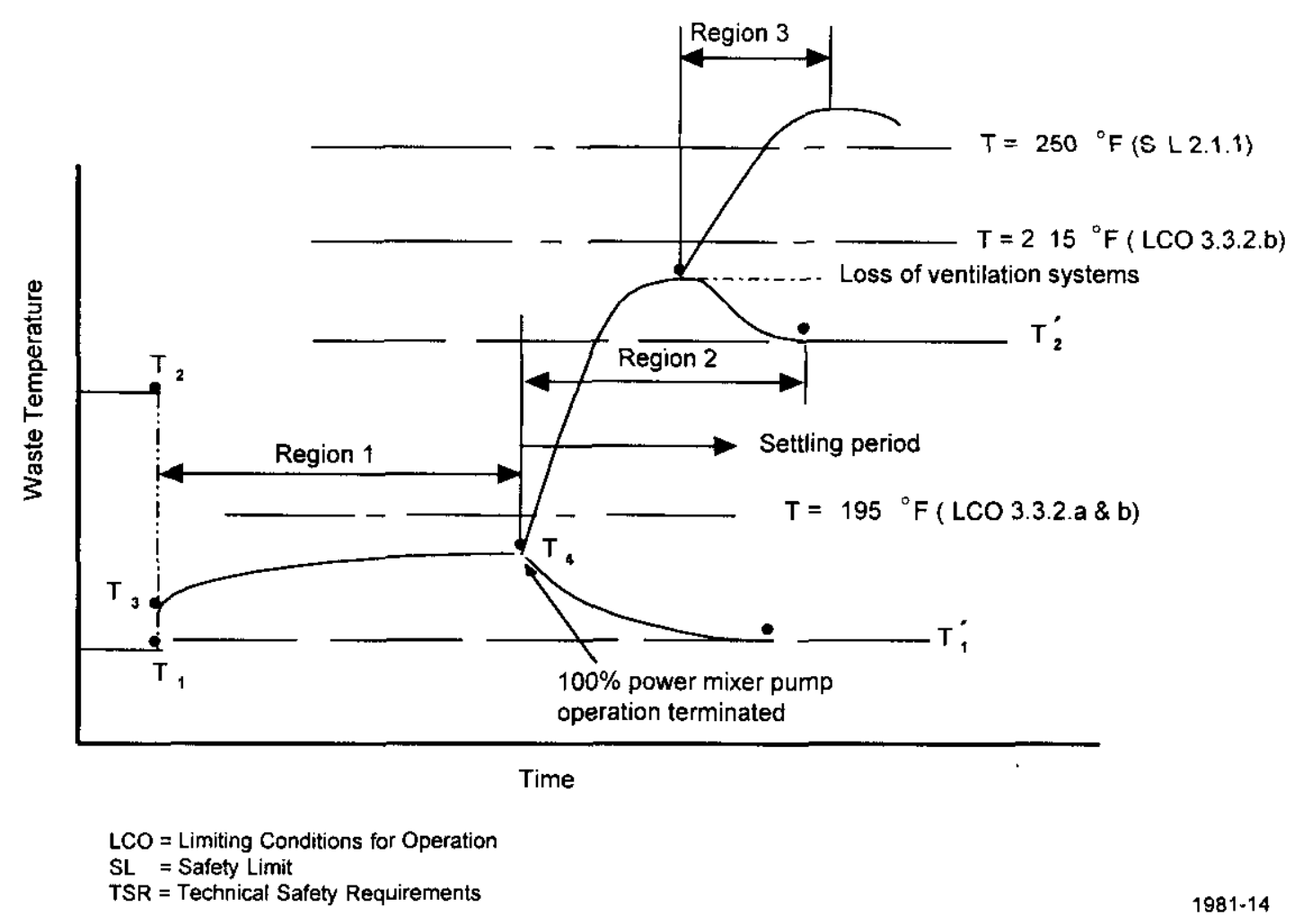

Region 3: This region characterizes the rate at which the waste temperature approaches the TSR Safety Limit. These parameters are not under administrative control and are specified with a degree of conservatism appropriate to the consequences associated with breaching a Safety Limit (HNF-SD-WM-SAR-067and HNF-SD-WM-TSR-006).

Drawings that define the logical relationships and the required geometric parameters for the models are identified in Section 7.0.

\section{B2.0 BOUNDING CASES: WASTE TANKS AND FLUFFING FACTORS}

This study is limited to the four tanks in the aging waste facility (241-AY-101, 241-AY-102, 241-AZ-101, 241-AZ-102). The Phase 1 privatization contract establishes specific requirements for the HLW feed to be delivered to BNFL Inc. The staging scenario that forms the basis for the selection of the tank contents that were analyzed in this report is case 3 as defined in HNF-SD-WM-SP-012. The bounding case tanks are 241-AY-102 and 241-AZ-102. These two tanks and their associated waste contents comprise the worst-case tanks and heat loads for the four HLW tanks in the aging waste facility. 
The contents of the four HLW tanks and the current contents plus future waste transfers combine to generate six possibilities for bounding conditions. These possibilities will be discussed in the following paragraphs.

\section{B2.1 THE HEAT SOURCE}

The most significant heat source for the primary-side ventilation system is the mixer pump. Although decay heat will contribute to the total heat load, the mixer-pump-induced heat load is an order-of-magnitude greater than the decay heat load.

The most significant heat source for the annulus-side ventilation system is the total decay heat in the sludge nonconvective layer.

\section{B2.2 THE FLUFFING FACTOR EFFECT}

The fluffing factor is defined as the fluffed-sludge depth divided by the settled and compacted sludge depth. An example of a settled and compacted sludge layer is the compacted layer on the bottom of Tank 241-AZ-102. Another example is the layer on the bottom of Tank 241-AY-102 that consists of the original contents; e.g., before the contents of Tank 241-C-106 were sluiced and transferred into Tank 241-AY-102. The nonconvective layer thickness that occurs after mixing is defined as the product of the fluffing factor and of the compacted sludge thickness.

The existing and transferred waste, which is considered in the process of determining the bounding case tanks, and the maximum fluffed-sludge depth are linked. This linkage occurs because the maximum differential temperature in the nonconvective sludge layer is proportional to the product of the thickness of the nonconvective layer and the total radioactive decay heat rate of the nonconvective layer.

\section{B2.3 BOUNDING CASE, FLUFFING FACTOR, AND HEAT LOAD: TANK 241-AY-102}

Because Tank 241-AY-102 bounds Tank 241-AY-101, Tank 241-AY-101 was eliminated as a candidate for thermal analysis. The heat load is considerably greater than the heat load in Tank 241-AY-101, and the sludge depth in Tank 241-AY-102 is almost twice that of Tank 241-AY-101. Accordingly, the maximum differential temperature in the nonconvective sludge layer, which is proportional to the product of the thickness of the nonconvective layer and the total radioactive decay heat rate of the nonconvective layer, is considerably greater in Tank 241-AY-102.

Tank 241-AY-101 contains 162,000 gal of dilute complexed waste, which includes 108,000 gal of sludge. The current heat load is $69,300 \mathrm{Btu} / \mathrm{h}$, and the sludge depth is approximately $3.2 \mathrm{ft}$.

The 241-AY-102 fluffed-sludge depth is $7.58 \mathrm{ft}$. The current depth is equal to the depth of the contents that existed before the Tank 241-C-106 waste transfer plus the depth of the transferred Tank 241-C-106 sluiced waste. The fluffed depth of the contents before the 
Tank 241-C-106 transfers was derived by applying the fluff factor of 2.0 (HNF-5177, The Settling and Compaction of Nuclear Waste Slurries) to the original depth of the contents. The depths for the incremental fluffed-waste additions transferred from Tank 241-C-106 are shown in Figure B2-1, a plot of the incremental sludge depth associated with waste transfers from Tank 241-C-106. The initial waste depth in Tank $241-\mathrm{AY}-102$ was $0.75 \mathrm{ft}$, so the fluffed depth is $1.5 \mathrm{ft}$. The fluffed depth of the incremental Tank 241-C-106 additions to Tank 241-AY-102 is $6.08 \mathrm{ft}$. Thus, the sum is $7.58 \mathrm{ft}$.

Figure B2-1. Settled Waste Level in Tank 241-AY-102.

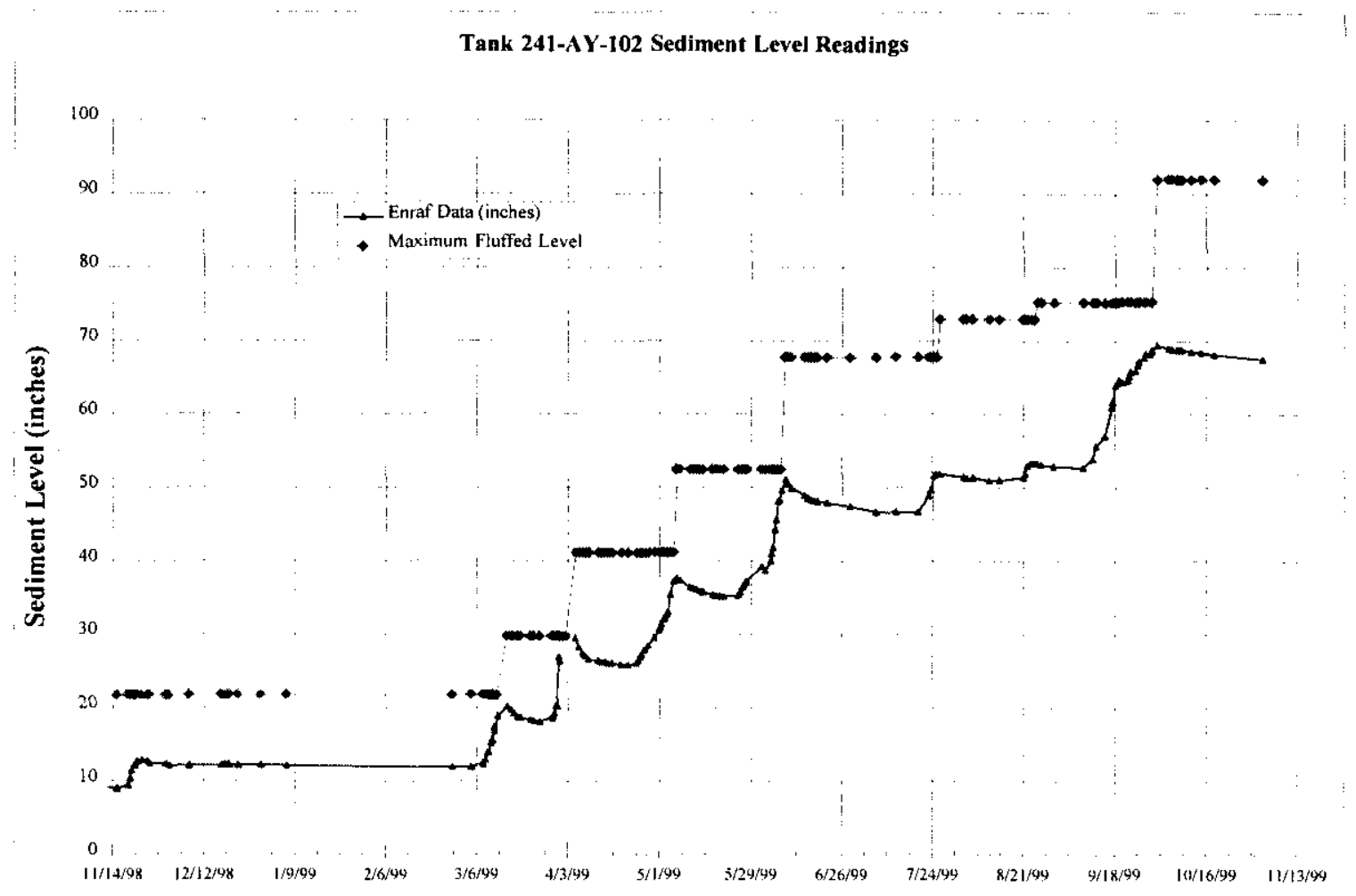

The best estimate total decay heat load for the waste in Tank 241-AY-102 is greater than $100,000 \mathrm{Btu} / \mathrm{h}$. The actual decay heat load, which is being determined, is expected to be less than the best estimate value.

Tank 241-AY-102 with current contents, which includes Tank 241-C-106 sluiced waste, bounds the effects of sludge depth and heat load in Tank 241-C-102 and Tank 241-C-104 waste. Specifically, the product of the nonconvective sludge layer depth and the total radioactive decay heat rate for Tank 241-AY-102 is greater than that for either Tank 241-C-102 or Tank 241-C-104. The current compacted sludge depth and heat load of Tank 241-C-102 are $9.5 \mathrm{ft}$ and $4,600 \mathrm{Btu} / \mathrm{h}$, respectively. The current compacted sludge depth and heat load of Tank 241-C-104 are $8.9 \mathrm{ft}$ and 16,000 Btu/h, respectively. The fluffed nonconvective sludge layer depths for Tank 241-C-102 and Tank 241-C-104 are 19 and $17.8 \mathrm{ft}$, respectively. 
The allowable total waste depth for Tank $241-\mathrm{AY}-102$ is approximately $30 \mathrm{ft}$. The steady-state differential temperature is proportional to the product of the fluffed waste depth and the total decay heat generation rate. Thus, even if the total waste is conservatively considered nonconvective, the heat load in Tank 241-AY-102 exceeds that of Tank 241-C-102 and Tank 241-C-104 and provides a conservative upper bound.

\section{B2.4 BOUNDING CASE, FLUFFING FACTOR, AND HEAT LOAD: TANK 241-AZ-102}

Tank 241-AZ-102 bounds Tank 241-AZ-101, thus Tank 241-AZ-101 was eliminated as a candidate for thermal analysis. The effect of total decay heat rate and fluffed-sludge thickness for Tank 241-AZ-102 is approximately twice that of Tank 241-AZ-101. In fact, the maximum differential temperature in the nonconvective sludge layer, which is product of the thickness of the nonconvective layer and the total radioactive decay heat rate of the nonconvective layer, is considerably greater in Tank 241-AZ-102.

Tank 241-AZ-101 has a sludge total heat decay rate approximately equal to $150,000 \mathrm{Btu} / \mathrm{h}$ and a compacted sludge depth equal to $1.42 \mathrm{ft}$. Tank $241-\mathrm{AZ}-102$ has a sludge total heat decay rate approximately equal to $130,000 \mathrm{Btu} / \mathrm{h}$ and a compacted sludge depth equal to $3.15 \mathrm{ft}$. The waste depths are based on data contained in HNF-EP-0182-133, Waste Tank Summary Report for Month Ending April 30, 1999. As indicated by the product of the sludge thickness and the total heat decay rate in the sludge, Tank 241-AZ-102 provides the bounding case for tanks 241-AZ-101 and 241-AZ-102.

Based on the results and conclusions presented in HNF-5177, a fluffing factor equal to 2.0 will be used to calculate the fluffed-sludge depth in Tank 241-AZ-102. The sludge contents of tanks 241-AZ-101 and 241-AZ-102 are listed as neutralized current acid waste (NCAW). A recently completed experimental program included tests using a simulant for NCAW (HNF-5177). Results presented in this study suggest that a fluffing factor equal to 2.0is appropriate for the slurries tested. The results presented for the NCAW simulant do not include the full-scale testing that was done for other simulants. Nevertheless, the small-scale NCAW tests compare well with the other simulant tests when subjected to the non-dimensionalization procedure suggested in the report. 


\section{B3.0 TANK 241-AZ-102 THERMAL PARAMETERS (BOUNDING CASE)}

The model input parameters for Tank 241-AZ-102 are presented in Table B3-1. Further discussion is given for those parameters that are used to define the bounding case. The parameters for Tank 241-AZ-101 are included in this table to support selection of Tank 241-AZ-102 as the bounding case. The parameters are appropriate for compacted sludge.

Table B3-1. Model Input Parameters for Tanks 241-AZ-101 and 241-AZ-102. (2 sheets)

\begin{tabular}{|c|c|c|c|c|}
\hline Waste Property & $\begin{array}{l}\text { Tank 241-AZ-101 } \\
\text { Parameter Value }\end{array}$ & References & $\begin{array}{l}\text { Tank 214-AZ-102 } \\
\text { Parameter Value }\end{array}$ & References \\
\hline Liquid Volume & $\begin{array}{c}114,400 \mathrm{ft}^{3} \\
(3,240,000 \mathrm{~L})\end{array}$ & $a, b$ & $\begin{array}{c}124,700 \mathrm{ft}^{3} \\
(3,531,000 \mathrm{~L})\end{array}$ & $\mathrm{a}$ \\
\hline Solids Volume & $\begin{array}{c}1,448 \mathrm{ft}^{3} \\
(41,000 \mathrm{~L})\end{array}$ & $a, b$ & $\begin{array}{c}2,200 \mathrm{ft}^{3} \\
(62,300 \mathrm{~L})\end{array}$ & a \\
\hline Total Waste Volume & $\begin{array}{c}116,231 \mathrm{ft}^{3} \\
(3,281,000 \mathrm{~L})\end{array}$ & $\mathrm{a}, \mathrm{b}$ & $126,900 \mathrm{ft}^{3}$ & $\mathrm{a}$ \\
\hline Liquid Density & $\begin{array}{l}73.66 \mathrm{lbm} / \mathrm{ft}^{3} \\
\left(1.18 \mathrm{gm} / \mathrm{cm}^{3}\right)\end{array}$ & $a, b$ & $\begin{array}{l}68.64 \mathrm{lbm} / \mathrm{ft}^{3} \\
\left(1.1 \mathrm{gm} / \mathrm{cm}^{3}\right)\end{array}$ & $a, c, d$ \\
\hline Solids Density & $\begin{array}{l}199.8 \mathrm{lbm} / \mathrm{ft}^{3} \\
(3.2 \mathrm{gm} / \mathrm{cm} 3) \\
\end{array}$ & $a, b$ & $\begin{array}{l}237.1 \mathrm{lbm} / \mathrm{ft}^{3} \\
(3.8 \mathrm{gm} / \mathrm{cm} 3)\end{array}$ & $\mathrm{a}, \mathrm{c}$ \\
\hline Liquid Heat Capacity & $\begin{array}{c}0.7643 \mathrm{Btu} / \mathrm{lbm}-{ }^{\circ} \mathrm{R} \\
\left(3.2 \mathrm{~kJ} / \mathrm{kg}{ }^{\circ} \mathrm{C}\right)\end{array}$ & $\mathrm{a}, \mathrm{b}$ & $1.0 \mathrm{Btu} / \mathrm{lbm}-{ }^{\circ} \mathrm{R}$ & $a, b$ \\
\hline Solids Heat Capacity & $\begin{array}{c}0.2627 \mathrm{Btu} / \mathrm{lbm}-{ }^{\circ} \mathrm{R} \\
\left(1.1 \mathrm{~kJ} / \mathrm{kg}{ }^{\circ} \mathrm{C}\right)\end{array}$ & $a, b$ & $0.2 \mathrm{Btu} / \mathrm{lbm}-{ }^{\circ} \mathrm{R}$ & $a, b$ \\
\hline $\begin{array}{l}\text { Liquid Specific Heat } \\
\text { Generation Rate }\end{array}$ & $\begin{array}{l}0.01408 \mathrm{Btu} / \mathrm{lbm}-\mathrm{h} \\
(0.0091 \text { watts } / \mathrm{kg})\end{array}$ & $\mathrm{a}, \mathrm{b}$ & $\begin{array}{c}0.009 \mathrm{Btu} / \mathrm{lbm}-\mathrm{h} \\
(0.0058 \mathrm{watts} / \mathrm{kg})\end{array}$ & $\mathrm{a}, \mathrm{c}$ \\
\hline $\begin{array}{l}\text { Solids Specific Heat } \\
\text { Generation Rate }\end{array}$ & $\begin{array}{c}0.5262 \mathrm{Btu} / \mathrm{lbm}-\mathrm{h} \\
(0.34 \text { watts } / \mathrm{kg})\end{array}$ & $\mathrm{a}, \mathrm{b}$ & $\begin{array}{l}0.2544 \overline{\mathrm{Btu}} / \mathrm{lbm}-\mathrm{h} \\
(0.1644 \mathrm{watts} / \mathrm{kg})\end{array}$ & $\mathrm{a}, \mathrm{c}$ \\
\hline $\begin{array}{l}\text { Thermal Conductivity } \\
\text { of Aqueous Solution }\end{array}$ & $0.35 \mathrm{Btu} / \mathrm{h}-\mathrm{ft}-{ }^{\circ} \mathrm{R} \backslash$ & $\mathrm{e}$ & $0.35 \mathrm{Btu} / \mathrm{h}-\mathrm{ft}-{ }^{\circ} \mathrm{R}$ & $\mathrm{e}$ \\
\hline $\begin{array}{l}\text { Thermal Conductivity } \\
\text { of Solids }\end{array}$ & $5.0 \mathrm{Btu} / \mathrm{h}-\mathrm{ft}-{ }^{\circ} \mathrm{R}$ & e & $5.0 \mathrm{Btu} / \mathrm{h}-\mathrm{ft}-{ }^{\circ} \mathrm{R}$ & e \\
\hline Sludge & $\begin{array}{l}47,000 \mathrm{gal} \\
\left(6283 \mathrm{ft}^{3}\right)\end{array}$ & $\mathrm{f}, \mathrm{a}$ & $\begin{array}{c}95,000 \mathrm{gal} \\
\left(127,000 \mathrm{ft}^{3}\right)\end{array}$ & $\mathrm{f}, \mathrm{a}$ \\
\hline Supernatant Liquid & $\begin{array}{c}812,000 \text { gal } \\
\left(108,500 \mathrm{ft}^{3}\right)\end{array}$ & $f, a$ & $\begin{array}{l}854,000 \mathrm{gal} \\
114,200 \mathrm{ft}^{3}\end{array}$ & $\mathrm{f}, \mathrm{a}$ \\
\hline Sludge Depth & $\begin{array}{l}17 \text { in. } \\
16 \text { to } 17.75 \mathrm{in.}\end{array}$ & $\mathrm{a}, \mathrm{g}$ & 34.5 in. & a \\
\hline $\begin{array}{l}\text { Weight Fraction of } \\
\text { Solids }\end{array}$ & 0.45 & $\mathrm{a}, \mathrm{g}$ & 0.42 & a \\
\hline $\begin{array}{l}\text { Volume Fraction of } \\
\text { Solids }\end{array}$ & 0.23 & a & 0.17 & a \\
\hline
\end{tabular}


Table B3-1. Model Input Parameters for Tanks 241-AZ-101 and 241-AZ-102. (2 sheets)

\begin{tabular}{|l|c|c|c|c|}
\hline \multicolumn{1}{|c|}{ Waste Property } & $\begin{array}{c}\text { Tank 241-AZ-101 } \\
\text { Parameter Value }\end{array}$ & References & $\begin{array}{c}\text { Tank 214-AZ-102 } \\
\text { Parameter Value }\end{array}$ & References \\
\hline $\begin{array}{l}\text { Heat Load in } \\
\text { Supernatant Liquid }\end{array}$ & $113,700 \mathrm{Btu} / \mathrm{h}$ & $\mathrm{a}$ & $67,000 \mathrm{Btu} / \mathrm{h}$ & $\mathrm{a}$ \\
\hline Heat Load in Sludge & $157,200 \mathrm{Btu} / \mathrm{h}$ & $\mathrm{a}$ & $132,700 \mathrm{Btu} / \mathrm{h}$ & $\mathrm{a}$ \\
& & & & $199,700 \mathrm{Btu} / \mathrm{h}$ \\
\hline $\begin{array}{l}\text { Total Heat Generation } \\
\text { Rate in Tank Waste }\end{array}$ & $270,900 \mathrm{Btu} / \mathrm{h}$ & $\mathrm{a}, \mathrm{b}$ & $199,457 \mathrm{Btu} / \mathrm{h}$ & $\mathrm{a}$ \\
& $272,000 \mathrm{Btu} / \mathrm{h}$ & & & \\
\hline
\end{tabular}

${ }^{\mathrm{a}} \mathrm{HNF}-5386,1999$, Thermal Hydraulic Analysis of High-Level Waste Tanks for Phase 1 Waste Feed Delivery, Rev. 0, Numatec Hanford Corporation, Richland, Washington.

${ }^{\mathrm{b}}$ MacLean, G. T., 1998, Parameters for Use in CFD Simulations of the Mixing and Settling of Tank 24l-AZ-101, Letter Report COGEMA-98-521, COGEMA Engineering Corporation, Richland, Washington.

${ }^{\mathrm{c}} \mathrm{HNF}$-SD-W030-ER-004, 1997, Evaluation of Waste Temperatures in AWF Tanks for Bypass Mode Operation of the 702-AZ Ventilation System (Project W-030), Rev. 0, Numatec Hanford Corporation, Richland, Washington.

${ }^{\mathrm{d}}$ WHC-SD-WM-ER-411, 1995, Tank Characterization Report for Double-Shell Tank 241-AZ-102, Rev. 0, Westinghouse Hanford Company, Richland, Washington.

${ }^{\mathrm{e}}$ WHC-SD-WM-ER-198, 1993, Development of A Dynamic Computer Simulator For Aging Waste Tank Operations and Safety Assessment, Rev. 0, Westinghouse Hanford Company, Richland, Washington.

${ }^{f}$ HNF-EP-01 82-109, 1997, Waste Tank Summary Report for Month Ending April 30, 1997, Flour Daniel Hanford, Inc., Richland, Washington.

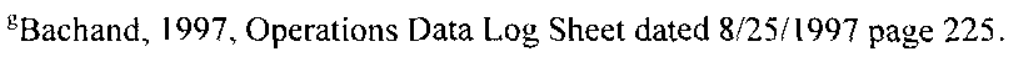

\section{B3.1 WASTE VOLUME}

\section{Tank 241-AZ-101}

As of June 30,1999, the waste contents of the tank are as given in Table B3-2.

Table B3-2. Waste Contents of Tank 214-AZ-101.

\begin{tabular}{|l|l|}
\hline \multicolumn{1}{|c|}{ Tank Total Waste Volume } & \multicolumn{1}{c|}{845,000 gal } \\
\hline Supernatant Liquid & 799,000 gal \\
\hline Sludge & 46,000 gal \\
\hline Waste Surface Level & 307.3 in. \\
\hline
\end{tabular}

Source: HNF-EP-0182-137, 1999, Waste Tank Summary Report for Month Ending August 31, 1999, Flour Daniel Hanford, Inc., Richland, Washington.

\section{Tank 241-AZ-102}

Waste contents of Tank 241-AZ-101 as of June 30,1999, are shown in Table B3-3. 
Table B3-3. Waste Contents of Tank 241-AZ-102.

\begin{tabular}{|l|l|}
\hline Tank Total Waste Volume & $926,000 \mathrm{gal}$ \\
\hline Supernatant Liquid & $838,000 \mathrm{gal}$ \\
\hline Sludge & $88,000 \mathrm{gal}$ \\
\hline Waste Surface Level & $336.7 \mathrm{in}$. \\
\hline
\end{tabular}

Source: HNF-EP-0182-137, 1999, Waste Tank Summary Report for Month Ending

August 31, 1999, Flour Daniel Hanford, Inc., Richland, Washington.

\section{B3.2 HEAT LOAD}

\section{Tank 241-AZ-101}

WHC-SD-WM-ER-410, Tank Characterization Report for Double-Shell

Tank 241-AZ-101, reported that the heat load in Tank 241-AZ-101 was 241,600 Btu/h in 1995. MacLean (1998) reported the heat load as approximately $272,000 \mathrm{Btu} / \mathrm{h}$ based on best estimate inventory data and 1997 sludge depth (HNF-EP-0182-109). However, HNF-5386 calculated a heat load of $270,900 \mathrm{Btu} / \mathrm{h}$ based on specific heat-generation values of liquid and solids and tank waste contents reported in HNF-EP-0182-109. The heat load of 270,000 Btu/h differs by less than $0.5 \%$ from the MacLean (1998) value and it was considered a conservative value compared with WHC-SD-WM-ER-410 data. Most recently Willis (1999) reported a value of $273,000 \mathrm{Btu} / \mathrm{h}$.

\section{Tank 241-AZ-102}

WHC-SD-WM-ER-411, Tank Characterization Report for Double-Shell

Tank 24I-AZ-102, reported that the total heat load of Tank $241-\mathrm{AZ}-102$ waste was $199,457 \mathrm{Btu} / \mathrm{h}$ (58.441 kW). HNF-5386 calculated the total heat load of $199,700 \mathrm{Btu} / \mathrm{h}$ based on the total liquid heat and solid heat values of HNF-SD-W030-ER-004, Project $W-320$ SAR and Process Control Thermal Analyses. Using the same best basis inventory data as HNF-SD-W030-ER-004, Bachand (1997) calculated a radionuclide heat load of 159,000 Btu/h. Bachand's value is much below all the other three reported values.

Reevaluation of radionuclide decay heat load of the waste in Tank 241-AZ-102 is strongly suggested because this is the bounding case for the combined parameters of waste and heat loading of the tank for alternatives generation and analysis (AGA) analysis.

\section{B3.3 SLUDGE DEPTH}

The sludge volume in Tank 241-AZ-101 was reported in WHC-SD-WM-ER-410 as 35,000 gal. Sludge depth measurements in August 1997 showed an average depth of 17 in., which is about 47,000 gal. HNF-EP-0182-137, Waste Tank Summary Report for Month Ending August 31, 1999, reports a sludge volume of 46,000 gal, which is a sludge depth of about 16.7 in. 
The sludge volume in Tank 241-AZ-102 was reported in HNF-EP-0182-109 as 95,000 gal, which results in a sludge depth about 34.5 in. HNF-EP-0182-137 shows a sludge volume of 88,000 gal, which is a sludge depth of about 32 in.

\section{B3.4 THERMAL CONDUCTIVITY}

Based on the data in Table B3-1 for Tank 241-AZ-101 and assuming that all the solids are in the sludge, the sludge will have 23 volume percent of solids or about 45 weight percent of solids. Using a series conductivity model, the sludge thermal conductivity is $0.45 \mathrm{Btu} / \mathrm{h}-\mathrm{ft}-{ }^{\circ} \mathrm{R}$ (HNF-5386).

Based on the data in Table B3-1 for Tank 241-AZ-102 and assuming that all the solids are in the sludge, the sludge will have about 17 volume percent of solids or about 42 weight percent of solids. Using a series conductivity model, the sludge thermal conductivity is about $0.42 \mathrm{Btu} / \mathrm{h}-\mathrm{ft}-{ }^{\circ} \mathrm{R}$ (HNF-5386).

\section{B4.0 TANK 241-AY-102 THERMAL PARAMETERS (BOUNDING CASE)}

The model input parameters for Tank 241-AY-102 in the fluffed sludge condition are presented in Table B4-1.

Table B4-1. Model Input Parameters for Tank 241-AY-102.

\begin{tabular}{|l|c|}
\hline \multicolumn{1}{|c|}{ Waste Property } & Parameter Value \\
\hline Supernatant Liquid Volume & $424,000 \mathrm{gal}$ \\
\hline Sludge Volume & $186,000 \mathrm{gal}$ \\
\hline Total Waste Volume & $222 \mathrm{in}$. \\
& $610,000 \mathrm{gal}$ \\
\hline Liquid Density & $62.4 \mathrm{lbm} / \mathrm{ft}^{3}$ \\
\hline Solids Density & $120.4 \mathrm{lbm} / \mathrm{ft}^{3}$ \\
\hline Liquid Heat Capacity & $0.8 \mathrm{Btu} / \mathrm{lbm}{ }^{\circ} \mathrm{F}$ \\
\hline Solids Heat Capacity & $0.2 \mathrm{Btu} / \mathrm{lbm}{ }^{\circ} \mathrm{F}$ \\
\hline Thermal Conductivity of Solids & $5.0 \mathrm{Btu} / \mathrm{h}-\mathrm{ft}^{\circ} \mathrm{F}$ \\
\hline Sludge Depth & $91 \mathrm{in}$. \\
\hline Heat Load in Supernatant Liquid & 0 \\
\hline Heat Load in Sludge & $116,000 \mathrm{Btu} / \mathrm{h}$ \\
\hline
\end{tabular}




\section{B4.1 HEAT LOAD}

The heat loads of tanks 241-AY-102 and 241-C-106 were estimated in HNF-SD-W320-ER-004, Project W-320 SAR and Process Control Thermal Analyses. The following are heat load estimates for September 1997. All heat loads should be decayed assuming a half-life of strontium 90 ( $\sim 28$ years).

- Tank 241-AY-102 41,200 Btu/h

- Tank 241-C-106 118,000 Btu/h.

Project W-320 removed from 60,000 to $80,000 \mathrm{Btu} / \mathrm{h}$ of heat from Tank 241-C-106. For the purposes of the AGA study, the transferred heat load will be assumed to be $77,000 \mathrm{Btu} / \mathrm{h}$. Thus, the total heat in Tank 241-AY-102 in November 1999 is assumed to be 116,000 Btu/h.

One hundred percent of the heat load will be considered to be in the sludge.

\section{B4.2 FLUFFING FACTOR}

The best-estimate fluffing factor selected for the Project W-320 transfer of waste into Tank 241-AY-102 was 1.4 (HNF-SD-W320-ER-004). This estimate was based on laboratory settling data. The 2 sigma upper bound was estimated to be 1.8 . A value of 1.8 will be used for AGA supporting analyses for Tank 241-AY-102. This will provide a level of conservatism. The fluffing factor will be used for calculating waste properties only.

\section{B4.3 WASTE DEPTH}

Figure B2-1 shows the settled waste level in Tank 241-AY-102 based on Enraf densitometer measurements. The Project W-320 sluicing was initiated early in November 1998. Each waste transfer results in an increase in the settled waste level of Tank 241-AY-102. The Enraf data show a rapid settling of the waste followed by a slower settling rate. The other curve shown in Figure B2-1 represents the expected maximum waste depth if the waste were mixed with a mixer pump. The initial settled waste ( 9 in. deep) is assumed to fluff to a depth of 18 in. The transferred waste will only increase to the depth of the waste immediately following the waste transfer from Tank 241-C-106. The figure shows that the maximum depth of waste following mixer pump operation is 91 inches.

\section{B4.4 THERMAL CONDUCTIVITY}

A thermal conductivity model is required to determine the waste conductivity. The waste properties for the Tank 241-AY-102 waste will be obtained from the Tank 241-C-106 parameters and the application of the waste-fluffing factor.

The model input parameters are based on the Project W-320 process control plan (HNF-SD-WM-PCP-013, Tank 241-C-106 Waste Retrieval Sluicing System Process Control Plan).

- Sludge bulk specific gravity 1.55 
- Weight percent water in interstitial fluid

$78.6 \mathrm{wt} \%$

- Weight fraction of solids $\quad 47 \%$

The specific gravity of the solid particles and the interstitial fluid were selected to be consistent with the above items.

- Interstitial fluid specific gravity $\quad 1.27$

- Particle specific gravity 1.93

The particle volume fraction was derived from these parameters.

- Particle volume fraction $43 \%$

The following are estimates of the particle and liquid thermal conductivities (HNF-SD-W320-ER-004).

- Liquid thermal conductivity

$0.35 \mathrm{Btu} / \mathrm{h}-\mathrm{ft}-{ }^{\circ} \mathrm{F}$

- Particle thermal conductivity

$5.0 \mathrm{Btu} / \mathrm{h}-\mathrm{ft}-{ }^{\circ} \mathrm{F}$

\section{B5.0 TRANSPORT PROPERTY - VAPOR PRESSURE OF AQUEOUS WASTE SOLUTIONS}

Dissolving either salts or basic materials in water lowers the vapor pressure for a given solution temperature. The temperature of the solution must rise until a vapor pressure is reached equal to water for a given amount of heat to be removed by evaporation. GOTH thermal hydraulic model incorporates this effect to calculate the solution saturation temperature (WHC-SD-WM-ER-198). The value chosen is for this aqueous waste solution is $85 \%$ of the value of water.

\section{B6.0 FREE SETTLING VELOCITY}

The free settling velocity of the slurry particles after mixing stops effects the time that the maximum temperature develops in the settled sludge layer. The non-convective layer will form faster for large velocity values. If the particles instantaneously settle to the fluffed sludge depth so that the sludge becomes non-convective, the maximum sludge temperature will develop. If the particles remain suspended the waste remains in a convective state and the heat load will be distributed equally. The particle settling velocity effects the system thermal response. Accordingly, the velocity value will effect the ventilation system design.

Input parameters, such as particle size and density, and liquid properties, such as viscosity, affect the slurry settling velocity. Some of these parameters have been specified in the table of input parameters and some are implied by other material or physical properties. All applicable input properties will not be defined. A constraint on the results will be specified to ensure that settling is sufficiently rapid to be conservative. 
HNF-5177 discusses slurry-settling velocity as part of the investigation into the overall fluffing and compaction of nuclear waste slurries. Some of these data were developed specifically for the effort and some are from previous investigations. The data, in terms of interface level as a function of time, were plotted for all the available data. The velocity plots were developed from the plotted data. The following observation was developed with this data.

"The rapid settling velocity for a slurry in any size test vessel will approximate the rapid settling for a large-scale vessel such/ as a waste storage tank."

Based on this observation and HNF-5177 data for NCAW simulant (which shows a range of interface velocities from 0.66 to $0.87 \mathrm{in} . / \mathrm{h}$ ) the constraint is as follows: The average interface velocity from the time that pumps are shut off until the fluffed-sludge depth is achieved should be not less than $1 \mathrm{in} . / \mathrm{h}$.

\section{B7.0 BOUNDARY CONDITIONS - VENTILATION INLET NOMINAL TEMPERATURE AND ABSOLUTE HUMIDITY}

The value of the inlet dry-bulb air temperatures depends on the observation that the thermal time constant for a waste tank is on the order of two weeks. Based on this observation, it is appropriate to use temperatures averaged over a month as a basis for defining the ambient inlet conditions. Records of temperature and relative humidity dating for the last fifty years are provided by the Hanford Meteorological Station. The highest average monthly temperature of $82.2^{\circ} \mathrm{F}$ occurred in July of 1985 . The average for July is $76.3^{\circ} \mathrm{F}$. A dry-bulb temperature of $76^{\circ} \mathrm{F}$ should be used as a constant boundary condition to define thermal performance during the first segment of $t$ he transient temperature response. Along with this value a humidity ratio (pounds moisture per pound of dry air) of 0.0066 should be used based on the same data source and reasoning. A dry-bulb temperature of $82^{\circ} \mathrm{F}$ should be used as a constant boundary condition during the following two segments. The same humidity ratio should be used because when the pump is off, the heat removal mechanism that has the strongest effect on the maximum waste temperature is the sensible heat removal provided by the annulus ventilation system. The drybulb temperature is the driver for maximizing the temperature excursion, not the humidity ratio.

\section{B7.1 VENTILATION SYSTEMS OPERATION BOUNDARY CONDITIONS}

The four tanks in the Aging Waste Facility are served by a common primary ventilation system. This system consists of a dedicated recirculation module and inlet station for each of the four tanks in the facility. These recirculation modules feed a common central exhaust facility that contains the chiller-driven condenser, the filters, the fans, and the stack discharge point for the facility. Each one of the tanks can be operated either in the recirculation mode or a oncethrough mode; however, only one tank in the facility can be operated in the once-through mode at a time. In addition, each tank in the AY Tank Farm is served by a tank-specific annulus ventilation system. A common annulus ventilation system serves the two tanks in the AZ Tank Farm. 


\section{B7.1.1 Primary Ventilation System Flow Rates}

When operated in the once-through mode, the net discharge flow from the tank is increased from the nominal value of 100 to $200 \mathrm{ft}^{3} / \mathrm{min}$ (standard) to $500 \mathrm{ft}^{3} / \mathrm{min}$ (standard). This is the defined condition to use for these analyses.

For the once-through case, the primary ventilation flow rate is set at $500 \mathrm{ft}^{3} / \mathrm{min}$ (standard) based on capabilities of the 702-AZ vent system. For the recirculation case with $20 \%$ through flow with chiller, the ambient air inlet should be $100 \mathrm{ft}^{3} / \mathrm{min}$. The recirculation flow should be $400 \mathrm{ft}^{3} / \mathrm{min}$. To model this as an enhancement to the existing system, the recirculation flow should be treated as though it exits from a chiller.

The current operating capabilities are as described below. The cooling tower on the recirculation loop is capable of cooling the condenser flow at full load to within $20^{\circ} \mathrm{F}$ of the wetbulb temperature. There may be as much as $20^{\circ} \mathrm{F}$ temperature rise in the loop flow between the tower and the condenser because of condenser tube side and transport temperature differential. The wet-bulb temperature for the bounding dry bulb and humidity ratio is $57^{\circ} \mathrm{F}$, so it is reasonable that the recirculation flow entering the tank under these conditions is $97^{\circ} \mathrm{F}$ and $100 \%$ relative humidity. Nominal full load for the primary cooling system for both Tank 241-AY-102 and Tank 241-AZ-102 is defined as 1,000,000 Btu/h (SD-600-FDC-001, Functional Design Criteria for the Tank Farm Ventilation Upgrade Project W-030). The mixer pump will add about $50 \%$ more heat than the design basis for the current system. It will be conservative in increase the return air flow dry bulb temperature by an additional $20^{\circ} \mathrm{F}$ (to $117^{\circ} \mathrm{F}$ ) and consider that it will enter the Tank at $100 \%$ relative humidity when the point described as $\mathrm{T}_{4}$ on Figure B1-1 is reached.

\section{B7.1.2 Annulus Ventilation System Flow Rate}

Current operational experience with the annulus ventilation system for Tank 241-AY-102 indicates that a flow rate of $1000 \mathrm{ft}^{3} / \mathrm{min}$ (standard) is possible once certain configuration changes have been made using the existing blower configuration. An upgrade path appears to exist to raise the flow to $2000 \mathrm{ft}^{3} / \mathrm{min}$ (standard) through the installation of a double-blower arrangement. An analysis should be performed at each of these flows both for ambient inlet condition and chilled inlet condition.

It is recommended that these two flow rates be used for the annulus flow rate: $1,000 \mathrm{ft}^{3} / \mathrm{min}$ (standard) as the base case and $2,000 \mathrm{ft}^{3} / \mathrm{min}$ (standard) as the enhanced case.

\section{B7.2 CHILLER OUTLET NOMINAL TEMPERATURE AND HUMIDITY}

A reasonable outlet temperature for a chiller installed in either the primary recirculation loop or in the annulus inlet is $40^{\circ} \mathrm{F}$. This temperature provides adequate margin from freezing and is well within the capabilities of commercial off-the-shelf hardware. Operating in a subfreezing mode requires that moisture be removed from the inlet air before cooling it. Although methods and hardware exist to perform this operation, they are not without significant 
costs, both initially and operationally. The moisture ratio that can be expected is $0.005-\mathrm{lbm}$ water/lbm dry air.

\section{B7.3 PUMP HORSEPOWER}

The energy from mixer pump horsepower in all cases should be modeled as 600 horsepower deposited in the waste by two 300-horsepower mixer pumps, equaling $1,526,000 \mathrm{Btu} / \mathrm{h}$.

\section{B8.0 DRAWINGS}

The geometrical and logical relationships required to construct the model are contained in the following drawings:

- Tank 241-AY-102

- H-2-64449 Tank Elevation and Details

- H-2-64307 Structural Insulating Concrete Plan \& Details

- H-2-131063 P\&ID 241-AY102K4 Recirc Vent Cooling

- Tank 241-AZ-102

- H-2-67317 Tanks 101 \&102 Section \& Details AZ Tank Farm

- H-2-67244 Structural Insulating Concrete Plan \& Details

- H-2-131065 P\&ID AZ102K4 Recirc Vent Cooling

\section{B9.0 REFERENCES}

Bachand, 1997, Operations Data Log Sheet dated 8/25/1997 page 225.

HNF-5177, 1999, The Settling and Compaction of Nuclear Waste Slurries, Fluor Daniel Northwest, Richland, Washington.

HNF-5386, 1999, Thermal Hydraulic Analysis of High-Level Waste Tanks for Phase 1 Waste Feed Delivery, Rev. 0, Numatec Hanford Corporation, Richland, Washington.

HNF-EP-0182-109, 1997, Waste Tank Summary Report for Month Ending April 30, 1997, Flour Daniel Hanford, Inc., Richland, Washington.

HNF-EP-0182-133, 1999, Waste Tank Summary Report for Month Ending April 30, 1999, Fluor Daniel Hanford, Inc., Richland, Washington. 
HNF-EP-0182-137, 1999, Waste Tank Summary Report for Month Ending August 31, 1999, Flour Daniel Hanford, Inc., Richland, Washington.

HNF-SD-W030-ER-004, 1997, Evaluation of Waste Temperatures in AWF Tanks for Bypass Mode Operation of the 702-AZ Ventilation System (Project W-030), Rev. 0, Numatec Hanford Corporation, Richland, Washington.

HNF-SD-W320-ER-004, 1998, Project W-320 SAR and Process Control Thermal Analyses, Rev. 1, prepared by Numatec Hanford Corporation for Fluor Daniel Hanford, Inc., Richland, Washington.

HNF-SD-WM-PCP-013, 1999, Tank 241-C-106 Waste Retrieval Sluicing System Process Control Plan, Rev. 2, Fluor Daniel Hanford, Inc., Richland, Washington.

HNF-SD-WM-SAR-067, 1999, Tank Waste Remediation System Final Safety Analysis Report, Rev. 1, Fluor Daniel Hanford, Inc., Richland, Washington.

HNF-SD-WM-TSR-006, 1999, Tank Waste Remediation System Technical Safety Requirements, Rev. 1, Fluor Daniel Hanford, Inc., Richland, Washington.

MacLean, G. T., 1998, Parameters for Use in CFD Simulations of the Mixing and Settling of Tank 241-AZ-101, Letter Report COGEMA-98-521, COGEMA Engineering Corporation, Richland, Washington.

SD-600-FDC-001, 1990, Functional Design Criteria for the Tank Farm Ventilation Upgrade Project W-030, Rev. 3, Westinghouse Hanford Company, Richland, Washington.

WHC-SD-WM-ER-198, 1993, Development of A Dynamic Computer Simulator For Aging Waste Tank Operations and Safety Assessment, Rev. 0, Westinghouse Hanford Company, Richland, Washington.

WHC-SD-WM-ER-410, 1995, Tank Characterization Report for Double-Shell Tank 24l-AZ-101, Rev. 0, Westinghouse Hanford Company, Richland, Washington.

WHC-SD-WM-ER-410, 1999, Tank Characterization Report for Double-Shell Tank 241-AZ-101, , Rev. 0-B, Lockheed Martin Hanford Corporation, Richland, Washington.

WHC-SD-WM-ER-411, 1995, Tank Characterization Report for Double-Shell Tank 241-AZ-102, Rev. 0, Westinghouse Hanford Company, Richland, Washington.

Willis, William L., 1999, Bounding Case Tanks-Heat Loads, e-mail message to Blaine Crea et al., dated November 17, 1999 (provided in Appendix D). 
RPP-5637

Rev. 0

APPENDIX C

GOTH-SNF VERSION 5.0 VERIFICATION AND VALIDATION NOTEBOOK

C-i 
RPP-5637

Rev. 0

This page intentionally left blank.

\section{C-ii}




\section{CONTENTS}

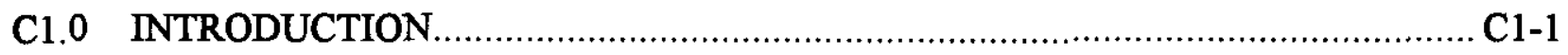

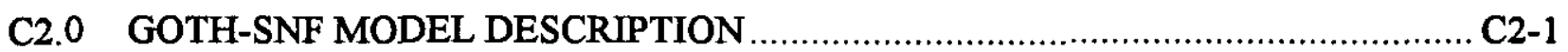

C2.1 GOTH-SNF COMPUTER CODE ........................................................ 2 2-1

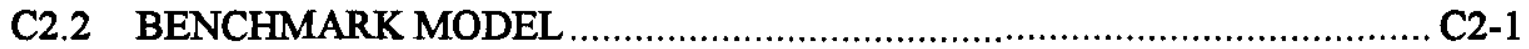

C2.2.1 Control Volumes .................................................................. C2-1

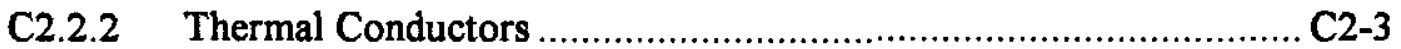

C2.2.3 Boundary Conditions ...................................................................... 2 2-4

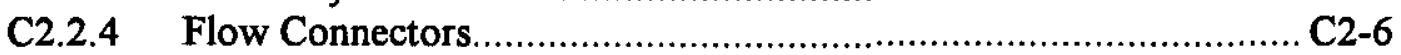

C2.2.5 Annulus Floor Heat Transfer Model.............................................. C2-6

Waste Thermal Conductivity Model.......................................................... 2 2-7

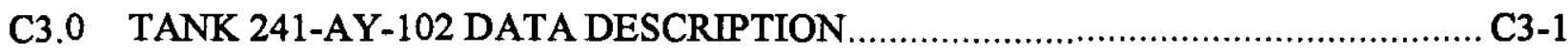

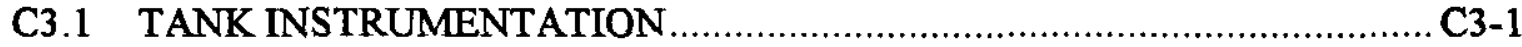

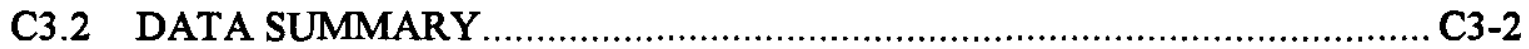

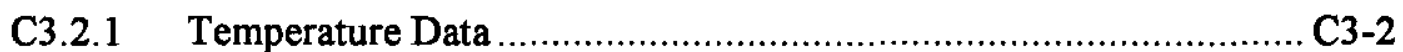

C3.2.2 Waste Level Data .......................................................................... 3 -4

C3.2.3 Waste Settling Time ……..........................................................

C3.3 TANK 241-AY-102 ENERGY BALANCE ……...................................... $3-6$

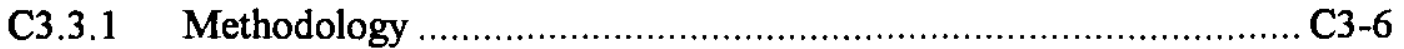

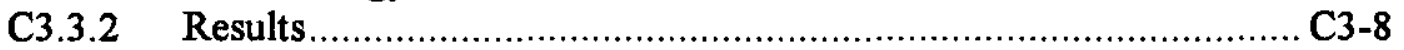

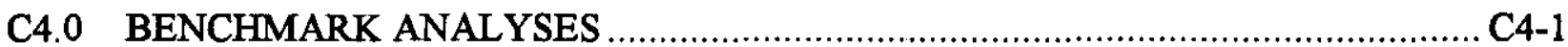

C4.1 PRE-SLUICING DATA BENCHMARK ………........................................ C4-1

C4.1.1 Dome Head Space Temperature....................................................... C4-1

C4.1.2 Supernatant liquid Temperature ................................................... C4-1

C4.1.3 Annulus Outlet Temperature....................................................... 4 -2

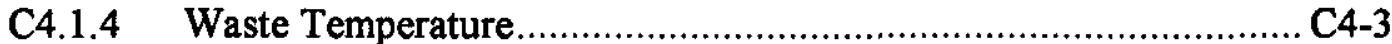

C4.2 POST-SLUICING DATA BENCHMARK ..................................................

C4.2.1 Dome Head Space Temperature................................................... C4-4

C4.2.2 Supernatant liquid Temperature ................................................... 44

C4.2.3 Annulus Outlet Temperature .......................................................... C4-6

C4.2.4 Waste Temperature................................................................ C4

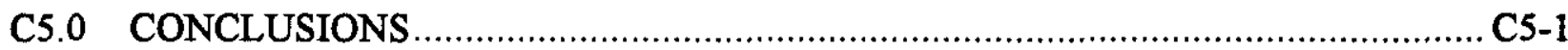

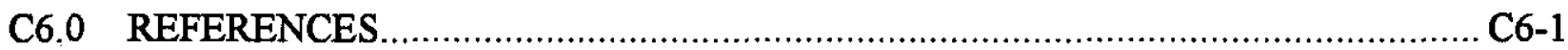




\section{FIGURES}

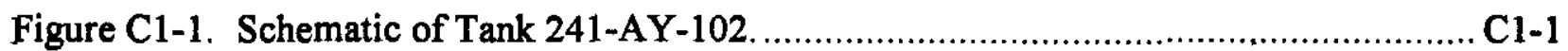

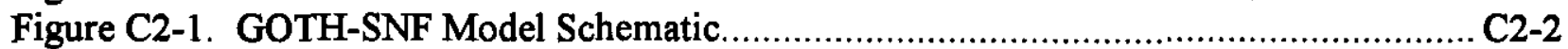

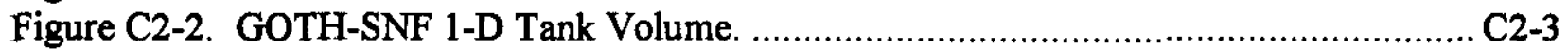

Figure C2-3. Ambient Conditions for Benchmark Analyses. ........................................... C2-4

Figure C2-4. Ventilation Flow for Benchmark Analyses. …....................................... C2-6

Figure C2-5. Annulus Ventilation Floor Slot Configuration. ......................................... C2-7

Figure C2-6. Waste Thermal Conductivity Model. .......................................................... C2-8

Figure C3-1. Overview of Tank 241-AY-102 Instrumentation........................................... $3-2$

Figure C3-2. Tank 241-AY-102 Benchmark Data. ...........................................................

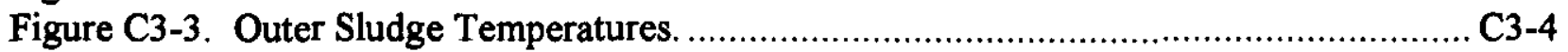

Figure C3-4. Tank 241-AY-102 Enraf Densitometer Data.................................................. C3-5

Figure C3-5. Setting Time Data for Tank 241-AY-102 .............................................. C3-6

Figure C4-1. Pre-sluice Dome Space Temperature Comparison. ........................................ C4-1

Figure C4-2. Pre-Sluice Supernatant liquid Temperature Comparison. .............................. C4-2

Figure C4-3. Pre-Sluice Annulus Outlet Air Temperature Comparison................................. C4-3

Figure C4-4. Pre-Sluice Waste Temperature Comparison .................................................. C4-4

Figure C4-5. Post-Sluice Dome Space Temperature Comparison. ......................................... C4-5

Figure C4-6. Post-Sluice Supernatant liquid Temperature Comparison................................. C4-6

Figure C4-7. Post-Sluice Annulus Outlet Air Temperature Comparison. ............................ C4-7

Figure C4-8. Post-Sluice Waste Temperature Comparison. ................................................ $4-8$

Figure C4-9. Outer Bottom Sludge Temperature .............................................................

\section{TABLES}

Table C3-1 Summary of Tank 241-AY-102 Energy Balance.

C3-8 TERMS 
RPP-5637

Rev. 0

This page intentionally left blank.

C-V 


\section{APPENDIX C}

Rev. 0

\section{GOTH-SNF VERSION 5.0 VERIFICATION AND VALIDATION NOTEBOOK}

\section{C1.0 INTRODUCTION}

The GOTH-SNF, Version 5.0 computer code ${ }^{1}$ (Thurgood 1999a) is being used to evaluate two alternatives for the heat removal for the high-level waste (HLW), double-shell tanks (DST). This evaluation supports the Alternatives Generation and Analyses (AGA). The two alternatives evaluated include primary side heating, ventilation and air conditioning (HVAC) system enhancements and secondary or annulus side HVAC enhancements. The two cooling alternatives are evaluated for bounding waste tanks, 241-AZ-102 and 241-AY-102. A schematic of tank 241-AY-102 is shown in Figure C1-1. The thermal hydraulic evaluation of the two cooling alternatives will determine the minimum enhancements required to maintain supernatant liquid and waste temperatures below Limiting Conditions for Operation (LCO) temperature limits. Thermal hydraulic analyses were used to evaluate four periods of tank operation:

1. Steady state normal operation

2. Steady state fully mixed condition

3. Steady state resettled condition

4. Loss of ventilation flow during waste re-settling

The GOTH-SNF computer code and tank models were benchmarked using tank 241-AY-102 temperature and waste level data. A description of the GOTH-SNF computer code and model is provided in Section 2.0. The data for the benchmark analyses were collected in support of the process control activities defined by Project W-320 (Carothers 1998). Project W-320 provided the Waste Retrieval Sluicing System (WRSS) used to transfer waste from tank 241-C-106 to tank 241-AY-102. Overviews of these data are provided in Section 3.0. The benchmark analyses for tank 241-AY-102, together with previous GOTH-SNF verification and validation (Thurgood 1999), provide the basis for the application of GOTH-SNF to the AGA alternatives study.

Benchmark analyses were performed for two periods of tank operation. The first period was the pre-sluicing period prior to any significant waste transfers. The second benchmark analyses was performed for the post-sluicing tank conditions, after the completion of all waste transfers from tank 241-C-106. The results of the benchmark analyses are provided in Section 4.0.

\footnotetext{
${ }^{1}$ GOTH-SNF is a proprietary code of John Marvin, Inc.
} 
Figure C1-1. Schematic of Tank 241-AY-102.

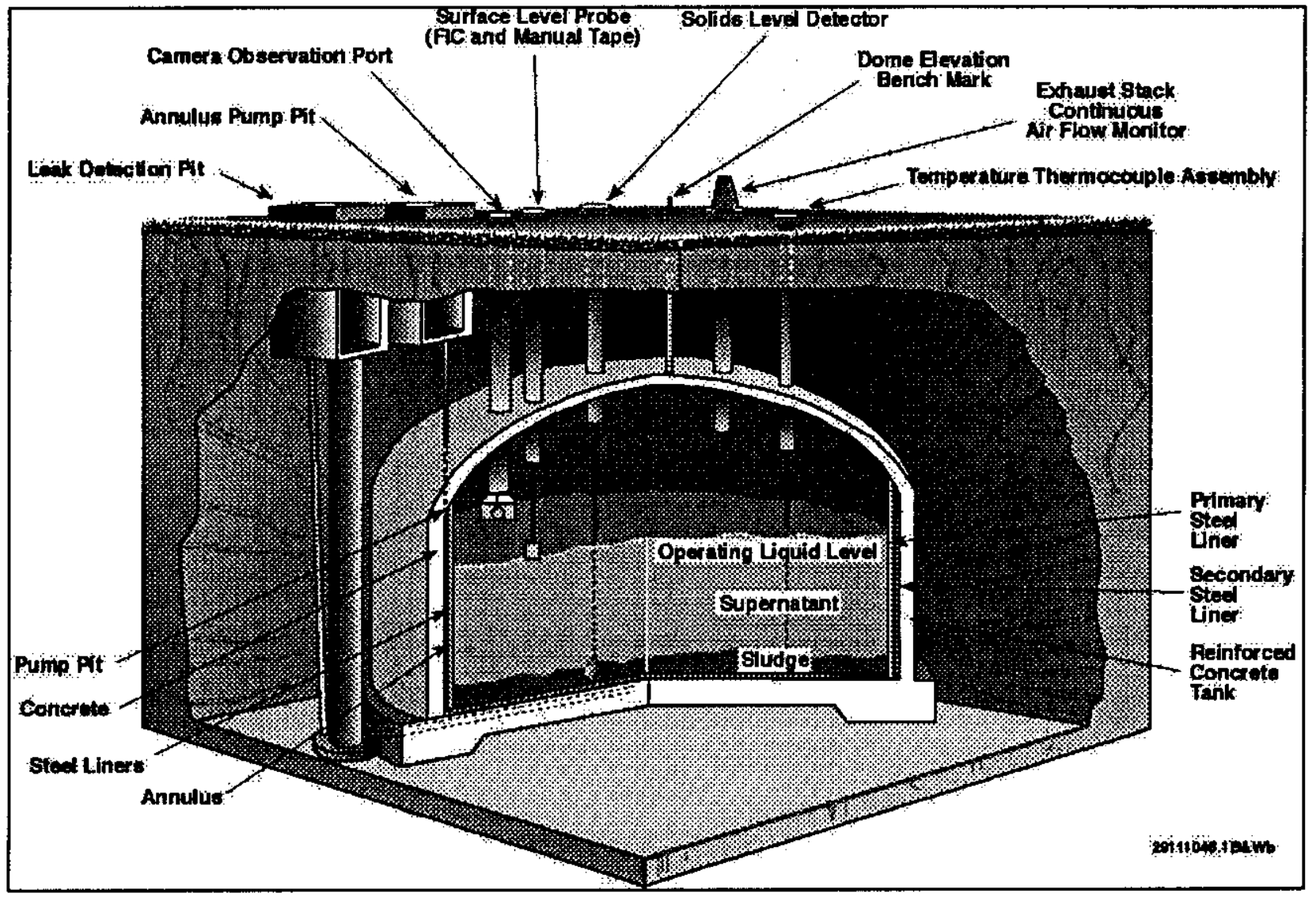




\section{C2.0 GOTH-SNF MODEL DESCRIPTION}

\section{C2.1 GOTH-SNF COMPUTER CODE}

The GOTH-SNF is a general-purpose, thermal-hydraulics computer program developed by John Marvin, Inc (JMI). The current version and the predecessor program GOTH (Sathyanarayana 1996) have been used extensively at Hanford, other Department of Energy sites, and the commercial nuclear industry for design, safety, and operations analyses. GOTH-SNF has been verified, validated (Thurgood 1999) and is controlled through the JMI Quality Assurance Program (Thurgood, Ogden 1999).

\section{C2.2 BENCHMARK MODEL}

Schematics of the GOTH-SNF basic model used for the benchmark analyses and AGA alternative study is are shown in Figures C2-1 and C2-2. The model incorporates lumpedparameter and distributed parameter volumes, heat conductors, and flow and pressure boundary conditions to provide a one-dimensional (1-D) model of tanks 241-AY-102 and 241-AZ-102. The basic model is applied to both waste tanks. The models differ only in the specification of tank specific parameters, which include ventilation flow rates, waste geometry / properties and floor annulus configuration. The model is described in the following sections.

\section{C2.2.1 Control Volumes}

The control volumes for the GOTH-SNF model are shown in Figure C2-1. The volume inside the tank inner liner is modeled with GOTH-SNF Volume 1s. This is a distributed parameter volume with a 1-D model of the waste, supernatant liquid, and dome space. The noding scheme for Volume 1s for tank 241-AY-102 is shown in Figure C2-2. The waste is modeled with eight sub-volumes. The initial 241-AY-102 waste is divided into 2 volumes so that the center of the second volume corresponds to the location of a waste thermal-couple, to facilitate the comparison with measure waste temperatures. The remaining six sub-volumes of the waste correspond to increments of transferred waste, from tank 241-C-106. These are discussed in Section 3.0. The supernatant liquid is subdivided into multiple volumes. This subdivision provides for the modeling of the resettled waste height after the operation of the mixer pumps. The dome space above the supernatant liquid is modeled with a single sub-volume. A small volume of the supernatant liquid pool is contained in the sub-volume to model the evaporation from the liquid pool.

GOTH-SNF control volume 2 corresponds to the flow volume of the annulus system, in the floor of the tank. This is shown pictorially in Figure $\mathrm{C2}-1$. The flow volume in the annulus ventilation system, between the steel inner liner and outer liner, is modeled with control volume 3 . Volume 5 models the inlet annulus piping. This includes the drop-legs in the wall annulus region and the horizontal runs of piping leading to the center of the tank. Control volume 4 shown in Figure C2-1 physically corresponds to the piping volume of the primary ventilation system downstream of the tank outlet. The GOTH-SNF model uses this volume only for condensing water vapor, which is returned through Valve 1 (Figure C2-1) to the liquid pool and extracting the dome air during primary system re-circulation operation. 
Figure C2-1. GOTH-SNF Model Schematic.

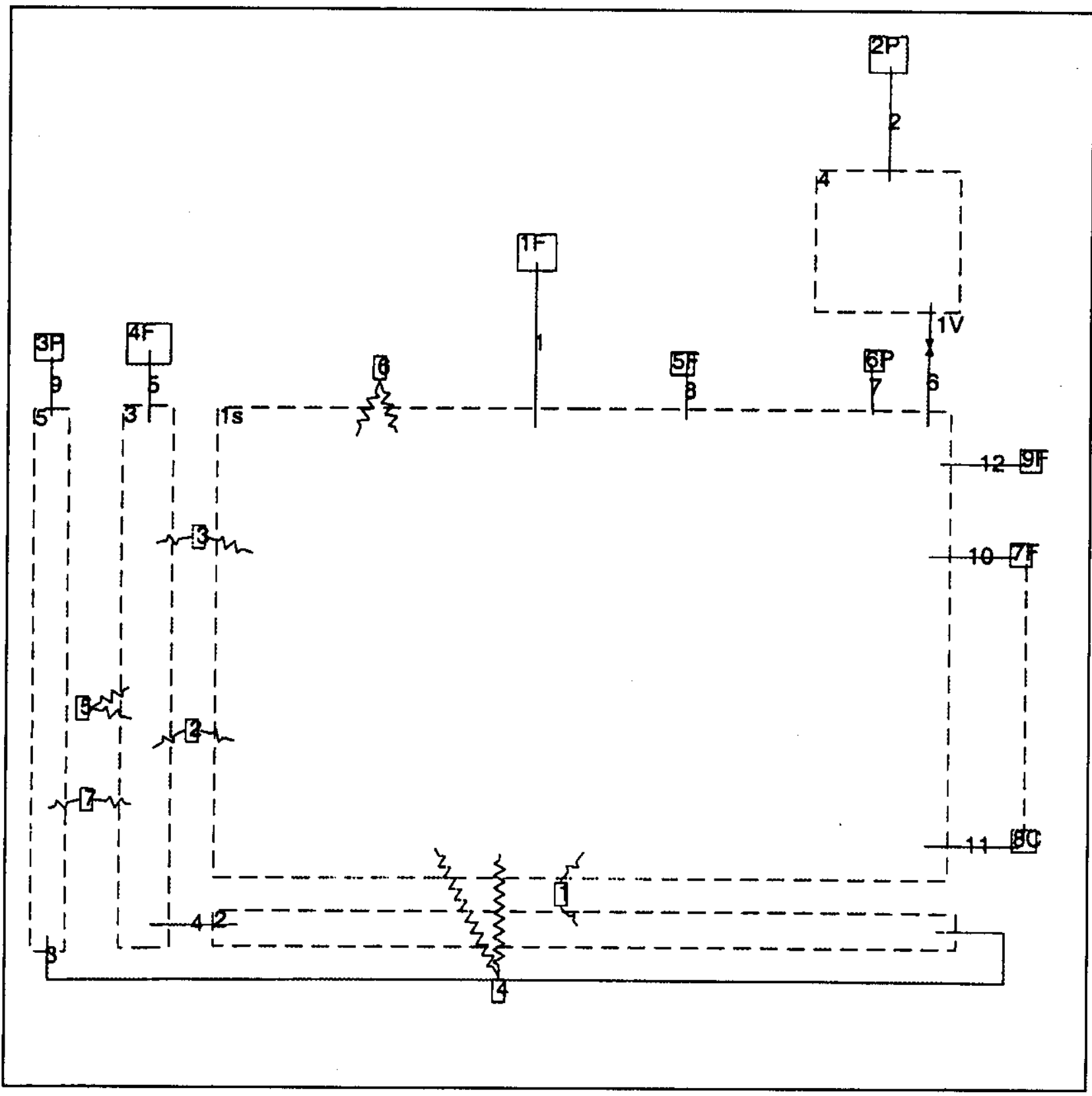


Figure C2-2. GOTH-SNF 1-D Tank Volume.

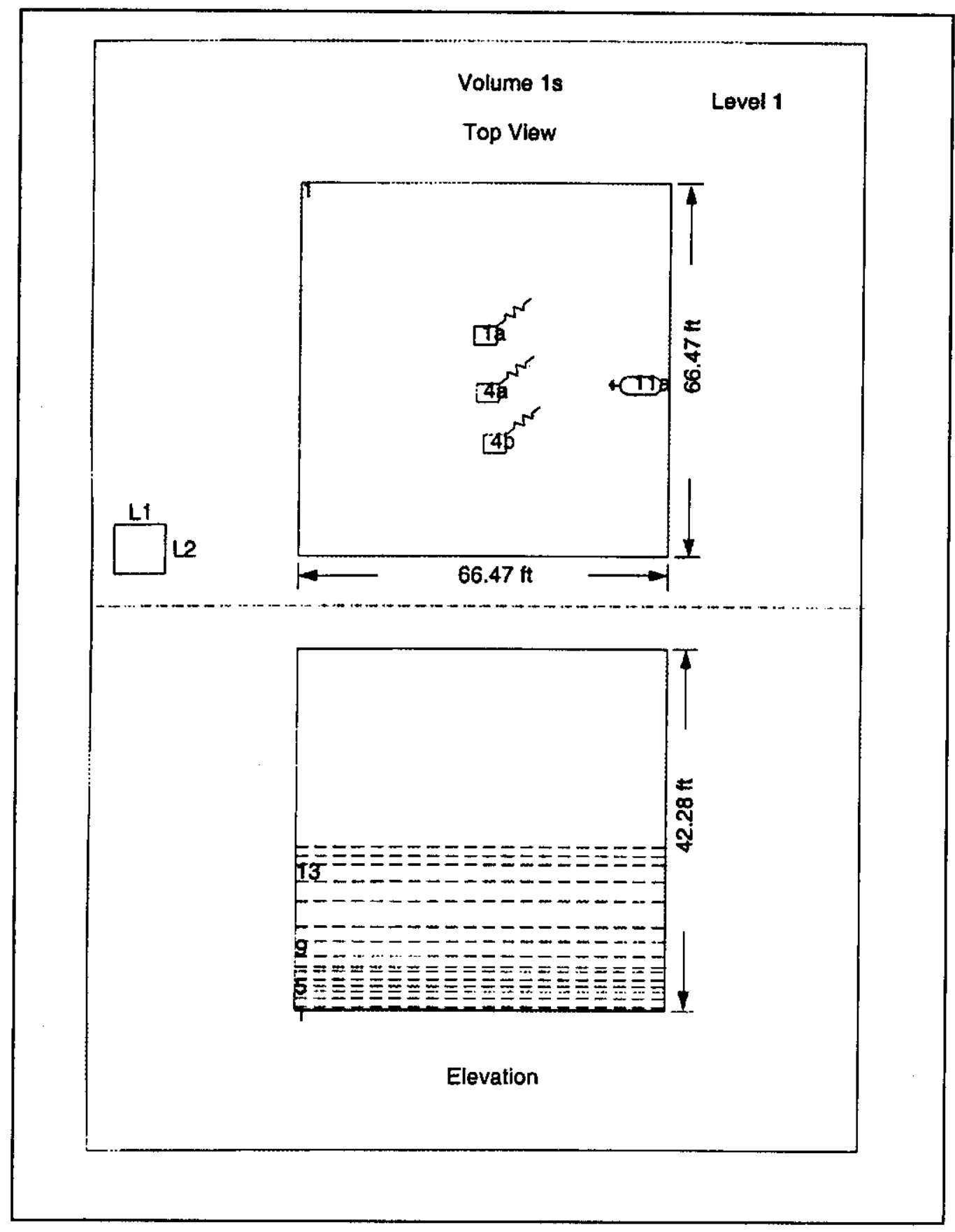

\section{C2.2.2 Thermal Conductors}

The GOTH-SNF model treats the tank waste and supernatant liquid as fluid volumes with conduction heat transfer, when the mixer pumps are not operating. Other thermal masses associated with the waste tanks are modeled with 1-D thermal conductors. The soil directly above the tank is modeled with a one-dimensional wall conductor (thermal conductor 6) shown in Figure C2-1. The thickness of this conductor corresponds to the average soil depth above the tank. This conductor uses the measured ambient temperatures for the top surface and calculated dome temperatures for the bottom surface. 
The soil surrounding the tank side is modeled with tube thermal conductor 5 . The inside of the tube is connected to the wall annulus (Volume 3). The thickness of the tube conductor corresponds to the mid-point between the modeled tank and the surrounding tanks. The thermal conductor boundary is assumed adiabatic for the outside surface of the tube conductor. The soil below the tank is modeled with a 1-D wall conductor (thermal conductor 4). The thickness of this conductor is $200 \mathrm{ft}$, corresponding to the approximate distance to the water table below the tanks. A constant $54^{\circ} \mathrm{F}$ temperature is used for this surface of the thermal conductor. This is the average annual ambient temperature, and therefore the soil temperature at a distance removed from the tanks.

The steel plates of the inner liner are modeled with three conductors. Thermal conductors 1 corresponds to the bottom plate, while conductors 2 and 3 model the side wall liner. The remaining thermal conductor 8, shown in Figure C2-1 is not related to any of the physical features of the tanks. It is used to condense vapor from the tank outlet flow and return it through valve 1 to the liquid pool. This maintains the pool level at a constant value.

\section{C2.2.3 Boundary Conditions}

The GOTH-SNF model uses the boundary condition component to establish the temperature, humidity, and ventilation flow rates for the primary and annulus ventilation systems. Boundary conditions $1 \mathrm{P}$ and 3P, shown in Figure $\mathrm{C} 2-1$, define the ambient temperature and humidity conditions. The benchmark analyses for tank 241-AY-102 used measured meteorological data from the Hanford weather station (need reference). These data are shown in Figure C2-3. The ambient conditions shown in Figure C2-3 were replaced with conservative constant temperature and humidity for the AGA Analyses (Appendix B).

The primary and annulus flow conditions are modeled with flow boundary conditions $5 \mathrm{~F}$ and $4 \mathrm{~F}$ shown in Figure C2-1. The benchmark analyses used measured flow data shown in Figure C2-4. The measured flow data was replaced with constant flow conditions for the AGA analyses.

Figure C2-3. Ambient Conditions for Benchmark Analyses.

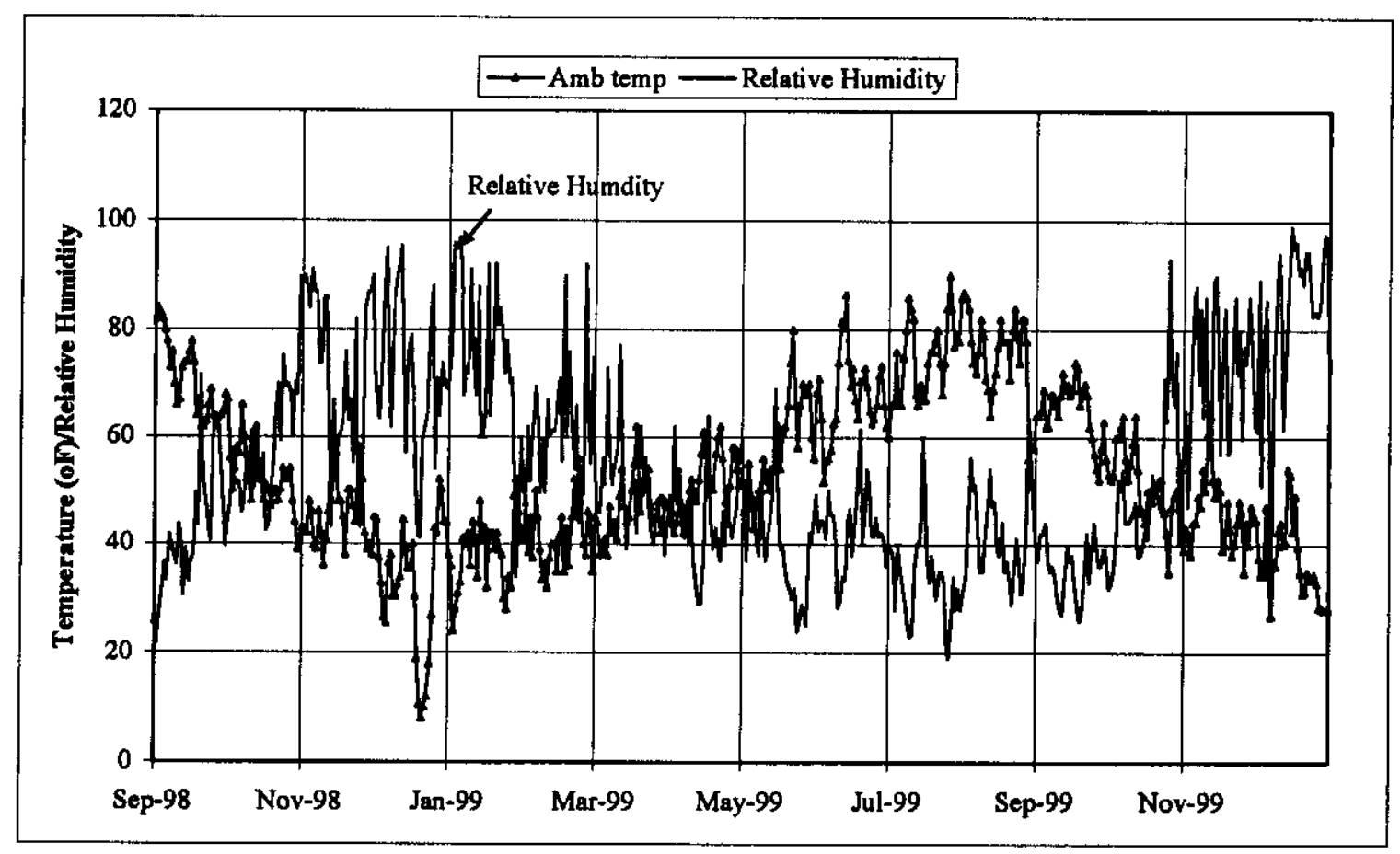


Flow boundary condition 9F shown in Figure C2-1 is used to model the mixer pump flow. Liquid is drawn from the supernatant liquid pool and injected into the bottom level of waste. This provides a mixing of the settled waste. The heat associated with the operation of the pumps is modeled with a GOTH-SNF heater component shown in Figure C2-2. This component is located near the middle of the liquid pool. 
Figure C2-4. Ventilation Flow for Benchmark Analyses.

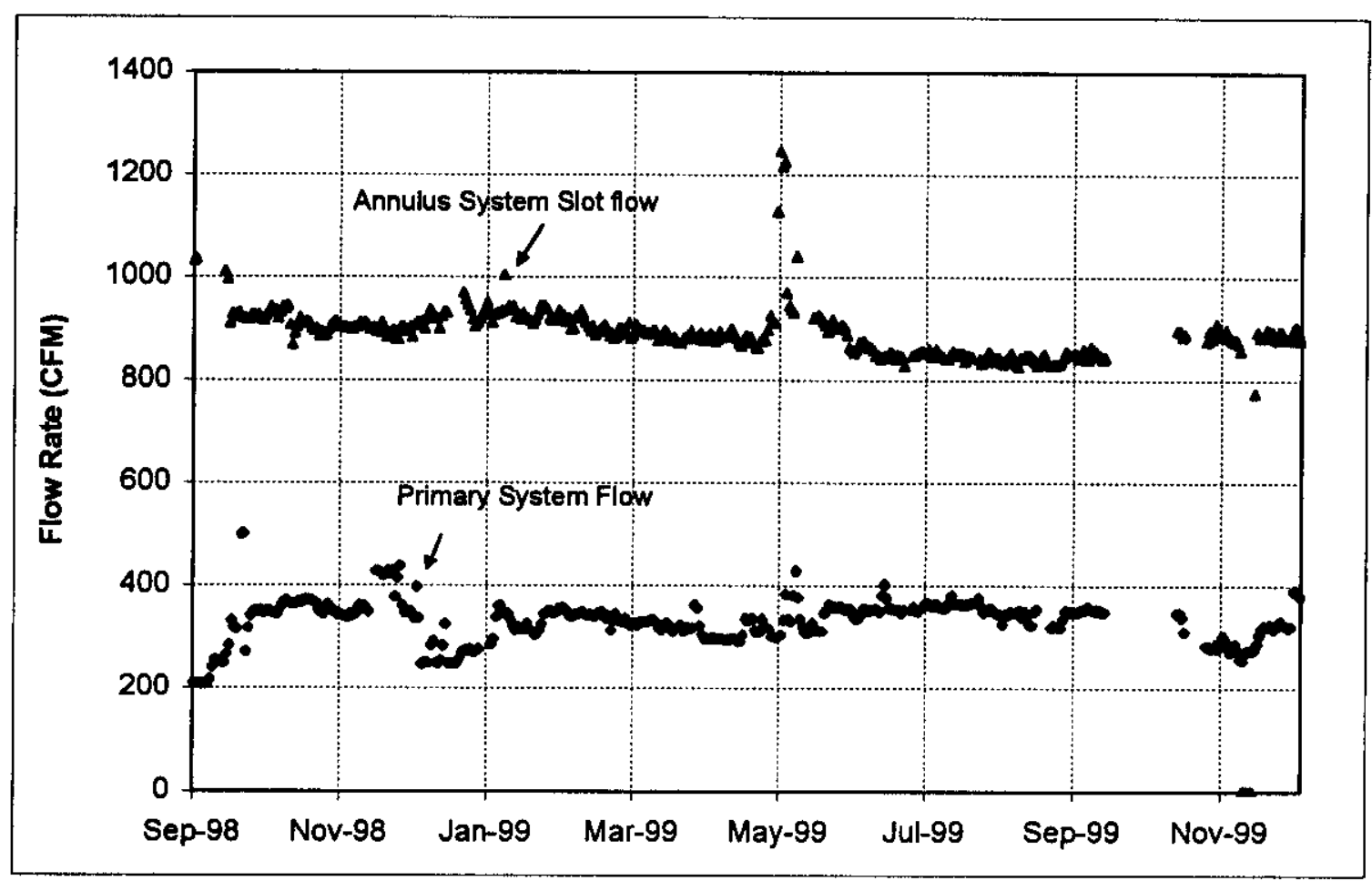

\section{C2.2.4 Flow Connectors}

Figure C2-1 shows the flow connectors used in the GOTH-SNF model. These flow connectors connect the control volumes using flow areas representative of the physical flow area of the tank ventilation system.

\section{C2.2.5 Annulus Floor Heat Transfer Model}

Figure C2-5 shows a schematic of the annulus-ventilation, flow channel configuration for tank 241-AY-102. There are three radial regions of the tank floor. The number of cooling slots doubles for each radial region and the distance between cooling slots increases. The channel side and top surfaces are available for heat transfer to the waste. Figure C2-5 shows a sketch of the cooling slot configuration for tank 241-AY-102. The cooling slot cross-section areas range is size from 1.5 in $\times 3$ in for the inner region to 1.5 in $\times 1.5$ in for the outer region.

The floor channel cooling configuration is modeled by averaging the forced flow heat transfer coefficient (Dittius-Boelter Correlation, reference) for the three regions of the tank. Only the top-channel surface area is modeled for heat transfer. Using this minimum surface area helps offset the conduction distance between cooling slots. This heat transfer model will be benchmarked with tank data. 
Figure C2-5. Annulus Ventilation Floor Slot Configuration.

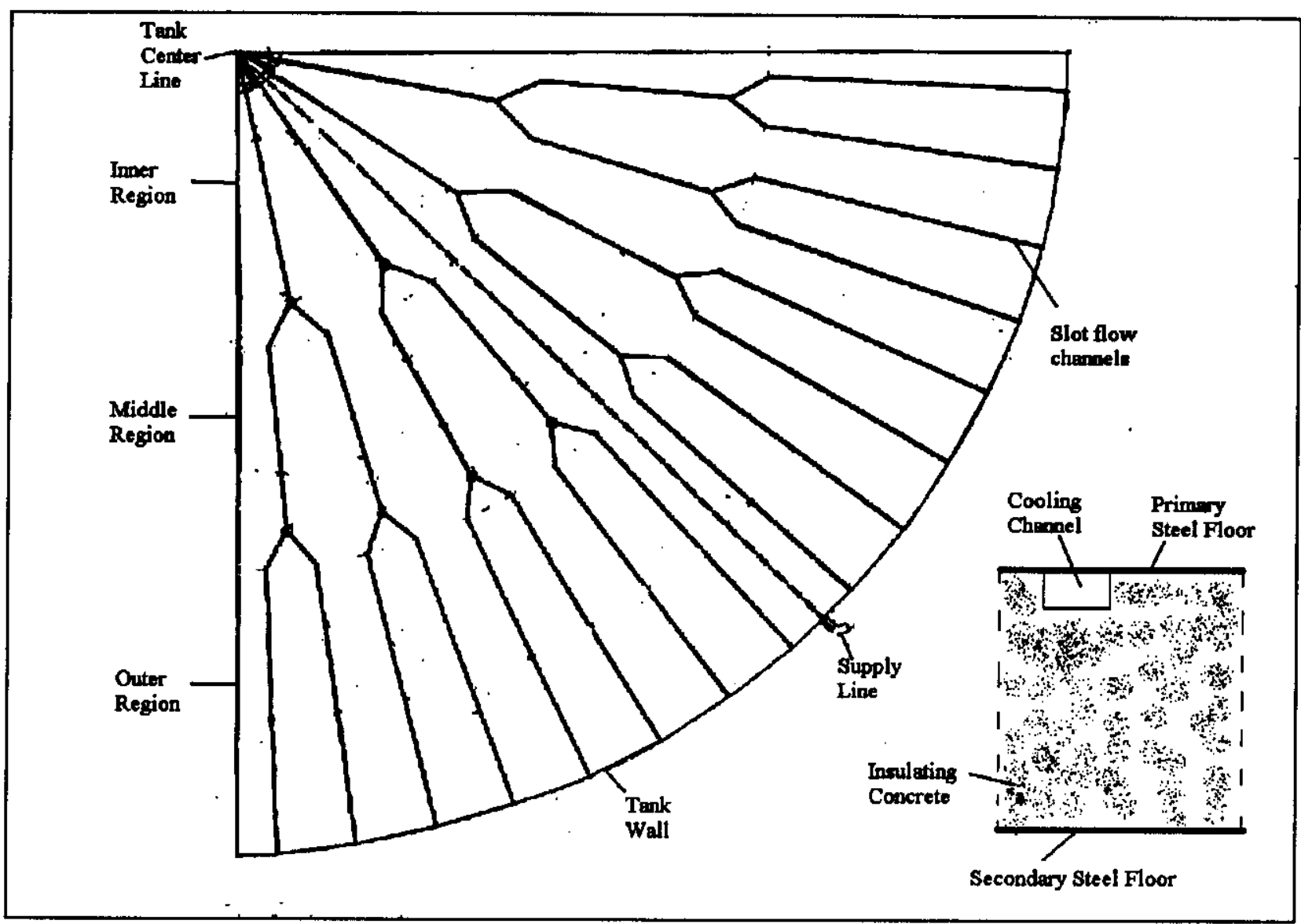

\section{C2.2.6 Waste Thermal Conductivity Model}

The input specifications provided in Appendix B describe several thermal conductivity models available for modeling thermal conduction in the tank waste. The Maxwell and Series conduction models are shown in Figure C2-6. They are plotted as a function of particle volume fraction. The Series model is a conservative conduction model, while the Maxwell model is a more phenomenological based model. The GOTH-SNF program currently uses the Series model. Because of uncertainty the most appropriate conduction model to apply, the conservative series model will be applied both to the benchmark and AGA analyses. 
Figure C2-6. Waste Thermal Conductivity Model.

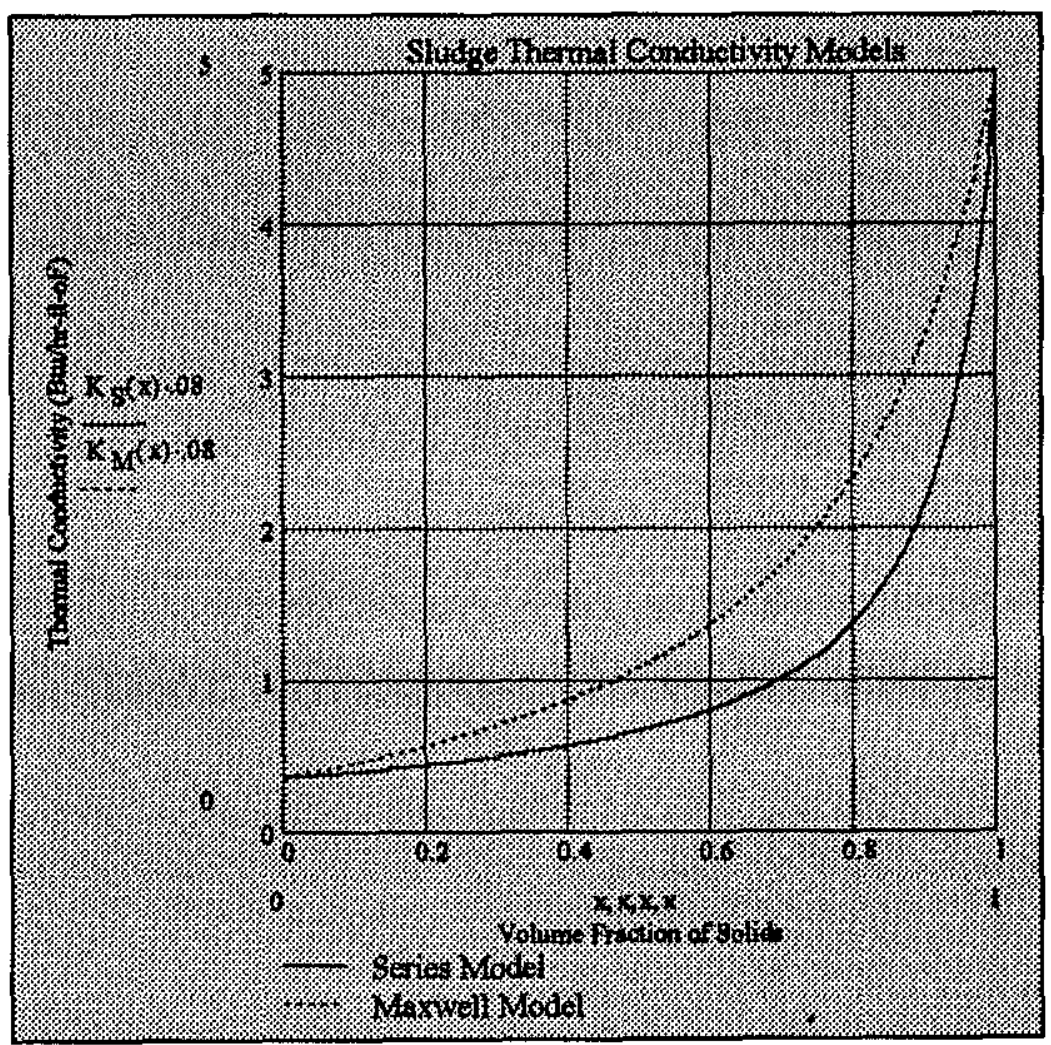




\section{C3.0 TANK 241-AY-102 DATA DESCRIPTION}

This section provides an overview of the tank 241-AY-102 data used for the GOTH-SNF model benchmark. Data is shown for the period from September of 1998 to December of 1999.

\section{C3.1 TANK INSTRUMENTATION}

Figure C3-1 shows an overview of the location of the liquid level and waste temperature instruments for tank 241-AY-102. The temperature data includes:

1. Bottom Waste Temperatures

The bottom waste temperatures are measured by thermocouples located on thermocouple trees existing in the tank prior to Project W-320. The thermocouples are located $\sim 3$ inches from the tank floor. In addition, each air lift circulator in tank 241-AY-102, included a thermocouple also located a few inches from the tank floor. The location of the thermocouple trees and ACL's are shown in Figure C3-1.

2. Insulating Concrete Temperatures

The tank floor is instrumented with thermocouples imbedded in the insulating concrete below the tank liner. These thermocouples are located at three radial locations, approximately 7,21 , and 36 feet from the tank centerline. These are identified as "bottom temps" in the legend of Figure C3-1.

3. Multifunction-Instrument Tree

A multifunction instrument tree (MIT) was installed in tank 241-AY-102 for Projects W-320. The MIT provides measurement of the axial temperature profile within the waste and supernatant pool and dome space. This is shown at the bottom center of Figure C3-1.

4. ENRAF Level

The tank level for tank 241-AY-102 is measured by the Enraf gauge located midway between the tank wall and centerline. This instrument provides a near continuous measurement of the level of the supernatant pool. The Enraf gauge can also be used as a densitometer. In this mode, the instrument can determine the location of the settled sludge liquid interface. The location of the Enraf densitometer measurements is near the north wall of the tank as shown in Figure C3-1.

5. Other Tank Instrumentation

Additional measurements not shown in Figure C3-1 were also made during the retrieval of waste from tank 241-C-106. These included the primary and annulus system volumetric flow rates, primary and annulus system outlet air temperatures and the tank dome space humidity. 
Figure C3-1. Overview of Tank 241-AY-102 Instrumentation.

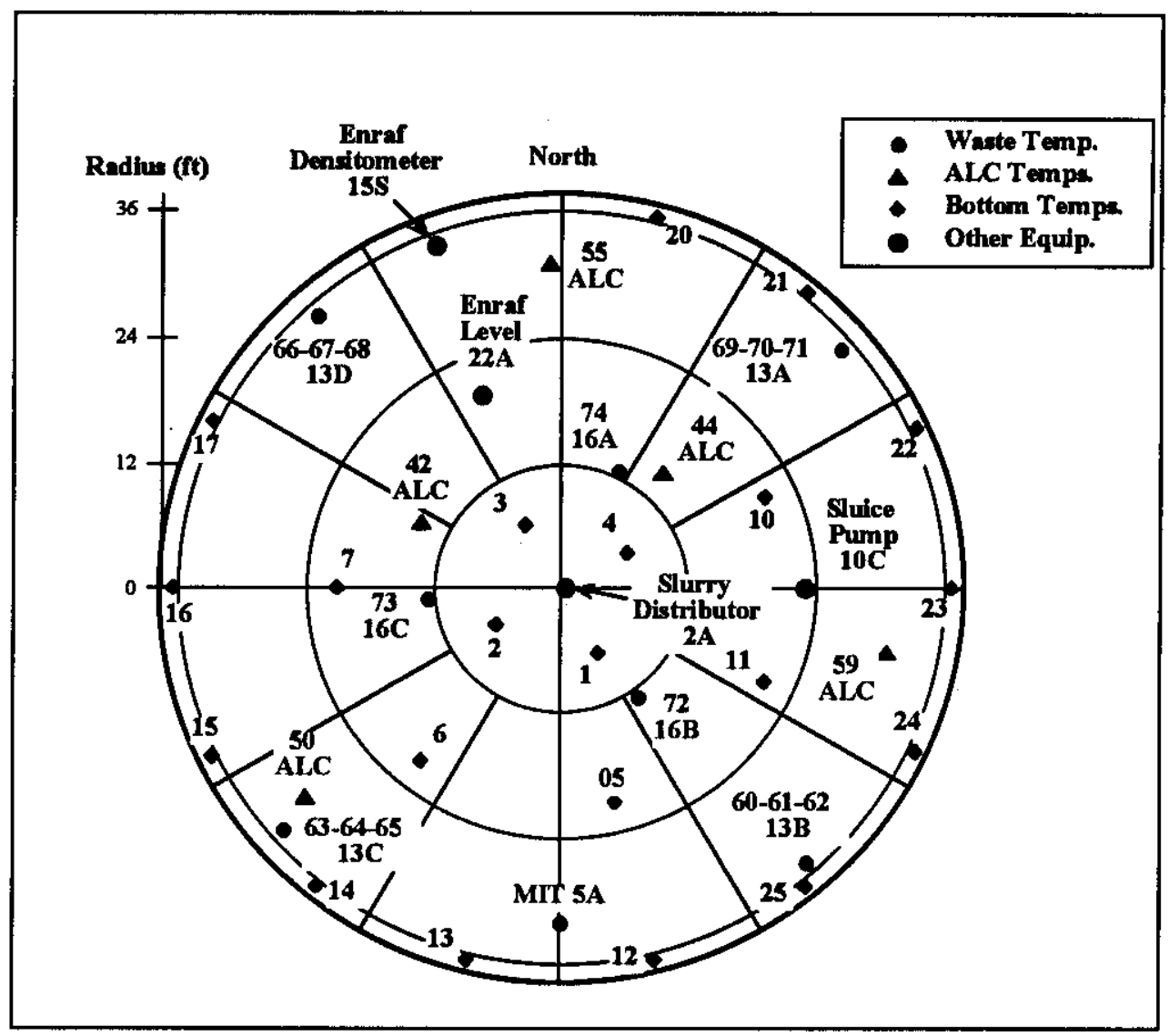

\section{C3.2 DATA SUMMARY}

\section{C3.2.1 Temperature Data}

A summary of the tank 241-AY-102 temperature data used for the GOTH-SNF model benchmark is shown in Figure C3-2. These data were selected because they are related to the energy removal and storage in the tank and indicate the maximum waste temperature. They include the primary and annulus outlet air temperatures, the liquid temperature, and the sludge temperatures.

The ventilation system, outlet temperatures are a measure of the heat removed by the ventilation systems. The dome space humidity is also an important parameter for energy removal from the primary system. However, the measured value is nearly constant at $100 \%$ and thus a time history plot is not provided.

The rate-of-change of liquid and sludge temperatures are an indication of the energy storage in the tank. These data are included in the benchmark analyses and are shown in Figure C3-2.

The maximum waste temperature will be compared with the temperature criteria for the AGA alternative study. It is therefore an important parameter for the benchmark analyses. The selected data for the benchmark analyses provides an assessment of the capability of the GOTH-SNF model to account for the heat generation, removal from tank 241-AY-102 and the prediction of the maximum waste temperature. 
Figure C3-3 shows the outer sludge temperatures for tank 241-AY-102. The locations of the TC's are shown in Figure C3-1. The average temperature is also shown in the figure. The TC's are distributed in the azimuthal direction around the tank floor. These data illustrate the variation in temperature at nearly the same radial distance from the tank centerline. Some of this variation is due to the location of the temperature measurement, relative to the floor-cooling channel. Three times the standard deviation for data is also shown in Figure C3-3. This provides an estimate for the maximum expected waste temperature. The conservative waste thermal conductivity model was selected to bound this variation, which is due impart, to higher waste temperatures for waste located between cooling channels.

Figure C3-2. Tank 241-AY-102 Benchmark Data.

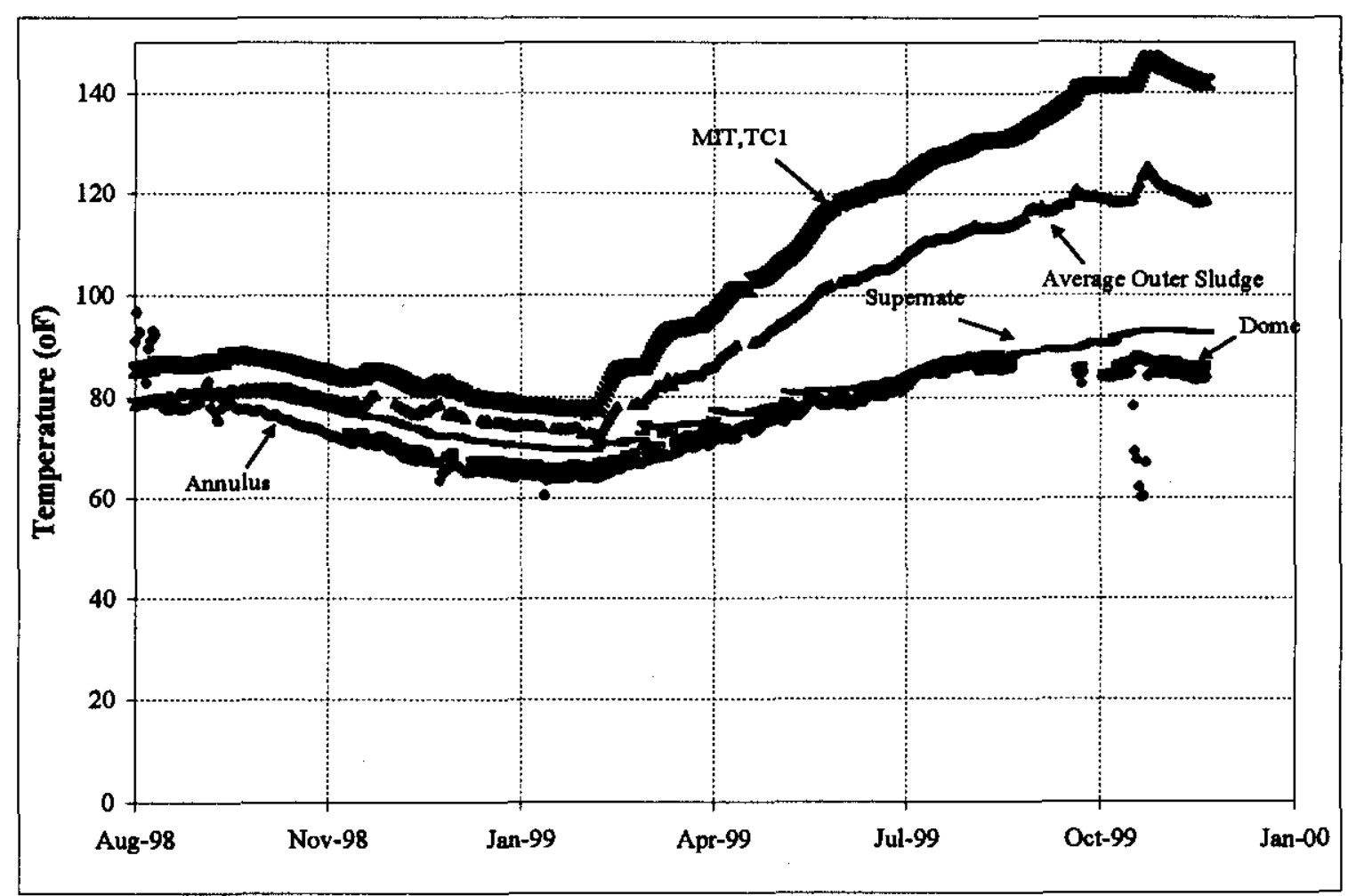


Figure C3-3. Outer Sludge Temperatures.

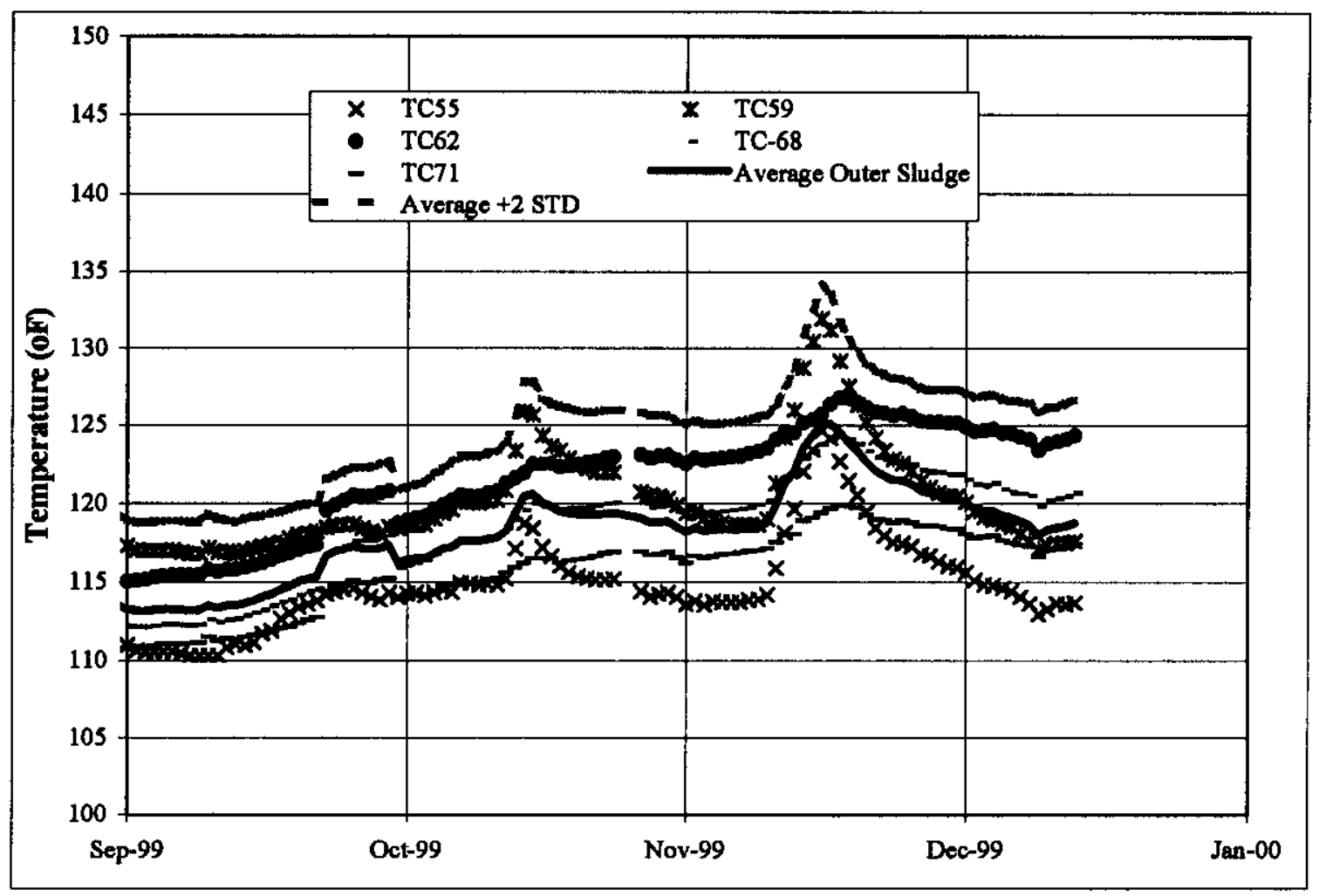

\section{C3.2.2 Waste Level Data}

The Enraf densitometer measurements of the settled waste level are shown in Figure C3-4. This data shows the settled waste level near the tank wall (Figure C3-1). The increase in level seen in the figure is a result of waste transfers from tank 241-C-106. The waste transfers were initiated in November 1998 and were completed in early October 1999. Two regions of data were selected for the benchmark analyses as seen in Figure C3-3. The first region, which is identified as "pre-sluice benchmark data," includes the period from September 1998 to March 1998. Two small waste transfers were performed during this period. However, the conditions in the tank are close to pre-sluice conditions. The second region, denoted as the "post-sluice benchmark data," includes the period from September 1999 to December 1999. The final waste transfers were completed early in this period. These data characterize the behavior of the tank waste at the completion of the waste transfers from tank 241-C-106. These tank conditions will be used for the AGA alternative study. 
Figure C3-4. Tank 241-AY-102 Enraf Densitometer Data.

Figure C3-3 shows that the first waste transfer was performed in November 1998 and that the

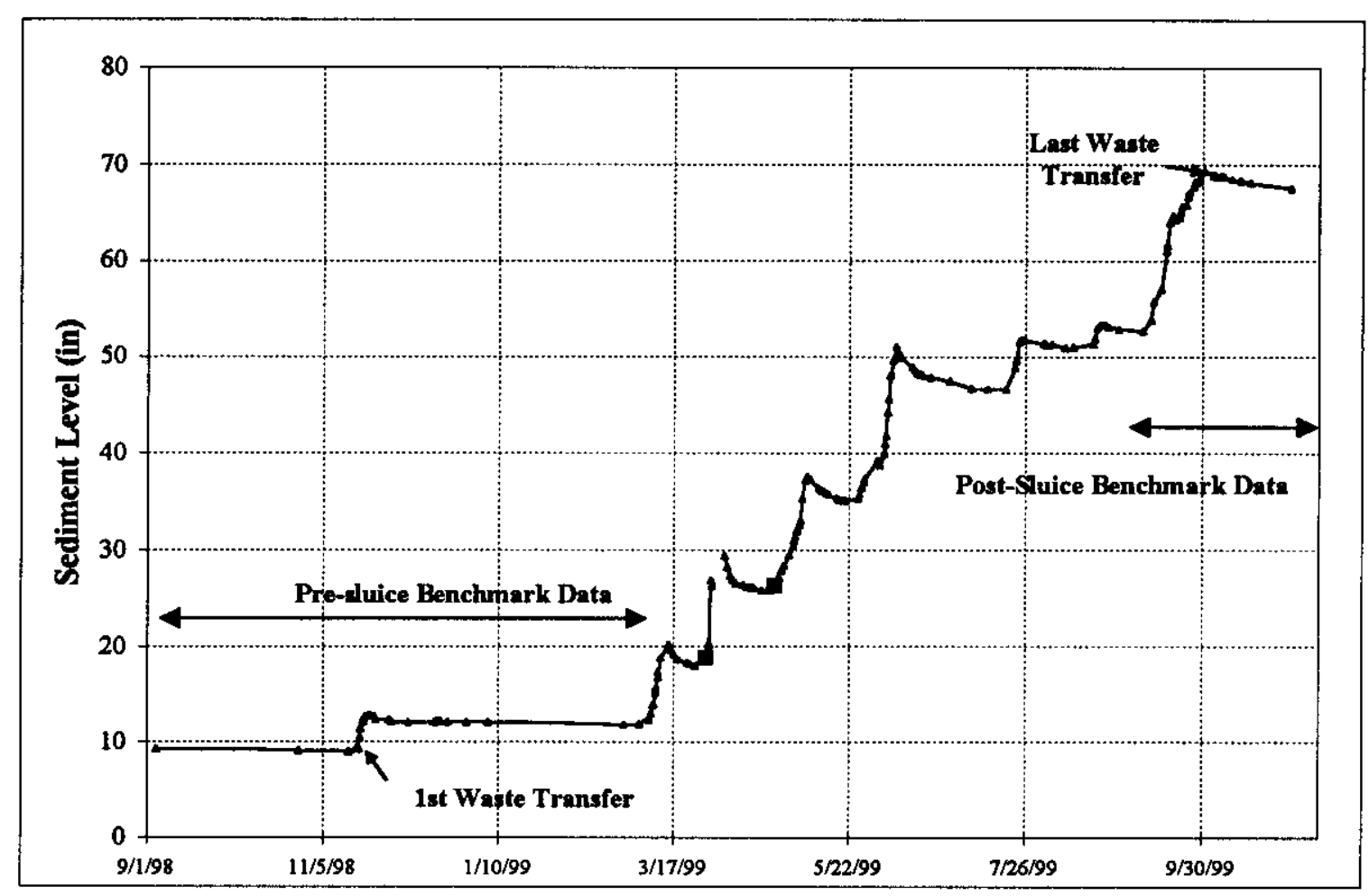

measured sediment level prior to the first transfer was 9 inches. Figure C3-2 shows the temperature data for $\mathrm{TCl}$ of the MIT, which is 11.2 inches from the tank floor. The supernatant liquid temperature is also shown in the figure. It can be noted that the measured temperature at TC1 exceeds the supernatant liquid temperature. This is only possible if that TC is covered by waste. The second thermocouple, TC2 located at 23.2 inches, measures supernatant liquid temperatures during this period. This indicates that the waste level at the location of the MIT (Figure C3-1) is higher than at the location of the Enraf densitometer gauge (their location is nearly diametrically opposed to each other). The level is between 11.2 inches and 23.2 inches. The higher initial waste-depth measure by the MIT temperatures was used for the benchmark analyses and AGA study. A value 17 inches (mid-way between the two thermocouples) was selected for the benchmark and AGA analyses. The change in level measured by the Enraf gauge was used to determine the post-sluicing waste depth in tank 241-AY-102. The postsluicing waste depth used for the analyses was 85 inches.

\section{C3.2.3 Waste Settling Time}

A potentially important parameter for the AGA analyses is the settling time of the tank waste, after elimination of mixer pump operation. The Enraf level data for tank 241-AY-102 provides an estimate of this settling time. The level data are shown in shown in Figure C3-5. The sluicing start date and the date the waste achieved a maximum settled depth are shown in the figure for four waste transfers. These waste transfers were selected because a significant amount of waste was transferred in one sluicing operation. This provides a good estimate of the settling time. The settling times range from six days to nine days (including the day of sluicing). The benchmark analyses will not include a comparison of these settling times. However, the settling 
times for the AGA analyses will be compared with these data to ensure that the predicted settling times for the AGA analyses are reasonable.

Figure C3-5. Setting Time Data for Tank 241-AY-102.

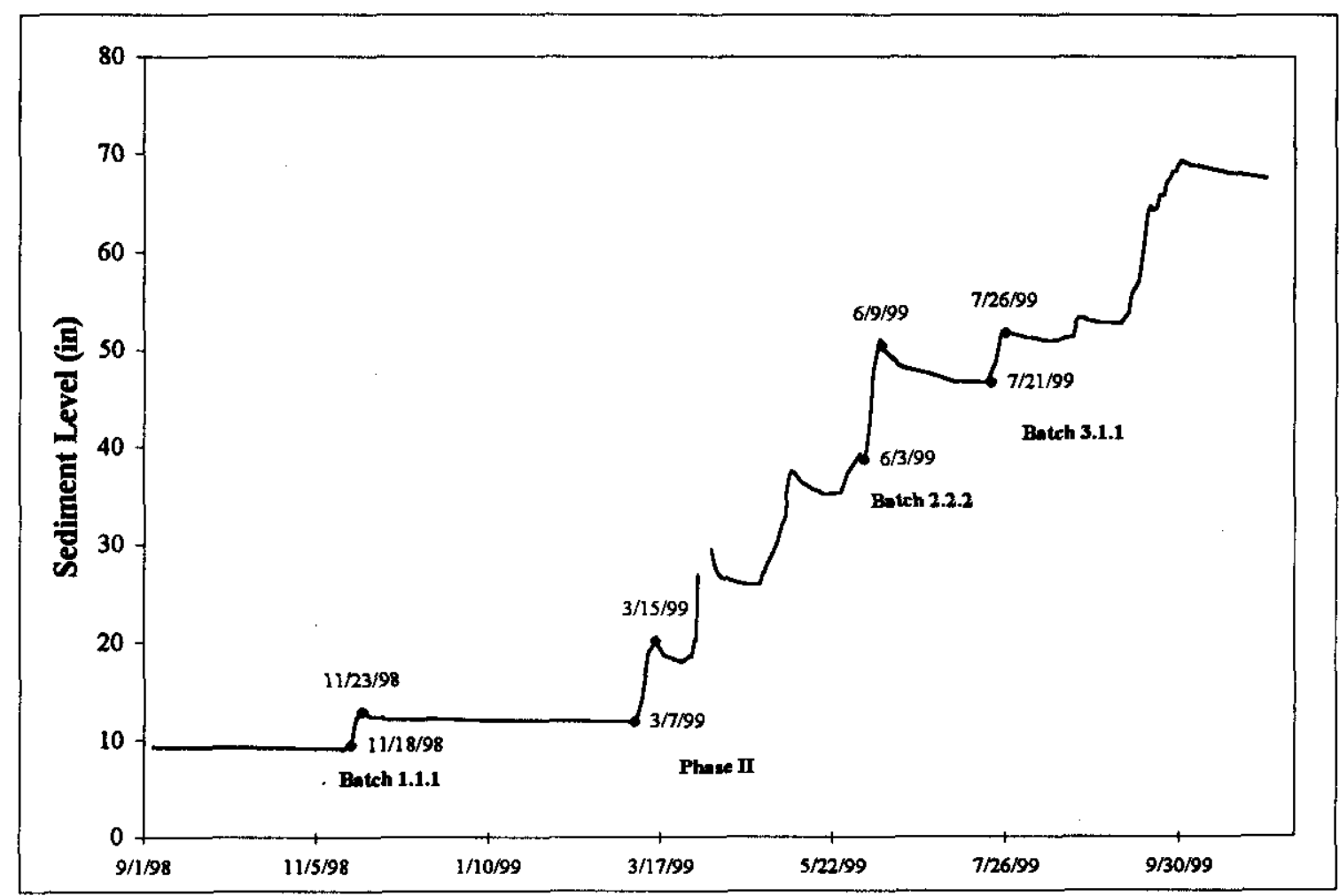

\section{C3.3 TANK 241-AY-102 ENERGY BALANCE}

The heat load for tank 241-AY-102, following the completion of waste transfers from tank 241-C-106, was estimated by performing an energy balance based upon measured tank temperature and ventilation flow data. The methodology and results are presented below.

\section{C3.3.1 Methodology}

Figure C3-2 shows that the waste temperature for tank 241-AY-102 reached seasonal maximum temperatures in December 1999. During this period, the energy storage in the supernatant liquid and sludge is small and can be neglected in the energy balance. The temperature and flow data for the middle of December was averaged over a one week period. These average values were used for the energy balance.

The following is a summary of the averaged temperature and ventilation flow data:

$\mathrm{T}_{\text {dome }}=90^{\circ} \mathrm{F}$

$\mathrm{T}_{\text {ambient }}=42^{\circ} \mathrm{F}$

$T_{\text {annulus }}=85^{\circ} \mathrm{F}$

$Q_{\text {primary }}=350 \mathrm{cfm}$

$\mathrm{Q}_{\text {primary }}=890 \mathrm{cfm}$
Dome and primary ventilation outlet air temperature

Ambient inlet air temperature

Annulus ventilation outlet air temperature

Primary system volumetric flow rate.

Annulus system volumetric flow rate.

In addition to these data, the dome relative humidity and average ambient relative humidity were used to determine the inlet and dome space water vapor density $\rho_{\text {inlot vapor }}$ and $\rho_{\text {domo vapor. }}$. The 
dome space relative humidity was a constant $100 \%$ and the average ambient relative humidity was near $50 \%$.

Constants used for the energy balance included:

$\mathrm{Cp}$ air $=$ Air specific heat

$\rho_{\text {air }}=$ Inlet air density

$\mathbf{k}$.soil $=$ Soil thermal conductivity

$\mathrm{A}_{\mathrm{tank}}=$ Tank cross-sectional area

$$
L_{\text {soil }}=\text { Depth of soil above tank }
$$

$\mathrm{h}_{\mathrm{fg}}=$ Heat of evaporation

The heat removed through the primary ventilation system by sensible heat, soil conduction and evaporation (latent heat) are given by:

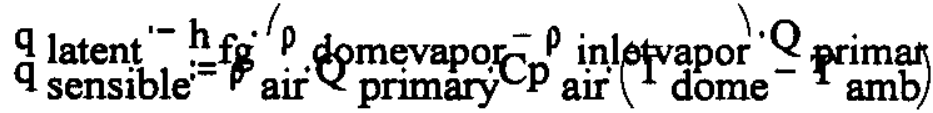

$q_{\text {primary }}:=q_{\text {sensible }}+q_{\text {conduction }}+q_{\text {laten }}$

$\mathrm{q}_{\text {conduction }}:=\frac{\mathrm{k}_{\text {soir }} \mathrm{A}_{\text {tank }}}{\mathrm{L}_{\text {soil }}} \cdot\left(\mathrm{T}_{\text {dome }}-\mathrm{T}_{\text {amb }}\right)$

Energy removed by the annulus ventilation sensible heat removal and the total heat removal are given by:

$q_{\text {annulus }}=\rho$ air $Q$ annulus $C p$ air $\left(T\right.$ annulus ${ }^{-T}$ amb $)$

$\mathrm{q}_{\text {total }}:=\mathrm{q}_{\text {primary }}+\mathrm{q}_{\text {annulu }}$ 


\section{C3.3.2 Results}

The results of the energy balance are summarized in Table C3-1. The total heat removal is $117,000 \mathrm{BTU} / \mathrm{hr}$. This includes the heat initially in tank 241-AY-102 (41,200 BTU/hr, Ogden 1998) waste prior to the waste transfers from tank 241-C-106. This provides a best estimate of the heat in tank 241-AY-102 to be used for the AGA analyses. Table C3-1 shows the relative contribution of the various heat removal mechanisms. During the period of maximum, waste temperatures (November to December), the primary ventilation system removes about $50 \%$ more heat than the annulus ventilation system. Evaporative heat removal is the dominant heat-removal mechanism during this time of year.

Table C3-1 Summary of Tank 241-AY-102

Energy Balance.

\begin{tabular}{|l|c|}
\hline Energy Balance Parameter & Energy Balance Estimate (BTU/hr) \\
\hline$Q_{\text {sensible }}$ & 17,200 \\
\hline$Q_{\text {conduction }}$ & 6,110 \\
\hline$Q_{\text {latent }}$ & 54,600 \\
\hline$Q_{\text {primary }}$ & 77,900 \\
\hline$Q_{\text {annulus }}$ & 38,600 \\
\hline$Q_{\text {total }}$ & 117,000 \\
\hline
\end{tabular}




\section{C4.0 BENCHMARK ANALYSES}

Analyses were performed with the GOTH-SNF model of tank 241-AY-102. The results were compared with measured tank data. The data comparison provides a benchmark of the model and demonstrates the applicability of the model for the AGA analyses. Both pre-sluicing and post-sluicing data were used for the benchmark analyses.

\section{C4.1 PRE-SLUICING DATA BENCHMARK}

\section{C4.1.1 Dome Head Space Temperature}

The dome space temperature and relative humidity are indicators of the latent and sensible heat removal by the primary system. The GOTH-SNF predicted relative humidity agrees with the 241-AY-102 measured dome space humidity of 100\%. The water vapor in the dome space air is at saturation conditions. A comparison of the dome-space temperature data, for the pre-sluice tank conditions, and the GOTH-SNF model predicted temperatures, is shown in Figure C4-1. There is excellent agreement with the measured data. This demonstrates that the heat removal mechanisms of evaporation, convection, and soil conduction are well modeled.

Figure C4-1. Pre-sluice Dome Space Temperature Comparison.

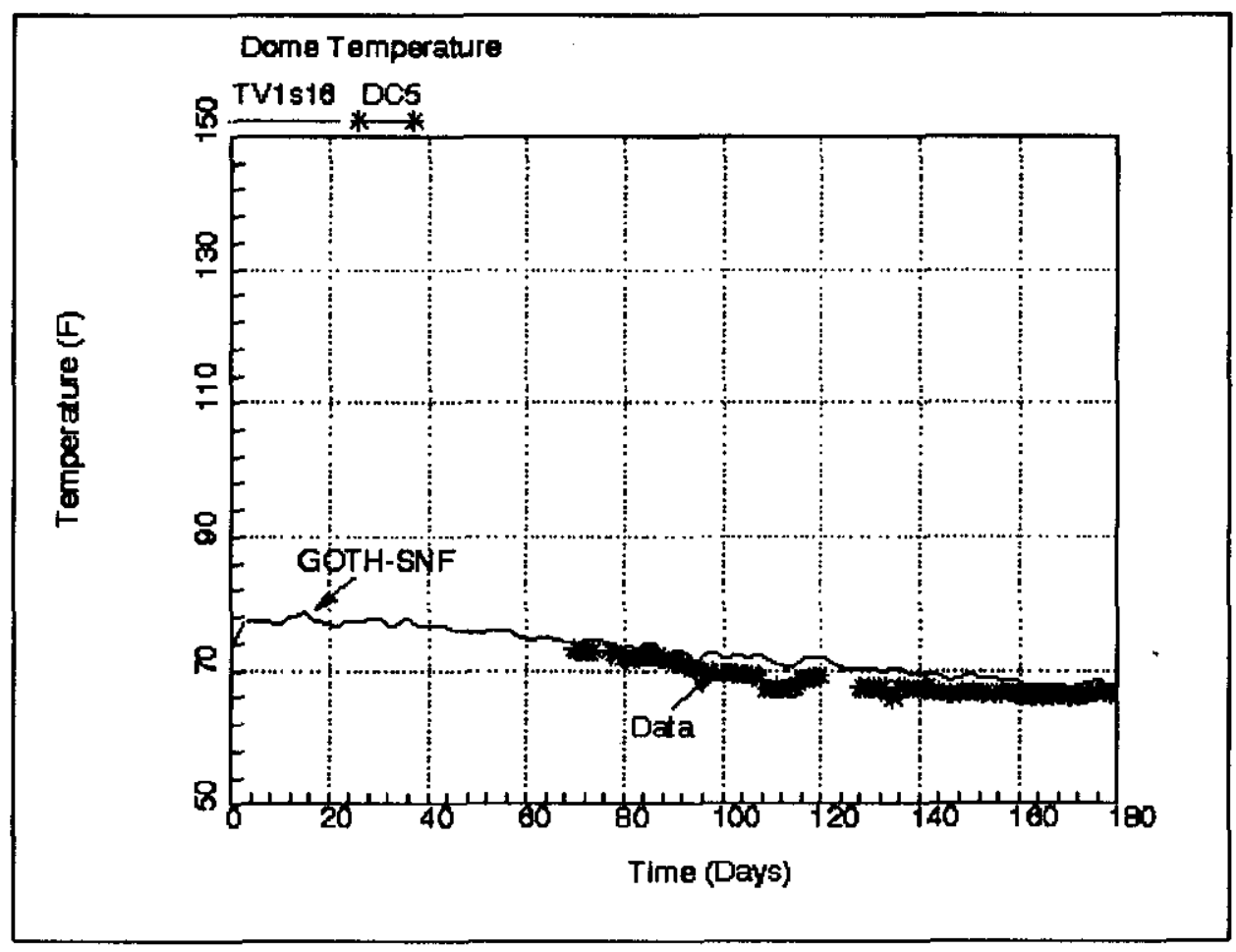

\section{C4.1.2 Supernatant liquid Temperature}

The supernatant liquid temperature is an indicator of the heat removal from the primary system and the heat stored in the liquid pool. Figure C4-2 shows a comparison of the measured data and predicted supernatant liquid temperature. The GOTH-SNF model is initialized with constant 
soil, sludge, and liquid temperatures. Between 20 to 30 days of simulation-time is required for the model to bring these thermal components into equilibrium. There is close agreement with the data after this time. This shows that the energy storage in the supernatant liquid pool and removal from the primary system ventilation is modeled correctly.

Figure C4-2. Pre-Sluice Supernatant liquid Temperature Comparison.

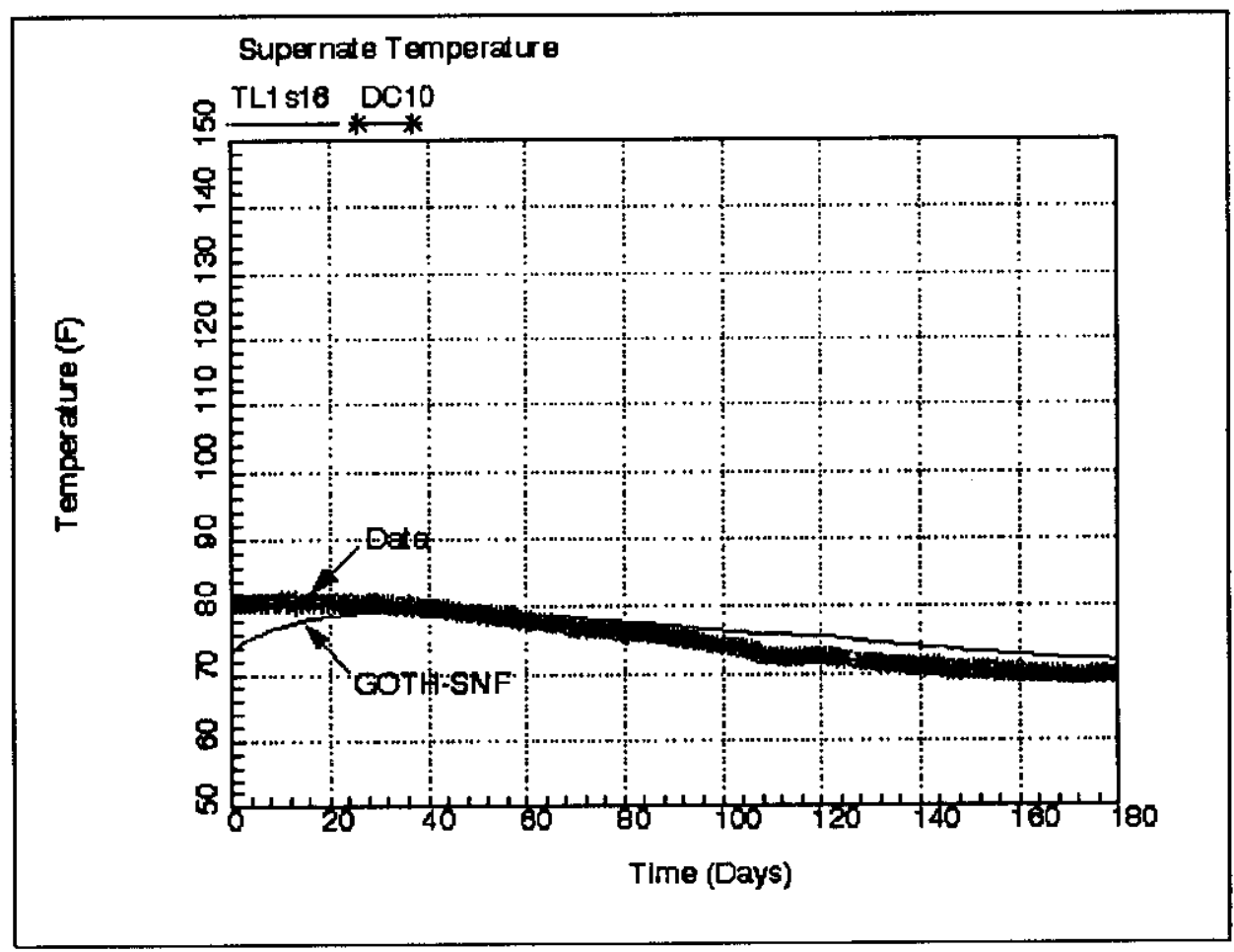

\section{C4.1.3 Annulus Outlet Temperature}

The annulus outlet air temperature is an indicator of the energy removed by the annulus ventilation system. A comparison of the predicted and measured annulus temperature is shown in Figure C4-3. The prediction temperature is approximately $4^{\circ} \mathrm{F}$ higher than the measured temperature in 180 days. Overall, the agreement is reasonable. The heat removal by the annulus system is well modeled by the GOTH-SNF model. 
Figure C4-3. Pre-Sluice Annulus Outlet Air Temperature Comparison.

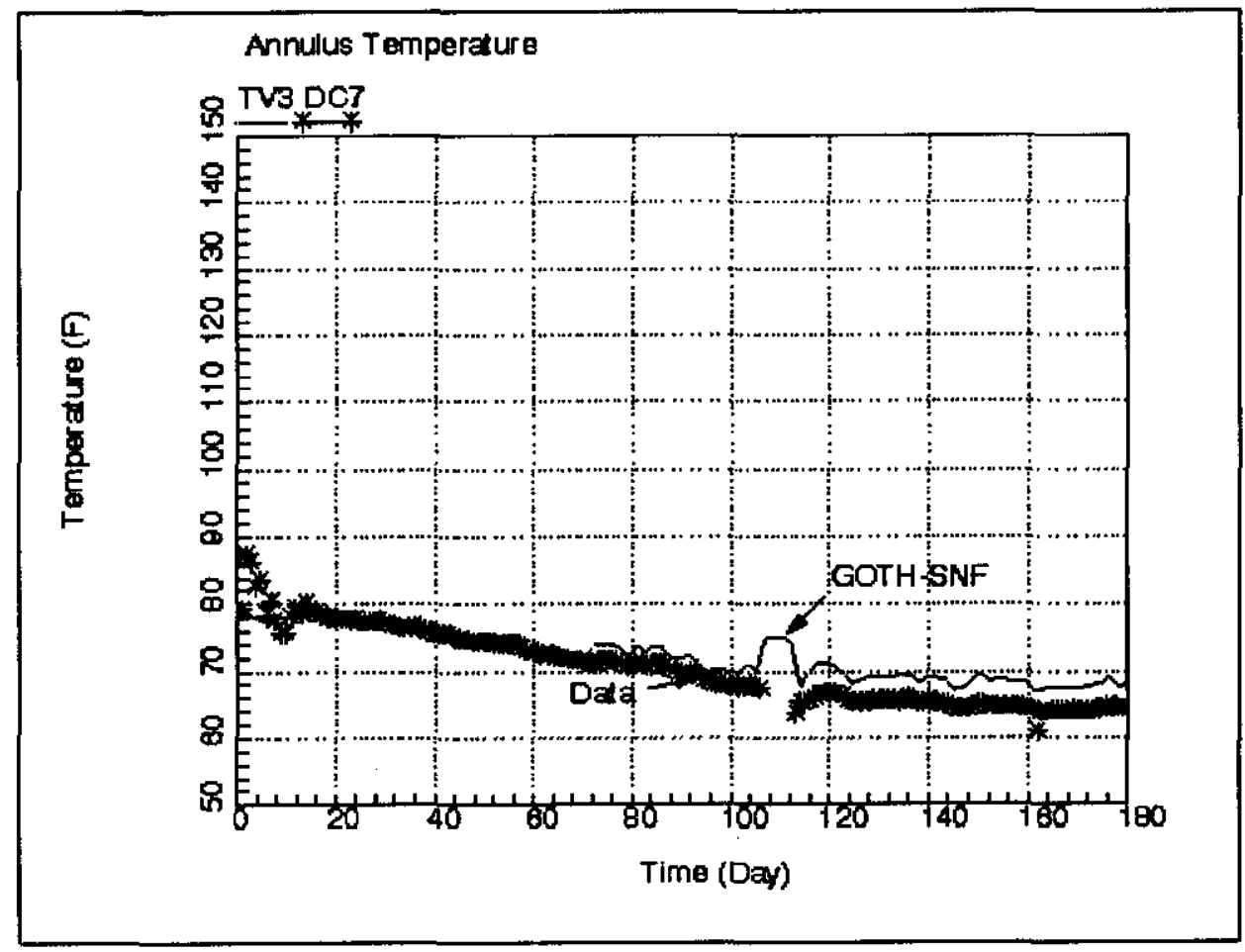

\section{C4.1.4 Waste Temperature}

The waste temperature is an indicator of the energy storage in the waste and is an important parameter for the AGA analyses. A comparison with the predicted and measured waste temperature, at the location of TC1 of the MIT, is shown in Figure C4-4. The agreement with the data is good, however, the waste temperature is over-predicted. This is expected because of the use of the conservative, waste thermal conductivity model. At approximately 110 days in Figure C4-4, the waste temperature increases for a short period. This increase resulted from the loss of annulus ventilation. The waste temperature increase was well predicted by the GOTH-SNF model. 
Figure C4-4. Pre-Sluice Waste Temperature Comparison.

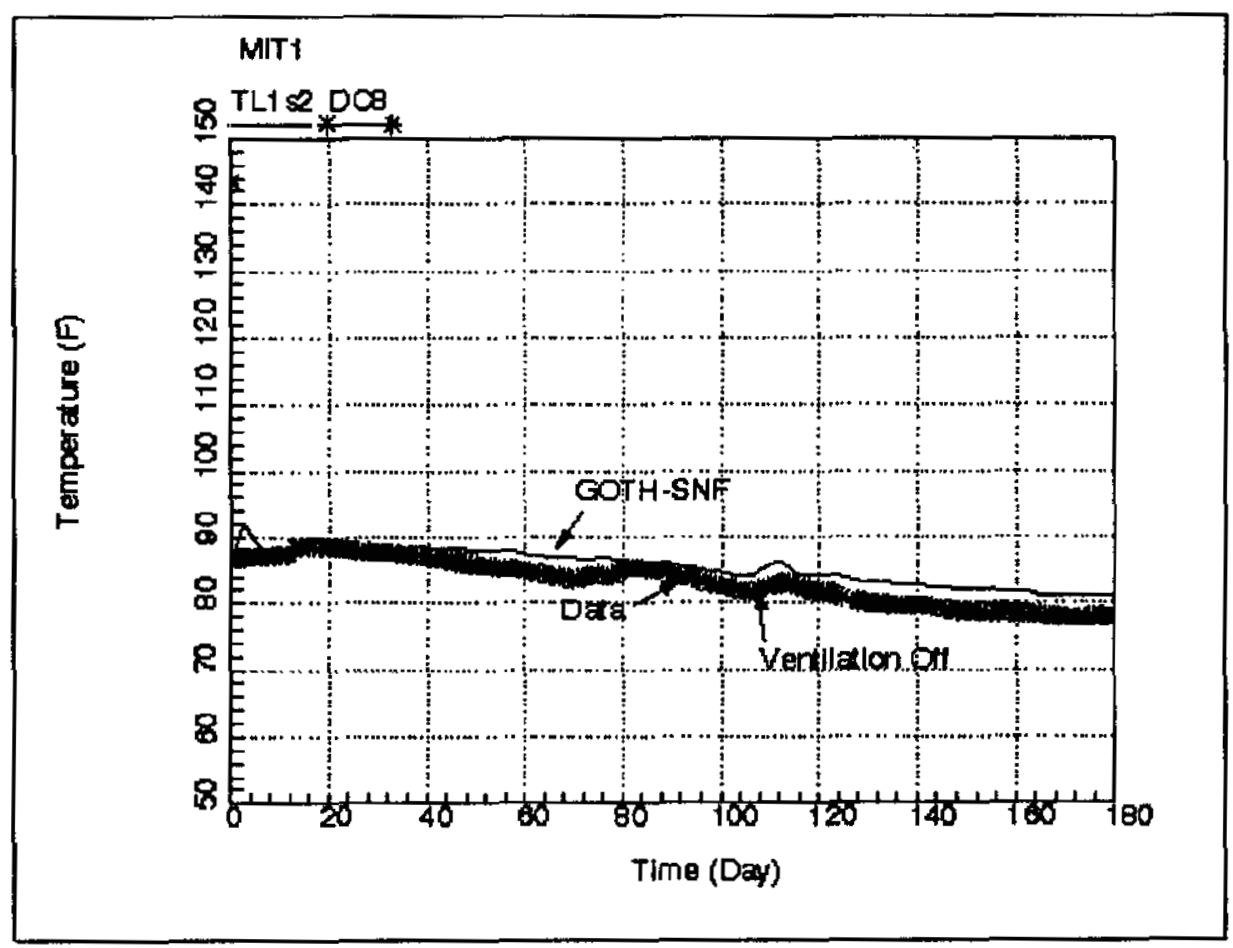

\section{C4.2 POST-SLUICING DATA BENCHMARK}

Benchmark analyses were performed for the post-sluicing data. This provides an assessment of the current conditions in tank 241-AY-102. Comparison with tank data is provided in the following sub-sections.

\section{C4.2.1 Dome Head Space Temperature}

The dome space outlet air temperature is shown in Figure C4-5 for post-sluice tank conditions. The data are compared with GOTH-SNF model predicted temperatures. The agreement is excellent. Thus, the GOTH-SNF model, with the transferred waste from tank 241-C-106, predicts the energy removal from the primary ventilation system well. 
Figure C4-5. Post-Sluice Dome Space Temperature Comparison.

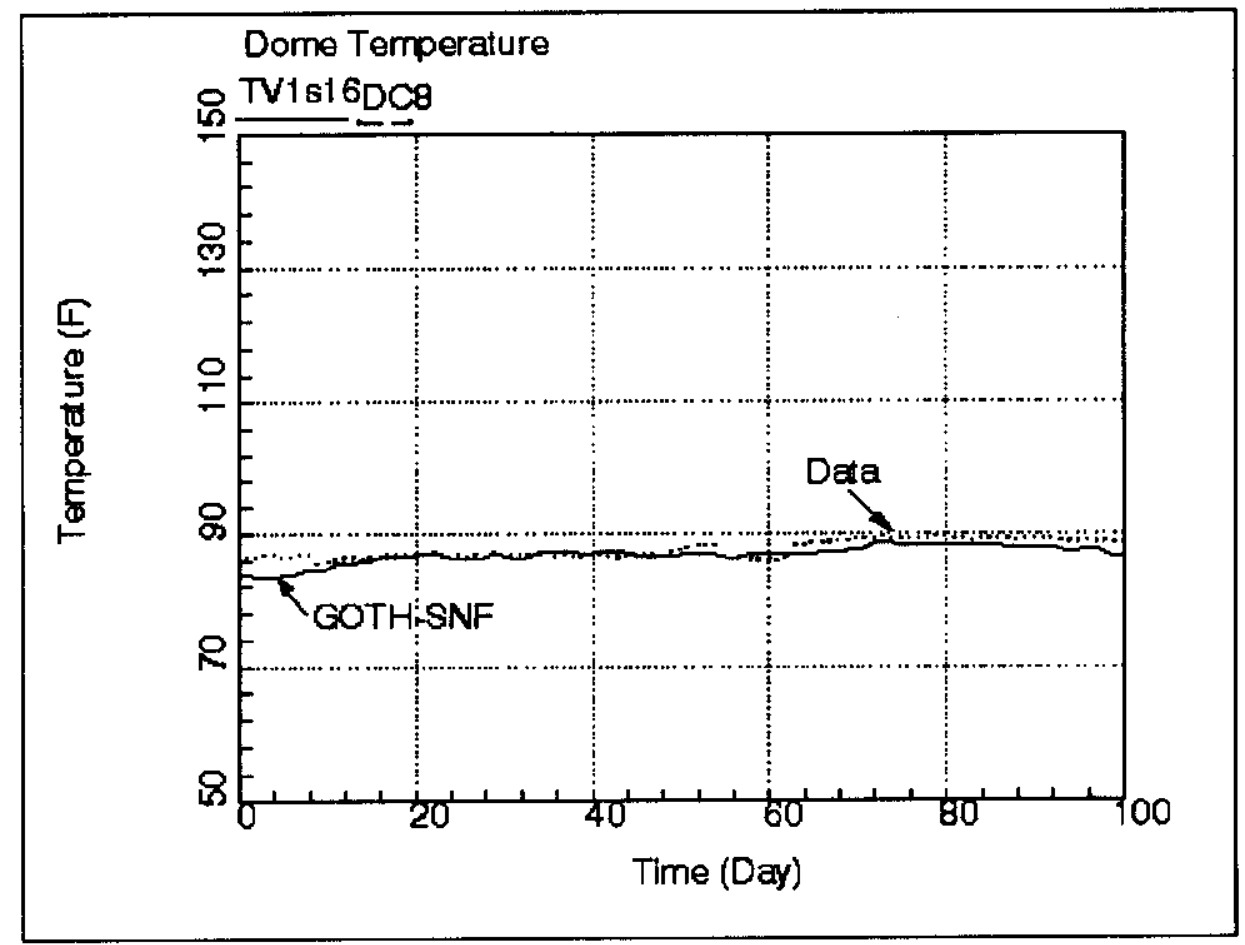

\section{C4.2.2 Supernatant liquid Temperature}

A comparison of the GOTH-SFN benchmark analyses and the post-sluicing supernatant liquid temperature is shown in Figure C4-6. There is close agreement with the data. The ambient air temperature is also shown on the figure. The pool temperature remains near constant for many days, while the ambient temperature is decreasing significantly. The close agreement with the supernatant liquid temperature demonstrates that the GOTH-SNF model correctly models the energy storage and removal mechanisms from the waste tank. 
Figure C4-6. Post-Sluice Supernatant liquid Temperature Comparison.

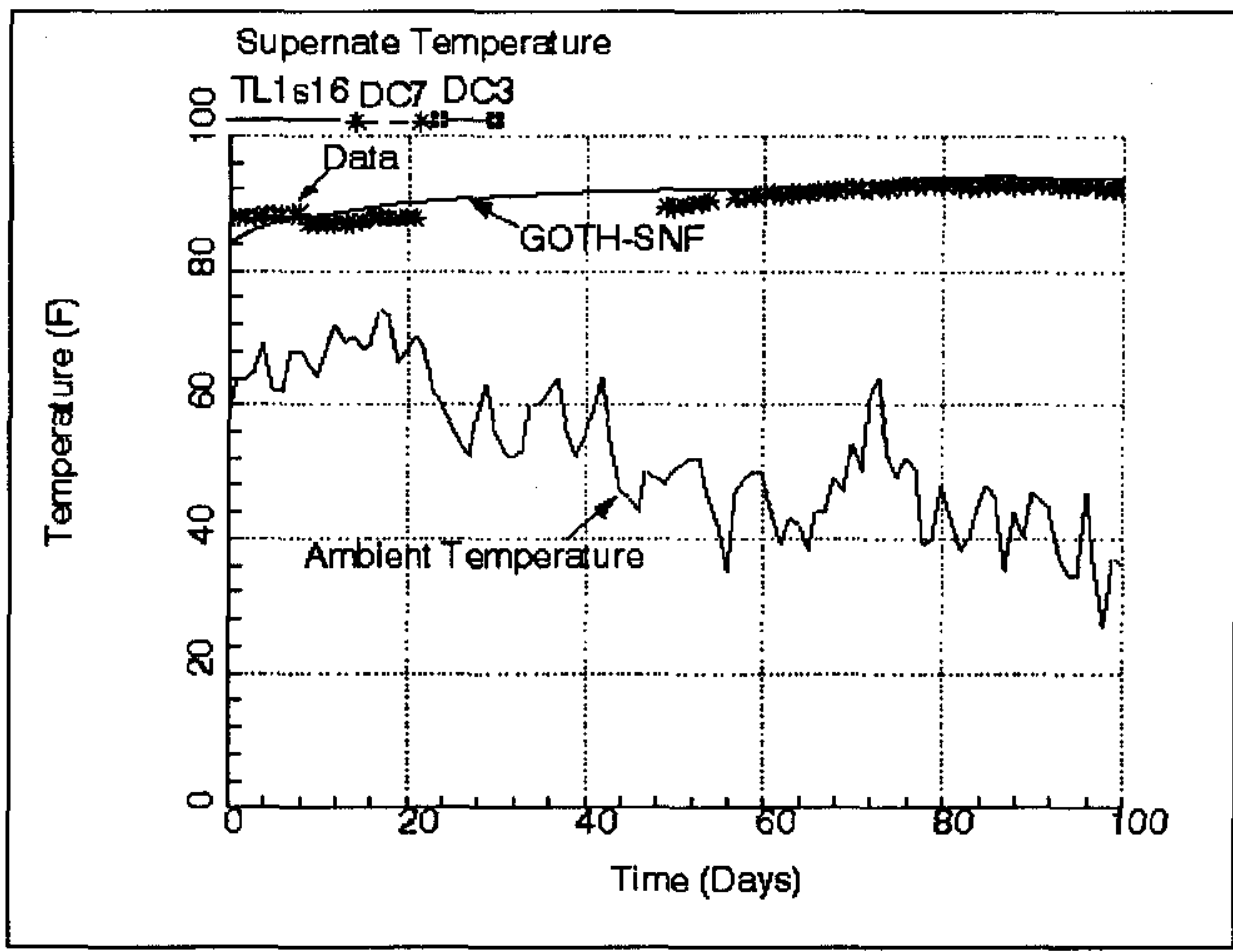

\section{C4.2.3 Annulus Outlet Temperature}

A comparison of the measured annulus-ventilation system outlet air temperature with the GOTH-SNF model prediction is shown in Figure C4-7. There is close agreement with the data. The GOTH-SNF model correctly models the energy removal by the annulus system. This demonstrates that the average slot heat transfer coefficient, with the top-slot surface area, provides a good representation of the heat transfer from the waste to the annulus air. 
Figure C4-7. Post-Sluice Annulus Outlet Air Temperature Comparison.

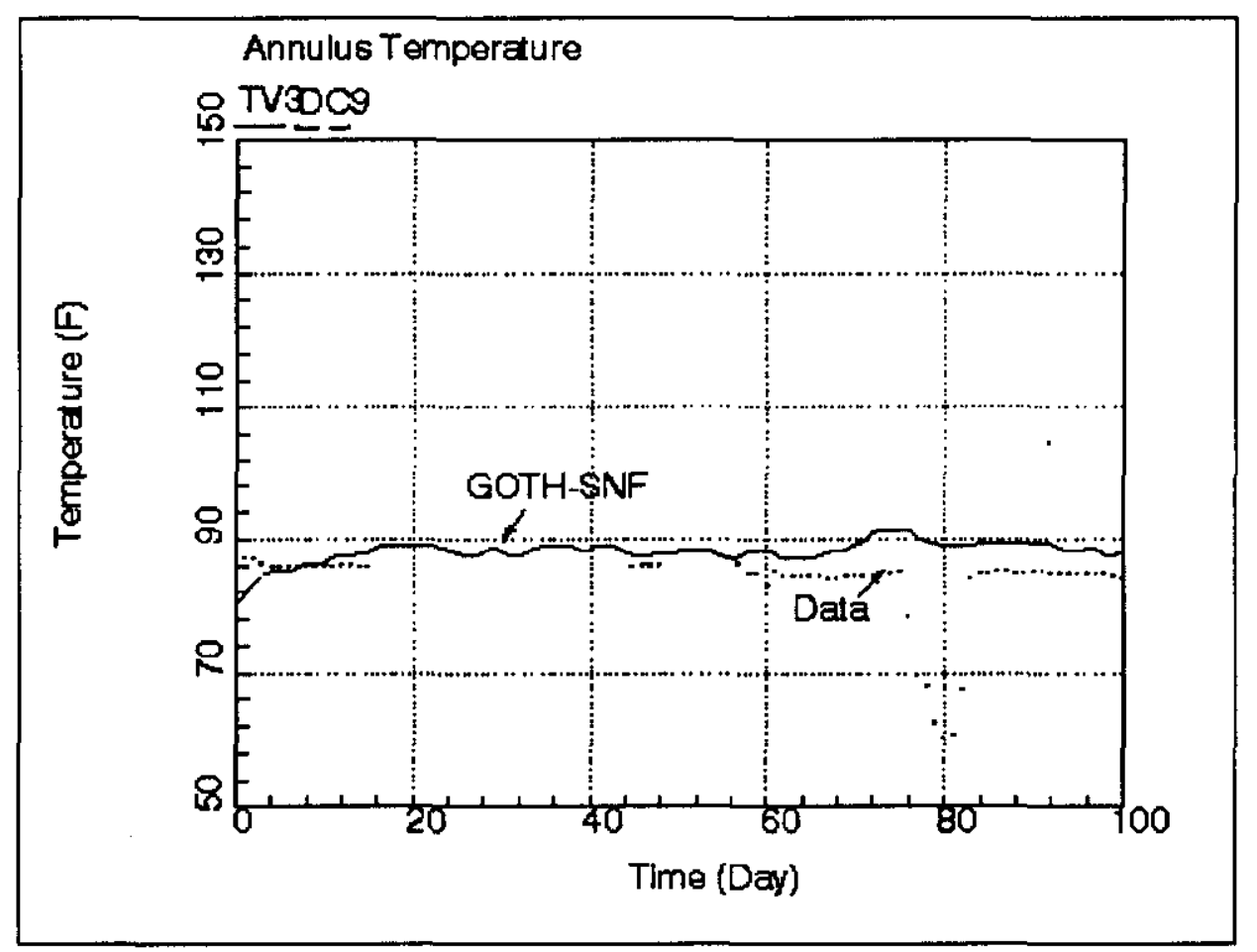

\section{C4.2.4 Waste Temperature}

The measured waste temperature at TC1 of the MIT (11.2 inches from the tank floor) is compared with predicted waste temperatures in Figure C4-8. The GOTH-SNF model overpredicts the waste temperature by 10 to $15^{\circ} \mathrm{F}$. This is a result of the waste conduction model discussed in Section C2.2.4. The Series conduction model is conservative, as expected, resulting in higher predicted temperatures.

The annulus ventilation system was off for a short period following the completion of sluicing from tank 241-C-106. The waste temperature increase, resulting from this loss of ventilation, is shown Figure C4-8. There is good agreement with the data and the GOTH-SNF model predicted temperature increase following the loss of ventilation. This further demonstrates that the GOTH-SNF model can model the waste temperature response. 
Figure C4-8. Post-Sluice Waste Temperature Comparison.

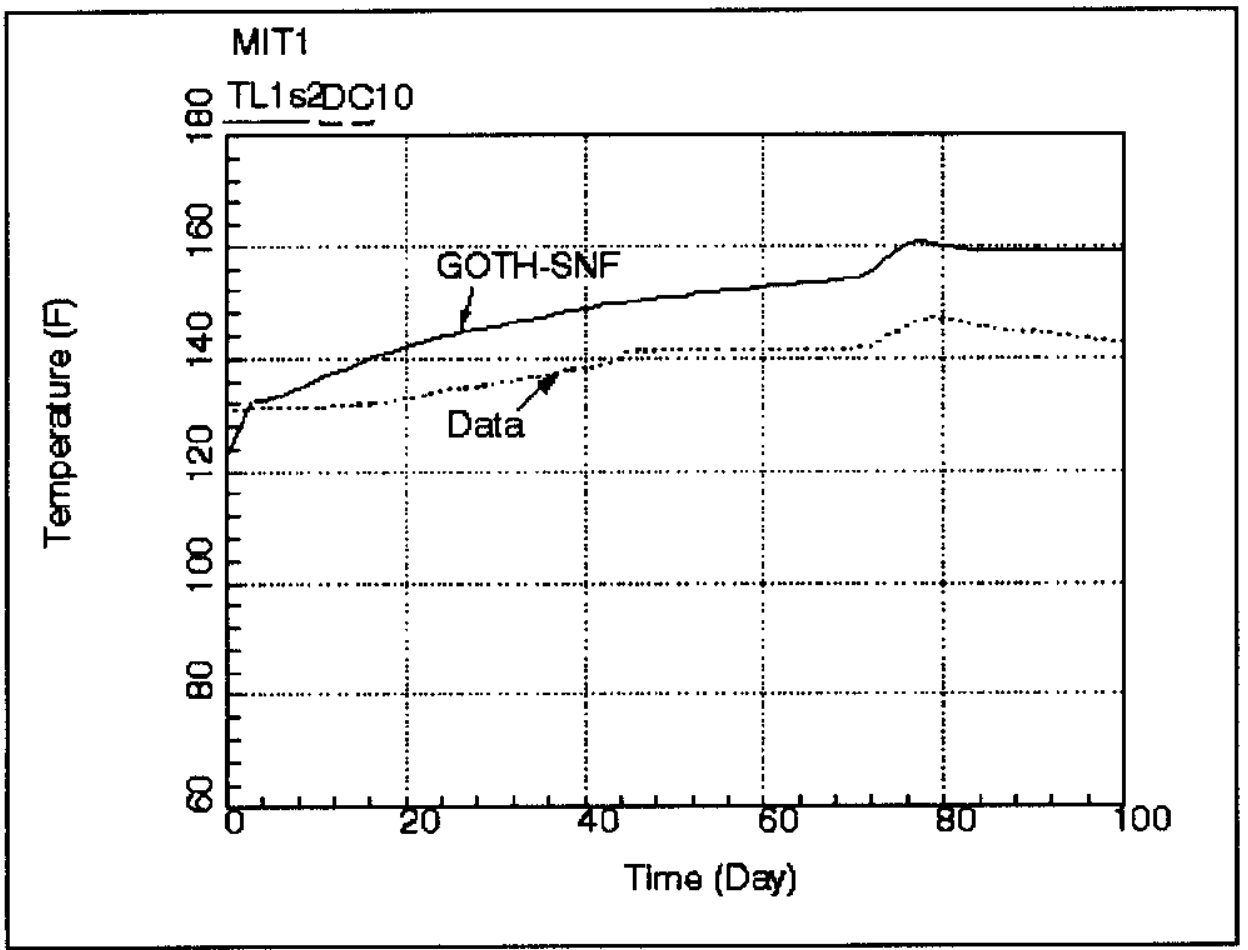

Figure C4-9 compares the predicted outer bottom waste sludge temperatures with the average measured data. The figure also shows the maximum expected waste temperature based upon three times the standard deviation in the data. The predicted bottom waste temperatures using the conservative Series conduction model exceeds the average and maximum data. Thus, the application of the Series conduction model bounds the expected azimuthal variation in waste temperature. 
Figure C4-9. Outer Bottom Sludge Temperature.

Rev. 0

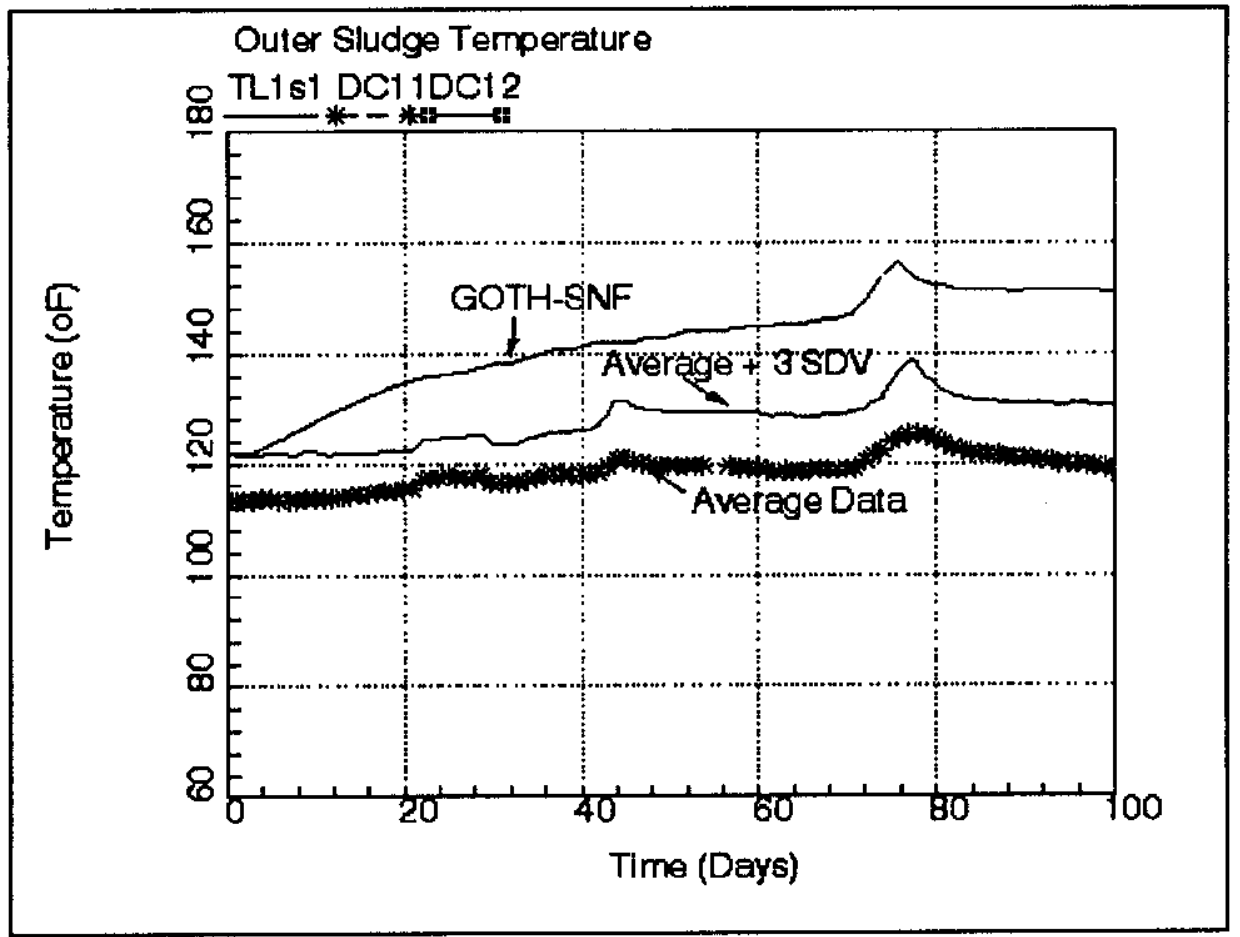


RPP-5637

Rev. 0

This page intentionally left blank.

C4-10 


\section{C5.0 CONCLUSIONS}

- The GOTH-SNF predicted dome, supernatant liquid and annulus outlet temperatures agree well with both the pre-sluicing and post-sluicing tank data.

- The GOTH-SNF model adequately models the heat removal from the primary and annulus ventilation systems.

- The GOTH-SNF model provides a conservative prediction of the maximum waste temperatures. The conservative prediction of waste temperatures bounds the expected azimuthal variation in waste temperature.

- The benchmark analyses using tank 241-AY-102 data, demonstrate that the heat transfer and storage mechanisms for double-shell waste tanks, have been adequately modeled by the GOTH-SNF model. The model is suitable for application to the AGA alternatives study. 
RPP-5637

Rev. 0

This page intentionally left blank. 


\section{C6.0 REFERENCES}

Thurgood, M. J., 1999, Technical Manual For GOTH_SNF Version 5.0, JMI-980306-3, Rev. 1, John Marvin, Inc., West Richland, Washington.

Thurgood, M.J. and D.M. Ogden, 1999, Quality Assurance Manual And Procedures, JMI-980306-1, Rev 3, John Marvin, Inc., West Richland, Washington.

Sathyanarayana, K and B. C. Fryer; 1996, WHC-SD-WM-CN-022, Rev. 0, Evaluation of Potential and Consequences of Steam Bump in High Heat Waste Tanks and Assessment and Validation of GOTH Computer Code. 
RPP-5637

Rev. 0

This page intentionally left blank.

C6-2 
APPENDIX D

RELATED CORRESPONDENCE

D-i 
RPP-5637

Rev. 0

This page intentionally left blank.

D-ii 


\section{CONTENTS}

1. ESTIMATE OF RECOVERY TIME OF RIVER PROTECTION PROJECT'S ACTIVE DOUBLE-SHELL TANK VENTILATION SYSTEMS (LOCKHEED MARTIN INTERNAL LETTER TO W.J. MILLSAP FROM J. KRISKOVICH, DECEMBER 3, 1999)

2. BOUNDING CASE TANKS (ELECTRONIC E-MAIL TO BLAINE A. CREA

ET AL. FROM WILLIAM L. WILLIS, NOVEMBER 17, 1999 WITH

ATTACHMENTS) D-3 
RPP-5637

Rev. 0

This page intentionally left blank. 
INTEROFFICE MEMO
LOCKHEED MARTINT/

R1-56

74700-99-JRK-046

\begin{tabular}{lll}
\hline From: & Equipment Engineering & R1-56 \\
Phone: & $373-3686$ & \\
Date: & December 3, 1999 \\
Subject: & ESTIMATE OF RECOVERY TIME OF RIVER PROTECTION \\
& PROJECT'S ACTIVE DOUBLE SHELL TANK VENTILATION \\
& SYSTEMS
\end{tabular}

To:

W. J. Millsap

R3-73

cc: P. J. Certa

R3-73

T. J. Conrads

R3-73

A. H. Friberg

R1-56

R. D. Gustavson

R1-56

J. B. Truitt

R1-56

JRK/File/LB

R1-56

The estimated recovery time from the failure of the heating, ventilation, and air conditioning (HVAC) system in the double-shell tanks will form the basis of the waste temperature analysis to ensure that the waste temperature safety limit is not exceeded during mixer pump operation. The estimated recovery time also will be used in conjunction with a defense-in-depth argument for operation of the mixer pump, which asserts that should the HVAC system become inoperable for a certain period of time, the defense would be operation of a low-speed mixer pump.

Following is an engineering estimate. It is strongly recommend that a formal Failure Modes and Effects Analysis (FMEA) be performed to validate this estimate.

The current configuration of the active ventilation systems in the double-shell tanks includes dual components for those "major" items of the system. The dual components include a complete filter train assembly (motor-operated isolation valves, heater, prefilter and two stages of high-efficiency particulate air (HEPA) filtration), two separate fans, and two separate vacuum pumps for the sampling system.

The redundancy of major components provides inherent reliability and operational flexibility. Even if a component were to fail, the dual portion of the system would be capable of meeting the need, thus allowing time for maintenance and repair of the failed component. This in itself provides a strong technical basis for estimating and allowing some duration for recovery time.

The other major components in the active ventilation system include the vacuum pumps, which are an integral part of the stack sampling system. The stack sampling system consists of a continuous air monitor (CAM), record sampler, various valves, flow control, and dual/back-up vacuum pumps. 
The recent poor reliability of the stack sampling system can be attributed to the failure or shutdown of the vacuum pumps. Although failures have occurred, two pumps are installed and the other pump is available to support the sampling requirements.

The fans, vacuum pumps, and motor-operated isolation valves are the only dynamic components in the active ventilation system. History has shown the fans and motoroperated isolation valves to be very reliable. The only credible failures have been loss of a fan belt, for the belt driven units, and failure of a bearing.

Belt replacement is a routine maintenance activity and could be completed in a short timeframe. Bearing replacement, although more difficult, also is also a routine maintenance activity and could also be completed in a short time period. In addition, a vibration analysis program has been implemented as part of the maintenance program to help determine bearing failure before it occurs. The systems contain two fans, which in the event of a failure the redundancy help ensure system operation.

The motor-operated isolation valves can be manually manipulated, eliminating the credible failure and restoring operability.

Vacuum pump failures have been fairly high. Spare pumps are readily available and replacing the pump is also a routine maintenance activity. Replacing the pumps may take some time to complete, but the other pump will be able to support the sampling needs.

Engineering judgment and experience indicate that an approximate reasonable recovery time to restore active ventilation could be up to 50 hours. This is based primarily. No analysis has been completed and this approximation has not been validated. A formal FMEA of the ventilation system is needed to confirm this value. Without performing a formal FMEA the 50 hours has minimal technical merit.

To help support the recovery time identified above, I recommend maintenance work packages be prepared and ready to perform the routine maintenance activities discussed above along with assuring spare parts are available for those components identified above.

If you have any questions, please contact me at 373-3686.

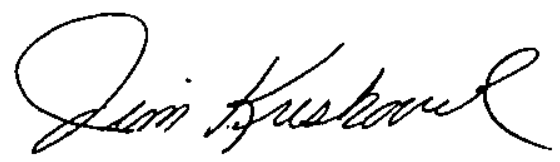

Jim Kriskovich, HVAC Design Authority Equipment Engineering

\section{Fam}




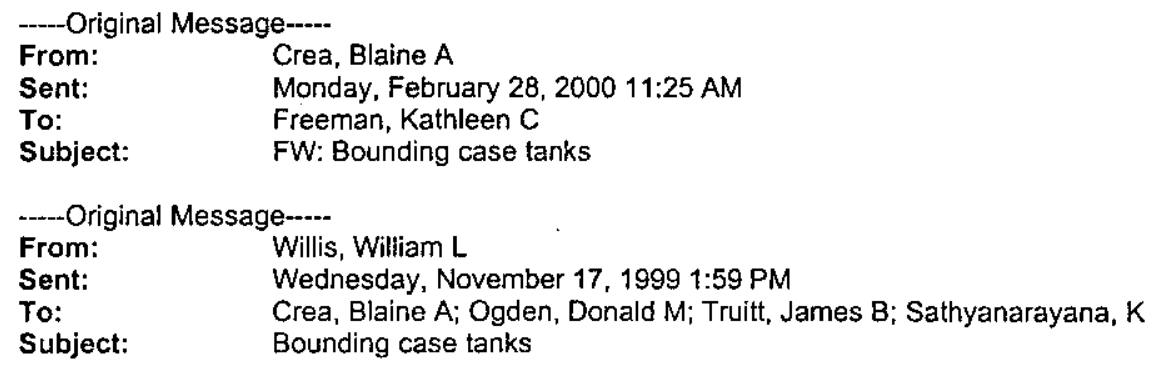

Blaine,

This is my attempt to come up with the bounding heat loads in the sludge layer. Using the best basis inventory radionuclide numbers for all 177 tanks, I started by looking at the tanks with greater than or equal to one mega Curie of strontium 90 . I then estimated the total heat in those tanks using the specific heats for each nuclide. Please note that $A Z-101$ is has by far the highest decay heat, and that the combination of all AY-102 and C-106 (must be pre-slucing) results in the largest inventory of strontium 90. I don't know to what date this inventory has been decayed, and you may be able to find better numbers. Please let me know what else we need to do (possibly determine which tanks are to be retrieved so we'll know what combinations need to be looked at) to determine the bounding tanks.

Bill Willis

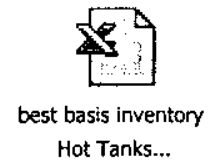




\begin{tabular}{|c|c|c|c|c|c|c|c|c|c|c|c|c|c|c|c|c|c|c|c|c|c|c|c|c|c|c|c|c|c|c|c|}
\hline & 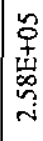 & 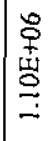 & 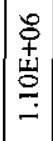 & 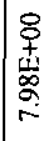 & 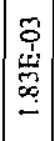 & 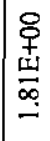 & $\mid \begin{array}{c}\overline{0} \\
\dot{1} \\
\omega \\
0 \\
0 \\
\alpha\end{array}$ & 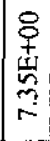 & $\left|\begin{array}{c}0 \\
0 \\
\dot{d} \\
2 \\
=\end{array}\right|$ & $\begin{array}{l}0 \\
0 \\
4 \\
0 \\
0 \\
\end{array}$ & 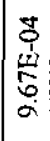 & $\begin{array}{l}\overline{0} \\
\text { w } \\
5\end{array}$ & 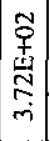 & 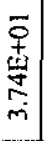 & $\begin{array}{l}\overline{0} \\
\vdots \\
\vdots \\
\vdots \\
0\end{array}$ & $\mid \begin{array}{l}\overrightarrow{0} \\
\vec{\omega} \\
\vec{n}\end{array}$ & 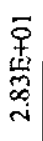 & 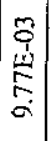 & 怠 & 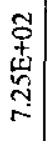 & 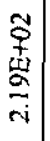 & 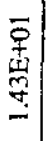 & 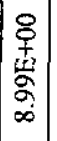 & 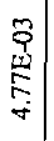 & $\left|\begin{array}{c}0 \\
0 \\
0 \\
0 \\
\infty \\
\infty\end{array}\right|$ & 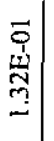 & 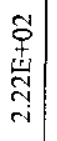 & 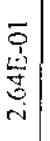 & 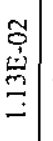 & 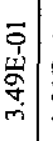 & \\
\hline & & 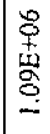 & 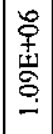 & $\begin{array}{l}\overline{ } \\
\text { 㠀 } \\
\stackrel{2}{2}\end{array}$ & 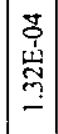 & 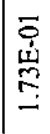 & 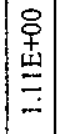 & $\begin{array}{l}8 \\
\$ \\
4 \\
0 \\
0 \\
0 \\
6\end{array}$ & $\left|\begin{array}{c}\tilde{0} \\
+ \\
w \\
0 \\
\sigma \\
\sigma\end{array}\right|$ & $\begin{array}{l}0 \\
0 \\
\dot{\omega} \\
\dot{\omega} \\
\stackrel{\infty}{0}\end{array}$ & 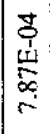 & 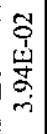 & 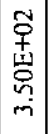 & 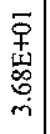 & 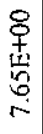 & 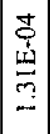 & 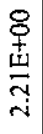 & $\begin{array}{l}0 \\
\text { 是 } \\
\frac{6}{6}\end{array}$ & $\begin{array}{l}8 \\
\text { 要 }\end{array}$ & 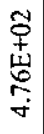 & 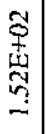 & 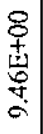 & 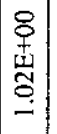 & 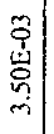 & 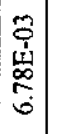 & \begin{tabular}{l}
$\mathcal{Y}$ \\
0 \\
0 \\
0 \\
0 \\
\hdashline \\
-1
\end{tabular} & 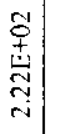 & 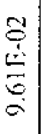 & 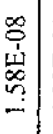 & & \\
\hline & & 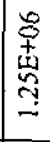 & 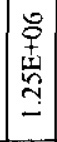 & 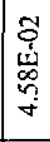 & $\mid \begin{array}{l}0 \\
0 \\
0 \\
0 \\
0 \\
=\end{array}$ & 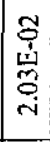 & 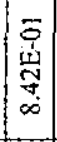 & 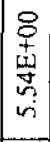 & $\left|\begin{array}{c}\tilde{Q} \\
\underline{w} \\
\tilde{N} \\
\alpha\end{array}\right|$ & $\begin{array}{l}0 \\
0 \\
0 \\
0 \\
-j\end{array}$ & . & $\mid \begin{array}{c}\overline{0} \\
\dot{1} \\
\vec{\gamma}\end{array}$ & 豈 & 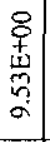 & 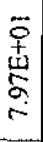 & 总 & 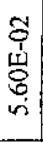 & 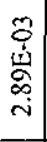 & 矛 & 客 & $\widetilde{q}$ & 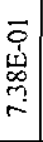 & $\begin{array}{l}0 \\
0 \\
4 \\
\text { 空 } \\
\text { i }\end{array}$ & 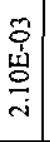 & $\begin{array}{c}0 \\
0 \\
0 \\
0 \\
0 \\
\dot{\sim n}\end{array}$ & 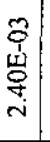 & 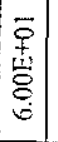 & 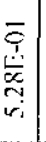 & ఫे & & \\
\hline & & 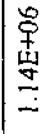 & $\begin{array}{l}\text { 号 } \\
\text { 离 } \\
\text { 三 }\end{array}$ & 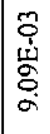 & $\mid \begin{array}{l}0 \\
0 \\
0 \\
\vdots \\
0 \\
0 \\
0 \\
0\end{array}$ & 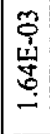 & 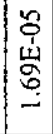 & $\begin{array}{l}8 \\
\text { 古 } \\
\text { 出 }\end{array}$ & $\left|\begin{array}{c}5 \\
0 \\
\omega \\
0 \\
0 \\
ن\end{array}\right|$ & 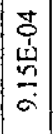 & & 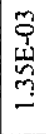 & $\begin{array}{l}\widetilde{⿱} \\
+ \\
\text { w }\end{array}$ & & $\begin{array}{l}\overrightarrow{0} \\
\dot{1} \\
\overrightarrow{9} \\
\vec{i}\end{array}$ & 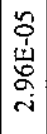 & 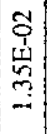 & 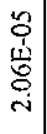 & & 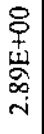 & & 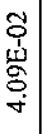 & 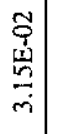 & $\begin{array}{l}0 \\
0 \\
\vdots \\
\vdots \\
\vdots \\
\sigma\end{array}$ & 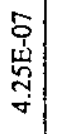 & 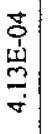 & 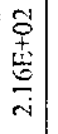 & & $\frac{0}{\frac{1}{4}}$ & & \\
\hline & & 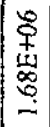 & 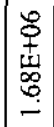 & 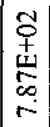 & 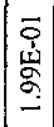 & 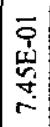 & 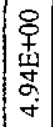 & $\bar{q}$ & 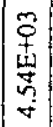 & 虽 & & 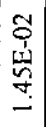 & 旁 & & $\begin{array}{c}\text { 草 } \\
\text { 怠 }\end{array}$ & & & 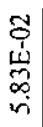 & & $\begin{array}{c}\text { 点 } \\
\text { 穷 }\end{array}$ & & 辛 & $\begin{array}{l}\overline{0} \\
\dot{d} \\
\end{array}$ & 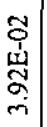 & 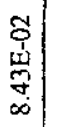 & 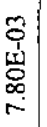 & 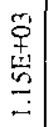 & & 总 & & \\
\hline
\end{tabular}

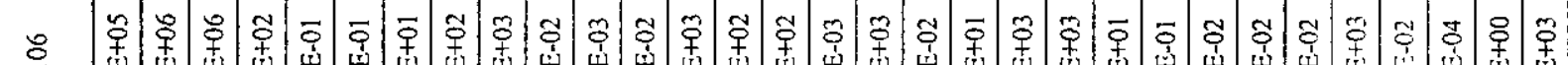

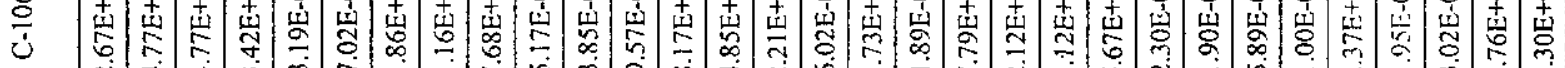

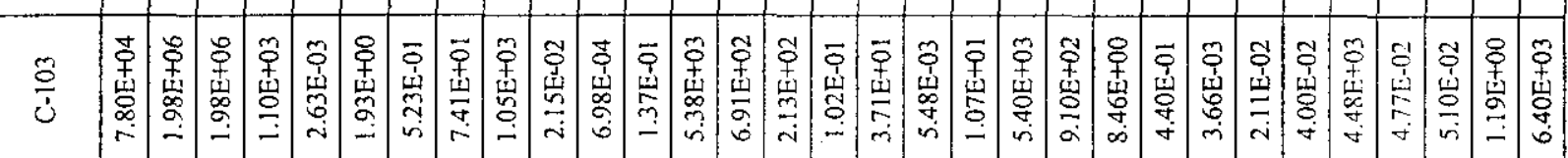

శَ

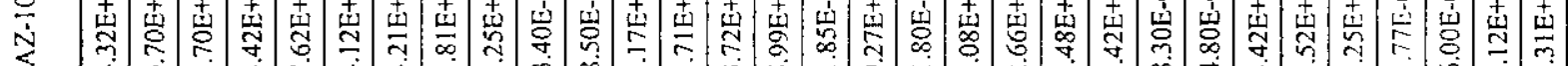

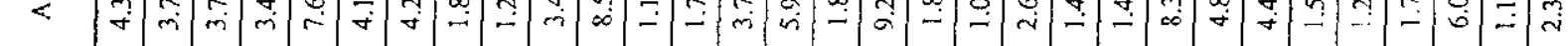

○

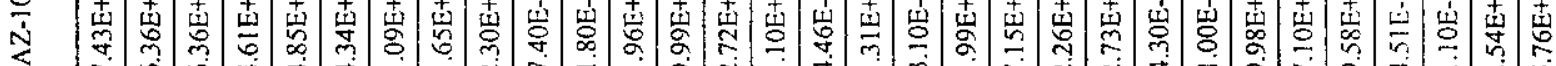

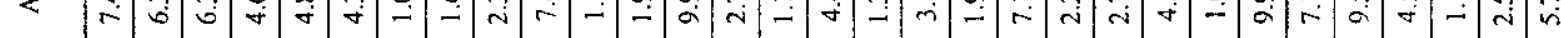

定

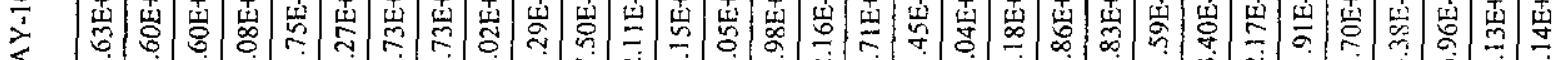

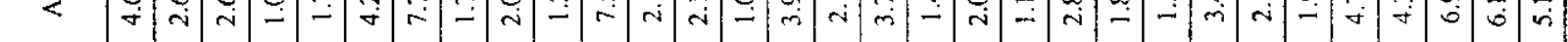

三

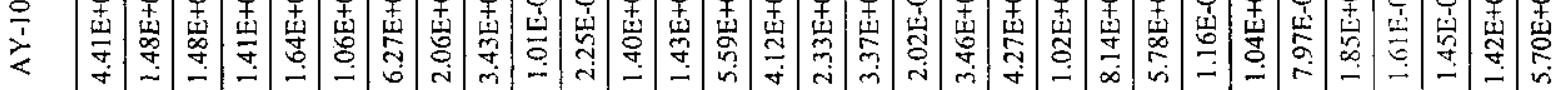

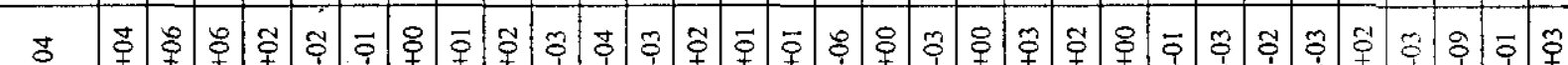

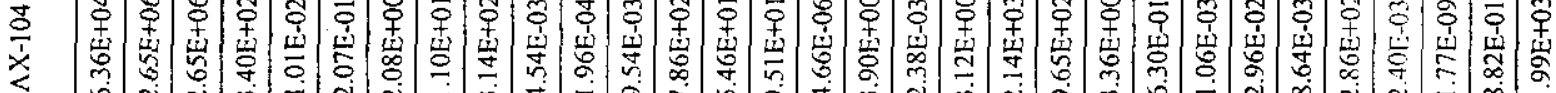

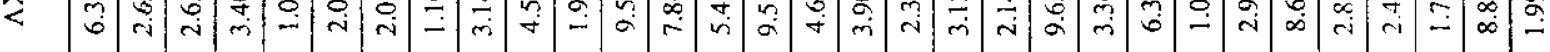

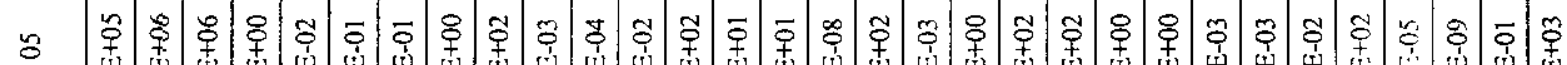
之

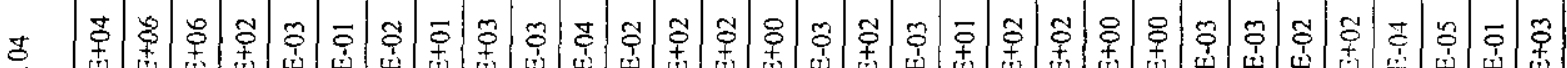

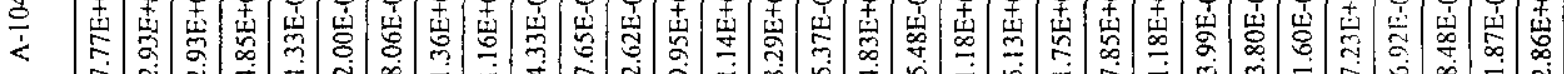

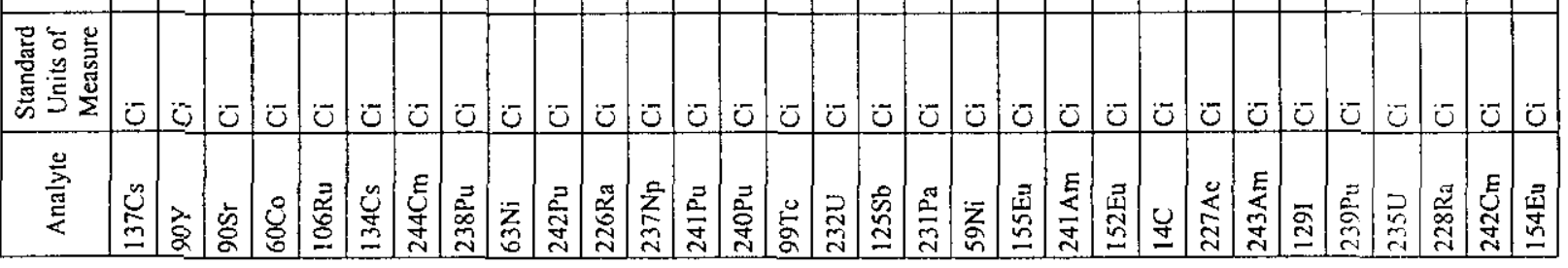




\begin{tabular}{|c|c|c|c|c|c|c|c|c|c|c|c|c|}
\hline$\frac{8}{\dot{x}}$ & 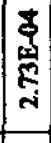 & 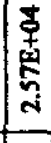 & $\begin{array}{l}\overline{\mathbf{p}} \\
\text { 离 } \\
\text { స్ }\end{array}$ & 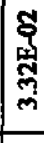 & \begin{tabular}{l}
8 \\
8 \\
9 \\
\multirow{2}{*}{}
\end{tabular} & 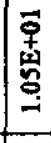 & $\mid \begin{array}{c}\overrightarrow{9} \\
: \\
0 \\
- \\
-\end{array}$ & 耪 & 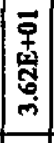 & 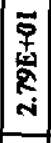 & & 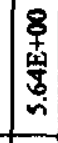 \\
\hline$\frac{\infty}{\stackrel{\Delta}{x}}$ & 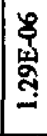 & 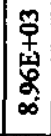 & 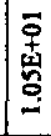 & 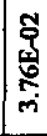 & 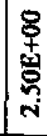 & $\begin{array}{l}8 \\
+ \\
\text { 离 } \\
\frac{1}{m}\end{array}$ & 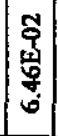 & 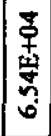 & 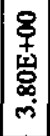 & $\begin{array}{c}8 \\
+ \\
0 \\
\vdots \\
\alpha \\
\alpha \\
\alpha\end{array}$ & & 辛 \\
\hline$\frac{\Xi}{J}$ & 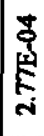 & 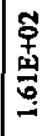 & 㝘 & 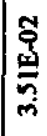 & $\begin{array}{l}\overrightarrow{5} \\
\mathbf{9} \\
\overline{2}\end{array}$ & 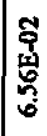 & $\begin{array}{l}\overline{\mathbf{g}} \\
\mathbf{g} \\
\underline{\mathbf{g}} \\
=\end{array}$ & 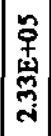 & $\begin{array}{l}\overrightarrow{9} \\
\mathbf{9} \\
\mathbf{5} \\
\text {. }\end{array}$ & 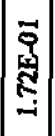 & 罣 & 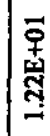 \\
\hline$\vec{\Xi}$ & 离 & 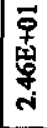 & 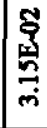 & : & 总 & 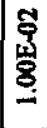 & 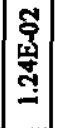 & 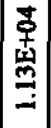 & 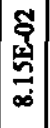 & 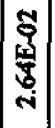 & 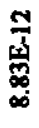 & 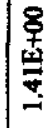 \\
\hline$\frac{5}{8}$ & 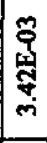 & 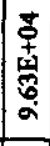 & 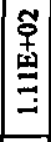 & 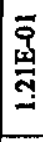 & 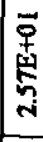 & 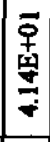 & $\begin{array}{l}8 \\
\mathbf{1} \\
\text { 娄 } \\
8 \\
0\end{array}$ & 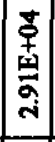 & 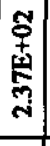 & $\begin{array}{c}0 \\
0 \\
0 \\
0 \\
5 \\
\alpha\end{array}$ & 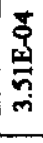 & $\begin{array}{l}8 \\
+ \\
4 \\
\\
\end{array}$ \\
\hline$\frac{8}{3}$ & 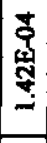 & 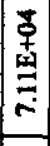 & 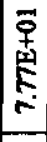 & 触 & 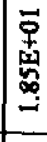 & 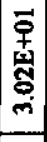 & $\begin{array}{c}0 \\
0 \\
\vdots \\
\vdots \\
0 \\
0 \\
\end{array}$ & 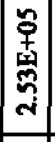 & 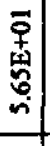 & 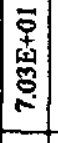 & 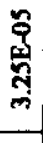 & $\begin{array}{l}\overline{5} \\
0 \\
0 \\
0 \\
0 \\
0\end{array}$ \\
\hline$\stackrel{m}{g}$ & 离 & 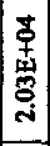 & 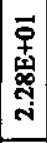 & 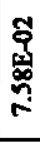 & $\begin{array}{l}8 \\
\text { 怘 } \\
\text { 恶 }\end{array}$ & $\begin{array}{c}8 \\
\mathbf{1} \\
\mathbf{1} \\
\mathbf{5} \\
\infty \\
\infty\end{array}$ & 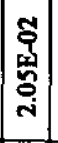 & 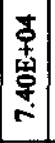 & $\begin{array}{l}\overline{0} \\
+4 \\
0 \\
0\end{array}$ & $\mid \begin{array}{c}0 \\
0 \\
0 \\
0 \\
0 \\
i\end{array}$ & 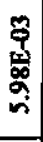 & 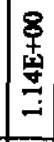 \\
\hline$\frac{s}{\frac{1}{8}}$ & 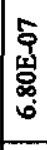 & 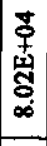 & 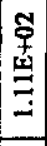 & 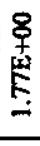 & 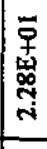 & $\begin{array}{c}\bar{p} \\
\hat{w} \\
\tilde{w} \\
m\end{array}$ & 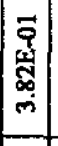 & 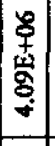 & 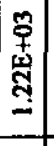 & 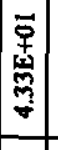 & & $\begin{array}{l}8 \\
\mathbf{8} \\
\mathbf{1} \\
\mathbf{2} \\
\mathrm{m}\end{array}$ \\
\hline$\frac{\bar{\sigma}}{\frac{N}{\alpha}}$ & 点 & 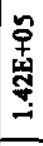 & 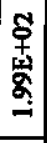 & 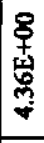 & 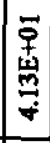 & $\begin{array}{l}\vec{\sigma} \\
+ \\
\underline{\omega} \\
\hat{w} \\
b\end{array}$ & 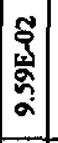 & 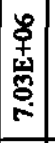 & 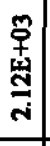 & 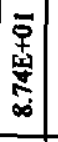 & 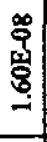 & 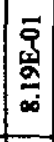 \\
\hline 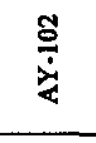 & 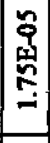 & 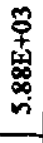 & 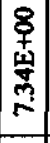 & 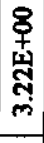 & 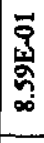 & 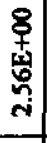 & 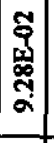 & 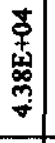 & 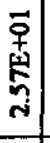 & $\begin{array}{c}8 \\
⿱ \\
9 \\
\vdots \\
\vdots \\
\vdots\end{array}$ & $\begin{array}{l}\vdots \\
\vdots \\
\vdots \\
\vdots \\
\vdots \\
\vdots\end{array}$ & 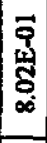 \\
\hline 禜 & 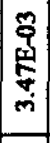 & 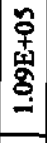 & 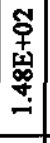 & 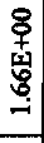 & 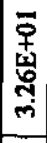 & 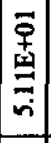 & 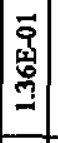 & $\begin{array}{c}n \\
+ \\
0 \\
0 \\
\vdots \\
\vdots\end{array}$ & 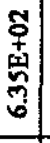 & 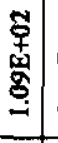 & 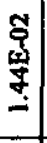 & 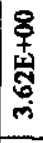 \\
\hline$\frac{\text { 离 }}{\dot{x}}$ & & 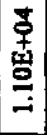 & 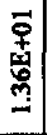 & 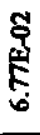 & 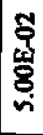 & 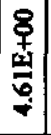 & 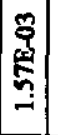 & 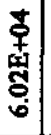 & 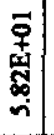 & $\begin{array}{l}\overline{\mathbf{p}} \\
\text { s. } \\
\text { s. }\end{array}$ & 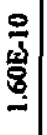 & $\begin{array}{l}5 \\
\vdots \\
8 \\
8 \\
\text { n. }\end{array}$ \\
\hline$\frac{\check{O}}{\dot{q}}$ & & 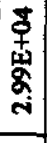 & 站 & 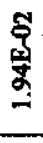 & 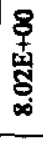 & 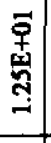 & 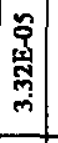 & 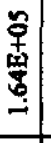 & 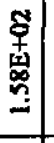 & & & \\
\hline$\frac{\pi}{4}$ & & 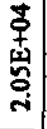 & $\begin{array}{l}\bar{\rho} \\
+\end{array}$ & $\begin{array}{l}\text { S్ } \\
\text { W. } \\
\text { s. }\end{array}$ & 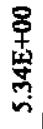 & 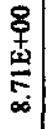 & $\begin{array}{l}\square \\
\vdots \\
0 \\
0 \\
0 \\
\sigma\end{array}$ & & 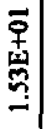 & 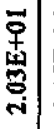 & 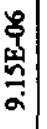 & \\
\hline 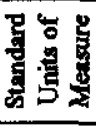 & & $\tilde{\theta}$ & 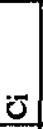 & 5 & $u$ & 5 & 0 & 0 & 0 & 0 & 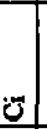 & \\
\hline & 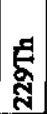 & & & & & & (2) & & 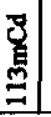 & & & \\
\hline
\end{tabular}




\begin{tabular}{|c|c|c|c|c|c|c|c|c|c|c|c|c|c|c|c|c|c|c|c|c|c|c|c|c|c|c|c|c|c|}
\hline$\frac{\hat{\sigma}}{\dot{m}}$ & 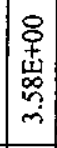 & 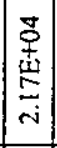 & 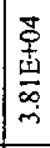 & 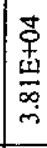 & $\begin{array}{l}\frac{8}{9} \\
\frac{1}{1} \\
\frac{1}{\infty} \\
\infty\end{array}$ & 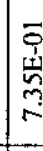 & 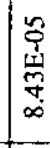 & 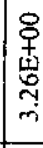 & 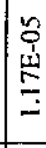 & 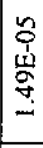 & 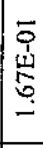 & 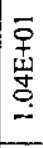 & 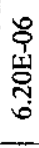 & 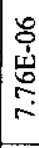 & 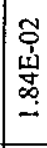 & $\frac{4}{g}$ & 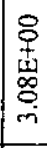 & & 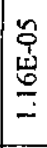 & 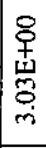 & & 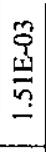 & 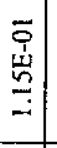 & 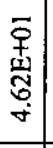 & $\begin{array}{l}\overline{0} \\
\dot{\omega} \\
\hat{\omega} \\
\vdots \\
-\end{array}$ & 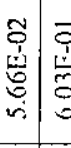 & 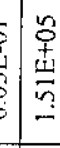 & 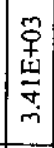 & 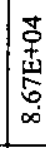 \\
\hline$\stackrel{\circ}{\dot{1}}$ & 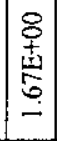 & 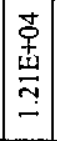 & $\begin{array}{l}\text { 草 } \\
\text { 索 } \\
\text { 出 }\end{array}$ & 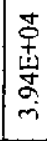 & 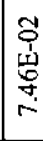 & 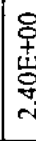 & $\begin{array}{l}8 \\
\stackrel{1}{1} \\
\stackrel{1}{2} \\
i \\
m\end{array}$ & 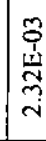 & 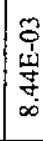 & 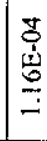 & 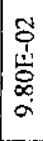 & 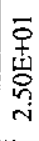 & $\frac{n}{9}$ & $\stackrel{1}{1}$ & 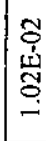 & $\begin{array}{l}8 \\
+ \\
\text { 章 } \\
\text { r }\end{array}$ & 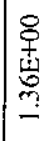 & $\stackrel{\mathrm{S}}{\mathrm{S}}$ & 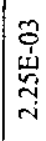 & 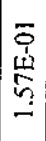 & 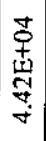 & 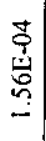 & $\mid \begin{array}{l}\bar{D} \\
\dot{d} \\
\stackrel{2}{a} \\
\stackrel{\sim}{i}\end{array}$ & 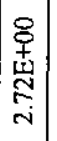 & $\begin{array}{c}\bar{o} \\
\dot{W} \\
\tilde{v} \\
\tilde{m}\end{array}$ & 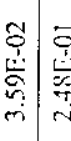 & 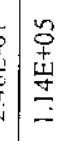 & 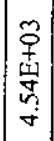 & \\
\hline$\frac{\ddots}{\dot{\phi}}$ & $\begin{array}{c}8 \\
⿱ \\
\text { 岁 } \\
\stackrel{2}{2}\end{array}$ & 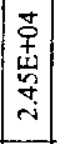 & 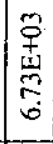 & 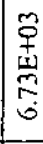 & 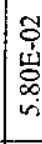 & 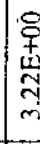 & 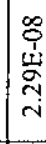 & 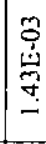 & 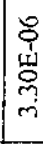 & 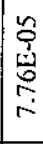 & 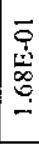 & 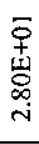 & 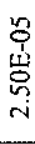 & 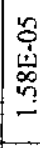 & 总 & 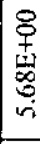 & 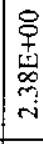 & 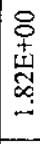 & 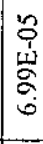 & 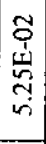 & 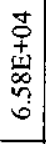 & 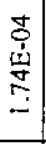 & 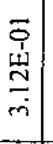 & 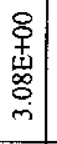 & 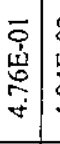 & 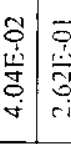 & 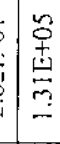 & $\left|\begin{array}{c}0 \\
⿱ \\
\omega \\
0 \\
0 \\
\dot{m}\end{array}\right|$ & 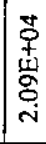 \\
\hline$\frac{\vec{d}}{\dot{\omega}}$ & 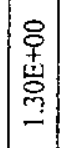 & 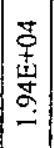 & 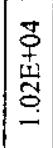 & 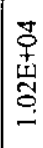 & 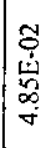 & 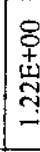 & 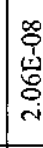 & 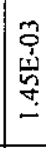 & 号 & 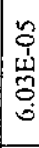 & 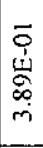 & 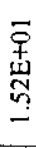 & 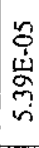 & 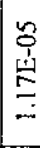 & $\begin{array}{l}3 \\
\vdots \\
\dot{1} \\
\alpha \\
\alpha \\
\infty\end{array}$ & $\begin{array}{l}\bar{c} \\
\overline{1} \\
\bar{w} \\
\bar{w} \\
\underline{y}\end{array}$ & 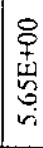 & 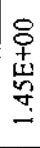 & 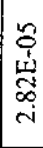 & 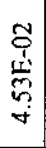 & 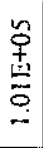 & $\begin{array}{c}\stackrel{+}{0} \\
\stackrel{\leftrightarrow}{9} \\
\stackrel{m}{-}\end{array}$ & 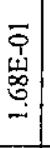 & 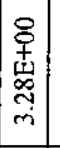 & $\begin{array}{l}0 \\
0 \\
\dot{d} \\
\dot{d} \\
\dot{m}\end{array}$ & 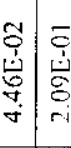 & 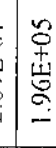 & 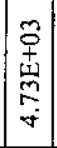 & 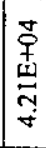 \\
\hline ڤ̊ & 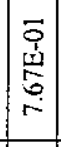 & 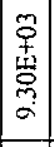 & 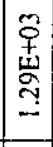 & 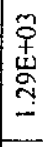 & 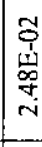 & 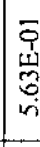 & 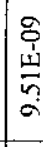 & 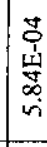 & 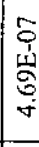 & 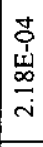 & 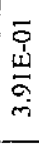 & 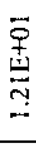 & 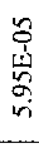 & 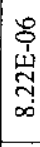 & 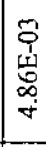 & 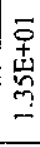 & 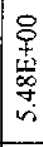 & 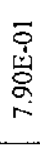 & 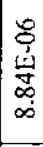 & 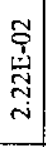 & 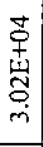 & 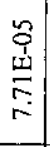 & 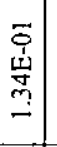 & 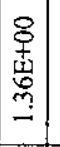 & 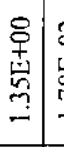 & 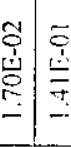 & 龺 & 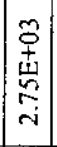 & 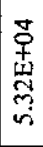 \\
\hline $\begin{array}{l}\tilde{\sigma} \\
\dot{\omega}\end{array}$ & 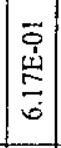 & 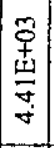 & 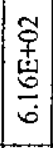 & 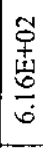 & 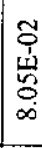 & 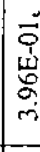 & 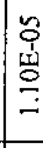 & 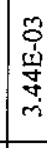 & 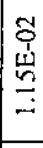 & 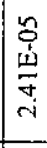 & 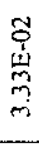 & 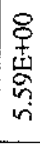 & 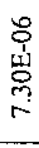 & 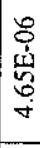 & 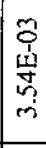 & 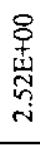 & 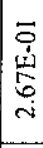 & 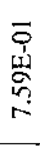 & 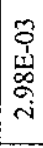 & 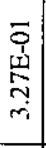 & 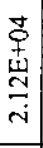 & 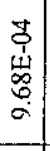 & 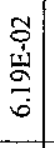 & $\begin{array}{l}\text { 吕 } \\
\text { 我 } \\
= \\
=\end{array}$ & 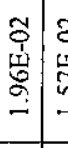 & 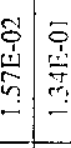 & 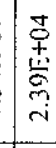 & 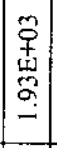 & \\
\hline$\stackrel{\bar{\emptyset}}{\dot{\omega}}$ & 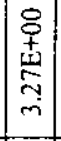 & 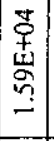 & 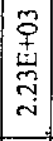 & $\begin{array}{l}\text { 耪 } \\
\text { तु } \\
\text { }\end{array}$ & 立 & 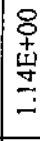 & 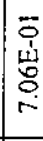 & 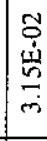 & 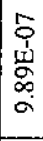 & 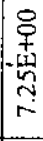 & 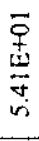 & 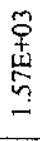 & 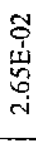 & $\begin{array}{l}\text { 草 } \\
\text { 离 } \\
\text { 总 }\end{array}$ & 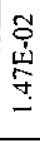 & 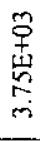 & 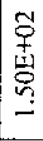 & $\begin{array}{l}8 \\
\text { 古 } \\
\frac{\omega}{n} \\
\text { m. }\end{array}$ & 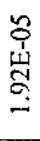 & 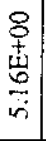 & 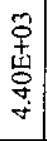 & 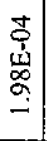 & & 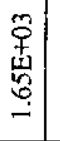 & 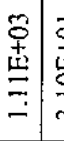 & 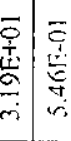 & 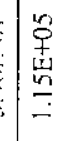 & 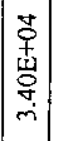 & \\
\hline$\frac{\mathscr{\delta}}{\frac{1}{4}}$ & 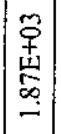 & 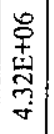 & 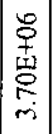 & 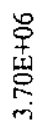 & 8 & 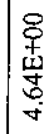 & 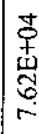 & 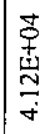 & 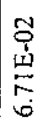 & 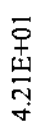 & 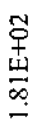 & 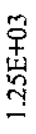 & 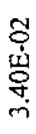 & 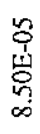 & 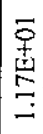 & 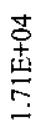 & 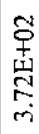 & $\begin{array}{l}\tilde{+} \\
\text { 索 } \\
\text { n. }\end{array}$ & 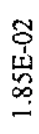 & 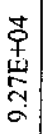 & 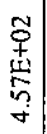 & 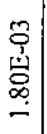 & 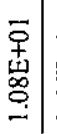 & 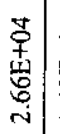 & 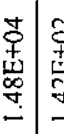 & 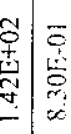 & 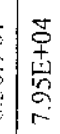 & $\left|\begin{array}{c}0 \\
0 \\
w \\
0 \\
0 \\
0 \\
\end{array}\right|$ & \\
\hline $\begin{array}{l}\frac{\bar{O}}{\bar{N}} \\
\frac{1}{2}\end{array}$ & 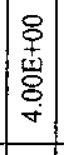 & 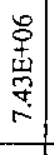 & 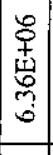 & 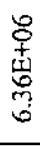 & & 怘 & 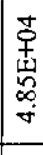 & 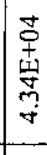 & 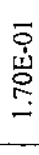 & 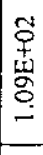 & 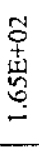 & 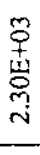 & 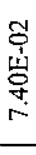 & 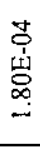 & 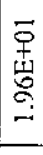 & 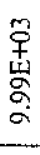 & 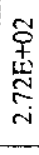 & 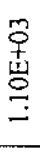 & 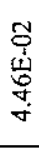 & 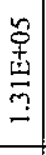 & 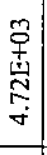 & 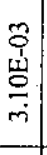 & 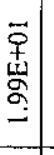 & 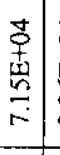 & 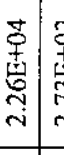 & 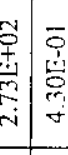 & 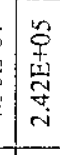 & 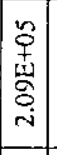 & \\
\hline 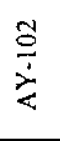 & 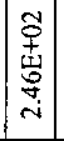 & 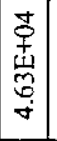 & 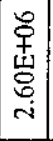 & $\begin{array}{l}\text { 字 } \\
\text { 炭 }\end{array}$ & & \begin{tabular}{l}
8 \\
+ \\
\multirow{1}{n}{} \\
$=$ \\
$=$
\end{tabular} & 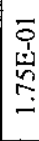 & 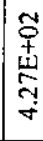 & 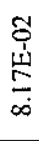 & 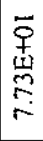 & 舒 & & 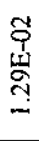 & 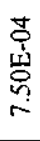 & 亮 & 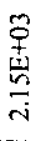 & 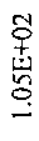 & 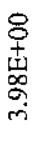 & $\stackrel{\vec{i}}{\stackrel{4}{i}}$ & 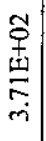 & 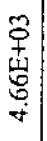 & 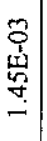 & 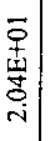 & 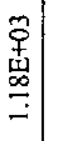 & 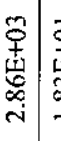 & 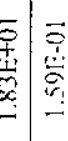 & 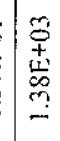 & $\left|\begin{array}{c}0 \\
+ \\
+ \\
w \\
\infty \\
i \\
i\end{array}\right|$ & \\
\hline$\frac{\overline{9}}{\frac{1}{\alpha}}$ & 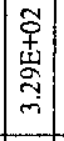 & 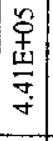 & 号 & 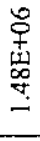 & & $\begin{array}{l}\stackrel{8}{+} \\
\text { 焉 } \\
\text { r }\end{array}$ & 章 & $\begin{array}{l}0 \\
0 \\
0 \\
0 \\
0 \\
-\end{array}$ & 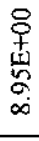 & 审 & $\begin{array}{l}\text { S } \\
+ \\
\text { ثैة }\end{array}$ & & $\begin{array}{l}\text { 号 } \\
\text { 恶 }\end{array}$ & 矛 & 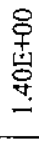 & 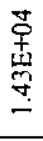 & $\underset{\wp}{\varnothing}$ & 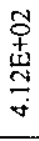 & 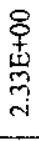 & 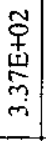 & 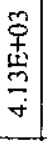 & 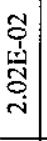 & 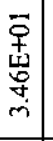 & 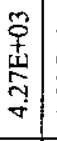 & 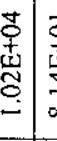 & 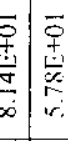 & 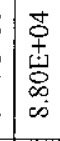 & 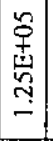 & \\
\hline $\begin{array}{l}\frac{d}{0} \\
\frac{\dot{x}}{x}\end{array}$ & 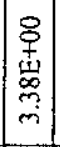 & 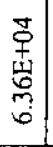 & 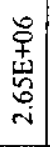 & & & 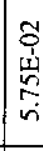 & 昱 & 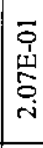 & 离 & 2 & 辛 & & & 宔 & i & $\begin{array}{l}\text { 号 } \\
\text { 获 }\end{array}$ & 品 & 审 & 0 & 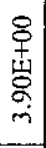 & 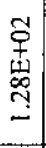 & 命 & 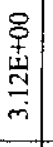 & 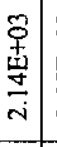 & & 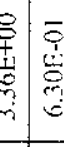 & & 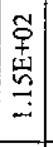 & \\
\hline$\frac{\hat{\varrho}}{\frac{\dot{x}}{x}}$ & $\mid \begin{array}{l}\bar{c} \\
\mathbf{9} \\
\mathbf{1} \\
z \\
r \\
r\end{array}$ & 㝨 & $\begin{array}{l}\text { 呆 } \\
\text { 壳 }\end{array}$ & 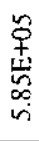 & 7 & 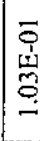 & 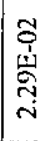 & 早 & $\overline{1}$ & & $\begin{array}{l}8 \\
\text { 怘 }\end{array}$ & 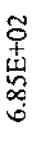 & & 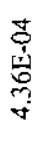 & & 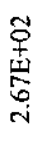 & 怘 & 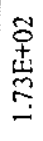 & 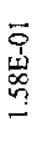 & 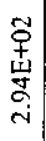 & 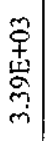 & $\begin{array}{l}0 \\
0 \\
\vdots \\
\hat{u} \\
0 \\
0 \\
0\end{array}$ & 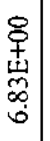 & 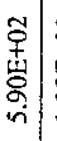 & 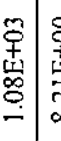 & 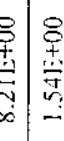 & 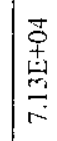 & 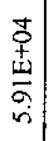 & \\
\hline$\frac{\widetilde{O}}{\dot{x}}$ & 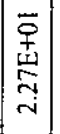 & 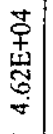 & $m$ & & & & & & & $\begin{array}{l}\infty \\
\infty\end{array}$ & & & & & & & $n$ & $N$ & $1-$ & & 㕝 & & $\begin{array}{l}8 \\
\$ \\
\text { 索 }\end{array}$ & 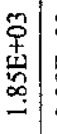 & & 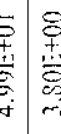 & 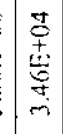 & 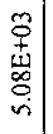 & \\
\hline
\end{tabular}

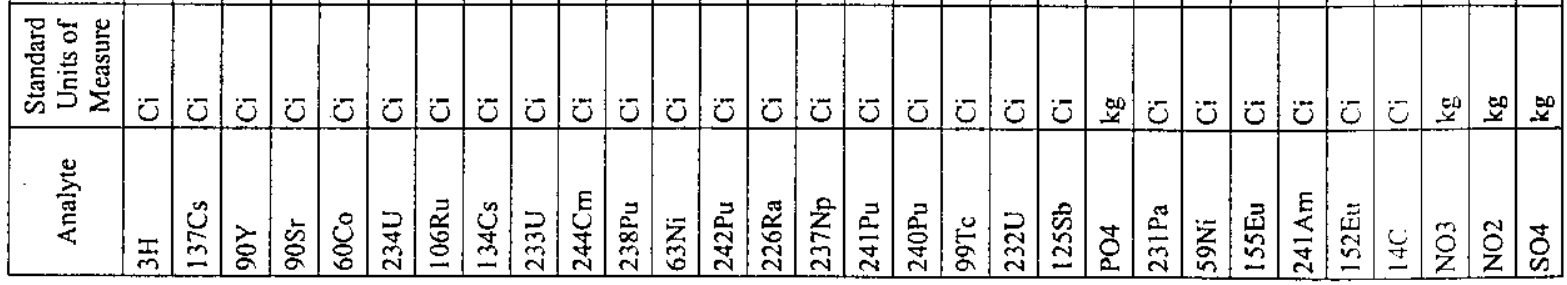




\begin{tabular}{|c|c|c|c|c|c|c|c|c|c|c|c|c|c|c|c|c|c|c|c|c|c|c|c|c|c|c|c|c|c|c|c|}
\hline$\frac{s}{a b}$ & & 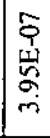 & 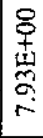 & 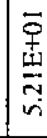 & 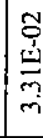 & $\begin{array}{l}8 \\
0 \\
0 \\
0 \\
0\end{array}$ & 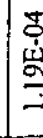 & 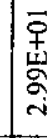 & 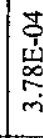 & 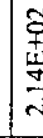 & & & & 高 & 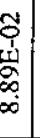 & 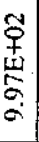 & 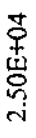 & & $\begin{array}{l}0 \\
0 \\
\dot{\omega} \\
0 \\
0 \\
\dot{+}\end{array}$ & 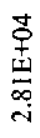 & 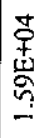 & 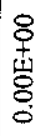 & 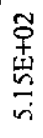 & 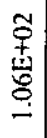 & 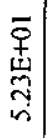 & $\begin{array}{l}\overrightarrow{0} \\
+ \\
\dot{山} \\
\dot{8} \\
\dot{\forall}\end{array}$ & 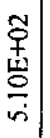 & 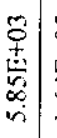 & & & 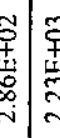 \\
\hline 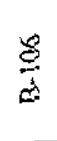 & & 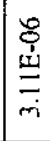 & 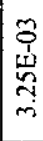 & 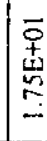 & 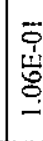 & 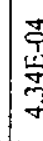 & 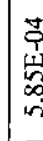 & 蛮 & 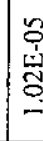 & 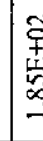 & 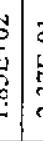 & & & 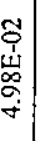 & 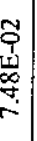 & 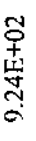 & 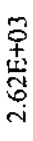 & 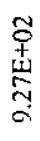 & 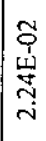 & 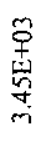 & $\begin{array}{l}\text { 辛 } \\
\text { w. } \\
\infty \\
\infty \\
\infty \\
\infty\end{array}$ & 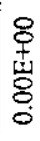 & 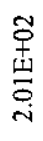 & 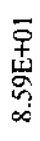 & 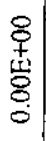 & 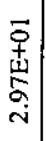 & 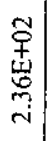 & & 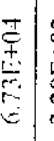 & & 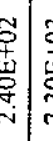 \\
\hline$\stackrel{w}{:}$ & & 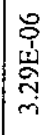 & \begin{tabular}{|l}
$\tilde{O}$ \\
$\dot{\omega}$ \\
$\tilde{v}$ \\
$\vec{m}$
\end{tabular} & 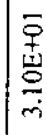 & 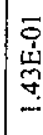 & 量 & 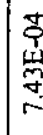 & 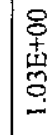 & \begin{tabular}{|c}
$\infty$ \\
0 \\
0 \\
$\frac{1}{5}$ \\
0 \\
0
\end{tabular} & 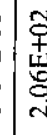 & 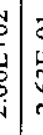 & & & 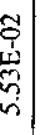 & & مू & & 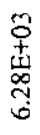 & 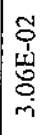 & & 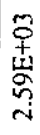 & & $\begin{array}{l}8 \\
\text { + } \\
\text { 尊 } \\
0\end{array}$ & & 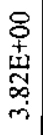 & 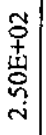 & 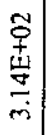 & & 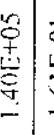 & & 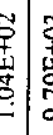 \\
\hline 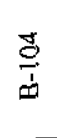 & & 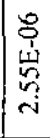 & 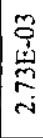 & 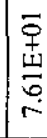 & 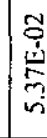 & $\mid \begin{array}{l}9 \\
0 \\
0\end{array}$ & 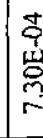 & $\begin{array}{l}\overline{5} \\
\text { o } \\
\text { 列 } \\
\infty \\
\infty\end{array}$ & 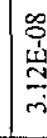 & 唗 & $\begin{array}{l}3 \\
\vdots \\
\vdots\end{array}$ & 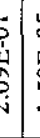 & 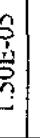 & 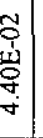 & है) & 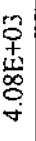 & 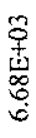 & $\begin{array}{l}\text { 古 } \\
\stackrel{4}{N} \\
\text { = }\end{array}$ & 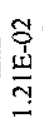 & & 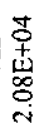 & & 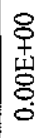 & & 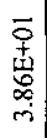 & 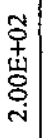 & 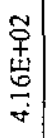 & 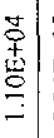 & 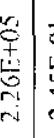 & & 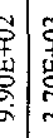 \\
\hline$\tilde{d}$ & & $\begin{array}{l}8 \\
0 \\
\text { 蒠 }\end{array}$ & 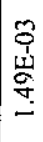 & 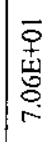 & 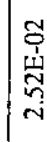 & $\overline{\bar{t}}$ & 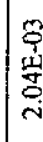 & 总 & 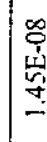 & 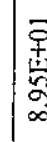 & & 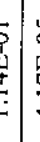 & & 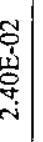 & 6 & & & 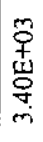 & 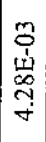 & & 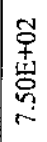 & & 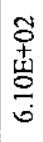 & & $\begin{array}{c}\text { 古 } \\
\text { 容 } \\
0\end{array}$ & 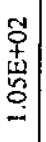 & 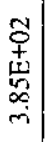 & 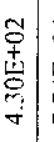 & & & 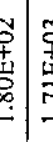 \\
\hline$\frac{\widetilde{d}}{\stackrel{c}{c}}$ & & 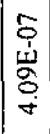 & 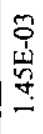 & 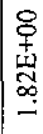 & 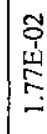 & 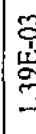 & 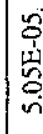 & 号 & 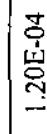 & 㝘 & & & & 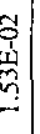 & & كै. & & 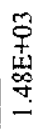 & 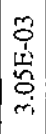 & & 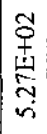 & & 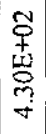 & & $\begin{array}{l}\text { 嵩 } \\
\text { 㟋 } \\
\stackrel{2}{2}\end{array}$ & 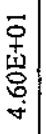 & 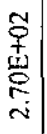 & 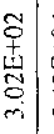 & 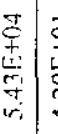 & & 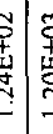 \\
\hline $\bar{c}$ & & $\begin{array}{l}\overline{0} \\
\mathbf{1} \\
\underline{0}\end{array}$ & 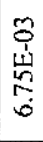 & 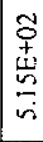 & 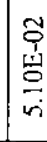 & $\begin{array}{l}\frac{\infty}{3} \\
\frac{1}{y}\end{array}$ & 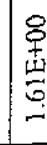 & 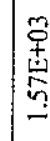 & 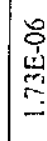 & 䓌 & & & 5 & 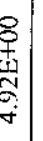 & 8 & 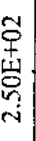 & & 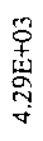 & 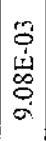 & & 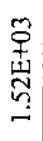 & & 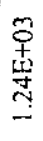 & & $\begin{array}{l}0 \\
+ \\
+1 \\
0 \\
0\end{array}$ & 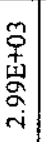 & 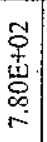 & 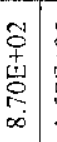 & $\frac{1}{2}$ & & 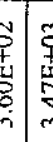 \\
\hline$\frac{\tilde{\delta}}{\tilde{N}}$ & & 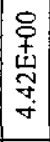 & 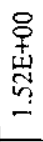 & 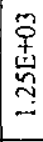 & 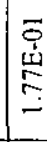 & 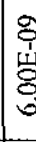 & 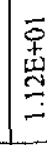 & 苦 & 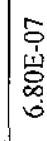 & 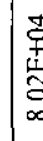 & & & 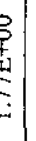 & 童 & 6 & 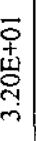 & $\begin{array}{l}\text { 覀 } \\
\text { ले }\end{array}$ & 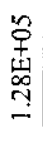 & 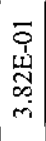 & & 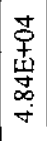 & & $\begin{array}{l}\widetilde{1} \\
\mathbf{4} \\
\dot{0} \\
\dot{+}\end{array}$ & & 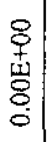 & 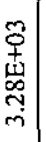 & $\begin{array}{l}\text { 古 } \\
\text { 兒 } \\
\end{array}$ & 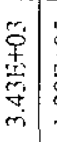 & 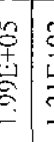 & & 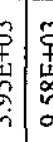 \\
\hline 은 & & $\begin{array}{c}8 \\
0 \\
w \\
0 \\
\alpha \\
\alpha\end{array}$ & 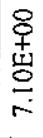 & $\mid \begin{array}{c}\tilde{o} \\
+ \\
w \\
\infty \\
0 \\
\alpha \\
\alpha\end{array}$ & \begin{tabular}{|c}
$\tilde{1}$ \\
$\underline{\omega}$
\end{tabular} & $\stackrel{1}{0}_{0}^{\infty}$ & 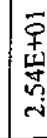 & 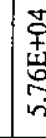 & 离 & 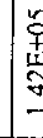 & & & 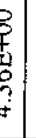 & 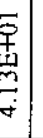 & $\bar{\varphi}$ & I & & $\begin{array}{l}\text { 呆 } \\
\stackrel{4}{5} \\
\text { - } \\
-\end{array}$ & 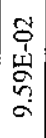 & & 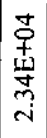 & & $\begin{array}{l}\text { 号 } \\
\text { 崫 } \\
\text { 子 }\end{array}$ & & $\begin{array}{l}\text { 呆 } \\
\text { 岁 } \\
0\end{array}$ & & 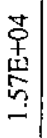 & 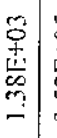 & 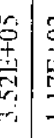 & & 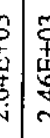 \\
\hline$\frac{0}{\frac{1}{2}}$ & & $\frac{7}{9}$ & 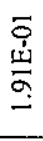 & 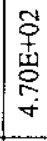 & 8 & $\begin{array}{l}\frac{1}{0} \\
\frac{1}{2} \\
0 \\
0\end{array}$ & 量 & 亳 & 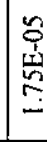 & $\mid \begin{array}{c}\tilde{q} \\
\tilde{w} \\
\tilde{\infty} \\
\tilde{w}\end{array}$ & & & & $\begin{array}{l}\vdots \\
\vdots \\
\vdots \\
\vdots \\
\vdots \\
\vdots\end{array}$ & & 5 & & 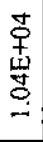 & 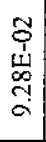 & & 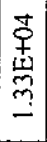 & & 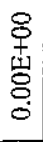 & 声 & 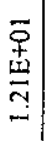 & 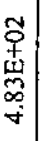 & 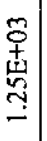 & 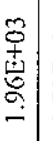 & $\frac{+}{2}$ & & 5 \\
\hline$\frac{\overline{0}}{\frac{1}{2}}$ & 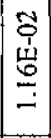 & 晕 & 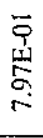 & 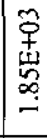 & 宫 & 量 & 虽 & 弚 & 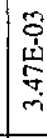 & 战 & & & . & 密 & & & & 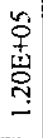 & $\begin{array}{l}\overrightarrow{0} \\
\stackrel{0}{0} \\
\stackrel{0}{2} \\
\end{array}$ & & 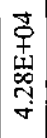 & & $\begin{array}{l}\text { 采 } \\
\text { 帘 } \\
\text { i }\end{array}$ & 4 & $\begin{array}{l}8 \\
0 \\
+1 \\
8 \\
0 \\
0\end{array}$ & 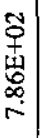 & $\begin{array}{c}\stackrel{0}{0} \\
\stackrel{9}{9} \\
\stackrel{9}{9}\end{array}$ & 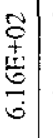 & 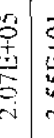 & & : \\
\hline$\frac{d}{\dot{x}}$ & & $\begin{array}{l}2 \\
0 \\
0 \\
0 \\
0\end{array}$ & 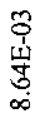 & 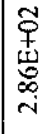 & 荘 & 要 & $\frac{\pi}{N}$ & 彦 & 5 & 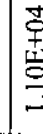 & & & & & & & & 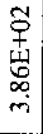 & $\begin{array}{l}\hat{0} \\
\hat{1} \\
\tilde{\nu}\end{array}$ & & 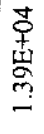 & & 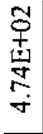 & & 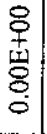 & 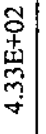 & & 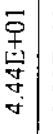 & 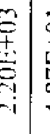 & & 5 \\
\hline$\frac{\tilde{Q}}{\dot{x}}$ & & 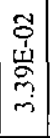 & 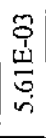 & $\mid \begin{array}{c}\bar{y} \\
4 \\
\frac{1}{L} \\
\bar{L}\end{array}$ & & $\begin{array}{l}\overline{9} \\
\underline{\underline{J}} \\
\end{array}$ & $1-$ & 筫 & $\stackrel{i}{i}$ & 2 & & & & & & & & 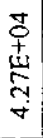 & 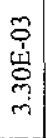 & & 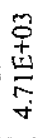 & & 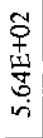 & & 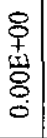 & 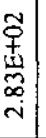 & 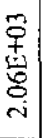 & 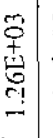 & 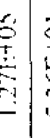 & & $\frac{a}{a}$ \\
\hline$\frac{\widetilde{d}}{\frac{d}{x}}$ & 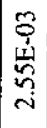 & 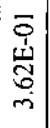 & 인 & & & & 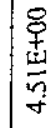 & 享 & & T & & & & & & & & & 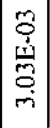 & & 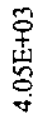 & & $\begin{array}{l}\overline{0} \\
+ \\
4 \\
0 \\
+ \\
\dot{m}\end{array}$ & & $\begin{array}{l}8 \\
\vdots \\
\vdots \\
\vdots \\
\vdots\end{array}$ & 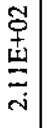 & 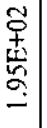 & 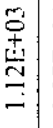 & 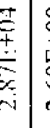 & & 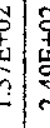 \\
\hline
\end{tabular}

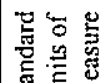

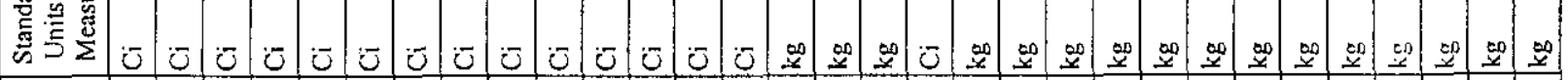

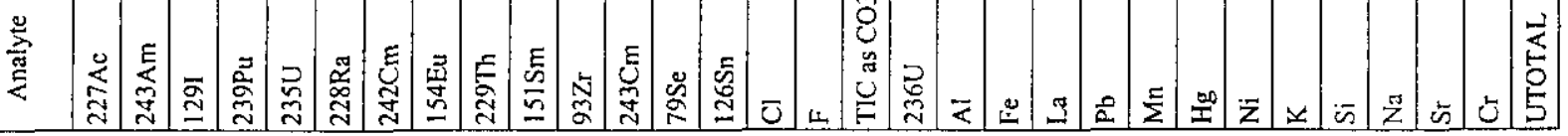


RPP-5637

\begin{tabular}{|c|c|c|c|c|c|c|c|c|c|c|}
\hline$\frac{5}{\dot{\omega}}$ & 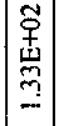 & 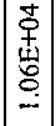 & 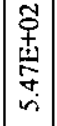 & 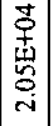 & 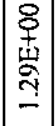 & 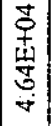 & $\mid \begin{array}{c}\bar{O} \\
\dot{\omega} \\
\vec{i} \\
\sim\end{array}$ & 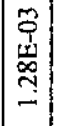 & 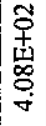 & 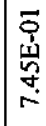 \\
\hline$\frac{8}{\dot{\omega}}$ & $\begin{array}{c}\bar{p} \\
\underline{+} \\
\dot{0} \\
\dot{+} \\
\dot{+}\end{array}$ & 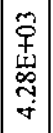 & 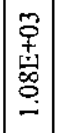 & 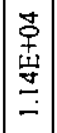 & 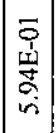 & 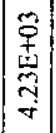 & $\begin{array}{c}\overline{0} \\
\dot{d} \\
\alpha \\
\underline{2}\end{array}$ & $\left|\begin{array}{c}2 \\
0 \\
1 \\
0 \\
\infty \\
i \\
-1\end{array}\right|$ & 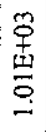 & $\begin{array}{l}\stackrel{8}{+} \\
\text { 索 } \\
\text { N }\end{array}$ \\
\hline$\frac{\stackrel{c}{o}}{\dot{\omega}}$ & 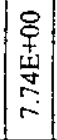 & 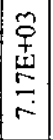 & 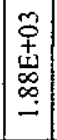 & $\left|\begin{array}{c}0 \\
⿱ \\
w \\
w \\
\sim \\
\sim\end{array}\right|$ & $\mid \begin{array}{c}0 \\
0 \\
0 \\
0 \\
0\end{array}$ & 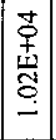 & $\left|\begin{array}{l}\overline{0} \\
\stackrel{u}{\sim} \\
\underset{\sim}{\sim}\end{array}\right|$ & $\begin{array}{c}\overline{1} \\
\frac{\omega}{5} \\
\stackrel{5}{2}\end{array}$ & 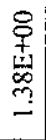 & 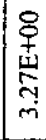 \\
\hline$\frac{\overrightarrow{0}}{\dot{\omega}}$ & 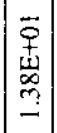 & $\left|\begin{array}{c}0 \\
0 \\
\omega \\
\\
\end{array}\right|$ & $\mid \begin{array}{c}\tilde{Y} \\
0 \\
0 \\
0 \\
0 \\
0\end{array}$ & 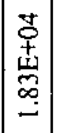 & $\mid \begin{array}{c}\overline{0} \\
\text { 岁 } \\
\dot{v}\end{array}$ & 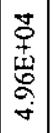 & 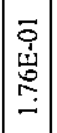 & $\begin{array}{l}\overline{\overline{1}} \\
\hat{2} \\
\dot{2} \\
\dot{v}\end{array}$ & 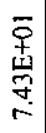 & 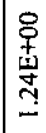 \\
\hline$\frac{\tilde{\theta}}{\dot{\infty}}$ & $\begin{array}{l}\overline{0} \\
+ \\
\stackrel{4}{8} \\
0 \\
0\end{array}$ & $\mid \begin{array}{c}0 \\
0 \\
\omega \\
\vdots \\
-1\end{array}$ & $\mid \begin{array}{c}0 \\
0 \\
\mathbf{w} \\
8 \\
0 \\
0\end{array}$ & 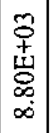 & 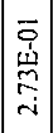 & 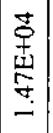 & 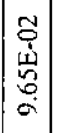 & 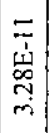 & 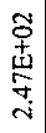 & 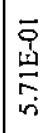 \\
\hline$\frac{\tilde{D}}{\mathscr{n}}$ & $\begin{array}{l}\overrightarrow{0} \\
\vec{u} \\
\vec{\sim} \\
\stackrel{\sim}{*}\end{array}$ & 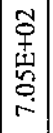 & 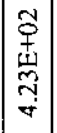 & 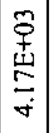 & 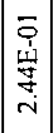 & 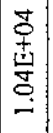 & 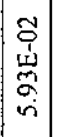 & $\begin{array}{l}0 \\
0 \\
\dot{y} \\
\alpha \\
\sigma\end{array}$ & 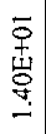 & 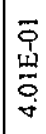 \\
\hline$\frac{\bar{c}}{\dot{\omega}}$ & 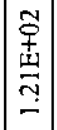 & 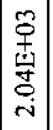 & 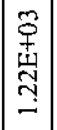 & 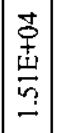 & 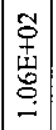 & 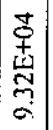 & 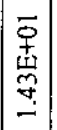 & \begin{tabular}{l}
0 \\
\multirow{2}{*}{} \\
2 \\
2
\end{tabular} & 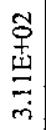 & \begin{tabular}{l}
8 \\
0 \\
0 \\
0 \\
0 \\
\hdashline \\
$=$
\end{tabular} \\
\hline$\frac{\widetilde{\delta}}{\stackrel{1}{~}}$ & 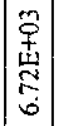 & 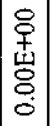 & 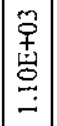 & 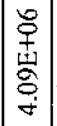 & 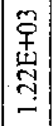 & 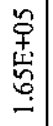 & $\mid \begin{array}{c}\vec{q} \\
⿱ 山 山 \\
m \\
\stackrel{v}{v}\end{array}$ & $\begin{array}{l}0 \\
0 \\
\vec{d} \\
2 \\
2\end{array}$ & 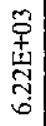 & 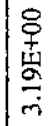 \\
\hline$\frac{\overline{0}}{1}$ & 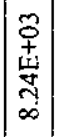 & $\begin{array}{c}8 \\
\vdots \\
+ \\
0 \\
0 \\
0\end{array}$ & 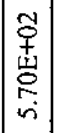 & 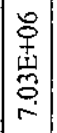 & 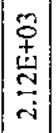 & $\begin{array}{c}0 \\
0 \\
0 \\
\text { 怘 } \\
\stackrel{i}{i}\end{array}$ & 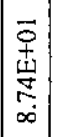 & 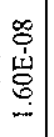 & 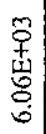 & 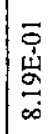 \\
\hline$\frac{\widetilde{\sigma}}{\frac{1}{2}}$ & $\begin{array}{c}\bar{p} \\
+ \\
\frac{y}{\sigma}\end{array}$ & $\begin{array}{l}8 \\
+ \\
\mathbf{5} \\
0 \\
0\end{array}$ & 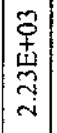 & 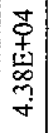 & $\left|\begin{array}{c}\overline{0} \\
+ \\
w \\
w \\
i \\
i\end{array}\right|$ & 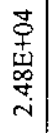 & 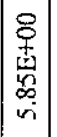 & $\begin{array}{l}0 \\
0 \\
\mathrm{u} \\
5 \\
0\end{array}$ & 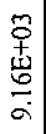 & $\begin{array}{l}\overline{0} \\
\text { 嵌 } \\
0 \\
\infty\end{array}$ \\
\hline$\frac{x}{k}$ & 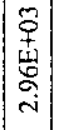 & \begin{tabular}{|c}
0 \\
9 \\
4 \\
0 \\
0 \\
0
\end{tabular} \mid & 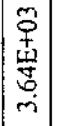 & 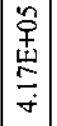 & 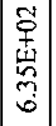 & $\left|\begin{array}{c}0 \\
⿱ \\
4 \\
\omega \\
6 \\
\sigma\end{array}\right|$ & 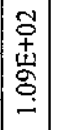 & 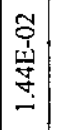 & 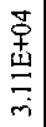 & 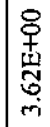 \\
\hline 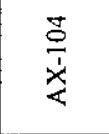 & 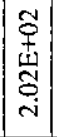 & \begin{tabular}{|}
8 \\
0 \\
4 \\
8 \\
8 \\
0
\end{tabular} & 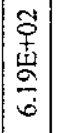 & 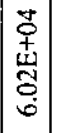 & 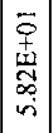 & 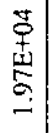 & 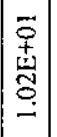 & 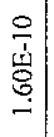 & 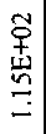 & 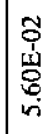 \\
\hline$\frac{\Re}{\frac{x}{x}}$ & 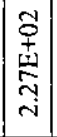 & 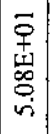 & 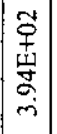 & 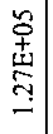 & $\mid \begin{array}{c}\tilde{O} \\
+4 \\
\stackrel{4}{\sigma} \\
-\end{array}$ & 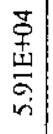 & $\mid$\begin{tabular}{c}
$\bar{p}$ \\
+ \\
\multirow{v}{*}{} \\
$\sim$
\end{tabular} & 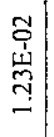 & 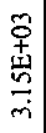 & 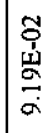 \\
\hline$\frac{\ddot{o}}{\ddot{x}}$ & 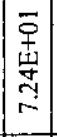 & $\begin{array}{c}\bar{D} \\
⿱ 亠 凶 \\
m \\
\bar{N}\end{array} \mid$ & 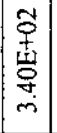 & 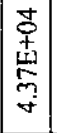 & 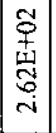 & 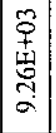 & 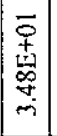 & 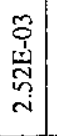 & 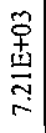 & 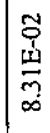 \\
\hline 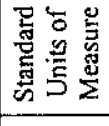 & 些 & $\because$ & $\stackrel{0}{\circ}$ & $\bar{U}$ & 0 & $\ddot{2}$ & 0 & 0 & $\stackrel{50}{ \pm}$ & 0 \\
\hline 劳 & & & & & 导 & $\mid$ & $\mid$ & $\tilde{n}$ & & \\
\hline
\end{tabular}

Rev. 0 
RPP-5637

Rev. 0

APPENDIX E

NOTEBOOK FOR GOTH_SNF SIMULATION OF TANK AY-102 DURING AND AFTER MIXER PUMP OPERATION 
RPP-5637

Rev. 0

JMI-9910-01, Rev, 0

\section{NOTEBOOK FOR GOTH SNF SIMULATION OF TANK AY-102 DURING AND AFTER MIXER PUMP OPERATION}

February 9, 2000

PREPARED BY

Marvin J. Thurgood

JOHN MARVIN, INC.

Prepared for

Locliheed Martin Hanford Corporation

Richland, WA

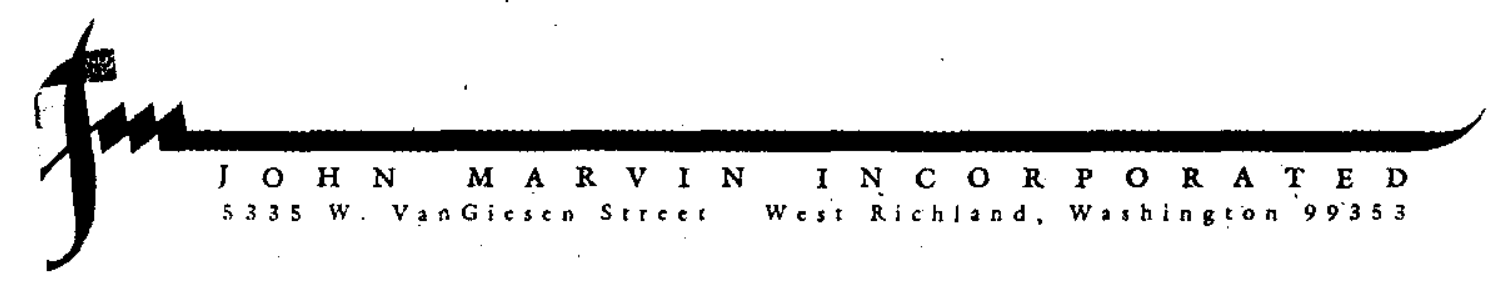


RPP-5637

Rev. 0

This page intentionally left blank.

E-2 


\section{Comments on AY-102 Notebook}

These comments are directed towards some of the specified model parameters that are not consistent with other data sources. An important point to note is that there is not a major dependency between these parameters and the end results. Nevertheless, these discrepancies need to be resolved prior to performing any subsequent work based on these models.

- Based on MIT thermocouple data, the non-convective layer thickness in Tank 241-AY-102 is about 84 inches rather than 75.5 inches as inferred from ENRAF densitometer data.

- The total heat of the waste based on the Don Ogden's bench mark calculations was 118,000 $\mathrm{Btu} / \mathrm{hr}$. The heal load used however seems to be $116,000 \mathrm{Btu} / \mathrm{hr}$ as per this note-book.

- On page 12 , the volume fraction of solids has been specified as $48.9 \%$. What is the reference?

- The specific heat of liquid is specified as $1 \mathrm{Btu} / \mathrm{lbm}-\mathrm{R}$. Since the specific gravity of liquid used is more than 1 (actual value used is $1.11 \mathrm{eq} .3 .37$ ) shows that some salts are dissolved in the liquid which will reduce the specific heat of liquid.

- The specific gravity of particles is given as 1.925 . No reference cited for most of these parameters. Since the insoluble solid components of this mixture individually have specific gravities greater than 2.2 , there is no possibility that these solids average specific gravity will be less than this. For the waste in Tank $241-C-106$, the best estimate solid density was 2.61 . But out of these components of the waste some are dissolved during sluicing and transferring process. A rough estimate from an earlier ESP study of this waste has shown that a specific gravity of these undissolved solids around 2.8 to 2.9 .

- Need reference for the volume fraction of particles in the transferred waste value of 0.281 . 
RPP-5637

Rev. 0

This page intentionally left blank.

E-4 
JOHN MARVIN, INC.

Analyst: Marvin J. Thurgood

Reviewer: Harold E. Adkins
Calculation Number: JMI-9910_01

Subject: Notebook for GOTH_SNF Simulation of Tank-AY102

\section{TABLE OF CONTENTS}

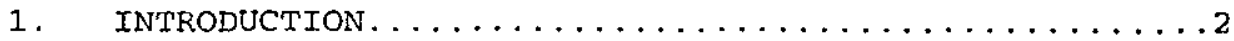

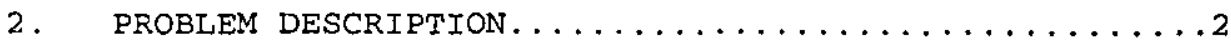

2.1. Cases and Evaluation Criteria............

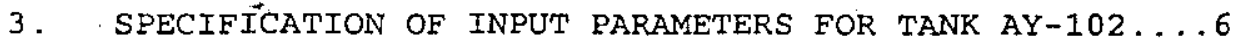

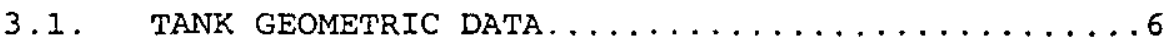

3.1.1. Tank Shell Geometric Data...........6

3.1.2. Air Distributor Geometric Data.........10

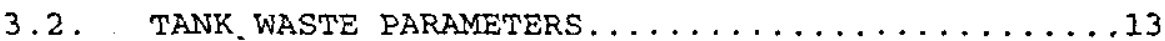

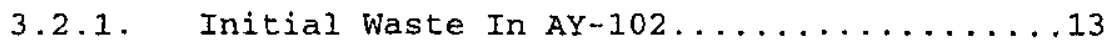

3.2.2. Waste Added to AY-102 from $\mathrm{C}-106 \ldots \ldots \ldots 14$

3.2.3. The Initial Depth of Slurry in $A Y-102 \ldots 17$

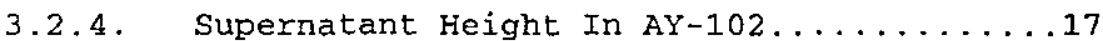

3.2.5. VENTILATION INLET TEMPERATURE AND

HUMIDITY . . . . . . . . . . . . . . 17

3.2.6. VENTILATION FLOW RATE............. 19

3.2.6.1. Primary Ventilation Flow Rate......19

3.2.6.2. Secondary Ventilation Flow Rate....20

4. GOTH_SNF MODEL DESCRIPTION.................

5. DEVELOPMENT OF INPUT PARAMETERS FOR THE GOTH_SNF

MODEL . . . . . . . . . . . . . . . . . . . . . 24

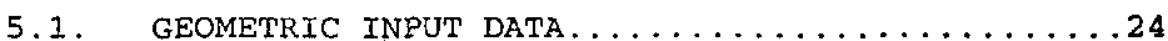

5.1.1. Useful Functions and Parameters.......24

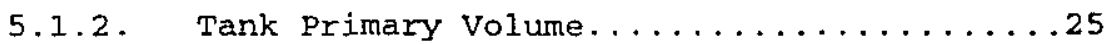

5.1.2.1. Area of Tank Primary volume......25

5.1.2.2. Volume of Tank Primary volume......26

5.1.2.3. Bottom Elevation of Tank Primary

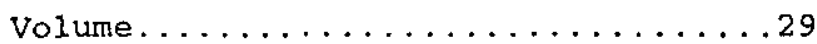

5.1.2.4. Height of the Tank Primary Volume...30

5.1.2.5. Subdivisions of Primary Tank

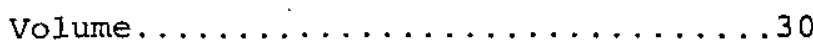

5.1.2.6. Hydraulic Diameter of Tank Primary

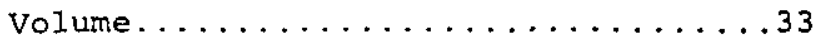

i of $\mathrm{v}$ 
JOHN MARVIN, INC.

Analyst: Marvin J. Thurgood

Reviewer: Harold E. Adkins

Subject: Notebook for GOTH_SNF Simulation of Tank-AY102
Calculation Number: JMI-9910_01

5.1.2.7. Dimensions of Conductor at the Top of

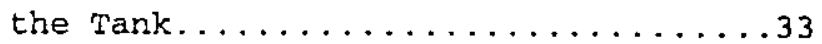

5.1.2.8. Dimensions of Conaluctor at the Bottom

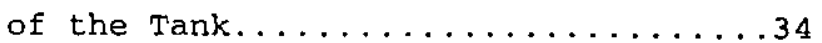

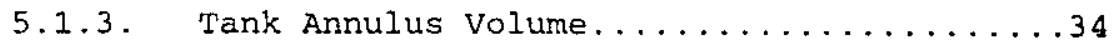

5.1.3.1. Area of Tank Annulus Volume........34

5.1.3.2. Volume of Tank Annulus Volume.......35

5.1.3.3. Bottom Elevation of Tank Annulus

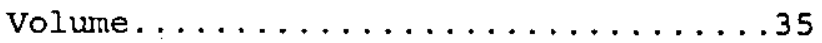

5.1.3.4. Height of the Tank Annulus Volume...36

5.1.3.5. Hydraulic Diameter of Tank Annulus

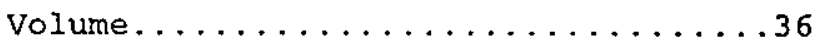

5.1.3.6. Dimensions for Conductor Between Primary Air Volume and Annulus Air...36

5.1.3.7. Dimensions for Conductor Between Supernatant and Annulus Air.......37

5.1.3.8. Dimension for Conductor Between Annulus Air And Soil Around the sides

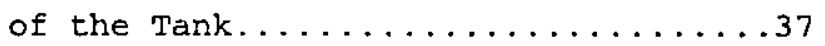

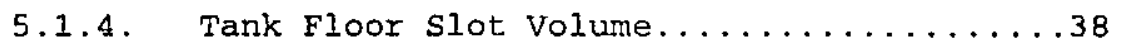

5.1.4.1. Area of Floor slot volume.........38

5.1.4.2. Volume of Floor slot volume......4.47

5.1.4.3. Elevation of Floor slot volume.....47

5.1.4.4. Height of Floor slot volume.......47

5.1.4.5. Hydraulic Diameter of the Floor

Volume...................48

5.1.4.6. Slot Conductor Dimensions........48

5.1.5. Floor slot Air Inlet volume...........48

5.1.5.1. Supply pipe Volume.............48

5.1.5.2. Supply Pipe Area............49

5.1.5.3. Supply Pipe Elevation...........50

5.1.5.4. Supply Pipe Height............50

5.1.5.5. Supply Pipe Hydraulic Diameter:....50

5.1.5.6. Supply Pipe Conductor Dimensions....50

5.1 .6 . Water Refili sump................53

5.1 .6 .1 . Volume of sump volume...........53

5.1.6.2. Cross-sectional Area of Sump

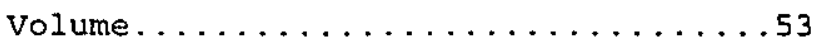

5.1.6.3. Elevation of Sump volume.........54 
JOHN MARVIN, INC.

Analyst: Marvin J. Thurgood

Reviewer: Harold E. Adkins

Subject: Notebook for GOTH

5.1 .6 .4 .

Height of Sump Volume.

5.1.6.5. Sump Hydraulic Diameter.........54

5.1.7. Summary of Geometric Input Data........54

5.1.7.1. Volume Input Data............54

5.1.7.2, Conductor Input Data...........55

5.1.7.3. Conductor Type Input Data........56

5.1.7.4. Flow Path Input Data..........57

5.1.7.5. Boundary Condition Input Data.....58

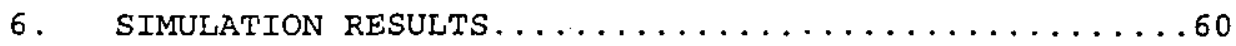

6.1. NOMINAL PRIMARY AND FLOOR SLOT VENTILATION

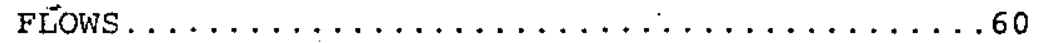

6.2. LOSS OF VENTILATION FLOW WHEN PUMPS ARE TURNED

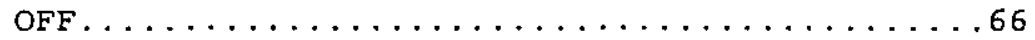

6.3. NOMINAL PRIMARY AND NO FLOOR SLOT VENTILATION

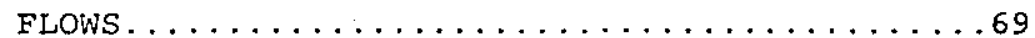

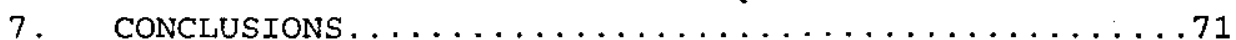

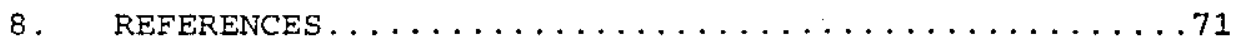

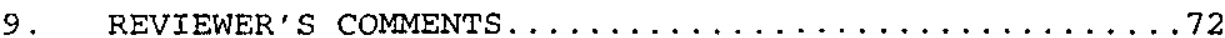

iii of $v$ 
JOHN MARVIN, INC.

Analyst: Marvin J. Thurgood

Reviewer: Harold E. Adkins

Subject: Notebook for GOTH
Calculation Number: JMI-9910_01

Date: Feb 9, 2000

\section{LIST OF TABLES}

5.1 Subdivision Heights and Pressures. ............... 31

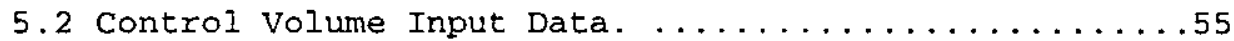

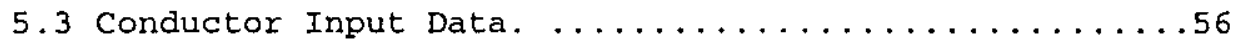

5.4 Conductör Type Input Data. ..............56

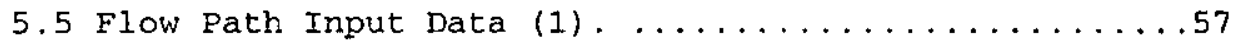

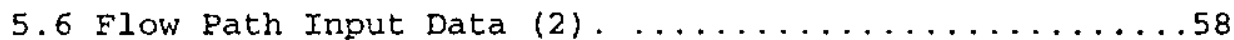

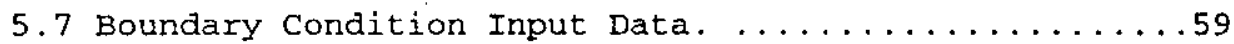

6.1 Axial Temperature Distribution in Tank. .........64 
JOHN MARVIN, INC.

Analyst: Marvin J. Thurgood

Reviewer: Harold E. Adkins

Subject: Notebook for GOTH_SNF Simulation of Tank-AY102
Calculation Number: JMI-9910_01

Date: Feb 9, 2000

\section{LIST OF FIGURES}

2.1 Distribution of Material In Tank. ............4

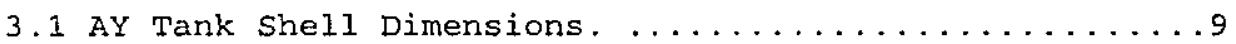

3.2 Secondary Ventilation Air slot Layout. . . . . . . . . . . . . .

4.1 GOTH_SNE Model of Tank AY-102 . . . . . . . . . . . 22

4.2 GOTH_SNF Model Node Layout of Tank AY-102 . ......23

5.1 Approximation of Primary Dome Shape. ...........29

6.1 Temperatures From the Initial steady-State Conditions Through pump Mixing.............62

6.2 Important Waste Temperatures After Pumps are shut off ............................63

6.3 Maximum Axial Temperature Distribution in Tank Before, $\mathrm{T} 2$, and After $\left(\mathrm{T} 2{ }^{\prime}\right)$, Mixing...........65

6.4 Water Vapor Mass Rate Carried Over By the Primary. Ventilation system..................66

6.5 Temperatures From the Initial Steady-state Conditions Through Heat Up Following Loss of Ventilation...........................69

6.6 Temperatures From the Initial steady-state Temperature Determination ................70 
JOHN MARVIN, INC. Calculation Number: JMI-9910_01

Analyst: Marvin J. Thurgood

Date: Feb 9, 2000

Reviewer: Harold E. Adkins Date: Feb 9, 2000

Subject: Notebook for GOTH_SNF Simulztion of Tank-AY102

(1)

exec ('pwd') $=\begin{aligned} & / \text { projects/AGA_parametric_study/Test_runs/AY } \\ & -102\end{aligned}$

info('file') = note_book

$[Q A-2]$

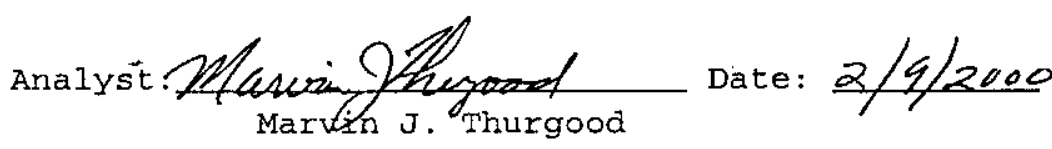
JMI Management: Plemeng Zhout Date: $2 / 4 / 2000$

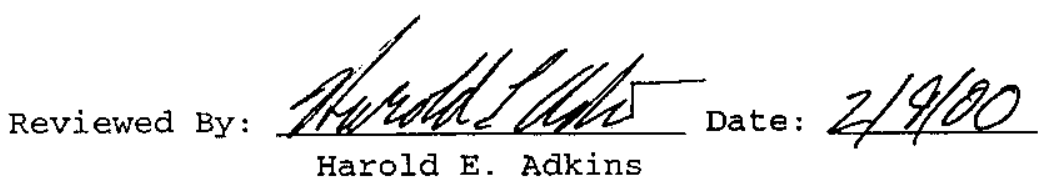




\begin{tabular}{|lr|}
\hline JoHN MARVIN, INC. & Calculation Number: JMI-9910_01 \\
\hline Analyst: Marvin J. Thurgood & Date: Feb 9, 2000 \\
\hline Reviewer: Harold E. Adkins & Date: Feb 9, 2000 \\
\hline Subject: Notebook for GOTH_SNF Simulation of Tank-AY102 \\
\hline
\end{tabular}

\section{INTRODUCTION.}

This notebook documents the methods, models and data required to set up the input deck for evaluating the ventilation requirements for tank $A Y-102$ once the mixing pumps have been installed. The results of these calculations are to be used to write the specifications for the tank ventilation systems. Tank AY-102 is used for the analysis because it is the bounding tank in the AY tank farm. The ventilation requirements for the other tanks in the farm will be over-specified because their requirements are lower than those for the bounding tank. The ventilation requirements for these other tanks can be reduced by additional analysis at a later time if necessary.

\section{PROBLEM DESCRIPTION.}

The problem consists of Tank AY-102 which has an initial settled slurry layer of 17 inches. Adaitional waste has been transferred into the tank from tank C-106. The partially settled thickness of the waste added to the tank from tank $\mathrm{C}-106$ is 58.50 inches bringing the total slurry height in the tank to 75.5 inches. The supernatant level of the tank is 225 inches following the final waste addition from C-106. The addition of materials to the tank and the various fluid regions of the tank are shown in Figure 2.1. The initial slurry layer and the settled slurry due to the waste additions from C-106 are illustrated in the figure along with the supernatant level at the end of the waste transfer from C-106. Also illustrated in the drawing are the primary and secondary ventilation flows that are used to cool the tank contents. The primary flow path also removes moisture from the tank dome as this air comes into direct contact with the 


\begin{tabular}{|lr|}
\hline JoHN MARVIN, INC. & Calculation Number: JMI-9910_01 \\
\hline Analyst: Marvin J. Thurgood & Date: Feb 9, 2000 \\
\hline Reviewer: Harold E. Adkins & Date: Feb 9, 2000 \\
\hline Subject: Notebook for GOTH_SNE Simulation of Tank-AY102 \\
\hline
\end{tabular}

supernatant in the tank.

The secondary flow enters at the center of the tank floor through pipes that pass through the concrete pad at the bottom of the tank. The air then flows radially outwards through flow channels formed into the concrete pad directly under the steel tank shell. This air flow removes heat from the bottom of the tank, cooling the settled slurry. 'This air then exits into the annulus formed by the tank's double shell where it flows upwards and is extracted from the top of the annulus through annulus ventilation piping.

The primary air is drawn into the tank through filtered inlet vents and leakage paths by the primary ventilation fans. The fans remove air from the dome via the primary system ventilation piping. This flow cools the tank by both sensible and evaporative heat removal from the surface of the supernatant pool. Dryer, usually cooler, air from the atmosphere removes heat and moisture from the tank dome atmosphere, allowing evaporation from the pool surface to occur. When the inlet air is cooler than the tank atmosphere the air also removes sensible heat from the pool.

Solid particles in the settled slurry generate heat due to radionuclide decay. The supernatant also contains dissolved radionuclides that also generate heat. This heat must be removed primarily by the ventilation flows, although some of it is conducted through the ground to the surface or to the ground water. 
JOHN MARVIN, INC.

Analyst: Marvin J. Thurgood

Reviewer: Harold E. Adkins
Subject: Notebook for GOTH_SNF Simulation of Tank-AY102

Calculation Number: JMI-9910_01

Date: Feb 9, 2000

Date: Feb 9, 2000

Date: Feb 9, 2000

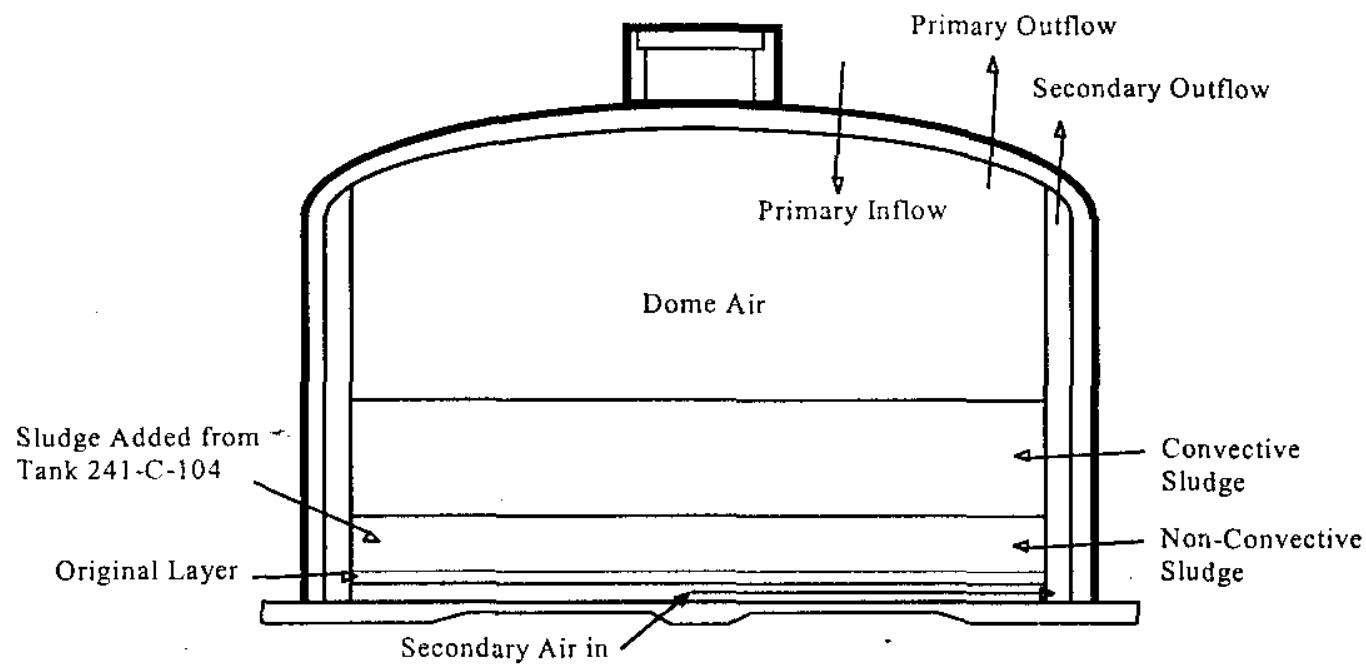

Figure 2.1 Distribution of Material In Tank.

The initial steady state at which the simulations begin is with the solid particles in an undisturbed slurry on the bottom of the tank. The mixer pumps are then turned on and the slurry in the bottom of the tank is mixed with the supernatant. The assertion is that the mixer pumps mix the waste to a homogeneous mixture with no slurry remaining on the bottom of the tank. The pumps are conservatively run until the supernatant comes to a steady state temperature for all evaluations.

The pumps are then turned off and the solid particles are allowed to resettle to the bottom of the tank. The rate the particles settle is a function of the particle size, particle density, supernatant density and supernatant viscosity. The code (GOTH_SNF) calculates this rate from the force balance on the particles. For all evaluated cases, the mixture is assumed to remain convective as long as the particle fraction in a computational cell remains below $0.75^{\star} \alpha_{p}$ mp. The slurry becomes non-convective once the particle fraction reaches this value and the slurry begins to heat up as the radioactive decay heat must be 
JOHN MARVIN, INC.

Analyst: Marvin J. Thurgood

Reviewer: Harold E. Adkins

Subject: Notebook for GOrH

Subject: Notebook for GOTH_SNF Simulation of Tank-AY102

removed by conduction through the siurry to the supernatant. Heat is removed from the surface of the supernatant by convective sensible heat transfer and evaporative heat transfer to the primary ventilation flow. Heat is also conducted down through the non-convective slurry to the air flowing through the slots in the floor of the tank and to the ground under the tank if the ground is cooler than the slurry at the bottom of the tank.

The purpose of the calculations is to evaluate the ventilation requirements for this tank as mixing pumps are run to mix the waste in preparation for retrieving the waste for the vitrification process. Additional heat is added to the tanks during the retrieval process due to the operation of the mixing pumps. This additional heat may require upgrading of the tank ventilation systems to handle the additional heat load. Results of these calculations will be used to develop the ventilation specifications for this tank and the tank farm associated with it.

\subsection{Cases and Evaluation Cxiteria}

Three cases involving the bounding tank AY-102 are evaluated herein. These are:

1. Nominal once through primary ventilation flow of 500 CFM and slot ventilation flow of $1000 \mathrm{CFM}$. Air inlet temperature for both flows is $82^{\circ} \mathrm{F}$.

2. Nominal once through primary flow and secondary flow with loss of both ventilation systems when pumps are turned off.

3. Nominal once through primary flow with no slot flow. Air inlet temperature is $82^{\circ} \mathrm{F}$.

All cases consider the tank to initially be filled with waste at steady state conditions and then a transient period enveloping pump start-up, operation, shut-down, and

5 of 73 
JOHN MARVIN, INC.

Analyst: Marvin J. Thurgoọ

Reviewer: Harold E. Adkins

Sub: $=c t:$ Notebook for GOTH_SNF Simulation of Tank-AY102
Calculation Number: JMI-9910_01

Date: Feb 9, 2000

Date: Feb 9, 2000

$r \in-e s t a b l i s h m e n t$ of steady state conditions.

The operation and safety related criteria that must be met in order for the ventilation. system to be deemed acceptable are that prior to and after mixing operations, no portion of the top 15 feet waste may exhibit temperatures in excess of $195^{\circ} \mathrm{F}$ (LCO 3.3.2.b), no waste temperatures may exceed $195^{\circ} \mathrm{F}$ at any time during mixer pump runtime (LCO 3.3.2.a), and no portion of the waste existing below the top 15 feet may exhibit temperatures in excess of $215^{\circ} \mathrm{F}$ prior to and after mixing operations (LCO.3.3.2.b) [Ref 6]. Additionally, in the event of a loss of ventilation, no waste temperature shall exceed $250^{\circ} \mathrm{F}$ during the recovery period (SL 2.1.1).

\section{SPECIFICATION OF INPUT PARAMETERS FOR TANK $A Y-102$.}

Preparation of the GOTH_SNF input file requires that tank geometric data, tank waste conditions, ventilation parameters and pump operation conditions be specified. The required data specifications are provided, with source references in this section.

\subsection{TANK GEOMETRIC DATA.}

The geometric data required to set up a GOTH_SNF input model for the tank is provided in this section. This data is divided into two basic groups; the tank shell geometric data and the floor air distributor geometric data.

\subsubsection{Task Shell Geometric Data.}

The basic dimensions of the primary and secondary tank shells are. shown in Figure 3.1. The parameters shown in the figure are:

Inside radius of primary shell, [Ref. 1]: 


\begin{tabular}{|lr|}
\hline JoHN MARVIN, INC. & Calculation Number: JMI-9910_01 \\
\hline Analyst: Marvin J. Thurgood & Date: Feb 9, 2000 \\
\hline Reviewer: Harold E. Adkins & Date: Feb 9, 2000 \\
\hline Subject: Notebook for GOTH_SNE Simulation of Tank-AY102 \\
\hline
\end{tabular}

$$
\text { PS_IR : }=37.5 \mathrm{ft}
$$

Dec/28/99

PS_IR $:=37.5$ ft

Harold E. Adki

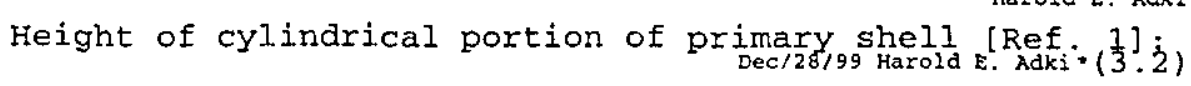

$$
\text { PS_CHT }:=31 \mathrm{ft}+9.5 \mathrm{in}+3 \mathrm{ft}+6 \mathrm{in}+\frac{13 \mathrm{in}}{16}=35.359 \mathrm{ft}
$$

Distance Between bottoms of primary and secondary shelis:

SS_PS_SPACE $:=8$ in

[QA-1]

Height of cylindrical portion of secondary shell [Ref ${ }_{\text {Dec/28/99 Harold } E \text {. Adk1 } *(3.5)}$ ] SS_CHT $:=31 \mathrm{ft}+9.5 \mathrm{in}+$ SS_PS_SPACE $=32.458 \mathrm{ft}$

other tank shell parameters of interest are:

Radius of curvature at shell cylinder and bottom plate junction [Ref. 1].

S_RC := $1 \mathrm{ft}$ Dec/28/99
$*(3 \cdot 6)$
Harold E. Adki

Secondary shell ellipsoid head major diameter [Ref. 1]:

SS_ELIP_MAJOR $:=80 \mathrm{ft}$ Dec/28/99 $(3.7)$

Secondary shell ellipsoid head minor diameter [Ref. 1]:

SS_ELIP_MINOR $:=30 \mathrm{ft}$

$\mathrm{Dec} / 28 / 99$ $(3,8)$

The radius of the bend in the primary shell between the cylindrical shell and the secondary shell head [Ref. 1]:

PS_TOP_RC $:=3 \mathrm{ft}+8 \mathrm{in}+\frac{3 \mathrm{in}}{8}=3.6979 \mathrm{ft}$

$\mathrm{Dec} / 2 \mathrm{~B} / 99$ Harold ${ }^{*}(3.9)$

The height of the primary shell tangency point with the secondary dome shell above the secondary tangent line is [Ref. 1]:

PS_SS_TP $:=6 \mathrm{ft}+6 \mathrm{in}+\frac{11 \mathrm{in}}{16}=6.5573 \mathrm{ft}$ 
RPP-5637

Rev. 0

JOHN MARVIN, INC.

Analyst: Marvin J. Thurgood

Reviewer: Harold E. Adkins

Subject: Notebook for GOTH_SNF Simulation of Tank-AYI02

The height of the primary tangent line above the secondary tangent line is [Ref. 1]:

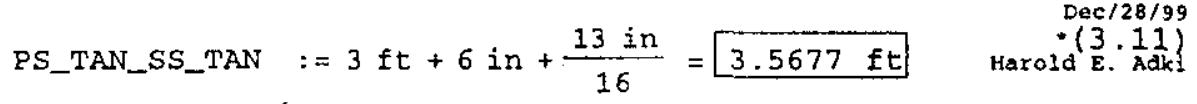

The distance from the tank centerline to the point of tangency between the primary tank shell and the secondary tank shell is [ReE. 1]:

$$
\text { PS_SS_TAN }:=35 \mathrm{ft}+11 \mathrm{in}+\frac{11 \mathrm{in}}{16}=35.974 \mathrm{ft} \quad \begin{gathered}
\text { Dec/20/99 } \\
(3.12)^{(3)}
\end{gathered}
$$

The primary tank cylinder wall is made of three thicknesses of carbon steel plate. Since the exact thickness of this plate does not strongly influence the thermal properties of the tank nor the volume of its contents, a constant

thickness will be assumed for the entire primary shell

[Ref. 1]:

$$
\text { PS_THK }:=\frac{3 \mathrm{in}}{8}=0.03125 \mathrm{ft}
$$

This is the actual thickness of the shell bottom plate and the shell dome plate. The side walls are thicker.

The secondary shell plate thickness is [Ref. 1]:

$$
\text { SS_THK }:=0.25 \text { in }=0.020833 \mathrm{ft}
$$


RPP-5637

Rev. 0

JOHN MARVIN, INC.

Calculation Number: JMI-9910_01

Analyst: Marvin J. Thurgood

Date: Feb 9, 2000

Reviewer: Harold E. Adkins

Date: Feb 9,2000

Subject: Notebook for GOTH_SNF Simulation of Tank-AY102

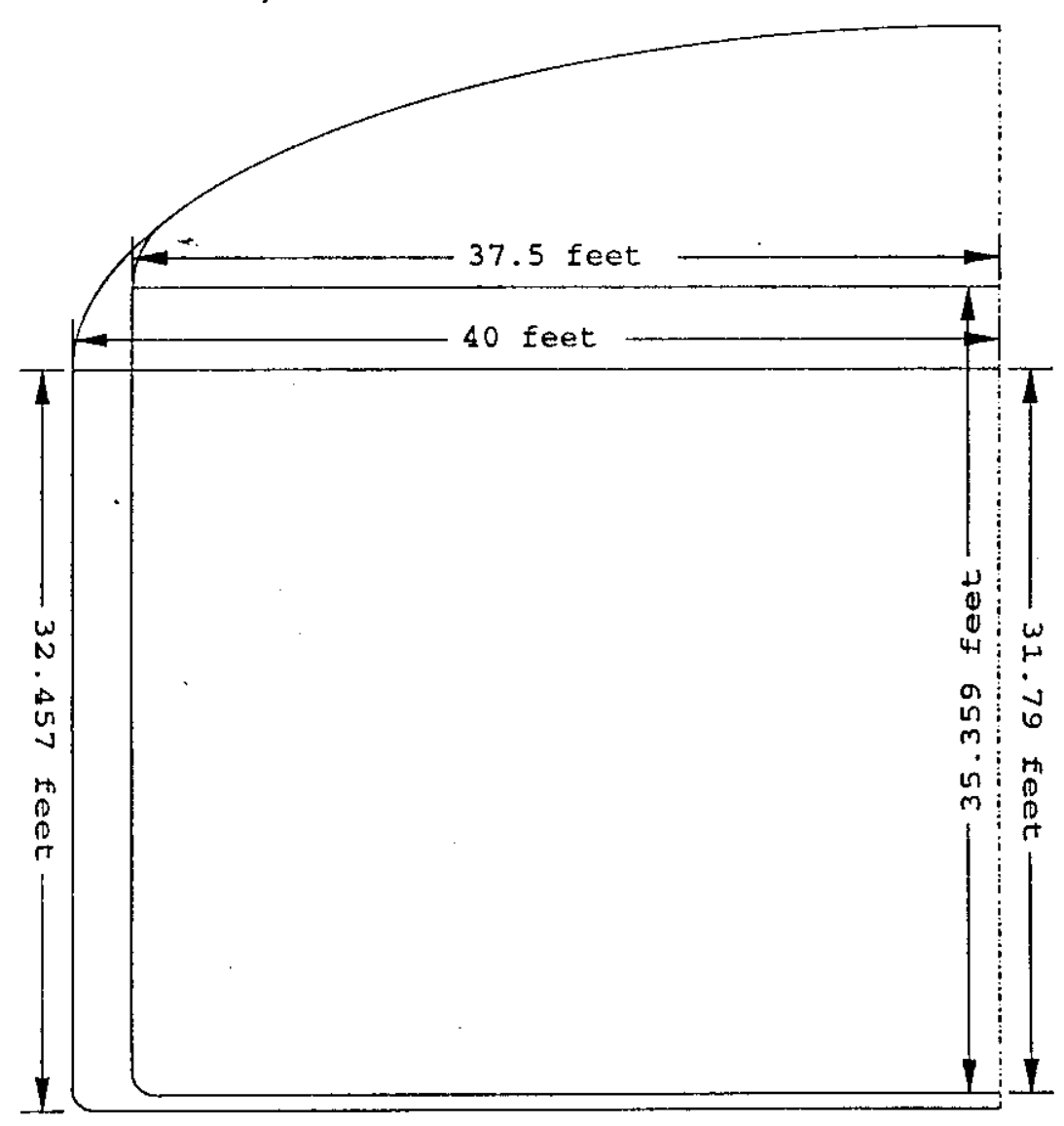

Figure 3.1 AY Tank Shell Dimensions.

9 of 73

E-18 
JOHN MARVIN, INC.

Analyst: Marvin J. Thurgood

Reviewer: Harold E. Adkins

Subject: Notebook for GOTH_SNF Simulation of Tank-AY102

Calculation Number: JMI-9910_01

Date: Feb 9, 2000

Date: Feb 9, 2000

\subsubsection{Air Distributor Geometric Data.}

The space at the bottom of the tank between the primary and secondary shells. is filled with an insulating concrete which has air flow slots molded into it, [Ref. 2]. The purpose of these slots is to allow air from the secondary ventilation system to flow radially outward from the center of the tank floor to the annulus formed by the primary and secondary cylindrical shells. This air flow provides cooling to the bottom of the tank. The plan view of the floor slots is shown in Figure 3.2. The radial slots are arranged in three sets across the radius of the tank. The first set contains 18 radial slots arranged azimuthally around the tank in $20^{\circ}$ intervals. The second set contains 36 radial slots at $10^{\circ}$ intervals. The third set has 72 radial slots at $5^{\circ}$ intervals. The center most end of the slots in the first radial group connect to the central air distributor. The three radial groups of slots are interconnected with circumferential slots that run between the first and second sets of slots and between the second and third sets of slots. The outermost end of the third set of slots connects to the annulus formed by the gap between the primary and secondary tank walls.

Cross-sectional views of the slots are also shown in Figure 3.2 with the dimensions of the slots. The type $A$ slots are near the center of the tank. Type B slots form the second ring of slots. Type C slots are on the outer perimeter of the tank. 
Analyst: Marvin J. Thurgood

Date: Feb 9, 2000

Reviewer: Harold E. Adkins

Date: Feb 9, 2000

Subject: Notebook for GOTH_SNF Simulation of Tank-AY102

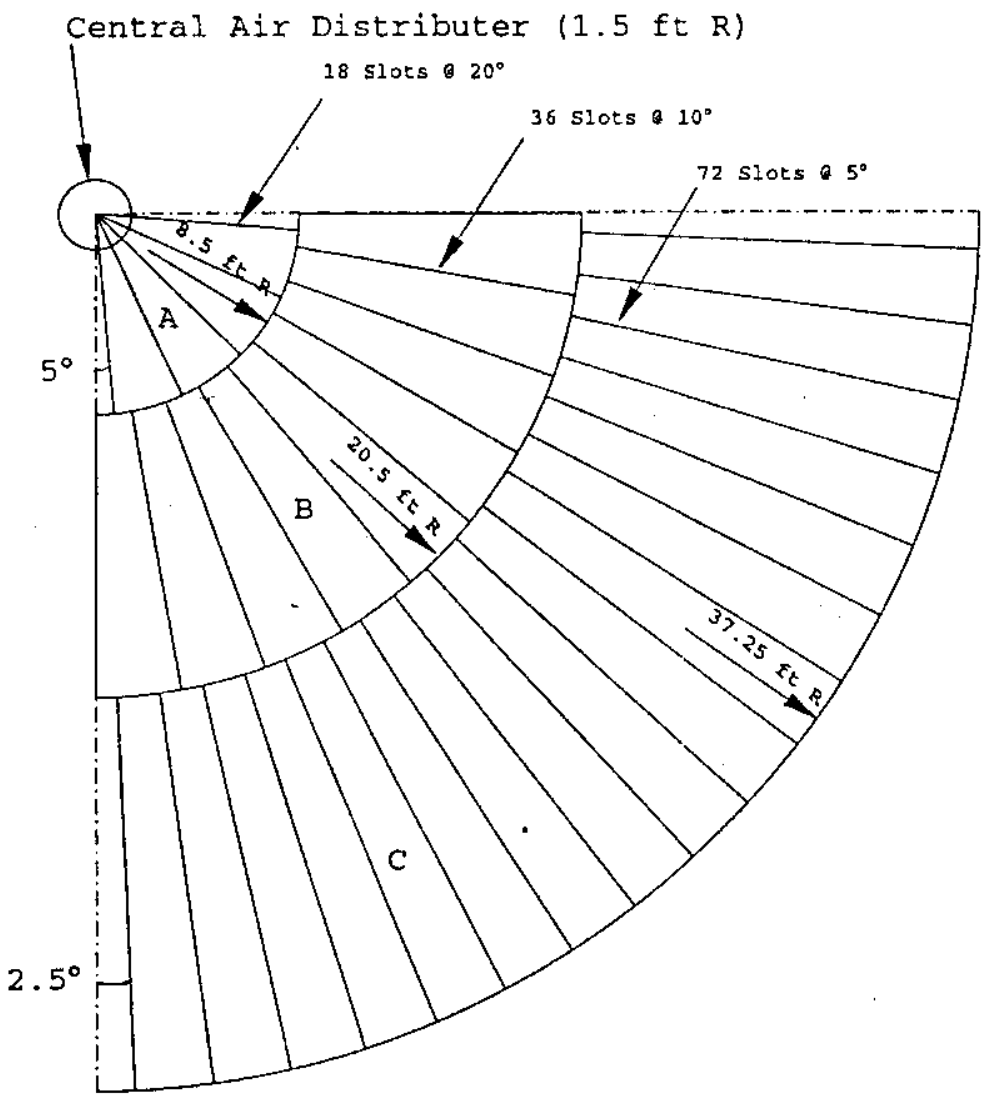

slot Types

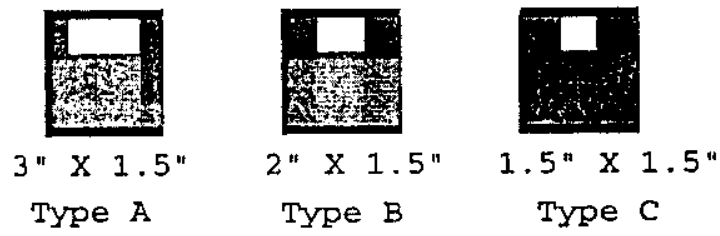

Figure.3.2 Secondary Ventilation Air slot Layout. The radius of the central air distributor is [Ref. 2]: 
JOHN MARVIN, INC.

Calculation Number: JMI-9910_01

Analyst: Marvin J. Thurgood Date: Feb 9, 2000

Reviewer: Harold E. Adkins Date: Feb 9, 2000

Subject: Notebook for GOTH_SNF simulation of Tank-AY102

$$
A D \_O R:=1.5 \mathrm{ft}
$$

Dec/28/99

$*(3.15)$

The outer radius of the first ring of slots (Type A slots) is [Ref. 2]:

$$
\text { R1_OR : }=8.5 \mathrm{ft}
$$

Dec/28/99

The outer radius of the second ring of slots (Type B slots) is [Ref. 2]:

$$
R 2 \_O R:=20.5 \mathrm{ft}
$$

Dec/28/99

$$
\text { R2-OR }:=20.5 \text { ft }
$$

The outer radius of the third ring of slots (Type Maroid $E \cdot$ Adki [Ref. 2] is:

$$
\text { R3_OR }:=37.25 \mathrm{ft}
$$

The height of all slots is [Ref. 2]:

$$
\text { SLOT_HT }:=1.5 \text { in }=0.125 \mathrm{ft}
$$

The width of the Type A slots is [Ref. 2]:

$$
\text { SLOT_A_WD }:=3 \mathrm{in}=0.25 \mathrm{ft}
$$

The width of the Type B slots is [Ref. 2]:

$$
\text { SLOT_B_WD }:=2 \text { in }=0.16667 \mathrm{ft}
$$

The width of the Type C slots is [Ref. 2]:

$$
\text { SLOT_C_WD }:=1.5 \text { in }=0.125 \mathrm{ft}
$$

The number of Type A slots is [Ref. 2] :

$$
\text { SLOT_A_N }:=18
$$

The number of Type B slots is [Ref. 2]:

$$
\text { SLOT_B_N }:=36
$$

The number of Type $C$ slots is [Ref. 2]:

$$
\text { SLOT_C_N }:=72
$$

The thickness of the insulating concrete that the slots are cut into is [Ref. 2]:

$$
\text { INSUL_CONC_TCK }:=8 \text { in }=0.66667 \mathrm{ft}
$$


JOHN MARVIN, INC.

Calculation Number: JMI-9910_01

Analyst: Marvin J. Thurgood Date: Feb 9, 2000

Reviewer: Harold E. Adkins Date: Feb 9, 2000

Subject: Notebook for GOTH_SNF Simulation of Tank-AY102

The air is supplied to the central air distributor in the center of the tank floor by 4 four inch supply lines which are spaced around the tank at $90^{\circ}$ intervals. The dimensions of these secondary ventilation inlet pipes are:

Inside Dianeter [Ref. 2], [Ref. 7]:

P4_ID := 4.026 in

Dec/28/99

Pipe wall thickness [Ref. 7]:

Harold $(3.27)$

P4_thk $:=0.237$ in

Dec/28/99

.$(3.28)$

Harold E. Adk

\subsection{TANK WASTE PARAMITTERS.}

The properties for the tank waste are'taken from [Ref 6].

\subsubsection{Initial Waste In AY-102.}

The vapor pressure of the mixed waste solution is established to be 858 of that of water [Ref 6].

The fluffing factor due to mixing for the original slurry in $A Y-102$ is:

FLUFF_FACT_AY102 : $=2.0$

Dec/28/99

$(3.29)$

The slurry height for the original waste in AY-102 is:

$$
\text { SLURRY_HT_AY102_ORG }:=17 \text { in }=1.4167 \mathrm{ft}
$$

Feb $/ 10 / 00$

$(3.30)$

The particle volume fraction for slurry in AY-102 is:

$$
\alpha_{p-102}:=0.489
$$

Feb/10/00

.$(3.31)$

The specific heat of the solid particles is:

$$
C_{p-P A R T}:=0.2 \frac{B t U}{1 b m-R}
$$

The specific heat of the supernatant is: 
JOHN MARVIN, INC.

Analyst: Marvin 3 . Thurgood

Reviewer: Harold E. Adkins

Subject: Notebook for GOTH_SNF Simulation of Tank-AY102

$$
C_{p-S U P E R}:=1 \frac{\text { Btu }}{1 \mathrm{bm}-\mathrm{R}}
$$

an/05/00

Harold $+(3 \cdot 33)$

The thermal conductivity of the solid particles is:

$$
\text { K_PART }:=5 \frac{\dot{B} t u}{h r-f t-R}
$$

The thermal conductivity of the supernatant is:

$$
\text { K_SUPER }:=0.35 \frac{\text { Btu }}{\mathrm{hr}-\mathrm{ft}-\mathrm{R}}
$$

The specific gravity of the solid particles is:

$$
\text { SPG_PART }:=1.925
$$

$\mathrm{Jan} / 05 / 00$

$*(3.36)$

The specific gravity of the supernatant is:

$$
\text { SPG_SUPER }:=1.11
$$

$\operatorname{Tan} / 05 / 00$

$(3.37)$

The density of water used in the specific gravity calculations is:

$$
\rho_{w}:=62 \frac{1 \mathrm{bm}}{\mathrm{ft}^{3}}
$$

$\mathrm{Jan} / 05 / 00$

$+(3.38)$

The density of the particles is:

$$
\rho \_P A R T:=\text { SPG_PART } \cdot \rho_{w}=119.35 \frac{1 \mathrm{bm}}{\mathrm{ft}^{3}}
$$

$\operatorname{San} / 05 / 00$

(3.39) Harold E. Adki

The density of the supernatant is:

$$
\rho \_ \text {SUPER }:=\rho_{w} \cdot S P G \_S U P E R=68.82 \frac{1 \mathrm{bm}}{\mathrm{ft}^{3}}
$$

$\operatorname{Jan} / 05 / 00$ .$(3.40)$ Harold E. Adki

\subsubsection{Waste Added to AY-102 from C-106.}

The total height of slurry in the tank after the waste has been transferred from $\mathrm{C}-106$ to $\mathrm{AY}-102$ based on the enraf data is:

$$
\text { SLURRY_HT }:=67.5 \mathrm{in}=5.625 \mathrm{ft}
$$

The amount of this thickness that is resettled slurry from $C-106$ is (I'm going to have to use 9 inches as the $A Y-102$ 
JOHN MARVIN, INC.

Analyst: Marvin J. Thurgood

Reviewer: Harold E. Adkins

Subject: Notebook for GOTH_SNF Simulation of Tank-AY102

slurry height here to be consistent with the ENRAF data):

SLURRY_HT_C106:= SLURRY_HT -9 in

$$
=58.5 \mathrm{in}
$$

The maximum height of each addition to the tank can be obtained from the enraf data. The sum of these heights gives the maximum fluffed height of the $\mathrm{C}-106$ waste that has been transferred to AY-102.

$$
\text { SLURRY_HT_C106_MIX }:=70.01 \text { in }
$$

$\mathrm{Feb} / 10 / 00$ $*(3.43)$ Harold E. Adki

Given the $\mathrm{C}-106$ resettled slurry height and the sum of the waste addition heights (which I take as the fluffed height of the C-106 slurry), the fluffing factor for the C-106 slurry that is in tank $A Y-102$ is: Jan/05/00 Hayold E. Adki * (3.44)

$$
\text { FLUFF_FACT_C106 }:=\frac{\text { SLURRY_HT_C106_MIX }}{\text { SLURRY_HT_C106 }}=1.1968
$$

The particle volume fraction in the transferred waste is:

$$
\alpha_{\mathrm{p}-106:=0.281}
$$

The average particle heat load for the $\mathrm{C}-106$ slurry is:

$$
\text { Q_PART }:=0.107 \frac{\text { Btu }}{\mathrm{hr}-\mathrm{lbm}}
$$

Check:

$$
\begin{gathered}
\text { Q_102 }:=\text { Q_PART } \cdot \rho \text { _PART } \cdot \text { SLURRY_HT_AY102_ORG } \cdot \pi \cdot(\text { PS_IR })^{2} \\
\cdot \alpha_{\mathrm{p} \_102}=39084 \frac{\mathrm{Btu}}{\mathrm{hr}}
\end{gathered}
$$

$$
\begin{gathered}
\text { Q_106:= Q_PART } \cdot P_{-} \text {PART } \cdot \text { SLURRY_HT_C106 } \cdot \pi \cdot{\text { (PS_IR })^{2}}^{2} \\
\cdot \alpha_{\mathrm{p}-106}=77286 \frac{\mathrm{Btu}}{\mathrm{hr}}
\end{gathered}
$$


RPP-5637

Rev. 0

JOHN MARVIN, INC.

Calculation Number: JMI-9910_01

Analyst: Marvin J. Thurgood

Date: Feb 9, 2000

Reviewer: Harold E. Adkins

Date: Feb 9, 2000

Subject: Notebook for GOTH_SNF Simulation of Tank-AY102

The maximum packing fraction that the particles will settle to after pump mixing is:

$$
\alpha_{\mathrm{p} m p}:=\frac{\alpha_{\mathrm{p}-106}}{\text { FLUFF_FACT_C106 }}=0.2348
$$

$\operatorname{Jan} / 04 / 00$

$*(3.49)$

This is the resettled particle volume fraction that should be used for the C-106 portion of the waste. Using this same maximum particle fraction for the AY-102 waste (as we must because the model allows only a single maximum packing fraction) results in the following fluffing factor for the original AY-102 waste:

$$
\text { FLUFF_FACT_AY102 }:=\frac{\alpha_{p}-102}{\alpha_{p} m p}=2.0826
$$

$\operatorname{Jan} / 04 / 00$ Harold E. $\begin{array}{r}* \\ \text { Adki }\end{array}$

This is sufficiently close to the specified fluffing factor of 2.0 for the waste and is conservative.

The density of the sIurry layers are:

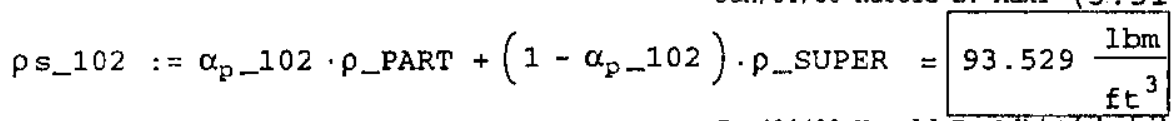

$$
\begin{aligned}
& \text { Jan } / 04 / 00 \text { Harold E. Adki } \times(3.52) \\
& \rho s_{-106}:=\alpha_{p \_106} \cdot \rho_{-P A R T}+\left(1-\alpha_{p-106}\right) \cdot \rho_{-} \text {SUPER }=83.019 \frac{\mathrm{lbm}}{\mathrm{ft}^{3}}
\end{aligned}
$$

The slurry conductivity can be calculated from these parameters using the series conductivity model:

$$
\operatorname{slurry\_ cond}\left(\alpha_{p}, k_{p}, k_{1}\right):=\frac{1.0}{\frac{\alpha_{p}}{k_{p}}+\frac{1-\alpha_{p}}{k_{1}}}
$$




\begin{tabular}{l} 
JOHN MARVIN, INC. \\
Analyst: Marvin J. Thurgood \\
Reviewer: Harold E. Adkins \\
\hline Subject: Notebook for GOTH_SNE Sid \\
$k_{s}:=$ Slurry_cond $\left(\alpha_{\mathrm{p}-102}\right.$ \\
, K_PART , \\
K_SUPER $)=0.64193 \frac{\mathrm{Btu}}{\mathrm{hr}-\mathrm{ft}-\mathrm{R}}$ \\
\hline
\end{tabular}

Calculation Number: JMI-9910_01

Date: Feb 9, 2000

Date: Feb 9, 2000

imulation of Tank-AY102

\subsubsection{The Initial Depth of Slurry in AY-102.}

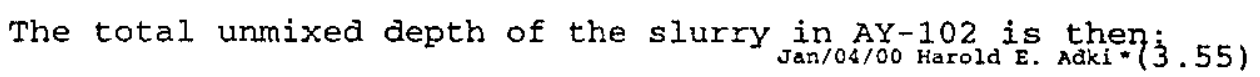

SLURRY_HT_MOD $:=$ SLURRY_HT_C106 + SLURRY_HT_AY102_ORG

$$
=75.5 \text { in }
$$

\subsubsection{Supernatant Height In $\mathrm{AX}-102$.}

SUPERNATANT_LEVEL $:=225$ in 


\begin{tabular}{|lr|}
\hline Jokn MARVIN, INC. & Calculation Number: JMI-9910_01 \\
\hline Analyst: Marvin J. Thurgood & Date: Feb 9, 2000 \\
\hline Reviewer: Harold E. Adkins & Date: Feb 9, 2000 \\
\hline Subject: Notebook for GOTH_SNF Simulation of Tank-AY102 \\
\hline
\end{tabular}

the slurry temperatures exceed the operating criterion. The higher of the two temperatures will $b=$ lised in all of the steps since the limit on supernatant temperature will not be controlling. The supernatant temperature will have to be lower. than the allowable in order for slurry temperatures to remain below their limit. The air inlet temperature that will be used for these calculations is:

$$
\text { AIR_INLET_TEMPERATURE }:=t f(82)=82 \mathrm{~F}
$$

The inlet absolute humidity is provided in pounds of moisture per pound of dry air [Ref 6].

$$
\text { AIR_INLET_ABSOLUTE_HUMIDITY } \quad:=0.0066 \frac{\mathrm{lbm}}{1 \mathrm{bm}} \quad \begin{array}{r}
\text { Jan } / 04 / 00 \\
(3.58) \\
\text { Harold } 2 . \text { Adki }
\end{array}
$$

This value will have to be converted to a pressure ratio for use in the code. The water vapor pressure ratio can be calculated assuming that the atmospheric pressure is 14.7 psia and the air temperature is that given by Equation 3.57. The mass fraction of water vapor at the specified absolute humidity is:

$$
\text { WV_mf }:=\frac{\text { AIR_INLET_ABSOLUTE_HUMIDITY }}{1+\text { AIR_INLET_ABSOLUTE_HUMIDITY }}=0.0065567
$$

The mass fraction of air is:

$$
\text { air_mf := } 1 \text { - wV_mf }=0.99344
$$

The molecular weight of water vapor is:

$$
\text { MW_watex }:=18.016 \frac{\mathrm{lbm}}{1 \mathrm{bm}-\mathrm{mole}}
$$

The molecular weight of air is:

$$
\text { MW_aix }:=28.96 \frac{1 \mathrm{bm}}{1 \mathrm{bm}-\mathrm{mole}}
$$

The lbm-moles of water vapor per $1 \mathrm{bm}$ of mixture is:

$$
\text { wv_moles: }:=\frac{\text { wV_mf }}{\text { MW_water }}=0.00036394 \text { mole }
$$

The Ibm_moles of air per lbm of mixture is: 


\begin{tabular}{|lr|}
\hline JOHN MARVIN, INC. & Calculation Number: JMI-9910_01 \\
\hline Analyst: Marvin J. Thurgood & Date: Feb 9, 2000 \\
\hline Reviewer: Harold E. Adkins & Date: Feb 9, 2000 \\
\hline Subject: Notebook for GOTH_SNF Simulation of Tank-AY102 \\
\hline
\end{tabular}

$$
\text { air_moles }:=\frac{\text { air_mf }}{\text { MW_air }}=0.034304 \text { mole } \quad \begin{array}{r}
\text { Jan } / 04 / 00 \\
(3.64)
\end{array}
$$

The total moles of mixture is:

$$
\text { tot_moles }:=\text { wV_moles }+ \text { air_moles }=0.034668 \text { mole }{ }^{J a n / 04 / 00 ~ H a r o l d ~} \varepsilon \text {. Adki } *(3.65)
$$

The mole fraction of water vapor is then:

$$
\text { WV_vf }:=\frac{\text { WV_moles }}{\text { tot_moles }}=0.010498 \quad \begin{array}{r}
\text { Jan } / 04 / 00 \\
\text { (3.66) }
\end{array} \quad \begin{aligned}
& \text { Harold } \mathrm{E} . \text { Adk } \\
& 0
\end{aligned}
$$

Atmospheric pressure is assumed to be:

$$
\begin{aligned}
& \text { P_tot }:=14.7 \mathrm{psi} \\
& \text { P_wv }:=\text { P_tot } \cdot \mathrm{wv} \text { _vf }=0.15432 \mathrm{psi}
\end{aligned}
$$

$$
\begin{array}{r}
J a n / 04 / 00 \\
(3.67) \\
\text { Harold E. Adki } \\
\text { Jan } / 04 / 00 \\
*(3.68)
\end{array}
$$

The mole fraction is the same as the pressure ratio so the water vapor pressure ratio for air at $82^{\circ} \mathrm{F}$ is:

$$
\text { wv_p_ratio }:=\text { wv_vf }=0.010498
$$

\subsubsection{VENTILATION FLOW RATE.}

\subsubsection{Primary Ventilation Flow Rate.}

The nominal once through primary ventilation flow for this tank is [Ref 6]:

$$
\text { Q_primary }:=500 \frac{\mathrm{ft}^{3}}{\mathrm{~min}}=8.3333 \frac{\mathrm{ft}^{3}}{\mathrm{~s}}
$$

The recirculation flow for this tank is, [Ref 6]:

$$
\text { Q._recirc }:=400 \frac{\mathrm{ft}^{3}}{\mathrm{~min}}=6.6667 \frac{\mathrm{ft}^{3}}{\mathrm{~s}}
$$

A flow of 100 \{ft $3 / \mathrm{min}\}$ is brought into the tank from the ambient air when the tank is operated in the recirculation mode [Ref 6]. 


\begin{tabular}{|lr|}
\hline JOHN MARVIN, INC. & Calculation Number: JMI-9910_01 \\
\hline Analyst: Marvin J. Thurgood & Date: Feb 9, 2000 \\
\hline Reviewer: Harold E. Adkins & Date: Feb 9, 2000 \\
\hline Subject: Notebook for GOTH_SNF Simulation of Tank-AY102 \\
\hline
\end{tabular}

$$
\begin{aligned}
& \text { Jan/04/00 Harald } \mathrm{s} \text {. A } \\
& \text { Q_inlet_recir : = Q_primary - Q_recirc }=\left[\begin{array}{c}
\mathrm{s} \\
1.6667 \frac{\mathrm{ft}^{3}}{\mathrm{~s}}
\end{array}\right.
\end{aligned}
$$

The tank inlet conditions for the recirculation flow is air at $117^{\circ} \mathrm{F}$ and 1008 relative humidity.

\subsubsection{Secondary Ventilation Flow Rate.}

The nominal secondary flow rate is [Ref 6]:

$$
\text { Q_secondary }:=1000 \frac{\mathrm{ft}^{3}}{\mathrm{~min}}
$$

\section{GOTH_SNF MODEL DESCRIPTION.}

A GOTH_SNF model has been constructed for performing the specified simulations. A schematic of the model is shown in Figure 4.1. As shown, the model includes the primary waste tank, the annulus formed by the primary and secondary shell of the waste tank, floor slots and their associated vent/feed pipes, a mixer pump, a water refill sump which mimics the interaction of the condenser, and a primary ventilation duct. The primary ventilation inlet and outlet are represented by a flow condition "1F" and a pressure condition "6P". These components form the primary flow path. The secondary flow path is formed by the inlet pipes, the floor slots, and the annulus. The secondary ventilation inlet and outlet are represented by a flow condition " $4 \mathrm{~F}$ " and a pressure condition " $3 \mathrm{P}$ ".

To accurately represent particle settling, slurry and supernatent interaction, and heat transfer characteristics within the tank waste, the primary waste tank volume was broken into 16 axially oriented subvolumes in 1-D fashion. The determination of the axial thicknesses will be presented later. The 1-D nodal layout illustrating the 16 subvolumes of the waste tank volume is shown in Figure 4.2. Also presented in this figure are the conductors representing the conductive link to the concrete 


\begin{tabular}{|lr|}
\hline JohN MARVIN, INC. & Calculation Number: JMI-S910_Ci \\
\hline Analyst: Marvin J. Thurgood & Date: Feb 9, 2000 \\
\hline Reviewer: Harold E. Adkins & Date: Feb 9, 2000 \\
\hline Subject: Notebook for GOTH_SNF Simulation of Tank-AY102 \\
\hline
\end{tabular}

pad on into the soil, and the convective link into the floor slots. The pump inlet is also shown.

To accurately represent the additional heat load of the mixer pump during operation, a heat source was added in the supernatent equaling $1.5 \times 10^{6} \mathrm{Btu} / \mathrm{hr}$. For this particular model, it was added to the 11 th subvolume from the bottom.

Finally, soil thickness of $100 \mathrm{ft}$ between the tank bottom and the $50^{\circ} \mathrm{F}$ water table, $7 \mathrm{ft}$ between the tank dome and the $82^{\circ} \mathrm{F}$ ambient, and $50 \mathrm{ft}$ spanning radially away from the annulus to an adiabatic boundary, were designated. 


\begin{tabular}{|lr|}
\hline JOHN MASVIN, INC. & Calcuiation Number: JMI-9910_01 \\
\hline Analyst: Marvin J. Thurgood & Date: Feb 9, 2000 \\
\hline Reviewer: Harold E. Adkins & Date: Feb 9, 2000 \\
\hline Subject: Notebook for GOTH_SNF Simulation of Tank-AY102 \\
\hline
\end{tabular}

Jan/18/00 Hazold E. Adki *

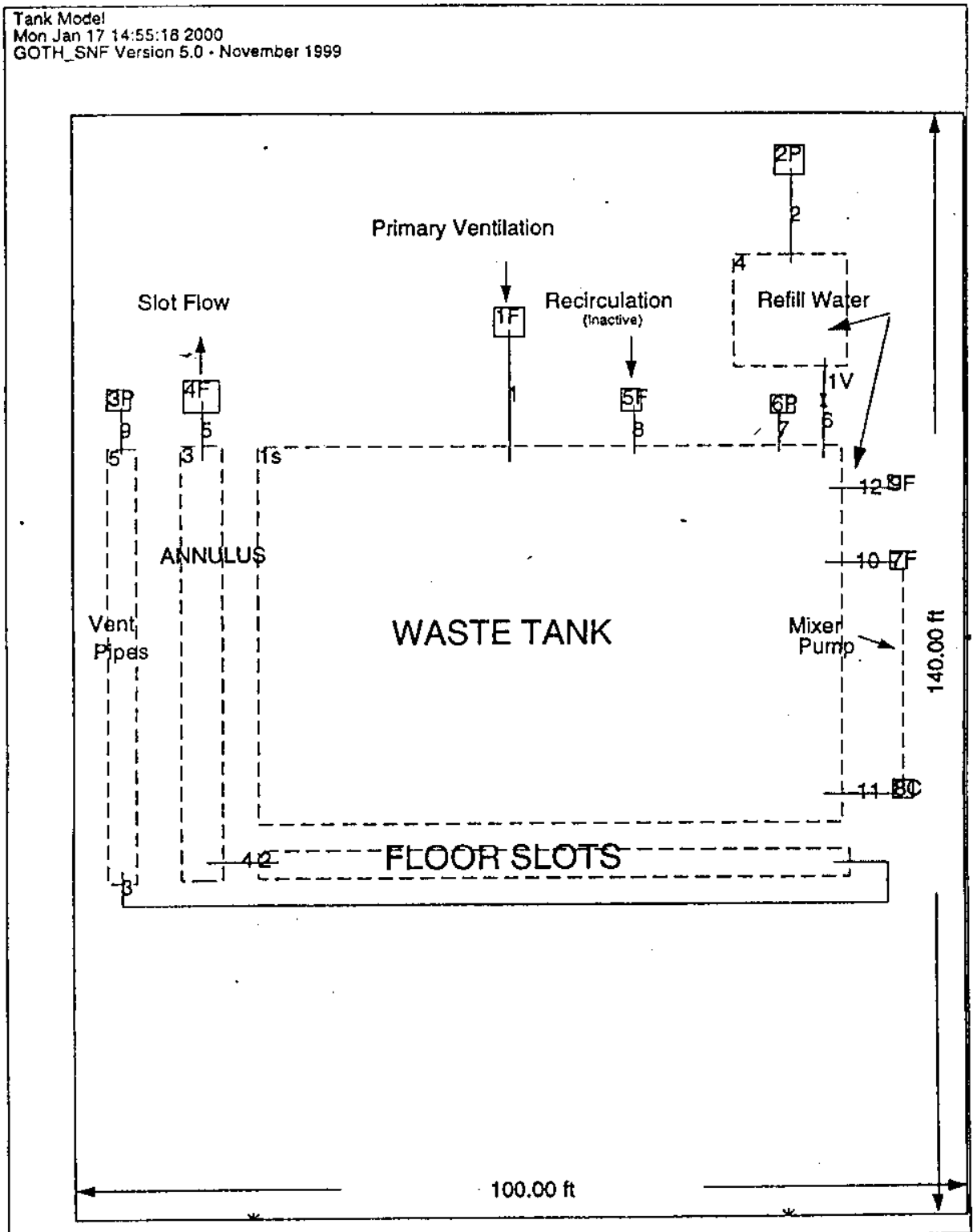

Figure 4.1 GOTH_SNF Model of Tank AY-102. 


\begin{tabular}{|lr|}
\hline JOHN MARVIN, INC. & Calculation Number: JMI-9910_01 \\
\hline Analyst: Marvin J. Thurgood & Date: Feb 9, 2000 \\
\hline Reviewer: Harold E. Adkins & Date: Feb 9, 2000 \\
\hline Subject: Notebook for GOTH_SNF Simulation of Tank-AY102 \\
\hline
\end{tabular}

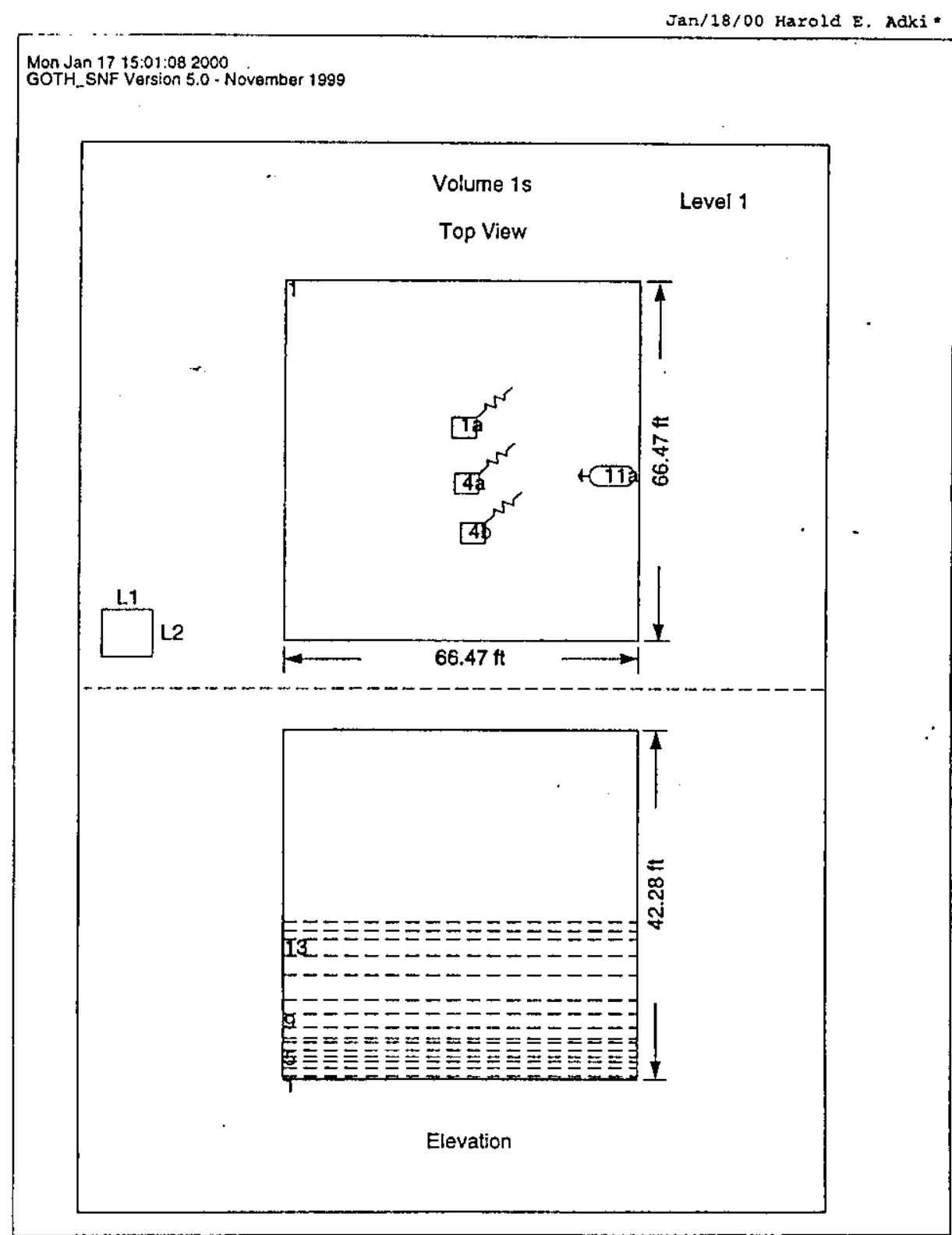

Figure 4.2 GOTH_SNF Model Node Layout of Tank AY-102. 
JOHN MARVIN, INC.

Analyst: Marvin J. Thurgood

Reviewer: Harold E. Adkins

Subject: Notebook for GOTH_SNF Simulation of Tank-AY102
Calculation Number: JMI-9910_01

Date: Feb 9, 2000

Date: Feb 9, 2000

\section{DEVELOPMENT OF INPUT PARAMETERS FOR THE GOTH_SNE MODEL.}

The raw data given in section 3 is used in this section to calculate the parameters that are required for the GOTH_SNF tank model described in section 4 .

\subsection{GEOMETRIC INPUT DATA.}

There are four volumes in the GOTH_SNF model of Tank AY-102. The first three of these represent fluid volumes determined by the tank geometry. The fourth is an auxiliary volume used, in the model, to condense water vapor out of the air leaving the tank and returning the condensate to the tank to maintain the liquid level at a constant. This volume can also be used to represent the operation of the condenser, or a chiller, if one is required to meet the tank operational and safety temperature limitations. The input parameters for each of these volumes will be calculated in this section. First, some useful functions are defined that will simplify doing the calculations.

\subsubsection{Useful Functions and Parameters.}

Area of a circle of radius $x$ [Ref. 3, p. 12]:

$$
A_{c}(r):=\pi \cdot r^{2}
$$

Area of an annular ring formed by a larger circle of radius $r 1$ and a smaller circle of radius $r 2$ [Ref. 3, p. 13]:

$$
A_{a}(x 1, r 2):=\pi \cdot\left(r 1^{2}-r 2^{2}\right)
$$

$\operatorname{Jan} / 04 / 00$

The perimeter of a circle of radius $r$ [Ref. 3, p, 12]:

$$
\mathrm{P}_{c}(r):=2 \cdot \pi \cdot r
$$

The perimeter of an annular ring formed by a larger

$\operatorname{Jan} / 04 / 00$

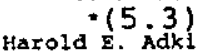




\begin{tabular}{|lr|}
\hline JOHN MARVIN, INC. & Calculation Number: JMI-9910_01 \\
\hline Analyst: Marvin J. Thurgood & Date: Feb 9, 2000 \\
\hline Reviewer: Harold E. Adkins & Date: Feb 9, 2000 \\
\hline Subject: Notebook for GOTH_SNF Simulation of Tank-AY102 \\
\hline
\end{tabular}

circle of radius $r 1$ and a smaller circle of radius $r 2$, [Ref. 3, p. 12] :

$$
P_{a}(r 1, r 2):=2 \cdot \pi \cdot\{r 1+r 2\}
$$

The hydraulic diameter of a flow path with flow area, A, and wetted perimeter, Pw, [Ref. 4, p. 165]:

$$
D_{h}(A, P w):=4 \cdot \frac{A}{P w}
$$

The volume of a cylinder of radius, $r$, and height, $h$, [Ref. 3, p. 16] :

$$
V_{C}(r, h):=A_{C}(r) \cdot h
$$

The volume of an annulus formed by a larger cylinder of inside radius, $r l$, and a smaller cylindex of outside radius, $r 2$, and of height $h$ [Ref. 3, p. 16]:

$$
V_{a}(r 1, r 2, h):=A_{a}(r 1, r 2) \cdot h
$$

The acceleration of gravity is:

$$
g:=32.2 \frac{\mathrm{ft}}{\mathrm{s}^{2}}
$$

\author{
Jan/08/00 \\ $(5.7)$ \\ Harola $E$. Adki
}

\title{
5.1.2. Tank Primary Volume.
}

The primary tank shell consists of a upright cylinder with a flat bottom and a dome top that has the shape of a body of revolution formed by a modified half ellipse. The dome of the secondary tank is a body of revolution formed by a half ellipse. The primary tank dome is formed by a body of revolution formed by the portion of a circle which is tangent to the primary tank cylindrical wall and the secondary tank dome.

5.1.2.1. Area of Tank Primary Volume. The cross-sectional area of the tank primary volume will be taken as the inside cross-sectional area of the cylindrical portion of the primary tank shell. This area shall be used for the pool area used to calculate the evaporation rate from the supernatant surface, the conduction area for heat 


\begin{tabular}{|l|r|}
\hline JOHN MARVIN, INC. & Calculation Number: JMI-9910_01 \\
\hline Analyst: Marvin J. Thurgood & Date: Feb 9, 2000 \\
\hline Reviewer: Harold E. Adkins & Date: Feb 9, 2000 \\
\hline Subject: Notebook for GOTH_SNF Simulation of Tank-AY102 \\
\hline
\end{tabular}

transfer in the waste and the flow area in the tank during pump mixing. The area of the primary tank volume is:

$$
\text { PS_area }:=A_{C}\left(P S \_I R\right)=\begin{array}{r}
\text { Jan } / 04100 \\
4417.9 \pm t^{2}
\end{array}
$$

\subsubsection{Volume of Tank Primary Volume.}

The volume of the cylindrical portion of the primary tank is:

$$
\begin{aligned}
& \text { Jan/04/00 Harold E. Adki * }(5,10) \\
& \text { PS_Cy1_Vol }:=V_{C}\left(P S \_I R, P S \_C H T\right)=1.5621 \times 10^{+05} \mathrm{ft}^{3}
\end{aligned}
$$

The centroid of the semi-ellipse of the size of that forming the secondary tank dome, [Ref. 3, p. 20]:

$$
\text { Elip_cent }:=\frac{4 \cdot \frac{\text { SS_ELLIP_MAJOR }}{2}}{3 \cdot \pi}=16.977 \mathrm{ft} \quad \begin{array}{r}
\begin{array}{l}
\text { Jan } / 04 / 00 \\
(5.11)
\end{array} \\
\text { Harold } \mathrm{E}: \text { Adxi }
\end{array}
$$

The cross-sectional area of the quarter eliipse formed by the planar half section of the secondary tank dome is, [Ref. 3, p.13]:

$$
\text { Elip_area }:=\frac{\pi}{4} \cdot \frac{\text { SS_ELIP_MAJOR }}{2} \cdot \frac{\text { SS_ELIP_MINOR }}{2}=471.24 \mathrm{Et}^{2}
$$

The volume of the body of revolution formed by the secondary dome shell is equal to the diameter of the circle formed by the centroid as the ellipse is rotated about the tank centerline times the area of the quarter ellipse, \{Ref. 3, p. 19\}.

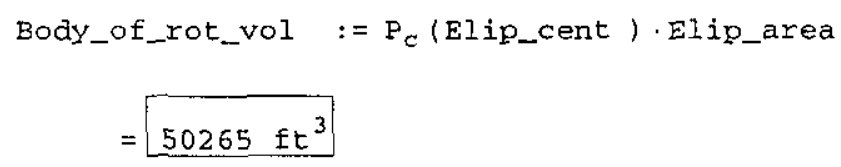$$
=50265 \mathrm{ft}^{3}
$$

Most, but not all of this volume is within the primaxy tank. A small portion of it is in the annulus. Some of this volume is also in the cylindrical portion of the primary tank. The above information will be used to calculate the volume of the anmulus once the volume of the 


\begin{tabular}{|lr|}
\hline JOHN MARVIN, INC. & Calculation Number: JMI-9910_01 \\
\hline Analyst: Marvin J. Thurgood & Date: Feb 9, 2000 \\
\hline Reviewer: Harold E. Adkins & Date: Feb 9, 2000 \\
\hline Subject: Notebook for GOTH_SNF Simulation of Tank-AY102 \\
\hline
\end{tabular}

primary tank dome is known.

The equation for an ellipse whose major axis is $2 \mathrm{a}$ and whose minor axis is $2 b$ and whose center is at the origin is, [Ref. 3, p. 365]:

$$
y_{e}(x, a, b):=\sqrt{\left(1-\frac{x^{2}}{a^{2}}\right) \cdot b^{2}}
$$

The equation for a circle of radius, $r$, whose origin is located at $(h, k)$ is [Ref. 3,p. 363]:

$$
y_{c}(x, r, h, k):=\sqrt{r^{2}-(x-h)^{2}}+k
$$

The shape of the dome of the primary shell can be plotted using these two functions. These functions are shown in Figure 5.1. The ellipse function is plotted from the tank centerline to the point of tangency between the primary and secondary shell and the circle function is plotted between the point of tangency of the primary and secondary shelis and the inside radius of the primary shell.

The cross-sectional area of the primary shell half dome is obtained by integrating the ellipse and circle functions over their appropriate ranges and sub-tracting the portion of the ellipse that is within the cylindrical portion of the primary tank shell. This is done in the following two equations.

Jan $/ 04 / 00$ Harold E. Adxi *(5.16)

$$
\begin{gathered}
\text { Aelip }:=\int_{0 \text { It }}^{\text {PS_SS_TAN }} y_{e}\left(x, \frac{\text { SS_ELIP_MAJOR }}{2} \cdot \frac{\text { SS_ELIP_MINOR }}{2}\right) d x \\
\text { - PS_IR } \cdot \text { PS_TAN_SS_TAN }=319.67 \mathrm{ft}^{2}
\end{gathered}
$$




\begin{tabular}{|lr|}
\hline JOHN MARVIN, INC. & Calculation Number: JMI-9910_01 \\
\hline Analyst: Marvin J. Thurgood & Date: Feb 9, 2000 \\
\hline Reviewer: Harold E. Adkins & Date: Feb 9, 2000 \\
\hline Subject: Notebook for GOTH_SNF Simulation of Tank-AY102
\end{tabular}

Jan/04/00 Harold E. Adki $*(5.17)$

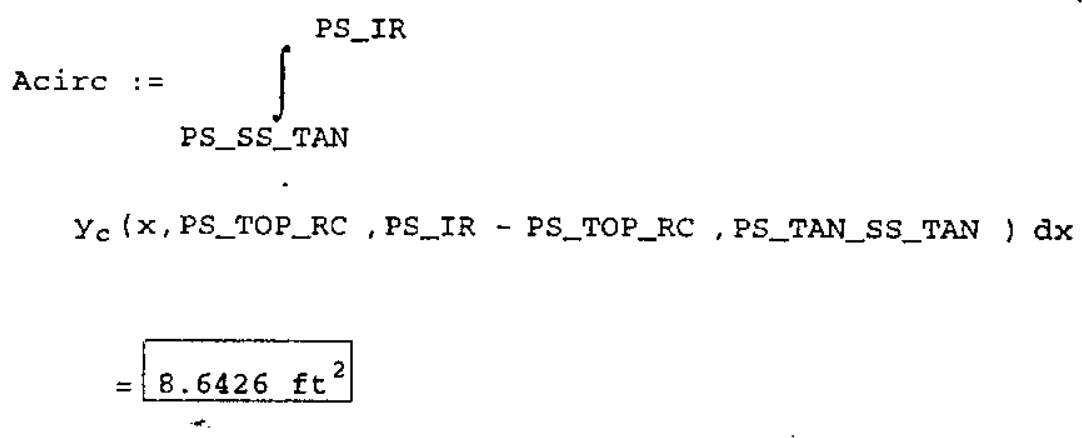

The volume of the primary tank dome can be obtained by multiplying the primary tank half dome area by the length of the path drawn by its centroid when the area is rotated about the tank centerline. The distance from the tank centerline to the centroid of the dome cross-sectional area is obtained by iteratively integrating the equation for the ellipse until one half of the dome cross-sectional area is obtained.

$$
\begin{aligned}
& \frac{\text { Ps_Dome_XArea }}{2}=164.15 \mathrm{ft}^{2} \\
& -14.82 \mathrm{ft} \cdot \text { PS_TAN_SS_TAN }=164.23 \mathrm{ft}^{2}
\end{aligned}
$$

Therefore, the distance to the centroid is:

$$
\text { Ps_dome_centroid }:=14.82 \mathrm{ft}
$$

and the primary tank dome volume is: 


\begin{tabular}{|lr|}
\hline JoHN MAZVIN, INC. & Calculation Number: JMI-9910_01 \\
\hline Analyst: Marvin J. Thurgood & Date: Feb 9, 2000 \\
\hline Reviewer: Harold E. Adkins & Date: Feb 9, 2000 \\
\hline Subject: Notebook for GOTH_SNF Simulation of Tank-AY102 \\
\hline
\end{tabular}

Ps_dome_vol := Ps_Dome_XArea $\cdot P_{c}$ (Ps_dome_centroid)

$$
=30571 \mathrm{ft}^{3}
$$

The total volume of the primary tank is:

$$
\begin{gathered}
\text { PS_vol }:=\text { PS_dome_vol }+A_{c} \text { (PS_IR) P PS_CHT } \\
=1.8678 \times 10^{+05} \mathrm{ft}^{3}
\end{gathered}
$$

$$
\text { PS_vol }=1.3972 \times 10^{+06} \mathrm{gal}
$$

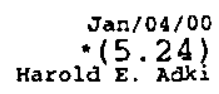

Jan/04/00 Harold E. Adk1.

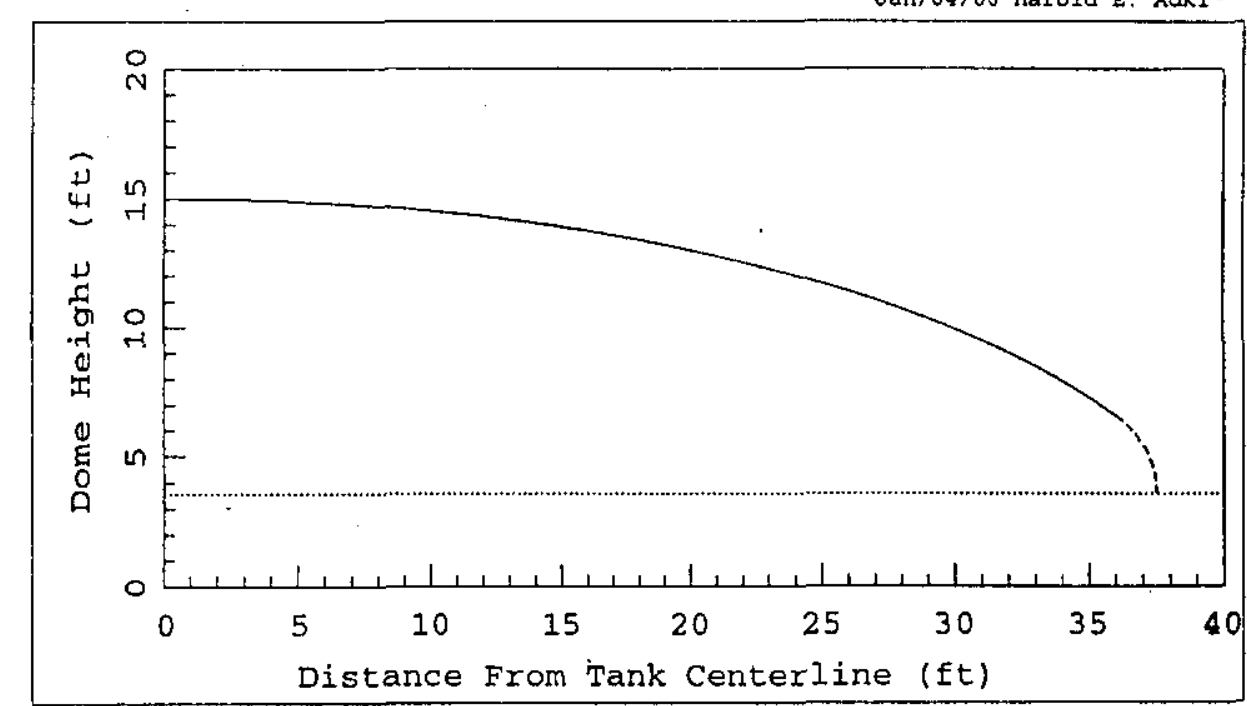

Figure 5.1 Approximation of Primary Dome Shape.

5.1.2.3. Bottom Elevation of Tank Primary Volume. The bottom of the tank annulus will be taken as zero, 


\begin{tabular}{|lr|}
\hline JoHN MARVIN, INC. & Calculation Number: JMI-9910_01 \\
\hline Analyst: Marvin J. Thurgood & Date: Feb 9, 2000 \\
\hline Reviewer: Harold E. Adkins & Date: Feb 9, 2000 \\
\hline Subject: Notebook for GOTH_SNF Simulation of Tank-AY102 \\
\hline
\end{tabular}

therefore, the bottom of the tank primary volume is:

$$
\text { PS_elev := SS_PS_SPACE }=0.66667 \mathrm{ft}
$$

\subsubsection{Height of the Tank Primary Volume.}

The height of this volume will be assumed to be equal to the volume of this volume divided by the area of this volume:

$$
\text { PS_ht }:=\frac{\text { PS_vol }}{\text { PS_area }}=42.279 \mathrm{ft}
$$

5.1.2.5. Subdivisions of Primary Tank Volume.

The primary tank will be vertically subdivided into several computational cells to model the settled slurry layer, the supernatant level, the level of the settled slurry after mixing and the location of thermocouples where possible. The subdivisions will be sized to give a reasonable representation of the conduction heat transfer within the settled, non-convective layer.

The location of the bottom thermocouple is about 11 inches off of the floor of the waste tank. The thickness of the slurry initial1y in AY-102 is 17 inches. Therefore, if we make the first node 5 inches hight and the second node 17 inches high, the center of the second node will be at the thermocouple location.

$$
\begin{aligned}
& \Delta \mathrm{x}_{1}:=5 \text { in }=0.41667 \mathrm{ft} \\
& \Delta \mathrm{x}_{2}:=12 \text { in }=1 \mathrm{ft}
\end{aligned}
$$

Location of center of node 2 :

$$
\Delta \mathrm{x}_{1}+0.5 \cdot \Delta \mathrm{x}_{2}=11 \text { in }
$$

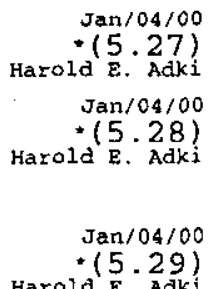




\begin{tabular}{|lr|}
\hline JoHN MARVIN, INC. & Calculation Number: JMI-9910_01 \\
\hline Analyst: Marvin J. Thurgood & Date: Feb 9, 2000 \\
\hline Reviewer: Harold E. Adkins & Date: Feb 9, 2000 \\
\hline Subject: Notebook for GoTH_SNF Simulation of Tank-AY102 \\
\hline
\end{tabular}

The cell subdivision heights selected for model construction are as displayed in Table 5.1.

Table 5.1 Subdivision Heights and Pressures.

\begin{tabular}{|c|c|c|c|c|}
\hline Level & Height & Pressure & Elevation & $\begin{array}{l}\text { Dist. to } \\
\text { Node Center } \\
\text { From Bot. } \\
\text { of Tank }\end{array}$ \\
\hline 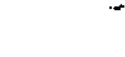 & ft & psi & $E t$ & Et \\
\hline 1 & 0.41667 & 25.49855 & 0.667 & 0.208 \\
\hline 2 & 1.00000 & 24.74739 & 1.083 & 0.917 \\
\hline 3 & 0.77700 & 24.19821 & 2.083 & 1.805 \\
\hline 4 & 0.60400 & 23.79980 & 2.860 & 2.496 \\
\hline 5 & 0.77100 & 23.40312 & 3.464 & 3.183 \\
\hline 6 & 0.95800 & 22.90432 & 4.235 & 4.048 \\
\hline 7 & 0.50600 & 22.48197 & 5.193 & 4.780 \\
\hline 8 & 1.28600 & 21.96499 & 5.699 & 5.676 \\
\hline 9 & 2.48456 & 20.87721 & 6.985 & 7.561 \\
\hline 10 & 1.68246 & 19.27394 & 9.470 & 9.644 \\
\hline 11 & 2.21203 & 18.25955 & 11.152 & 11.592 \\
\hline 12 & 2.34600 & 17.16949 & 13.364 & 13.871 \\
\hline 13 & 1.95600 & 16.14067 & 15.710 & 16.022 \\
\hline 14 & 1.00000 & 15.43373 & 17.666 & 17.500 \\
\hline 1.5 & 1.06808 & 14.95543 & 18.666 & 18.534 \\
\hline 16 & & & 19.734 & 18.750 \\
\hline
\end{tabular}

The computational cell elevations need to be set so that the level of the original AY-102 slurry lies on a node boundary, the current $\mathrm{C}-106$ slurry that has been added to C-106 lies on a node boundary and the level of the resettled mixed waste lies on a cell boundary.

The height of the original AY-102 slurry is:

$$
\text { SLURRY_HT_AY102_ORG }=1.4167 \mathrm{ft}
$$


JOHN MARVIN, INC.

Calculation Number: JMI-9910_01

Analyst: Marvin J. Thurgood

Date: Feb 9, 2000

Reviewer: Harold E. Adkins

Date: Feb 9, 2000

Subject: Notebook for GOTH_SNF Simulation of Tank-AY102

The current height of C-106 slurry that has been added to Tank AY-120 is:

$$
\text { SLURRY_HT_C106 }=4.875 \mathrm{ft}
$$

Jan $/ 18 / 00$ Harold $E .31)$

This gives a total slurry height in the tank of:

$$
\text { SLURRY_HT_MOD }=6.2917 \mathrm{ft}
$$

$\mathrm{Jan} / 18 / 00$

The resettled height of the original AY-102 slurry after it is mixed with the pumps is:

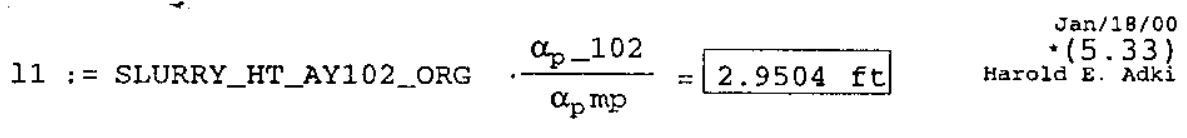

The resettled height of the $\mathrm{C}-106$ slurry after it is mixed with the pumps is:

$$
\text { I2 : = SLURRY_HT_C106 } \frac{\alpha_{\mathrm{p}-106}}{\alpha_{\mathrm{p}} \mathrm{mp}}=5.8342 \mathrm{ft} \quad \begin{array}{r}
\text { Jan } / 18 / 00 \\
(5.34)
\end{array}
$$

The total height of slurry in the tank after mixing is:

$$
11+12=8.7845 \mathrm{ft} \quad \begin{array}{r}
\text { Jan } / 18 / 00 \\
(5.35) \\
\text { Harold } \mathrm{E} . \text { Adki }
\end{array}
$$

Check the location of nodes in Table 5.1 to assure that all siurry interfaces are on node boundarys.

The total height of nodes 1 and 2 should be equal to the original AY-102 slurry height. Comparing the following equation with Equation 5.3 shows that this is true.

$$
\sum_{i=1}^{2} 1_{i, 2}=1.4167 \mathrm{ft}
$$

The total height of nodes 3 through 8 should be equal to the current height of the c-106 slurxy in the tank. Comparing equations 5.31 and 5.37 shows that this is essentially true. 
Analyst: Marvin J. Thurgood Date: Feb 9, 2000

Reviewer: Harold E. Adkins Date: Feb 9, 2000

Subject: Notebook for GOTH_SNF Simulation of Tank-AY102

$$
\sum_{i=3}^{8} 1_{i, 2}=4.902 \mathrm{ft}
$$

The total height of nodes 1 through 9 should be equal to the resettled height of slurry in the tank after pump mixing. Comparing equations 5.35 and 5.40 shows that this is essentially true.

$$
\sum_{i=1}^{9} I_{i .2}=8.8032 \mathrm{ft}
$$

\subsubsection{Hydraulic Diameter of Tank Primary Volume.}

The hydraulic diameter of this volume will be assumed to be equal to the primary tank diameter:

$$
\text { PS_hyd }:=2 \cdot \text { PS_IR }=75 \mathrm{ft}
$$

\subsubsection{Dimensions of Conductor at the Top of the Tank.}

Heat can be conducted through the soil covering the tank dome to (or from) the ambient air. This heat transfer path will be represented in the model with a conductor having the thermal properties of soil and the average thickness of the soil covering the tank dome. The ambient dry bulb temperature will be specified on the surface of this conductor and a natural convection heat transfer coefficient will be specified on the side facing the tank. dome space. The surface area of this conductor is:

$$
\text { Dome_soil_conductor_area }:=\text { PS_area }=4417.9 \mathrm{ft}^{2}
$$

The thickness of this conductor is:

$$
\text { Dome_soil_conductor_thk }:=84 \mathrm{in}=7 \mathrm{ft}
$$




\begin{tabular}{|lr|}
\hline JOHN MARVIN, INC. & Calculation Number: JMI-9910_01 \\
\hline Analyst: Marvin J. Thurgood & Date: Feb 9, 2000 \\
\hline Reviewer: Harold E. Adkins & Date: Feb 9, 2000 \\
\hline Subject: Notebook for GOTH_SNF Simulation of Tank-AY102 \\
\hline
\end{tabular}

The thermal properties for all soil conductors were assumed to be constant and to be $\rho=10 \div 1 \mathrm{bm} / \mathrm{ft}^{3}, \mathrm{k}=0.25$ $\mathrm{Btu} / \mathrm{hr}-\mathrm{Et}-{ }^{\circ} \mathrm{F}$, and $\mathrm{C}_{\mathrm{p}}=0.4 \mathrm{Btu} / \mathrm{lbm}-{ }^{\circ} \mathrm{F}$ [Ref. 8].

\subsubsection{Dimensions of Conductor at the Bottom of the} Tank.

Heat can be conducted through the soil under the tank to the ground water. This heat transfer path will be represented in the model with a conductor having the thermal properties of soil and the average thickness of the soil between the bottom of the tank and the ground water. The ground water temperature will be specified on the surface of this conductor and a natural convection heat transfer coefficient will be specified on the side facing the tank bottom. The surface area of this conductor is:

$$
\begin{aligned}
& \text { Jan } / 04 / 00 \text { Harold E. Adki *(5.42) } \\
& \text { Ground_soil_conductor_area :=PS_area }=4417.9 \mathrm{Et}^{2} \\
& \text { The thickness of this conductor is: } \\
& \text { Ground_soil_conductor_thk }:=1200 \text { in }=100 \mathrm{ft} \quad . \quad *(5.43)
\end{aligned}
$$

\subsubsection{Tank Annulus Volume.}

The tank annulus is formed by the space between the tank primary and secondary shell walis. It is a cylindrical annulus except for the top portion which is formed by the space between the secondary dome which is elliptical in shape and the primary tank dome which is circular in shape at the annulus boundary.

\subsubsection{Area of Tank Annulus Volume.}

The cross-sectional area of the tank annulus volume will be taken as the area of a annulus formed by the tank primary and tank secondary shell cylinders: 
Rev. 0

\begin{tabular}{|lr|}
\hline JOHN MARVIN, INC. & Calculation Number: JMI 9910_01 \\
\hline Analyst: Marvin J. Thurgood & Date: Feb 9, 2000 \\
\hline Reviewer: Harold E. Adkins & Date: Feb 9, 2000 \\
\hline Subject: Notebook for GOTH_SNF Simulation of Tank-AY102 \\
\hline
\end{tabular}

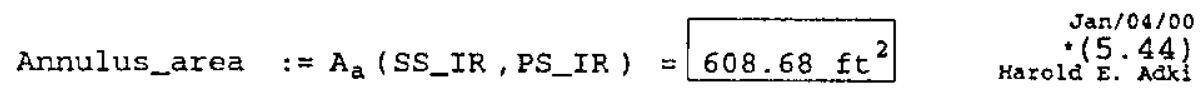

\subsubsection{Volume of Tank Annulus Volume.}

The tank annulus volume consists of the volume of the cylindrical annulus formed by the tank primary and secondary shells up to the height of the cylindrical portion of the secondary shell and by the volume formed by the boundaries of the secondary and primary domes above this height.

The volume of the cylindrical portion of the annulus is:

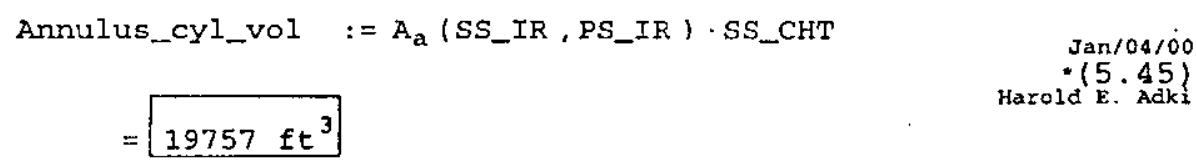

The volume of the dome portion of the annulus is the volume of the body of revolution formed by rotating the secondary shell ellipse about the tank centerline less the volume of the primary tank dome volume and the cylindrical portion of the secondary shell dome volume that is contained in the primary tank volume:

Annulus_dome_vol := Body_of_rot_vol - Ps_dome_vol

$$
-A_{C}\left(P S \_I R\right) \cdot P S \_T A N \_S S \_T A N=3932.8 \mathrm{ft}^{3}
$$

The total annulus volume is:

Annulus_vol := Annulus_cyl_vol + Annulus_dome_vol

$$
=23690 \mathrm{ft}^{3}
$$

5.1.3.3. Bottom Elevation of Tank Annulus Volume. 
JOEN MARVIN, INC.

Analyst: Marvin J. Thurgood

Reviewer: Harold E. Adkins

Subject: Notebook for GOTH_SNE Simulation of Tank-AY102

The bottom of the tank annulus will be taken as zero, therefore, the bottom of the tank annulus volume is:

$$
\text { SS_elev }:=0 \text { ft }
$$

\subsubsection{Height of the Tank Annulus Volume.}

The height of the tank annulus volume will be assumed to be equal to the tank annulus volume divided by the crosssectional area of the tank annulus

$$
\text { SS_ht }:=\frac{\text { Annulus_vol }}{\text { Annulus_area }}=38.92 \mathrm{ft}
$$

\subsubsection{Hydraulic Diameter of Tank Annulus Volume.}

The hydraulic diameter of this volume is:

$$
S S \_h y d:=D_{h}\left(\text { Annulus_area }, P_{a}\left(S S \_I R, P S \_I R\right)\right)=5 \mathrm{ft}
$$

\subsubsection{Dimensions for Conductor Between Primary Air Volume and Annulus Air.}

The surface area of the conductor between the tank dome air space and the annulus area is a function of the level of waste and supernatant in the tank.

slurry height in tank:

$$
\text { Slurry_ht := SLURRY_HT_MOD }=75.5 \text { in }
$$

Supernatant height: 
JOHN MARVIN, INC.

Calculation Number: JMI-9910_01

Analyst: Marvin J. Thurgood

Date: Feb 9, 2000

Reviewer: Harold E. Adkins

Date: Feb 9, 2000

Subject: Notebook for GOTH_SNF Simulation of Tank-AY102.

Waste_ht $:=$ Slurry_ht + Supernatant_ht $=18.75 \mathrm{ft}$. Aan/05/00 Harold E. Adki 15.53 )

The surface area of the conductor between the primary aix volume and the annulus air is:
Air_cond_area $:=($ SS_ht - Waste_ht $) \cdot P_{C}\left(P S_{\text {LIR }}\right)=4752.3 \mathrm{ft}^{2}$

The thickness of this conductor represents the tark shell thickness which is:

$$
\text { Air_cond_thk := PS_THK }=0.03125 \mathrm{ft}
$$

\subsubsection{Dimensions for Conductor Between Supernatant and} Annulus Air.

The surface area of the conductor between the supernatant and the annulus air is:

Supernatant_cond_area $:=$ Supernatant_ht $\cdot P_{c}$ (PS_IR)

$$
=2935.4 \mathrm{ft}^{2}
$$

The thickness of this conductor is:

$$
\text { Supernatant_cond_thk }:=\text { PS_THK }=0.03125 \mathrm{ft}
$$

5.1.3.8. Dimension for Conductor Between Annulus Air And Soil Around the sides of the Tank.

The surface area for the secondary shell conductor is:

$$
\begin{aligned}
& \text { surface area for the secondary shell conductor is: } \\
& \text { Side_soil_conductor_area }:=S S \_h t \cdot P_{c}\left(S S \_I R\right)=9781.5 \mathrm{ft}^{2}
\end{aligned}
$$

This conductor will have the properties of soil. The thickness of the conductor will be equal to the average distance between tanks. 


\begin{tabular}{|lr|}
\hline JOFN MARVIN, INC. & Calculation Number: JMI-9910_01 \\
\hline Analyst: Marvin J. Thurgood & Date: Feb 9, 2000 \\
\hline Reviewer: Harold E. Adkins & Date: Feb 9, 2000 \\
\hline Subject: Notebook for GOTH_SNE Simulation of Tank-AY102 \\
\hline
\end{tabular}

\subsubsection{Tank Floor slot volume.}

The tank floor slot volume represents the slots that are molded into insulating concrete that lie between the bottoms of the primary and secondary shells. Air is injected into this volume to remove heat from the bottom of the waste contained in the primary volume.

\subsubsection{Area of Floor slot Volume.}

The floor slots are arranged in three rings, as shown in Figure 3.2. The flow area of the individual slots in each ring are:

$$
\begin{aligned}
& \text { are: } \\
& \text { Slot_A_area }:=\text { SLOT_A_WD } \cdot \text { SLOT_HT }=\frac{\text { Jan/04/00 Harold E. Adki } *(5.60)}{0.03125 \mathrm{ft}^{2}} \\
& \text { Slot_Bad/00 Harold E. Adki } *(5.61) \\
& \text { Slot_C_area }:=\text { SLOT_C_WD } \cdot \text { SLOT_HT }=\frac{0.020833 \mathrm{ft}^{2}}{\text { Jan/04/00 Harold } E . ~ A d k i ~} *(5.62) \\
& 0.015625 \mathrm{ft}^{2}
\end{aligned}
$$

The wetted perimeter of the flow holes is:

$$
\begin{aligned}
& \text { Slot_A_wp }:=2 \cdot(\text { SLOT_A_WD + SLOT_HT })=0.75 \mathrm{Et} \quad \begin{array}{r}
\text { Jan } / 04 / 00 \\
(5.63)
\end{array} \\
& \text { Jan } 104100 \text { Harold E. Adki * (5.64) } \\
& \text { Slot_B_WD }:=2 \cdot(\text { SLOT_B_WD }+ \text { SLOT_HT })=0.58333 \text { ft } \\
& \text { Slot_C_WP }:=2 \cdot(\text { SLOT_C_WD + SLOT_HT })=0.5 \mathrm{ft} \\
& \text { Jan/04/00 } \\
& \text { Harold E. Adki }
\end{aligned}
$$

The hydraulic diameter of the flow holes is:

$$
\begin{aligned}
\text { Slot_A_hyd }:=D_{h}(\text { Slot_A_area , Slot_A_wp })=0.16667 \mathrm{ft} \\
\text { Jan/04/00 Harold E. Adki } *(5.67) \\
\text { Slot_B_hyd }:=D_{h}(\text { Slot_B_area, Slot_B_wp })=0.14286 \mathrm{ft}
\end{aligned}
$$


RPP-5637

Rev. 0

JOHN MARVIN, INC.

Calculation Number: JMI-9910_01

Analyst: Marvin J. Thurgood

Date: Feb 9, 2000

Reviewer: Harold E. Adkins

Date: Feb 9, 2000

Subject: Notebook for GOTH_SNF Simulation of Tank-AY102

Jan/04/00 Harold E. Adki $*(5.68)$

slot_c_hyd $:=D_{h}($ Slot_c_area , Slot_c_wp $)=0.125 \mathrm{ft}$

The total flow area of slots in each ring are:

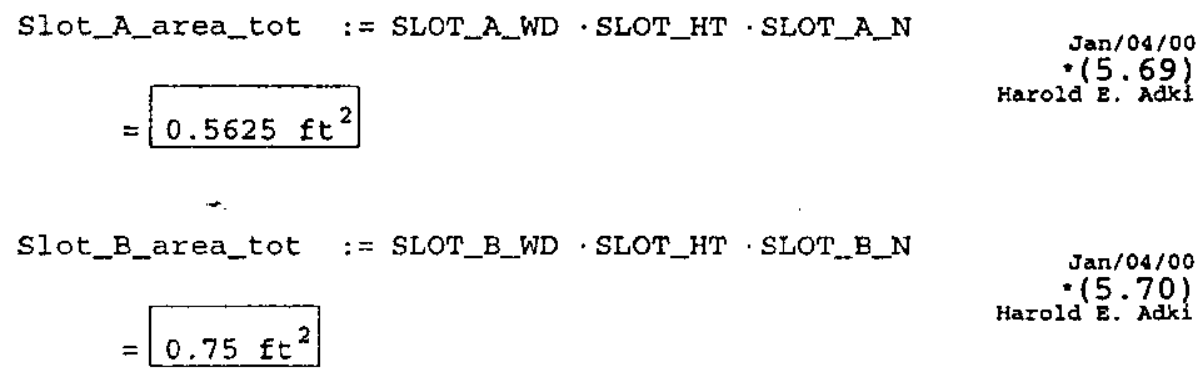

Slot_C_area_tot $:=$ SLOT_C_WD $\cdot$ SLOT_HT $\cdot$ SLOT_C_N

The total area for heat transfer between the air and the waste in each ring is (assume slot top area):

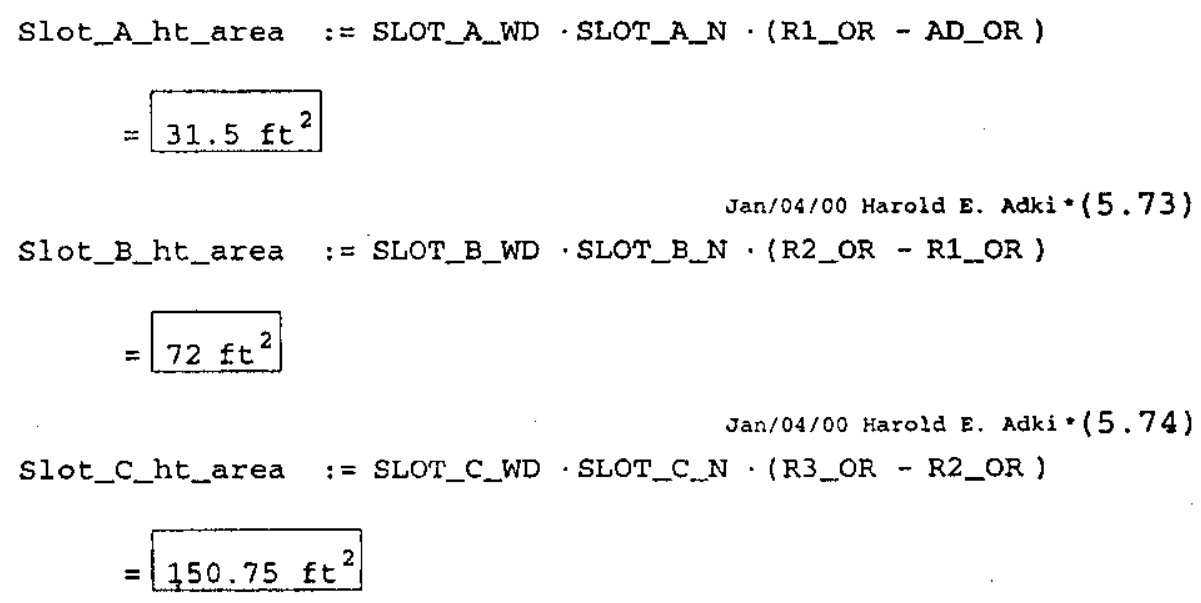




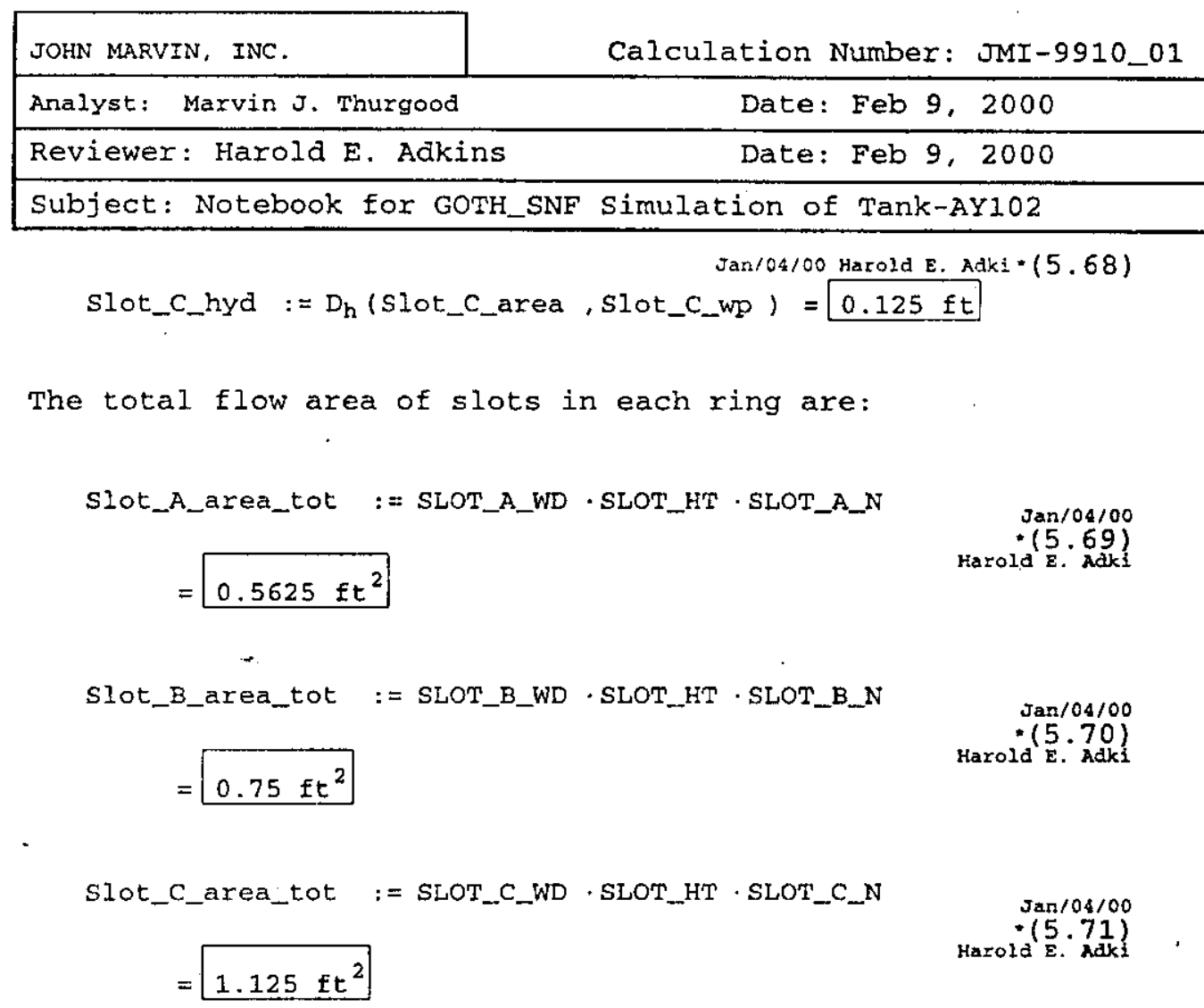

The total area for heat transfer between the air and the waste in each ring is (assume slot top area):

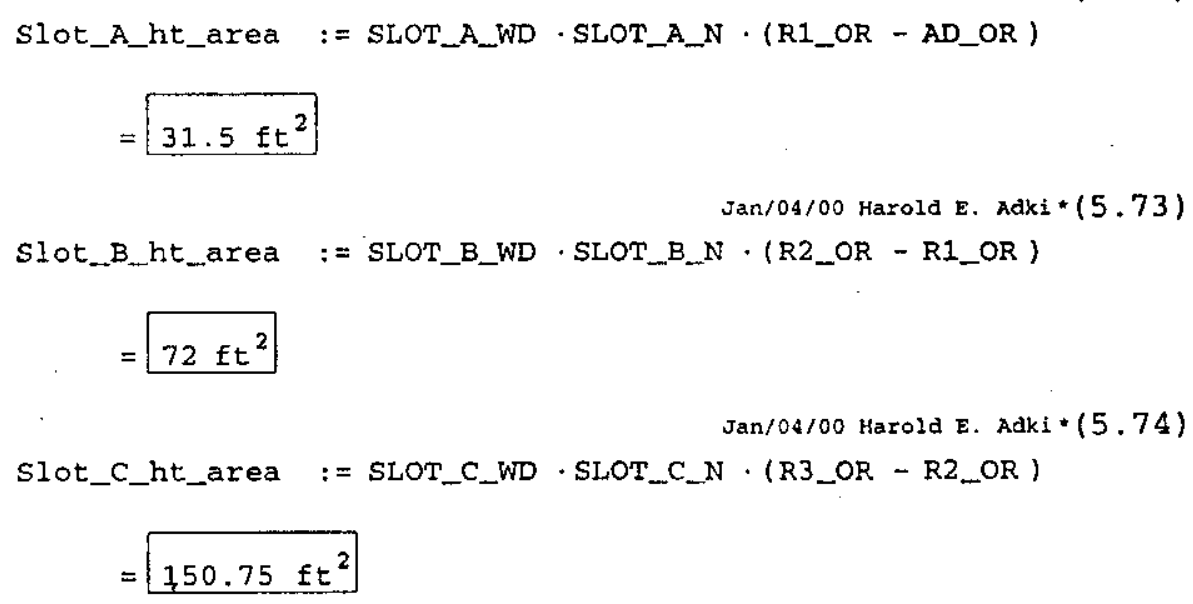


JOHN MARVIN, INC.

Analyst: Maxvin J. Thurgood

Reviewer: Harold E. Adkins
Calculation Number: JMI-9910_01

Date: Feb 9, 2000

Date: Feb 9, 2000

The flow area of the outer slots is twice the flow area of the inner slots, therefore, the Reynolds number will be halved. See what effect this has. The Reynolds number is given by [Ref. 5]:

$$
\operatorname{Re}(\rho, v, D, \mu):=\rho \cdot v \cdot \frac{D}{\mu}
$$

Jan $/ 04 / 00$

$\therefore(5.75)$

The assumed dry bulb air temperature is:

$$
T_{\AA}:=\operatorname{tf}(76)
$$

Jan 104100

$(5.76)$

The air pressure is:

$$
\mathrm{P}_{\mathrm{A}}:=14.7 \mathrm{psi}
$$

The gas constant for air is:

$$
R_{A}:=53.34 \frac{\mathrm{ft}-1 \mathrm{bf}}{1 \mathrm{bm}-\mathrm{R}}
$$

The density of air at these conditions is:

$$
\rho_{\mathrm{A}}:=\frac{\mathrm{P}_{\mathrm{A}}}{\mathrm{R}_{\mathrm{A}} \cdot \mathrm{T}_{\mathrm{A}}}=0.074085 \frac{\mathrm{lbm}}{\mathrm{ft}}
$$

The air flow rate is:

$$
\begin{aligned}
& Q_{A}:=Q_{-} \text {secondary }=1000 \frac{\mathrm{Et}^{3}}{\mathrm{~min}} \\
& \mathrm{~m}_{\mathrm{A}}:=Q_{\mathrm{A}} \cdot \rho_{\mathrm{A}}=1.2347 \frac{\mathrm{lbm}}{\mathrm{s}}
\end{aligned}
$$

$\operatorname{Jan} / 04 / 00$ $(5.77)$ Harold E. Adki

The viscosity of air at these conditions is [Ref. 5]:

$$
\mu_{\mathrm{A}}:=0.04 \times 10^{-5} \frac{\mathrm{lbE}-\mathrm{s}}{\mathrm{ft}}=0.00019152 \text { poise }
$$

$$
\begin{array}{r}
\text { Feb/10/00 } \\
(5.80) \\
\text { Harold E. Adki } \\
\\
\text { Jan } / 04 / 00 \\
(5.81) \\
\text { Harold E. Adk }
\end{array}
$$

The thermal conductivity of air at these conditions is

[Ref. 4]:

$$
\mathrm{k}_{\mathrm{A}}:=0.016 \frac{\mathrm{Btu}}{\mathrm{hr}-\mathrm{ft}-\mathrm{R}}
$$

$\operatorname{Jan} / 05100$

$+(5.83)$ harold $\mathrm{E}$. Adki

The specific heat of air at these conditions is [Ref. 4]: 
Subject: Notebook for GOTH_SNF Simulation of Tank-AY102

$$
C p_{A}:=0.24 \frac{B t u}{1 b m-R}
$$

The Prandle number for the air is:

$$
P I_{A}:=\mu_{A} \cdot \frac{C P_{A}}{k_{A}}=0.69496
$$

Jan $104 / 00$

Slot A:

$$
\begin{aligned}
& \rho_{A} A:=\frac{P_{A}}{R_{A} \cdot t f(97)}=0.07129 \frac{\mathrm{lbm}}{\mathrm{ft}^{3}} \\
& \text { Jan } / 04 / 00 \\
& \begin{array}{r}
*(5.86) \\
\text { Hayold E. Adki }
\end{array} \\
& \mu_{\mathrm{A}} \mathrm{A}:=0.0395 \times 10^{-5} \frac{\mathrm{lbF}-\mathrm{s}}{\mathrm{ft}^{2}}=0.00018913 \text { poise } \\
& \operatorname{Jan} / 05 / 00 \\
& (5.87) \\
& \text { harold E. AdkI } \\
& \mathrm{k}_{\mathrm{A}} \mathrm{A}:=0.0157 \frac{\mathrm{Btu}}{\mathrm{hr}-\mathrm{ft}-\mathrm{R}} \\
& \text { Jan } 105 / 00 \\
& \text { Harold E. Adki } \\
& \operatorname{Pr}_{A} A:=\mu_{A} A \cdot \frac{C P_{A}}{k_{A} A}=0.69939 \\
& \text { Jan } 15.89700 \\
& \text { Harold E. AdK }
\end{aligned}
$$

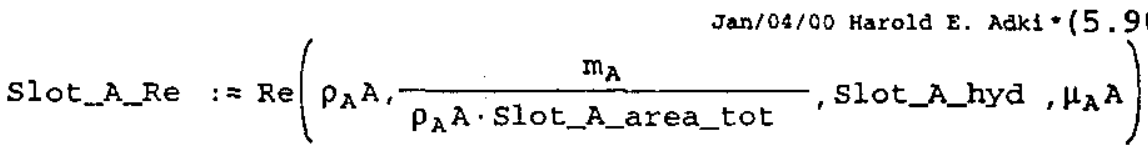

$$
\begin{aligned}
& =28787
\end{aligned}
$$

Slot B:

$$
\begin{aligned}
& \rho_{A} B:=\frac{P_{A}}{R_{A} \cdot t f(125)}=0.067876 \frac{1 \mathrm{bm}}{f t^{3}} \\
& \mu_{A} B:=0.041 \times 10^{-5} \frac{1 \mathrm{bf}-\mathrm{s}}{\mathrm{ft} t^{2}}=0.00019631 \text { poise }
\end{aligned}
$$


JOHN MARVIN, INC.

Analyst: Marvin J. Thurgood

Reviewer: Harold E. Adkins

Subject: Notebook for GOTH_SNF Simulation of Tank-AY102
Calculation Number: JMI-9910_01

Date: Feb 9, 2000 Date: Feb 9, 2000
$k_{A} B:=0.0162 \frac{B t u}{h r-f t-R}$

$\operatorname{Pr}_{A} B:=\mu_{A} B \cdot \frac{C_{P_{A}}}{k_{A} B}=0.70354$

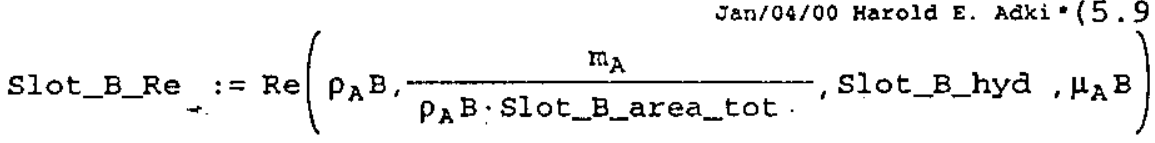

$$
=17829
$$

slot C:

$$
\begin{aligned}
& \rho_{A} C:=\frac{P_{A}}{R_{A} \cdot t f(153)}=0.064774 \frac{\mathrm{Ibm}}{\mathrm{ft}^{3}} \\
& \mu_{A} C:=0.0425 \times 10^{-5} \frac{1 \mathrm{bf}-\mathrm{s}}{\mathrm{ft}^{2}}=0.00020349 \text { poise } \\
& k_{A} C:=0.0167 \frac{B t u}{h r-f t-R} \\
& \operatorname{Pr}{ }_{A} C:=\mu_{A} c \cdot \frac{C P_{A}}{k_{A} C}=0.70744
\end{aligned}
$$

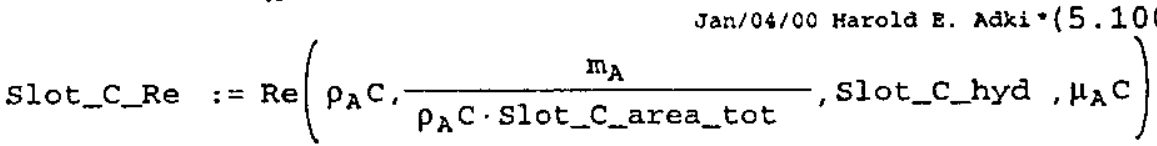

$$
\begin{aligned}
& =10033
\end{aligned}
$$

The heat transfer coefficient for flow in tubes will be Harold 8 . Adki

$\operatorname{Tan} / 04100$ Harold $(5.94)$ 

Date: Feb 9,2000

Subject: Notebook for GOTH_SNF Simulation of Tank-AY102

used for the heat transfer in the flow slots. The heat transfer coefficient will be the maximum of the laminar flow value [Ref. 4 ],

$$
h_{L}(D, k):=4.0 \cdot \frac{k}{D}
$$

and the turbulent flow value[Ref. 4];

$$
h_{T}(\operatorname{Re}, \operatorname{Pr}, k, D):=0.023 \cdot \operatorname{Re}^{0.8} \cdot \operatorname{Pr}^{0.4} \cdot \frac{k}{D}
$$

or:

$h(D, k, R e, \operatorname{Pr}):=\max \left(h_{L}(D, k), h_{T}(R e, \operatorname{Pr}, k, D)\right)$

$$
\begin{aligned}
\text { Slot_A_h }:=h\left(\text { Slot_A_hyd , } k_{A} A, \text { Slot_A_Re , PrA } A\right) \\
=6.9347 \frac{B t u}{h r-f t^{2}-\mathrm{R}}
\end{aligned}
$$

$$
\begin{aligned}
\text { Slot_B_h }:=h\left(\text { Slot_B_hyd , } k_{A} B, \text { Slot_B_Re , Pr } B\right) \\
=5.7037-\frac{B t u}{h r-f t^{2}-R}
\end{aligned}
$$

$$
\begin{aligned}
\text { Slot_c_h }: & =h\left(\text { slot_c_hyd }, k_{A} C, \text { slot_c_Re }, P x_{A} C\right) \\
& =4.2517 \frac{B t u}{h r-f t^{2}-R}
\end{aligned}
$$

Assuming a waste temperature of $200^{\circ} \mathrm{F}$ established from previous runs the slot outlet temperatures are determined as:

$$
T_{w}:=\operatorname{tf}(200)
$$


RPP-5637

Rev. 0

JOHN MARVIN, INC.

Calculation Number: JMI-9910_01

Analyst: Marvin J. Thurgood

Date: Feb 9, 2000

Reviewer: Harold E. Adxins Date: Feb 9, 2000

Subject: Notebook for GOTH_SNF Simulation of Tank-AY102

Jan/04/00 Harold E. Adki *(5.108)

$T_{A}$ out $\left(h, A, T w, T_{A}\right.$ in, $\left.m, C_{P}\right):=\frac{h \cdot A \cdot T w+m \cdot C_{p} \cdot T_{A} \text { in }}{m \cdot C_{p}+h \cdot A}$

Jan/04/00 Harold E. Adki $*(5,109)$

Slot_A_out $:=$

$T_{A} \operatorname{out}\left(S l o t \_A_{-} h, S l o t \_A_{-} h t_{-}\right.$area $\left., T_{W}, T_{A}, m_{A}, C p_{A}\right)$

$=97.075 \mathrm{~F}$

slot_B_out : :

Jan/04/00 Harold E. Adki*(5.110)

$T_{A}$ out $\left(S l o t \_B \_h\right.$, slot_B_ht_area,$T_{w}$, siot_A_out $\left., m_{A}, C p_{A}\right)$

$=125.68 \mathrm{~F}$

Jan $/ 04 / 00$ Harold E. Adki $*(5.111)$

slot_c_out : =

$$
\begin{aligned}
& \left.T_{A} \text { out (slot_c_h, slot_c_ht_area, } T_{w}, \text { slot_B_out, } m_{A}, C p_{A}\right) \\
& =153.58 \mathrm{~F}
\end{aligned}
$$

and the efficiency is determined to be:

$$
\text { eff }:=\frac{\text { slot_c_out }-T_{A}}{T_{w}-T_{A}}=0.62561
$$

Determine total slot heat transfer area:

Tot_slot_ht_area $:=$ slot_A_ht_area $^{\circ}$

$$
\begin{aligned}
& + \text { Slot_B_ht_area + Slot_C_ht_area } \\
& =254.25 \mathrm{ft}^{2}
\end{aligned}
$$

Look at total heat transfer per leg: 
JOHN MARVIN, INC.

Calculation Number: JMI-9910_01

Analyst: Marvin J. Thurgood Date: Feb 9, 2000

Reviewer: Harold E. Adkins Date: Feb 9, 2000

Subject: Notebook for GOTH_SNF Simulation of Tank-AY102

Jan/04/00 Harold E. Adki *(5.114)

Q_A $:=$ Slot_A_h $\cdot$ Slot_A_ht_area $\cdot\left(T_{w}-\right.$ Slot_A_out $)=22483 \frac{\text { Btu }}{\mathrm{hr}}$ Jan/04/00 Harold E. Adki $(5,115)$

Q_B := Slot_B_h $\cdot$ Slot_B_ht_area $\cdot\left(T_{w}-\right.$ Slot_B_out $)=30520 \frac{\text { Btu }}{\mathrm{hr}}$ Jan $/ 04 / 00$ Harold E. Adki $+(5.116)$

Q_C : : Slot_C_h $\cdot$ Slot_C_ht_area $\cdot\left(T_{w}-\right.$ slot_C_out $)=29756 \frac{\mathrm{Btu}}{\mathrm{hr}}$ Look at energy transfer for each leg:

$$
\begin{aligned}
& \text { MQ_A }:=m_{A} \cdot C P_{A} \cdot\left(\text { Slot_A_out }-T_{A}\right)=\begin{array}{rr}
\text { Jan } / 04 / 00 \\
+(5.117) \\
22483 \frac{\mathrm{Btu}}{\mathrm{hr}}
\end{array} \quad \begin{aligned}
\text { Harold E. Adki }
\end{aligned} \\
& \text { Jan/04/00 Harold E. Adk1 *(5.118) } \\
& M Q \_B:=m_{A} \cdot C p_{A} \cdot(\text { Slot_B_out }- \text { slot_A_out })=30520 \frac{\mathrm{Btu}}{\mathrm{hr}} \\
& \text { Jan } / 04 / 00 \text { Harold E. Adki } *(5.119)
\end{aligned}
$$

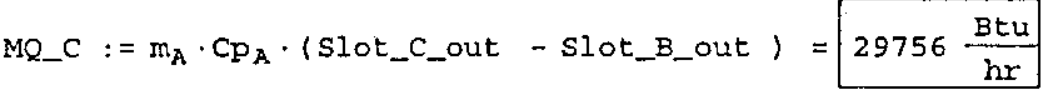

Total Heat Transfer to Secondary Air:

$$
\text { Q_tot }:=Q_{-} A+Q_{-} B+Q_{-} C=82759 \frac{\mathrm{Btu}}{\mathrm{hr}}
$$

The average heat transfer coefficient is:

$$
\begin{aligned}
\text { h_ave } & :=\frac{\text { Q_tot }}{\text { Tot_slot_ht_area }} \cdot\left(T_{w}-\text { Slot_C_out }\right) \\
& =7.0114 \frac{\mathrm{Btu}}{\mathrm{hr}-\mathrm{ft} \mathrm{t}^{2}-\mathrm{R}}
\end{aligned}
$$

Fraction of total heat:

$$
\text { Q_frac_sec }:=\frac{\text { Q_tot }}{\text { Q_102+0_106 }}=0.71117
$$

I come to the following conclusions from the above analyses: :

1. The temperature rise in the secondary inlet air 


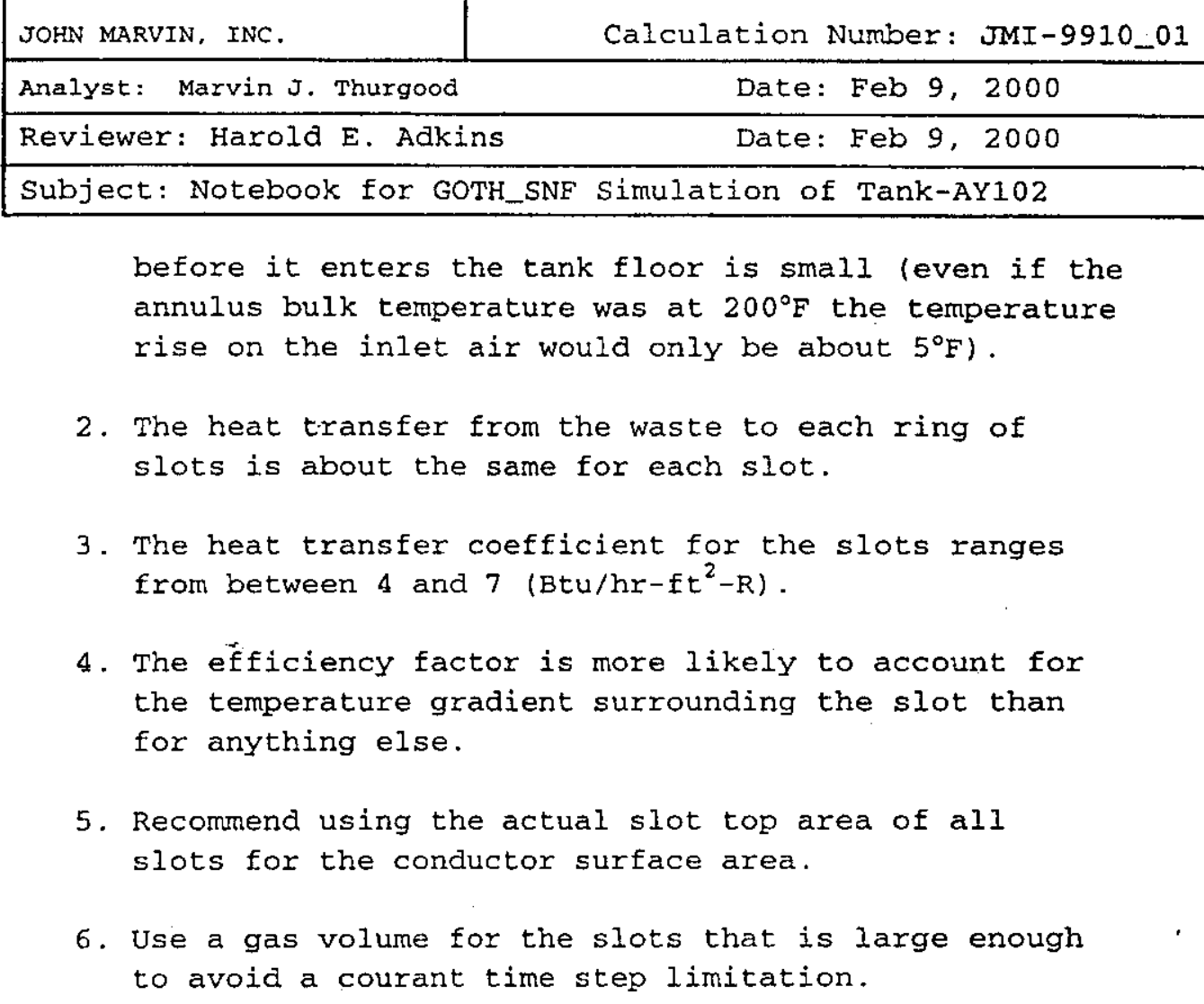

Velocity of air in annulus:

$$
\frac{Q_{\mathrm{A}}}{\text { Annulus_area }}=0.027381 \frac{\mathrm{ft}}{\mathrm{s}}
$$

Velocity of air in floor slots:

$$
\begin{gathered}
\frac{Q_{A}}{\text { slot_A_area_tot }}=29.63 \frac{\mathrm{ft}}{\mathrm{s}} \\
\frac{Q_{\mathrm{A}}}{\text { slot_B_area_tot }}=22.222 \frac{\mathrm{ft}}{\mathrm{s}} \\
\frac{Q_{\mathrm{A}}}{\text { Slot_C_area_tot }}=14.815 \frac{\mathrm{ft}}{\mathrm{s}}
\end{gathered}
$$

Jan $/ 04 / 00$

$*(5.124)$

Harold $\bar{E}$. Adki

$\operatorname{Jan} / 04 / 00$

.$(5.125)$

Harold $E$. Adki

$\operatorname{Jan} / 04 / 00$

.$(5.126)$

Harold E. Adki 


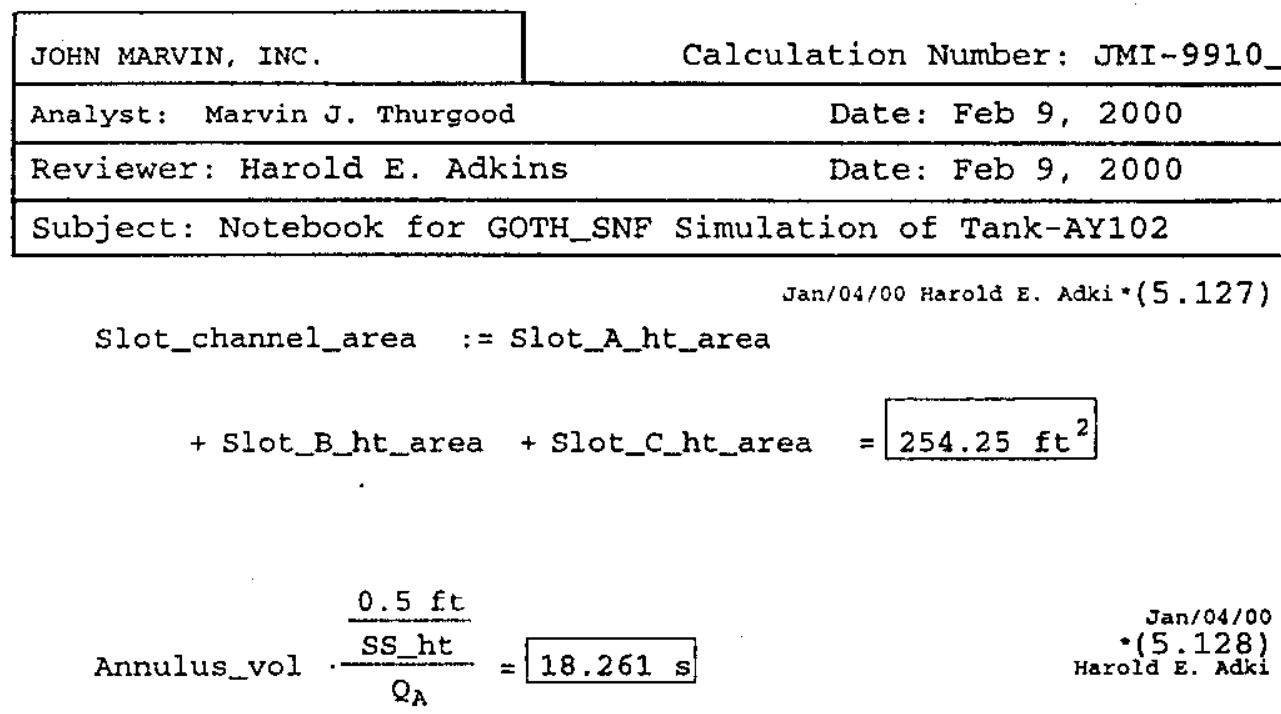

5.1.4.2. Volume of Floor slot Volume.

Jan/04/00 Harold E. Adk1*(5.129)

Slot_volume $:=$ Slot_A_area_tot $\cdot\left(R 1 \_O R-A D \_O R\right)$

+ Slot_B_area_tot $\cdot\left(R 2 \_O R\right.$ - R1_oR)

+ Slot_C_area_tot $\cdot\left(R 3 \_O R-R 2 \_O R\right)$

$=31.781 \mathrm{ft}^{3}$

$\frac{\text { Slot_volume }}{Q_{A}}=1.9069 \mathrm{~s}$

Jan $/ 04 / 00$

$*(5.130)$

Harold E. Adki

Volume will need to be made artificially large to avoid time step limitation.

$$
\text { Slot_volume_model }:=Q_{A} \cdot 160 \mathrm{~s}=2666.7 \mathrm{ft}^{3}
$$

5.1.4.3. Elevation of Floor slot Volume.

$$
\text { Slot_elev := SS_pS_SPACE - SLOT_HT }=0.004167 \mathrm{ft}
$$

5.1.4.4. Height of Floor Slot Volume. 


\begin{tabular}{|lr|}
\hline JoHN MARVIN, INC. & Calculation Number: JMI-9910_01 \\
\hline Analyst: Marvin J. Thurgood & Date: Feb 9, 2000 \\
\hline Reviewer: Harold E. Adkins & Date: Feb 9, 2000 \\
\hline Subject: Notebook for GOTH_SNF Simulation of Tank-AY102
\end{tabular}

$$
\text { Slot_ht }:=\text { SLOT_HT }=0.125 \mathrm{ft}
$$

\subsubsection{Hydraulic Diameter of the Floor Volume.}

The hydraulic diameter of the floor volume will be set to the hydraulic diameter of the out set of each floor slots.

$$
\text { slot_hyd }:=\text { slot_c_hyd }=0.125 \mathrm{ft}
$$

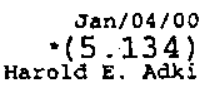

\subsubsection{Slot Conductor Dimensions.}

The surface area of this conductor is equal to the top area of all of the radial slots in the floor. The azimuthal slots will be ignored.

$$
\text { Slot_ht_area }:=\text { slot_channel_area }=254.25 \mathrm{ft}^{2}
$$

This conductor is made of steel plate. The thickness of this plate is:

$$
\text { Slot_cond_thk }:=\text { PS_THK }=0.03125 \mathrm{ft}
$$

\subsubsection{Floor slot Air Inlet Volume.}

This volume represents the four, 4 inch schedule 40 pipes that supply air to the floor slots. This volume is necessary to preheat the incoming air from the ambient conaitions to the temperature that the air will enter the floor slots at the center of the tank.

\subsubsection{Supply Pipe Volume.}

Well, lets look at the temperature increase that might occur to the inlet air as the air travels through the pipes to the floor of the tanks (never mind that these pipes pass at least 84 inches through the ground) before entering the 
JOHN MARVIN, INC.

Calculation Number: JMI-9910_01

Analyst: Marvin J. Thurgood

Date: Feb 9, 2000

Reviewer: Harold E. Adkins

Date: Feb 9, 2000

Subject: Notebook for GOTH_SNF Simulation of Tank-AY102

tank annulus.

Secondary ventilation inlet pipes:

Length:

P4_Len $:=R 3$ _OR $-A D \_O R=35.75 \mathrm{ft}$

$\mathrm{Jan} / 04 / 00$

$*(5.137)$

Flow Area:

P4_Area $:=A_{c}\left(\frac{P 4 \_I D}{2}\right)=0.088405 f t^{2}$

$\operatorname{San} 104 / 00$

(5.138)

Harold E. Adk

Single Pipe Volume:

P4_Vol $:=$ P4_Area $\cdot$ P4_Len $=3.1605 \mathrm{ft}^{3}$

Number of pipes:

an $/ 04 / 00$

.$(5.139)$

Harold $\dot{E}$. Adk

$\mathrm{P} 4 \_\mathrm{n}:=4$

Total Volume of Pipes:

P4_Vol_tot $:=$ P4_Vol $\cdot \mathrm{P} 4 \_n=12.642 \mathrm{ft}^{3}$

$\operatorname{Jan} / 04100$

$\bullet(5.140)$

Harold E. Adk

Total Flow Area of pipes:

P4_Area_tot $:=$ P4_Area $\cdot P 4 \_n=0.35362 \mathrm{ft}^{2}$

$\mathrm{Jan} / 04 / 00$

$(5.142)$

Harold $\dot{E}$. Adki

Courant Limit of Pipe volume:

$\frac{\text { P4_Vol_tot }}{Q_{A}}=0.75851 \mathrm{~s}$

$\operatorname{Jan} / 04 / 00$

$(5.143$

Harold $E$. AdK

The pipe volume will have to be increased to get

reasonable run times:

P4_vol_model $:=2000 \frac{\mathrm{ft}^{3}}{\mathrm{~min}} \cdot 160 \mathrm{~s}=5333.3 \mathrm{ft}^{3}$

\subsubsection{2. : Supply Pipe Area.}

49 of 73 
JOHN MARVIN, INC. Calculation Piniber: JMI-9910_01

Analyst: Marvin J. Thurgood Date: Feb 9, 2000

Reviewer: Harold E. Adkins Date: Feb 9,2000

Subject: Notebook for GOTH_SNF Simulation of Tank-AY102

P4_area_model $:=\frac{\text { P4_vol_model }}{\text { SS_ht }}=137.03 \mathrm{ft}^{2}$

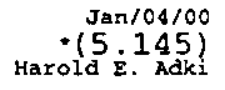

5.1.5.3. Supply Pipe Elevation.

The supply pipe elevation will be assumed to be the same as the bottom elevation of the tank annulus volume (this assumption is not important):

$$
\text { P4_elev : }=S S \_ \text {_elev }=0 \mathrm{ft}
$$

\subsubsection{Supply Pipe Height.}

The supply pipe volume height will be assumed to be equal to the height of the annulus (this assumption is not important :

$$
\text { P4_ht : }=\text { SS_ht }=38.92 \mathrm{ft}
$$

5.1.5.5. Supply Pipe Hydraulic Diameter:

$$
\text { P4_hyd }:=\text { P4_ID }=0.3355 \mathrm{ft}
$$

\subsubsection{Supply Pipe Conductor Dimensions.}

Reymolds Number:

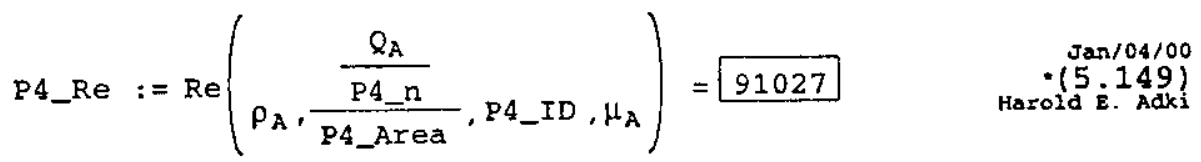

Heat transfer to air flowing through pipes in tank floor:

Heat Transfer Area: 
JOHN MARVIN, INC.

Calculation Number: JMI-9910_01

\begin{tabular}{|lr|}
\hline Analyst: Marvin J. Thurgood & Date: Feb 9, 2000 \\
\hline Reviewer: Harold E. Adkins & Date: Feb 9, 2000 \\
\hline Subject: Notebook for GOTH_SNF Simulation of Tank-AY102 \\
\hline
\end{tabular}

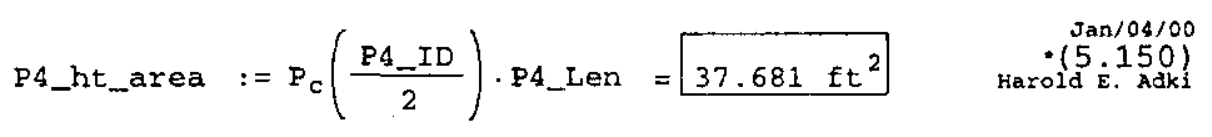

P4_ht_area_tot $:=$ P4_ht_area $\cdot \mathrm{P4} n=\sqrt{\mathrm{Jan} / 04 / 00 \text { Harold } E \text {. Adki } *(5.151)}$

Air side pipe heat transfer coefficient:

Air side pipe heat transfer Harold E. Adki*(5.152)

$P 4 \_h:=h\left(P 4 \_I D, k_{A}, P 4 \_R e, \operatorname{Pr}_{A}\right)=8.7958 \frac{B t u}{h r-f t^{2}-\mathrm{P}}$

Inlet temperature to bottom of tank:

P4_out : :=

$$
\begin{aligned}
& T_{A} \text { out }\left(P 4 \_h, P 4 \_h t \text { Prea }, T_{W}, T_{A}, \frac{m_{A}}{4}, C p_{A}\right) \\
& =144.71 \mathrm{~F}
\end{aligned}
$$

Look at waste side heat transfer coefficient:

Temperature drop across concrete[Ref. 4]:

$$
\begin{aligned}
& \mathrm{h}_{c}:=\frac{0.17 \frac{\mathrm{btu}}{\mathrm{hr-ft}-\mathrm{R}}}{1 \mathrm{in}}=2.04 \frac{\mathrm{Btu}}{\mathrm{hr-ft^{2 } - \mathrm { R }}} \\
& \begin{aligned}
\mathrm{P4} \text { _out }: & = \\
\mathrm{T}_{\mathrm{A}} \text { out }\left(\mathrm{h}_{\mathrm{C}}, \mathrm{P4} \text { _ht_area }, \mathrm{T}_{\mathrm{w}}, \mathrm{T}_{\mathrm{A}}, \frac{\mathrm{m}_{\mathrm{A}}}{4}, \mathrm{Cp}\right) & \\
& =103.74 \mathrm{~F}
\end{aligned}
\end{aligned}
$$

Look at natural convection heat transfer in annulus [Ref. 5] : 
JOHN MARVIN, INC.

Analyst: Marvin J. Thurgood

Reviewer: Harold $E$. Adkins

Subject: Notebook for GOTH_SNF Simulation of Tank-AY102

Date: Feb 9, 2000
Calculation Number: JMI-9910_01

Date: Feb 9, 2000

$\mathrm{Nu}=0.13\left(\mathrm{Gr}_{f} \operatorname{Pr}_{f}\right)^{0.333}$

$*(5.156)$

$G r=g \beta\left(T_{w}-T_{B}\right) \frac{x^{3}}{v^{2}}$

$\mathrm{Nu}=\mathrm{h} \frac{\mathrm{x}}{\mathrm{k}}$

$h=\frac{k}{x} 0.13\left(G_{f} \operatorname{Pr}_{f}\right)^{0.333}$

-(5.159)

Harold $\dot{E}$. Adk

$g:=32.2 \frac{\mathrm{ft}}{\mathrm{s}^{2}}$

$\beta:=\frac{1}{T_{A}}=0.0018668 \frac{1}{R}$

$v=\frac{\mu}{\rho}$

$\mathrm{Gr}=\mathrm{g} \beta\left(\mathrm{T}_{\mathrm{w}}-\mathrm{T}_{\mathrm{B}}\right) \mathrm{x}^{3} \frac{\rho^{2}}{\mu^{2}}$

$\mathrm{Gr}:=\mathrm{g} \cdot \beta \cdot\left(\mathrm{T}_{\mathrm{w}}-\mathrm{T}_{\mathrm{A}}\right) \cdot \frac{\rho_{\mathrm{A}}{ }^{2}}{\mu_{\mathrm{A}}{ }^{2}}=2.4701 \times 10^{+08} \frac{1}{\mathrm{ft} \mathrm{t}^{3}}$

$\mathrm{P} 4 \mathrm{a} \_\mathrm{h}:=\mathrm{k}_{\mathrm{A}} \cdot 0.13 \cdot\left(\mathrm{Gr} \cdot \mathrm{Pr}_{\mathrm{A}}\right)^{0.333}=1.1473 \frac{\mathrm{Btu}}{\mathrm{hr}-\mathrm{ft} \mathrm{t}^{2}-\mathrm{R}}$

P4a_ht_area $:=P_{C}\left(\frac{P 4 \_I D}{2}\right) \cdot S S \_h t=41.021 \mathrm{ft}^{2}$
Jan/04/00 Hazold $\mathrm{E} .160)$

$\mathrm{Jan} / 04 / 00$ Marold in. Adk

Jar $/ 04 / 00$

* (5.162)

Harold E. Adk

$\operatorname{Jan} / 04 / 00$

(5.163)

Harold $\dot{E}$. Adk $*(5.161)$

Jan/04/00 Hazold $\dot{E} 166)$ 


\begin{tabular}{|lr|}
\hline JOHN MARVIN, INC. & Calculation Number: JMI-9910_01 \\
\hline Analyst: Marvin J. Thurgood & Date: Feb 9, 2000 \\
\hline Reviewer: Harold E. Adkins & Date: Feb 9, 2000 \\
\hline Subject: Notebook for GOTH_SNF Simulation of Tank-AY102 \\
\hline
\end{tabular}

P4a_out : =

$$
\begin{aligned}
& T_{A} \text { out }\left(P 4 a \_h, P 4 a \_h t \_a r e a, t f(110), T_{A}, \frac{m_{A}}{4}, C p_{A}\right) \\
& =81.1 \mathrm{~F}
\end{aligned}
$$

Conclusion, main heating occurs in floor so heat transfer to these pipes will be that due to heat transfer between waste and air in pipe.

\subsubsection{Watex Refill sump.}

This volume has no importance other than to provide a computational volume to mimic the collection and return of the condensate formed through tank waste evaporation. The amount of water that is supplied by this computational volume in conjuction with supply line "9F" is directly dictated by the quantity which leaves the tank via evaporation. The refill water temperature is conservatively set at $110^{\circ} \mathrm{F}$.

\subsubsection{Volume of Sump Volume.}

This volume will simply be made large enough so that its volume does not limit the code time step.

$$
\text { Sump_vol }:=160 \mathrm{~s} \cdot 2000 \frac{\mathrm{ft}^{3}}{\mathrm{~min}}=5333.3 \mathrm{ft}^{3}
$$

\subsubsection{Cross-sectional Area of sump Volume.}

The area of this volume is chosen using a reasonable height.

$$
\text { Sump_area }:=\frac{\text { Sump_vol }}{10 \mathrm{ft}}=533.33 \mathrm{Et}^{2}
$$


JOHN MARVIN, INC.

Analyst: Marvin J. Thurgood

Reviewer: Harold E. Fakins

Subject: Notebook for GOTH_SNF Simulation of Tank-AY102

5.1.6.3. Elevation of Sump Volume.

The sump will placed at the top of the primary tank volume Sump_elev $:=$ PS_elev + PS_ht $+1.0 \mathrm{ft}=43.946 \mathrm{ft}$

5.1.6.4. Height of Sump Volume.

The height used to calculate the sump volume area will be used :

$$
\text { Sump_ht }:=10 \mathrm{ft}
$$

$\mathrm{Jan} / 19 / 00$

5.1.6.5. Sump Hyaraulic Diameter.

$$
\text { Sump_hyd }:=4 \cdot \frac{\text { Sump_area }}{4 \cdot \sqrt{\text { Sump_area }}}=23.094 \mathrm{ft}
$$

\subsubsection{Summary of Geometric Input Data.}

The geometric data required for GOTH_SNF input which has been calculated in the above section is summarized in this section.

5.1.7.1. Volume Input Data. The volume input data input into GOTH_SNF is tabulated in Table 5.2 .

54 of 73 


\begin{tabular}{|lr|}
\hline JOHN MARVIN, INC. & Calculation Number: JMI-9910_01 \\
\hline Analyst: Marvin J. Thurgood & Date: Feb 9, 2000 \\
\hline Reviewer: Harold E. Adkins & Date: Feb 9, 2000 \\
\hline Subject: Notebook for GOTH_SNF Simulation of Tank-AY102 \\
\hline
\end{tabular}

Table 5.2 Control Volume Input Data. Jan/19/00 Harold E. Adki*

\begin{tabular}{|c|c|c|c|c|c|c|}
\hline $\begin{array}{c}\text { Vol } \\
\#\end{array}$ & Description & Vol & Elev & Ht & Hyd. D & P1 Area \\
\hline & & $f t^{3}$ & ft & ft & $\mathrm{ft}$ & $f t^{2}$ \\
\hline 1 & Tank Primary & 186783.9 & 0.6667 & 42.279 & 75.000 & 4417.86 \\
\hline 2 & Floor slots & 2666.7 & 0.5417 & 0.125 & 0.125 & 254.25 \\
\hline 3 & Annulus & 23689.7 & 0.0000 & 38.920 & 5.000 & 608.68 \\
\hline 4 & Water Sump & 5333.3 & 43.945 & 10.000 & 23.094 & 533.33 \\
\hline 5 & Air Inlet Pipes & 5333.3 & 0.0000 & 38.920 & 0.336 & 137.03 \\
\hline
\end{tabular}

\subsubsection{Conductor Input Data.}

The input data for the thermal conductors is summarized in Table 5.3. All conductors will be initialized to the average ambient air temperature [Ref 6]. The values for heat transfer coefficient or side temperature given in this table are those which are to be specified by number. Some of these are flow dependent and will need to be updated for the flow being specified. The natural convection heat transfer option will be specified in the code when a value is not given in the table. The fluid temperature adjacent to the conductor surface will be used where a temperature is not specified in the table. 
Reviewer: Harold E. Adkins

Date: Feb 9, 2000

Subject: Notebook for GOTH_SNF Simulation of Tank-AY102

Table 5.3 Conductor Input Data.

Jan/18/00 Harold E. Adki *

\begin{tabular}{|c|c|c|c|c|c|c|c|}
\hline Con & Description & S. A. & $\begin{array}{l}\text { Init. } \\
\text { Ternp. }\end{array}$ & $\begin{array}{l}\text { Side } \\
\text { A } \\
\text { H.T.C }\end{array}$ & $\begin{array}{c}\text { Side } \\
\text { A } \\
\text { Temp. }\end{array}$ & $\begin{array}{c}\text { Side } \\
\text { B } \\
\text { H.T.C }\end{array}$ & $\begin{array}{c}\text { Side } \\
\text { B } \\
\text { Temp. }\end{array}$ \\
\hline & & \multirow[b]{2}{*}{$f t^{2}$} & \multirow[b]{2}{*}{$F$} & Btu & \multirow{2}{*}{$F$} & Btu & \multirow[b]{2}{*}{$R$} \\
\hline & & & & $h r-f t^{2}-F$ & & $h r-f t^{2}-R$ & \\
\hline 1 & Floor slots & 254.2 & 82.0 & 2.568 & ---- & 7.01 & $-\cdots$ \\
\hline 2 & Supernatant-Ann & 2935.4 & 82.0 & ----- & $-\cdots-$ & $\cdots+\cdots$ & --- \\
\hline 3 & Dome-annulus & 4752.3 & 82.0 & $\ldots+\cdots$ & $--\cdots$ & ------- & ---- \\
\hline 4 & Floor-ground & 4417.9 & 82.0 & 2.568 & ---- & $-\infty-\infty-\infty$ & 50.0 \\
\hline 5 & Annulus-ground & 9781.5 & 82.0 & $---\cdots$ & ---- & 0.00 & $--\cdots$ \\
\hline 6 & Dome-ground & 4417.9 & 82.0 & $----\cdots$ & $\ldots-$ & $--\infty \cdots$ & 76.0 \\
\hline 7 & Air inlet pipes & 150.7 & 82.0 & 8.796 & $-\cdots$ & 2.04 & \\
\hline
\end{tabular}

\subsubsection{Conductor Type Input Data.}

The input data for the conductor types are summarized in Table 5.4. All of the data in this table have been previously defined except for the conductor geometry and the material, which are defined in this table.

Table 5.4 Conductor Type Input Data.

\begin{tabular}{|c|c|c|c|c|c|}
\hline $\begin{array}{c}\text { Con } \\
\#\end{array}$ & Description & Geom & Thick & O.D. & Material \\
\hline \multicolumn{6}{|c|}{ in } \\
\hline 1 & Floor slots & Wall & 0.375 & $----\infty$ & Steel \\
\hline 2 & Supernatant-Ann & Tube & 0.375 & 900.75 & Steel \\
\hline 3 & Dome-annulus & Tube & 0.375 & 900.75 & Steel \\
\hline
\end{tabular}


RPP-5637

Rev. 0

Jan/04/00 Harold E. Adki *

\begin{tabular}{|c|c|c|c|c|c|}
\hline \multirow[t]{2}{*}{$\#$} & Description & Geom & Thick & O.D. & Material \\
\hline & - & & in & in & \\
\hline 4 & Floor-ground & Wall & 1200 & $--m--$ & Soil \\
\hline 5 & Annulus-ground & Tube & 600.0 & 2160.0 & Soil \\
\hline 6 & Dome-ground & Wall & 84.00 & ------ & Soil \\
\hline 7 & Air inlet pipes & Tube & 0.237 & 4.500 & steel \\
\hline
\end{tabular}


Subject: Notebook for GOTH_SNE Simulation of Tank-AY102

\subsubsection{Flow Path Input Data.}

The flow path data are summarized in Tables 5.5 and 5.6 .

The data for the flow paths are based on the elevations and heights of the volumes that they connect to. The flow areas are defined by the volumes that they connect to, where the area is not important, an arbitrary value is assigned. This can be done because pressure drops and fluid velocities are not important in this calculation.

Table 5.5 Flow Path Input Data (1).

Jan $/ 04 / 00$ Harold E. Adki

\begin{tabular}{|c|c|c|c|c|c|}
\hline \multirow[t]{2}{*}{$\begin{array}{c}\text { F.P. } \\
\#\end{array}$} & Description & $\begin{array}{l}\text { End A } \\
\text { Elev. }\end{array}$ & $\begin{array}{l}\text { End A } \\
\text { Ht }\end{array}$ & $\begin{array}{l}\text { End B } \\
\text { Elev. }\end{array}$ & $\begin{array}{c}\text { End B } \\
\mathrm{Ht}\end{array}$ \\
\hline & & ft & $f t$ & ft & ft \\
\hline 1 & Inlet Primary & 42.836 & 0.1000 & 50.946 & 0.100 \\
\hline 2 & Outlet Primary & 53.846 & 0.1000 & 54.946 & 0.100 \\
\hline 3 & Slot Inlet & 0.010 & 0.1000 & 0.552 & 0.100 \\
\hline 4 & slot outlet & 0.552 & 0.1000 & 0.552 & 0.100 \\
\hline 5 & Outlet secondar & 38.810 & 0.1000 & 46.920 & 0.100 \\
\hline 6 & Water Drain & 43.956 & 0.1000 & 41.946 & 0.100 \\
\hline 7 & Primary Fan & 41.946 & 0.1000 & 43.446 & 0.100 \\
\hline 8 & Fan Outlet & 45.946 & 0.1000 & 43.446 & 0.100 \\
\hline 9 & Recirc. Fan out & 41.946 & 0.1000 & 43.446 & 0.100 \\
\hline 10 & Recirc. Fan Inl & 45.946 & 0.1000 & 43.446 & 0.100 \\
\hline 11 & Annulus Air Inl & 38.810 & 0.1000 & 46.920 & 0.100 \\
\hline 12 & Pump Inlet & 18.917 & 0.1000 & 18.917 & 0.100 \\
\hline 13 & Pump outlet & 0.917 & 0.1000 & 0.917 & 0.100 \\
\hline
\end{tabular}


JOHN MARVIN, INC.

Analyst: Marvin J. Thurgood

Reviewer: Harold E. Adkins

Subject: Notebook for GOTH_SNF Simulation of Tank-AY102

Tabie 5.6 Flow Path Input Data (2).

Jas/04/CO Hazold E. Adiki.

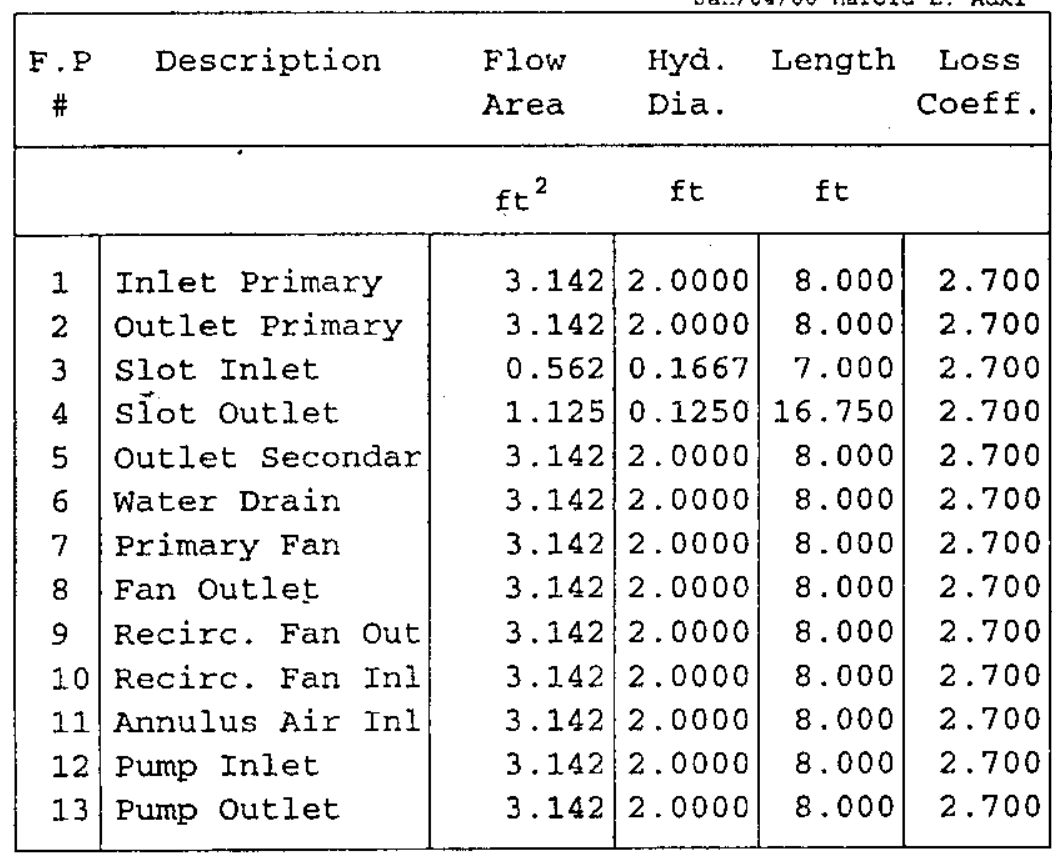

\subsubsection{Boundary Condition Input Data.}

Tabulated in Table 5.7 is the boundary condition input data for the problem described above. 


\begin{tabular}{|lc|}
\hline JOHN MARVIN, INC. & Calculation Number: JMI-9910_01 \\
\hline Analyst: Marvin J. Thurgood & Date: Feb 9, 2000 \\
\hline Reviewer: Harold E. Adkins & Date: Feb 9, 2000 \\
\hline Subject: Notebook for GOTH_SNE Simulation of Tank-AY102 \\
\hline
\end{tabular}

Table 5.7 Boundary Condition Input Data.

Jan/04/00 Hazold E. Adki.

\begin{tabular}{|c|c|c|c|c|c|}
\hline $\begin{array}{c}\text { F.P } \\
\#\end{array}$ & Description & Pressure & Temp. & Flow & $\begin{array}{l}\text { W.V. } \\
\text { Press. } \\
\text { Ratio }\end{array}$ \\
\hline & & psi & $\mathbf{F}$ & $\frac{\mathrm{et}}{\mathrm{s}}$ & \\
\hline 1 & Inlet Primary & 14.700 & 82.000 & 0.000 & 0.01050 \\
\hline 2 & Stack Inlet & 14.700 & 82.000 & 0.000 & 0.01050 \\
\hline 3 & slot Inlet & 14.700 & 82.000 & 0.000 & 0.01050 \\
\hline 4 & Slot outlet & 14.700 & 82.000 & 16.667 & 0.01050 \\
\hline 5 & Primary out & 14.700 & 82.000 & ----- & 0.01050 \\
\hline 6 & Primary Couple & 14.700 & 82.000 & 8.333 & 0.01050 \\
\hline 7 & Recir Out & 14.700 & 82.000 & 6.667 & 0.01050 \\
\hline 8 & Recirc Couple & 14.700 & 82.000 & $-\cdots$ & 0.01050 \\
\hline 9 & Pump Inlet & 14.700 & 82.000 & 46.180 & 0.01050 \\
\hline 10 & Pump outlet & 14.700 & 82.000 & ----- & 0.01050 \\
\hline
\end{tabular}

$(14 \cdot 0.5 \mathrm{ft}+22 \mathrm{ft}+0.5 \mathrm{ft}+32.5 \mathrm{ft}) \cdot$ PS_area $=\left[2.7391 \times 10^{+05} \mathrm{ft}^{3}\right.$

PS_vol $=1.3972 \times 10^{+06} \mathrm{gal}$

$17 \mathrm{in} \cdot \mathrm{ps}$ area $\cdot 0.417 \cdot 62.4 \frac{\mathrm{lbm}}{\mathrm{ft}^{3}} \cdot 1.925 \cdot 0.125 \frac{\mathrm{Btu}}{\mathrm{Ibm}-\mathrm{hr}}$

$$
=39187 \frac{\mathrm{Btu}}{\mathrm{hr}}
$$

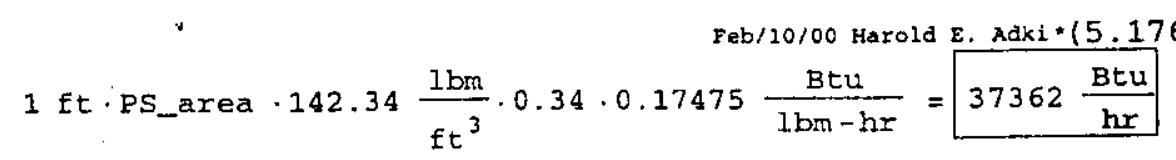




\begin{tabular}{|lr|}
\hline JoHN MiRVIN, INC. & Caictiction Number: JMI-9910_01 \\
\hline Analyst: Marvin J. Thurgood & Date: Feb 9, 2000 \\
\hline Reviewer: Harold E. Adkins & Date: Feb 9, 2000 \\
\hline Subject: Notebook for GOTH_SNF Simulation of Tank-AY102 \\
\hline
\end{tabular}

\section{SIMULATION RESULTS.}

The results of simulations that are required to determine ventilation requirements for maintaining waste temperatures below operational and safety limits are presented in this section. Three cases have been simulated. These are:

1. Nominal once through primary ventilation flow of 500 CFM and slot ventilation flow of $10.00 \mathrm{CFM}$. Air inlet temperature for both flows is $82^{\circ} \mathrm{F}$.

2. Nominal once through primary flow and secondary flow with loss of both ventilation systems when pumps are turned off.

3. Nominal once through primary flow with no slot flow. Air inlet temperature is $82^{\circ} \mathrm{F}$.

The results for each of these calculations are presented in the following sub-sections.

\subsection{NOMINAL PRIMARY AND FLOOR SLOT VENTILATION FLOWS.}

This case considers the tank to initially be filled with waste at the conditions at the end of waste transfers from C-106. The ventilation system consists of the nominal once through primary ventilation flow of $500 \mathrm{CFM}$ and the slot ventilation flow of $1000 \mathrm{CFM}$. The air inlet temperature for both systems is $82^{\circ} \mathrm{F}$. The simulation is run to the steady state temperature for ambient air conditions of $82^{\circ} \mathrm{F}$ with the solid particles in an undisturbed slurry on the bottom of the tank. The mixer pumps are then turned on and 
JOHN MARVIN, INC.

Analyst: Marvin J. Thurgood

Reviewer: Harold E. Adkins

Subject: Notebook for GOTH

Subject: Notebook for GOTH

the slurry in the bottom of the tank is mixed with the supernatant. The assertion is that the mixer pumps mix the waste to a homogeneous mixture with no slurry remaining on the bottom of the tank. The pumps are run until the supernatant comes to a steady state temperature. The pumps are then turned off and the solid particles are allowed to resettle to the bottom of the tank. The rate the particles settle is a function of the particle size, particle density, supernatant density and supernatant viscosity. The code calculates this rate from the force balance on the particles. The mixture remains convective as long as the particle fraction in a computational cell remains below $0.75^{*} \alpha_{\mathrm{p}}$ mp. The slurry becomes non-convective once the particle fraction reaches this value and the slurry begins to heat up as the radioactive decay heat must be removed by conduction through the slurry to the supernatant. Heat is removed from the surface of the supernatant by convective sensible heat transfer and evaporative heat transfer to the primary ventilation flow. Heat is also conducted down through the non-convective slurry to the air flowing through the slots in the floor of the tank and to the ground under the tank if the ground is cooler than the slurry at the bottom of the tank.

The important waste temperatures in the tank for the initial settled state and for the period when the pumps are running are shown in Figure 6.1. The steady-state supernatant temperature prior to pump operation is shown as point $\mathrm{T} 1$ in this figure. The peak slurry temperature for this state is shown as point $\mathrm{T} 2$ in this figure. The pumps are turned on and the waste comes to a uniform temperature, T3 in Figure 6.1. (Note: There is only one graphics dump between point $\mathrm{T} 2$ and $\mathrm{T} 3$ so the actual mixed temperature may be lower than that shown for T3 in the Eigure. This is not important as long as $\mathrm{T} 3$ is lower than the LCO supernatant temperature limit of $195^{\circ} \mathrm{F}$, which it is.) The pumps are run until the supernatant comes to a steady-state temperature, point T4 in Figure 6.1. 


\begin{tabular}{|lr|}
\hline JOHN MARVIN, INC. & Calculation Number: JMI-9910_01 \\
\hline Analyst: Marvin J. Thurgood & Date: Feb 9, 2000 \\
\hline Reviewer: Harold E. Adkins & Date: Feb 9, 2000 \\
\hline Subject: Notebook for GOTH_SNF Simulation of Tank-AY102 \\
\hline
\end{tabular}

$\operatorname{Jan} / 18 / 00$ Harold E. Adki *

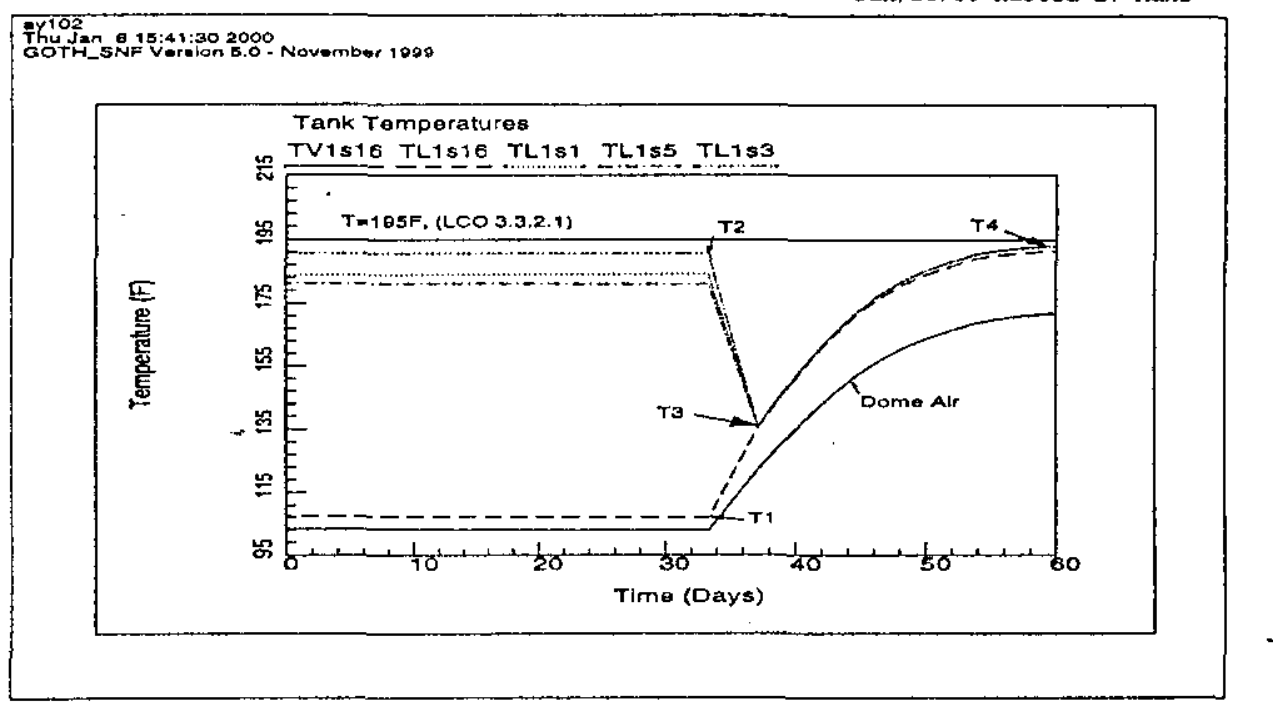

Figure 6.1 Temperatures From the Initial steady-State , Conditions Through Pump Mixing.

The temperatures $\mathrm{T} 1, \mathrm{~T} 3$ and $\mathrm{T} 4$ must be below the LCO limit of $195^{\circ} \mathrm{F}$ for the ventilation conditions specified for this case to be acceptable, and they aré. Temperature T2 must be below $215^{\circ} \mathrm{F}$ to be acceptable, and it is.

The pumps are then shut off and the solid particles settle out of the supernatant and once again form a non-convective layer. The waste cools prior to the layer becoming non-convective since the pumps are shut off and are no longer depositing energy into the waste and the primary ventilation system is removing a large amount of energy stored in the waste by evaporative cooling. The ground under the tank also cools as the waste cools. The cooler ground slows the heat up of the non-convective slurry in the bottom of the tank as it absorbs heat from the waste by conduction. The ground conductor is important here as it damps out the peak in temperature that would otherwise occur in the waste since the supernatant is still rejecting heat resulting from having run the pumps. 
The resulting peak slurry temperature is shown in Figure 6.4 as point T2'. This temperature must remain below $215^{\circ} \mathrm{F}$ for the ventilation system to be acceptable and it is. The temperature is still slowly increasing at this point due to slow increases in the particle concentration in the non-convective layer. This is not a concern, however, because of the time period involved (over a year). Ambient temperatures will have gone through a winter and will have cooled the waste down over this period. A constant ambient temperature of $82^{\circ} \mathrm{F}$ has been used in the calculation.

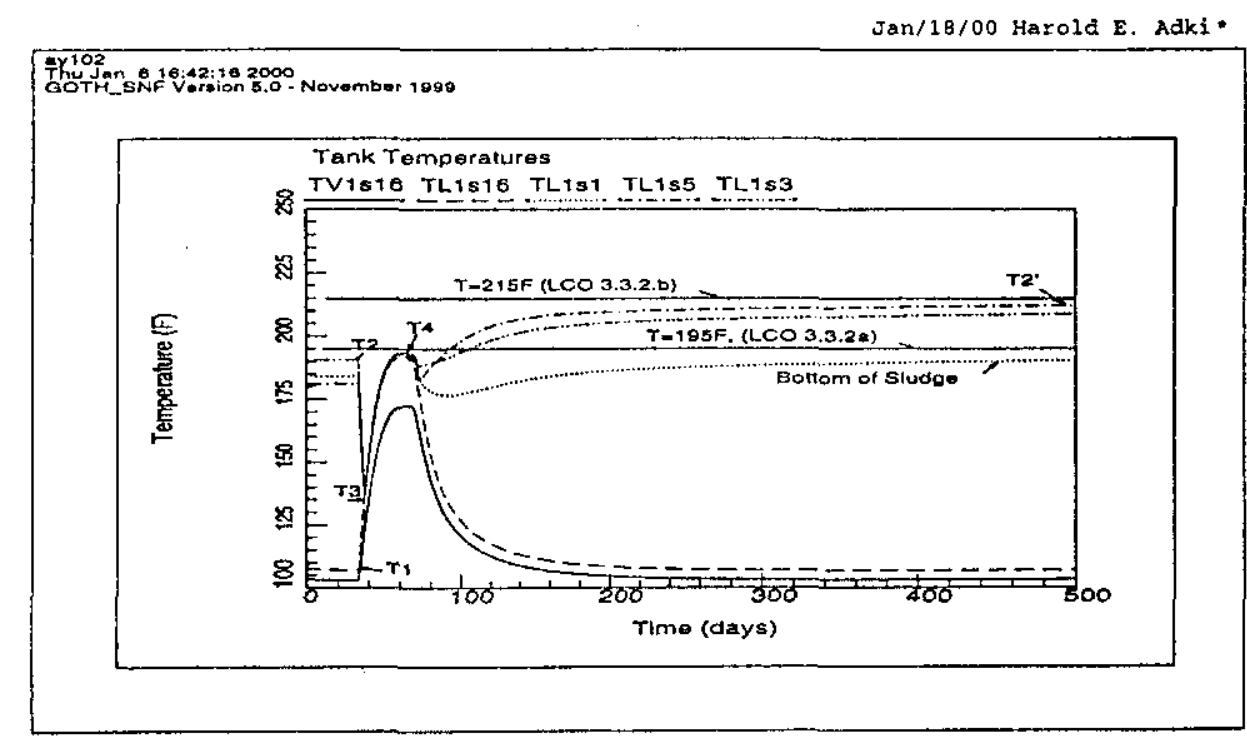

Figure 6.2 Important waste Temperatures After Pumps are Shut off.

The axial temperature profile in the waste prior to pump operation (T2) and after pump operation (T2') are given in Table 6.1 and are shown in Figure 6.3. 
JOHN MARVIN, INC.

Calculation Number: JMI-9910_01

Anslyst: Marvin J. Thurgood

Date: Feb 9, 2000

Reviewer: Harold E. Adkins

Date: Feb 9, 2000

Subject: Notebook for GOTH_SNF Simulation of Tank-AY102

Table 6.1 Axial Temperature Distribution in Tank.

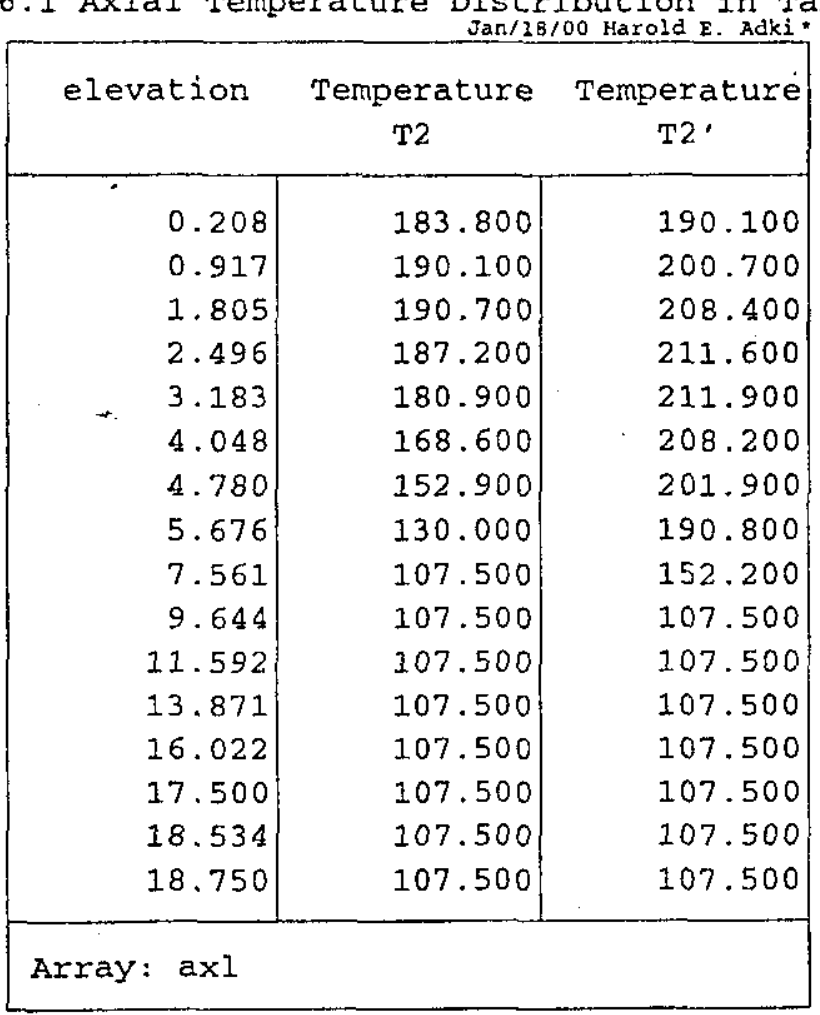

$\mathrm{T} 2:=\operatorname{array}(\operatorname{axl} 0,2 ; \operatorname{axl} 0,1)$
$\left.\left.\mathrm{T} 4:=\operatorname{array}(\operatorname{ax}]_{0,3}, \operatorname{ax}\right]_{0,1}\right)$

$\mathrm{T}^{2}, 2:=6.2917$

$\mathrm{T}_{10,2}:=8.7845$

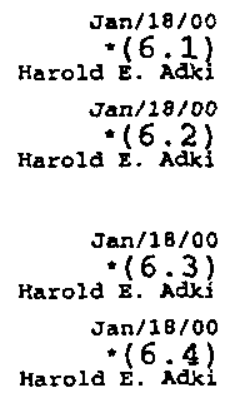

n/ 18100 E. idxi

$n / 28 / 00$

(6. 2 . 2$)$

/ $/ 18 / 00$

E. Adkj

( 6.4$)$

Harold E. idk 
Rev. 0

\begin{tabular}{|lr|}
\hline JoHN MARVIN, INC. & Calculation Number: JMI-9910_01 \\
\hline Analyst: Marvin J. Thurgood & Date: Feb 9, 2000 \\
\hline Reviewer: Harold E. Adkins & Date: Feb 9, 2000 \\
\hline Subject: Notebook for GOTH_SNF Simulation of Tank-AY102 \\
\hline
\end{tabular}

Jan/18/00 Harold E. Aaki *

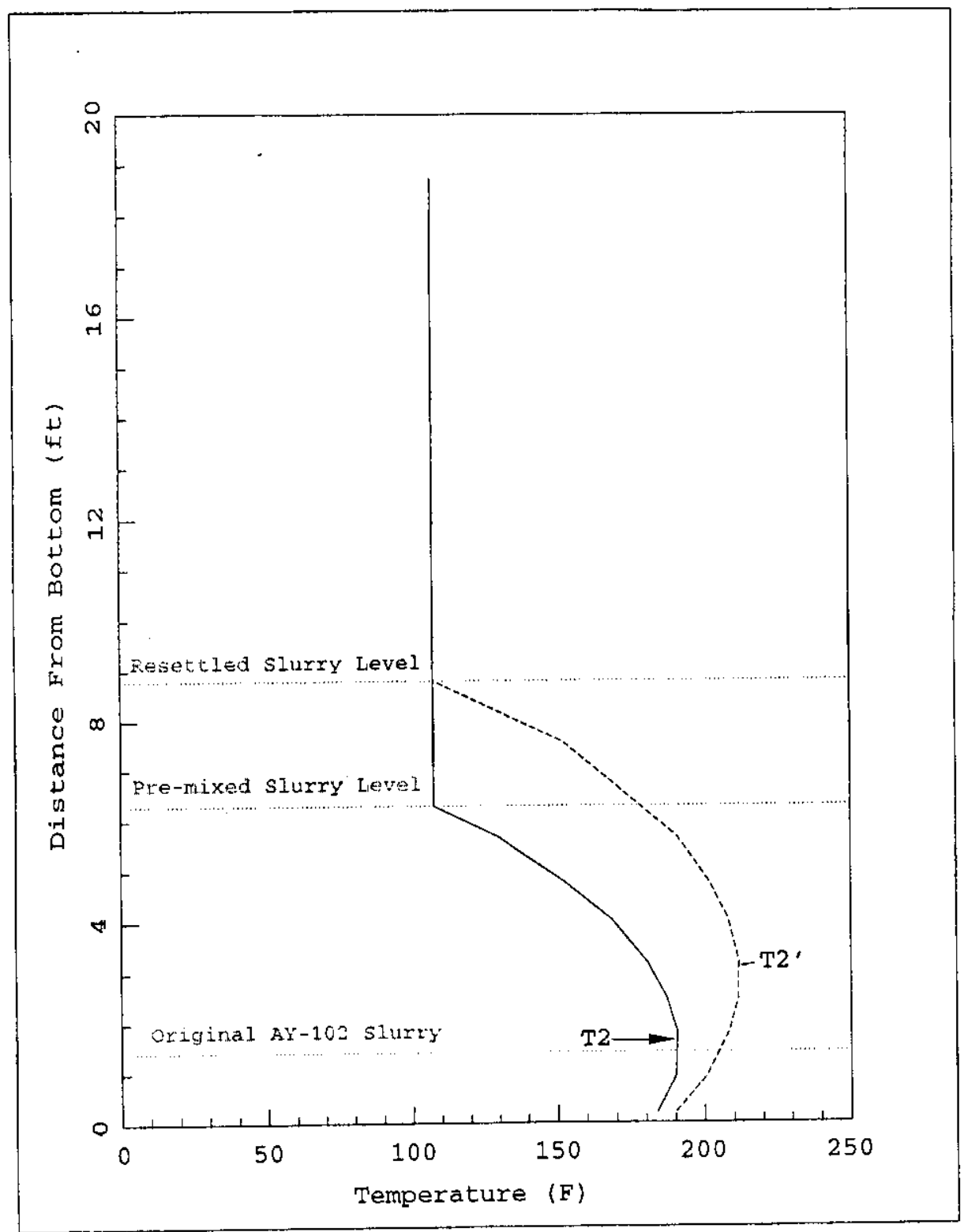

Figure 6.3, Maximum Axial Temperature Distribution in Tank Before, $\mathrm{T} 2$, and After $\left(\mathrm{T} 2^{\prime}\right)$, Mixing. 
JOHN MARVIN, INC.

Calculation Number: JMI-9910_01

Analyst: Marvin J. Thurgood Date: Feb 9, 2000

Reviewer: Harold E. Adkins Date: Feb 9, 2000

Subject: Notebook for GOTH_SNF Simulation of Tank-AY102

The high evaporative removal rate during mixing operations is shown in the water vapor mass flow rate results displayed in Figure 6.4. This figure shows the amount of water vapor that must be removed from the outlet air by the primary ventilation system condenser in order for dry air to enter the ventilation fans. As is shown, during mixing operations, the evaporation rate rises to $0.4 \mathrm{lbm} / \mathrm{s}$.

Since the primary ventilation flow can not be maintained at the specified level if this moisture is not removed, the ventilation system condenser must be rated such that it is capable of removing at least $0.4 \mathrm{lbm} / \mathrm{s}$.

$J a n / 18 / 00$ harold $E$. Adki *

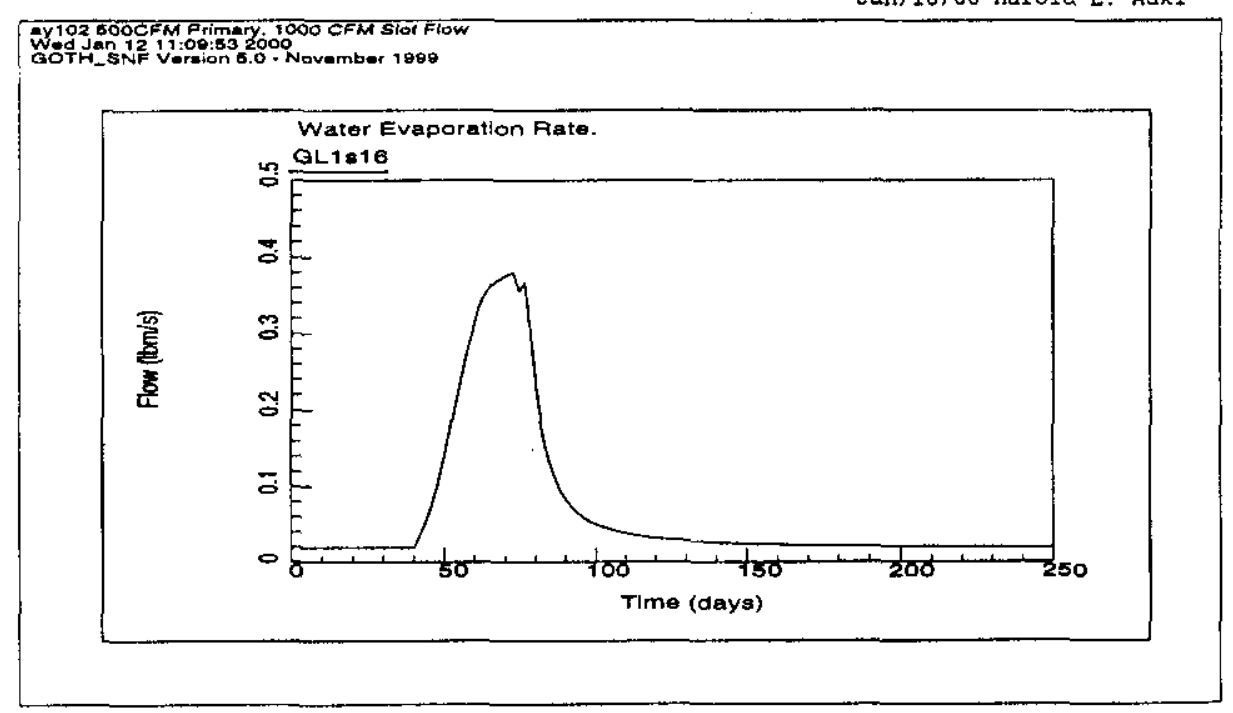

Figure 6.4 Water Vapor Mass Rate Carried Over By the Primary Ventilation system.

6.2. LOSS OF VENTILATION FLOW WHEN PUMPS ARE TURNED OFF. 
JOHN MARVIN, INC.

Analyst: Marvin J. Thurgood

Reviewer: Harold E, Adkins

Subject: Notebook for GOTH_SNF

The purpose of this simulation is to determine the time available to recover from loss of ventilation if it occurs. Loss of ventilation is assumed to occur after the pumps have run long enough for the supernatant to reach a steady state temperature. Losing ventilation at this time will result in the most rapid heat up of the waste. This case considers the tank to initially be filled with waste at the conditions at the end of waste transfers from $\mathrm{C}-106$. The ventilation system prior to pump operation consists of the nominal once through primary ventilation flow of $500 \mathrm{CFM}$ and the slot ventilation flow of 1000 CFM. The air inlet temperature for both systems is $82^{\circ} \mathrm{F}$. The simulation is run to the steady state temperature for ambient conditions of $82^{\circ} \mathrm{F}$ with the solid particles in an undisturbed slurry on the bottom of the tank. The mixer pumps are then turned on and the slurry in the bottom of the tank is mixed with the supernatant. The assertion is that the mixer pumps mix the waste to a homogeneous mixture with no slurry remaining on the bottom of the tank. The pumps are run until the supernatant comes to a steady state temperature. The pumps are then turned off and the solid particles are allowed to resettle to the bottom of the tank. Both the primary and secondary ventilations flows are shut off when the pumps are turned off to simulate loss of ventilation.

The rate the particles settle after the pumps are turned off is a function of the particle size, particle density, supernatant density and supernatant viscosity. The code calculates this rate from the force balance on the particles. The mixture remains convective as long as the particle fraction in a computational cell remains below $0.75^{*} \alpha_{\mathrm{p}} \mathrm{mp}$. The slurry becomes non-convective once the particle fraction reaches this value and the slurry begins to heat up as the radiolytic decay heat must be removed by conduction through the slurry to the supernatant. Heat is removed from the waste in this case by conduction through the ground only since ventilation flow has been lost.

The important waste temperatures in the tank for the initial settled state, for the period when the pumps are 


\begin{tabular}{|lr|}
\hline JOHN MARVIN, INC. & Calculation Number: JMI-9910_01 \\
\hline Analyst: Marvin J. Thurgood & Date: Feb 9, 2000 \\
\hline Reviewer: Harold E. Adkins & Date: Feb 9, 2000 \\
\hline Subject: Notebook for GOTH_SNF Simulation of Tank-AY102 \\
\hline
\end{tabular}

running and for the period when ventilation flows are lost are shown in Figure 6.5. The steady-state supernatant temperature prior to pump operation is shown as point $\mathrm{T} 1$ in this figure. The peak slurry temperature for this state is shown as point $\mathrm{T} 2$ in this figure. The pumps are turned on and the waste comes to a uniform temperature, T3 in Figure 6.5. (Note: There is only one graphics dump between point $\mathrm{T} 2$ and $\mathrm{T} 3$ so the actual mixed temperature may be lower than that shown for $T 3$ in the figure. This is not important as long as $\mathrm{T} 3$ is lower than the LCO supernatant temperature limit of $195^{\circ} \mathrm{F}$, which it is.) The pumps are run until the supernatant comes to a steady-state temperature, point T4 in Figure 6.5. The particles settle after the pumps are turned off, forming a new non-convective layer at the new fluffed height. The supernatant and the slurry heat up as a result of the decay heat in the waste and the loss of ventilation flow. The temperatures continues to increase until the waste reaches the local saturation temperature. The temperature then becomes constant as steam forms in the slurry.

The time required for the waste to reach the saturation temperature or the $250^{\circ} \mathrm{F}$ safety limit is important as it determines the amount of time available to repair the existing ventilation system or put into operation a backup ventilation system. The time between loss of ventilation and when the safety limit is reached is 60 days in this case. This is much longer than the 50 hours allowed by the AGA parameter specification so this criterion is satisfied. 


\begin{tabular}{|lr}
\hline JOHN MARVIN, INC. & Calculation Number: JMI-9910_01 \\
\hline Analyst: Marvin J. Thurgood & Date: Feb 9, 2000 \\
\hline Reviewer: Harold E. Adkins & Date: Feb 9, 2000 \\
\hline Subject: Notebook for GOTH_SNF Simulation of Tank-AY102
\end{tabular}

Jan/18/00 Harold E. Adki *

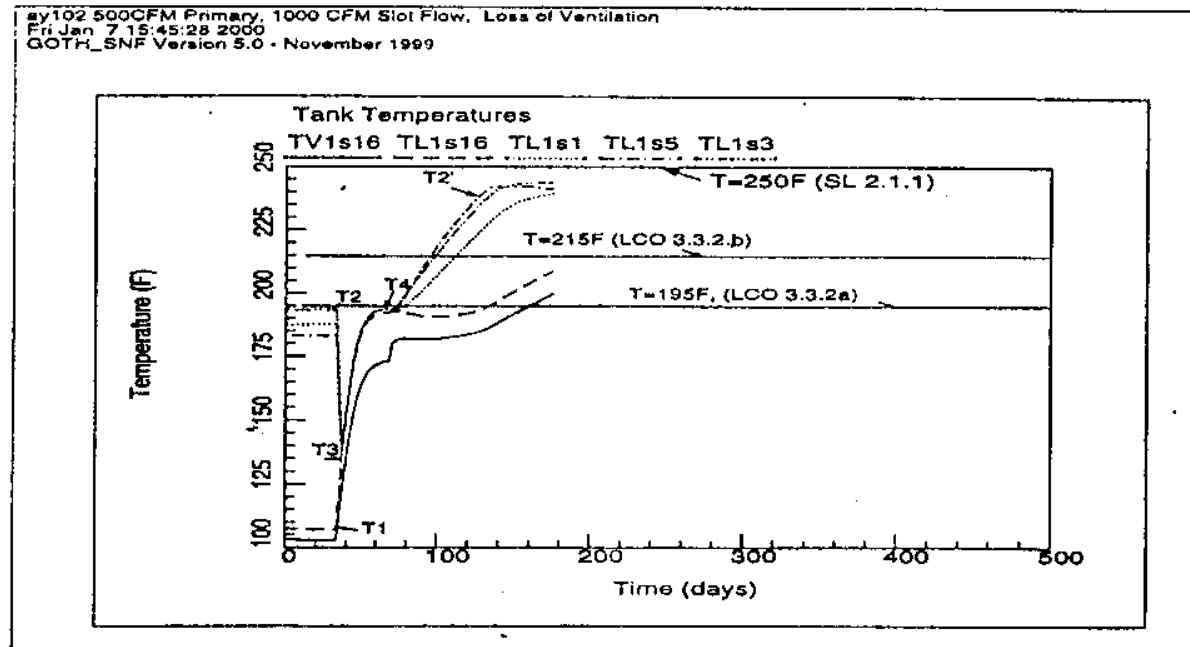

Figure 6.5 Temperatures From the Initial Steady-State Conditions Through Heat Up Following Loss of ventilation.

The temperatures $\mathrm{T} 1, \mathrm{~T} 3$ and $\mathrm{T} 4$ must be below the LCO Iimit of $195^{\circ} \mathrm{F}$ for the ventilation conditions specified for this case to be acceptable, and they are. Temperature T2 must be below $215^{\circ} \mathrm{F}$ to be acceptable, and it is.

\subsection{NOMINAL PRIMARY AND NO FLOOR SLOT VENTILATION FLOWS.}

This case considers the tank to initially be filled with waste at the conditions at the end of waste transfers from C-106. The ventilation system consists of the nominal once through primary ventilation flow of $500 \mathrm{CFM}$ only. The slot ventilation flow is disabled. The air inlet temperature for the primary ventilation systems is $82^{\circ} \mathrm{F}$. The simulation is run to approximately steady state temperature, for ambient air conditions of $82^{\circ} \mathrm{F}$ with the solid particles in an undisturbed slurry on the bottom of the tank. During this period heat is removed from the surface of the supernatant by convective sensible heat 
JOHN MARVIN, INC.

Calculation Number: JMI-9910_01

Analyst: Marvin J. Thurgood

Date: Feb 9, 2000

Reviewer: Harold E. Aakins

Date: Feb 9, 2000

Subject: Notebook for GOTH_SNF Simulation of Tank-AY102

transfer and evaporative heat transfer to the primary ventilation flow. Heat is also conducted down through the non-convective slurry to the ground under the tank if the ground is cooler than the slurry at the bottom of the tank.

Figure 6.6 shows the critical temperatures as the numerical model converges of the near steady state solution for the initial undisturbed state. As shown, the steady-state slurry temperatures exceed the LCO slurry temperature limit of $215^{\circ} \mathrm{F}$ [Ref 6] prior to adding the heat load associated with mixing operations. Hence, this ventilation configuration is not acceptable at any time or for any purpose.

Jan/18/00 Harold E. Adxi *

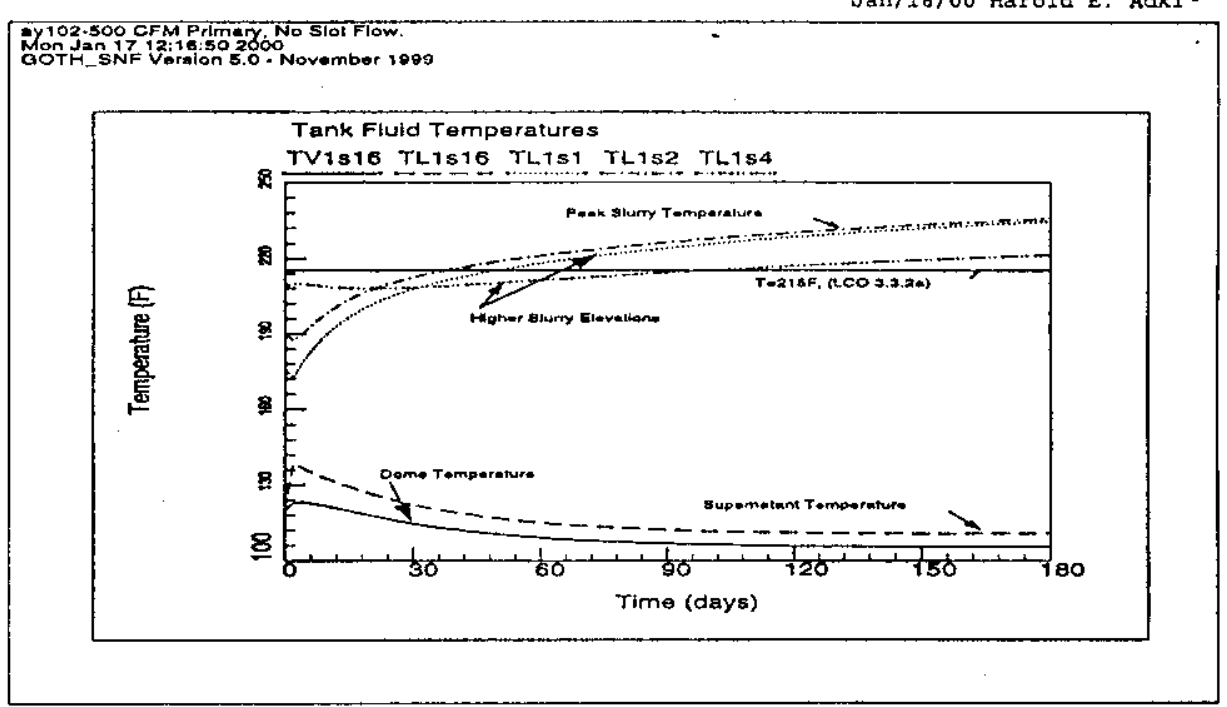

Figure 6.6 Temperatures From the Initial steady-State Temperature Determination 


\begin{tabular}{|lr|}
\hline JOHN MARVIN, INC. & Calculation Number: JMI-9910_01 \\
\hline Analyst: Marvin J. Thurgood & Date: Feb 9, 2000 \\
\hline Reviewer: Harold E. Adkins & Date: Feb 9, 2000 \\
\hline Subject: Notebook for GOTH_SNF Simulation of Tank-AY102 \\
\hline
\end{tabular}

\section{CONCLUSIONS.}

As has been shown in the normal operations case evaluation featured in Section 6.2 , a ventilation system configuration consisting of a nominal once through primary ventilation flow of $500 \mathrm{CFM}$ and a slot ventilation flow of 1000 CFM adequately maintains AY-102 tank waste temperatures below the established normal operations temperature limits during all pre, current and post-mixing operations. This is provided that the system is equipped with a condenser capable of removing at least $0.4 \mathrm{lbm} / \mathrm{s}$. As shown in section 6.2 for this ventilation configuration, the maximum allowable recovery duration that can be allowed for this system if a hypothetical loss of ventilation event occurs is 60 days.

Finally, it has been determined that a ventilation system configuration consisting of the nominal primary and disabled floor slot ventilation flows $(500 \mathrm{CFM} \& 0 \mathrm{CFM}$, respectively) with an inlet temperature of $82^{\circ} \mathrm{F}$ is an unacceptable configuration. The steady-state siurry temperatures exceed the LCO slurry temperature limit of $215^{\circ} \mathrm{F}$ [Ref 6] prior to adding the heat load associated with mixing operations.

\section{REFERENCES}

[1] Drawing H-2-64449 Rev. 6, Tank Elevation And Details, Aug. 1, 1970 .

[2] Drawing, $\mathrm{H}-2-64307$, Structural Insulating Concrete Plan \& Details, 241-AY, Rev. 4, June 22, 1970.

[3] Selby, Samuel M., Standard Mathematical Tables, Seventeenth Edition, The Chemical Rubber Co., Cleveland, 
JOHN MARVIN, INC.

Analyst: Marvin J. Thurgood

Reviewer: Harola E. Adkins

Subject: Notebook for GOTH_SNF Simulation of Tank-AY102
Calculation Number: JMI-9910_01

Date: Feb 9, 2000

Ohio, 1969.

[4] Holman, J.P., Heat Transfer, Second Edition, McGraw-Hill Book Co., San Francisco, 1968.

[5] Binder, Raymond C., Fluid Mechanics, Fourth Edition, Prentice Hall, Inc., Englewood Cliffs, N.J., 1962.

[6] Letter to JMI, A parametric Study to Characterize AGA Alternatives for Removal of Heat from High-Level Waste Tanks, December 1999.

[7] CRANE, Flow of Fluids Through Valves, Fittings, and Pipe, Crane, Co., Joliet, IL., Technical Paper 410, 1988.

[8] Bous, D.G., Thermal Conductivity of Hanford Waste Tank Solids and SX Tank Farm Soil Samples, ARH-CD-378, Atlantic Richfield Hanford Company, Richland WA, 1975.

\section{REVIEWER'S COMMENT'S}

[QA-1] Comment by: Harold E. Adkins Date:

$\mathrm{Jan} / 18 / 00$

As indicated by the analyst, no reference (explicitly stating this parameter) is available. However, this concrete pad thickness (between shells) identifies with construction practices commonly used on the Hanford site.

[QA-2] Comment by: Harold E. Adkins Date: $\mathrm{Jan} / 18 / 00$

The depth of my review includes review of input data, equational relationships, derivations, consistency with cited references, and review of GOTH_SNF input and 
JOHN MARVIN, INC.

Analyst: Marvin J. Thurgood

Reviewer: Harold E. Adkins

Subject: Notebook for GOTH_SNF Simulation of Tank-AY102

output.

Output results are consistent with input.

Calculation Number: JMI-9910_01

Date: Feb 9, 2000

Date: Feb 9, 2000

Date: Feb 9, 2000


RPP-5637

Rev. 0

\section{ENGINEERING NOTEBOOK AND REPORT REVIEW CHECKLIST}

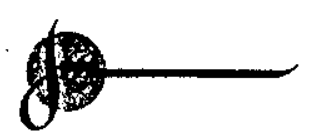

Engineering Report No.

Engineering Notebook No. $J M Z Z-9910-01$

\begin{tabular}{|c|c|c|c|c|}
\hline 1. & $\begin{array}{l}\text { Is the purpose of the engineering analysis clearly } \\
\text { stated? }\end{array}$ & tes & No & $\overline{\mathrm{NA}}$ \\
\hline 2. & $\begin{array}{l}\text { Are required inputs and information sources } \\
\text { provided? }\end{array}$ & des & No & NA \\
\hline 3. & Is the methodology clearly identified? & 20es & No & NA \\
\hline 4. & Have the limits of applicability been identified? & tess & No & $\overline{\mathrm{NA}}$ \\
\hline 5. & $\begin{array}{l}\text { Is all supporting data/information referenced or } \\
\text { provided in the project files? }\end{array}$ & Fes & No & NA \\
\hline 6. & $\begin{array}{l}\text { Are the assumptions and conservatism's clearly } \\
\text { identified? }\end{array}$ & YTs & No & $\mathrm{NA}$ \\
\hline 7. & $\begin{array}{l}\text { Are all calculation notes or engineering notes } \\
\text { uniquely identified and pages sequentially } \\
\text { numbered? }\end{array}$ & TES & No & $\overline{\mathrm{NA}}$ \\
\hline 8. & Are the computer codes and models identified? & Yes & No & NA \\
\hline 9. & Are all computer analyses clearly identified? & Yes & No & NA \\
\hline 10. & $\begin{array}{l}\text { Were the computer codes under configuration } \\
\text { control? }\end{array}$ & Des & No & NA \\
\hline 11. & $\begin{array}{l}\text { Were the computer codes and models applicable for } \\
\text { the stated purpose of the analyses? }\end{array}$ & DES & No & NA \\
\hline 12. & Are the results and conclusions clearly presented? & सes & No & $\mathrm{NA}$ \\
\hline 13. & Are open technical issues properly identified? & Yes & No & $\Delta A$ \\
\hline 14. & $\begin{array}{l}\text { Were customer organization Design Control } \\
\text { practices followed? }\end{array}$ & Yes & No & XVD \\
\hline
\end{tabular}

Note: If NO to any of the above, identify justification on attached page or reference report or notebook page \#.

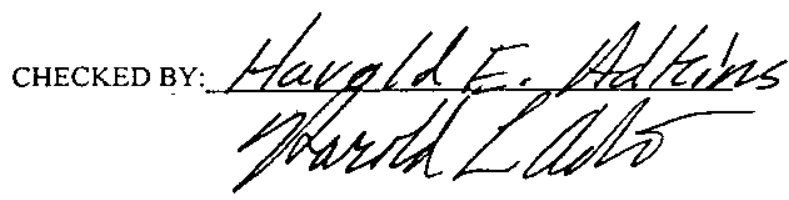

Date: $21 \% / 2$ 
RPP-5637

Rev. 0

This page intentionally left blank. 
RPP-5637

Rev. 0

\section{APPENDIX F}

NOTEBOOK FOR GOTH_SNF SIMULATION OF

TANK AZ-102 DURING AND AFTER MIXER

PUMP OPERATION 
RPP-5637

Rev. 0

This page intentionally left blank.

F-ii 


\section{NOTEBOOK FOR GOTH SNF SIMULATION OF TANK AZ-102 DURING AND AFTER MIXER PUMP OPERATION}

February 9, 2000

PREPARED BY

Marvin J. Thurgood

JOHN MARVIN, INC.

Prepared for

Lockheed Martin Hanford Corporation

Richland, WA

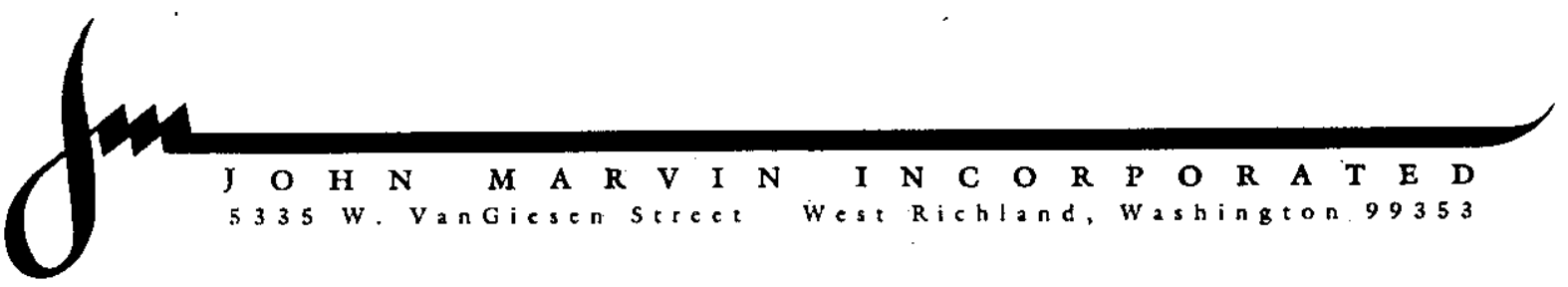


This page intentionally left blank.

F-2 


\section{Comments on AZ-102 Notebook}

This comment is directed towards the soil thermal properties that are used as model parameters. There is an inconsistency between the values used and other site specific data sources. An important point to note is that there is not a major dependency between these parameters and the end results. Nevertheless, these discrepancies need to be resolved prior to performing any subsequent work based on this model

The heat capacity value of $0.4 \mathrm{Bu} / \mathrm{lbm}-\mathrm{F}$ is inconsistent with that given in other sources for Hanford sand and backfill, where values of .18 - .24 for natural sand and 0.18-0.34 for backfill are cited ( Shannon \& Wilson, Inc, Irwin). The thermal conductivity also seems to be on the low side of the range given in some references. 
RPP-5637

Rev. 0

This page intentionally left blank. 
JOHN MARVIN, INC.

Calculation Number: JMI-9910_02

Analyst: Marvin J. Thurgood

Reviewer: Harold E. Adkins

Subject: Notebook for GOTH_SNE Simulation of Tank AZ-102

\section{TABLE OF CONTENTS}

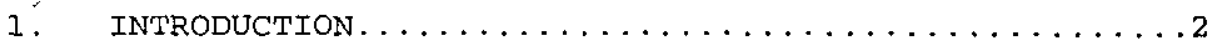

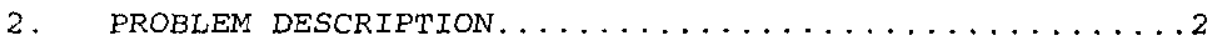

2.1. Cases and Evaluation Criteria............

3. SPECIFICATION OF INPUT PARAMETERS FOR TANK AZ-102 ..6

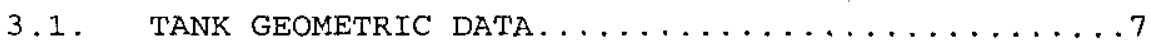

3.1.1. Tank Shell Geometric Data............

3.1.2. Air Distributor Geometric Data..........11

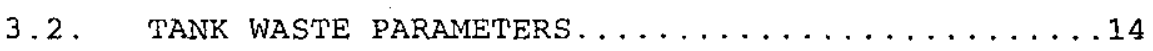

3.2.1. Initial waste In $A Z-102 \ldots \ldots \ldots . \ldots 14^{\circ}$

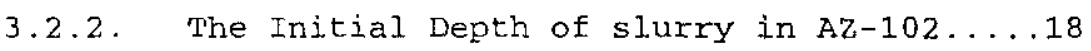

3.2.3. Supernatant Height In $A Z-102 \ldots \ldots \ldots \ldots 18$

3.2.4. VENTILATION INLET TEMPERATURE AND

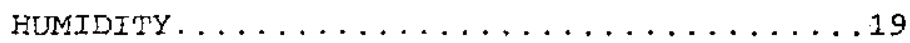

3.2.5. VENTILATION FLOW RATE. ............. 21

3.2.5.1. Primary Ventilation Flow Rate......21

3.2.5.2. Secondary Ventilation Flow Rate.....21

4. GOTH_SNF MODEL DESCRIPTION . . . . . . . . . . . 22

5. DEVELOPMENT OF INPUT PARAMETERS FOR THE GOTH_SNF

MODEE . . . . . . . . . . . . . . . . . . . . 26

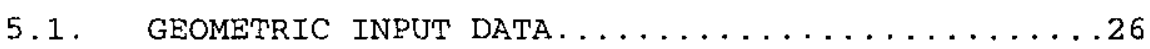

5.1.1. Useful Functions and Parameters........26

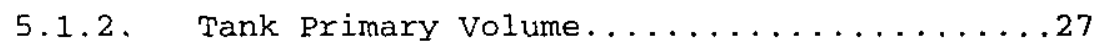

5.1.2.1. Area of Tank Primary Volume........28

5.1.2.2. Volume of Tank Primary volume.....28

5.1.2.3. Bottom Elevation of Tank Primary

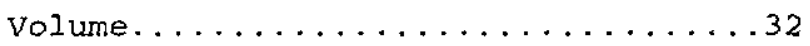

5.1.2.4. Height of the Tank Primary Volume....32

5.1.2.5. Subdivisions of Primary Tank

volume......................... 33

5.1.2.6. Hydraulic Diameter of Tank Primary

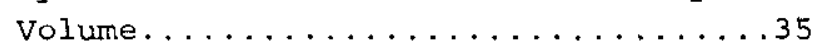

5.1.2.7. Dimensions of Conductor at the Top of

i of $v i$ 


\begin{tabular}{|lr|}
\hline JOHN MARVIN, INC. & Calculation Number: JMI-9910_02 \\
\hline Analyst: Marvin J. Thurgood & Date: Feb 9, 2000 \\
\hline Reviewer: Harold E. Adkins & Date: Feb 9, 2000 \\
\hline Subject: Notebook for GOTH_SNF Simulation of Tank AZ-102 \\
\hline
\end{tabular}

the Tank....................... 35

5.1.2.8. Dimensions of Conductor at the Bottom

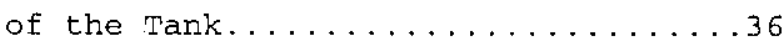

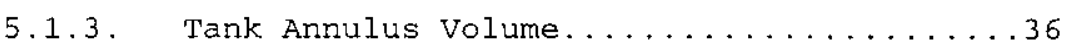

5.1.3.1. Area of Tank Annulus Volume.......36

5.1.3.2. Volume of Tank Annulus Volume......37

5.1.3.3. Bottom Elevation of Tank Annulus

Volume........................ 37

5.1.3.4. Height of the Tank Annulus Volume...38

5.1.3.5. Hydraulic Diameter of Tank Annulus

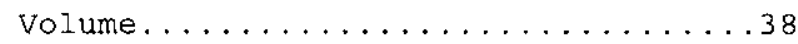

5.1.3.6. Dimensions for Conductor Between

Primary Air Volume and Annulus Air...38

5.1.3.7. Dimensions for Conductor Between

Supernatant and Annulus Air........39

5.1.3.8. Dimension for Conductor Between

Annulus Air And Soil Around the sides

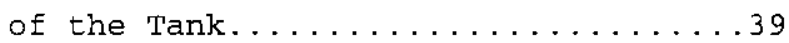

5.1.4. Tank Floor slot volume............40

5.1 .4 .1 . Area of Floor slot volume.........40

5.1.4.2. Volume of Floor Slot Volume........51

5.1.4.3. Elevation of Floor slot volume......51

5.1.4.4. Height of Floor slot volume.......52

5.1.4.5. Hydraulic Diameter of the Floor

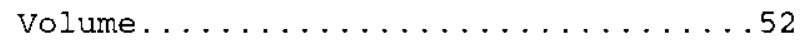

5.1.4.6. Slot Conductor Dimensions........52

5.1.5. Floor slot Air Inlet volume............52

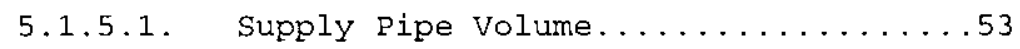

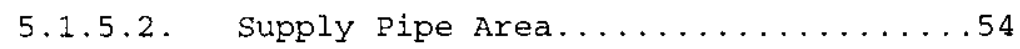

5.1.5.3. Supply Pipe Elevation...........54

5.1 .5 .4$. Supply Pipe Height............54

5.1.5.5. Supply Pipe Hydraulic Diameter:... . 54

5.1.5.6. Supply Pipe Conductor Dimensions....54

5.1.6. water Refill sump................ 57

5.1 .6 .1 . Volume of sump volume...........57

5.1.6.2. Cross-sectional Area of Sump

, Volume.................. 58

$5.1 .6 .3 . \quad$ Elevation of Sump Volume...........58

5.1 .6 .4 . Height of sump volume...........58

ii of vi 


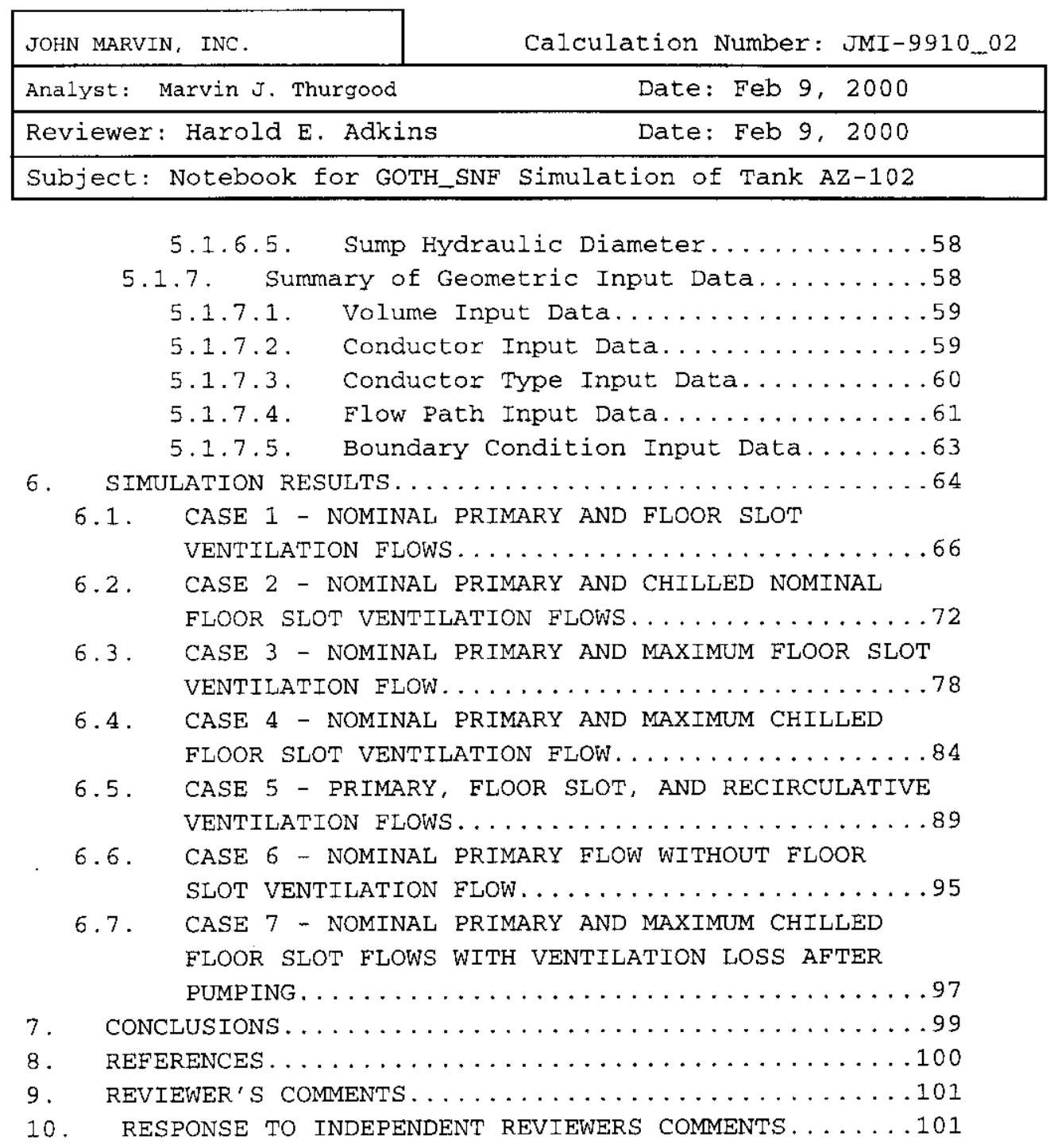




\begin{tabular}{|lr|}
\hline JOHN MARVIN, INC. & Calculation Number: JMI-9910_02 \\
\hline Analyst: Marvin J. Thurgood & Date: Feb 9, 2000 \\
\hline Reviewer: Harold E. Adkins & Date: Feb 9, 2000 \\
\hline Subject: Notebook for GOTH_SNF Simulation of Tank AZ-102 \\
\hline
\end{tabular}

\section{LIST OF TABLES}

5.1 Subdivision Heights and Pressures. . . . . . . . . 34

5.2 Control volume Input Data. .................. 59

5.3 Conductor Input Data. .................60

5.4 Conductor Type Input Data. ...............61

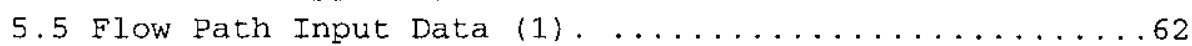

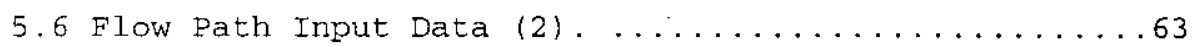

5.7 Boundary Condition Input Data. ............64

6.1 Axial Temperature Distributions in Tank ........70

6.2 Axial Temperature Distributions in Tank ........76

6.3 Axial Temperature Distributions in Tank .........81

6.4 Axial Temperature Distributions in Tank ........87

6.5 Axial Temperature Distributions in Tank .........93

iv of vi 
JOHN MARVIN, INC.

Calculation Number: JMI-9910_02

Analyst: Marvin J. Thurgood Date: Feb 9, 2000

Reviewer: Harold $E$. Adkins

Date: Feb 9, 2000

Subject: Notebook for GOTH_SNF Simulation of Tank AZ-102

\section{IIST OF FIGURES}

2.1 Distribution of Material in Tank. ............

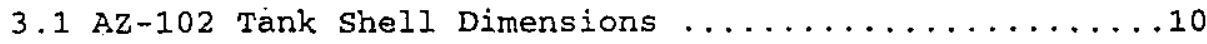

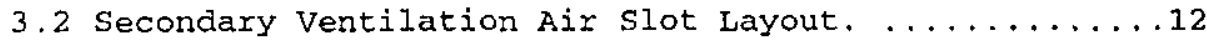

4.1 GOTH_SNE Model of Tank AZ-102. ...............24

4.2 GOTH_SNF Model Nodal Layout of Tank AZ-102 . . . . 25

5.1 Approximation of Primary Dome Shape. ..........32

6.1 Temperatures From the Initial steady-State Conditions Through Pump Mixing (Case 1) .......67

6.2 Critical Waste Temperatures After Pumps are shut off.

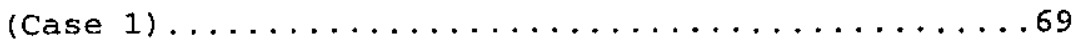

6.3 Axial Temperature Distributions in Tank waste Before

(T2), Peak After (T2'), and steady state After

Mixing (T2"') (Case 1) ..................... 11

6.4 Water Vapor Mass Rate Carried over By the Primary Ventilation System (Case 1) ...............72

6.5 Temperatures From the Initial steady-State Conditions Through Pump Mixing (Case 2).......73

6.6 Critical waste Temperatures After Pumps are Shut off (Case 2) .......................... . . . . .

6.7 Axial Temperature Distribution in Tank waste Before (T2), Peak After (T2'), and steady state After Mixing (T2'“) (Case 2). ....................

6.8 Water Vapor Mass Rate Carried over By the Primary Ventilation system (Case 2) .................

6.9 Temperatures From the Initial steady-State Conditions Through Pump Mixing (Case 3) ........79

6.10 Critical Waste Temperatures After Pumps are Shut off (Case 3 ) .........................

6.11 Axial Temperature Distributions in Tank Before (T2), Peak After (T2'), and steady state After

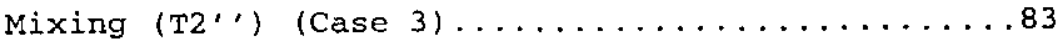

$\mathrm{v}$ of $\mathrm{vi}$ 


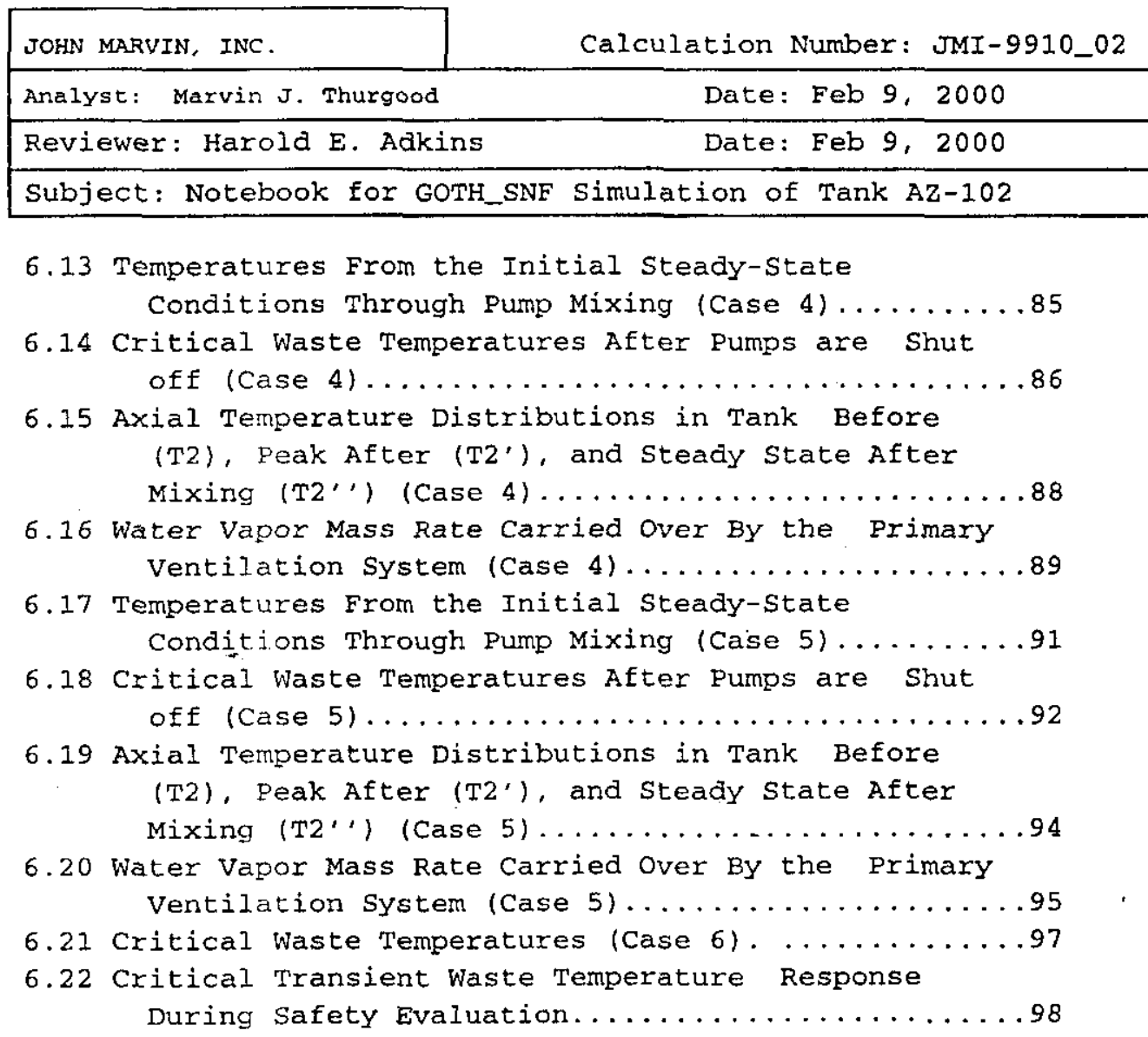

$v i$ of $v i$ 


\begin{tabular}{|lr|}
\hline JOHN MARVIN, INC. & Calculation Number: JMI-9910_02 \\
\hline Analyst: Marvin J. Thurgood & Date: Feb 9, 2000 \\
\hline Reviewer: Harold E. Adkins & Date: Feb 9, 2000 \\
\hline Subject: Notebook for GOTH_SNF Simulation of Tank AZ-102 \\
\hline
\end{tabular}

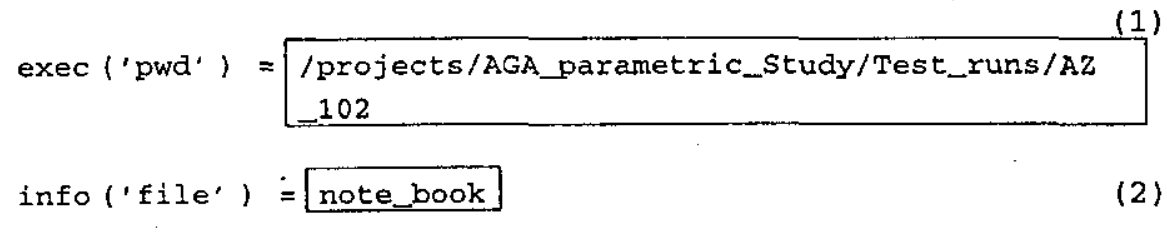

[QA-1]
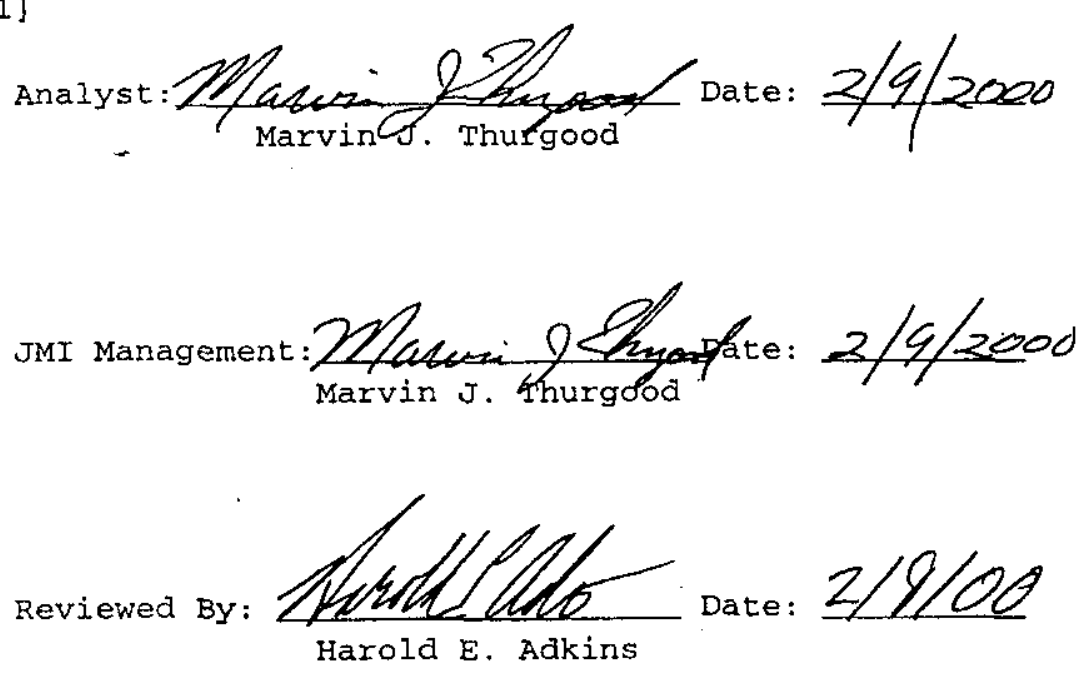

1 of 102 


\begin{tabular}{|lr|}
\hline JoHN MARVIN, INC. & Calculation Number: JMI-9910_02 \\
\hline Analyst: Maxvin J. Thurgood & Date: Feb 9, 2000 \\
\hline Reviewer: Harold E. Adkins & Date: Feb 9, 2000 \\
\hline Subject: Notebook for GOTH_SNE Simulation of Tank AZ-102 \\
\hline
\end{tabular}

\section{INTRODUCTION.}

This notebook documents the methods, models and data required to set up the input deck for evaluating the ventilation requirements for tank AZ-102 once the mixing pumps have been installed. The results of these calculations are to be used to write the specifications for the tank ventilation systems. Tank AZ-102 is used for the analysis because it is the bounding tank in the AZ tank farm. The ventilation requirements for the other tanks in the farm will be over-specified because their requirements are lower than those for the bounding tank. The ventilation requirements for these other tanks can be reduced by additional analysis at a later time if necessary.

\section{PROBLEM DESCRIPTION.}

The problem consists of Tank AZ-102 which has an initial settled slurry layer of 2.87 feet. No additional slurry from other tanks is expected to be transferred to this tank before the existing waste in the tank is retrieved. The supernatant liquid level of the tank is 344.7 inches. The tank has a total heat load of 199,700 Btu/hr. The various fluid regions of the tank are shown in Figure 2.1. The slurry layer and the supernatant liquid level are illustrated in the figure. Also illustrated are the primary and secondary ventilation flows that are used to cool the tank contents. The primary flow path also removes moisture from the tank dome as this air comes into direct contact with the supernatant liquid in the tank.

The secondary flow enters at the center of the tank floor through pipes that pass through the concrete pad at the 


\begin{tabular}{|lr|}
\hline JOHN MARVIN, INC. & Calculation Number: JMI-9910_02 \\
\hline Analyst: Marvin J. Thurgood & Date: Feb 9, 2000 \\
\hline Reviewer: Harold E. Adkins & Date: Feb 9, 2000 \\
\hline Subject: Notebook for GOTH_SNF Simulation of Tank AZ-102 \\
\hline
\end{tabular}

bottom of the tank. The air. then flows radially outwards through flow channels formed into the concrete pad directly under the steel tank shell. This air flow removes heat from the bottom of the tank, cooling the settled slurry. This air then exits into the annulus formed by the tank's double shell where it flows upwards and is extracted from the top of the annulus through annulus ventilation piping.

The primary air is arawn into the tank through filtered inlet vents and leakage paths by the primary ventilation Eans. The fans remove air from the dome via the primary system ventilation piping. This flow cools the tank by both sensible and evaporative heat removal from the surface of the supernatant liquid pool. Dryer, usually cooler, air from the atmosphere removes heat and moisture from the tank dome atmosphere, allowing evaporation from the pool surface to occur. When the inlet air is cooler than the tank atmosphere the air also removes sensible heat from the pool.

Solid particles in the settled slurry generate heat due to radionuclide decay. The supernatant liquid also contains dissolved radionuclides that also generate heat. This heat must be removed primarily by the ventilation flows, although some of it is conducted through the ground to the surface or to the ground water. 


\begin{tabular}{|lr|}
\hline JOHN MARVIN, INC. & Calculation Number: JMI-9910_02 \\
\hline Analyst: Marvin J. Thurgood & Date: Feb 9, 2000 \\
\hline Reviewer: Harold E. Adkins & Date: Feb 9, 2000 \\
\hline Subject: Notebook for GOTH_SNE Simulation of Tank AZ-102 \\
\hline
\end{tabular}

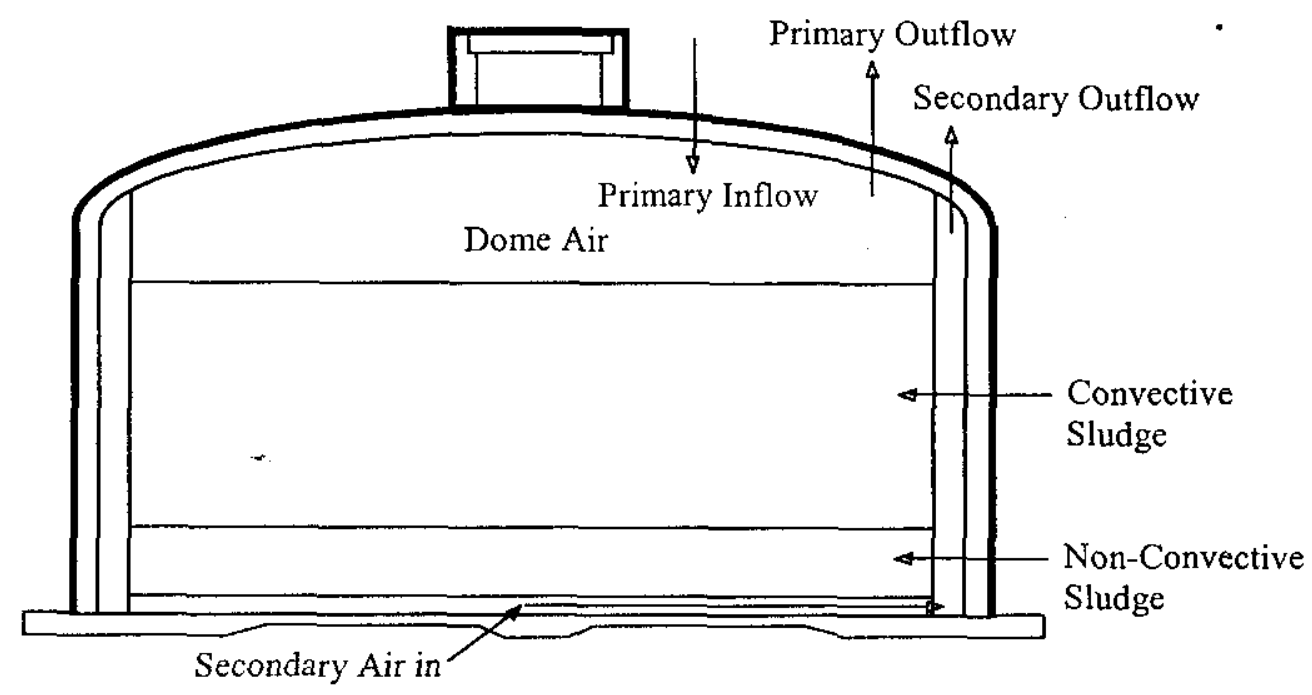

Figure 2.1 Distribution of Material In Tank.

The initial steady state at which the simulations begin is with the solid particles in an undisturbed slurry on the bottom of the tank. The mixer pumps are then turned on and the slurry in the bottom of the tank is mixed with the supernatant liquid. The assertion is that the mixer pumps mix the waste to a homogeneous mixture with no slurry remaining on the bottom of the tank. The pumps are conservatively run until the supernatant liquid comes to a steady state temperature for all evaluations.

The pumps are then turned off and the solid particles are allowed to resettle to the bottom of the tank. The rate the particles settle is a function of the particle size, particle density, supernatant liquid density and supernatant liquid viscosity. The code (GOTH_SNF) calculates this rate from the force balance on the particles. For all evaluated cases, the mixture is assumed to remain convective as long as the particle fraction in a computational cell remains below $0.75^{\star} \alpha_{\mathrm{p}} \mathrm{mp}$. This value has been chosen to match the time for a non-convective layer to 


\begin{tabular}{|lr|}
\hline JOHN MARVIN, INC. & Calculation Number: JMI-9910_02 \\
\hline Analyst: Marvin J. Thurgood & Date: Feb 9, 2000 \\
\hline Reviewer: Harold E. Adkins & Date: Feb 9, 2000 \\
\hline Subject: Notebook for GOTH_SNF Simulation of Tank Az-102 \\
\hline
\end{tabular}

form following waste transfers into $\mathrm{AY}-102$ and it matches the settling rates specified by the input specification document [Ref 6]. The slurry becomes non-convective once the particle fraction reaches this value and the slurry begins to heat up as the radioactive decay heat must be removed by conduction through the slurxy to the supernatant liquid. Heat is removed from the surface of the supernatant liquid by convective sensible heat transfer and evaporative heat transfer to the primary ventilation flow. Heat is also conducted down through the non-convective siurry to the air flowing through the slots in the floor of the tank and to the ground under the tank if the ground is cooler than the slurry at the bottom of the tank.

The purpose of the calculations is to evaluate the ventilation requirements for this tank as mixing pumps axe run to mix the waste in preparation for retrieving the waste for the vitrification process. Additional heat is added to the tanks during the retrieval process due to the operation of the mixing pumps. This additional heat may require upgrading of the tank ventilation systems to handle the additional heat load. Results of these calculations will be used to develop the ventilation specifications for this tank and the tank farm associated with it.

\subsection{Cases and Evaluation Criteria}

Seven cases involving the bounding tank AZ-102 are evaluated herein. These consist of six potential ventilation configurations being evaluated under criteria applying to normal operating conditions, and one being evaluated under criteria established as safety limits for the system in question. This latter case involves the evaluation of a loss of ventilation. All cases consider the tank to initially be filled with waste at steady state conditions. A transient period enveloping pump start-up. operation, shut-down, and re-establishment of steady state conditions is then simulated. 


\begin{tabular}{|lr|}
\hline JohN MARVIN, INC. & Calculation Number: JMI-9910_02 \\
\hline Analyst: Maxvin J. Thurgood & Date: Feb 9, 2000 \\
\hline Reviewer: Harold E. Adkins & Date: Feb 9, 2000 \\
\hline Subject: Notebook for GOTH_SNF Simulation of Tank AZ-102 \\
\hline
\end{tabular}

Unless specified otherwise, the ventilation system consists of a nominal once through primary ventilation flow of 500 CFM and a slot ventilation flow of 1000 CFM or $2000 \mathrm{CFM}$. The air inlet temperature for the primary ventilation system as well as the ambient air conditions are specified to be $82^{\circ} \mathrm{F}$. Whereas the slot ventilation flow temperature is either specified to be that of the ambient $\left(82^{\circ} \mathrm{F}\right)$ or chilled to $40^{\circ} \mathrm{F}$ prior to duct entry. A constant ambient temperature of $82^{\circ} \mathrm{F}$ has been used in all simulations. Case specific input parameters are presented with the respective results in the appropriate sections.

The operation and safety related criteria that must be met in order for the ventilation system to be deemed acceptable are that prior to and after mixing operations, no portion of the top 15 feet waste may exhibit temperatures in excess of $195^{\circ} \mathrm{F}$ (LCO 3.3.2.b), no waste temperatures may exceed $195^{\circ} \mathrm{F}$ at any time during mixer pump runtime ( $L C O$ 3.3.2.a), and no portion of the waste existing below the top 15 feet may exhibit temperatures in excess of $215^{\circ} \mathrm{F}$ prior to and after mixing operations (LCO 3.3.2.b)

[Ref 6]. Additionally, in the event of a loss of ventilation, no waste temperature shall exceed $250^{\circ} \mathrm{F}$ during the recovery period (SL 2.1.1).

Loss of ventilation evaluations are performed on ventilation system configurations deemed acceptable only.

\section{SPECIFICATION OF INPUT PARAMETERS FOR TANK $A Z-102$.}

Preparation of the GOTH_SNF input file requires that tank geometric data, tank waste conaitions, ventilation parameters and pump operation conditions be specified. The required data specifications are provided, with source references in this section. 
JOHN MARVIN, INC.

Analyst: Marvin J. Thurgood

Reviewer: Harold E. Adkins

Subject: Notebook for GOTH_SNF Simulation of Tank AZ-102

Calculation Number: JMI-9910_02

Date: Feb 9, 2000

Date: Feb 9, 2000

\subsection{TANK GEOMETRIC DATA.}

The geometric data required to set up a GOTH_SNF input model for the tank is provided in this section. This data is divided into two basic groups; the tank shell geometric data and the floor air distributor geometric data.

\subsubsection{Tank Shell Geometric Data.}

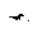

The basic dimensions of the primary and secondary tank shells are shown in Figure 3.1. The parameters shown in the figure are:

Inside radius of primary shell, [Ref. 1]:

PS_IR : $=37.5 \mathrm{ft}$

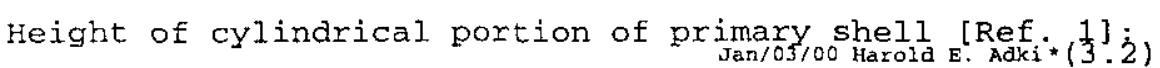

PS_CHT $:=31 \mathrm{ft}+9.5 \mathrm{in}+3 \mathrm{ft}+4 \mathrm{in}+\frac{13 \mathrm{in}}{16}=35.1927 \mathrm{ft}$

Inside radius of secondary shell, [Ref. 1]:

SS_IR $:=40 \mathrm{ft}$

Distance Between bottoms of primary and secondary

shells [Ref. 1]:

SS_PS_SPACE $:=8$ in

$\mathrm{Jan} / 03 / 00$ Harold E. Adki

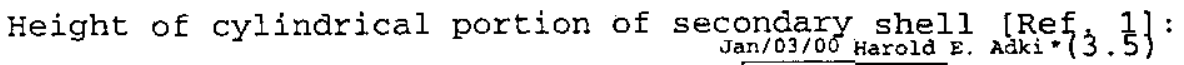
SS_CHT : $=31 \mathrm{ft}+9.5 \mathrm{in}+$ SS_PS_SPACE $=32.4583 \mathrm{ft}$

other tank shell parameters of interest are:

Radius of curvature at shell cylinder and bottom plate junctian [Ref. 1].

S_RC := $1 \mathrm{ft}$ 
JOHN MARVIN, INC.

Calculation Number: JMI-9910_02

Analyst: Marvin J. Thurgood Date: Feb 9, 2000

Reviewer: Harold E. Adkins

Date: Feb 9, 2000

Subject: Notebook for GOTH_SNF Simulation of Tank AZ-102

Secondary shell ellipsoid head major diameter [Ref, 1]:

SS_ELIP_MAJOR $:=80 \mathrm{ft}$

Jan 103100

Secondary shell ellips

harold E. A 7 dki

SS_ELIP_MINOR $:=30 \mathrm{ft}$

[Ref. 1]:

The radius of the bend

$\operatorname{Jan} / 03 / 00$
Harold $(3.8)$
E.

The radius of the bend in the primary shell between the cylindrical shell and the secondary shell head [Ref. 1]:

PS_TOP_RC $:=4 \mathrm{ft}=4 \mathrm{ft}$

$\mathrm{Jan} / 03 / 00$

$*(3.9)$

The height of the primary shell tangency point with the secondary dome shell above the secondary tangent line is [Ref. 1]:

PS_SS_TP $:=6 \mathrm{ft}+6 \mathrm{in}+\frac{7 \mathrm{in}}{8}=6.57292 \mathrm{ft}$

The height of the primary tangent line above the secondary tangent line is [Ref. 1]:

PS_TAN_SS_TAN $:=3 \mathrm{ft}+4 \mathrm{in}+\frac{13 \mathrm{in}}{16}=3.40104 \mathrm{ft}$

The distance from the tank centerline to the point of tangency between the primary tank shell and the secondary tank shell is [Ref. 1]:

$$
\text { PS_SS_TAN }:=35 \mathrm{ft}+11 \mathrm{in}+\frac{7 \mathrm{in}}{16}=\begin{array}{r}
\mathrm{Jan} / 03 / 00 \\
(35.9531 \mathrm{ft} \quad(32)
\end{array}
$$

The primary tank cylinder wall is made of three thicknesses of carbon steel plate. Since the exact thickness of this plate does not strongly influence the thermal properties of the tank nor the volume of its contents, a constant thickness will be assumed for the entire primary shell

[Ref. 1]:

$$
\text { PS_THK }:=\frac{3 \text { in }}{8}=0.03125 \mathrm{ft}
$$

This is the actual thickness of the shell bottom plate and the shell dome plate. The side walls are thicker.

8 of 102 
RPP-5637

Rev. 0

JOHN MARVIN, INC.

Calculation Number: JMI-9910_02

Analyst: Marvin J. Thurgood Date: Feb 9, 2000

Reviewer: Harold E. Adkins Date: Feb 9,2000

Subject: Notebook for GOTH_SNF Simulation of Tank AZ-102

The secondary shell plate thickness is [Ref. 1]:
SS_THK $:=\frac{3 \text { in }}{8}=0.03125 \mathrm{ft}$
$\operatorname{Jan} / 03 / 00$
$*(3.14)$
Harold E. Adk

9 of 102

F-19 
RPP-5637

Rev. 0

\begin{tabular}{|lr|}
\hline JOHN MARVIN, INC. & Calculation Number: JMI-9910_02 \\
\hline Analyst: Marvin J. Thurgood & Date: Feb 9, 2000 \\
\hline Reviewer: Harold E. Adkins & Date: Feb 9, 2000 \\
\hline Subject: Notebook for GOTH_SNF Simulation of Tank AZ-102 \\
\hline
\end{tabular}

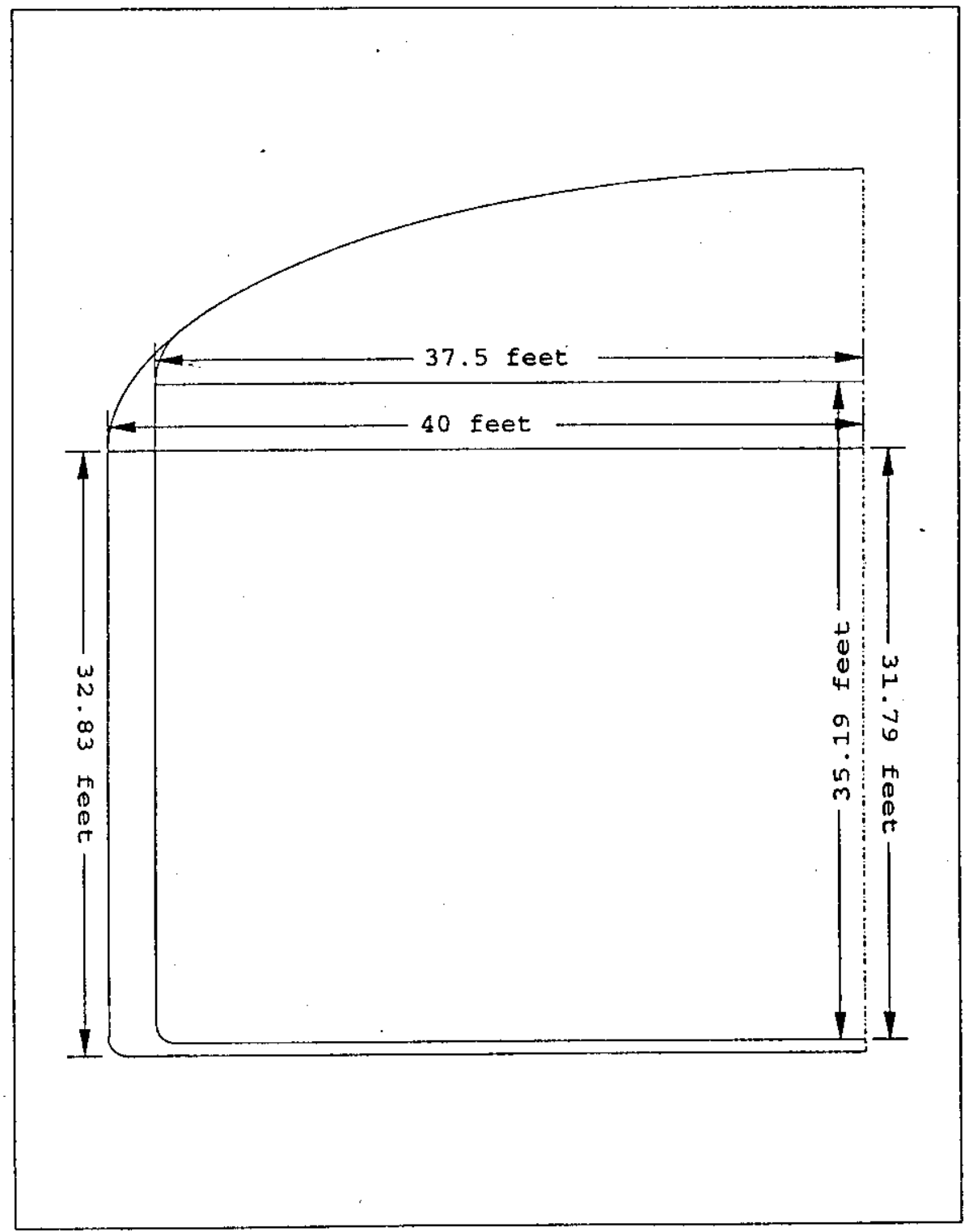

Figure 3.1 Az-102 Tank Shell Dimensions

10 of 102 


\begin{tabular}{|lr|}
\hline JoHN MARVIN, INC. & Calculation Number: JMI-9910_02 \\
\hline Analyst: Marvin J. Thurgood & Date: Feb 9, 2000 \\
\hline Reviewer: Harold E. Adkins & Date: Feb 9, 2000 \\
\hline Subject: Notebook Eor GOTH_SNF Simulation of Tank AZ-102 \\
\hline
\end{tabular}

\subsubsection{Aix Distributor Geometric Data.}

The space at the bottom of the tank between the primary and secondary shells is filled with an insulating concrete which has air flow slots molded into it, [Ref. 2]. The purpose of these slots is to allow air from the secondary ventilation system to flow radially outward from the center of the tank floor to the annulus formed by the primary and secondary cylindrical shells. This air flow provides cooling to the bottom of the tank. The plan view of the floor slots is shown in Figure 3.2. The radial slots are arranged in three sets across the radius of the tank. The first set contains 16 radial slots arranged azimuthally around the tank in $22.5^{\circ}$ intervals. The second set contains 32 radial slots at $11.25^{\circ}$ intervals. The third set has 64 radial slots at 5.625 intervals. The center most end of the slots in the first radial group connect to the central air distributor. The outer most end of each slot in the inner ring of slots connects to two slots in the center ring of slots via a $y$ connection. Each slot in the midale ring of slots connects on its outer most end to two slots in the outer ring of slots via a $y$ connection. The outermost end of the third set of slots connects to the annulus formed by the gap between the primary and secondary tank walls.

Cross-sectional views of the slots are also shown in Figure 3.2 with the dimensions of the slots. The type $A$ slots are near the center of the tank. Type B slots form the second ring of slots. Type $C$ slots are on the outer perimeter of the tank. 


\begin{tabular}{|lr|}
\hline JoHN MARVIN, INC. & Calculation Number: JMI-9910_02 \\
\hline Analyst: Marvin J. Thurgood & Date: Feb 9, 2000 \\
\hline Reviewer: Harold E. Adkins & Date: Feb 9, 2000 \\
\hline Subject: Notebook for GOTH_SNF Simulation of Tank AZ-102 \\
\hline
\end{tabular}

Feb/10/00 Marold E. Adki *

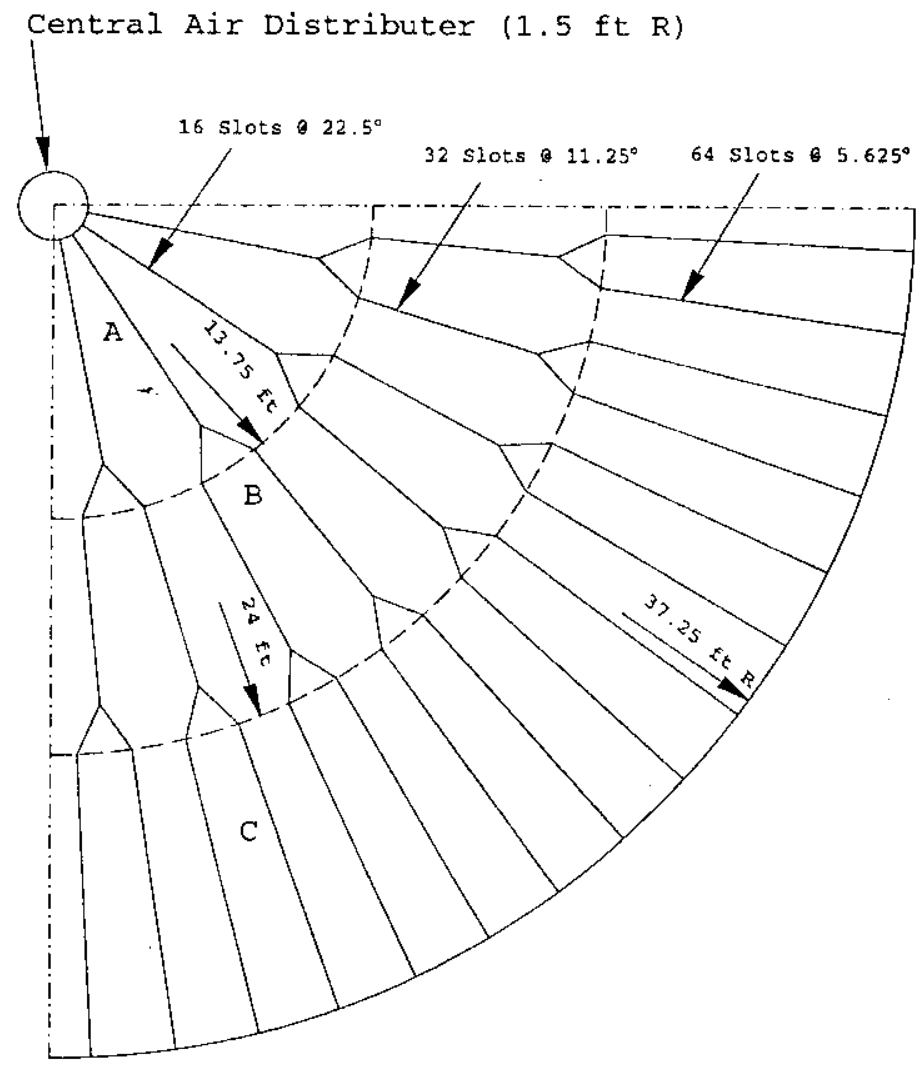

Slot Types

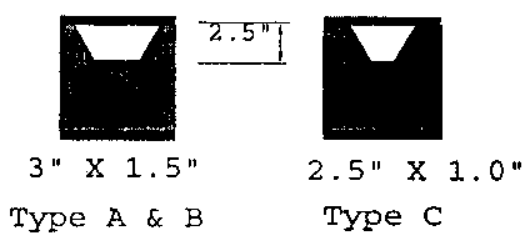

Figure, 3.2 Secondary Ventilation Air slot Layout. 
JOHN MARVIN, INC.

Calculation Number: JMI-9910_02

Analyst: Marvin J. Thurgood

Date: Feb 9,2000

Reviewer: Harold E. Adkins

Date: Feb 9, 2000

Subject: Notebook for GOTH_SNF Simulation of Tank AZ-102

The radius of the central air distributor is [Ref. 2]:

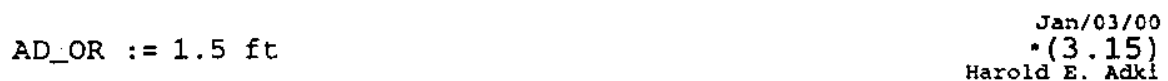

The outer radius of the first ring of slots (Type A slots)

is [Ref. 2]:

$$
R 1 \_O R:=13 \mathrm{ft}+9 \mathrm{in}=13.75 \mathrm{ft}
$$

The outer radius of the second ring of slots (Type B slots)

is [Ref. 2]:

$$
R 2 \text { OR : }=24 \mathrm{ft} \quad \begin{array}{r}
\text { Jan } / 03 / 00 \\
(3.17) \\
\text { Harold } E . \text { Adki }
\end{array}
$$

The outer radius of the third ring of slots (Type C slots)

[Ref. 2] is:

$$
\text { R3_OR }:=37.25 \mathrm{ft}
$$

The height of all slots is [Ref. 2]:

$$
\text { SLOT_HT }:=2.5 \mathrm{in}=0.208333 \mathrm{ft}
$$

The top wiath of the Type A slots is [Ref. 2]:

$$
\text { SLOT_A_TWD }:=3 \text { in }=0.25 \mathrm{ft}
$$

$\operatorname{Jan} / 03 / 00$
$+(3 \cdot 18)$
Harold E. Adki

The bottom width of the Type A slots is [Ref. 2]:

$$
\text { SLOT_A_BWD }:=1.5 \text { in }=0.125 \mathrm{ft}
$$

The top width of the Type B slots is [Ref. 2]:

$$
\text { SLOT_B_TWD }:=3 \text { in }=0.25 \mathrm{ft}
$$

$\operatorname{Jan} / 03 / 00$ Harold $*(3 \cdot 19)$

The bottom width of the Type B slots is [Ref. 2]:

$$
\text { SLOT_B_BWD }:=1.5 \text { in }=0.125 \mathrm{ft}
$$

The top width of the Type $C$ slots is [Ref. 2]:

$$
\text { SLOT_C_TWD }:=2.5 \mathrm{in}=0.208333 \mathrm{ft}
$$

The bottom width of the Type C slots is [Ref. 2]:

$$
\text { SLOT_C_BWD }:=1.0 \text { in }=0.0833333 \mathrm{ft}
$$

The number of Type A slots is [Ref. 2]:

$$
\text { SLOT_A_N }:=16
$$

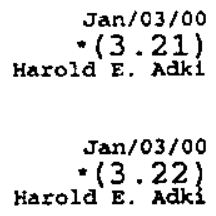

Jan $/ 03 / 00$ Harold $(3 \cdot 23)$

$\operatorname{Jan} / 03 / 00$ $+(3.24)$ Harold $E$. Adki

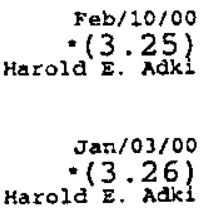




\begin{tabular}{|lr|}
\hline JOHN MARVIN, INC. & Calculation Number: JMI-9910_02 \\
\hline Analyst: Marvin J. Thurgood & Date: Feb 9, 2000 \\
\hline Reviewer: Harold E. Adkins & Date: Feb 9, 2000 \\
\hline Subject: Notebook for GOTH_SNF Simulation of Tank AZ-102 \\
\hline
\end{tabular}

The number of Type B slots is [Ref. 2]:

$$
\text { SLOT_B_N }:=32
$$

The number of Type $C$ slots is [Ref. 2]:

$$
\text { SLOT_C_N }:=64^{\circ}
$$

$$
\begin{array}{r}
\text { Jan } / 03 / 00 \\
\text { (3.27) } \\
\text { Harold E. Adki }
\end{array}
$$
The thickness of the insulating concrete that the slots are cut into is [Ref. 2]:

$$
\text { INSUL_CONC_TCK }:=8 \text { in }=0.666667 \mathrm{ft}
$$

$\operatorname{Jan} / 03 / 00$ $(3.29)$

The air is supplied to the central air distributor in the center of the tank floor by 4 four inch supply lines which are spaced around the tank at $90^{\circ}$ intervals. The dimensions of these secondary ventilation inlet pipes are:

Inside Diameter [Ref. 2], [Ref. 7]:

P4_ID $:=4.026$ in

Pipe wall thickness [Ref. 7]:

P4..thk $:=0.237$ in

\subsection{TANK WASTE PARAMETERS.}

The properties for the tank waste are taken from [Ref 6].

\subsubsection{Initial Waste In Az-102.}

The vapor pressure of the mixed waste solution is established to be 858 of that of water [Ref 6].

The fluffing factor due to mixing for the original slurry in $\mathrm{AZ}-102$ is:

$$
\text { FLUFF_FACT_AZ102 : }=2.0
$$

The slurry height for the waste in Az-102 is: 
Reviewer: Harold E. Adkins

Date: Feb 9, 2000

Subject: Notebook for GOTH_SNF Simulation of Tank AZ-102

$$
\text { slurry_HT_AZ102_ORG }:=34.5 \text { in }=2.875 \mathrm{ft} \quad \begin{array}{r}
50 \pi 103 / 00 \\
(3.33)
\end{array}
$$

The volume of the supernatant liquid layer in Az-102 is:

$$
\text { SUPER_VOL }:=854000 \mathrm{gal}=114163 \mathrm{ft}^{3}
$$

The volume of the slurry layer is:

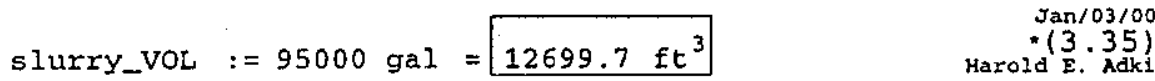

The total heat load for the supernatant liquid layer is:

$$
\text { SUPER_Q }:=67000 \frac{\text { Btu }}{\mathrm{hr}}
$$

$\operatorname{Jan} / 03 / 00$ Harold $E \cdot 3$ Adk

The total heat load for the slurry layer is:

$$
\text { slurry_Q }:=132700 \frac{\mathrm{Btu}}{\mathrm{hr}}
$$

Jan $103 / 00$ Harold $E \cdot$ Adki

The total heat load for the tank is:

$$
\text { TOTAL_Q := SUPER_Q + slurry_Q = } 199700 \frac{\mathrm{Btu}}{\mathrm{hr}} \quad \begin{array}{r}
\text { Jan } / 03 / 00 \\
\begin{array}{r}
*(3.38) \\
\operatorname{Marold} \mathrm{E} \cdot \text { Adk }
\end{array}
\end{array}
$$

The particle volume fraction for sluxry in Az-102 is:

$$
\alpha_{\mathrm{p} \ldots 102}:=0.17
$$

The specific heat of the solid particles is:

$$
C_{p-P A R T}:=0.2 \frac{B t U}{1 b m-R}
$$

The specific heat of the supernatant liquid is:

$$
C_{p-S U P E R}:=1 \frac{\text { Btu }}{1 \mathrm{bm}-\mathrm{R}}
$$

The thermal conductivity of the solid particles is:

$$
\text { K_PART }:=5 \frac{\mathrm{BtL}}{\mathrm{hr}-\mathrm{ft}-\mathrm{R}}
$$

The thermal conductivity of the supernatant liquid is:

$$
\text { K_SUPER }:=0.35 \frac{\mathrm{Btu}}{\mathrm{hr}-\mathrm{ft}-\mathrm{R}}
$$




$$
\text { JOHN MATVIN, INC. }
$$

Calculation Number: JMI-9910_02

Analyst: Marvin J. Thurgood

Date: Feb 9, 2000

Reviewer: Harold E. Adkins Date: Feb 9, 2000

Subject: Notebook for GOTH_SNF Simulation of Tank AZ-102

The specific gravity of the solid particles is:

$$
\text { SPG_PART }:=\frac{237.1 \frac{1 \mathrm{bm}}{\mathrm{ft}^{3}}}{62 \frac{1 \mathrm{bm}}{\mathrm{ft}^{3}}}=3.82419
$$

The specific gravity of the supernatant liquid is:

$$
\text { SPG_SUPER }:=\frac{68.64 \frac{\mathrm{lbm}}{\mathrm{ft}^{3}}}{62 \frac{\mathrm{lbm}}{\mathrm{ft}^{3}}}=1.1071
$$

The density of water used in the specific gravity calculations is:

$$
\rho_{w}:=62 \frac{\mathrm{lbm}}{\mathrm{ft}^{3}}
$$

The density of the particles is:

$$
\rho \_ \text {PART }:=\text { SPG_PART } \cdot \rho_{w}=237.1 \frac{\mathrm{lbm}}{\mathrm{ft}^{3}}
$$

,

$\operatorname{San} / 03 / 00$

$\div(3.47)$

Narold E. Adki

The density of the supernatant liquid is:

$$
\rho \_S U P E R \quad:=\rho_{w} \cdot S P G \_S U P E R=68.64 \frac{1 \mathrm{bm}}{\mathrm{ft}^{3}}
$$

Jan $/ 03 / 00$

$(3.48)$

Harold E. Adki

The total mass of the supernatant liquid is:

$$
\text { SUPER_MASS }:=\rho \text { SUPER } \cdot \text { SUPER_VOL }=7.83616 \times 10^{+06} 1 \mathrm{bm}
$$

The specific heat load for the supernatant liquid is:

$$
\text { Super_g }:=\frac{\text { SUPER_Q }}{\text { SUPER_MASS }}=0.0085501 \frac{\mathrm{Btu}}{1 \mathrm{bm}-\mathrm{hr}}
$$

The mass of particles in the slurry is: 
JOHN MARVIN, INC.

Analyst: Marvin J. Thurgood

Reviewer: Harold E. Adkins

Subject: Notebook for GOTH_S

$$
\text { Part_Mass }:=\alpha_{p \_102} \text { slurry_VOL } \cdot \text { P_PART }=5118851 \mathrm{bm}
$$

The mass of supernatant liguid in the sluryy is:

Super_Mass $:=\left(1.0-\alpha_{p} \_102\right) \cdot$ slurry_VOL $\cdot \rho_{-}$SUPER

$=723514 \quad 1 \mathrm{bm}$

The density of the slurry is:

$$
\rho s:=\frac{\text { Part_Mass + Super_Mass }}{\text { slurry_VoL }}=97.2782 \frac{1 \mathrm{bm}}{\mathrm{ft}^{3}}
$$

The average particle heat load for the Az-102 slurry is:

$$
\begin{aligned}
\text { Q.PART } & :=\frac{\text { slurry_Q }- \text { Super_Mass } \cdot \text { Super_g }}{\text { Part_Mass }} \\
& =0.247153 \frac{\mathrm{Btu}}{\mathrm{hr}-1 \mathrm{bm}}
\end{aligned}
$$

The maximum packing fraction that the particles will settle to after pump mixing is:

$$
\alpha_{p \text { MP }}:=\frac{\alpha_{p}-102}{\text { FLUFF_FACT_AZ102 }}=0.085
$$

The slurxy conductivity can be calculated from these parameters using the series conductivity model:

$$
\text { slurry_cond }\left(\alpha_{p}, k_{p}, k_{2}\right):=\frac{1.0}{\frac{\alpha_{p}}{k_{p}}+\frac{1-\alpha_{p}}{k_{1}}}
$$


JOHN MARVIN, INC.

Analyst: Marvin J. Thurgood

Reviewer: Harold $\mathrm{E}$. Adkins

Subject: Notebook for GOTH_SNE Simulation of Tank AZ-102

Date: Feb 9, 2000

Date: Feb 9, 2000
$\operatorname{Jan} / 05 / 00$

.$(3.57)$
Calculation Number: JMI-9910_02

Harold $E$. Adk

\subsubsection{The Initial Depth of slurry in Az-102.}

The total unmixed depth of the slurry is A-102 is then:

$$
\begin{gathered}
\text { SlurrY_HT_MOD }:=\text { slurYY_HT_AZ102_ORG } \\
=34.5 \mathrm{in} .
\end{gathered}
$$

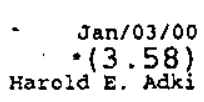

3.2.3. Supernatant Height In Az-102.

The tank cross-sectional area is given by:

$$
\text { tank_area }:=\frac{\text { slurry_VOL }}{\text { slurry_HT_MOD }}=4417.27 \mathrm{ft}^{2} \quad \begin{array}{r}
\text { Jan } / 03 / 00 \\
(3.59) \\
\text { Harold E. Adk1 }
\end{array}
$$

The supernatant liquid height is given by:

$$
\text { SUPERNATANT_HT }:=\frac{\text { SUPER_VOL }}{\text { tank_area }}=25.8447 \mathrm{ft} \quad \begin{array}{r}
\mathrm{Jan} / 03 / 00 \\
(3.60)
\end{array}
$$

The waste level in the tank is:

SUPERNATANT_LEVEL $:=$ SUPERNATANT_HT + sIUrYY_HT_MOD

$=28.7197 \mathrm{ft}$ 


\begin{tabular}{|lc|}
\hline JOHN MARVIN, INC. & Calculation Number: JMI-9910_02 \\
\hline Analyst: Marvin J. Thurgood & Date: Feb 9, 2000 \\
\hline Reviewer: Harold E. Adkins & Date: Feb 9, 2000 \\
\hline Subject: Notebook for GOTH_SNF Simulation of Tank AZ-102 \\
\hline
\end{tabular}

\subsubsection{VENTILATION INLET TEMPERATURE AND HUMIDITY.}

Two temperatures are specified in the input parameter specifications for this analysis [Ref 6]. The first of these is to be used during step one of the analysis and the higher is to be used with all of the remaining steps. This is of little real benefit and unnecessarily complicates the analysis. The lower of the temperatures is recommended for step one since all one has to do is turn the pumps off if the temperature criteria for the supernatant liquid is exceeded. The higher ternperature is recommended for calculating the settled waste temperatures before and after pump operation since no action can be taken to mitigate the situation if the slurry temperatures exceed the operating criterion. The higher of the two temperatures will be used in all of the steps since the limit on supernatant liquid. temperature will not be controlling. The supernatant liquid temperature will have to be lower than the allowable. in order for slurry temperatures to remain below their limit. The aix inlet temperature that will be used for these calculations is:

$$
\text { AIR_INLET_TEMPERATURE }:=t f(82)=82 \mathrm{~F}
$$

The inlet absolute humidity is provided in pounds of moisture per pound of dry air [Ref 6].

$$
\text { AIR_INLET_ABSOLUTE_HUMIDITY } \quad:=0.0066 \frac{1 \mathrm{bm}}{1 \mathrm{bm}} \begin{array}{r}
\text { Jant } / 03 / 00 \\
(3.63)
\end{array}
$$

This value will have to be converted to a pressure ratio for use in the code. The water vapor pressure ratio can be calculated assuming that the atmospheric pressure is 14.7 psia and the air temperature is that given by Equation 3.62. The mass fraction of water vapor at the specified absolute humidity is:

$$
\text { WV_mf }:=\frac{\text { AIR_INLET_ABSOLUTE_HUMIDITY }}{1+\text { AIR_INLET_.ABSOLUTE_HUMIDITY }}=0.00655673
$$

The mass fraction of air is: 


\begin{tabular}{|lr|}
\hline JoHN MARVIN, INC. & Calculation Number: JMI-9910_02 \\
\hline Analyst: Marvin J. Thurgood & Date: Feb 9, 2000 \\
\hline Reviewer: Harold E. Adkins & Date: Feb 9, 2000 \\
\hline Subject: Notebook for GOTH_SNF Simulation of Tank AZ-102 \\
\hline
\end{tabular}

$$
\text { air_mf }:=1-\text { wV_mf }=0.993443
$$

$\operatorname{Jan} / 03 / 00$

The molecular weight of water vapor is:

.$(3.65)$

$$
\text { MW_water }:=18.016 \frac{1 \mathrm{bm}}{1 \mathrm{bm}-\mathrm{mole}}
$$

$\operatorname{san} / 03 / 00$

$\therefore(3.66)$

The molecular weight of air is:

$$
\text { MW_aix }:=28.96 \frac{\mathrm{lbm}}{1 \mathrm{bm}-\mathrm{mole}}
$$

The lbm-moles of water vapor per $1 \mathrm{bm}$ of mixture is:

$$
\text { Wv_moles }:=\frac{\text { wV_mf }}{\text { MW_water }}=0.000363939 \text { mole }
$$

The Ibm_moles of air per $1 \mathrm{bm}$ of mixture is:

$$
\text { air_moles }:=\frac{\text { air_mf }}{\text { MW_air }}=0.034304 \text { mole }
$$

The total moles of mixture is:

$$
\text { tot_moles }:=\text { wV_moles }+ \text { air_moles }=0.0346679 \text { mole }
$$

The mole fraction of water vapor is then:

$$
\text { wv_vf }:=\frac{\text { wv_moles }}{\text { tot_moles }}=0.0104979
$$

Atmospheric pressure is assumed to be:

$$
\begin{aligned}
& \text { P_tot }:=14.7 \mathrm{psi} \\
& \text { P_wV }:=\text { P_tot } \cdot \mathrm{wv} \text { _vf }=0.154319 \mathrm{psi}
\end{aligned}
$$

(3.72) Harold $(3 \cdot 72)$

Jan $/ 03 / 00$

The mole fraction is the same as the pressure ratio so the water vapor pressure ratio for air at $82^{\circ} \mathrm{F}$ is:

$$
\text { wV_p_ratio }:=\text { wv_vE }=0.0104979
$$


JOHN MARVIN, INC.

Analyst: Marvin J. Thurgood

Reviewer: Harold E. Adkins

Subject: Notebook for GOTH_SNF Simulation of Tank AZ-102

\subsubsection{VENTILATION FLOW RATE.}

\subsubsection{Primary Ventilation Flow Rate.}

The nominal once through primary ventilation flow for this tank is [Ref 6]:

$$
\text { Q.primary }:=500 \frac{\mathrm{ft}^{3}}{\mathrm{~min}}=8.33333 \frac{\mathrm{ft}^{3}}{\mathrm{~s}}
$$

The recirculation flow for this tank is, [Ref 6]:

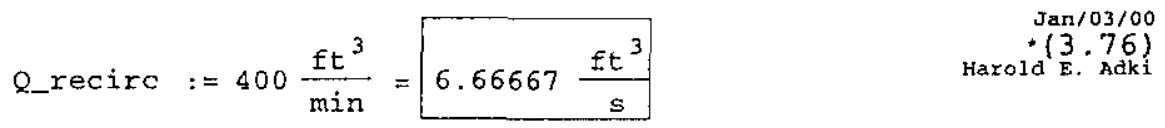

A flow of 100 \{ft $3 / \mathrm{min}$ \} is brought into the tank from the ambient air when the tank is operated in the recirculation mode [Ref 6].

$$
\text { Q_inlet_recir := Q_primary - Q_recirc }=1.66667 \frac{\mathrm{ft}^{3}}{\mathrm{~s}}
$$

The tank inlet conditions for the recirculation flow is air at $117^{\circ} \mathrm{F}$ and 1008 relative humidity.

These flows are at standard conditions so the ventilation recirculation flow at $40^{\circ} \mathrm{F}$ corresponds to a volumetric flow of:

$$
\begin{aligned}
& t 1:=t f(70)=529.67 \mathrm{R} \\
& t 2:=t f(40)=499.67 \mathrm{R} \\
& 400 \frac{\mathrm{Et}}{\mathrm{min}} \cdot \frac{\mathrm{t2}}{\mathrm{t} 1}=377.344 \frac{\mathrm{Et}}{\mathrm{min}}
\end{aligned}
$$

3.2.5.2. Secondary Ventilation Flow Rate.

The nominal secondary flow rate is [Ref 6]: 


\begin{tabular}{|lr|}
\hline JokN MARVIN, INC. & Calculation Number: JMI-9910_02 \\
\hline Analyst: Marvin J. Thurgood & Date: Feb 9, 2000 \\
\hline Reviewer: Harold E. Adkins & Date: Feb 9, 2000 \\
\hline Subject: Notebook for GOTH_SNF Simulation of Tank AZ-102 \\
\hline
\end{tabular}

$$
\text { Q_secondary }:=1000 \frac{\mathrm{ft}^{3}}{\mathrm{~min}}
$$

\section{GOTH_SNF MODEL DESCRIPTION.}

A GOTH_SNF model has been constructed for performing the specified simulations. A schematic of the model is shown in Figure 4.1. As shown, the model includes the primary waste tank, the annulus formed by the primary and secondary shell of the waste tank, floor slots and their associated vent/feed pipes, a mixer pump, a water refill sump which mimics the interaction of the condenser, and a primary ventilation duct. The primary ventilation inlet and outlet are represented by a flow condition "1F" and a pressure condition "6P". These components form the primary flow path. The secondary flow path is formed by the inlet pipes, the floor slots, and the annulus. The secondary ventilation inlet and outlet are represented by a flow condition " $4 \mathrm{~F}$ " and a pressure condition " $3 \mathrm{P}$ ".

To accurately represent particle settiing, slurry and supernatent interaction, and heat transfer characteristics within the tank waste, the primary waste tank volume was broken into 17 axially oriented subvolumes in 1-D fashion. The determination of the axial. thicknesses will be presented later. The 1-D nodal layout illustrating the 17 subvolumes of the waste tank volume is shown in Figure 4.2. Also presented in this figure are the conductors representing the conductive link to the concrete pad on into the soil, and the convective link into the floor slots. The pump inlet is also shown.

To accurately represent the additional heat load of the mixer pump during operation, a heat source was added in the supernatent equaling $1.5 \times 10^{6} \mathrm{Btu} / \mathrm{hr}$. For this particular model, it was added to the 12 th subvolume from the bottom. 
RPP-5637

Rev. 0

JOHN MARVIN, INC.

Calculation Number: JMI-9910_02

Analyst: Marvin J. Thurgood

Date: Feb 9, 2000

Reviewer: Harold E. Adkins

Date: Feb 9, 2000

Subject: Notebook for GOTH_SNF Simulation of Tank AZ-102

The pump heat is dissipated in the tank as the kinetic energy of the outlet jet is converted into thermal energy. The exact location of the heat addition is not important as the flow driven by the pump mixes the waste to a uniform temperature.

Finally, soil thickness of $100 \mathrm{ft}$ between the tank bottom and the $50^{\circ} \mathrm{F}$ water table, $7 \mathrm{ft}$ between the tank dome and the $82^{\circ} \mathrm{F}$ ambient, and $50 \mathrm{ft}$ spanning radially away from the annulus to an adiabatic boundary, were designated. 
RPP-5637

Rev. 0

\begin{tabular}{|lr|}
\hline JoHN MARVIN, INC. & Calculation Number: JMI-9910_02 \\
\hline Analyst: Marvin J. Thurgood & Date: Feb 9, 2000 \\
\hline Reviewer: Harold E. Adkins & Date: Feb 9, 2000 \\
\hline Subject: Notebook for GoTH_SNF Simulation of Tank AZ-102 \\
\hline
\end{tabular}

Jan/18/00 Harold E. Adki*

Tank Madel $2: 182000$

Mon Jan 17 14:55:18 2000
GOTH_SNF Version 5.0-November 1999

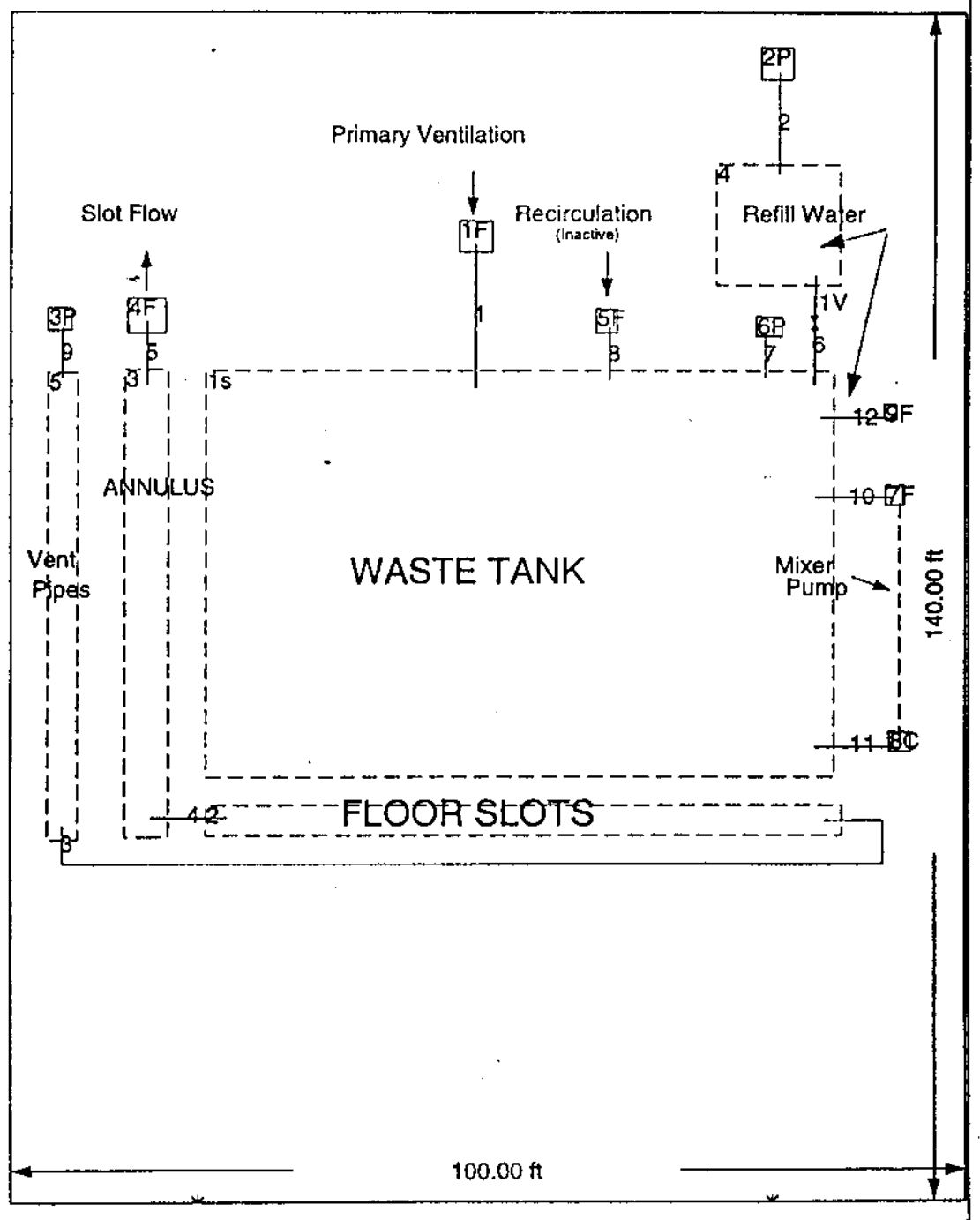

Figure 4.1 GOTH_SNF Model of Tank AZ-102.

24 of 102 
RPP-5637

Rev. 0

JOHN MARVIN, INC.

Calculation Number: JMI-9910_02

Analyst: Marvin J. Thurgood

Date: Feb 9, 2000

Reviewer: Harold $E$. Adkins

Date: Feb 9, 2000

Subject: Notebook for GOTH_SNF Simulation of Tank AZ-102

$\operatorname{Jan} / 18 / 00$ Harold E. Aaki.

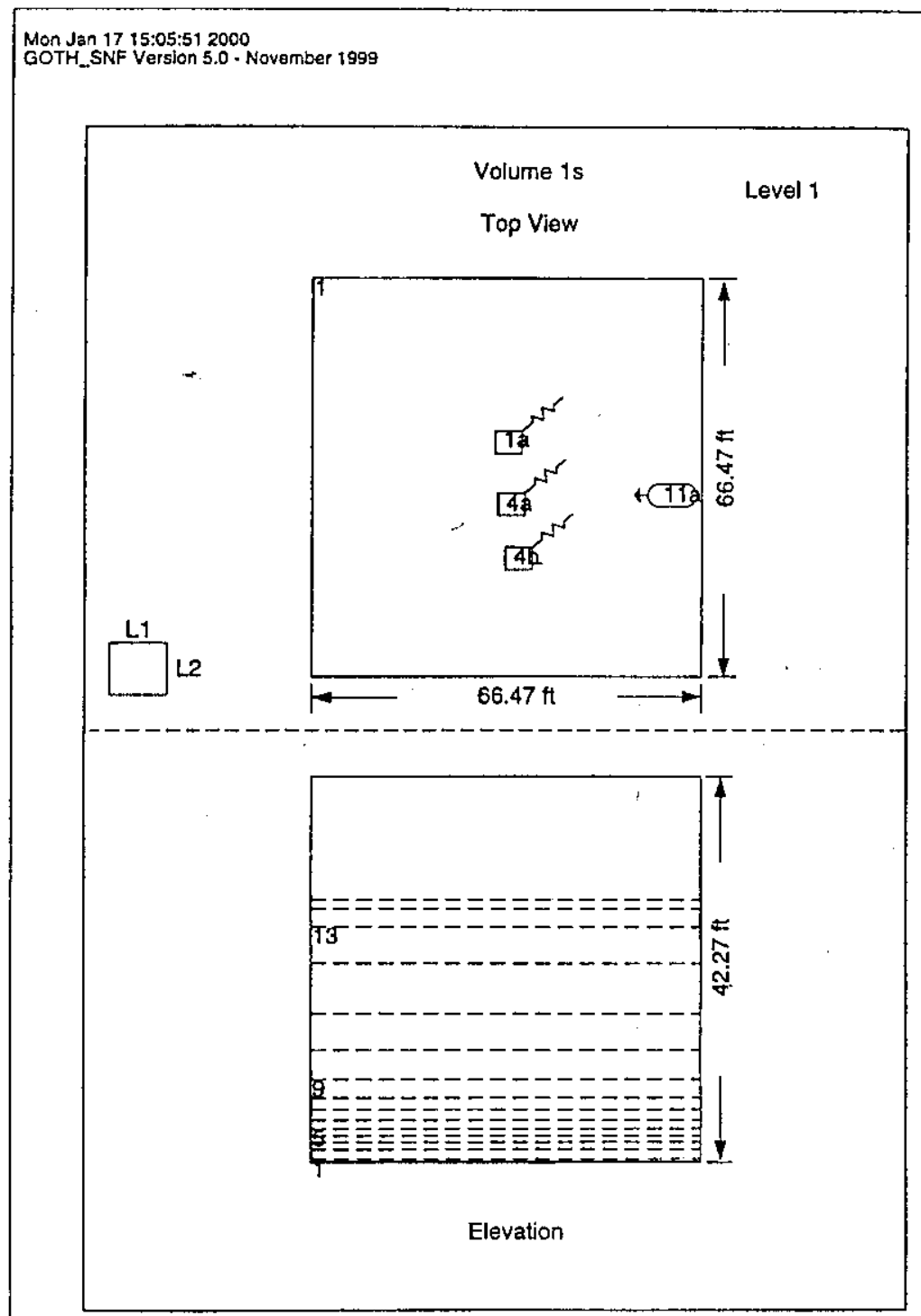

Figure 4.2 GOTH_SNF Model Nodal Layout of Tank AZ-102. 
RPP-5637

Rev. 0

\begin{tabular}{|lr|}
\hline JOHN MARVIN, INC. & Calculation Number: JMI-9910_02 \\
\hline Analyst: Marvin J. Thurgood & Date: Feb 9, 2000 \\
\hline Reviewer: Harold E. Adkins & Date: Feb 9, 2000 \\
\hline Subject: Notebook for GOTH_SNF Simulation of Tank AZ-102 \\
\hline
\end{tabular}

\section{DEVELOPMENT OF INPUT PARAMETERS FOR THE GOTH_SNF MODEL .}

The raw data given in section 3 is used in this section to calculate the parameters that are required for the GOTH_SNF tank model described in section 4 .

\subsection{GEOMETRIC INPUT DATA.}

There are four volumes in the GOTH_SNF model of Tank AZ-102. The first three of these represent fluid volumes determined by the tank geometry. The fourth is an auxiliary volume used, in the model, to condense water vapor out of the air leaving the tank and return the condensate to the tank to maintain the liquid level constant. This volume can also be used to represent the operation of the condenser, or a chiller, if one is required to meet the tank operational and safety temperature limitations. The input parameters for each of these volumes will be calculated in this section. First, some useful functions are defined that will simplify doing the calculations.

\subsubsection{Useful Functions and Parameters.}

Area of a circle of radius $r$ [Ref. 3, p. 12]:

$$
A_{C}(r):=\pi \cdot r^{2}
$$

Area of an annular ring formed by a larger circle of radius $r 1$ and a smaller circle of radius r2 [Ref. 3, p. 13]: 
JOHN MARVIN, INC.

Analyst: Marvin J. Thurgood

Reviewer: Harold E. Adkins

Subject: Notebook for GOTH_SNF Simulation of Tank AZ-102
Calculation Number: JMI-9910_02

Date: Feb 9, 2000

Date: Feb 9, 2000

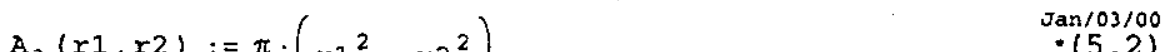

i $(5.2)$

The perimeter of a circle of radius $r$ [Ref. 3, p. 12]:

$$
P_{C}(r):=2 \cdot \pi \cdot r \text {. }
$$

The perimeter of an annular ring formed by a larger

circle of radius $r 1$ and a smaller circle of radius $r 2$,

[Ref. 3, p. 12]:

$$
p_{a}(r 1, r 2):=2 \cdot \pi \cdot(r 1+r 2)
$$

$\mathrm{Jan} / 03 / 00$ Harold E. Adki

The hydraulic diameter of a flow path with flow area, $A$, and wetted perimeter, $P_{w}$, [Ref. 4, p. 165]:

$$
D_{h}(A, P w):=4 \cdot \frac{A}{P_{W}} \quad \begin{array}{r}
\operatorname{Jan} / 03 / 00 \\
*(5 \cdot 5) \\
E
\end{array}
$$

The volume of a cylinder of radius, $r$, and height, $h$;

[Ref. 3, p. 16] :

$$
V_{c}(r, h):=A_{c}(r) \cdot h
$$

The volume of an annulus formed by a larger cylinder of inside radius, $r 1$, and a smaller cylinder of outside. radius, $r 2$, and of height $h$ [Ref. 3, p. 16]:

$$
V_{a}(r 1, r 2, h):=A_{a}(r 1, r 2) \cdot h
$$

The acceleration of gravity is:

$$
g:=32.2 \frac{\mathrm{ft}}{\mathrm{s}^{2}}
$$

$\operatorname{Jan} 103 / 00$ Hazold E. $(5,8)$

\subsubsection{Tank Primary Volume.}

The primary tank shell consists of a upright cylinder with a flat bottom and a dome top that has the shape of a body of revolution formed by a modified half ellipse. The dome of the secondary tank is a body of revolution formed by a half ellipse. The primary tank dome is formed by a body of revolution formed by the portion of a circle which is tangent to the primary tank cylindrical wall and the secondary tank dome. 
JOHN MARVIN, INC.

Analyst: Marvin J. Thurgood

Reviewer: Harold E. Adkins

Subject: Notebook for GOTH

\subsubsection{Area of Tank primary Volume.}

The cross-sectional area of the tank primary volume will be taken as the inside cross-sectional area of the cylindrical portion of the primary tank shell. This area shall be used for the pool area used to calculate the evaporation rate from the supernatant liquid surface, the conduction area for heat transfer in the waste and the flow area in the tank during pump mixing. The area of the primary tank volume is:

$$
\text { PS_area }:=A_{C}\left(P S_{-} I R\right)=4417.86 \mathrm{ft}^{2}
$$

\subsubsection{Volume of Tank Pximary Volume.}

The volume of the cylindrical portion of the primary tank is:

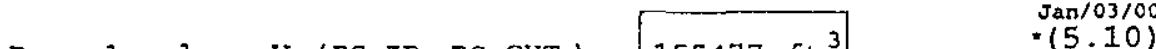

$$
\begin{aligned}
& \text { PS_CY1_vol }:=V_{C}\left(P S \_I R, P S \_C H T\right)=155477 \mathrm{ft}^{3} \quad \begin{array}{l}
*(5.10) \\
\text { Harold E. Adki }
\end{array}
\end{aligned}
$$

The centroid of the semi-ellipse of the size of that

forming the secondary tank dome, [Ref. 3, p. 20]:

$$
\text { Elip_cent }:=\frac{4 \cdot \frac{\text { SS_ELIP_MAJOR }}{2}}{3 \cdot \pi}=16.9765 \mathrm{ft} \quad \begin{array}{r}
\begin{array}{c}
\text { Jan } / 03 / 00 \\
(5 \cdot 11)
\end{array} \\
\text { Harold } \mathrm{E} \cdot \mathrm{Adki}
\end{array}
$$

The cross-sectional area of the quarter ellipse formed by the planar half section of the secondary tank dome is, [Ref. 3, p.13] :

$$
\text { Elip_area }:=\frac{\pi}{4} \cdot \frac{\text { SS_ELIIP_MAJOR }}{2} \cdot \frac{\text { SS_ELIP_MINOR }}{2}=47.239 \mathrm{Et}^{2}
$$

The volume of the body of revolution formed by the secondary dome shell is equal to the diameter of the circle formed by the centroid as the ellipse is rotated about the tank centerline times the area of the guarter ellipse, [Ref. 3, p. 19]. 


\begin{tabular}{|lr|}
\hline JokN MARVIN, INC. & CaICulation Number: JMI-9910_02 \\
\hline Analyst: Marvin J. Thurgood & Date: Feb 9, 2000 \\
\hline Reviewer: Harold E. Adkins & Date: Feb 9, 2000 \\
\hline Subject: Notebook for GOTH_SNF Simulation of Tank AZ-102 \\
\hline
\end{tabular}

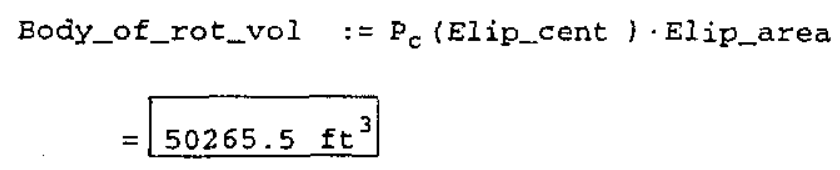

Most, but not all of this volume is within the primary tank. A small portion of it is in the annulus. Some of this volume is also in the cylindrical portion of the primary tank. The above information will be used to calculate the volume of the annulus once the volume of the primary tank-dome is known.

The equation for an ellipse whose major axis is $2 \mathrm{a}$ and whose minor axis is $2 b$ and whose center is at the origin is, [Ref. 3, p. 365]:

$$
y_{e}(x, a, b):=\sqrt{\left(1-\frac{x^{2}}{a^{2}}\right) \cdot b^{2}}
$$

The equation for a circle of radius, $r$, whose origin is located at $(h, k)$ is [Ref. 3,p. 363]:

$$
y_{c}(x, r, h, k):=\sqrt{r^{2}-(x-h)^{2}}+k
$$

The shape of the dome of the primary shell can be plotted using these two functions. These functions are shown in Figure 5.1. The ellipse function is plotted from the tank centerline to the point of tangency between the primary and secondary shell and the circle function is plotted between the point of tangency of the primary and secondary shells and the inside radius of the primary shell.

The cross-sectional area of the primary shell half dome is obtained by integrating the ellipse and circle functions over their appropriate ranges and subtracting the portion of the ellipse that is within the cylindrical portion of the primary: tank shell. This is done in the following two equations. 


\begin{tabular}{|lr|}
\hline JohN MARVIN, INC. & Calculation Number: JMI-9910_02 \\
\hline Analyst: Marvin J. Thurgood & Date: Feb 9, 2000 \\
\hline Reviewer: Harold E. Adkins & Date: Feb 9, 2000 \\
\hline Subject: Notebook Eor GOTH_SNF Simulation of Tank A2-102 \\
\hline
\end{tabular}

Jan/03/00 Hazold E. Adki *(5.16)

$$
\begin{gathered}
\text { Aelip }:=\int_{0 \mathrm{ft}}^{\text {PS_SS_TAN }} Y_{e}\left(x, \frac{\text { SS_ELIP_MAJOR }}{2}, \frac{\text { SS_ELIP_MINOR }}{2}\right) d x \\
\text { - PS_IR } \cdot \text { PS_TAN_SS_TAN }=325.779 \mathrm{Et}^{2}
\end{gathered}
$$

Jan/03/00 Harold E. Aaki $*(5.17)$

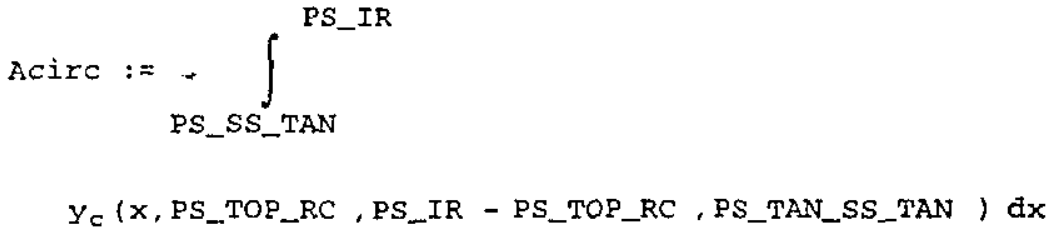

The volume of the primary tank dome can be obtained by multiplying the primary tank half dome area by the length of the path drawn by its centroid when the area is rotated about the tank centerline. The distance from the tank centerline to the centroid of the dome cross-sectional area is obtained by iteratively integrating the equation for the ellipse until one half of the dome cross-sectional area is obtainea.

$\frac{\text { Ps_Dome_XArea }}{2}=167.225 \mathrm{ft}^{2}$ 
JOHN MARVIN, INC.

Calculation Number: JMI-9910_02

Analyst: Marvin J. Thurgood

Date: Feb 9, 2000

Reviewer: Harold E. Adkins

Date: Feb 9, 2000

Subject: Notebook for GOTH_SNF Simulation of Tank AZ-102

Jan/03/00 Hazold E. Adki*(5.20)

$$
\begin{gathered}
\text { Aelip_cent }:=\int_{0 \mathrm{Et}}^{14.87 \mathrm{ft}} \mathrm{y}_{\mathbf{e}}\left(x, \frac{\text { SS_ELIP_MAJOR }}{2}, \frac{\text { SS_ELIP_MINOR }}{2} \mathrm{dx}\right. \\
-14.87 \mathrm{ft} \cdot \text { PS_TAN_SS_TAN }=167.227 \mathrm{ft}^{2}
\end{gathered}
$$

Therefore, the distance to the centroid is:

$$
\text { Ps_dome_centroid }:=14.87 \mathrm{ft}
$$

and the primary tank dome volume is:

Ps_dome_vol := PS_Dome_XArea $\cdot P_{c}$ (Ps_dome_centroid)

$=31248 \mathrm{ft}^{3}$

(31248.

The total volume of the primary tank is:
PS_vol $:=$ PS_dome_vol $+A_{c}$ (PS_IR) PS_CHT
$\operatorname{Jan} / 03 / 00$
.$(5.23)$
$=186725 \mathrm{ft}^{3}$
Harold E. Adk
PS_vol $=1.3968 \times 10^{+06} \mathrm{gal}$
$\operatorname{Jan} / 03 / 00$
$(5.24)$

31 of 102 


\begin{tabular}{|lr|}
\hline JoHN MARVIN, INC. & Calculation Number: JMI-9910_02 \\
\hline Analyst: Marvin J. Thurgood & Date: Feb 9, 2000 \\
\hline Reviewer: Harold E. Adkins & Date: Feb 9, 2000 \\
\hline Subject: Notebook for GOTH_SNF Simulation of Tank AZ-102 \\
\hline
\end{tabular}

Jan/03/00 Harold E. Adki *

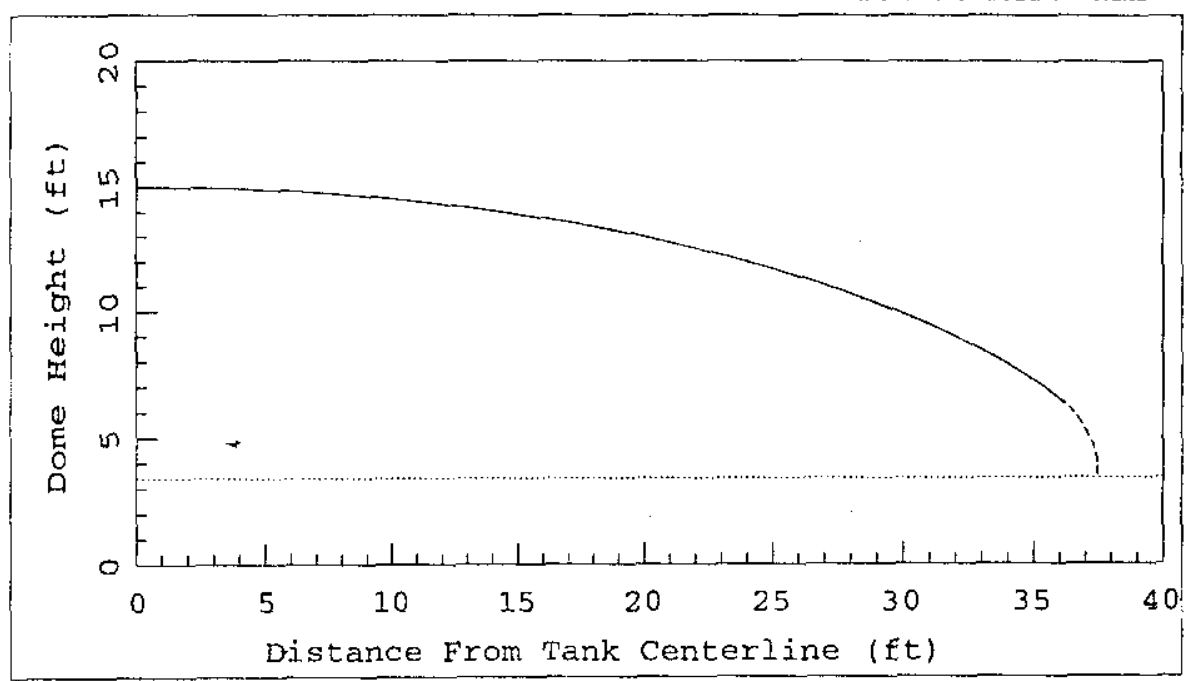

Figure 5.1 Approximation of Primary Dome Shape.

\subsubsection{Bottom Elevation of Tank Primary Volume.}

The bottom of the tank annulus will be taken as zero, therefore, the bottom of the tank primary volume is:

$$
\text { PS_elev := SS_PS_SPACE }=0.666667 \mathrm{ft} \quad \begin{array}{r}
\text { Jan } / 03 / 00 \\
(5.25) \\
\text { Harold E. Adki }
\end{array}
$$

\subsubsection{Height of the Tank Primary Volume.}

The height of the tank primary volume will be assumed to be equal to its volume divided by its area:

$$
\text { PS_ht }:=\frac{\text { PS_vol }}{\text { PS_area }}=42.2658 \mathrm{ft}
$$


RPP-5637

Rev. 0

JOHN MARVIN, INC.

Calculation Number: JMI-9910_02

Analyst: Marvin J. Thurgood

Reviewer: Harold E. Adkins

Date: Feb 9, 2000

Subject: Notebook for GOTH_SNF Simulation of Tank AZ-102

\subsubsection{Subdivisions of Primary Tank Volume.}

The primary tank will be vertically subdivided into several computational cells to model the settled slurry layer, the supernatant liquid level, the level of the settled slurry after mixing and the location of thermocouples where possible. The subdivisions will be sized to give a reasonable representation of the conduction heat transfer within the settled, non-convective layer.

The location of the bottom thermocouple is about 11 inches off of the floor of the waste tank. The thickness of the slurry initially in Az-102 is 17 inches. Therefore, if we make the first node 5 inches high and the second node 17 inches high, the center of the second node will be at the thermocouple location.

$$
\begin{gathered}
\Delta \mathrm{x}_{1}:=5 \text { in }=0.416667 \mathrm{ft} \\
\Delta \mathrm{x}_{2}:=12 \text { in }=1 \mathrm{ft} \\
\text { Location of center of node } 2 \text { : }
\end{gathered}
$$

$$
\Delta \mathrm{x}_{1}+0.5 \cdot \Delta \mathrm{x}_{2}=11 \text { in }
$$

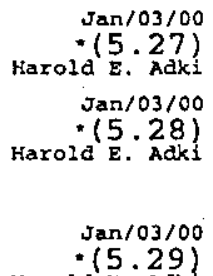

$\mathrm{Jan} / 03 / 00$

$*(5.27)$

Harold $E$. Adki

Jan $103 / 00$

. (5.28)

Harold E. Adki

Jan $/ 03 / 00$

- (5.29)

Dons values for $\Delta x$ : 
RPP-5637

Rev. 0

\begin{tabular}{|lr|}
\hline JOHN MARVIN, INC. & Calculation Number: JMI-9910_02 \\
\hline Analyst: Marvin J. Thurgood & Date: Feb 9, 2000 \\
\hline Reviewer: Harold E. Adkins & Date: Feb 9, 2000 \\
\hline Subject: Notebook for GOTH_SNF Simulation of Tank AZ-102 \\
\hline
\end{tabular}

Table 5.1 Subdivision Heights and Pressures.

Fab/10/00 Harold E. Adki *

\begin{tabular}{|c|c|c|c|c|}
\hline Level & Height & Pressure & Elevation & $\begin{array}{l}\text { Dist. to } \\
\text { Node Cente } \\
\text { From Bot. } \\
\text { of Tank }\end{array}$ \\
\hline & ft & $p s i$ & ft & ft \\
\hline 1 & 0.41667 & 29.52754 & 0.66667 & 0.20833 \\
\hline 2 & 1.00000 & 29.04864 & 1.08333 & 0.91667 \\
\hline 3 & 0.77700 & 28.44794 & 2.08333 & 1.80517 \\
\hline 4 & 0.68133 & 27.95496 & 2.86033 & 2.53433 \\
\hline 5 & 0.77100 & 27.46400 & 3.54166 & 3.26050 \\
\hline 6 & 0.95800 & 26.87953 & 4.31266 & 4.12500 \\
\hline 7 & 1.14600 & 26.04514 & .5 .27066 & 5.17700 \\
\hline 8 & 1.28600 & 25.35100 & 6.41666 & 6.39300 \\
\hline 9 & 2.00000 & 24.56720 & 7.70266 & 8.03600 \\
\hline 10 & 3.20000 & 23.32687 & 9.70266 & 10.63600 \\
\hline 11 & 4.00000 & 21.60949 & 12.90266 & 14.23600 \\
\hline 12 & 5.48374 & 19.34737 & 16.90266 & 18.97787 \\
\hline 13 & 4.00000 & 17.08526 & 22.38640 & 23.71974 \\
\hline 14 & 2.00000 & 15.65410 & 26.38640 & 26.71974 \\
\hline 15 & 1.00000 & 14.93853 & 28.38640 & 28.21974 \\
\hline
\end{tabular}

slurry_HT_MOD $=2.875 \mathrm{ft}$

$2 \cdot$ slurry_HT_MOD $=5.75 \mathrm{ft}$

SUPERNATANT_LEVEL $=28.7197 \mathrm{ft}$

$\left(\sum_{i=1}^{4} 1_{i, 2}\right)=2.875 \mathrm{ft}$
Feb/10/00

Harold $(5 \cdot 30)$

Feb/10/00

.$(5.31)$

Harold $E$. Adki

Feb/10/00

Harold $(5,32)$

Feb $/ 10 / 00$

$(5.33)$ 


$$
\begin{aligned}
& \left(\sum_{i=1}^{7} 1_{i, 2}\right)=5.75 \mathrm{ft} \\
& \left(\sum_{i=1}^{15} 1_{i, 2}\right)=28.7197 \mathrm{ft}
\end{aligned}
$$

\subsubsection{Hydraulic Diameter of Tank Primary Volume.}

The hydraulic diameter of this volume will be assumed to be equal to the primary tank diameter:

$$
\text { PS_hyd }:=2 \cdot \text { PS_IR }=75 \mathrm{ft}
$$

\subsubsection{Dimensions of Conductor at the Top of the Tank.}

Heat can be conducted through the soil covering the tank dome to (or from) the ambient air. This heat transfer path will be represented in the model with a conductor having the thermal properties of soil and the average thickness of the soil covering the tank dome. The ambient dry bulb temperature will be specified on the surface of this conductor and a natural convection heat transfer coefficient will be specified on the side facing the tank dome space. The surface area of this conductor is:

$$
\text { Dome_soil_conductor_area }:=\text { PS_area }=4417.86 \mathrm{ft}^{2}
$$

The thickness of this conductor is:

$$
\text { Dome_soil_conductor_thk }:=84 \text { in }=7 \mathrm{ft}
$$

The thermal properties for all soil conductors were assumed to be constant and to be $\rho=104 \mathrm{Ibm} / \mathrm{ft}^{3}, \mathrm{k}=0.25$ Btu/hr-ft- ${ }^{\circ} \mathrm{F}$, and $C_{p}=0.4 \mathrm{Btu} / 1 \mathrm{bm}-{ }^{\circ} \mathrm{F}$ [Ref. 8]. 
RPP-5637

Rev. 0

JOHN MARVIN, INC.

Analyst: Marvin J. Thurgood

Reviewer: Harold E. Adkins

Subject: Notebook for GOTH_S
Calculation Number: JMI-9910_02

\subsubsection{Dimensions of Conductor at the Bottom of the Tank.}

Heat can be conducted through the soil under the tank to the ground water.. This heat transfer path will be represented in the model with a conductor having the thermal properties of soil and the average thickness of the soil between the bottom of the tank and the ground water. The ground water temperature will be specified on the surface of this conductor and a natural convection heat transfer coefficient will be specified on the side facing the tank bottom. The surface area of this conductor is:

$$
\begin{aligned}
& \text { Ground_soil_conductor_area }:=\text { PS_area }=4417.86 \mathrm{ft}^{2} \\
& \text { The thickness of this conductor is: } \\
& \text { Ground_soil_conductor_thk }:=1200 \mathrm{in}=100 \mathrm{ft}
\end{aligned}
$$

\subsubsection{Tank Annulus Volume.}

The tank annulus is formed by the space between the tank primary and secondary shell walls. It is a cylinarical annulus except for the top portion which is formed by the space between the secondary dome which is elliptical in shape and the primary tank dome which is circular in shape at the annulus boundary.

\subsubsection{Area of Tank Annulus Volume.}

The cross-sectional area of the tank annulus volume will be taken as the area of a annulus formed by the tank primary and tank secondary shell cylinders:

$$
\text { Annulus_area }:=A_{a}\left(S S_{-} I R, P S \_I R\right)=608.684 \mathrm{ft}^{2} \quad \begin{array}{r}
\operatorname{Jan} / 03 / 00 \\
(5.41)
\end{array}
$$


JOHN MARVIN, INC.

Analyst: Marvin J. Thurgood

Reviewer: Harold E. Adkins

Subject: Notebook for GOTH_SNF Simulation of Tank AZ-102

\subsubsection{Volume of Tank Annulus Volume.}

The tank annulus volume consists of the volume of the cylindrical annulus formed by the tank primary and secondary shells up to the height of the cylindrical portion of the secondary shell and by the volume formed by the boundaries of the secondary and primary domes above this height.

The volume of the cylinarical portion of the annulus is:

Annulus_CY1_vol $:=A_{a}\left(S S \_I R, P S \_I R\right) \cdot S S \_C H T$

$$
=19756.9 \mathrm{ft}^{3}
$$

The volume of the dome portion of the annulus is the volume of the body of revolution formed by rotating the secondaxy shell ellipse about the tank centerline less the volume of the primary tank dome volume and the cylindrical portion of the secondary shell dome volume that is contained in the primary tank volume:

$$
\begin{gathered}
\text { Annulus_dome_vol }:=\text { Body_of_rot_vol - Ps_dome_vol } \\
\text { - Ac (PS_IR) ·PS_TAN_SS_TAN }=3992.19 \mathrm{ft}^{3}
\end{gathered}
$$

The total annulus volume is:

Annulus_vol : = Annulus_cyl_vol + Annulus_dome_vol

$$
=23749 \mathrm{ft}^{3}
$$

\subsubsection{Bottom Elevation of Tank Annulus Volume.}

The bottom of the tank annulus will be taken as zero, therefore, the bottom of the tank annulus volume is: 
JOHN MARVIN, INC.

Analyst: Marvin J. Thurgood

Reviewer: Harold E. Adkins

Subject: Notebook for GOTH_SNF Simulation of Tank AZ-102
Calculation Number: JMI-9910_02

Date: Feb 9, 2000

Date: Feb 9, 2000

$\operatorname{Jan} / 03 / 00$

$(5.45)$

\subsubsection{Height of the Tank Annulus Volume.}

The height of the tank annulus volume will be assumed to be equal to its volume divided by, its area:

$$
\text { SS_ht . }:=\frac{\text { Annulus_vol }}{\text { Annulus_area }}=39.0171 \mathrm{ft}
$$

\subsubsection{Hydraulic Diameter of Tank Annulus Volume.}

The hydraulic diameter of this volume is:

$$
\text { SS_hyd }:=D_{h}\left(\text { Annulus_area }, P_{a}\left(S S_{-} I R, P S \_I R\right)\right)=5 \mathrm{ft}
$$

\subsubsection{Dimensions for Conductor Between Primary Air Volume and Annulus Air.}

The surface area of the conductor between the tank dome air space and the annulus area is a function of the level of waste and supernatant Iiquid in the tank.

slurry height in tank:

$$
\text { slurry_ht }:=\text { slurry_HT_MOD }=34.5 \text { in }
$$
Harold $E$. AdKi

Supernatant liquid height:

Supernatant_ht := SUPERNATANT_LEVEL - slurry_ht

$$
=25.8447 \mathrm{ft}
$$

Total waste height: 


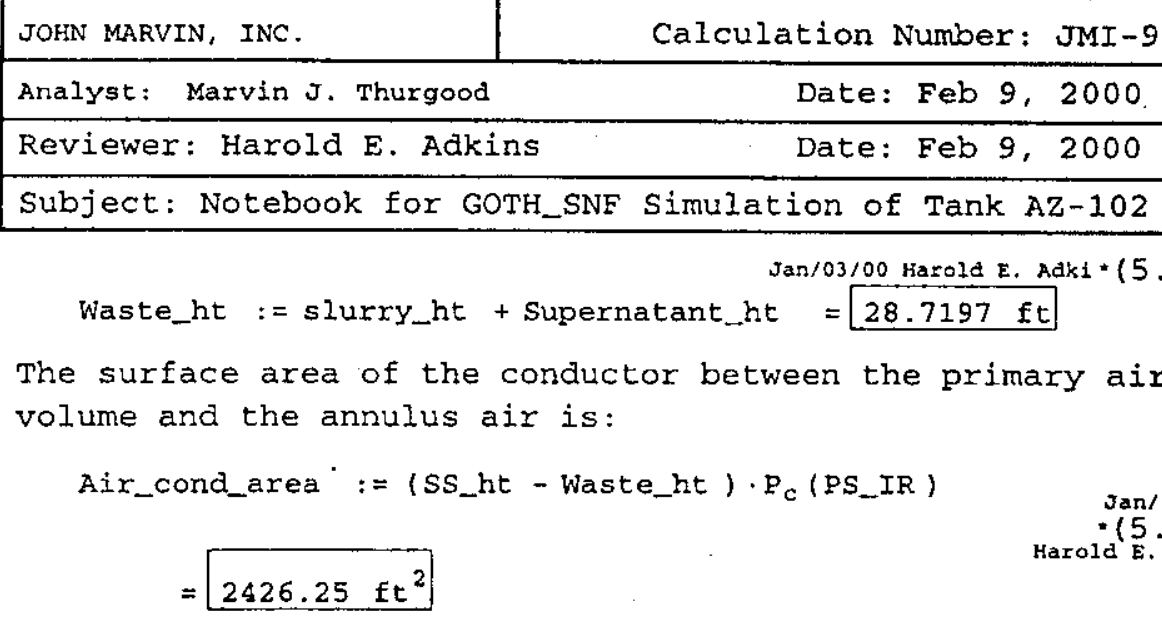

The thickness of this conductor is:

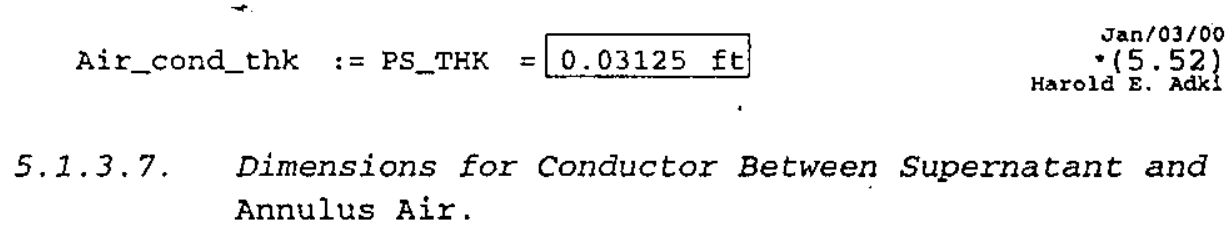

The surface area of the conductor between the supernatant liquid and the annulus air is:

Supernatant_cond_area $:=$ Supernatant_ht $\cdot P_{c}$ (PS_IR)

$$
=6089.52 \mathrm{ft}^{2}
$$

The thickness of this conductor is:

$$
\text { Supernatant_cond_thk }:=\text { PS_THK }=0.03125 \mathrm{ft}
$$

5.1.3.8. Dimension for Conductor Between Annulus Air And Soil Around the sides of the Tank.

The surface area for the secondary shell conductor is: 
JOHN MARVIN, INC.

Calculation Number: JMI-9910_02

Analyst: Marvin J. Thurgood

Date: Feb 9, 2000

Reviewer: Harold $\mathrm{E}$. Adkins

Date: Feb 9, 2000

Subject: Notebook for GOTH_SNF Simulation of Tank AZ-102

Side_soil_conductor_area $:=$ SS_ht $\cdot P_{C}$ (SS_IR)

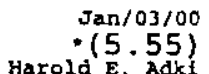

$$
=9806.06 \mathrm{ft}^{2}
$$

This conductor will have the properties of soil. The thickness of the conductor will be equal to the average distance between tanks.

Side_soil_conductor_thk $:=600 \mathrm{in}=50 \mathrm{ft}$

$\operatorname{Jan} 105 \%$ Marold $(5.56)$

\subsection{4. - Tank Floor slot Volume.}

The tank floor slot volume represents the slots that are molded into insulating concrete that lie between the bottoms of the primary and secondary shells. Air is injected into this volume to remove heat from the bottom of the waste contained in the primary volume.

\subsubsection{Area of Floor Slot Volume.}

The floor slots are arranged in three rings, as shown in Figure 3.2. The flow area of the individual slots in each ring are:

Jan/03/00 Harold E. Adki * (5.57)

$$
\begin{aligned}
\text { Slot_A_area }:=\frac{\text { SLOT_A_TWD }+ \text { SLOT_A_BWD }}{2} \cdot \text { SLOT_HT } \\
=0.0390625 \mathrm{ft}^{2}
\end{aligned}
$$


RPP-5637

Rev. 0

JOHN MARVIN, INC.

Analyst: Marvin J. Thurgood

Reviewer: Harold E. Adkins

Subject: Notebook for GOTH_SNF Simulation of Tank AZ-102

Jan $/ 03 / 00$ Harold E. Adki $*(5.58)$

Slot_B_area $:=\frac{\text { SLOT_B_TWD }+ \text { SLOT_B_BWD }}{2} \cdot$ SLOT_HT

$=0.0390625 \mathrm{ft}^{2}$

Jan/03/00 Hazold E. Adki*(5.59)

Slot_C_area $:=\frac{\text { SLOT_C_TWD }+ \text { SLOT_C_BWD }}{2} \cdot$ SLOT_HT

$=0.0303819 \mathrm{ft}^{2}$

The wetted perimeter of the flow holes is

Jan $/ 03 / 00$ Harold E. Adki $*(5,60)$

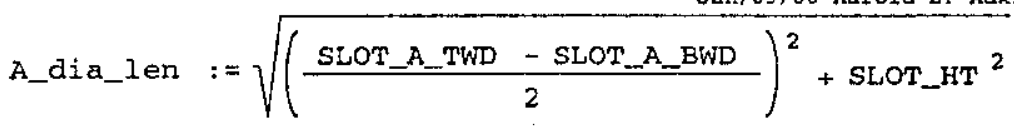

$=0.217506 \mathrm{ft}$

Jan/03/00 Harold E. Adki $*(5.61)$

B_dia_Ien $:=\sqrt{\left(\frac{\text { SLOT_B_TWD }- \text { SLOT_B_BWD }}{2}\right)^{2}+\text { SLOT_HT }^{2}}$

$=0.217506 \mathrm{ft}$

Jan $/ 03 / 00$ Marold E. Adk1 $*(5.62)$

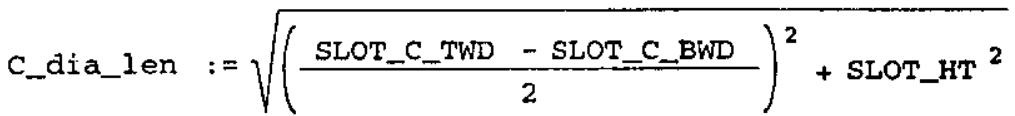

$=0.217506 \mathrm{ft}$

Jan/03/00 Harold E. Adxi $*(5.63)$

Slot_A_WP $:=$ SLOT_A_TWD + SLOT_A_BWD + 2 A_dia_len

$=0.810013 \mathrm{tt}$ 


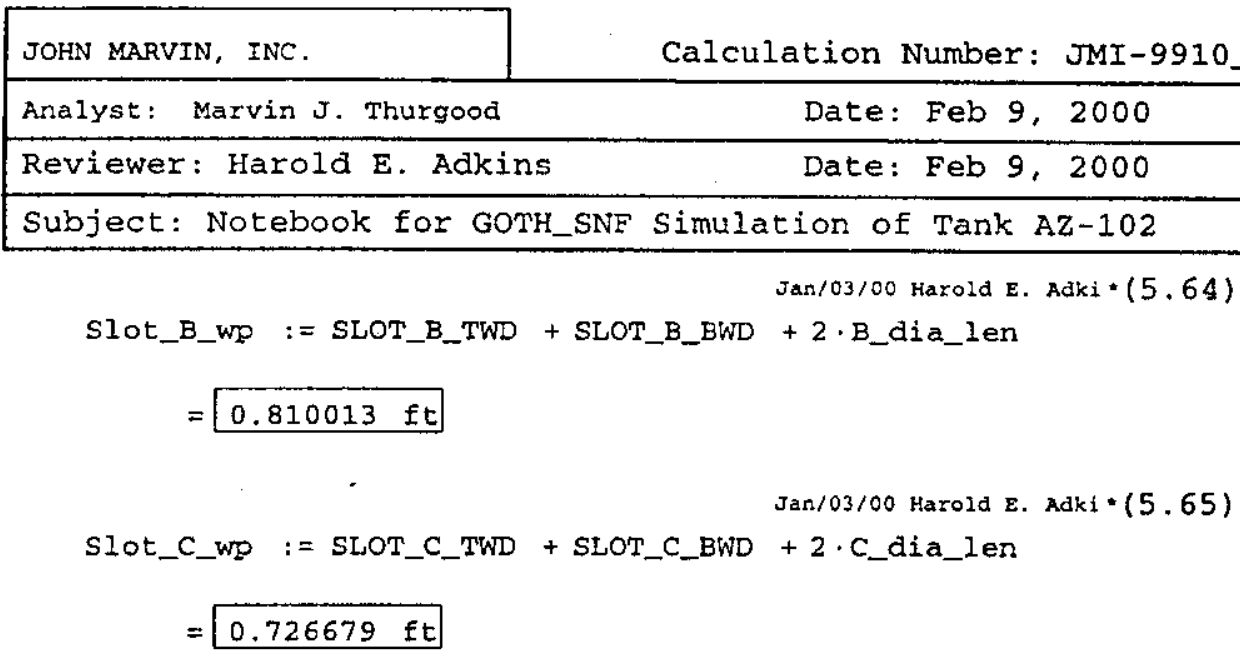

The hydraulic diameter of the flow holes is:

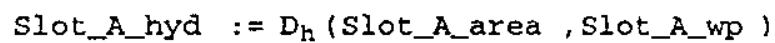

$=0.192898 \mathrm{ft}$

Slot_B_hyd $:=D_{h}($ Slot_B_area , Slot_B_wp $)$

$=0.192898 \quad \mathrm{ft}$

Slot_c_hyd $:=D_{h}($ slot_c_area , slot_c_wp )

$=0.167237 \mathrm{ft}$

The total flow area of slots in each ring are:

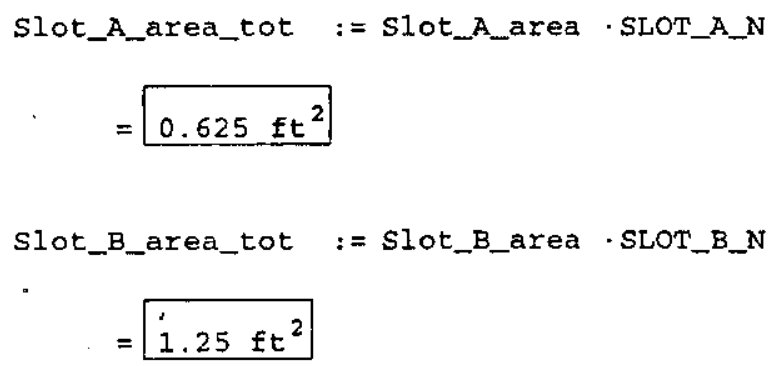


RPP-5637

Rev. 0

JOKN MARVIN, INC.

Calculation Number: JMI-9910_02

Analyst: Marvin J. Thurgood

Date: Feb 9, 2000

Reviewer: Harold E. Adkins

Date: Feb 9, 2000

Subject: Notebook for GOTH_SNF Simulation of Tank AZ-102

slot_C_area_tot $:=$ slot_C_area $\cdot$ SLOT_C_N

$=1.94444 \mathrm{ft}^{2}$

Jan $/ 03 / 00$

Harold E. Adki

The total area for heat transfer between the air and the waste (assume slot top area):

Jan/03/00 Harold E. Adki *(5.72)

Slot_A_ht_area $:=$ SLOT_A_TWD $\cdot S L O T \_A \_N \cdot\left(R 1 \_O R-A D \_O R\right)$

$$
=49 \pm t^{2}
$$

Jan/03/00 Harold E. Adki $*(5.73)$

Slot_B_ht_area $:=$ SLOT_B_TWD $\cdot$ SLOT_B_N $\cdot\left(R 2 \_O R-R 1 \_O R\right)$

$$
=82 \mathrm{ft} t^{2}
$$

Jan/03/00 Harold E. Adki $*(5.74)$

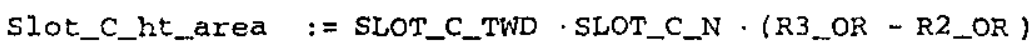

$=176.667 \mathrm{ft}^{2}$

The flow area of the outer slots is larger than the flow area of the inner slots, therefore, the Reynolds number will be reduced. See what effect this has. The Reymolds number is given by [Ref. 5]:

$$
\operatorname{Re}(\rho, V, D, \mu):=\rho \cdot v \cdot \frac{D}{\mu}
$$

The ary bulb air temperature is:

$$
T_{\mathrm{A}}:=t f(82)
$$

The air pressure is:

$$
P_{A}:=14.7 \mathrm{psi}
$$

$\operatorname{Jan} / 03 / 00$

$$
\text { * (5.77) }
$$

The gas constant for air is: 
JOFN MARVIN, INC.

Analyst: Marvin J. Thurgood

Reviewer: Harold E. Adkins

Subject: Notebook for GOTH_SNF Simulation of Tank AZ-102
Calculation Number: JMI-9910_02

Date: Feb 9, 2000

Date: Feb 9, 2000

$$
R_{A}:=53.34 \frac{\mathrm{ft}-1 \mathrm{bf}}{1 \mathrm{bm}-\mathrm{R}}
$$

$03 / 00$

Haroid $\mathrm{E} \cdot 7 \mathrm{Adk}$.

The density of air at these conditions is:

$$
\rho_{A}:=\frac{P_{A}}{R_{A} \cdot T_{A}}=0.0732642 \frac{1 \mathrm{bm}}{\mathrm{ft}^{3}}
$$

$$
\begin{array}{r}
\tan / 03 / 00 \\
+(5.79) \\
\text { Harold } 2 . \text { Adk }
\end{array}
$$

The air flow rate is:

$$
\begin{aligned}
& Q_{A}:=\text { Q_sècondary }=1000 \frac{\mathrm{ft}^{3}}{\mathrm{~min}} \\
& \mathrm{~m}_{\mathrm{A}}:=Q_{\mathrm{A}} \cdot \rho_{\mathrm{A}}=1.22107 \frac{\mathrm{lbm}}{\mathrm{s}}
\end{aligned}
$$$$
\begin{array}{r}
J a n / 05 / 00 \\
*(5.80) \\
\text { Harold } \mathrm{E} \cdot \text { Adki }
\end{array}
$$$$
\begin{array}{r}
\operatorname{san} 103 / 00 \\
*(5.81)
\end{array}
$$$$
\text { Haroid } \mathbf{E}^{*} \cdot \mathbf{A d k}
$$

The viscosity of air at these conditions is [Ref. 5]:

$$
\mu_{\mathrm{A}}:=0.04 \times 10^{-5} \frac{\mathrm{lbf}-\mathrm{s}}{\mathrm{ft^{2 }}}=0.000191521 \text { poise }
$$

The thermal conductivity of air at these conditions is [Ref. 4]:

$$
k_{A}:=0.016 \frac{\text { Btu }}{h x-f t-R}
$$

$\operatorname{san} / 05 / 00$

(5.83) Harold E. Adki

The specific heat of air at these conditions is [Ref. 4]:

$$
C p_{A}:=0.24 \frac{B t u}{I b m-R}
$$

The Prandtl number for the air is:

$$
\operatorname{Pr} A:=\mu_{A} \cdot \frac{C P_{A}}{k_{A}}=0.694959
$$

Slot A: 


\begin{tabular}{|lr|}
\hline JokN MARVIN, INC. & CaIculation Number: JMI-9910_02 \\
\hline Analyst: Marvin J. Thurgood & Date: Feb 9, 2000 \\
\hline Reviewer: Harold E. Adkins & Date: Feb 9, 2000 \\
\hline Subject: Notebook for GOTH_SNF Simulation of Tank AZ-102 \\
\hline
\end{tabular}

$$
\begin{aligned}
& \rho_{A} A:=\frac{P_{A}}{R_{A} \cdot t f(108.2)}=0.069884 \frac{1 \mathrm{bm}}{\mathrm{ft}^{3}} \\
& \mu_{A} A:=0.0395 \times 10^{-5} \frac{I b f-s}{f t^{2}}=0.000189127 \text { poise } \\
& k_{A} A:=0.0157 \frac{B t u}{h x-f t-R} \\
& \operatorname{Pr}_{A} A:=\mu_{A} A \cdot \frac{C_{A}}{k_{A} A}=0.699386
\end{aligned}
$$

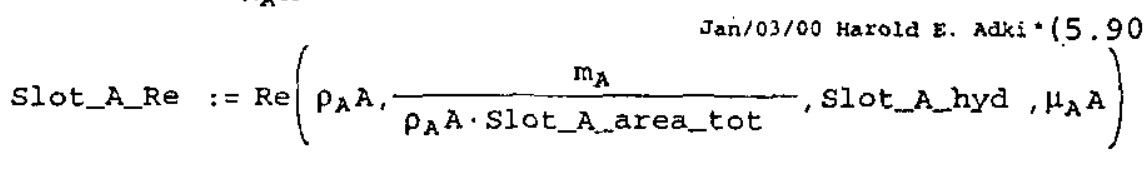

$$
\begin{aligned}
& =29654.2
\end{aligned}
$$
$\operatorname{San} 103 / 00$
(5.89)
Haxold E. Adki

slot B:

$$
\begin{aligned}
& P_{A} B:=\frac{P_{A}}{R_{A} \cdot t f(127.9)}=0.0675409 \frac{1 \mathrm{bm}}{\mathrm{ft}^{3}} \\
& \mu_{A} B:=0.041 \times 10^{-5} \frac{1 \mathrm{bf}-\mathrm{s}}{f t^{2}}=0.000196309 \text { poise } \\
& k_{A} B:=0.0162 \frac{\mathrm{Btu}}{\mathrm{hr}-\mathrm{ft}-\mathrm{R}} \\
& \operatorname{Pr}_{A} B:=\mu_{A} B \cdot \frac{C p_{A}}{k_{A} B}=0.703539
\end{aligned}
$$

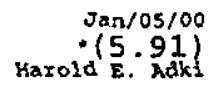

$\operatorname{Jan} / 05 / 00$

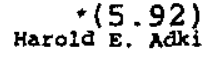
Jan $/ 05 / 00$
$-(5.93)$
Harold E. Adk

$\operatorname{Jan} / 03 / 00$ $\cdot(5.94)$ Harold E. Adk 


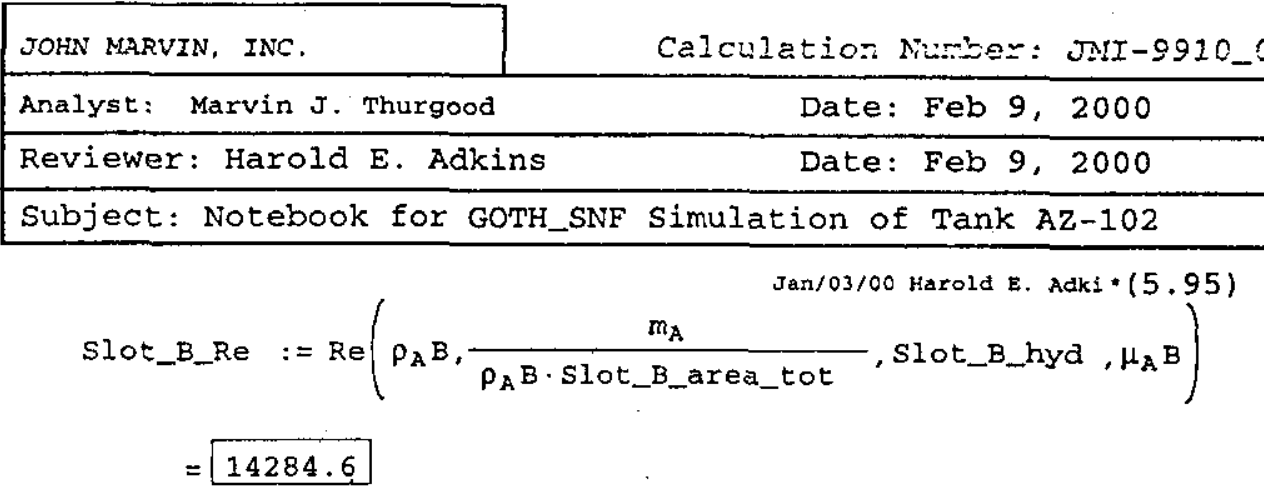

slot C:

$$
\begin{aligned}
& \rho_{A} C:=\frac{P_{A}}{R_{A}: t f(147.8)}=0.0653284 \frac{1 b m}{\mathrm{ft}^{3}} \\
& \mu_{A} C:=0.0425 \times 10^{-5} \frac{1 \mathrm{bf}-\mathrm{s}}{\mathrm{ft}^{2}}=0.000203491 \text { poise } \\
& k_{A} C:=0.0167 \frac{\text { Btu }}{\text { hr-ft-R }} \\
& \operatorname{Pr} C:=\mu_{A} C \cdot \frac{C p_{A}}{k_{A} C}=0.707444
\end{aligned}
$$

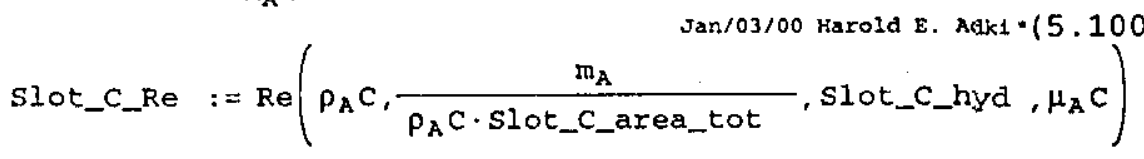

$$
\begin{aligned}
& =7680.39 \\
& \text { (5.99) }
\end{aligned}
$$

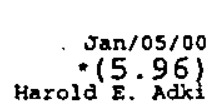

-


RPP-5637

Rev. 0

JOHN MARVIN, INC.

Calculation Number: JMI-9910_02

Analyst: Marvin J. Thurgood

Date: Feb 9, 2000

Reviewer: Harold E. Adkins

Date: Feb 9, 2000

Subject: Notebook for GOTH_SNF Simulation of Tank AZ-102

$h_{T}(R e, P r, k, D):=0.023 \cdot \operatorname{Re}^{0 . B} \cdot \mathrm{Pr}^{0.4} \cdot \frac{\mathrm{k}}{\mathrm{D}}$

Jan 103100

Haxold $\dot{\varepsilon} .102)$

or:

$h(D, k, R e, P r) \vdots=\max \left(h_{L}(D, k), h_{T}(R e, P r, k, D)\right)$

$\operatorname{Jan} / 03 / 00$

Harold $\dot{E} .103)$

Slot_A_h $:=h\left(\right.$ SIot_A_hyd,$k_{A} A$, slot_A_Re, $\left.\operatorname{Pr}_{A} A\right)$

$=6 .-13557 \frac{\mathrm{Btu}}{\mathrm{hr}-\mathrm{ft} \mathrm{t}^{2}-\mathrm{B}}$

$J a n / 03 / 00$
$*(5.104)$
Harold $\dot{\varepsilon}$. Adki

slot_B_h $:=h\left(\operatorname{slot} \_B \_h y d, k_{A} B, s l o t \_B \_R e, P r_{A} B\right)$

$=3.53774 \frac{\mathrm{Btu}}{\mathrm{hr}-\mathrm{ft}^{2}-\mathrm{R}}$

Jan $/ 03 / 00$

$*(5.105)$
Harold E. Adki

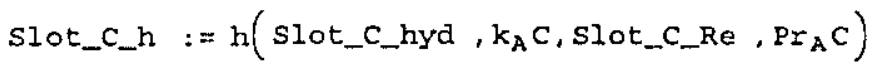

$=2.56623 \frac{\mathrm{Btu}}{\mathrm{hr}-\mathrm{ft}^{2}-\mathrm{R}}$

$\operatorname{Jan} / 03 / 00$

$:(5.106)$

Harold E. Adki

Assuming a waste temperature of $200^{\circ} \mathrm{F}$ as determined through analyses and performing an energy balance, assuming that heat transfer takes place using the air outlet temperature:

$$
\begin{aligned}
& T_{w}:=t f(200) \\
& T_{A} \text { out }\left(h, A, T w, T_{A} \text { in }, m, C_{p}\right):=\frac{h \cdot A \cdot T w+m \cdot C_{P} \cdot T_{A} \text { in }}{\text { Jan/03/00 Harold }}
\end{aligned}
$$


JOHN MARVIN, INC.

Analyst: Marvin J. Thurgood

Reviewer: Harold E. Adkins

Subject: Notebook for GOTH_SNF Simulation of Tank AZ-102

Jan/03/00 Harold E. Adki $*(5.109)$

Slot_A_out : =

$T_{A}$ out $\left(\right.$ slot_A_h, slot_A_ht_area $\left., T_{w}, T_{A}, m_{A}, C P_{A}\right)$

$=108.169 \mathrm{~F}$

Jan/03/00 Harold E. Adki $\cdot(5.110)$

Slot_B_out : =

$T_{A}$ out $\left(\right.$ Slot_B_h, slot_B_ht_area, $T_{w}$, slot_A_out $\left., m_{A}, C p_{A}\right)$

$=127.974 \mathrm{~F}$

Jan $/ 03 / 00$ Harold E. Adki * $(5.111)$

slot_c_out :=

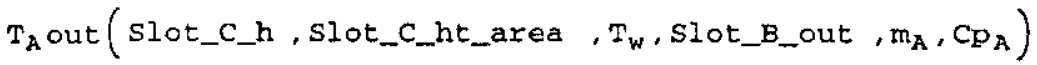

$=149.623 \mathrm{~F}$

eff $:=\frac{\text { Slot_C_out }-T_{A}}{T_{W}-T_{A}}=0.573073$

Tot_slot_ht_area :=slot_A_ht_area

+Slot_B_ht_area + Slot_C_ht_area

$=307.667 \mathrm{ft}^{2}$

Look at total heat transfer:
$\mathrm{Jan} / 03 / 00$

Harold E. Adki

48 of 102 
RPP-5637

Rev. 0

$$
\begin{aligned}
& \text { JOHN MARVIN, INC. } \\
& \text { Calculation Number: JMI-9910_02 } \\
& \text { Analyst: Marvin J. Thurgood } \\
& \text { Date: Feb 9, } 2000 \\
& \text { Reviewer: Harold E. Adkins } \\
& \text { Date: Feb 9, } 2000 \\
& \text { Subject: Notebook for GOTH_SNF Simulation of Tank AZ-102 } \\
& \text { Q_A : = Slot_A_h } \cdot \text { Slot_A_ht_area } \cdot\left(T_{W} \begin{array}{c}
\text { Jan/04/00 Harold } E \\
\text { Slot_A_out }
\end{array}\right) \\
& =27608.4 \frac{\mathrm{Btu}}{\mathrm{hr}} \\
& \text { Q_B := Slot_B_h } \cdot \text { Slot_B_ht_area } \cdot\left(T_{w}-\right.\text { San/04/00 Hazold E } \\
& =20894.4 \frac{\mathrm{Btu}}{\mathrm{hr}}
\end{aligned}
$$

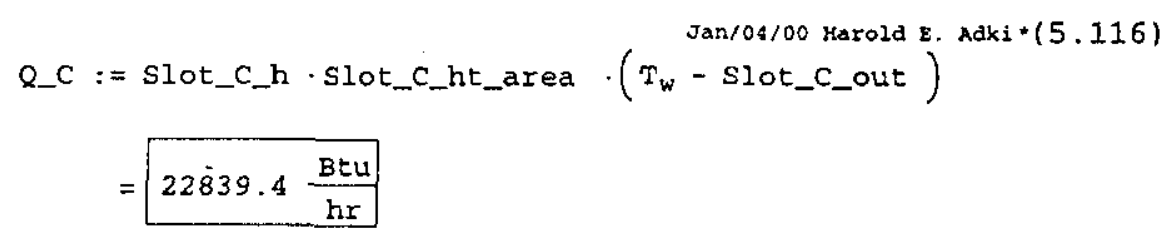

Look at energy transfer:

$$
\begin{array}{rlr}
\text { MQ_A } & :=m_{A} \cdot C p_{A} \cdot\left(\text { Slot_A_out }-T_{A}\right) \\
& =27608.4 \frac{\text { Btu }}{\mathrm{hr}} & \begin{array}{r}
\text { Jan } / 04 / 00 \\
(5.117) \\
\text { Harold } \mathrm{E} . \text { Adki }
\end{array}
\end{array}
$$

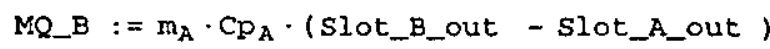

$$
=20894.4 \frac{\mathrm{Btu}}{\mathrm{hr}}
$$

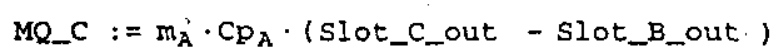

$$
=22839.4-\frac{B t u}{h r}
$$

Total Heat "Transfer to Secondary Air: 
JOHN MARVIN, INC.

Calculation Number: JMI-9910_02

Analyst: Marvin J. Thurgood Date: Feb 9, 2000

Reviewer: Harold E. Adkins

Date: Feb 9,2000

Subject: Notebook for GOTH_SNF Simulation of Tank AZ-102

$$
\text { Q_tot }:=0 \_A+Q B B+Q \_C=71342.2 \frac{\mathrm{Btu}}{\mathrm{hr}}
$$

The average heat transfer coefficient is:

$$
\begin{aligned}
\text { h_ave } & :=\frac{Q_{\text {_tot }}}{\text { Tot_slot_ht_area } \cdot\left(T_{\mathrm{w}}-\text { slot_C_out }\right)} \\
& =4.60288 \frac{\mathrm{Btu}}{\mathrm{hr}-\mathrm{ft}^{2}-\mathrm{R}}
\end{aligned}
$$

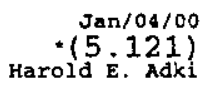

Fraction of total heat:

$$
\text { Q_frac_sec }:=\frac{Q \text { _tot }}{\text { slurry_Q }+ \text { SUPER_Q }}=0.357247
$$

Jan $/ 04 / 00$ $-(5.122)$ Harold $\mathbf{E}$. Adki

I come to the following conclusions from the above analyses:

1. The temperature rise in the secondary inlet air before it enters the tank floor is small (even if the annulus bulk temperature was at $20^{\circ} \mathrm{F}$ the temperature rise on the inlet air would only be about $5^{\circ} \mathrm{F}$ ).

2. The heat transfer from the waste to each ring of slots is about the same for each slot.

3. The heat txansfer coefficient for the slots ranges from between 2 and 6 (Btu/hr-ft ${ }^{2}-R$ ).

4. The efficiency factor is more likely to account for the temperature gradient surrounding the slot than for anything else.

5. Recommend using the actual slot top area of all slots for the conductor surface area.

6. Use a gas volume for the slots that is large enough to avoid a courant time step limitation. 
RPP-5637

Rev. 0

JOHN MARVIN, INC.

Calculation Number: JMI-9910_02

Analyst: Marvin J. Thurgood

Date: Feb 9, 2000

Reviewer: Harold E. Adkins

Date: Feb 9, 2000

Subject: Notebook for GOTH_SNF Simulation of Tank AZ-102

Jan/04/00 Harold E. Adki*(5.123)

Slot_channel_area :=Slot_A_ht_area

+ Slot_B_ht_area + Slot_c_ht_area $=307.667 \mathrm{ft}^{2}$

5.1.4.2. Volume of Floor slot Volume.

Jan $/ 04 / 00$ Harold E. Adki $*(5.124)$

Slot_volume $:=$ Slot_A_area_tot $\cdot(R 1$ _oR - AD_OR $)$

+ Slot_B_area_tot $\cdot\left(R 2 \_O R-R 1 \_O R\right)$

+ Slot_C_area_tot $\cdot\left(R 3 \_O R-R 2 \_O R\right)$

$=46.2326 \mathrm{ft}^{3}$

$\frac{\text { slot_volume }}{Q_{\mathrm{A}}}=2.77396 \mathrm{~s}$

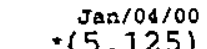

Harold $\bar{E}$. Adki

Volume will need to be made artificially large to avoid

time step limitation.

Slot_volume_model $:=Q_{\mathrm{A}} \cdot 160 \mathrm{~s}=2666.67 \mathrm{ft}^{3}$

$\operatorname{Jan} / 04 / 00$

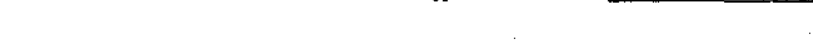

Harold $\dot{2}$. Adki

5.1.4.3. Elevation of Floor slot volume.

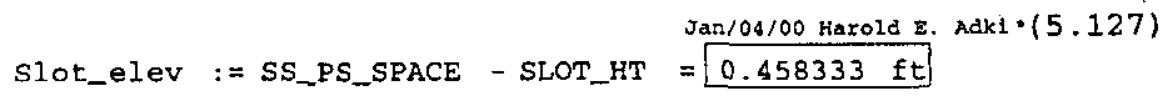

51 of 102 
5.1.4.4. Height of Floor slot Volume.

$$
\text { Slot_ht }:=\text { SLOT_HT }=0.208333 \mathrm{ft}
$$

\subsubsection{Hydraulic Diameter of the Floor Volume.}

The hydraulic diameter of the floor volume will be set to the hydraulic diameter of the outer set of floor slots. This is not critical since the volume is made artificially large anyway to accomodate a reasonable courant time step limitation, flows are specified, pressure drop across the flow slots is not important in this calculation and the heat transfer coefficient is specified.

$$
\text { Slot_hyd }:=\text { slot_c_hyd }=0.167237 \mathrm{ft}
$$

\subsubsection{Slot Conductor Dimensions.}

The surface area of this conductor is equal to the top area of all of the radial slots in the floor.
slot_ht_area $:=$ slot_channel_area $=307.667 \mathrm{ft}^{2}$
This conductor is made of steel plate. The thickness of this plate is:

$$
\text { slot_cond_thk }:=\text { PS_THK }=0.03125 \mathrm{ft}
$$

\subsubsection{Floor slot Alr Inlet volume.}

This volume represents the four, 4 inch schedule 40 pipes that supply ais to the floor slots. This volume is necessary to preheat the incoming air from the ambient conditions, to the temperature that the air will enter the floor slots at the center of the tank. 


\subsubsection{Supply Pipe Volume.}

Well, lets look at the temperature increase that might occur to the inlet air as the air travels through the pipes to the floor of the tanks (never mind that these pipes pass at least 84 inches through the ground) before entering the tank annulus.

Secondary ventilation inlet pipes:

Length:

P4_Len $:=R 3 \_O R-A D \_O R=35.75 \mathrm{ft}$

Flow Area:

P4_Area $:=A_{c}\left(\frac{\text { P4_ID }}{2}\right)=0.0884046 \mathrm{ft}^{2}$

Single Pipe Volume:

P4_Vol := P4_Area P4_Ler $=3.16046 \mathrm{ft}^{3}$

Number of pipes:

Harold $E$. Adk

P4_n : = 4

Jan/04/00

( 5.135$)$

Total Volume of Pipes:

P4_Vo1_tot $:=$ P4_Vol $\cdot \mathrm{P4} n=12.6419 \mathrm{ft}^{3}$

Jan $/ 04 / 00$

.$(5.136)$

Harold $\mathbf{E}$. Adki

Total Flow Area of Pipes:

P4_Area_tot $:=$ P4_Area $\cdot P 4 \_n=0.353618 \mathrm{ft}^{2}$

Jan $/ 04 / 00$

Courant Limit of Pipe volume:

$\frac{\text { P4_Vo1_tot }}{Q_{\text {A }}}=0.758512 \mathrm{~s}$

The pipe volume will have to be increased to get reasonable run times: 
JOHN MARVIN, INC.

Calculation Number: JMI-9910_02

Analyst: Marvin J. Thurgood

Reviewer: Harold E. Adkins

Date: Feb 9, 2000

Subject: Notebook for GOTH_SNF Simulation of Tank AZ-102

$$
\text { P4_vol_model }:=2000 \frac{\mathrm{ft}^{3}}{\mathrm{~min}} \cdot 160 \mathrm{~s}=5333.33 \mathrm{ft}^{3}
$$

$J a n / 04 / 00$

Hazold $(5.139)$

\subsubsection{Supply Pipe Area.}

$$
\text { P4_area_model }:=\frac{\text { P4_Vol_model }}{\text { SS_ht }}=136.692 \mathrm{ft}^{2}
$$

\subsubsection{Supply Pipe Elevation.}

The supply pipe elevation will be assumed to be the same as the bottom elevation of the tank annulus volume (this assumption is not important:

$$
\text { p4_elev := SS_elev }=0 \mathrm{ft}
$$

\subsubsection{Supply Pipe Height.}

The supply pipe volume height will be assumed to be equal to the height of the annulus (this assumption is not important :

$$
\text { P4_ht := SS_ht }=39.0171 \mathrm{ft}
$$

\subsubsection{Supply Pipe Hydraulic Diameter:}

$$
\text { P4_hyd }:=\text { P4_ID }=0.3355 \mathrm{ft}
$$

5.1.5.6. Supply Pipe Conductor Dimensions.

Reymolds Number: 
JOHN MARVIN, INC.

Analyst: Marvin J. Thurgood

Reviewer: Harold E. Adkins

Subject: Notebook for GOTH
Carouetion Mumber: TMI-9910_02

Date: Feb 9, 2000 Date: Feb 9,2000

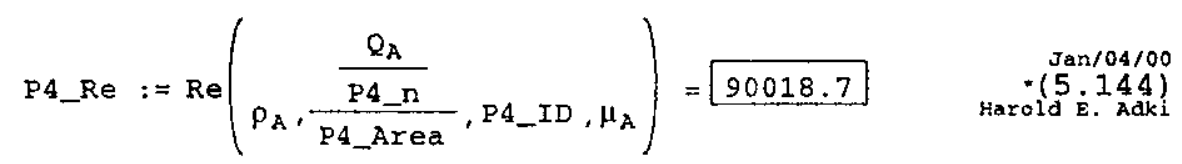

Heat transfer to air flowing through pipes in tank floor: Heat Transfer Area:

P4_ht_area $:=P_{C}\left(\frac{P 4 \_I D}{2}\right) \cdot P 4 \_L e n=\begin{array}{r}\text { Jan } / 06 / 00 \\ (5.145) \\ \text { Harold E. Adki }\end{array}$ P4_ht_area_tot $:=$ P4_ht_area P4_n $=150.723 \mathrm{ft}^{2}$ Air side pipe heat transfer coefficient:

$$
P 4 \_h:=h\left(P 4 \_I D, k_{A}, P 4 \_R e, \operatorname{Pr}_{A}\right)=8.71777 \frac{B t L}{h r-f t^{2}-R}
$$

Inlet temperature to bottom of tank:

P4_out :=

$$
\begin{aligned}
& T_{A} \text { out }\left(P 4 \_h, p_{\text {_nt_area }}, T_{w}, T_{A}, \frac{m_{A}}{4}, C p_{A}\right) \\
& =147.449 \mathrm{~F}
\end{aligned}
$$

Look at waste side heat transfer coefficient:

The temperature drop across the concrete pad is based on a concrete conduction coefficient presented by [Ref. 4]:

$$
h_{c}:=\frac{0.17 \frac{b t u}{h r-f t-R}}{1 \text { in }}=2.04 \frac{B t u}{h r-f t^{2}-R}
$$


JOK: V.PYIN, INT.

Analyst: Marvin J. Thurgood

Reviewer: Harold E. Adkins

Subject: Notebook for GOTH_SNF Simulation of Tank AZ-102
P4_out :=

$$
\begin{aligned}
& T_{A} \text { out }\left(h_{C}, P 4_{-} h_{t} \text { area }, T_{w}, T_{A}, \frac{m_{A}}{4}, C p_{A}\right) \\
& =108.629 \mathrm{~F}
\end{aligned}
$$

Jan $/ 04 / 00$

.$(5.150)$

Harold $\dot{E}$. Adk

Look at natural convection heat transfer in annulus:

$$
\begin{aligned}
& \mathrm{Nu}=0.13\left(G r_{f} \operatorname{Pr}_{f}\right)^{0.333} \\
& \mathrm{Gr}=g \beta\left(\mathrm{T}_{\mathrm{w}}-\mathrm{T}_{\mathrm{B}}\right) \frac{\mathrm{x}^{3}}{v^{2}}
\end{aligned}
$$$$
\mathrm{Nu}=\mathrm{h} \frac{\mathrm{x}}{\mathrm{k}}
$$$$
h=\frac{k}{x} 0.13\left(G r_{f} \operatorname{Pr}_{f}\right)^{0.333}
$$$$
g:=32.2 \frac{f t}{s^{2}}
$$$$
\beta:=\frac{1}{T_{A}}=0.00184614 \frac{1}{R}
$$$$
v=\frac{\mu}{\rho}
$$$$
G r=g \beta\left(T_{w}-T_{B}\right) x^{3} \frac{p^{2}}{\mu^{2}}
$$

Jan $/ 04 / 00$ Marold $\dot{E} .151)$ $*(5.152)$
Harold $\mathrm{E} . \mathrm{Adk}$

$$
\text { Jan } / 04 / 00
$$
Harold 8.153$)$ .$(5,154)$ Harold E. Adki farold $\dot{E}$. Adki

Jan $/ 04 / 00$ $\cdot(5,156)$ Jan $/ 04 / 00$
$-(5.157)$
Harold $\mathrm{E}$. Adk] Harold $E$, Adk $J a n / 04 / 00$
.$\{5.158\}$
Harold $\dot{E}$. Adki 


\begin{tabular}{|lr|}
\hline Jow MAPVIN, INic. & Calcliztion Number: JII-0910_02 \\
\hline Analyst: Marvin J. Thurgood & Date: Feb 9, 2000 \\
\hline Reviewer: Harold E. Adkins & Date: Feb 9, 2000 \\
\hline Subject: Notebook for GOTH_SNF Simulation of Tank AZ-102 \\
\hline
\end{tabular}

Feb/10/00 Harold $\varepsilon$. Adxi $*(5.159)$

$$
\text { Gr_over_x }{ }^{3}:=g \cdot \beta \cdot\left(T_{w}-T_{A}\right) \cdot \frac{\rho_{A}^{2}}{\mu_{A}^{2}}=2.27329 \times 10^{+08} \frac{1}{\mathrm{ft}^{3}}
$$

Feb/10/00 Harold E. Adki $*(5.160)$

P4a_h $:=k_{A} \cdot 0.13 \cdot\left(G_{\text {_over_o }}{ }^{3} \cdot \operatorname{Pr}_{\mathrm{A}}\right)^{0.333}=1.11606 \frac{\mathrm{Btu}}{\mathrm{hr}-\mathrm{ft}^{2}-\mathrm{g}}$

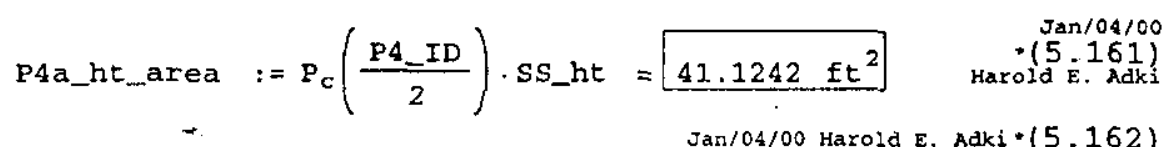

P4a_out :=

$$
\begin{aligned}
& T_{A} \text { out }\left(P 4 a \_h, p 4 a \_h t_{-a r e a,} t f(110), T_{A}, \frac{m_{A}}{4}, C p_{A}\right) \\
& =86.1502 \mathrm{~F}
\end{aligned}
$$

Conclusion, main heating occurs in floor so heat transfer to these pipes will be that due to heat transfer between waste and air in pipe.

\subsubsection{Water Refill sump.}

This volume has no importance other than to provide a computational volume to mimic the collection and return of the condensate formed through tank waste evaporation. The amount of water that is supplied by this computational volume in conjuction with supply line "9F" is directly dictated by the quantity which leaves the tank via evaporation. The refill water temperature is conservatively set at $110^{\circ} \mathrm{F}$.

\subsubsection{Volume of Sump Volume.}

This volume will simply be made large enough so that its 
volume does not limit the code time step.

$$
\text { Sump_vol }:=160 \mathrm{~s} \cdot 2000 \frac{\mathrm{ft}^{3}}{\mathrm{~min}}=5333.33 \mathrm{ft}^{3}
$$

\subsubsection{Cross-sectional Area of Sump Volume.}

The area of this volume is chosen using a reasonable height.

$$
\text { Sump_area _: }=\frac{\text { Sump_vol }}{10 \mathrm{ft}}=533.333 \mathrm{ft}^{2}
$$

\subsubsection{Elevation of Sump Volume.}

The sump will placed at the top of the primary tank volume

$$
\text { Sump_elev }:=\text { PS_elev }+ \text { PS_ht }+1.0 \mathrm{ft}=43.9325 \mathrm{ft}
$$

5.1.6.4. Height of Sump Volume.

The height used to calculate the sump volume area will be. used:

$$
\text { Sump_ht }:=10 \mathrm{ft}
$$

5.1.6.5. Sump Hydraulic Diameter:

$$
\text { Sump_hyd }:=4 \cdot \frac{\text { Sump_area }}{4 \cdot \sqrt{\text { Sump_area }}}=23.094 \mathrm{ft}
$$

$\mathrm{Jan} / 19 / 00$

$*(5.167)$

\subsubsection{Sumary of Geometric Input Data.}

The geometric data required for GOTH_SNF input which has been calculated in the above section is summarized in this section.

58 of 102 


\begin{tabular}{|lr|}
\hline JoHN M:Z:, INC. & Calculation Number: JMI-9910_02 \\
\hline Analyst: Marvin J. Thurgood & Date: Feb 9, 2000 \\
\hline Reviewer: Harold E. Adkins & Date: Feb 9, 2000 \\
\hline Subject: Notebook for GOTH_SNF Simulation of Tank AZ-102 \\
\hline
\end{tabular}

5.1.7.1. Volume Input Data.

The volume input data input into GOTH_SNF is tabulated in Table 5.2.

Table. 5.2 Control Volume Input Data.

\begin{tabular}{|c|c|c|c|c|c|c|}
\hline $\begin{array}{c}\text { Vol } \\
\#\end{array}$ & Description & Vol & Elev & Ht & Hya. D & Pl Area \\
\hline & & $E t^{3}$ & ft & ft & ft & $f t^{2}$ \\
\hline 1 & Tank Primary & 186724.6 & 0.6667 & 42.266 & 75.000 & 4417.86 \\
\hline 2 & Floor slots & 2666.7 & 0.4583 & 0.208 & 0.183 & 307.67 \\
\hline 3 & Annulus & 23749.0 & 0.0000 & 39.017 & 5.000 & 608.68 \\
\hline 4 & Water Sump & 5333.3 & 43.932 & 10.000 & 23.094 & 533.33 \\
\hline 5 & Air Inlet Pipes & 5333.3 & 0.0000 & 39.017 & 0.336 & 136.69 \\
\hline
\end{tabular}

\subsubsection{Conductor Input Data.}

The input data for the thermal conductors is summarized in Table 5.3. All conductors will be initialized to the average ambient air temperature [Ref 6]. The values for heat transfer coefficient or side temperature given in this table are those which are to be specified by number. Some of these are flow dependent and will need to be updated for the flow being. specified. The natural convection heat transfer option will be specified in the code when a value is not given in the table. The fluid temperature adjacent to the conductor surface will be used where a temperature is not specified in the table. 
Table 5.3 Conductor Input Data

\begin{tabular}{|c|c|c|c|c|c|c|c|}
\hline \multirow[t]{3}{*}{$\begin{array}{c}\text { Con } \\
\#\end{array}$} & Description & S. A. & $\begin{array}{l}\text { Init. } \\
\text { Temp. }\end{array}$ & $\begin{array}{c}\text { Side } \\
\text { A } \\
\text { H.T.C }\end{array}$ & $\begin{array}{c}\text { Side } \\
\text { A } \\
\text { Temp. }\end{array}$ & $\begin{array}{c}\text { Side } \\
\text { B } \\
\text { H.T.C }\end{array}$ & $\begin{array}{c}\text { Side } \\
\text { B } \\
\text { Temp. }\end{array}$ \\
\hline & & \multirow{2}{*}{$\mathrm{Et} \mathrm{t}^{2}$} & \multirow[b]{2}{*}{$F$} & Btu & \multirow{2}{*}{$F$} & Btu & \multirow{2}{*}{$F$} \\
\hline & & & & $h r-f t^{2}-R$ & & $r-E t^{2}-R$ & \\
\hline 1 & Floor slots & 307.7 & 82.0 & 1.663 & ---- & 4.32 & ----- \\
\hline 2 & Supernatant-Arn & 6089.5 & 82.0 & ------ & ---- & ------ & ---- \\
\hline 3 & Dome-annulus & 2426.3 & 82.0 & ------ & $--\cdots$ & $---\infty-\infty$ & $-\infty--$ \\
\hline 4 & Floor-grouna & 4417.9 & 82.0 & 1.663 & ----- & $---\cdots$ & 50.0 \\
\hline 5 & Annulus-ground & 9806.1 & 82.0 & ----- & ----- & 0.00 & ---- \\
\hline 6 & Dome-ground & 4417.9 & 82.0 & $\ldots---$ & ----- & $----\cdot$ & 82.0 \\
\hline 7 & Air inlet pipes & 150.7 & 82.0 & 8.718 & ----- & 2.04 & \\
\hline
\end{tabular}

The heat transfer coefficient for waste side of conductors connecting to the bottom of the waste are given by the conductivity of the sludge divided by half the length of the bottom sludge node, $h=2 \star k_{s} / \Delta x_{1}$.

\subsubsection{Conductor Type Input Data.}

The input data for the conductor types are summarized in Table 5.4. All of the data in this table have been previously defined except for the conductor geometry and the material, which are defined in this table. 


\begin{tabular}{|lr|}
\hline JOHN MARVIN, INC. & Calculation Number: JMI-9910_02 \\
\hline Analyst: Marvin J. Thurgood & Date: Feb 9, 2000 \\
\hline Reviewer: Harold E. Adkins & Date: Feb 9, 2000 \\
\hline Subject: Notebook for GOTH_SNF Simulation of Tank AZ-102 \\
\hline
\end{tabular}

Table 5.4 Conductor Type Input Data.

\begin{tabular}{|c|c|c|c|c|c|}
\hline $\begin{array}{c}\text { Con } \\
\#\end{array}$ & Description & Georn & Thick & $0 . \mathrm{D}$ & Material \\
\hline \multicolumn{6}{|c|}{ in } \\
\hline 1 & Floor slots & Wall & 0.375 & $----\infty$ & Steel \\
\hline 2 & Supernatant-Ann & Tube & 0.375 & 900.75 & Steel \\
\hline 3 & Dome-annulus & Tube & 0.375 & 900.75 & Steel \\
\hline 4 & Floor-ground & Wall & 1200 & $-\cdots \cdots$ & Soil \\
\hline 5 & Annulus-ground & Tube & 600.0 & 2160.0 & Soil \\
\hline 6 & Dome-ground & Wall & 84.00 & $--\infty$ & Soil \\
\hline 7 & Air inlet pipes & Tube & 0.237 & 4.500 & Steel \\
\hline
\end{tabular}

\subsubsection{Flow Path Input Data.}

The flow path data are sumarized in Tables 5.5 and 5.6. The data for the flow paths are based on the elevations and heights of the volumes that they connect to. The flow areas are defined by the volumes that they connect to, where the area is not important, an arbitrary value is assigned. This can be done because pressure drops and fluid velocities are not important in this calculation. 


\begin{tabular}{|lr|}
\hline JOHN MARVIN, INC. & Calculation Number: JMI-9910_02 \\
\hline Analyst: Marvin J. Thurgood & Date: Feb 9, 2000 \\
\hline Reviewer: Harold E. Adkins & Date: Feb 9, 2000 \\
\hline Subject: Notebook for GOTH_SNF Simulation of Tank AZ-102 \\
\hline
\end{tabular}

Table 5.5 Flow Path Input Data (1).

\begin{tabular}{|c|c|c|c|c|c|}
\hline \multirow[t]{2}{*}{$\begin{array}{c}F . P \\
\#\end{array}$} & Description & $\begin{array}{l}\text { End } A \\
\text { Elev. }\end{array}$ & $\begin{array}{l}\text { End A } \\
\text { Ht }\end{array}$ & $\begin{array}{l}\text { End B } \\
\text { Elev. }\end{array}$ & $\begin{array}{c}\text { End B } \\
\text { Ht }\end{array}$ \\
\hline & & ft & Et & $\mathrm{ft}$ & ft \\
\hline 1 & Inlet Primary & 42.822 & 0.1000 & 50.932 & 0.100 \\
\hline 2 & Outlet Primary & 53.832 & 0.1000 & 54.932 & 0.100 \\
\hline 3 & slot Inlet & 0.010 & 0.1000 & 0.468 & 0.100 \\
\hline 4 & slot outlet & 0.468 & 0.1000 & 0.468 & 0.100 \\
\hline 5 & Outlet Secondar & 38.907 & 0.1000 & 47.017 & 0.100 \\
\hline 6 & Water Drain & 43.942 & 0.1000 & 41.932 & 0.100 \\
\hline 7 & Primary Fan & 41.932 & 0.1000 & 43.432 & 0.100 \\
\hline 8 & Fan outlet & 45.932 & 0.1000 & 43.432 & 0.100 \\
\hline 9 & Recirc. Fan Out & 41.932 & 0.1000 & 43.432 & 0.100 \\
\hline 10 & Recirc. Fan Inl & 45.932 & 0.1000 & 43.432 & $0: 100$ \\
\hline 11 & Annulus Air Inl & 38.907 & 0.1000 & 47.017 & 0.100 \\
\hline 12 & Pump Inlet & 28.886 & 0.1000 & 28.886 & 0.100 \\
\hline 13 & Pump outlet & 0.917 & 0.1000 & 0.917 & 0.100 \\
\hline
\end{tabular}




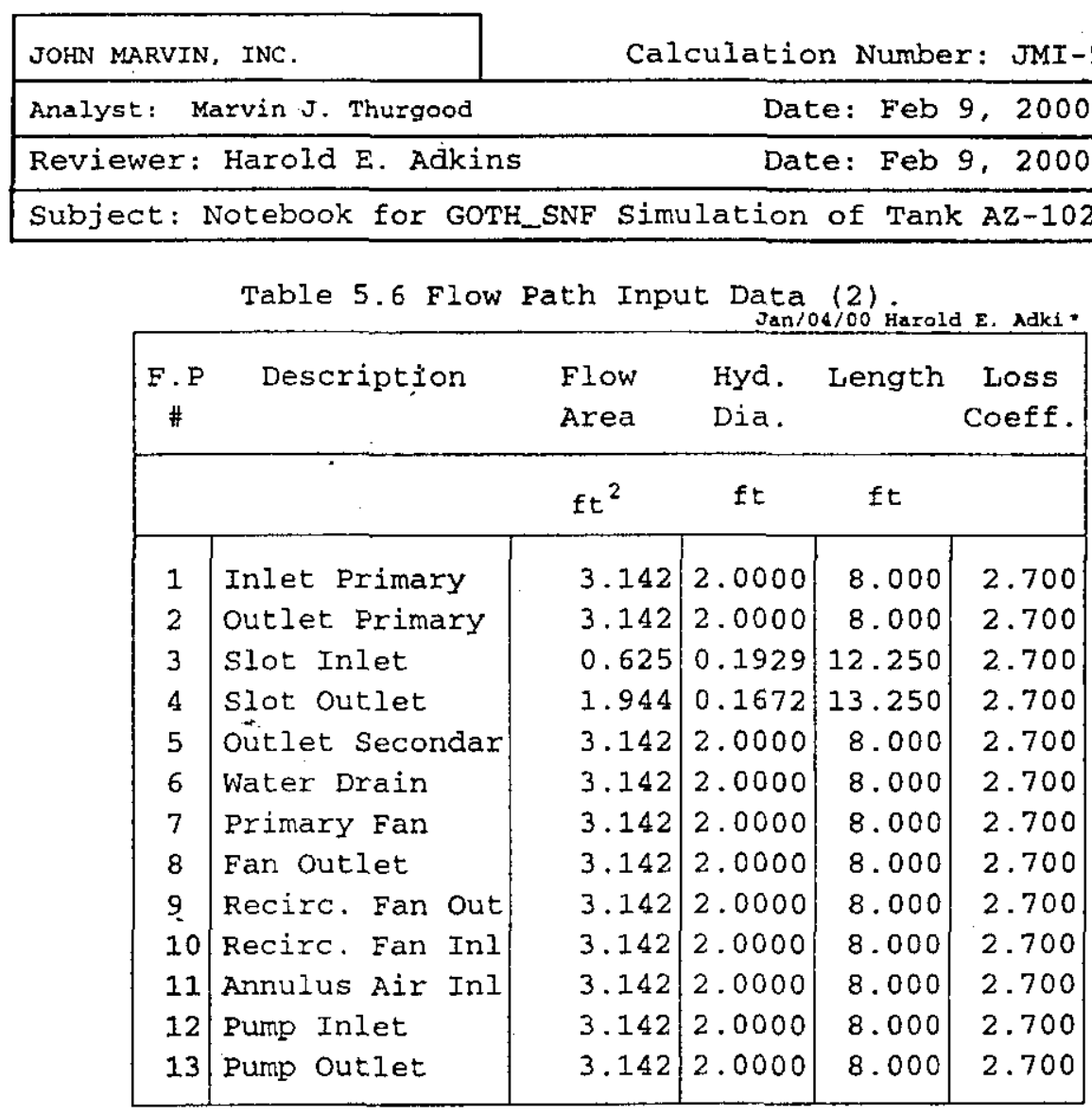

\subsubsection{Boundary Condition Input Data.}

The boundary condition input data used in the model described above is tabulated in Table 5.7 . 


\begin{tabular}{|lr|}
\hline JOHN MARVIN, INC. & Calculation Number: JMI-9910_02 \\
\hline Analyst: Marvin J. Thurgood & Date: Feb 9, 2000 \\
\hline Reviewer: Harold E. Adkins & Date: Feb 9, 2000 \\
\hline Subject: Notebook for GOTH_SNF Simulation of Tank AZ-102 \\
\hline
\end{tabular}

Table 5.7 Boundary Condition Input Data.

\begin{tabular}{|c|c|c|c|c|c|}
\hline $\begin{array}{c}\text { F.P } \\
\#\end{array}$ & Description & Pressure & Temp. & Flow & $\begin{array}{l}\text { W.V. } \\
\text { Press. } \\
\text { Ratio }\end{array}$ \\
\hline & psi & F & $\mathrm{Et} \mathrm{t}^{3}$ & \\
\hline 1 & Inlet Primary & 14.700 & 82.000 & 0.000 & 0.01050 \\
\hline 2 & Stack Inlet & 14.700 & 82.000 & 0.000 & 0.01050 \\
\hline 3 & slot Inlet & 14.700 & 82.000 & 0.000 & 0.01050 \\
\hline 4 & slot outlet & 14.700 & 82.000 & 16.667 & 0.01050 \\
\hline 5 & Primary out & 14.700 & 82.000 & ------ & 0.01050 \\
\hline 6 & Primary Couple & 14.700 & 82.000 & 8.333 & 0.01050 \\
\hline 7 & Recir out & 14.700 & 82.000 & 6.667 & 0.01050 \\
\hline 8 & Recirc Couple & 14.700 & 82.000 & $\cdots \cdots---$ & 0.01050 \\
\hline 9 & Pump Inlet & 14.700 & 82.000 & 46.180 & 0.01050 \\
\hline 10 & Pump outlet & 14.700 & 82.000 & ------ & 0.01050 \\
\hline
\end{tabular}

The mixer pump flow is set to a value high enough to mix sludge with supernatant without resettling but low enough not to excessively limit the time step size.

\section{SIMULATION RESULTS.} $\cdots$

Presented in this section are the simulation results concerning heat removal from high-level waste tank Az-102 during pre, current and post-mixing operations. Seven cases are evaluated herein. These consist of six potential ventilation configurations being evaluated under criteria applying to normal operations conditions, and one being evaluated under criteria established as safety limits for the system in question. This latter case involves the evaluation of a loss of ventilation. All cases consider the tank to initially be filled with waste 


\begin{tabular}{|lr|}
\hline JOHN MARVIN. INC. & Calculation Number: JMI-9910_02 \\
\hline Analyst: Marvin J. Thurgood & Date: Feb 9, 2000 \\
\hline Reviewer: Harold E. Adkins & Date: Feb 9, 2000 \\
\hline Subject: Notebook for GOTH_SNF Simulation of Tank AZ-102 \\
\hline
\end{tabular}

at steady state conditions and then a transient period enveloping pump start-up, shut-down, and re-establishment of steady state conditions.

Unless specified otherwise, the ventilation system consists of a nominal once through primary ventilation flow of $500 \mathrm{CFM}$ and a slot ventilation flow of $1000 \mathrm{CFM}$ or $2000 \mathrm{CFM}$. The air inlet temperature for the primary ventilation system as well as the ambient air conditions are specified to be $82^{\circ} \mathrm{F}$. Whereas the slot ventilation flow temperature is either specified to be that of the ambient $\left(82^{\circ} \mathrm{F}\right)$ or chilied to $40^{\circ} \mathrm{F}$ prior to duct entry. A constant ambient temperature of $82^{\circ} \mathrm{F}$ has been used in all simulations. Case specific input parameters are presented with the respective results in the appropriate sections below.

The initial steady state at which the simulation begins is with the solid particles in an undisturbed slurry on the bottom of the tank. The mixer pumps are then turned on and the sluryy in the bottom of the tank is mixed with the supernatant liquid. The assertion is that the mixer pumps mix the waste to a homogeneous mixture with no slurry remaining on the bottom of the tank. The pumps are conservatively run until the supernatant liquid comes to a steady state temperature.

The pumps are then turned off and the solid particles are allowed to resettle to the bottom of the tank. The rate the particles settle is a function of the particle size, particle density, supernatant liquid density and supernatant liquid viscosity. The code (GOTH_SNF) calculates this rate from the force balance on the particles. For all evaluated cases, the mixture is assumed to remain convective as long as the particle fraction in a computational cell remains below $0.75^{*} \alpha_{\mathrm{p}}$ mp. The slurry becomes nop-convective once the particle fraction reaches this value and the slurry begins to heat up as the radioactive decay heat must be removed by conduction 
through the slurry to the supernatant liquid. Heat is removed from the surface of the supernatant liquid by convective sensible heat transfer and evaporative heat transfer to the primary ventilation flow. Heat is also conducted down through the non-convective slurry to the air flowing through the slots in the floor of the tank and to the ground under the tank if the ground is cooler than the slurry at the bottom of the tank.

A brief recap of the operation and safety related criteria that must be met in order for the ventilation system to be deemed acceptable are that prior to and after mixing operations, no portion of the top 15 feet waste may exhibit temperatures in excess of $195^{\circ} \mathrm{F}$ (LCO 3.3.2.b), no waste temperatures may exceed $195^{\circ} \mathrm{F}$ at any time during mixer pump runtime (LCO 3.3.2.a), and no portion of. the waste existing below the top 15 feet may exhibit temperatures in excess of $215^{\circ} \mathrm{F}$ prior to and after mixing operations (LCO $3.3 .2 . \mathrm{b}$ ). Additionally, in the event of a loss of ventilation, no waste temperature shall exceed $250^{\circ} \mathrm{F}$ during the recovery period (SL 2.1.1).

Loss of ventilation evaluations have been performed on ventilation syster configurations deemed acceptable only.

\subsection{CASE 1 - NOMINAL PRIMARY AND FLOOR SLOT VENTILATION FLOWS.}

The ventilation system for this case consists of the nominal once through primary ventilation flow of 500 CFM and the slot ventilation flow of $1000 \mathrm{CFM}$. The air inlet temperature for both systems is $82^{\circ} \mathrm{F}$.

The critical waste temperatures in the tank for the initial settled state and for the period when the pumps are running are shown in Figure 6.1. The steady-state supernatant liquid temperature prior to pump operation is 


\begin{tabular}{|lr|}
\hline JOHN MARVIN, INC. & Calculation Number: JMI-9910_02 \\
\hline Analyst: Marvin J. Thurgood & Date: Feb 9, 2000 \\
\hline Reviewer: Harold E. Adkins & Date: Feb 9, 2000 \\
\hline Subject: Notebook for GOTH_SNF Simulation of Tank Az-102 \\
\hline
\end{tabular}

shown as point "T1" in this figure. The peak slurry temperature for this state is shown as point "T2" in this figure. The horizontal lines preceeding these locations to a time of $t=34$ days are simply displaying the existence of model mathematical equilibrium.

The pumps are turned on (time $t=34$ days) and the waste comes to a uniform temperature, "T3" in Figure 6.1 (time $t$ $=38$ days). (Note: There is only one graphics dump between point " $T 2$ " and " $T 3$ " so the actual mixed temperature may be lower than that shown for "T3" in this figure. This is not critical as long as "T3" is lower than the LCO supernatant liquid temperature limit of $195^{\circ} \mathrm{F}$, which it is.) The pumps are then run until the supernatant liquid comes to a steady-state temperature, point " $T 4$ " in Figure 6.1 .

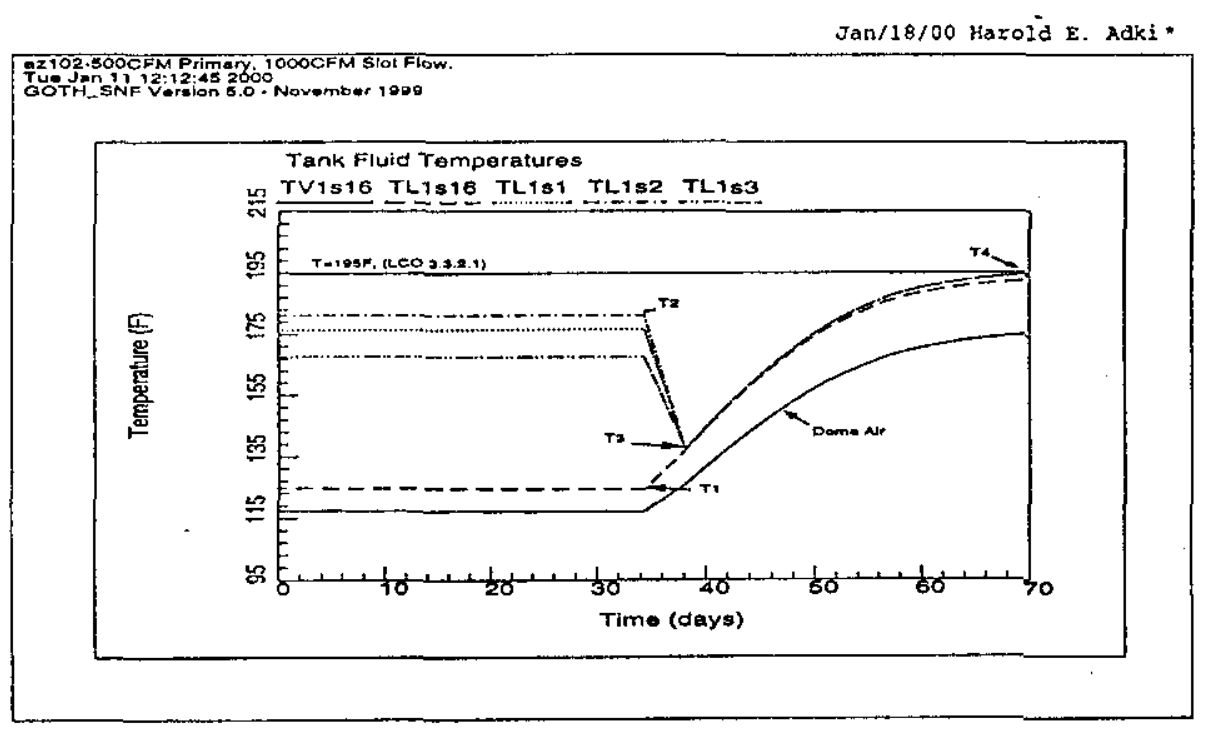

Figure 6.1 Temperatures From the Initial Steady-State Conditions Through Pump Mixing (Case 1),

As shown in Figure 6.1 , the tank waste temperature climbs as the pumps deposit energy into the waste during the mixing process. In this figure, the temperatures "T1", 
JOHN MARVIN, INC.

Analyst: Marvin $J$. Thurgood

Reviewer: Harold $\mathrm{E}$. Adkins

Subject: Notebook for GOPH_SNE Simulation of Tank AZ-102

"T3" and "T4" must be below the LCO 1imit of $195^{\circ} \mathrm{F}$ for this ventilation system configuration to be deemed acceptable, and they are. Also, temperature "T2" must be below $215^{\circ} \mathrm{F}$ to meet the acceptability criteria, as it is. However, all acceptability criteria has not yet been met.

The pumps are then shut off (time $t=70$ days) and the solid particles settle out of the supernatant liquid to form a non-convective layer. The waste cools prior to the layer becoming non-convective since the pumps are shut off and are no longer depositing energy into the waste and the primary ventilation system is removing a large amount of energy stored in the waste by evaporative cooling. The ground under the tank also cools as the waste cools. The cooler ground slows the heat-up of the non-convective slurry in the bottom of the tank as it absorbs heat from the waste by conduction. Ground conduction is important here as it damps out the peak in temperature that would otherwise occur in the waste since the supernatant liquid is still rejecting heat deposited during pump operation. This is displayed as a temporary decline in temperature shortly after the mixer pumps are shut off (line "TL1s1" at time $70 \mathrm{hrs} \leq t \leq 85 \mathrm{hrs}$ is a good example).

The resulting peak slurry temperature is shown in Figure 6.2 as point "T2"". This temperature must remain below $215^{\circ} \mathrm{F}$ at all times before and after mixing for the ventilation system to be deemed acceptable. As shown in this figure, the peak temperature for this case exceeds the established criteria. Hence, the ventilation system, as operated in its nominal configuration, is unacceptable. 


\begin{tabular}{|lr|}
\hline JoHN MARVIN, INC. & Calculation Number: JMI-9910_02 \\
\hline Analyst: Marvin J. Thurgood & Date: Feb 9, 2000 \\
\hline Reviewer: Harold E. Adkins & Date: Feb 9, 2000 \\
\hline Subject: Notebook for GOTH_SNE Simulation of Tank AZ-102 \\
\hline
\end{tabular}

Jan/18/00 Harold E. Adki *

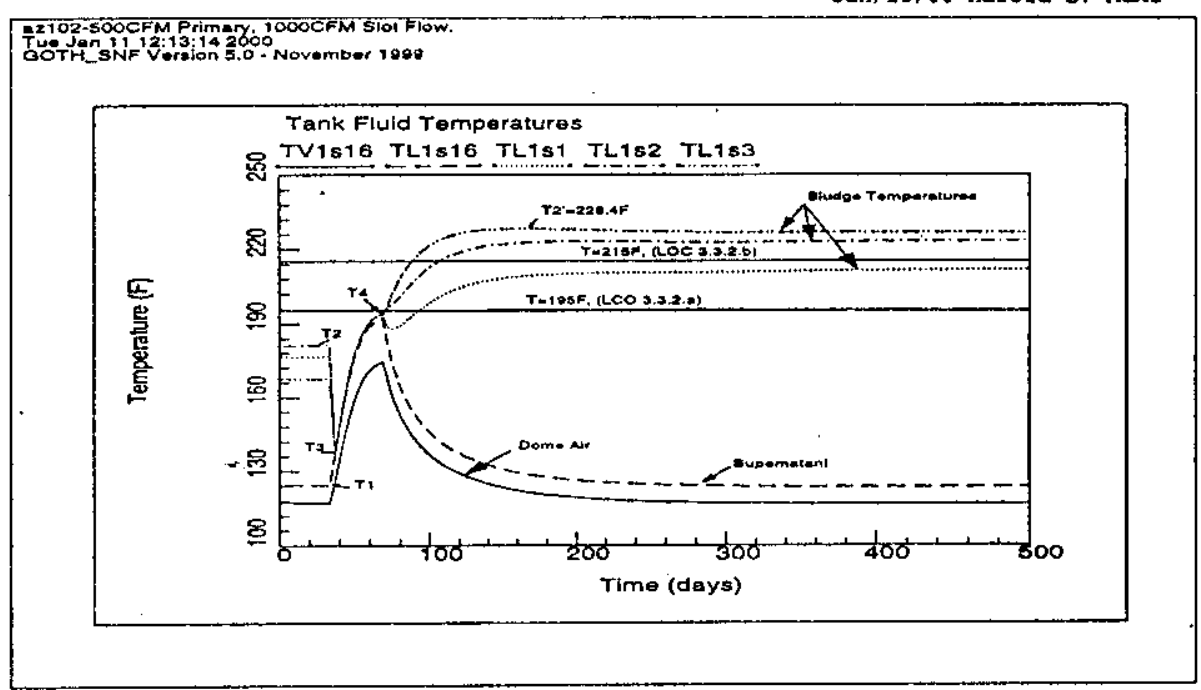

Figure 6.2 Critical Waste Temperatures After Pumps are shut off (Case 1).

The axial temperature profile in the waste prior to mixing operations (T2), for the point at which the peak slurry temperature occurs after mixing operations (T2'), and steady state conditions after mixing operations (T'") are given in Table 6.1 and are shown in Figure 6.3. 


\begin{tabular}{|lr|}
\hline JOHN MARVIN, INC. & Calculation Number: JMI-9910_02 \\
\hline Analyst: Marvin J. Thurgood & Date: Feb 9, 2000 \\
\hline Reviewer: Harold E. Adkins & Date: Feb 9, 2000 \\
\hline Subject: Notebook for GOTH_SNF Simulation of Tank AZ-102 \\
\hline
\end{tabular}

Table 6.1 Axial Temperature Distributions in Tank (Case 1).

Jan/18/00 Harold E. Adk1.

\begin{tabular}{|r|r|r|r|}
\hline elevation & $\begin{array}{r}\text { Temperature } \\
\text { T2 }\end{array}$ & $\begin{array}{c}\text { Temperatid } \\
\text { T2' }\end{array}$ & $\begin{array}{c}\text { Temperature } \\
\text { T2. }\end{array}$ \\
\hline 0.208 & 176.600 & 209.300 & 212.700 \\
0.917 & 181.000 & 222.500 & 223.700 \\
1.805 & 167.500 & 228.200 & 226.300 \\
2.534 & 143.700 & 225.900 & 222.900 \\
3.260 & 126.300 & 216.900 & 213.100 \\
4.125 & 126.200 & 197.400 & 193.200 \\
5.177 & 126.200 & 160.300 & 155.500 \\
6.393 & 126.200 & 130.700 & 125.600 \\
8.036 & 126.200 & 130.700 & 125.600 \\
10.636 & 126.200 & 130.700 & 125.600 \\
14.236 & 126.200 & 130.700 & 125.600 \\
18.978 & 126.200 & 130.700 & 125.600 \\
23.720 & 126.200 & 130.700 & 125.600 \\
26.720 & 126.200 & 130.700 & 125.600 \\
28.220 & 126.200 & 130.700 & 125.600 \\
\hline Array: ax1 & & & \\
\hline
\end{tabular}

$$
\begin{aligned}
& \text { - } \left.\mathrm{T2}:=\operatorname{array}(\operatorname{ax}]_{0,2}, \operatorname{axl} 0,1\right) \\
& T 4:=\operatorname{array}\left(\operatorname{axl} 0,3, a x l_{0,1}\right) \\
& \text { T5 : }=\operatorname{array}\left(\operatorname{ax} 1_{0,4}, \operatorname{axl} 0,1\right) \\
& T 2,2:=2.875 \\
& \mathrm{~T}_{8,2}:=5.7500 \\
& T 5_{8,2}:=5.7500
\end{aligned}
$$

Jan $/ 1 B / 00$
$(6,1)$
Harold E. Adki
$J a n / 18 / 00$
$(6,2)$
Harold E. Adki
Jan $/ 18 / 00$
$(6.3)$
Harold $E$. Adki
Jan $/ 18 / 00$
$(6.4)$
Harold $E$. Adki
$\operatorname{Jan} / 1 B / 00$
$(6.5)$
Harold $E$. Adki
Jan $/ 18 / 00$
$(6.6)$
Harold E. Adki




\begin{tabular}{|lc|}
\hline JoHN MARVIN, INC. & Calculation Number: JMI-9910_02 \\
\hline Analyst: Marvin J. Thurgood & Date: Feb 9, 2000 \\
\hline Reviewer: Harold E. Adkins & Date: Feb 9, 2000 \\
\hline Subject: Notebook for GOTH_SNF Simulation of Tank AZ-102 \\
\hline
\end{tabular}

Jan/18/00 Harold E. Adki *

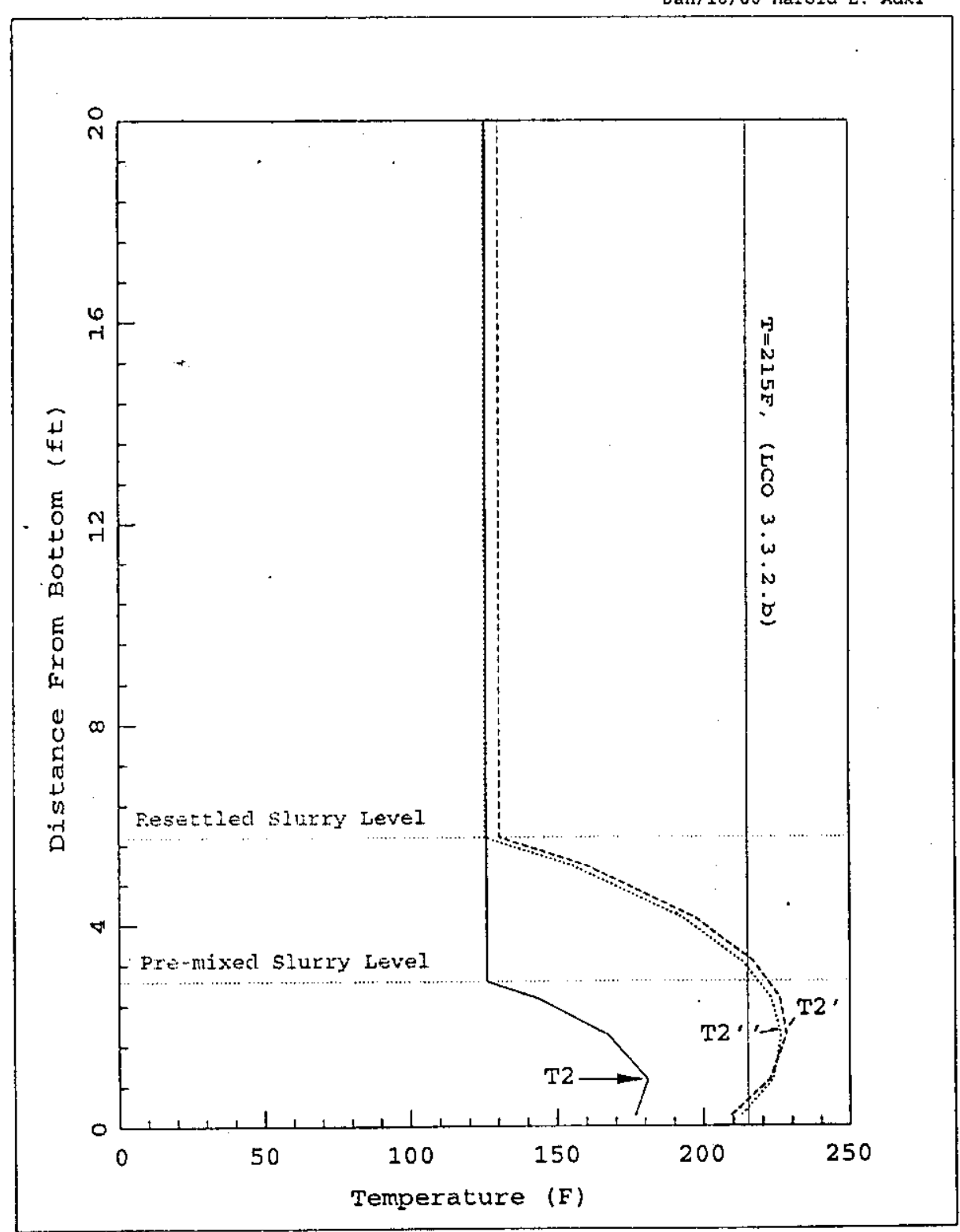

Figure 6.3 Axial Temperature Distributions in Tank Waste Before (T2), Peak After (T2'), and Steady State After Mixing (T2") (Case 1). 
The high evaporative removal rate during mixing operations is shown in the water vapor mass flow rate results displayed in Figure 6.4. This figure shows the amount of water vapor that. must be removed from the outlet air by the primary ventilation system condenser (if the ventilation system had been determined to be acceptable) in order for dry air to enter the ventilation fans. The primary ventilation flow can not be maintained at the specified level if this moisture is not removed.

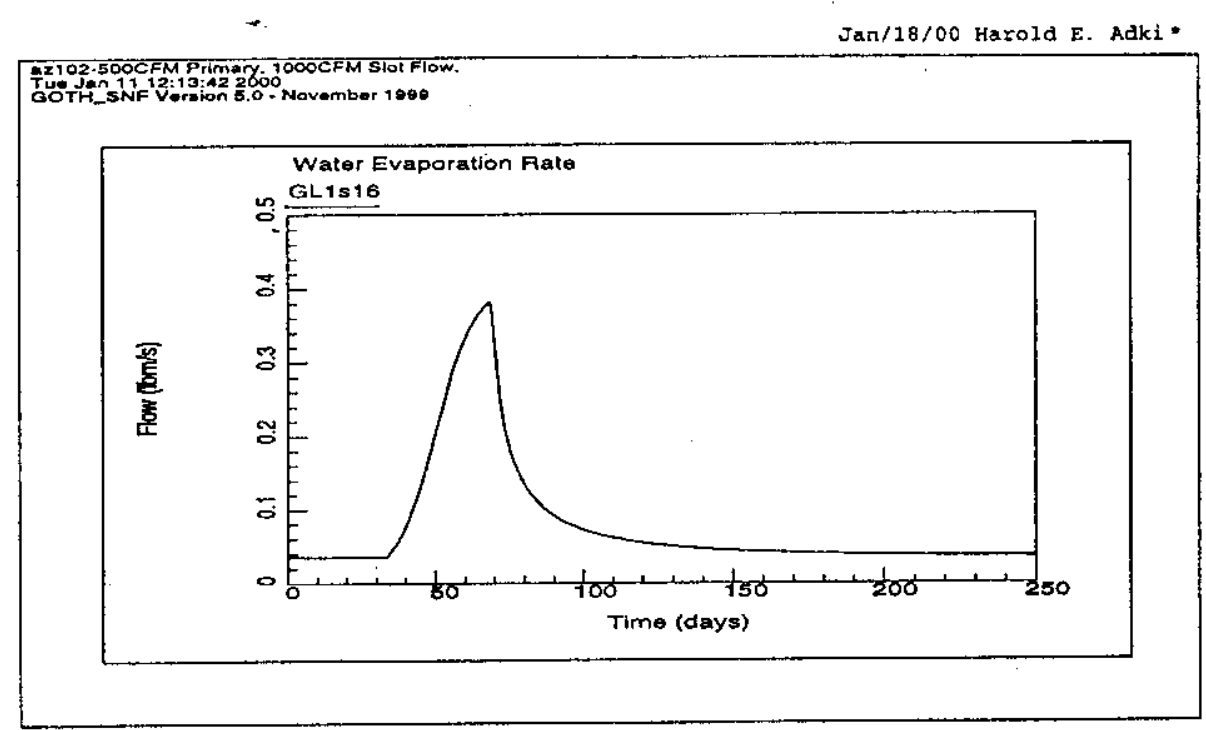

Figure 6.4 Water Vapor Mass Rate Carried over By the Primary Ventilation System (Case 1).

\subsection{CASE 2 - NOMINAL PRIMARY AND CHILLED NOMINAI FLOOR SLOT VENTILATION FLOWS.}

Similar to the previous case, the ventilation system for this case consists of the nominal once through primary ventilation flow of $500 \mathrm{CFM}$ and the slot ventilation flow 
JOHN MARVIN, INC.

Analyst: Marvin 3 . Thurgood

Reviewer: Harold E. Adkins

Subject: Notebook for GOTH_SNF Simulation of Tank AZ-102

of $1000 \mathrm{CFM}$. However, for this case the slot ventilation flow is chilled to $40^{\circ} \mathrm{F}$ while the air inlet temperature for the primary ventilation system is maintained at the original $82^{\circ} \mathrm{F}$.

In this particular case, the critical tank waste temperatures for the initial settled state and for the period when the pumps are running are shown in Figure 6.5. The steady-state supernatant liquid temperature and peak. slurry temperature prior to mixing operations are shown in this figure as point "T1" and point "T2", respectively. As in previous figures, the horizontal lines preceeding these locations to a time of $t=34$ days are simply displaying the existence of model mathematical equilibrium.

The pumps are turned on (time $t=34$ days) and the waste comes to a uniform temperature, "T3" in Figure 6.5 (time $t$ $=38$ days). The pumps are then run until the supernatant Iiquid comes to a steady-state temperature, point "T4" in Figure 6.5. $\mathrm{Jan} / 18 / 00$ Harold E. Adki *

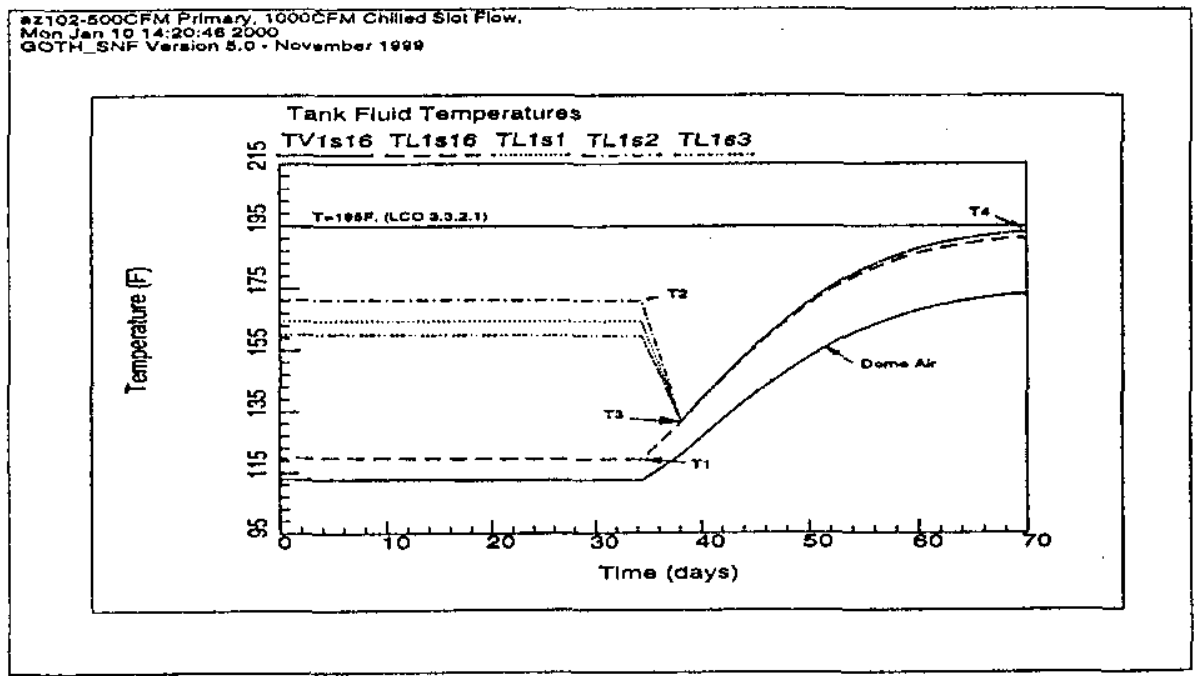

Figure 6.5 Temperatures From the Initial steady-State Conditions Through Pump Mixing (Case 2). 
JOHN MARVIN, INC.

Calculation Number: JMI-9910_02

Analyst: Marvin J. Thurgood

Date: Feb 9, 2000

Reviewer: Harold E. Adkins

Date: Feb 9, 2000

Subject: Notebook for GOTH_SNF Simulation of Tank AZ-102

In this figure, the temperatures "T1", "T3" and "T4" must

be below the LCO limit of $195^{\circ} \mathrm{F}$ for this ventilation

system configuration to be deemed acceptable, and they

are. Also, temperature " $\mathrm{T} 2$ " must be below $215^{\circ} \mathrm{F}$ to meet

the acceptability criteria, as it is. However, all

acceptability criteria has not yet been met.

The pumps are then shut off ( $t$ ime $t=70$ days) and the

solid particles settle out of the supernatant liquid and

once again form a non-convective layer. The waste cools

priar to the layer becoming non-convective since the pumps

are shut off and are no longer depositing energy into the

waste and the primary ventilation system is removing a

large amount of energy through evaporative cooling. The

damping effect that the ground beneath the tank provided for the previous case (shown as a temporary decrease in " slurry temperature shortly after mixing has ceased $t=38$ hours in Figure 6.2) is not visible for this case. Its absence is attributed to the fact that the slot ventilation inlet temperature for this case is $40^{\circ} \mathrm{F}$ instead of $82^{\circ} \mathrm{F}$.

The resulting peak slurry temperature is show in Figure 6.6 as point "T2"". This temperature must remain below $215^{\circ} \mathrm{F}$ at all times before and after mixing for the ventilation system to be deemed acceptable. As shown in this figure, the peak temperature for this case exceeds the established criteria by slightly more than $5^{\circ} \mathrm{F}$ for approximately 180 days. Hence, despite the added cooling capability provided by chilling the slot flow, the ventilation system configuration as defined for this case is unacceptable. 
JOHN MARVIN, INC.

Analyst: Marvin J. Thurgood

Reviewer: Harold E. Adkins

Subject: Notebook for GOTH_SNF Simulation of Tank AZ-102

$\mathrm{Jan} / 18 / 00$ Harold $\varepsilon$, Adki *

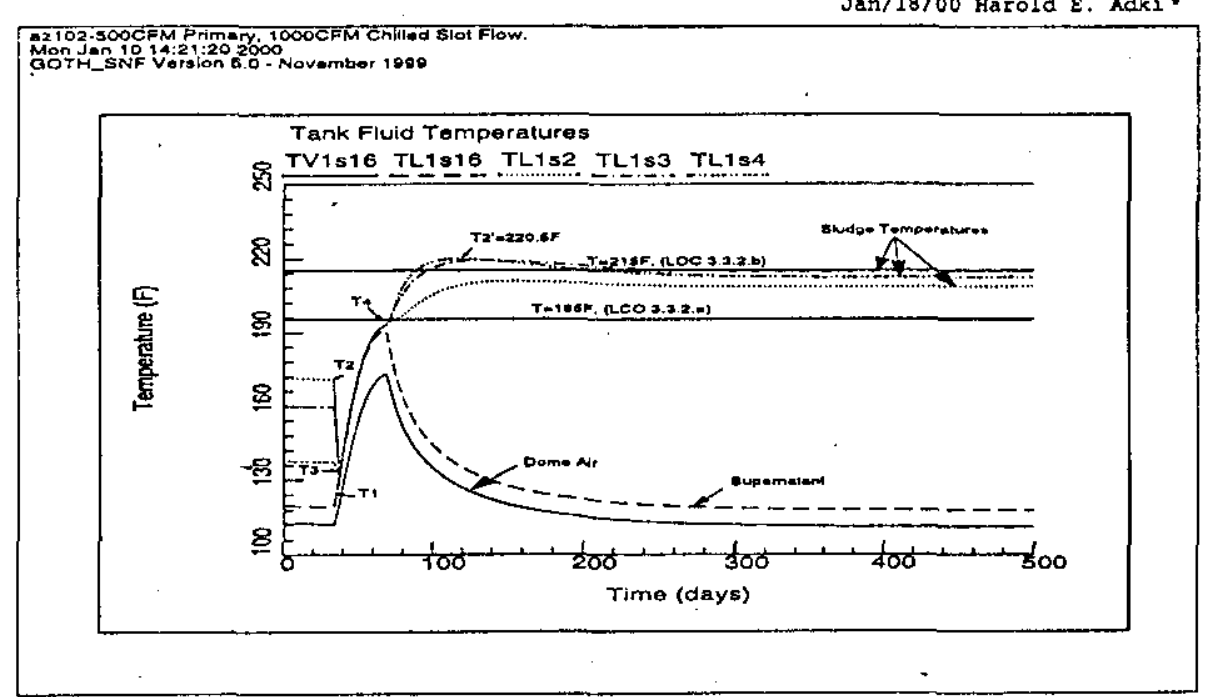

Figure 6.6 Critical waste Temperatures After Pumps are Shut off (Case 2).

The axial temperature profile in the waste prior to pump operation ('T2), for the point at which the peak siurry temperature occurs after pump operation $\left(\mathrm{T}^{\prime}\right)$, and steady state conditions after pump operation (T'') are given in Table 6.2 and are shown in Figure 6.7 . 
Table 6.2 Axial Temperature Distributions in Tank (Case 2).

Jan/18/00 Harold E. Adki.

\begin{tabular}{|r|r|r|r|}
\hline \multicolumn{1}{|r|}{ elevation } & $\begin{array}{c}\text { Temperature } \\
\text { T2 }\end{array}$ & $\begin{array}{c}\text { Temperature } \\
\text { T2' }\end{array}$ & $\begin{array}{c}\text { Temperature } \\
\text { T2', }\end{array}$ \\
\hline 0.208 & 163.400 & 192.600 & 197.200 \\
0.917 & 171.100 & 208.500 & 210.700 \\
1.805 & 159.800 & 219.000 & 216.400 \\
2.534 & 137.200 & 220.500 & 213.700 \\
3.260 & 121.000 & 214.900 & 205.100 \\
4.125 & 121.000 & 199.800 & 185.500 \\
5.177 & 121.000 & 166.600 & 148.100 \\
6.393 & 121.000 & 137.500 & 119.400 \\
8.036 & 121.000 & 137.500 & 119.400 \\
10.636 & 121.000 & 137.500 & 119.400 \\
14.236 & 121.000 & 137.500 & 119.400 \\
18.978 & 121.000 & 137.500 & 119.400 \\
23.720 & 121.000 & 137.500 & 119.400 \\
26.720 & 121.000 & 137.500 & 119.400 \\
28.220 & 121.000 & 137.500 & 119.400 \\
\hline Array: ax1 & & & \\
\hline
\end{tabular}

$$
\begin{aligned}
& \mathrm{T} 2:=\operatorname{array}\left(\operatorname{ax} 1_{0,2}, \operatorname{ax} 10,1\right) \\
& \mathrm{T} 4:=\operatorname{array}\left(\operatorname{ax} 1_{0,3}, \operatorname{ax} 1_{0,1}\right) \\
& \mathrm{T} 5:=\operatorname{array}\left(\operatorname{ax} 1_{0,4}, \operatorname{ax} 1_{0,1}\right) \\
& \mathrm{T}_{5,2}:=2.875 \\
& \mathrm{~T}_{\mathrm{B}, 2}:=5.7500 \\
& \mathrm{~T}_{8,2}:=5.7500
\end{aligned}
$$

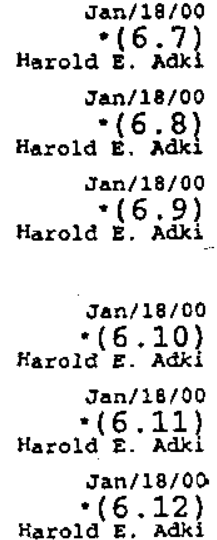




\begin{tabular}{|lr|}
\hline JOFN MARVIN, INC. & Calculation Number: JMI-9910_02 \\
\hline Analyst: Marvin J. Thurgood & Date: Feb 9, 2000 \\
\hline Reviewer: Harold E. Adkins & Date: Feb 9, 2000 \\
\hline Subject: Notebook for GOTH_SNF Simulation of Tank AZ-102 \\
\hline
\end{tabular}

Jan/18/00 Harold E. Adki *

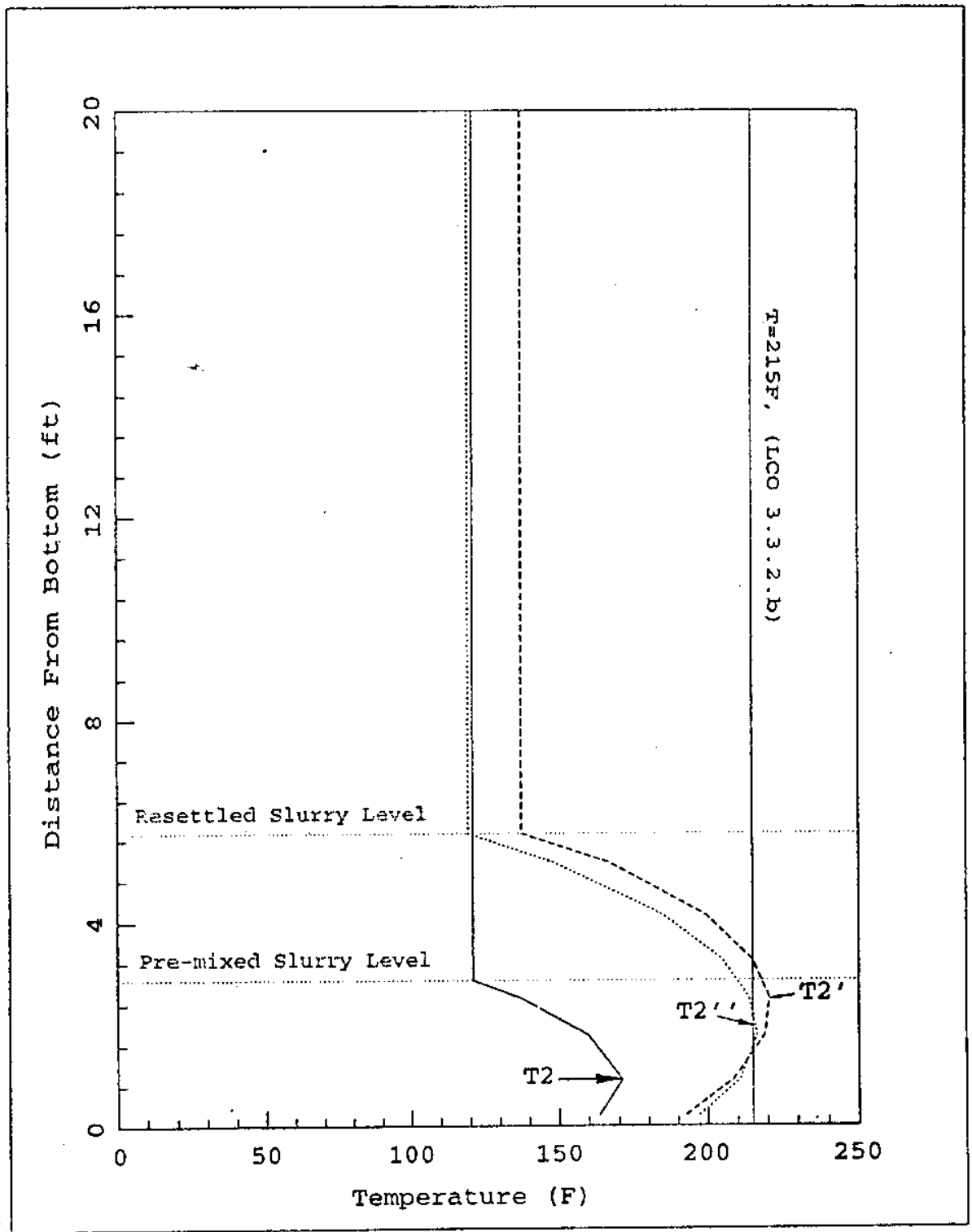

Figure 6.7 Axial Temperature Distribution in Tank Waste Before (T2), Peak After (T2'), and steady state After Mixing (T2"') (Case 2). 
JOHN MARVIN, INC.

Analyst: Marvin $J$. Thurgood

Reviewer: Harold E. Adkins

Subject: Notebook for GOTH_SNF Simulation of Tank AZ-102
Calculation Number: JMI-9910_02 Date: Feb 9, 2000

Date: Feb 9, 2000

The resulting high evaporative removal rate during pump operation for this case is shown in the water vapor mass flow rate displayed in Figure 6.8 . This figure shows the amount of water vapor that must be removed from the outlet air by the primary ventilation system condenser (if the ventilation system had been determined to be acceptable) in ordex for dry air to enter the ventilation fans. The primary ventilation flow would not be maintained at the specified level if this moisture is not removed.

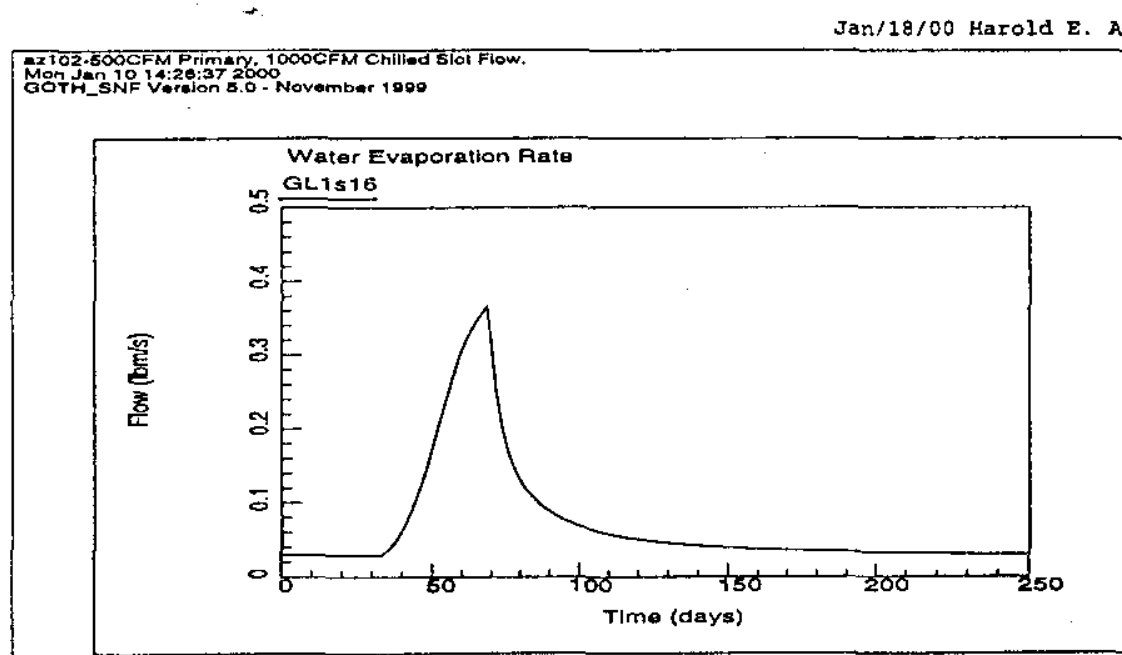

Figure 6.8 water Vapor Mass Rate Carried over By the Primary Ventilation System (Case 2).

\subsection{CASE 3 - NOMINAL PRIMARY AND MAXIMUM FLOOR SLOT VENTILATION ELOW.}

The ventilation system for this case consists of the nominal once through primary ventilation flow of 500 CFM. However, the slot ventilation flow has been upgraded to 
JOHN MARVIN, INC.

Calculation Number: JMI-9910_02

Analyst: Marvin $I$. Thurgood

Reviewer: Harold E. Adkins

Subject: Notebook for GOTH_SNF Simulation of Tank AZ-102

Date: Feb 9, 2000

Date: Feb 9, 2000

provide a flow rate of $2000 \mathrm{CFM}$. The inlet temperature for both systems is $82^{\circ} \mathrm{F}$.

The critical waste temperatures for the initial settled state and period when the pumps are running for this particular case are shown in Figure 6.9. The steady-state supernatant liquid temperature and peak slurry temperature prior to mixing operations are shown in this figure as point "T1" and point "T2", respectively.

At time $t=34$ days, the pumps are turned on and the waste comes to a uniform temperature, " $T 3$ " at time $t=38$ days. The pumps are then run until the supernatant liquid comes to a steady-state temperature, point "T4".

Jan/18/00 Harold E. Adki.

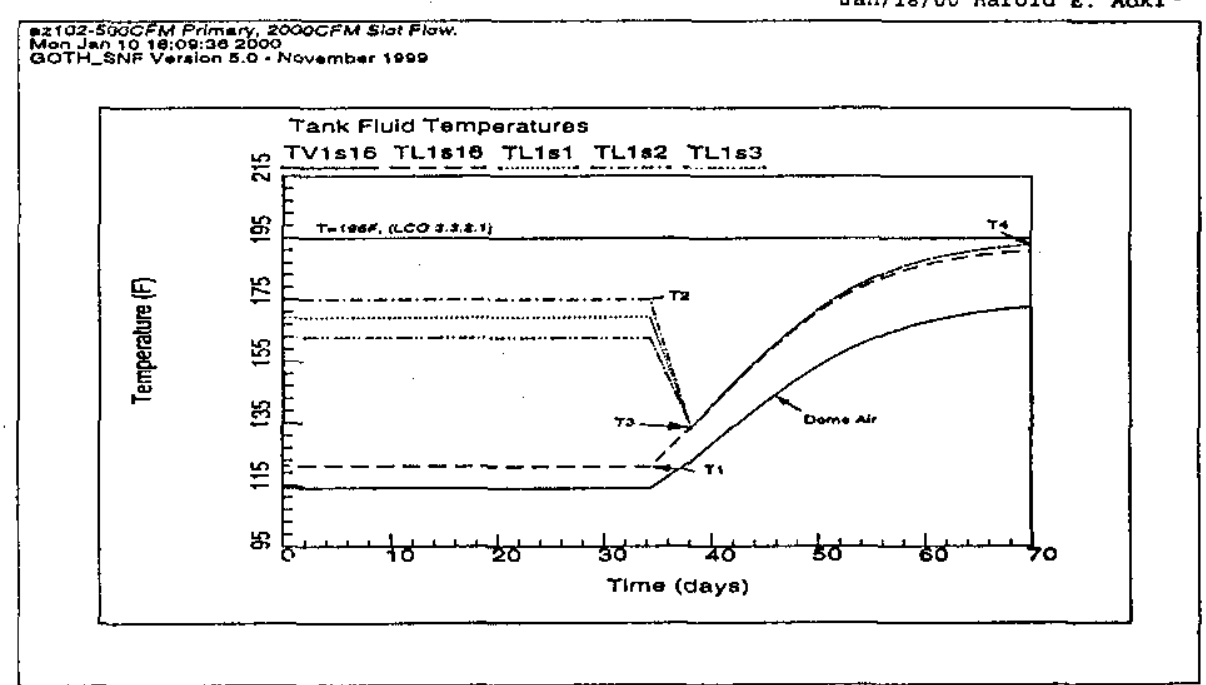

Figure 6.9 Temperatures From the Initial Steady-State Conditions Through Pump Mixing (Case 3).

Just as that for previous cases, the temperatures "T1", "T3" and "T4" must be below the LCO limit of $195^{\circ} \mathrm{F}$ for this ventilation system configuration to be deemed acceptable, and they are. Also, temperature "T2" must be below $215^{\circ} \mathrm{F}$

79 of 102 
JOHN MARVIN, INC.

Analyst: Marvin J. Thurgood

Reviewer: Harold E. Adkins

Subject: Notebook for GOTH_S

to meet the acceptability criteria, as it is.

The pumps are then shut off (time $t=70$ days) and the solid particles settle out of the supernatant liquid and once again form the non-convective slurry layer. The resulting peak slurry temperature is shown in Figure 6.10 as point "T2" ". This temperature must remain below $215^{\circ} \mathrm{F}$ at all times before and after mixing for the ventilation system to be deemed acceptable.

As shown in Figure 6.10, the peak temperature for this case exceeds the established criteria by slightly more than $6^{\circ} \mathrm{F}$. As is also shown, the peak temperature remains above the established limits even after reaching steady state. Hence, despite the added cooling capability provided by the upgraded slot flow ventilation flow rate, the ventilation system configuration as defined for this case is also unacceptable.

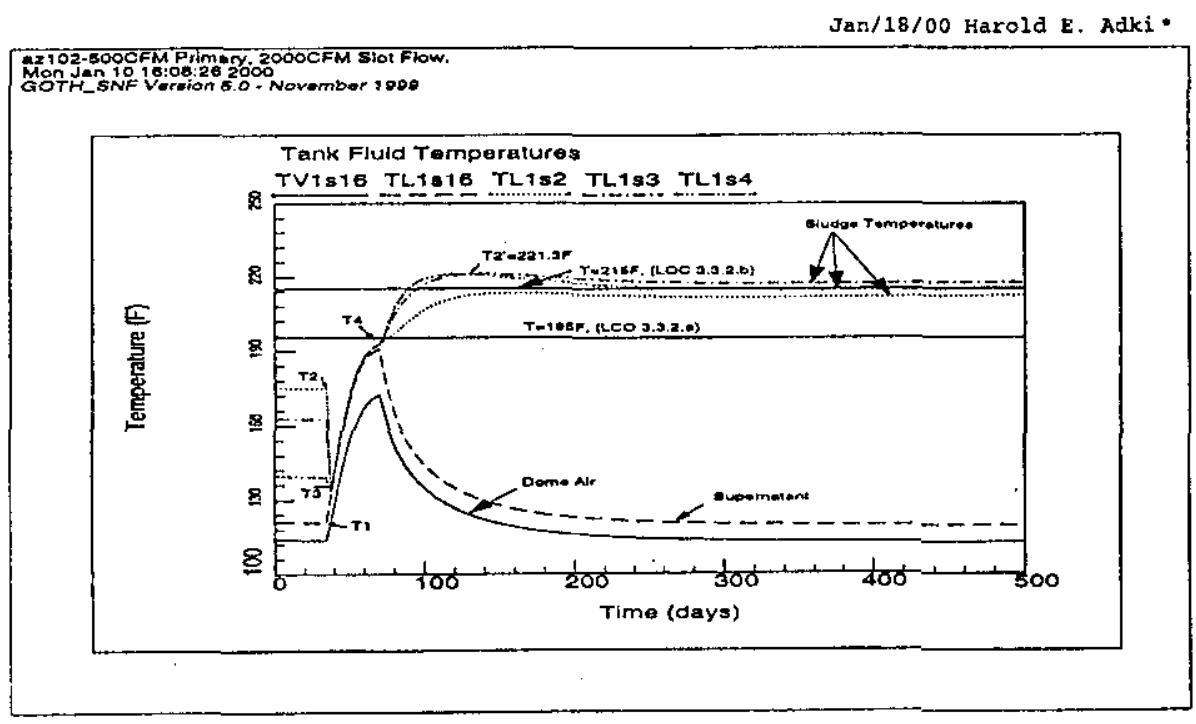

Figure 6.10 Critical Waste Temperatures After Pumps are Shut off (Case 3 ).

80 of 102 
Analyst: Marvin J. Thurgood

Date: Feb 9, 2000

Reviewer: Harold E. Adkins

Date: Feb 9, 2000

Subject: Notebook for GOTH_SNF Simulation of Tank AZ-102

The axial temperature profile in the waste prior to pump operation (T2) and after pump operation (T2') are given in Table 6.3 and are shown in Figure 6.11 .

Table 6.3 Axial Temperature Distributions in Tank (Case 3).

Jan/18/00 Harold E. Adki *

\begin{tabular}{|c|c|c|c|}
\hline elevation & $\begin{array}{c}\text { Temperature } \\
\text { T2 }\end{array}$ & $\begin{array}{c}\text { Temperature } \\
\text { T2 }\end{array}$ & $\begin{array}{c}\text { Temperature } \\
\text { T2' }\end{array}$ \\
\hline 0.208 & 169.200 & 197.900 & 200.500 \\
\hline 0.917 & 174.900 & 213.400 & 213.700 \\
\hline 1.805 & 162.400 & 221.300 & 218.700 \\
\hline 2.534 & 139.100 & 220.500 & 216.000 \\
\hline 3.260 & 122.800 & 213.300 & 207.000 \\
\hline 4.125 & 122.600 & 196.200 & 187.800 \\
\hline 5.177 & 122.600 & 160.300 & 150.300 \\
\hline 6.393 & 222.600 & 131.300 & 121.100 \\
\hline 8.036 & 122.600 & 131.300 & 121.100 \\
\hline 10.636 & 122.600 & 131.300 & 121.100 \\
\hline 14.236 & 122.600 & 131.300 & 121.100 \\
\hline 18.978 & 122.600 & 131.300 & 121.100 \\
\hline 23.720 & 122.600 & 131.300 & 121.100 \\
\hline 26.720 & 122.600 & 131.300 & 121.100 \\
\hline 28.220 & 122.600 & 131.300 & 121.100 \\
\hline
\end{tabular}

$$
\begin{gathered}
\mathrm{T} 2:=\operatorname{array}(a \times 20,2, a \times 20,1) \\
\mathrm{T} 4:=\operatorname{array}(\mathrm{ax} 20,3, \mathrm{ax} 20,1) \\
\mathrm{T} 5:=\operatorname{array}\left(\mathrm{ax} 2_{0,4}, \mathrm{ax} 2_{0,1}\right) \\
\mathrm{T}_{5,2}:=2.875
\end{gathered}
$$


RPP-5637

Rev. 0

JOHN MARVIN, INC.

Calculation Number: JMI-9910_02

Analyst: Marvin J. Thurgood Date: Feb 9, 2000

Reviewer: Harold E. Adkins Date: Feb 9, 2000

Subject: Notebook for GOTH_SNF simulation of Tank AZ-102

T4, $:=5.7500$

$T 5_{8,2}:=5.7500$
Jan 18100

(6.17)

$\mathrm{Jan} / 18 / 00$

$*(6.18)$ 


\begin{tabular}{|lr|}
\hline JoHN MARVIN, INC. & Calculation Number: JMI-9910_02 \\
\hline Analyst: Marvin J. Thurgood & Date: Feb 9, 2000 \\
\hline Reviewer: Harold E. Adkins & Date: Feb 9, 2000 \\
\hline Subject: Notebook for GOTH_SNF Simulation of Tank AZ-302 \\
\hline
\end{tabular}

Jan/18/00 Harold E. Adki *

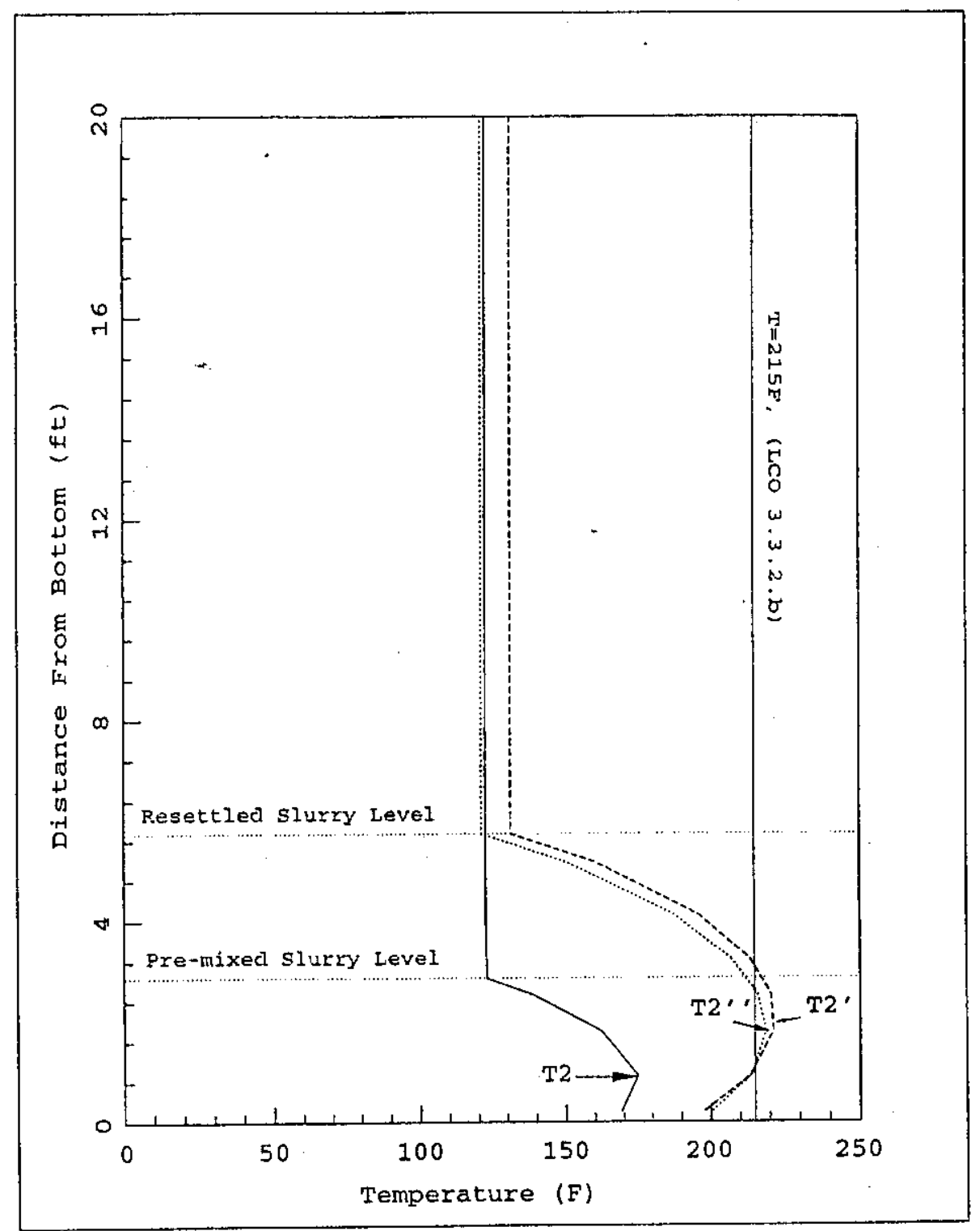

Figure 6.11 Axial Temperature Distributions in Tank Before (T2), Peak After (T2'), and steady state After Mixing (T2',) (Case 3 ). 
JOHN MARVIN, INC.

Calculation Number: JMI-9910_02

Analyst: Marvin J. Thurgood

Date: Feb 9, 2000

Reviewer: Harold E. Adkins

Date: Feb 9, 2000

Subject: Notebook for GOTH_SNF Simulation of Tank AZ-102

The resulting evaporative removal rate during pump operation for this case is shown in the water vapor mass flow rate displayed in Figure 6.12 .

Jan/18/00 Harold E. Adki *

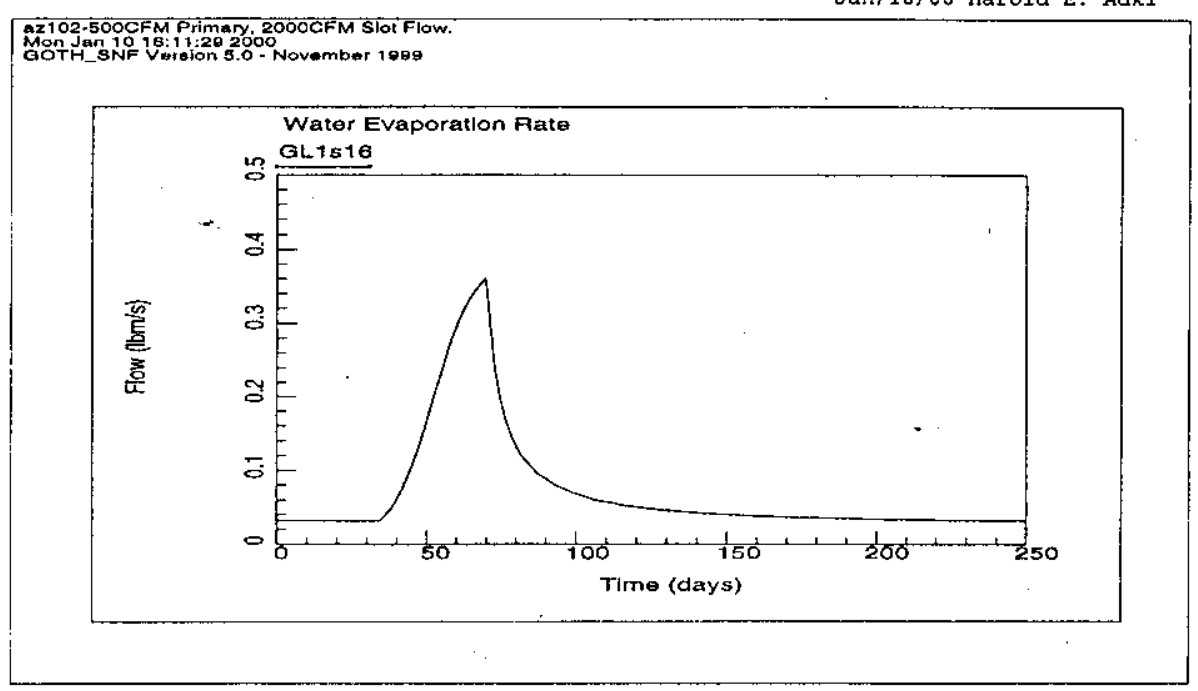

Figure 6.12 water Vapor Mass Rate Carried over By the Primary Ventilation System (Case 3).

\subsection{CASE 4 - NOMINAI PRIMARY AND MAXIMUM CHILLED FLOOR SLOT VENTILATION FLOW.}

The ventilation system for this case consists of the nominal once through primary ventilation flow of 500 CFM and the slot ventilation flow has been upgraded to provide a flow rate of 2000 CFM just as in the previous case. However, for this case the slot ventilation flow is chilled to $40^{\circ} \mathrm{F}$ while the air inlet temperature for the primary ventilation system is maintained at the ambient $82^{\circ} \mathrm{F}$. 
JOHN MARVIN, INC.

Calculation Number: JMI-9910_02

Analyst: Marvin J. Thurgood

Date: Feb 9, 2000

Reviewer: Harold E. Adkins

Date: Feb 9, 2000

Subject: Notebook for GOTH_SNF Simulation of Tank AZ-102

The critical waste temperatures for the initial settled state and period when the mixer pumps are running are shown in Figure 6.13. The steady-state supernatant liquid temperature and peak slurry temperature prior to mixing operations are shown in this figure as point "Tl" and point "T2", respectively.

At time $t=34$ days, the pumps are turned on and the waste comes to a uniform temperature, "T3" at time $t=38$ days. The pumps are then run until the supernatant liquid comes to a steadŷy-state temperature, point "T4"

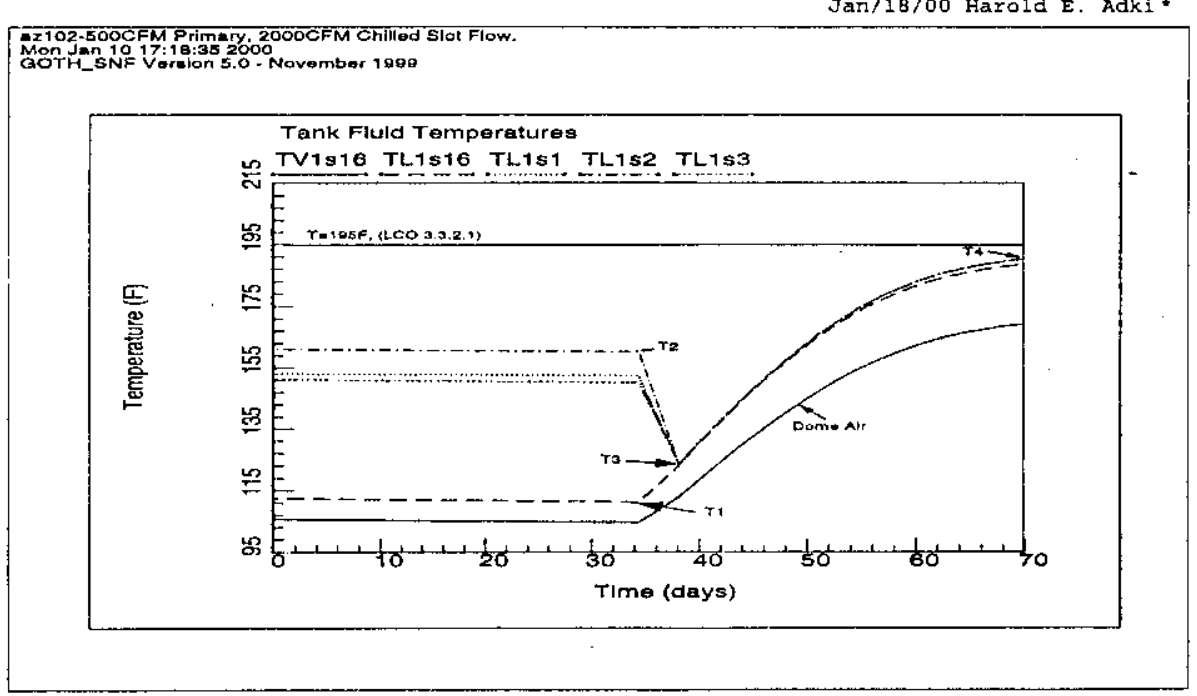

Figure 6.13 Temperatures From the Initial steady-State Conditions Through Pump Mixing (Case 4).

Just as specified for all previous cases, the temperatures "T1", "T3" and "T4" must be below the LCO limit of $195^{\circ} \mathrm{F}$ and temperature "T2" must be below $215^{\circ} \mathrm{F}$ in order for this ventilation system configuration to be deemed acceptable. As shown, these specific acceptability criteria are met.

After the pumps are then shut off, the resulting peak slurry temperature rises to $213.7^{\circ} \mathrm{F}$ which is below the 
JOHN MARVIN, INC.

Analyst: Marvin J. Thurgood

Reviewer: Harold E. Adkins

Subject: Notebook for GOTH_SNF Simulation of Tank AZ-102

acceptability Iimit of $215^{\circ} \mathrm{F}$. This is shown in Figure 6.14 as point "T2" " This temperature must remain below $215^{\circ} \mathrm{F}$ at all times before and after mixing for the ventilation system to be deemed acceptable. Additionally, as shown in Table 6.4 and Figure 6.15, all waste existing within the top 15 feet is below the LCO limit of $195^{\circ} \mathrm{F}$. Hence, this particular ventilation system configuration is acceptable for maintaining waste temperatures below their respective normal operational temperature limits provided that the ventilation system condenser is rated to handle the water vapor mass flow rate associated with this configuration.

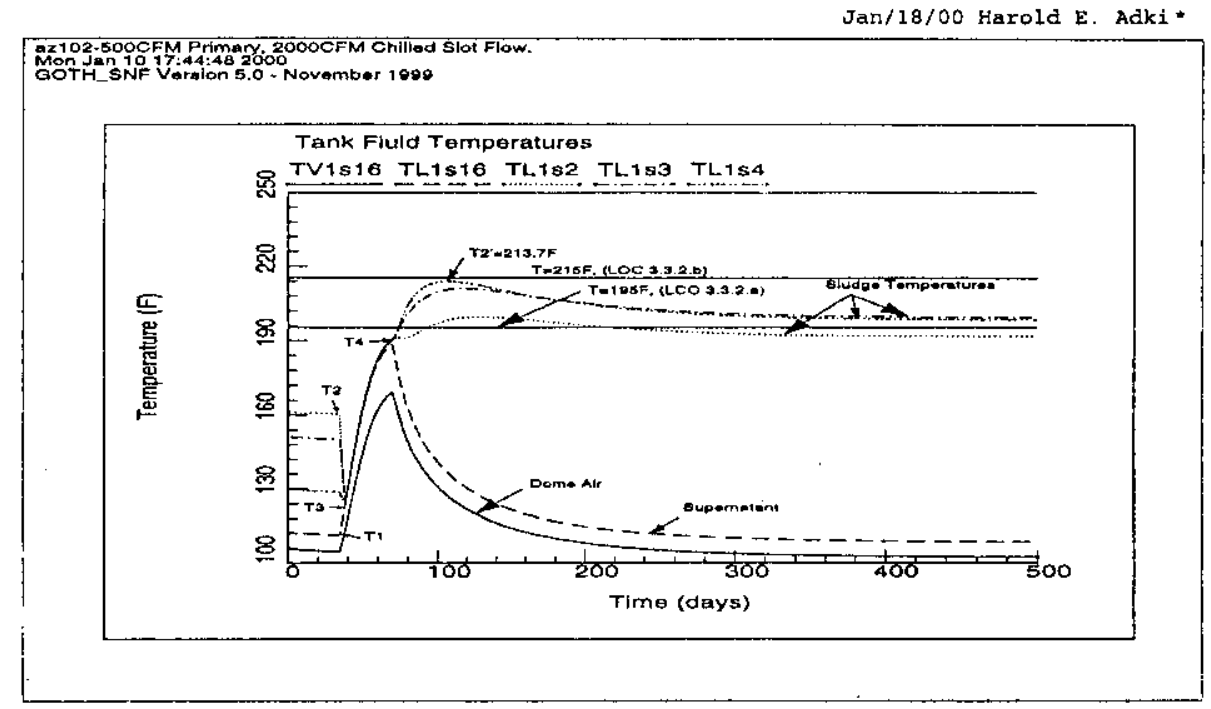

Figure 6.14 Critical waste Temperatures After Pumps are shut off (Case 4). 


\begin{tabular}{|lr|}
\hline JOHN MARVIN, INC. & Calculation Number: JMI-9910_02 \\
\hline Analyst: Marvin J. Thurgood & Date: Feb 9, 2000 \\
\hline Reviewer: Harold E. Adkins & Date: Feb 9, 2000 \\
\hline Subject: Notebook for GOTH_SNF Simulation of Tank Az-102 \\
\hline
\end{tabular}

Table 6.4 Axial Temperature Distributions in Tank (Case 4).

Jan/18/00 Harold E. Adki *

\begin{tabular}{|c|c|c|c|}
\hline elevation & $\begin{array}{c}\text { Temperature } \\
\text { T2 }\end{array}$ & $\begin{array}{c}\text { Temperature } \\
\text { T2 }\end{array}$ & $\begin{array}{c}\text { Temperature } \\
\text { T2', }\end{array}$ \\
\hline 0.208 & 152.300 & 179.800 & 177.200 \\
\hline 0.917 & 160.200 & 198.300 & 192.200 \\
\hline 1.805 & 150.400 & 210.700 & 199.800 \\
\hline 2.534 & 128.900 & 213.700 & 198.700 \\
\hline+3.260 & 113.000 & 210.400 & 191.100 \\
\hline 4.125 & 112.700 & 199.000 & 173.400 \\
\hline 5.177 & 112.700 & 169.200 & 137.900 \\
\hline 6.393 & 112.700 & 141.300 & 109.600 \\
\hline 8.036 & 112.700 & 141.300 & 109.600 \\
\hline 10.636 & 112.700 & 141.300 & 109.600 \\
\hline 14.236 & 112.700 & 141.300 & 109.600 \\
\hline 18.978 & 112.700 & 141.300 & 109.600 \\
\hline 23.720 & 112.700 & 141.300 & 109.600 \\
\hline 26.720 & 112.700 & 141.300 & 109.600 \\
\hline 28.220 & 112.700 & 141.300 & 109.600 \\
\hline
\end{tabular}

$$
\begin{aligned}
& \mathrm{T} 2:=\operatorname{array}\left(\operatorname{ax}_{3} 0,2, \operatorname{ax} 30,1\right) \\
& \mathrm{T} 4:=\operatorname{array}\left(\operatorname{ax}^{3} 0,3, a \times 30,1\right) \\
& \mathrm{T} 5:=\operatorname{array}\left(\operatorname{ax}^{3} 0,4, \mathrm{ax}^{3} 0,1\right) \\
& \mathrm{T}_{5,2}:=2.875 \\
& \mathrm{~T}_{8,2}:=5.7500 \\
& \mathrm{~T}_{8,2}:=5.7500
\end{aligned}
$$

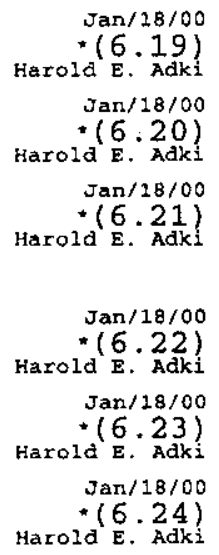

87 of 102 
JOHN MARVIN, INC.

Calculation Number: JMI-9910_02

Analyst: Marvin J. Thurgood

Date: Feb 9, 2000

Reviewer: Harold E. Adkins

Date: Feb 9, 2000

Subject: Notebook for GOTH_.SNF Simulation of Tank AZ-102

Jan/18/00 Harold E. Adki *

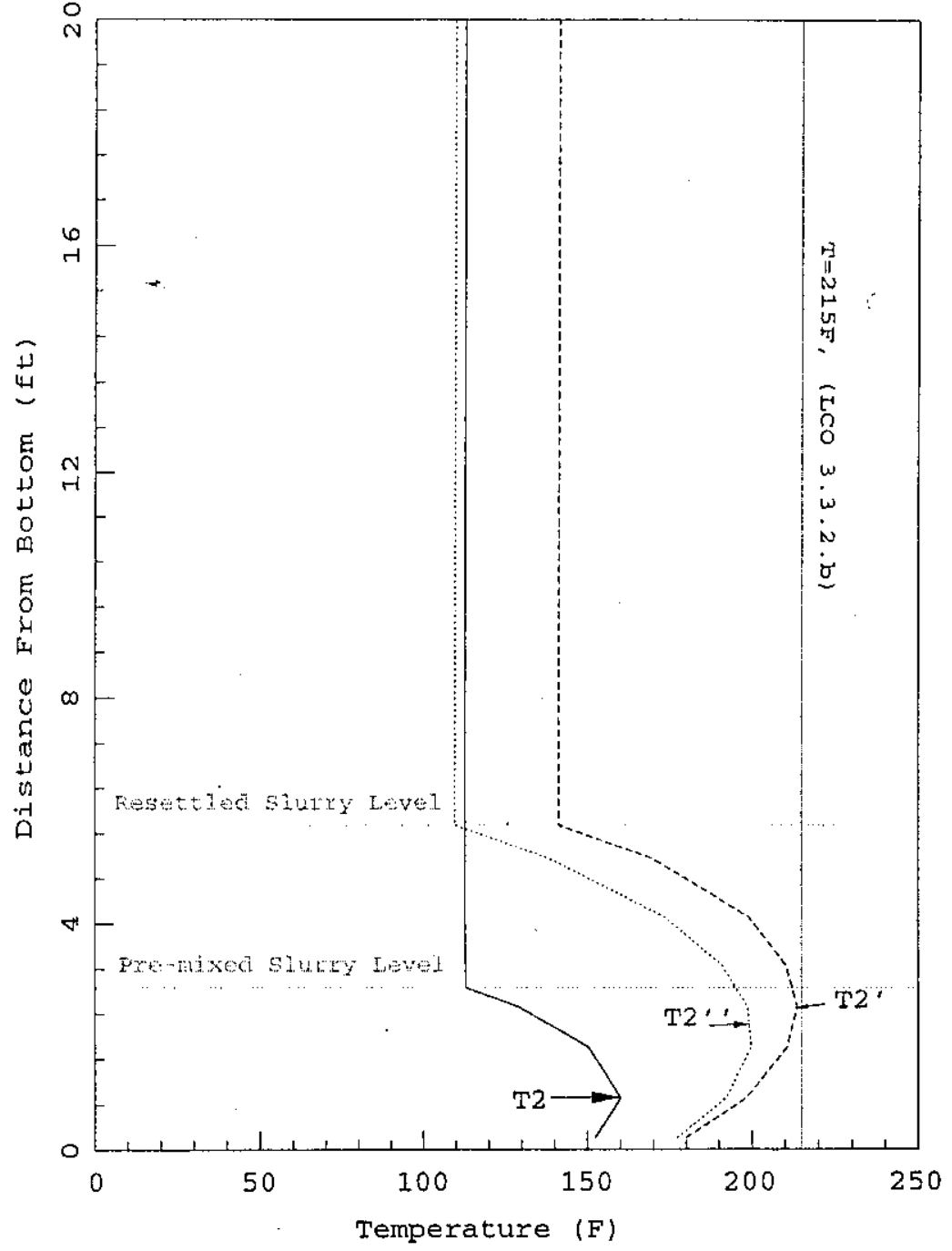

Figure 6.15 Axial Temperature Distributions in Tank Before (T2), Peak After (T2'), and steady State After Mixing (T2'") (Case 4).

88 of 102 
Analyst: Marvin J. Thurgood Date: Feb 9, 2000

Reviewer: Harold E. Adkins

Date: Feb 9, 2000

Subject: Notebogk for GOTH SNF Simulation of Tank AZ-102

The high evaporative removal rate during mixing operations is shown in the water vapor mass flow rate results displayed in Figure 6.16. This figure shows the amount of water vapor that must be removed from the outlet air by the primary ventilation system condenser in order for dry air to enter the ventilation fans. As is shown, during mixing operations, the evaporation rate rises to $0.34 \mathrm{lbm} / \mathrm{s}$. since the primary ventilation flow can not be maintained at the specified level if this moisture is not removed, the ventilation system condenser must be rated such that it is capable of removing at least $0.34 \mathrm{lbm} / \mathrm{s}$.

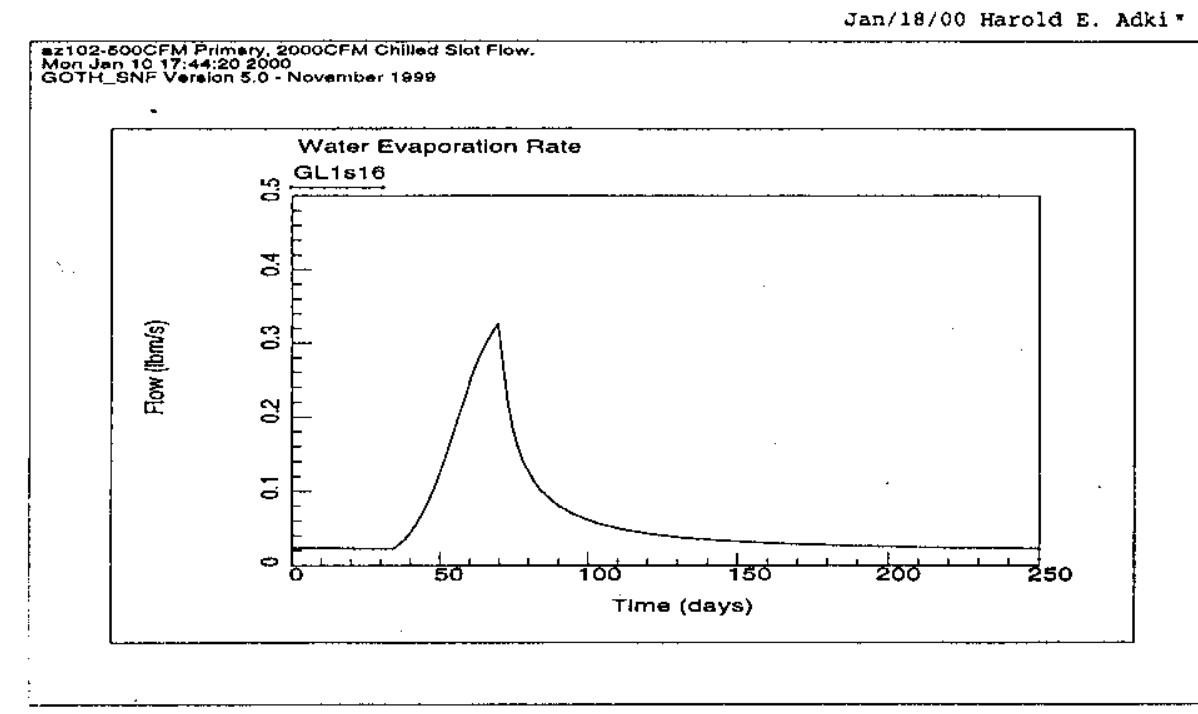

Figure 6.16 water Vapor Mass Rate Carried Over By the Primary Ventilation System (Case 4).

\subsection{CASE 5 - PRIMARY, FLOOR SLOT, AND RECTRCULATIVE VENTILATION FLOWS.}

Prior to presenting results for this case, a note should be brought to the readers attention. The convective 


\begin{tabular}{|lr|}
\hline JOHN MARVIN, INC. & Calculation Number: JMI-9910_02 \\
\hline Analyst: Marvin J. Thurgood & Date: Feb 9, 2000 \\
\hline Reviewer: Harold E. Adkins & Date: Feb 9, 2000 \\
\hline Subject: Notebook for GOTH_SNF Simulation of Tank Az-102 \\
\hline
\end{tabular}

coefficient of conductance for the floor slot flow is lower for this case than the other cases evaluated because it was based on preliminary modeling results which used the outlet slot heat transfer coefficient rather than the average slot heat transfer coefficient. This lead to artificially higher temperature results for this case than would result if the average heat transfer coefficient had been used. This should be kept in mind when performing cross-comparisons of the cases presented. Due to the absence of time, the coefficient could not be modified, and results could not be re-evaluated. However, the overall outcome of ventilation system acceptability is not expected to change.

The ventilation system for this case consists of the reduced once through primary ventilation flow of $100 \mathrm{CFM}$, a 400 CFM recirculation flow supplementing the primary ventilation, and a slot ventilation flow of $1000 \mathrm{CFM}$. The air inlet temperature for the primary and slot ventilation is $82^{\circ} \mathrm{F}$.

The critical waste temperatures in the tank for the initial settled state as well as for the period when the pumps are running are shown in Figure 6.17. As in all previous cases, the steady-state supernatant liquid and peak slurry temperature prior to pump operation are shown as point "T1" and point "T2", respectively. At time $t=34$ days, the pumps are turned on and the waste comes to a uniform temperature at " 13 " ( $t$ ime $t=38$ days). The pumps are then run until the supernatant liquid comes to a steady-state temperature, point "T4". 
RPP-5637

Rev. 0

\begin{tabular}{|lr|}
\hline JOHN MARVIN, INC. & Calculation Number: JMI-9910_02 \\
\hline Analyst: Marvin J. Thurgood & Date: Feb 9, 2000 \\
\hline Reviewer: Harold E. Adkins & Date: Feb 9, 2000 \\
\hline Subject: Notebook for GOTH_SNE Simulation of Tank AZ-102 \\
\hline
\end{tabular}

Jan/18/00 Harold E. Adki*

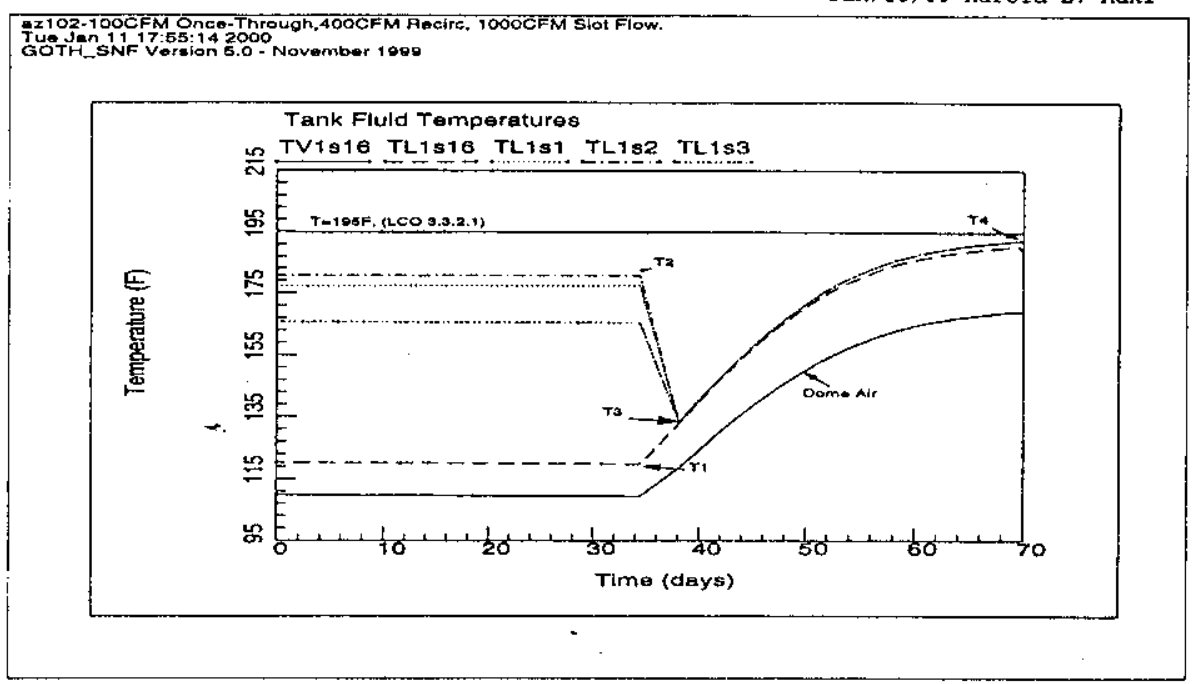

Figure 6.17 Temperatures From the Initial steady-State Conditions Through Pump Mixing (Case 5).

The temperatures "T1", "T3" and "T4" must be below the LCO limit of $195^{\circ} \mathrm{F}$ and temperature "T2" must be below $215^{\circ} \mathrm{F}$ in order for this ventilation system configuration to be deemed acceptable. As shown, these specific acceptability criteria are met.

At time $t=70$ days, the pumps are then shut off and the solid particles settle out of the supernatant liquid to form the non-convective slurry layer. The maximum reported slurry temperature is shown in Figure 6.18 at point "T2" " as $234^{\circ} \mathrm{F}$. However, as is also shown in this figure, waste temperatures are still on the rise. Since this temperature far exceeds the limit of $215^{\circ} \mathrm{F}$ in the first place, this ventilation configuration as defined for this case is determined to be unacceptable. 
JOHN MARVIN, INC.

Calculation Number: JMI-9910_02

Analyst: Marvin $J$. Thurgood

Date: Feb 9, 2000

Reviewer: Harold E. Adkins

Date: Feb 9, 2000

Subject: Notebook for GOTH_SNF Simulation of Tank AZ-102

Jan/18/00 Harold E. Adki *

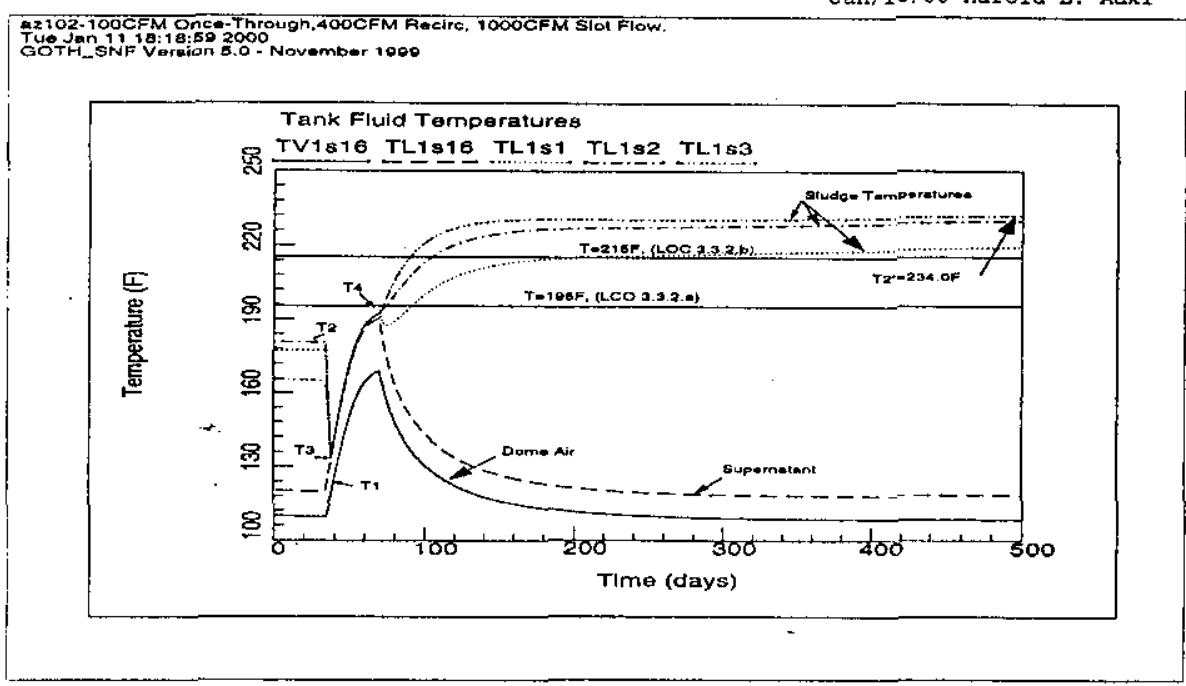

Figure 6.18 Critical Waste Temperatures After Pumps are Shut off (Case 5).

The axial temperature profile in the waste prior to pump operation (T2) and after pump operation (T2') for this unacceptable configuration are given in Table 6.5 and are shown in Figure 6.19. 
RPP-5637

Rev. 0

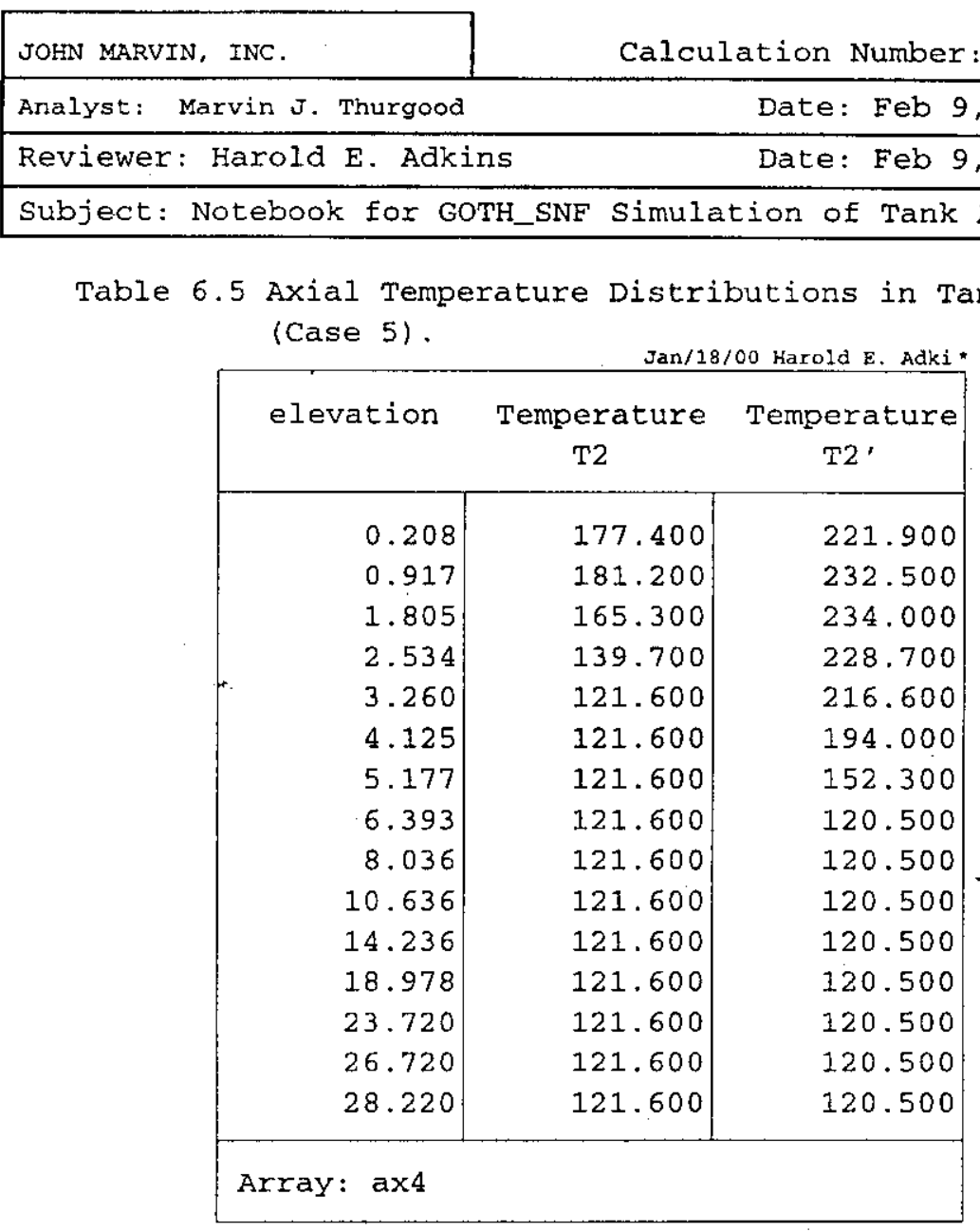

$$
\begin{aligned}
& \mathrm{T} 2:=\operatorname{array}\left(\mathrm{ax} 4_{0,2}, \mathrm{ax} 4_{0,1}\right) \\
& \mathrm{T} 4:=\operatorname{array}\left(\operatorname{ax} 4_{0,3}, \mathrm{ax} 4_{0,1}\right) \\
& \mathrm{T}_{5,2}:=2.875 \\
& \mathrm{~T}_{8,2}:=5.7500
\end{aligned}
$$

Jan $/ 18 / 00$

$*(6.25)$ Harold E. Adki $\mathrm{Jan} / 28 / 00$ .$(6.26)$ Hazold $E$. Adki Jan $/ 2 B / 00$ $+(6.27)$ harold $\mathrm{E}$. Adk $\mathrm{Jan} / 1 \mathrm{~B} / 00$ $*(6.28)$ Harold $\mathrm{E}$. Adki 


\begin{tabular}{|lr|}
\hline JOHN MARVIN, INC. & Calculation Number: JMI-9910_02 \\
\hline Analyst: Marvin J. Thurgood & Date: Feb 9, 2000 \\
\hline Reviewer: Harold E. Adkins & Date: Feb 9, 2000 \\
\hline Subject: Notebook for GOTH_SNF Simulation of Tank AZ-102 \\
\hline
\end{tabular}

Jan/18/00 Harold E. Adki *

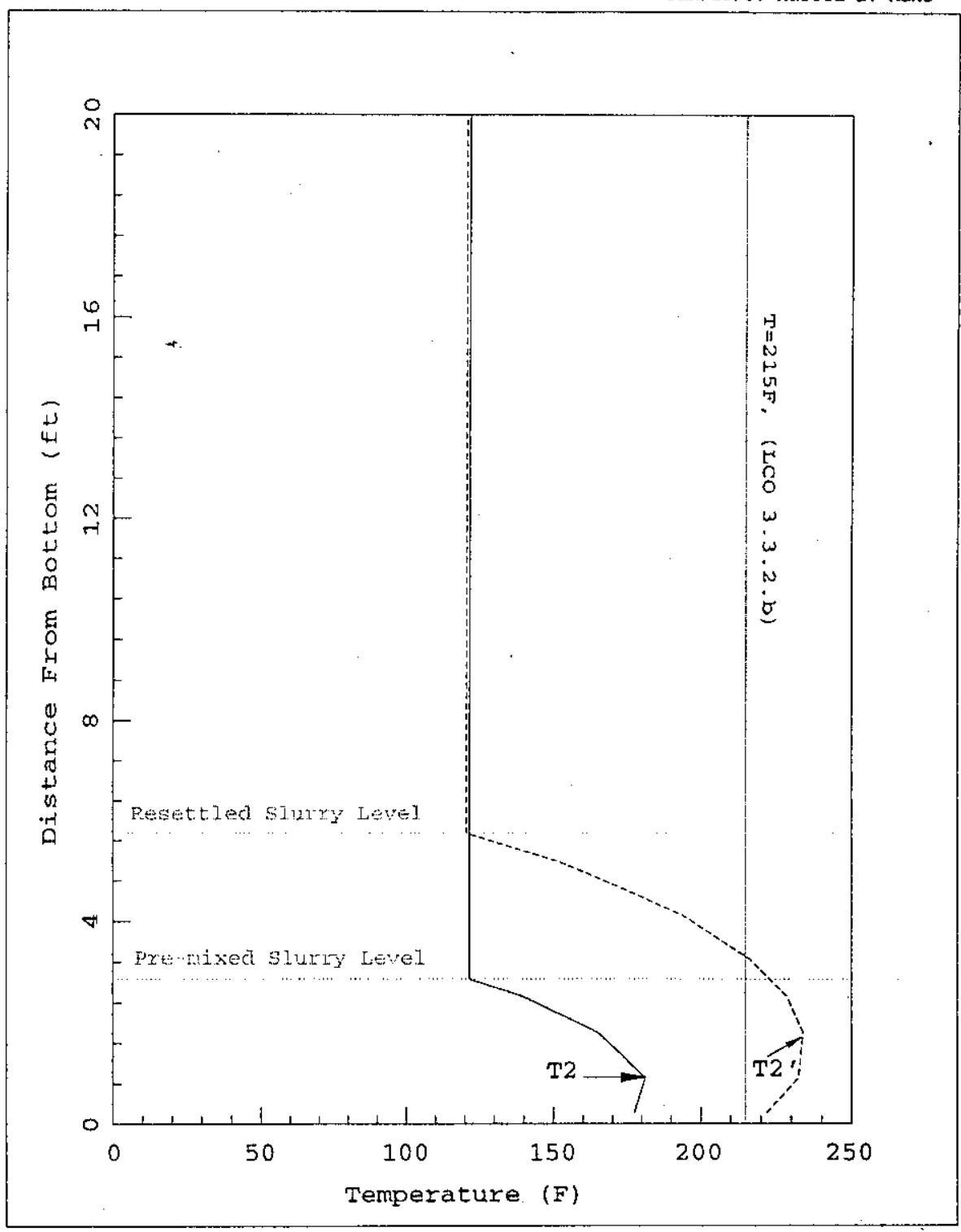

Figure 6.19 Axial Temperature Distributions in Tank Before (T2), Peak After (T2'), and steady state After Mixing (T2'') (Case 5). 
JOHN MARVIN, INC.

Calculation Number: JMI-9910_02

Analyst: Marvin J. Thurgood

Date: Feb 9, 2000

Reviewer: Harold E. Adkins

Date: Feb 9, 2000

Subject: Notebook for GOTH_SNF Simulation of Tank AZ-102

The resulting high evaporative removal rate during pump operation for this unacceptable ventilation configuration case is shown in the water vapor mass flow rate displayed in Figure 6.20.

Jan/18/00 Harold E. Adki *

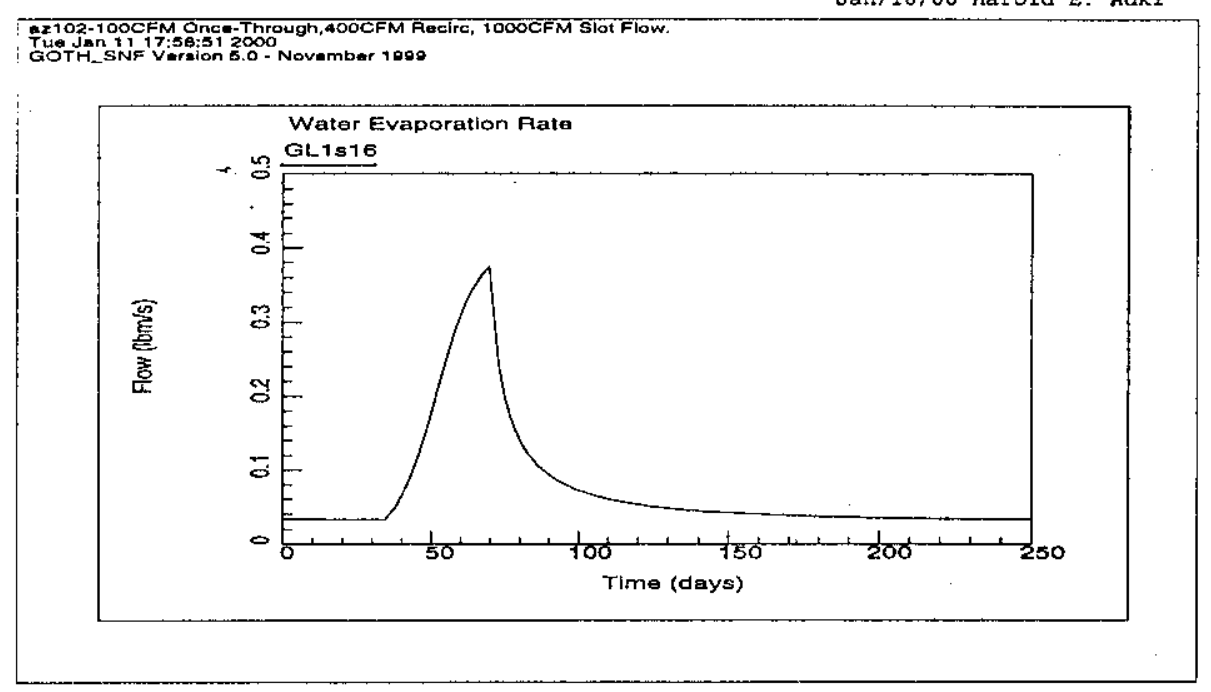

Figure 6.20 Water Vapor Mass Rate Carried over By the Primary Ventilation System (Case 5).

\subsection{CASE 6 - NOMINAL PRIMARY FLOW WITHOUT FLOOR SLOT VENTILATION FLOW.}

The ventilation system configuration for this case consists of the nominal once through primary ventilation flow of 500 CFM. However, the floor slot ventilation flow has been disrupted (O CFM). The inlet air temperature for the primary ventilation systems is $82^{\circ} \mathrm{F}$.

The critical waste temperatures for the initial settled state and period when the pumps are running for this particular case are shown in Figure 6.21. The steady-state 
JOHN MARVIN, INC.

Analyst: Marvin J. Thurgood

Reviewer: Harold E. Adkins

Subject: Notebook for GOTH

supernatant liquid temperature and peak slurry temperature prior to mixing operations are shown in this figure as point "T1" and point "T2", respectively.

At time $t=34$ days, the pumps are turned on and the waste comes to a uniform temperature, "T3" at time $t=38$ days. The pumps are then run until the supernatant liquid comes to a steady-state temperature, point "T4". As shown, even before the mixer pumps are shut down, the LCO temperature limit which applies during mixer pump runtime is already exceeded $\left(195^{\circ} \mathrm{F}\right.$ - ICO 3.2.2.a). As is also shown, matters become even worse after the mixer pumps are shut off and the solid particles settle out of the supernatant liquid to form a non-convective layer. As the non-convective layer forms waste temperatures soar even beyond the safety related temperature limits. This is indicated a point "T2" .

Despite these occurrances, the reader should note that prior to any mixing operations, this ventilation configuration met the acceptability criteria. "T1" is below the LCO limit of $195^{\circ} \mathrm{F}$ and "T2" is below $215^{\circ} \mathrm{F}$. 


\begin{tabular}{|lr|}
\hline JOHN MARVIN, INC. & Calculation Number: JMI-9910_02 \\
\hline Analyst: Marvin J. Thurgood & Date: Feb 9, 2000 \\
\hline Reviewer: Harold E. Adkins & Date: Feb 9, 2000 \\
\hline Subject: Notebook for GOTH_SNF Simulation of Tank Az-102 \\
\hline
\end{tabular}

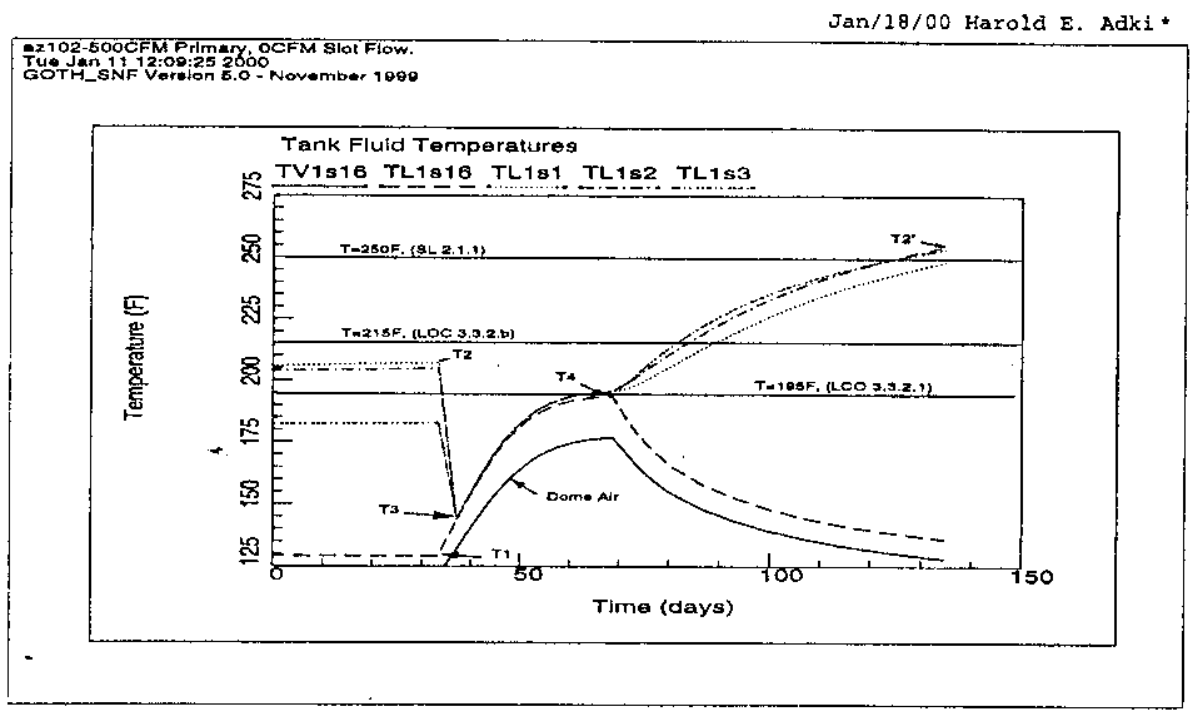

Figure 6.21 Critical Waste Temperatures (Case 6).

\subsection{CASE 7 - NOMINAL PRIMARY AND MAXIMUM CHILLED FLOOR SLOT FLOWS WITH VENTILATION LOSS AFTER PUMPING.}

As has been shown in the normal operations case evaluation "Case 4", a ventilation system configuration consisting of a nominal once through primary ventilation flow of 500 CFM and a slot ventilation flow upgraded to provide a chilled $40^{\circ} \mathrm{F}$ flow rate of $2000 \mathrm{CFM}$ adequately maintains AZ-102 tank waste temperatures below the established normal operations temperature limits during all pre, current and post-mixing operations. This is provided that the system is equipped with a condenser capable of removing at least $0.34 \mathrm{lbm} / \mathrm{s}$ of water vapor from the primary exhaust system.

Even though this configuration has been determined to be acceptable, under normal operating conditions, it is required to know the allowable "recovery duration" in a hypothetical "loss of ventilation" event. This case 
JOHN MARVIN, INC.

Calculation Number: JMI-9910_02

Analyst: Marvin J. Thurgood

Date: Feb 9, 2000

Reviewer: Harold E. Adkins

Date: Feb 9, 2000

Subject: Notebook for GOTH_SNF Simulation of Tank AZ-102

evaluation serves the purpose of determining that quantity and is posed as follows.

The ventilation configuration for this case is specified to be identical to that featured in the "Case 4" evaluation covered in section 6.4. The loss of ventilation is assumed to take place directly after mixing waste temperatures have reached steady state and the pumps are shut off (70 days - point $\mathrm{T} 4$ of Figure 14). The resulting critical waste temperatures for this case are presented in Figure $6.2 \overrightarrow{2}$. As shown, the waste temperatures exceed the safety limit just after 117 days. This specifies that the maximum allowable recovery duration that can be allowed is 47 days.

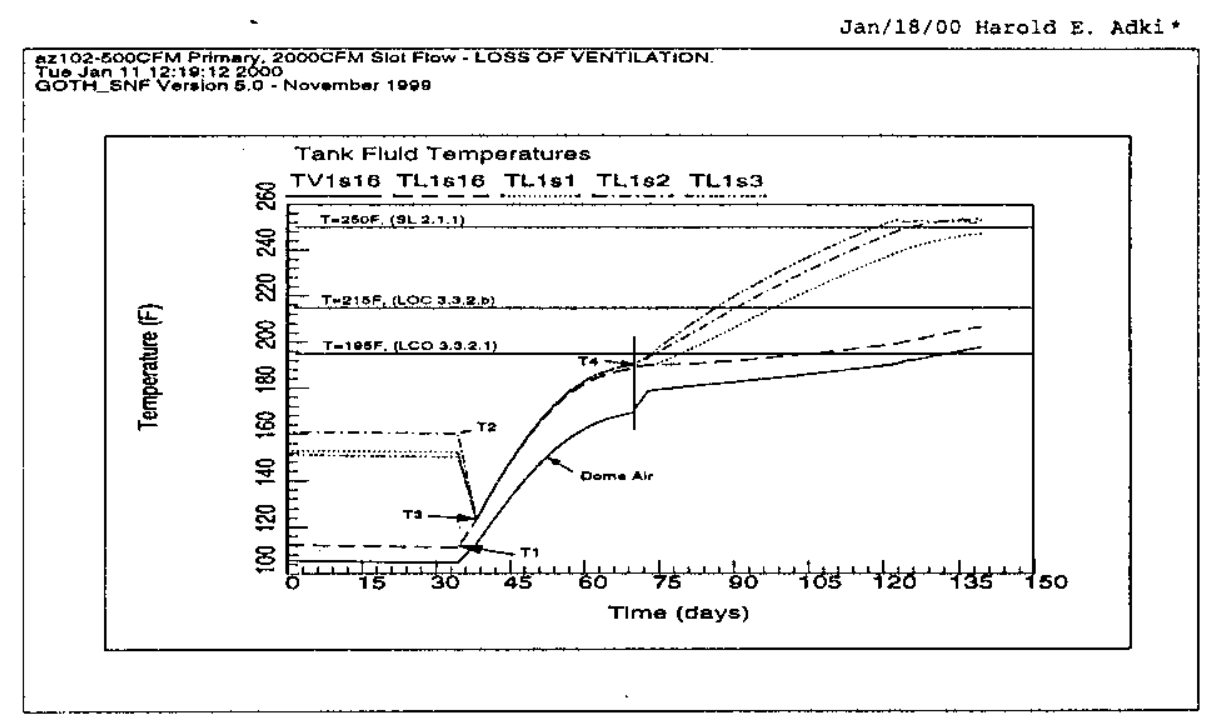

Figure 6.22 Critical Transient Waste Temperature Response During Safety Evaluation (Case 7).

Initiating the loss of ventilation at this point in time provides the most conservative estimate of recovery duration. The energy stored in the equivalently heated 


\begin{tabular}{|lr|}
\hline JOHN MARVIN, INC. & Calculation Number: JMI-9910_02 \\
\hline Analyst: Marvin J. Thurgood & Date: Feb 9, 2000 \\
\hline Reviewer: Harold E. Adkins & Date: Feb 9, 2000 \\
\hline Subject: Notebook for GOTH_SNF Simulation of Tank AZ-102 \\
\hline
\end{tabular}

supernatent and the highly reduced evaporative and convective cooling which takes place at the supernatent surface will cause waste temperatures to increase at a greater rate. This problem will be compounded as the non-convective layer builds within the waste. This behavior can be verified through close examination of Figure 14 and Figure 22 between the time span of 70 and 150 days.

\section{CONCLUSIONS.}

As has been shown in the normal operations case evaluation "Case 4" feature in Section 6.4, a ventilation system configuration consisting of a nominal once through primary ventilation flow of $500 \mathrm{CFM}$ and a slot ventilation flow upgraded to provide a chilled $40^{\circ} \mathrm{F}$ flow rate of $2000 \mathrm{CFM}$ adequately maintains AZ-102 tank waste temperatures below the established normal operations temperature limits during all pre, current and post-mixing operations. This is provided that the system is equipped with a condenser capable of removing at least $0.34 \mathrm{lbm} / \mathrm{s}$. As shown in Section 6.7 for this ventilation configuration, the maximum allowable recovery duration that can be allowed for this system if a hypothetical loss of ventilation event occurs is 47 days.

Finally, it has been determined in Case 6 that a ventilation system configuration consisting of the nominal primary and disabled floor slot ventilation flows (500 CFM \& 0 CFM, respectively) maintained waste temperatures below the established temperature limits provide mixing operations were initiated. This signifies that the floor slot ventilation flow could be shut down in order to perform servicing and/or make modifications. 
RPP-5637

Rev. 0

\begin{tabular}{|lr|}
\hline JOHN MARVIN, INC. & Calculation Number: JMI-9910_02 \\
\hline Analyst: Marvin J. Thurgood & Date: Feb 9, 2000 \\
\hline Reviewer: Harold E. Adkins & Date: Feb 9, 2000 \\
\hline Subject: Notebook for GOTH_SNF Simulation of Tank AZ-102 \\
\hline
\end{tabular}

\section{REFERENCES}

[1] Drawing H-2-67317 Rev. 1, Tank Section And Details, sep. 21, 1970 .

[2] Drawing, H-2-67244, Structural Insulating Concrete Plan \& Details, 241-AZ, Rev. 1, Sep 21,1970.

[3] Selby, Samuel M., Standard Mathematical Tables, Seventeenth Edition, The Chemical Rubber Co., Cleveland, ohio, 1969.

[4] Holman, J.P., Heat Transfer, Second Edition, MCGraw-Hill Book Co., San Francisco, 1968.

[5] Binder, Raymond C., Fluid Mechanics, Fourth Edition, Prentice Hall, Inc., Englewood Cliffs, N.J., 1962.

[6] Letter to JMI, A Parametric Study to Characterize AGA Alternatives for Removal of Heat from High-Level waste Tanks, December 1999.

[7] CRANE, Flow of Fluids Through Valves, Fittings, and

[8] Bous, D.G., Thermal Conductivity of Hanford Waste Tank Solids and SX Tank Farm Soil Samples, ARH-CD-378, Atlantic Richfield Hanford Company, Richland WA, 1975. 


\begin{tabular}{|lr|}
\hline JoHN MARVIN, INC. & Calculation Number: JMI-9910_02 \\
\hline Analyst: Marvin J. Thurgood & Date: Feb 9, 2000 \\
\hline Reviewer: Harold E. Adkins & Date: Feb 9, 2000 \\
\hline Subject: Notebook for GOTH_SNF Simulation of Tank AZ-102 \\
\hline
\end{tabular}

\section{REVIEWER'S COMMENTS}

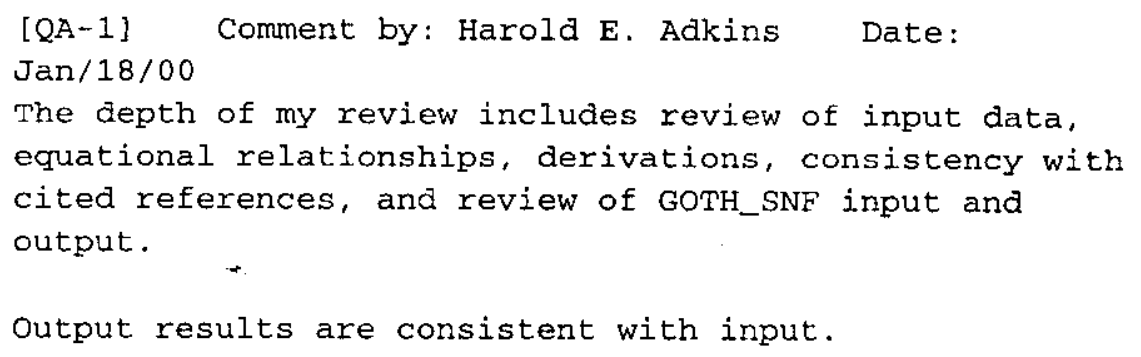

\section{RESPONSE TO INDEPENDENT REVIEWERS COMMENTS.}

All of the comments made by the independent reviewer have been incorporated into the note book. Two comments require further explaination.

First, the width of the bottom of the outer row of slots was incorrect in the original notebook. The original value was 1.5 inches and the correct value is 1.0 inches. The value is corrected in the notebook and all of the affected numbers updated. This does not necessitate a change in the input decks and reruning the problem since the heat transfer coefficients in the slots are not significantly affected by this value. The average heat transfer coefficient changes from a value of 4.32 to 4.60 Btu/hr-ft2,-R. The value used in the analysis is sligher lower resulting in slightly more conservative temperatures. The corrected value should be used in any repeat analysis 
JOHN MARVIN, INC.

Analyst: Marvin J. Thurgood

Reviewer: Harold E. Adkins

Subject: Notebook for GOTH_S
Calculation Number: JMI-9910_02

Date: Feb 9, 2000

Date: Feb 9, 2000

Second, the heat capacity of the soil used in the analysis may be slightly higher $0.4 \mathrm{Btu} / \mathrm{lbm}-\mathrm{R}$ versus the backfill value upper range of $0.34 \mathrm{Btu} / 1 \mathrm{bm}-\mathrm{R}$ or the natural material to the 65 foot depth of $0.26 \mathrm{Btu} / 1 \mathrm{bm}-\mathrm{R}$. Also, the conductivity of the soil used, $0.25 \mathrm{Btu} / \mathrm{hr}-\mathrm{ft}-\mathrm{R}$, may be low for the natural sand material, 0.235 to $1.06 \mathrm{Btu} / \mathrm{hr}-\mathrm{ft}-\mathrm{R}$ and for moist backfill material, 1.21 to $1.85 \mathrm{Btu} / \mathrm{hr}-\mathrm{ft}-\mathrm{R}$. No value for density of the material is provided by the reviewer so no evaluation of the effect on change in specific heat can be made. Soil properties were not identified as an important set of parameters in the input specification document and its significance realized only as a result of the analysis. The correct set of soil parameters that should be used for each region of the tank should be provided in the input specification document and used in the analysis should any future analysis be performed. The values used in the analysis are sufficiently close to those provided by the reviewer that no significant change in peak waste temperatures is expected. 


\section{ENGINEERING NOTEBOOK AND REPORT REVIEW CHECKLIST}

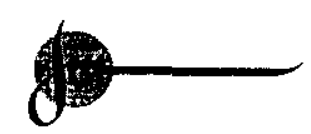

Engineering Report No

Engineering Notebook No.TMI-9910-O2

\begin{tabular}{|c|c|c|c|c|}
\hline 1. & $\begin{array}{l}\text { Is the purpose of the engineering analysis clearly } \\
\text { stated? }\end{array}$ & Yes & No & NA \\
\hline 2. & $\begin{array}{l}\text { Are required inputs and information sources } \\
\text { provided? }\end{array}$ & TeS & No & NA \\
\hline 3. & Is the methodology clearly identified? & $+\overline{e s}$ & No & NA \\
\hline 4. & Have the limits of applicability been identified? & xess & No & NA \\
\hline 5. & $\begin{array}{l}\text { Is all supporting data/information referenced or } \\
\text { provided in the project files? }\end{array}$ & Yes & No & $\mathrm{NA}$ \\
\hline 6. & $\begin{array}{l}\text { Are the assumptions and conservatism's clearly } \\
\text { identified? }\end{array}$ & 1Es & No & $\mathrm{NA}$ \\
\hline 7. & $\begin{array}{l}\text { Are all calculation notes or engineering notes } \\
\text { uniquely identified and pages sequentially } \\
\text { numbered? }\end{array}$ & Tes & No & $\mathrm{NA}$ \\
\hline 8. & Are the computer codes and models identified? & Yes & No & $\mathrm{NA}$ \\
\hline 9. & Are all computer analyses clearly identified? & Yes & No & $\overline{\mathrm{NA}}$ \\
\hline 10. & $\begin{array}{l}\text { Were the computer codes under configuration } \\
\text { control? }\end{array}$ & Yes & No & $\mathrm{NA}$ \\
\hline 11. & $\begin{array}{l}\text { Were the computer codes and models applicable for } \\
\text { the stated purpose of the analyses? }\end{array}$ & Yes & No & NA \\
\hline 12. & Are the results and conclusions clearly presented? & Fes & No & $\mathrm{NA}$ \\
\hline 13. & Are open technical issues properly identified? & Yes & No & \\
\hline 14. & $\begin{array}{l}\text { Were customer organization Design Control } \\
\text { practices followed? }\end{array}$ & Yes & No & \\
\hline
\end{tabular}

Note: If NO to any of the above, identify justification on attached page or reference report or notebook page \#.
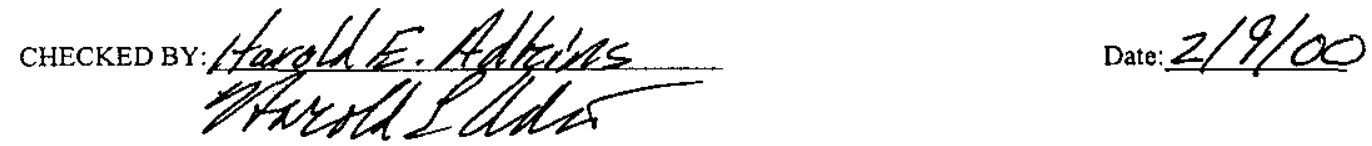
RPP-5637

Rev. 0

This page intentionally left blank.

F-114 


\section{DISTRIBUTION SHEET}

To

Retrieval system Development

Project Title/Work Order

Parametric Analyses of Heat Removal from High-Level Waste Tanks (111851/EJOO)

Name

Fluor Hanford

B.A. Crea

S. L. Hecht

K. Sathyanarayana (3)

M. J. Schliebe

Numatec Hanford Corporation

A. B. Carlson

P. J. Certa

A. F. Choho

T. J. Conrad

D. P. Fassett

C. E. Grenard

W. J. Millsap

W. L. Willis

John Marvin, Inc.

M. J. Thurgood

D. M. Odgen

CH2M Hill Hanford Group, Inc.

D. L. Banning

J. R. Bellomy

D. R. Bratzel

A. H. Friberg

T. G. Goetz

J. L. Homan

N. W. Kirch

C. E. Leach

J. W. Lentsch

G. C. DeWeese

From

Process Modeling/Eng Ana/Eng Lab

rocess Modeling/Eng Ana/ Eng Lab

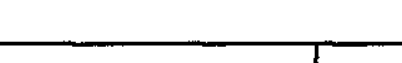




\section{DISTRIBUTION SHEET}

To

Retrieval system Development

Project TitleNork Order

Parametric Analyses of Heat Removal from High-Level Waste Tanks (111851/EJOO)

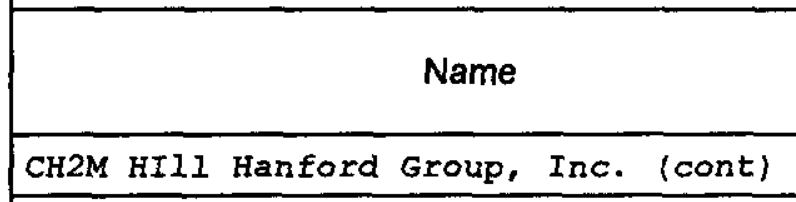

พ. J. Powell

S. H. Rifaey

D. A. Reynolds

Central Files (Original + 2)

DOE Reading Room

T.W. Craw ford

P. Schmitz
From

Process Modeling/Eng Ana/Eng Lab

Tex

\section{)}

_

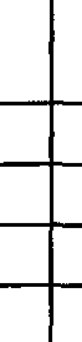

\begin{tabular}{|c|c|c|}
\hline MSIN & $\begin{array}{c}\text { Text } \\
\text { With All } \\
\text { Attach. }\end{array}$ & Text Only \\
\hline s5-13 & $x$ & \\
\hline R2-58 & $x$ & \\
\hline R2-11 & $x$ & \\
\hline B1-07 & $x$ & \\
\hline $\mathrm{H} 2-53$ & $x$ & \\
\hline $23-73$ & $x$ & \\
\hline$R_{3}-73$ & $x$ & \\
\hline
\end{tabular}

Page 2 of 2
Date $04 / 04 / 2000$
EDT No. 613077
ECN No.

Attach I Appendix Only 